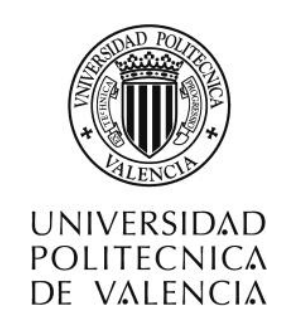

\title{
Diseño de una política eficiente de precios del agua integrando costes de oportunidad del recurso a escala de cuenca.
}

Aplicación a la Directiva Marco europea del Agua

\section{TESIS DOCTORAL}

Presentada por:

Eduardo Álvarez Mendiola

Director:

Dr. Manuel Pulido Velázquez

Codirector:

Dr. Joaquín Andreu Álvarez 



\title{
Diseño de una política eficiente de precios del agua integrando costes de oportunidad del recurso a escala de cuenca.
}

Aplicación a la Directiva Marco europea del Agua

\author{
Tesis doctoral presentada por \\ Eduardo Álvarez Mendiola
}

Directores:

Manuel A. Pulido Velázquez

Joaquín Andreu Álvarez

Programa doctoral:

Ingeniería Hidráulica y Medio Ambiente

Departamento:

Ingeniería Hidráulica y Medio Ambiente

Beca de estudios:

PROMEP-SEP

Diciembre, 2010 

Gracias Señor Jesús, por ser mi Salvador y Señor y mi

ayudador en todo tiempo

\section{A mi amada esposa Perlita por su amor, comprensión y apoyo incondicional.}

"Tú tienes cuidado de la tierra; le envías Iluvia y la haces producir; tú, con arroyos caudalosos, haces crecer los trigales. iAsí preparas el campo!" (La Biblia, Salmos 65:9)

"La escasez física actual de agua no es la cuestión principal en la mayoría de las regiones. Parece, más bien, que prevalecen las condiciones de escasez económica: hay bastante agua para satisfacer las necesidades de la sociedad, pero pocos incentivos para lograr un uso inteligente $y$ ahorrador de los recursos o para efectuar una asignación eficiente entre demandas alternativas" (Gibbons, 1986) 



\section{Agradecimientos}

De todo corazón agradezco el apoyo incondicional, la enorme ayuda, el ánimo constante, la guía clara y la alegría de vivir a Manuel Pulido Velázquez, director de la tesis, quién confió en mí para el desarrollo y culminación del trabajo. Gracias Manuel, por haber podido compartirme todo ese gran saber que en materia hidro-económica has adquirido a lo largo de los años y porque has sido un valioso ejemplo de persona comprometida con el cuidado y gestión eficiente del agua.

Agradezco también enormemente a Joaquín Andreu, codirector de esta tesis, su ayuda incondicional que me otorgó desde el inicio de los estudios, así como el haber podido aprender de él la pasión por la Gestión del Recurso Hídrico. Gracias Joaquín, has sido y serás un gran ejemplo y referente obligado de hombre con una visión clara y bien definida en los problemas inherentes a la Planificación y Gestión Hídrica.

Doy gracias igualmente a los profesores que me enseñaron nuevos conceptos, nuevas ideas y nuevas metodologías en materia de hidrología y gestión y planificación del recurso hídrico, específicamente agradezco a Andrés Sahuquillo, Eduardo Cassiraga, Juan Marco Segura, y José Capilla. Agradezco también a David Pulido por lo que compartió en clase y a Javier Paredes por su ayuda en momentos finales de la modelación de la gestión.

Estoy profundamente agradecido con Carlos Segura por todo el apoyo informático recibido durante mi estancia en la UPV y por la traducción del resumen al idioma valenciano. Gracias Carlos porque en momentos críticos me ayudaste en el cuidado de mi ordenador portátil y estuviste pendiente de que todo marchara bien, eres una persona de las que ya quedan pocas: siempre dispuesto a ayudar y ver por los demás.

Agradezco el compañerismo y amistad que tuve con mis compañeros de estudio: Ángel Villalobos, Leonardo Hernández, Guillermo Collazos, Gabriel Lozano, Eduardo Triana, Davide Deidda, Diana Quevedo, Matías Pereda.

Doy gracias por las charlas en los cafés y reuniones caseras a mis amigos y compañeros estudiantes Ahmed Al Aoussimi, Armando Serrano, Rosa Orient, Israel Sánchez y Marco Morales. Gracias también a Miguel Carrión y Chiara Medici quienes en algunos momentos de mi estancia fueron de gran apoyo y alegría para mi esposa y para mí.

Mi agradecimiento también a la Facultad de Ingeniería de la Universidad Autónoma de Querétaro, México, por haberme permitido venir a Valencia a realizar los estudios de doctorado. Gracias específicamente a René Gutiérrez y Gilberto Herrera, director de la facultad al inicio de mis estudios y director actual respectivamente, quienes depositaron 
su confianza en mí, y en todo momento estuvieron pendientes de mi estancia en la madre patria. Agradezco también la confianza y ayuda recibida por Darío Hurtado, secretario académico de la Facultad de Ingeniería, quién estuvo siempre con disposición para apoyarme en los momentos finales de los estudios doctorales.

Agradezco a la Oficina de Planificación Hidrológica de la Confederación Hidrográfica del Júcar, por la información proporcionada para desarrollar el modelo de simulación del Sistema de Explotación de la cuenca del río Mijares.

El modelo utilizado para la estimación del CMOR se basó en el informe elaborado por el Departamento de Ingeniería Hidráulica y Medio Ambiente de la Universidad Politécnica de Valencia y la empresa INITEC INFRAESTRUCTURAS, S.A.U., para la Confederación Hidrográfica del Segura. Se agradece específicamente a la Oficina de Planificación de la CHS y al director de la empresa INITEC, Jesús Mora, los datos y la colaboración para la realización de dicho informe, así como la ayuda de Antonio Benítez y Carmen Iracheta.

Mucho agradezco la ayuda de Salvador Peña, mi compatriota y buen compañero de estudios, en la realización, desarrollo y puesta a punto del modelo de optimización del caso sintético y por sus valiosos comentarios y opiniones en el tema desarrollado.

Agradezco al Dr. Franklin M. Fisher y la Dra. Annette Huber-Lee por facilitarme el modelo que desarrollaron para la gestión y resolución de conflictos del agua en el Medio Oriente.

Gracias también a los compañeros de la Secretaría del Departamento. Gracias a Javier Montalvo, Paqui, Mercedes y Rosa por sus finas atenciones para con mi persona y por solventar siempre cualquier asunto administrativo que se me atravesaba en el camino.

Estoy muy agradecido y gozoso por la amistad incondicional que tuve, durante mis años de estancia en Valencia, con personas que confiesan la misma fe que yo. Gracias Pilar y Rafa por su amor incondicional y ánimo constante para conmigo; gracias Bet y Vicente por ser amigos incondicionales y "orejas amigas" en momentos difíciles por los que pasé juntamente con Perlita; gracias Santi y Pedro, por su enorme hospitalidad y compartimiento para con nosotros, gracias por ser nuestros amigos; gracias Eli y Javi por su alegría y sencillez de corazón y porque son como son, siempre me animaron a terminar "la escuela" como me decían; gracias Ma Dolores y Antonio por haber sido para nosotros un apoyo y ayuda en todo momento y por amarnos tal cual somos. Gracias Eduardo y Eli por estar al pendiente espiritual y físicamente de mi persona y de mi familia, sobre todo durante los momentos difíciles que vivió mi hijo mayor. Gracias a todos los hermanos y amigos de la Iglesia Evangélica de la calle de Quart, porque en todo momento sentí su amor y apoyo en todo tipo de cuestiones y porque me abrieron lo más valioso: la puerta de su corazón. 
Hijos míos Alejandro, Eduardo y Andrea: gracias por haber estado a mi lado por un largo periodo de tiempo y por haber sacrificado sus amistades en México para estar con su madre y conmigo. Gracias por su alegría y gracias por el ánimo que en todo momento recibí de ustedes. iLos amo!

Carla y Andrea C.: gracias por estar en todo momento al lado de mis hijos y por apoyarme con su cariño y su compañía durante todo este largo tiempo. iLos amo!

Gracias Conchi y Jorge por amar a nuestro hijo Alejandro y estar siempre al pendiente de su salud. Gracias porque en momentos muy difíciles estuvieron a su lado y al lado nuestro. iLos queremos mucho! Este trabajo ha valido la pena porque Ale está con excelente salud.

Finalmente doy gracias a mis padres, Malena y Luis, quienes siempre me han apoyado en momentos difíciles de mi vida y a quienes debo lo que soy ahora. Gracias, papás, porque siempre he sentido su amor a pesar de la enorme distancia que nos separó por un largo periodo. 



\section{Resumen}

La gestión del agua cobra cada vez mayor importancia debido a la escasez hídrica que se presenta a nivel mundial. Las tendencias actuales van en la línea de mejorar la eficiencia en la gestión del recurso considerando también la eficiencia económica. En este último aspecto, la Unión Europea (a través de la Directiva Marco del Agua (DMA), 2000) ha hecho énfasis en la recuperación de costes y en el planteamiento de políticas eficientes de precios del agua.

El agua, como recurso escaso es un bien que tiene alto valor para aquellos que lo requieren. Por ello, ya no es suficiente realizar el estudio hidrológico por sí solo, sino que es menester considerar los aspectos económicos para evaluar la eficiencia en el suministro a las demandas del sistema de explotación. En una asignación económicamente eficiente, el beneficio marginal del uso de los recursos deberá ser igual para todos los sectores, con el fin de maximizar el bienestar social. En otras palabras, el beneficio de usar una unidad adicional del recurso en uno de los sectores, debería ser el mismo que en otro sector. Las políticas de precios del agua se establecen con el fin de lograr que la asignación del recurso hídrico entre los diferentes usos y usuarios sea eficiente, equitativa y sostenible. En la práctica al agua se le asigna sistemáticamente un precio por debajo de su valor real. Esto es evidente cuando se observa que la cantidad demandada frecuentemente excede el suministro. El énfasis en la suficiencia de ingresos promueve la idea de la tarifación a precios medios. Si el precio unitario es igual al precio medio, los ingresos igualan a los costes totales. Sin embargo, es importante determinar e incorporar costes marginales (en el precio) de forma que se transmita a los usuarios una señal del valor del recurso y su escasez mediante el precio.

En esta tesis doctoral se presenta una metodología que permite la valoración práctica de los costes de oportunidad del recurso hídrico (CMOR) a escala de cuenca y su incorporación en el diseño de una política eficiente de precios del agua a nivel de cuenca tomando en cuenta los requerimientos de la DMA. La metodología propuesta se basa en el desarrollo de modelos hidro-económicos a escala de cuenca. Para ello se parte de la caracterización hidrológica y económica del sistema mediante series mensuales de aportaciones al sistema, la aplicación de la ecuación de continuidad en los nudos del esquema planteado y la ecuación de balance en los embalses del sistema, incluyendo las ecuaciones empíricas que determinan las pérdidas por filtraciones y evaporaciones en embalses y conducciones. La caracterización económica comprende la utilización de funciones económicas de demanda para cada uso que conforma el sistema.

La estimación del CMOR se hace mediante dos enfoques: simulación de la gestión según prioridades y modus operandi actual y optimización económica. El primer enfoque 
considera la simulación hidro-económica de la gestión del sistema, empleando para ello dos módulos del Sistema de Apoyo a la Decisión AquaTool: el módulo de simulación (SimGes) y el de evaluación económica (EcoWin). Los resultados de la asignación mensual del recurso simulados en SimGes, junto con las funciones de valor económico del agua en los distintos usos, y de costes de operación, son inputs de entrada en el modelo de evaluación económica, que aproxima el valor del CMOR mediante comparación de los resultados económicos de la simulación del caso base con los de las simulaciones de la gestión del sistema disponiendo de una unidad adicional de agua en cada período de tiempo en el lugar seleccionado. El enfoque de optimización económica maximiza el valor económico neto del uso del agua durante el período de optimización. Se optimiza a nivel mensual sobre series hidrológicas extensas, representativas del rango de eventos hidrológicos probables en el futuro, obteniendo el flujo del agua en el sistema durante el período optimizado y los resultados económicos asociados.

Los resultados que se obtienen del evaluador económico sirven como punto de partida para el diseño de políticas de precios cuyo efecto se analiza empleando de nuevo el modelo de simulación. La mejora de la eficiencia económica resultante de la aplicación de las políticas de precios se valora comparando los resultados obtenidos con la simulación de la operación actual del sistema (según criterio de prioridad) y la obtenida con la simulación de la política de precios. Los resultados del modelo de optimización indican la máxima eficiencia económica alcanzable, la cual sirve como nivel de referencia. La distancia entre los beneficios simulados con la gestión actual y los beneficios máximos obtenidos en la optimización nos muestran el margen de ganancia sobre el que pueden actuar las políticas de precios.

Se pueden definir políticas de precios eficientes con los escalones de precios correspondientes a valores promedios del CMOR de simulación y de optimización para distintos rangos de volumen de embalse. Se planteó un esquema sintético para la aplicación del proceso metodológico planteado, observándose que el coste marginal de oportunidad del recurso (CMOR) además de ser un indicador de la escasez del recurso en el sistema, puede utilizarse como la base para el establecimiento de políticas eficientes de precios que incorporen costes de oportunidad a escala de cuenca. En el caso de estudio sintético, asumir precios escalonados derivados de los CMOR promedios del modelo de la simulación conduce a unos beneficios económicos que ya capturan un $80 \%$ de la distancia que separa la gestión sin política de precios de la gestión optimizada teórica. Las políticas de precios, además de partir de la base de los CMOR en los embalses del sistema, pueden tomar en cuenta tanto los volúmenes embalsados como las aportaciones previas a los embalses. El que una política de precios sea más eficiente que otra depende de muchos factores que son inherentes a la propia complejidad del sistema. Entre ellos podemos citar la estructura de dependencia temporal de las series de aportaciones y las propiedades 
estadísticas de las sequías del sistema, la configuración y características de la infraestructura del sistema, la capacidad de regulación, etc.

La metodología de simulación de políticas de precios es novedosa y puede incorporase en cualquier modelo de simulación de la gestión de un sistema de recursos hídricos para el que se definan las correspondientes curvas de demanda. Mediante el uso de los indicadores de alarma del módulo SimGes del SAD Aquatool, se transforman los precios en restricciones de suministro a las demandas del sistema. La política de precios propuesta queda así definida como una serie de restricciones que al simular la gestión producirán cambios en el suministro a las demandas, información a partir de la cual podemos estimar los beneficios de la aplicación de esa política.

La metodología se aplicó también a un caso de estudio real (cuenca del río Mijares) donde se corroboraron las hipótesis planteadas para el caso sintético. Los resultados son particularmente útiles para el establecimiento de políticas eficientes de precios que mejoren los beneficios económicos y haga eficiente el reparto del recurso a los diferentes usos del sistema. 



\section{Resum}

La gestió de l'aigua va cobrant una major importància a causa de l'escassetat hídrica que es presenta a nivell mundial. Les tendències actuals van en la línia de millorar l'eficiència en la gestió del recurs considerant també l'eficiència econòmica. En este últim aspecte, la Unió Europea (a través de la Directiva Marc de l'Aigua (DMA), 2000) ha fet èmfasi en la recuperació de costos i en el plantejament de polítiques eficients de preus de l'aigua.

L'aigua, com a recurs escàs és un bé que té alt valor per a aquells que ho requerixen. Per això, ja no és suficient realitzar l'estudi hidrològic per si sol, sinó que és menester considerar els aspectes econòmics per a evaluar la eficiència en el subministrament a les demandes del sistema d'explotació. En una assignació econòmicament eficient, el benefici marginal de l'ús dels recursos haurà de ser igual per a tots els sectors, a fi de maximitzar el benestar social. En altres paraules, el benefici d'usar una unitat addicional del recurs en un dels sectors, hauria de ser el mateix que en un altre sector. Les polítiques de preus de l'aigua s'establixen a fi de conseguir que l'assignació del recurs hídric entre els diferents usos i usuaris siga eficient, equitativa i sostenible. En la pràctica a l'aigua se li assigna sistemàticament un preu per davall del seu valor real. Açò és evident quan se observa que la quantitat demanada frecuentment excedix el suministre. L'èmfasis en la suficiència d'ingressos promou la idea de la tarificació a preus mitjos. Si el preu unitari és igual al preu mig, els ingressos igualen als costos totals. Aixina i tot, és important determinar i incorporar costos marginals (en el preu) de forma que es transmetra als usuaris una senyal del valor del recurs i la seua escassesa mitjançant el preu.

En esta tesi doctoral es presenta una metodologia que permet la valoració pràctica dels costos d'oportunitat del recurs hídric (CMOR) a escala de conca i la seua incorporació en el disseny d'una política eficient de preus de l'aigua a nivell de conca prenent en compte els requeriments de la DMA. La metodologia proposada es basa en el desenrrotllament de models hidro-econòmics a escala de conca. Per a açò es part de la caracterització hidrològica i econòmica del sistema mitjançant sèries mensuals d'aportacions al sistema; I'aplicació de l'equació de continuïtat en els nucs de l'esquema plantejat i l'equació de balanç en els embassaments del sistema, incloent les equacions empíriques que determinen les pèrdues per filtracions i evaporacions en embassaments $\mathrm{i}$ conduccions. La caracterització econòmica comprén la utilització de funcions econòmiques de demanda per a cada ús que conforma el sistema.

La estimació del CMOR es fa mitjançant dos enfocaments: simulació de la gestió segons prioritats i modus operandi actual i optimització económica. El primer enfocament considera la simulació hidro-econòmica de la gestió del sistema, emplenant per a això dos 
mòduls del Sistema de Recolzament a la Decisió AquaTool: el mòdul de simulació (SimGes) i el d'evaluació económica (EcoWin). Els resultats de l'assignació mensual del recurs simulats en SimGes, junt amb les funcions de valor econòmic de l'aigua en els distints usos, i costos d'operació, son inputs d'entrada en el model d'evaluació econòmica, que aproxima el valor del CMOR mitjançant la comparació dels resultats econòmics de la simulació del cas base amb els de les simulacions de la gestió del sistema disposant d'una unitat addicional d'aigua en cada període de temps en el lloc seleccionat. L'enfocament d'optimització económica maximitza el valor econòmic net de l'ús de l'aigua durant el període d'optimització. S'optimitza a nivell mensual sobre sèries hidrològiques extenses, representatives del rang d'esdeveniments hidrològics probables en el futur, obtenint el fluix de l'aigua en el sistema durant el període optimitzat i els resultats econòmics associats.

Els resultats que s'obtenen del evaluador econòmic servixen com punt de partida per al disseny de polítiques de preus de qui l'efecte s'analitza emplenant de nou el model de simulació. La millora de l'eficiència econòmica resultant de l'aplicació de les polítiques de preus es valora comparant els resultats obtinguts amb la simulació de la operación actual del sistema (segons el criteri de prioritat) i la obtinguda amb la simulació de la política de preus. Els resultats del model d'optimització indiquen la máxima eficiencia económica alcançable, la qual servix com nivel de referencia. La distància entre els beneficis simulats amb la gestió actual i els beneficis màxims obtinguts en la optimització ens mostren el marge de guany sobre el que poden actuar les polítiques de preus.

Es poden definir polítiques de preus eficients amb els escalons de preus corresponents als valors promitjos del CMOR de simulació i d'optimització per a distints rangs de volum d'embassament. Es va plantejar un esquema sintètic per a l'aplicació del procés metològic plantejat, observant-se que el cost marginal d'oportunitat del recurs (CMOR) a més de ser un indicador de la escasessa del recurs en el sistema, pot utilizar-se com la base per a l'establiment de polítiques eficients de preus que incorporen costos d'oportunitat a escala de conca. En el cas d'estudi sintètic, assumir preus escalonats derivats dels CMOR promitjos del model de la simulació conduix a uns beneficis econòmics que ja capturen un $80 \%$ de la distància que separa la gestió sense política de preus de la gestió optimitzada teòrica. Les polítiques de preus, a més de partir de la base dels CMOR en els embassaments del sistema, poden prendre en compte tant els volumens embassats com les aportacions prèvies als embassaments. El que una política de preus siga més eficient que un altra depèn de molts factors que són inherents a la pròpia complexitat del sistema. Entre ells podem citar l'estructura de dependència temporal de les sèries d'aportacions i les propietats estadístiques de les sequeres del sistema, la configuració i característiques de la infraestructura del sistema, la capacitat de regulació, etc. 
La metodologia de simulació de polítiques de preus és novedosa i pot incorporar-se en qualsevol model de simulació de la gestió d'un sistema de recursos hídrics per al que es definixen les corresponents curves de demanda. Mitjantçant l'ús dels indicadors d'alarma del mòdul SimGes del SAD AquaTool, es transformen els preus en restriccions de suministrament a les demandes del sistema. La política de preus proposada queda aixina definida com una sèrie de restriccions que al simular la gestió produirán canvis en el suministrament a les demandes, información a partir de la qual podem estimar els beneficis de l'aplicació de eixa política.

La metodologia es va aplicar també a un cas d'estudi reial (Conca del riu Millars) a on es van corroborar les hipòtesis plantejades per al cas sintètic. Els resultats són particularment útils per a l'establiment de polítiques eficients de preus que milloren els beneficis econòmics i faça eficient el repartiment del recurs als diferents usos del sistema. 



\section{Summary}

Water management is gaining greater importance due to water scarcity that occurs worldwide. Current trends are in line to improve efficiency in resource management also considering economic efficiency. In this latter respect, the European Union (through the Water Framework directive (WFD), 2000) has emphasized raising cost recovery mechanisms for this purpose, among which includes the approach of efficient policies for water pricing.

Water as a scarce resource is an asset that has high value for those who require it. Therefore it does not enough to perform the hydrologic study alone, it is necessary to consider economic aspects to evaluate the efficiency in supplying the demands of the operating system. In an economically efficient allocation, the marginal benefit of resource use must be equal for all sectors, in order to maximize social welfare. In other words, the benefit of using an additional unit of resource in one sector should be the same as in another sector. The water-pricing policies are established to ensure that the allocation of water resources among competing uses and users is efficient, equitable and sustainable. In practice, water is systematically assigned a price below its real value. This is evident when one observes that often the quantity demanded exceeds supply. The emphasis on income adequacy promotes the idea of charging average prices. If the unit price is equal to the average price, revenue equals total costs. However, it is important to identify and incorporate marginal costs (in price) so as to transmit a signal to users of resource value and scarcity through price.

This thesis presents a methodology that allows the practical assessment of opportunity costs of the water resource (MORC) at the catchment scale and the implications for the design of an efficient pricing water (basin-scale) in Spain taking into account the requirements of the WFD. The proposed methodology is based on the development of hydro-economic models at the catchment scale. It begins with the hydrological and economic characterization of the system through monthly inflow series to the system, the application of the continuity equation at the nodes of the proposed plan and the equation of balance in the reservoirs of the system, including the empirical equations that determine losses due to seepage and evaporation in reservoirs and pipelines. The economic characterization involves the use of economic demand functions for each application that makes up the system.

The MORC is estimated using two approaches: simulation of management according to current priorities and modus operandi and economic optimization. The first approach considers the simulation of hydro-economic management system, utilizing two modules of the Decision Support System AquaTool: the simulation module (SimGes) and economic 
evaluation (EcoWin). The results of the monthly supply of the resource simulated with SimGes, together with the functions of the economic value of water in different uses and operating costs, are inputs into the economic evaluation model which approximates the MORC value by comparing economic results of the base case simulation with simulations of management systems providing an additional unit of water in each time period in the selected location. The economic optimization approach maximizes the net economic value of water use during the optimization. Is optimized at large monthly hydrologic series, representing the range of probable hydrologic events in the future, getting the flow of water into the system during the period optimized and associated economic results.

The results obtained from the economic evaluations, serve as a starting point for the design of pricing policies whose effect has been analyzed again using the simulation model. Improved economic efficiency resulting from the application of pricing policies is assessed by comparing the results obtained by simulating the actual operation of the system (as per priority) and that obtained with the simulation of the pricing. The optimization model results indicate the maximum attainable economic efficiency, which serves as a benchmark. The distance between the simulated benefits with the current management and maximum benefits obtained from the optimization show the profit margin that can act on pricing policies.

It can define efficient pricing with price steps for CMOR average values of simulation and optimization for different ranges of volume of reservoir. It posed a synthetic scheme for the application of the methodology proposed, observed that the economic performance of the system, specifically marginal opportunity resource coste (MORC) apart from being an indicator of resource scarcity in the system can be used as the basis for the establishment of efficient pricing policies. In the synthetic case study, assume staggered price averages derived from CMOR simulation model leads to economic benefits already captured $80 \%$ of the gap between management without pricing and the management with optimized theory. Pricing policies as well from the base of the CMOR system in reservoirs, may take into account both the volume impounded as previous inflow to the reservoirs. The pricing that is more efficient than another depends on many factors that are inherent to the complexity of the system. These may include time-dependent structure of the inflow series and the statistical droughts properties of the system, configuration and infrastructure characteristics of the system, regulatory capacity, etc.

The methodology for the design of efficient pricing water is innovative and may incorporate in any simulation model for managing water resources system that has defined the relevant demand curves. Using the alarm indicators from the SimGes module (SSD Aquatool), the prices become into supply constraints to the demands of the system. The pricing policy proposal is thus defined as a set of constraints that produce changes in 
the supply to demand when the management is simulated. The information obtained can be used to calculate the benefits on the pricing policy considered

The methodology was applied to a real case study (Mijares River basin) where the hypotheses were confirmed for the synthetic case. The results are particularly useful for establishing efficient pricing policies that enhance economic benefits and make efficient resource allocation to different uses of the system. 



\section{Contenido general}

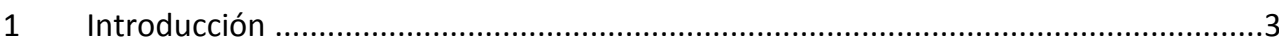

2 Precios del agua. Teoría y contexto institucional ................................................15

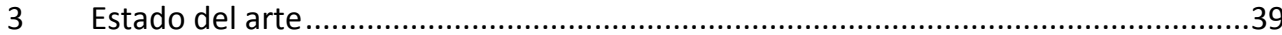

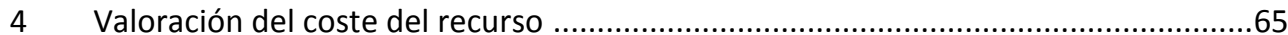

5 Metodología para el diseño de una política eficiente de precios.............................113

6 Caso de aplicación. Sistema de explotación del río Mijares .....................................155

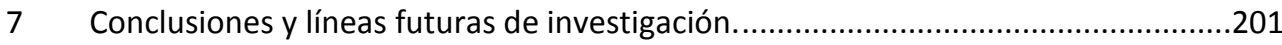

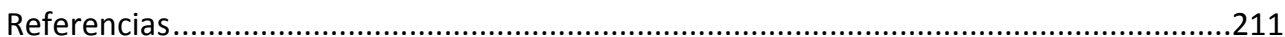

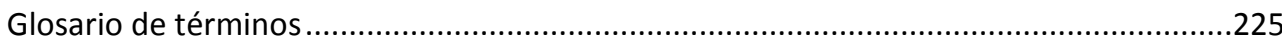

Anejo A: Recursos hídricos, infraestructura, modelo de gestión y datos económicos de la

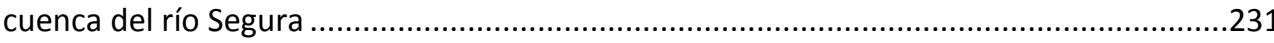

Anejo B: ECOWIN: evaluador económico del SAD AquaTool. ........................................277

Anejo C. Infraestructura del Sistema de Explotación del Río Mijares, curvas de demanda y coste de escasez 



\section{Contenido ampliado}

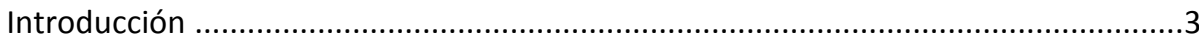

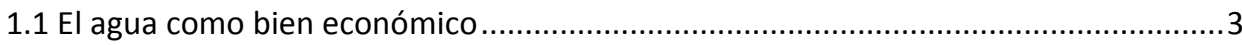

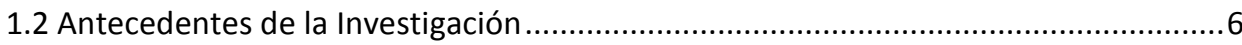

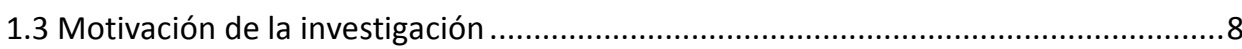

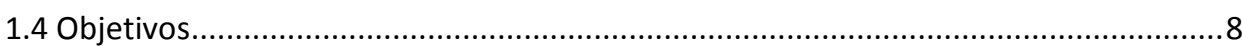

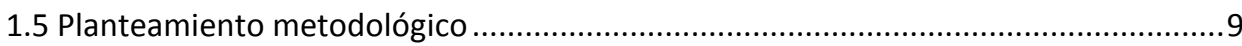

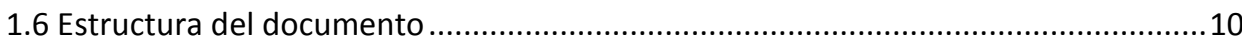

2 Precios del agua. Teoría y contexto institucional .........................................................15

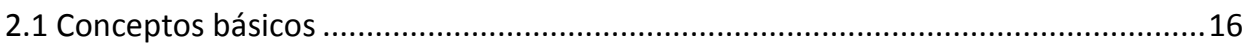

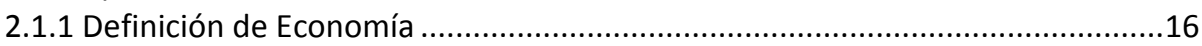

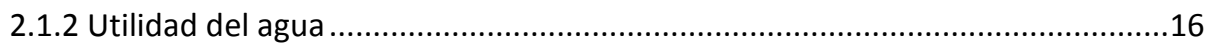

2.1.3 Demanda del agua. Perspectivas diferentes....................................................18

2.1.4 Mecanismos de asignación del agua ..............................................................20

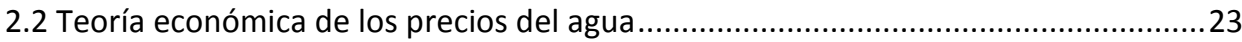

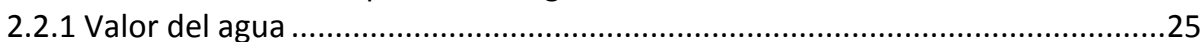

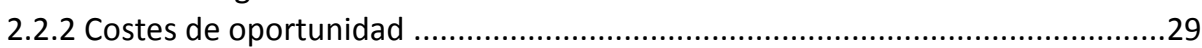

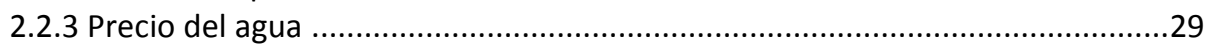

2.2.4 Políticas de precio, escasez y cambios estacionales .........................................32

2.3 Contexto institucional. Directiva Marco europea del Agua...........................................32

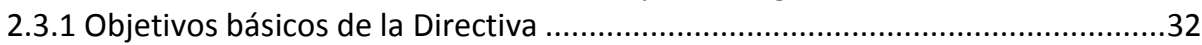

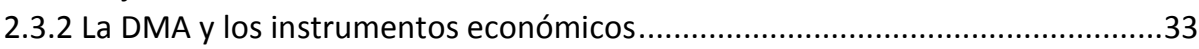

2.3.3 Recuperación de costes de los servicios del agua .............................................34

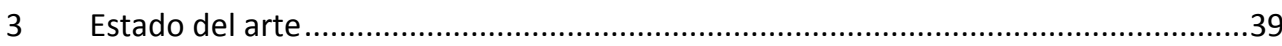

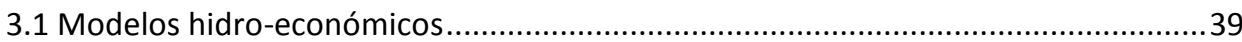

3.1.1 Modelo CALVIN del sistema de recursos hídricos de California ........................41

3.1.2 Modelo WAS del río Jordán (Oriente Medio) ..................................................42

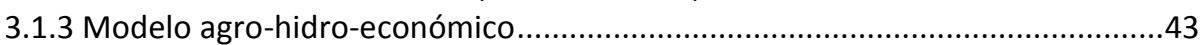

3.1.4 Modelo AgriCom Mozart DSS-AMDSS ..............................................................4

3.1.5 Modelo integrado para mitigación de sequías en el Río Grande........................46

3.1.6 Sistema de Apoyo a las Decisiones WSM .......................................................47

3.1.7 Sistema de Apoyo a las Decisiones Aquatool-EcoWin .......................................48

3.2 Caracterización económica de un sistema de recursos hídricos ................................49

3.2.1 Funciones económicas de demanda agrícola ......................................................50

3.2.2 Funciones económicas de demanda en el uso urbano ......................................52

3.2.3 Valor económico del agua en usos ambientales, estéticos, recreativos ............54

3.2.4 Valor marginal, beneficio y coste de escasez del agua .......................................54

3.3 Coste de oportunidad del recurso .........................................................................5

3.3.1 El grupo de expertos WATECO 


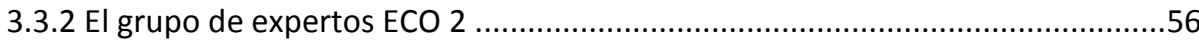

3.3.3 Aplicaciones e implicaciones en Alemania ..........................................................56

3.3.4 Proyecto Water Strategy Managment ................................................................58

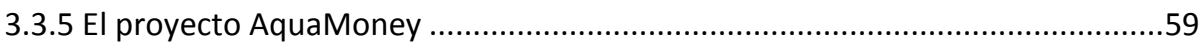

3.3.6 Metodología de la UPV. Modelos hidro-económicos y CMOR .........................61

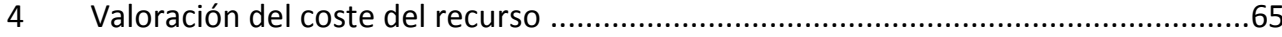

4.1 Coste Marginal de Oportunidad del Recurso .........................................................66

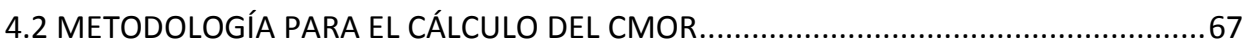

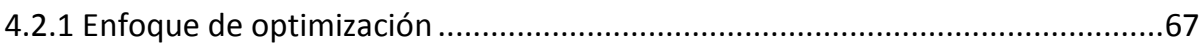

4.2.2 Enfoque de simulación ..........................................................................68

4.3 CMOR como Valores Sombra del Modelo de Optimización GAMS ...........................69

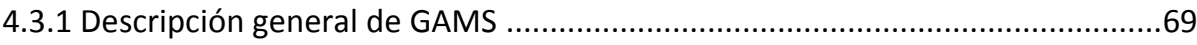

4.3.2 Optimización económica de la gestión ......................................................70

4.4 El CMOR mediante modelo de simulación del SAD Aquatool ..................................74

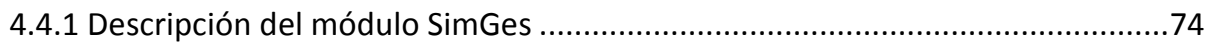

4.4.2 Simulación de la gestión mediante SimGes .................................................75

4.4.3 El evaluador económico EcoWin del SAD Aquatool .........................................77

4.5 Ejemplo. Aplicación al sistema de la cuenca del río Segura ....................................82

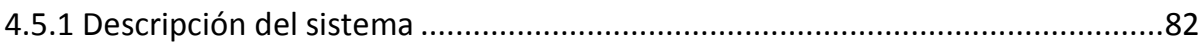

4.5.2 Modelo de gestión del sistema del Segura .........................................................91

4.5.3 Caracterización económica del sistema.....................................................101

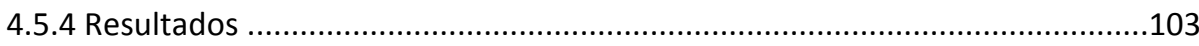

$5 \quad$ Metodología para el diseño de una política eficiente de precios ............................113

5.1 Descripción de la metodología .........................................................................114

5.1.1 Diferencias entre simulación y optimización. La predicción perfecta ..............119

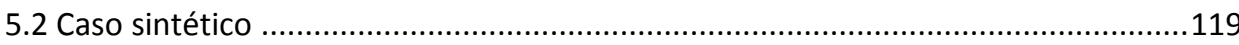

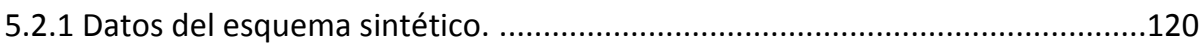

5.2.2 Simulación con prioridades y optimización económica................................122

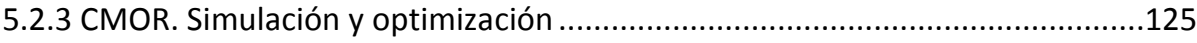

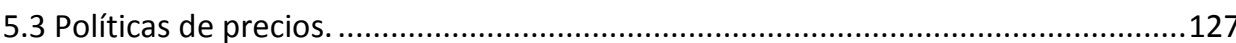

5.3.1 Políticas de precios escalonados en función del volumen almacenado ...........127

5.3.2 Precios escalonados según umbrales de aportaciones. ......................................133

5.3.3 Precios anuales constantes en función del volumen embalsado y aportaciones

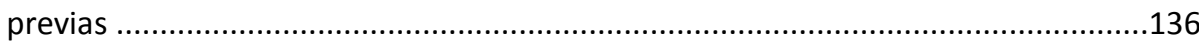

5.3.4 Precios estacionales en función del volumen embalsado y aportaciones

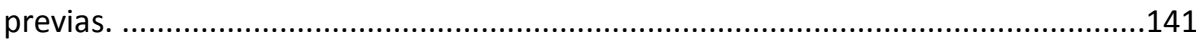

5.3.5 Análisis de la eficacia de precios con series sintéticas de aportaciones. ..........146

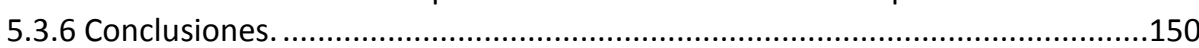

6 Caso de aplicación. Sistema de explotación del río Mijares ...................................155

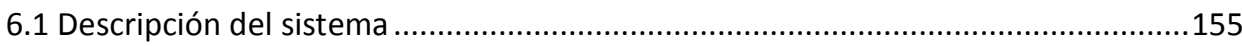

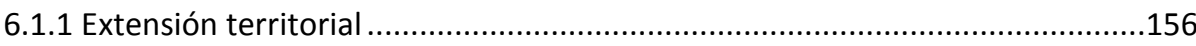

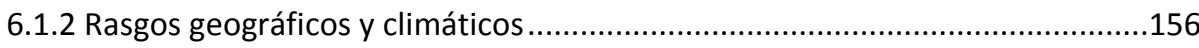

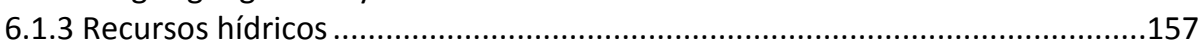




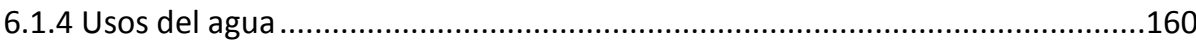

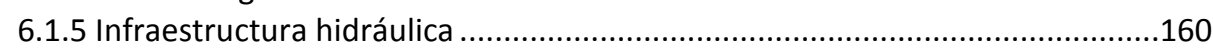

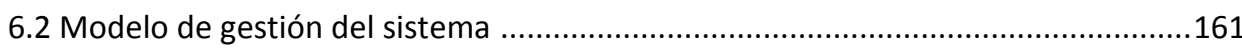

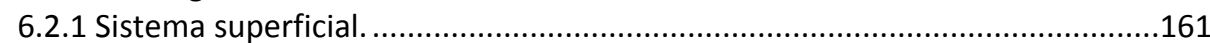

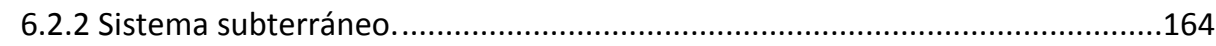

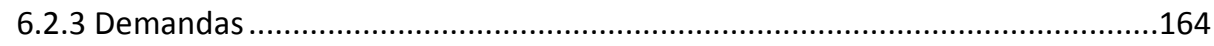

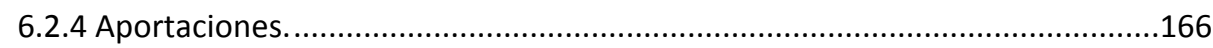

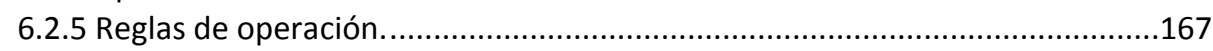

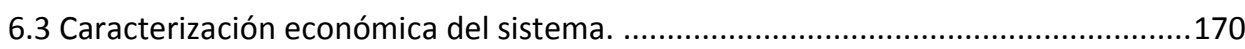

6.3.1 Curvas de demanda económica...................................................................170

6.3.2 Costes variables de operación del agua subterránea. ......................................175

6.4 Simulación con prioridades. Coste del Recurso.................................................175

6.4.1 Análisis de resultados de la simulación. Coste de escasez ..............................176

6.4.2 Análisis de resultados de la simulación. Coste del recurso en los embalses ...180

6.4.3 Coste marginal de oportunidad de caudal ecológico (CMOCE) .........................182

6.4.4 Análisis de sensibilidad del CMOR .............................................................183

6.5 Optimización económica de la gestión. Coste de escasez y CMOR ..........................184

6.5.1 Modelo de optimización de la gestión del río Mijares ....................................185

6.5.2 Análisis de resultados de la optimización económica. Coste de escasez y suministro a la demanda .................................................................................186 6.5.3 Análisis de resultados de la optimización económica. Coste del recurso en los embalses del sistema......................................................................................188 6.5.4 Comparación entre la simulación de la gestión y la optimización económica 188

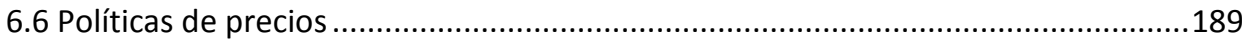

6.6.1 Precios escalonados a partir del CMOR en embalses ...................................189

6.6.2 Precios escalonados óptimos.......................................................................193

6.6.3 Conclusiones en la determinación de políticas eficientes de precios para la cuenca del Mijares............................................................................................ 195

7 Conclusiones y líneas futuras de investigación.....................................................201

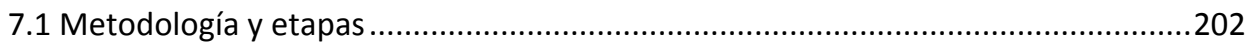

7.2 Políticas de precios y CMOR. Conclusiones de la aplicación a los casos de estudio 205

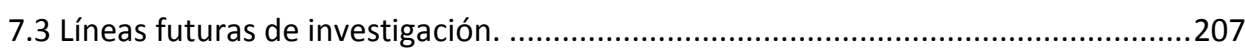

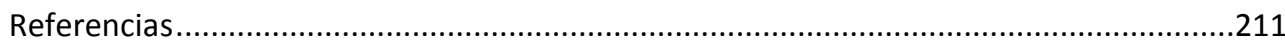

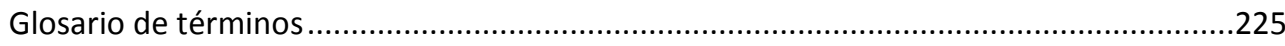

Anejo A: Recursos hídricos, infraestructura, modelo de gestión y datos económicos de la

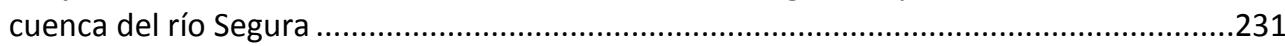

Anejo B: ECOWIN: evaluador económico del SAD AquaTool. .........................................277

Anejo C. Infraestructura del Sistema de Explotación del Río Mijares, curvas de demanda y coste de escasez. 



\section{Índice de figuras}

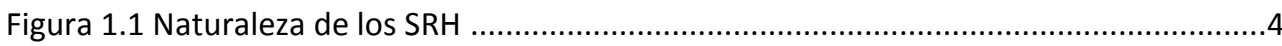

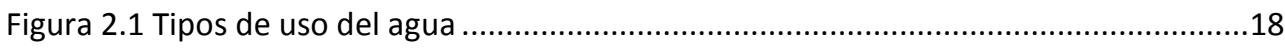

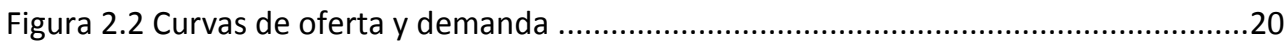

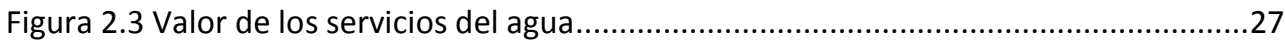

Figura 3.1 Funcionamiento del modelo Agricom-Mozart ................................................45

Figura 3.2 Opciones identificadas para la isla de Paros ..................................................48

Figura 3.3 Curva de demanda económica en el regadío .........................................................50

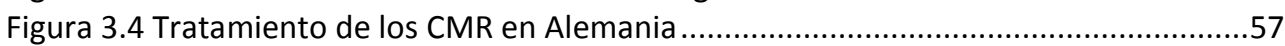

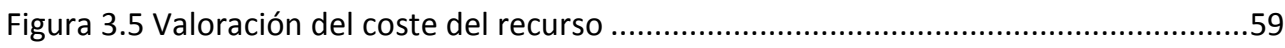

Figura 3.6 Integración del Coste Económico Total en los Países bajos ...............................60

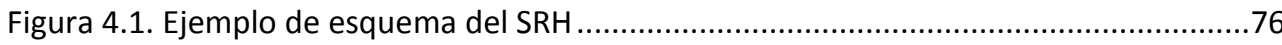

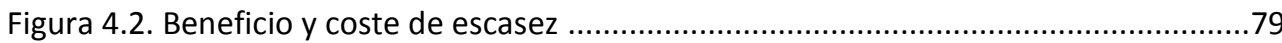

Figura 4.3 Aproximación del CMOR mediante simulación ................................................80

Figura 4.4 Diagrama de flujo para calcular el CMOR ..........................................................81

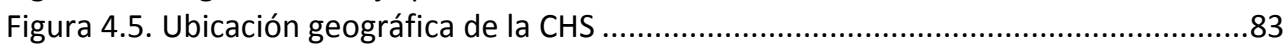

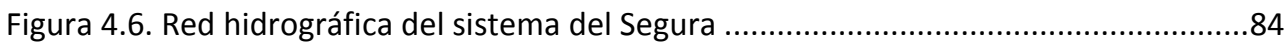

Figura 4.7 Precipitación media anual en el ámbito de la CHS (PHCS, 1998) ........................85

Figura 4.8 Distribución espacial de la precipitación media anual en el ámbito de la CHS ...85

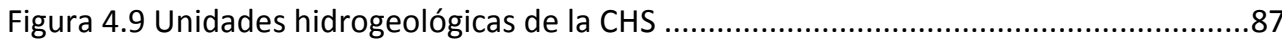

Figura 4.10 Demandas totales en el ámbito de la CHS....................................................8

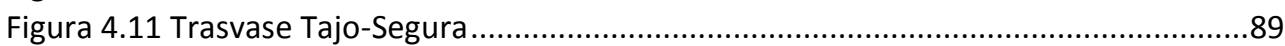

Figura 4.12 Principales embalses en el ámbito de la CHS ................................................91

Figura 4.13 Definición del tipo de conducción en el modelo hidrológico ...........................94

Figura 4.14 Aplicación del recurso hídrico al regadío .....................................................97

Figura 4.15 Aportaciones restituidas a régimen natural ................................................98

Figura 4.16 Aportaciones restituidas a régimen natural. Guardamar ...............................99

Figura 4.17 Serie de aportaciones al embalse de Cenajo..................................................99

Figura 4.18 Aportación según reglas de explotación del ATS .........................................100

Figura 4.19 Esquema SimGes para la Cuenca del Segura. Principales Cauces y embalses.101

Figura 4.20. Ejemplo de una curva de demanda económica ..............................................102

Figura 4.21 Coste de escasez y suministro a la demanda en Valle del Guadalentín, Vega

Media, Vega Baja y Regadíos Superficiales Tobarra-Albatara-Agramón............................104

Figura 4.22 Coste de escasez vs. Suministro a la demanda en UDAs: Nuevos Riegos

Trasvase, Canal de Helín, Vega del Mundo y Hellín-Tobarra ............................................105

Figura 4.23 Coste de escasez vs. Suministro a la demanda en UDAs: Tradicionales Vega

Alta, Yecla-Jumilla, Quibas-Crevillente y Regadíos Levante de la margen izquierda .........105

Figura 4.24 Coste de escasez vs. Suministro a la demanda en UDAs: Riegos embalse Argos,

Ascoy-Sopalmo, Acuifero Vega Alta, La Pedrera .......................................................106

Figura 4.25 Coste de escasez vs. Suministro a la demanda en UDAs: Campo Cartagena,

Mazarrón Águilas, Almería Sur y Río Mula ......................................................................107

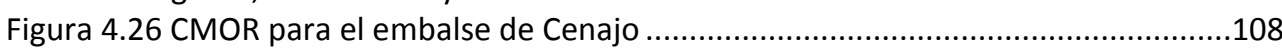

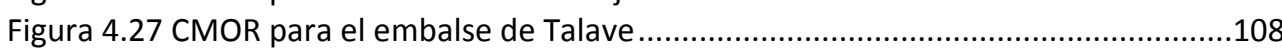

Figura 4.28 Estadísticos del CMOR para el embalse Cenajo .............................................109

Figura 4.29 Estadísticos del CMOR para el embalse de Talave ........................................109

Figura 5.1 Esquema de la metodología propuesta............................................................115

Figura 5.2 Proceso para la obtención de precios escalonados en ....................................116 
Figura 5.3. Políticas de precio. Cálculo de restricciones de suministro..............................117

Figura 5.4 Incorporación de precios en SimGes ...............................................................118

Figura 5.5 Esquema SimGes del caso sintético ..............................................................120

Figura 5.6 Aportaciones mensuales al embalse. Caso sintético......................................120

Figura 5.7 Aportaciones anuales al embalse. Caso sintético.............................................121

Figura 5.8 Demandas mensuales y anuales para los usos del caso sintético .....................121

Figura 5.9 Funciones económicas del caso sintético ...................................................122

Figura 5.10 Volumen embalsado. Optimización y Simulación .........................................123

Figura 5.11 Suministro a las demandas....................................................................124

Figura 5.12. Déficit de suministro a la demanda ..........................................................124

Figura 5.13 Coste de escasez mensual .....................................................................126

Figura 5.14 Series mensuales de volumen embalsado ......................................................126

Figura 5.15. CMOR por rango de volumen embalsado. Simulación y optimización ..........127

Figura 5.16. Políticas de precio derivadas del CMOR ....................................................128

Figura 5.17. Suministro a las demandas. Precios escalonados CMOR de simulación ........129

Figura 5.18. Beneficios Anuales. Precios con CMOR de simulación ....................................129

Figura 5.19. Suministro a las demandas. Precios escalonados, ........................................130

Figura 5.20. Beneficios anuales. Precios con CMOR de la optimización ...........................131

Figura 5.21. Política de precios escalonados óptimos.................................................132

Figura 5.22. Suministro a las demandas. Precios escalonados óptimos ..........................132

Figura 5.23. Beneficios anuales. Precios escalonados, ...............................................133

Figura 5.24. Sequías para el Caso sintético (con umbral igual a aportación media) ..........134

Figura 5.25. Política de precios para umbrales de aportaciones .....................................134

Figura 5.26. Suministro a las demandas. Precios escalonados, CMOR de la simulación,

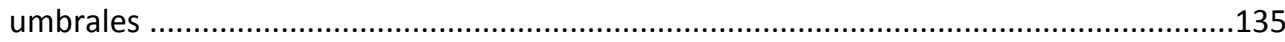

Figura 5.27. Beneficios anuales. Precios escalonados. CMOR de simulación .....................135

Figura 5.28. CMOR (valor sombra) de la optimización teórica y volumen embalsado ......137

Figura 5.29. Comparativa CMOR de optimización y valores de la función de precios ........138

Figura 5.30. Volumen mensual y valores de la función de precios (ctes. para cada año)..138

Figura 5.31. Beneficios anuales. Precios utilizando el CMOR............................................139

Figura 5.32. Comparativa de CMOR de simulación y función de precios ajustada ............140

Figura 5.33. Beneficios anuales. Precios utilizando el CMOR..............................................140

Figura 5.34. Comparativa CMOR de optimización y precios estacionales .........................142

Figura 5.35. Volumen mensual y valores de la función de precios ..................................143

Figura 5.36. Precios en función del volumen embalsado y aportaciones previas con ajustes

estacionales utilizando el CMOR (valor sombra) de optimización teórica .........................143

Figura 5.37 Ajuste del CMOR de la simulación por estaciones ............................................144

Figura 5.38. Precios en función del volumen embalsado y aportaciones previas con ajustes

estacionales utilizando el CMOR de la simulación sin precios ........................................145

Figura 5.39. Normalización de la serie de aportaciones ..............................................147

Figura 5.40. Función de autocorrelación mensual de la serie residual .............................148

Figura 5.41. Funciones de autocorrelación mensuales ................................................148

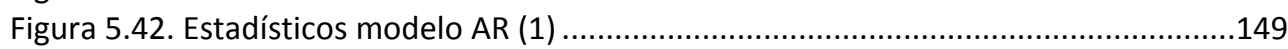

Figura 6.1 Ubicación geográfica del SRH del río Mijares................................................156

Figura 6.2 Red hidrográfica del sistema del Mijares .........................................................157

Figura 6.3 Unidades Hidrogeológicas en Mijares Plana de Castellón................................159

Figura 6.4 Demandas totales del sistema Mijares-Plana de Castellón................................160

Figura 6.5 Principales embalses del sistema Mijares-Plana de Castellón ...........................161 
Figura 6.6 Definición del tipo de conducción en el modelo de gestión ..............................163

Figura 6.7 Esquema del tramo final del Mijares................................................................164

Figura 6.8 Unidades de demanda agrícola del sistema del río Mijares.............................165

Figura 6.9 Distribución mensual de la asignación del agua en las demandas agrícolas.....165

Figura 6.10 Series restituidas a régimen natural en escala mensual .................................166

Figura 6.11 Curva de reserva del Convenio 1970 .........................................................167

Figura 6.12 Esquemas correspondientes al modelo de simulación de la gestión del sistema

del río Mijares .............................................................................................................169

Figura 6.13 Curva de demanda ajustada para la zona de Castellón ..................................170

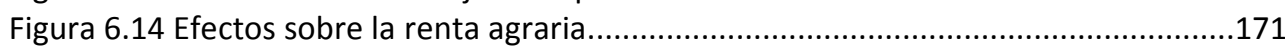

Figura 6.15 Ejemplo de una curva de demanda económica .........................................172

Figura 6.16 Consideraciones en las curvas de demanda .....................................................172

Figura 6.17 Ejemplo de curva de demanda económica completa ..................................173

Figura 6.18 Curvas de demanda urbana .................................................................174

Figura 6.19 Volumen embalsado en Arenós. Simulación ...................................................176

Figura 6.20 Coste de escasez y suministro en las UDAs consideradas en la simulación ....177

Figura 6.21 Déficit de suministro a las demandas.........................................................178

Figura 6.22 Coste de escasez agrícola y volumen embalsado ........................................178

Figura 6.23 Costes de escasez en diferentes UDAs ...........................................................179

Figura 6.24 Beneficios anuales en las diferentes UDAs del Mijares. Simulación ...............180

Figura 6.25 Valor del recurso en el embalse Arenós. Simulación ....................................181

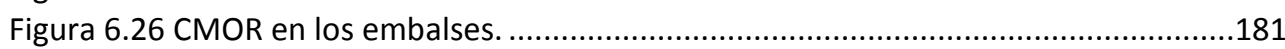

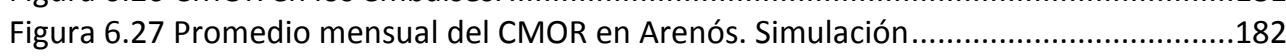

Figura 6.28 Coste marginal del recurso para caudal ecológico .........................................183

Figura 6.29 Variación en las curvas de demanda económica..........................................183

Figura 6.30 Variación del CMOR. Embalse de Arenós ...................................................184

Figura 6.31 Volumen embalsado en Arenós. Optimización ...........................................186

Figura 6.32 Suministro a las demandas.......................................................................186

Figura 6.33 Déficit de suministro a las demandas.........................................................187

Figura 6.34 Beneficios anuales en las diferentes UDAs del Mijares. Optimización............187

Figura 6.35 Valor marginal del recurso (CMOR) en el embalse Arenós. Optimización .......188

Figura 6.36. Políticas de precios derivadas del CMOR de simulación ................................190

Figura 6.37. Suministros a las demandas. Precios del CMOR de simulación ......................191

Figura 6.38. Beneficios medios anuales por uso. Precios del CMOR de simulación ..........191

Figura 6.39. Suministros a las demandas. Precios del CMOR de la optimización ...............192

Figura 6.40 Beneficios medios anuales por uso. Precios del CMOR de optimización ........193

Figura 6.41.Políticas de precios CMOR óptimos .........................................................194 



\section{Índice de Tablas}

Tabla 3.1 Implicaciones de la optimización económica e ingenieril. Modelo CALVIN .........42

Tabla 4.1 Caudales mínimos en los tramos de ríos modelados ..........................................94

Tabla 4.2 Plantas desalinizadoras consideradas en el modelo ........................................95

Tabla 4.3 Unidades de demanda urbana consideradas en el modelo .................................97

Tabla 4.4 Unidades de demanda industrial consideradas en el modelo .............................98

Tabla 5.1 Beneficios y déficits medios anuales ..............................................................125

Tabla 5.2 Beneficios medios anuales por metodologías. Caso sintético ..............................130

Tabla 5.3 Beneficios medios anuales por metodologías. Caso sintético .............................131

Tabla 5.4 Beneficios medios anuales por metodologías. Caso sintético .............................133

Tabla 5.5 Beneficios medios anuales por metodologías. Caso sintético ...........................136

Tabla 5.6 Beneficios medios anuales por metodologías. Caso sintético ............................139

Tabla 5.7 Beneficios medios anuales por metodologías. Caso sintético ............................141

Tabla 5.8 Beneficios medios anuales por metodologías. Caso sintético ............................144

Tabla 5.9 Beneficios medios anuales por metodologías. Caso sintético .............................146

Tabla 5.10. Estadísticos de las series de aportaciones anuales ........................................147

Tabla 5.11. Beneficios medios anuales por metodologías. Series de aportaciones ...........150

Tabla 5.12 Suministro medio anual por metodologías. Caso sintético ...............................151

Tabla 6.1 Características de los cauces del sistema Mijares-Plana de Castellón ...............158

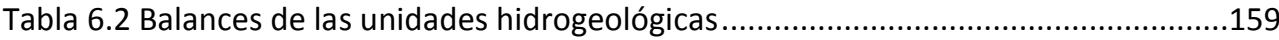

Tabla 6.3 Demanda urbana anual por UHG ....................................................................166

Tabla 6.4 Costes de extracción del agua subterránea. Mijares...........................................175

Tabla 6.5 Comparación de suministros anuales. Mijares ...................................................189

Tabla 6.6 Comparación de beneficios anuales. Mijares ................................................189

Tabla 6.7 Suministro anual. Precios escalonados...........................................................192

Tabla 6.8 Beneficio medio anual. Precios escalonados. Mijares ......................................193

Tabla 6.9 Suministro anual. Precios escalonados óptimos .............................................194

Tabla 6.10 Beneficio medio anual. Precios escalonados óptimos. Mijares.........................195

Tabla 6.11 Beneficio medio anual. Mijares ......................................................................196

Tabla 6.12 Suministro anual a las demandas .Mijares ...................................................197 

CAPÍTULO 1

Introducción 



\section{Introducción}

En este capítulo se describe la naturaleza del agua, considerada como un bien económico, con el fin de enmarcar en forma general el trabajo desarrollado en esta tesis; se indican los antecedentes en materia de valoración del coste del recurso hídrico y se presentan las ideas generales que fueron motivación para la realización del presente trabajo; se enumeran los objetivos planteados para el desarrollo de la tesis y se hace el planteamiento metodológico seguido para el desarrollo del trabajo presentado. Finalmente se hace una descripción breve de la estructura del documento.

\subsection{El agua como bien económico}

Los Sistemas de Recursos Hídricos (SRH, en adelante) poseen, en general, diferentes tipos de naturaleza (Figura 1.1). Por un lado, su propia naturaleza física permite que sean útiles como medio de transporte de cargas de todo tipo y aún de residuos; sirven como fuente generadora de energía que se aprovecha en los asentamientos humanos o industrias aledañas; se utilizan como el medio para la disolución de carga contaminante o de 
desecho de las industrias, con el fin de minimizar las afectaciones a los usuarios del recurso aguas abajo; dan, en gran medida, soporte biológico a la flora, la fauna y a los seres humanos; se utilizan también como agente refrigerante o transmisor de calor; $y$, por qué no, los SRH se usan como un elemento recreativo y de esparcimiento para el ser humano.

Por otro lado, los SRH deben conservar el estado ecológico del agua y del entorno, tal que no se provoquen daños al medio ambiente y que satisfagan la normativa de calidad necesaria para que el recurso hídrico satisfaga, en calidad y en cantidad, las demandas agrícolas, urbanas e industriales.

Los SRH poseen también una naturaleza de tipo sociopolítico. El estilo de vida, las tradiciones y el sentido de colectividad de un núcleo de población, darán como consecuencia que se le asigne siempre un valor de tipo social al agua. Es notorio mencionar, que hoy día el recurso hídrico juega un papel muy importante en las decisiones políticas y sociales de una entidad. En la asignación del recurso, se toma en cuenta -casi siempre- la afectación o beneficio que se le puede proporcionar a cierto núcleo de población o sector de utilización del agua.

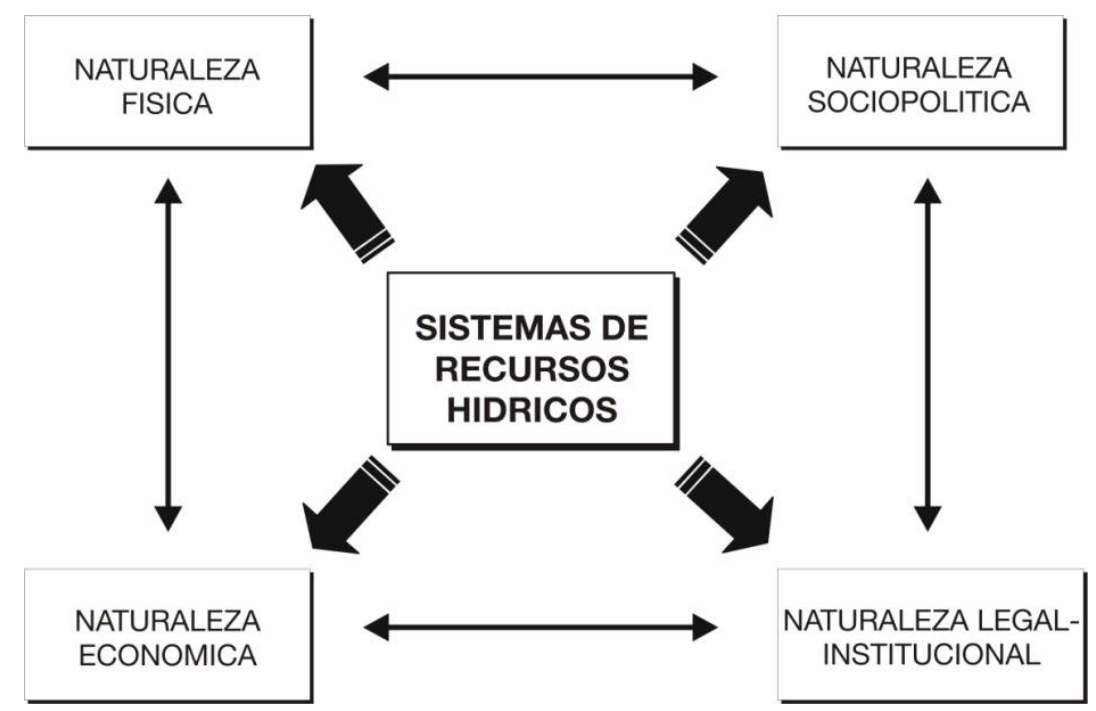

Figura 1.1 Naturaleza de los SRH

Adicionalmente los SRH poseen una naturaleza legal e institucional. Esta naturaleza se ha hecho propia porque el agua es considerada como un bien público que ha de administrarse conforme a planes y leyes que regulen las asignaciones del recurso a los diferentes sectores de la población. 
Uno de los aspectos muy importante del agua y que van cobrando mayor relevancia en la actualidad es su naturaleza económica. El agua es hoy por hoy considerada como un bien económico y es también un recurso limitado (capital) que los sectores económicos lo utilizan generando bienes de producción. En una asignación económicamente eficiente, el beneficio marginal del uso de los recursos deberá ser igual para todos los sectores con el fin de maximizar el bienestar social. En otras palabras, el beneficio de usar una unidad adicional del recurso en uno de los sectores debería ser el mismo que en otro sector. Si no es así, la sociedad se beneficiaría asignando agua al sector en donde los beneficios o retornos fueran los más altos. La asignación del recurso hídrico, además, debe basarse en la equidad. Los objetivos de la equidad se refieren principalmente a la justicia en la asignación del agua entre grupos económicos dispares y pueden, o no, ser consistentes con los objetivos relativos a la eficiencia (Dinar y Letey, 1996).

En la Declaración de Dublín sobre el Agua y el Desarrollo Sostenible (adoptada en la Conferencia Internacional sobre Agua y Medio Ambiente celebrada en dicha ciudad en 1992), se defendió que: el agua es un recurso finito y vulnerable, esencial para sostener la vida, el desarrollo y el medio ambiente; el aprovechamiento y la gestión del agua debe inspirarse en un planteamiento basado en la participación de los usuarios, los planificadores y los responsables de las decisiones a todos los niveles; las mujeres desempeñan un papel fundamental en el abastecimiento, gestión y cuidado del agua; el agua tiene un valor económico en todos sus diversos usos en competencia a los que se destina y debería reconocérsele como un bien económico. En virtud de este último principio, es esencial reconocer ante todo el derecho fundamental de todo ser humano a tener acceso a un agua limpia y al saneamiento por un precio asequible. La ignorancia, en el pasado, del valor económico del agua ha conducido al derroche y a la utilización de este recurso con efectos perjudiciales para el medio ambiente. La gestión del agua, en su condición de bien económico, es un medio importante de conseguir un aprovechamiento eficaz y equitativo y de favorecer la conservación y protección de los recursos hídricos.

Esta misma declaración hace énfasis en la conservación y reaprovechamiento del agua, e indica que existe un amplio campo para poder economizar un volumen considerable de agua en la agricultura, en la industria, y en el abastecimiento para uso doméstico. Además, indica la Declaración, "la agricultura de regadío contabiliza alrededor del $80 \%$ del agua consumida en el mundo y en muchos sistemas de riego se pierde hasta el $60 \%$ de agua desde su lugar de procedencia hasta su destino. Gracias a prácticas más eficientes de riego se podrá lograr un ahorro sustancial del agua. El reciclado podría disminuir el consumo de muchos consumidores del sector industrial en un 50\% como mínimo, además de ofrecer la ventaja complementaria de disminuir la contaminación. La aplicación del principio de que "quien contamina paga" y la fijación de precios que reflejen el valor real del agua fomentarán la conservación y el reaprovechamiento del recurso". 
Acota la Declaración que "en términos medios, el 36\% del agua suministrada por los servicios urbanos de abastecimiento de los países en desarrollo "desaparece". Una mejor gestión podría reducir estas costosas pérdidas. Gracias al efecto combinado de las economías realizadas en la agricultura, la industria y el abastecimiento de agua para uso doméstico podría diferirse de manera significativa la inversión en costosos proyectos nuevos de aprovechamiento de recursos hídricos, y ello influiría de manera considerable en la posibilidad de mantener la sostenibilidad de abastecimientos futuros. Podrían realizarse otras economías gracias al uso múltiple del agua. La observancia de normas eficaces de descarga basadas en nuevos objetivos de protección del agua permitirá a los sucesivos consumidores reaprovechar el agua que al presente está demasiado contaminada después del primer uso".

El más controvertido de los Principios de Dublín es el cuarto, y la mayoría del debate internacional se ha centrado en las ventajas y desventajas de los mercados libres y de la privatización. La eficiencia económica en el uso y asignación de las aguas es muy importante y las fuerzas del mercado juntamente con los incentivos económicos, incluidos los precios, son herramientas poderosas para aumentar la eficiencia. Los Principios de Dublín tratan de conciliar diferentes visiones en relación al recurso hídrico. El agua tiene un valor económico en todos sus usos que compiten entre sí y debería ser reconocido como un bien económico, pero también el agua debería ser reconocida como un recurso escaso, lo que significa que las reservas disponibles son insuficientes para satisfacer todas las demandas haciéndose necesario adoptar soluciones de compromiso al momento de asignarla a los diferentes usos (Bauer, 2004).

En España, la asignación de los recursos hídricos de sus cuencas es un proceso complejo que se desarrolla con base en sistemas institucionales y legales vigentes hasta hoy, los cuales establecen derechos de usos y prioridades entre los usuarios del recurso hídrico común. Sin embargo, de entre muchos factores involucrados en el proceso, el relativo a la eficiencia económica no suele tomarse en cuenta directamente (Collazos et al., 2004).

\subsection{Antecedentes de la Investigación}

La Directiva Marco europea del Agua (DMA, Comisión Europea, 2000) introduce en la política del agua los conceptos tanto de costes medioambientales y del recurso como costes de los servicios del agua. El artículo 9 de la DMA estipula que "los Estados miembros tendrán en cuenta el principio de recuperación de los costes de los servicios relacionados con el agua, incluyendo los costes medioambientales y los relativos a los recursos..." 
Sin embargo, en el texto de la directiva no se define con claridad cómo se valoran estos costes, por lo que para lograr tal cometido se constituyeron grupos europeos de trabajo como por ejemplo el grupo WATECO y el grupo DG Eco 2. El primer grupo ha estado conformado por expertos de los diferentes Estados Miembros de la Comunidad Europea y ha tenido interacción con otros grupos de trabajo. Se ha ocupado en definir la Guía para el Análisis Económico y tan solo se ha limitado a definir teóricamente los conceptos de los Costes Medio Ambientales y del Recurso. El segundo grupo de expertos (ECO2), creado en septiembre de 2003 en virtud de la Estrategia Común de Implementación (CIS, por sus siglas en inglés) del Grupo de Trabajo de Gestión integral de Cuencas (WG2B) preparó la redacción de la hoja de información no vinculante sobre la definición y evaluación de los costes ambientales y de recursos en el contexto de la aplicación de la DMA; aunque también sigue lo indicado por el grupo WATECO, adopta una lógica diferente para la evaluación de los costes. A pesar de esto, aporta poca guía en cuanto a la aplicación práctica de los Costes Medioambientales y del Recurso.

El proyecto AquaMoney financiado por el 60 Programa Marco de la Unión Europea (2006-2009) tuvo como objetivo desarrollar y probar guías prácticas para la valoración de los costes y beneficios medioambientales y del recurso, de acuerdo a lo estipulado en la DMA. Algunos logros del proyecto son: evaluación de la demanda responsable de la política de información sobre los costes ambientales y de recursos y beneficios, relacionadas con la aplicación de la DMA; desarrollo de directrices orientadas a la práctica sobre cómo evaluar los costes ambientales y de recursos y beneficios de una manera rápida y fiable, con especial énfasis en la transferencia de valores entre los diferentes sitios; prueba de estas directrices mediante la realización de estudios de valoración económica en diez diferentes cuencas fluviales europeas; análisis de las experiencias realizadas y formulación de recomendaciones para la toma de decisiones. La experiencia adquirida en los estudios de casos se ha utilizado para perfeccionar las directrices. El diseño común de los estudios de caso también ha permitido la investigación de técnicas para la transferencia de valores económicos de los costes ambientales y de recursos y los beneficios desde el nivel del agua en el cuerpo nacional e internacional a nivel de cuenca, y viceversa. Parte de este ejercicio ha sido investigar la posibilidad de utilizar sistemas de información geográfica (SIG) para la síntesis de los datos de los estudios de caso con el entorno físico y los datos disponibles del censo, a fin de generar mapas de los beneficios esperados de la mejor calidad del agua debido a la aplicación de la DMA.

En un informe de la Comisión de las Comunidades Europeas (COM, 2000) se señala que la política de tarificación del agua deberá ser aplicada de manera que se promueva la recuperación de los costes del servicio y que se dé un mejor uso al recurso hídrico; además hay la necesidad de contar con información más abundante y precisa referente a las demandas, los costes y los beneficios que permitan determinar niveles y estructuras de precios adecuados. 
En España, el grupo de Ingeniería de Recurso Hídricos del Instituto de Ingeniería del Agua y Medio Ambiente ( http://www.iiama.upv.es ) ha participado activamente en los estudios de implementación de la DMA en distintas cuencas en España, desarrollando metodologías y herramientas para establecer modelos de gestión y modelos hidroeconómicos a escala de cuenca (véase por ejemplo: Pulido Velázquez, 2003; Collazos 2004; Pulido-Velázquez et al., 2006a; Heinz et al. 2007).

\subsection{Motivación de la investigación}

Esta investigación surge del planteamiento llevado a cabo por la Directiva Marco del Agua (DMA) con relación a las políticas de agua que los estados miembros de la Comunidad Europea tendrán que adoptar. Una de las grandes necesidades que cada estado tendrá que satisfacer es la relacionada con la recuperación de los costes del recurso del agua, y el establecimiento de políticas de precios que consideren el punto anterior y que contribuyan de forma eficiente a lograr los objetivos de la DMA.

Todos los Estados Miembros tendrán que implementar políticas de precios del agua de manera que cubran los costes de los servicios del agua, proporcionando incentivos para que los usuarios utilicen de forma eficiente los recursos hídricos (art. 9, DMA). Bajo esta perspectiva, resulta necesario investigar cuál es el funcionamiento actual de las tarifas, cánones y precios del agua actualmente en España, así como el impacto que una nueva política de precios establecida tenga sobre el coste del recurso hídrico.

Por lo general las políticas de precio se definen con base en criterios políticos e institucionales, fundamentados en la recuperación (generalmente parcial y en forma muy subvencionada) de los costes financieros de inversión. La intención con este trabajo es, como reza el título de la tesis, definir una metodología para derivar políticas de precios eficientes a escala de cuenca que incorporen los costes marginales de oportunidad del recurso.

\subsection{Objetivos}

El objetivo principal de la tesis es definir un procedimiento metodológico que permita la valoración práctica de los costes de oportunidad de los servicios del agua a escala de cuenca y las implicaciones en el diseño de una política de precios eficiente a escala de cuenca, tomando en cuenta los requerimientos de la Directiva Marco europea del Agua (DMA).

El objetivo principal puede dividirse en los siguientes objetivos o metas específicas: 
- Investigar las diferentes metodologías o propuestas metodológicas que se han llevado a cabo en los Estados de la Unión Europea para la valoración de los costes del recurso.

- Investigar la integración del modelo económico al modelo de simulación hidrológica en la gestión del recurso.

- Revisar los modelos hidro-económicos existentes.

- Plantear modelos hidro-económicos de simulación y optimización de un Sistema de Recursos Hídricos.

- Investigar la interpretación de los resultados del modelo hidro-económico, incluyendo los costes de oportunidad en la asignación y el uso del agua.

- Desarrollar una metodología para obtener políticas de precios del agua que incorporen los costes de oportunidad del recurso a escala de cuenca.

- Comparar la eficiencia de las distintas políticas de precios establecidas.

- Estudiar la implicación de distintas políticas de gestión en términos de costes de oportunidad.

- Analizar el impacto económico de distintas políticas de precios que incorporen los costes de oportunidad del recurso.

- Aplicar las metodologías desarrolladas a un caso de estudio.

- Evaluar los resultados obtenidos del caso de estudio y obtener conclusiones viables para su operatividad en el ámbito señalado por la DMA.

\subsection{Planteamiento metodológico}

La investigación se iniciará con la revisión de las metodologías y modelos hidroeconómicos que a la fecha se utilizan en los Estados de la Unión Europea para la determinación de los costes medioambientales y del recurso de acuerdo a los lineamientos de la Directiva Marco europea del Agua (DMA). Se desarrollarán metodologías planteando un modelo hidro-económico tanto simulación como de optimización de un sistema de recursos hídricos.

Se definirá la manera de interpretar los resultados del modelo hidro-económico propuesto, de manera que se adopten a los principios establecidos por la DMA. La hipótesis básica en relación al coste del recurso es asociarlo con el coste de oportunidad en el uso de un recurso escaso. Dicho coste se integrará al modelo hidro-económico bajo los enfoques de simulación de la gestión del recurso y de optimización económica en la asignación del agua. 
Se propondrá un proceso metodológico que permita integrar adecuadamente el modelo hidro-económico a un caso específico y que permita una clara interpretación de los resultados económicos conforme a los planteamientos establecidos por la DMA.

Se analizará la variabilidad espacio-temporal del coste del recurso. Se buscarán correlaciones entre el coste del recurso y los volúmenes embalsados en las presas del sistema de recursos hídricos.

Se definirá la integración de los elementos de un sistema de recursos hídricos en el evaluador económico, de manera que se pueda calcular el beneficio total que supone aumentar o disminuir volúmenes de bombeo de desalación o caudales ecológicos en dicho sistema.

Se analizará el impacto económico de distintas estrategias de diseño/gestión. Se estudiará la incorporación de costes de oportunidad en el diseño de políticas de precios del agua, de acuerdo con los criterios de la DMA.

Por último, se validará la metodología propuesta para el diseño de políticas de precios con un caso de estudio de una cuenca hidrográfica en España.

\subsection{Estructura del documento}

Con el fin de cumplir con los objetivos definidos, el trabajo se ha estructurado de la siguiente manera: nueve capítulos dentro de los cuales se incluye la presente introducción y las conclusiones y las líneas futuras de investigación (capítulos 1 y 7 respectivamente).

El capítulo dos da cuenta de algunos aspectos teóricos relativos al precio del agua y su contexto institucional, incluyendo la definición de economía, de valor, coste y precio del agua, y de políticas de precios y coste de escasez del recurso. Se presenta también un resumen descriptivo de los aspectos principales que la Directiva Marco europea del Agua ha planteado en materia de agua para los estados miembros de la Comunidad Europea.

En el capítulo tres se presenta la revisión del estado del arte de aspectos económicos relevantes para la investigación como son: modelos hidro-económicos y el coste marginal de oportunidad del recurso (CMOR).

En el capítulo cuatro se presenta la metodología para la valoración del coste del recurso, describiéndose los modelos de optimización, GAMS; simulación, SimGes; y de cálculo económico, EcoWin. La metodología se aplica a una cuenca hidrográfica en España (cuenca del río Segura). 
En el quinto capítulo se revisan las implicaciones del CMOR en el precio del agua y se presentan los criterios adoptados en la incorporación de precios al modelo hidroeconómico, así como el procedimiento para la interpretación de los resultados y su relación con el coste del recurso hídrico. Para ello, se ha definido un caso sintético en donde se consideran diferentes escenarios de políticas de precio.

En el capítulo sexto se presenta la aplicación de la metodología propuesta para el diseño de políticas de precios al caso de estudio del sistema de explotación del río Mijares. Se incluyen los siguientes aspectos: descripción de la zona de estudio; descripción del modelo de simulación hidrológica; caracterización económica del sistema; y resultados obtenidos de la modelación hidroeconómica y sus implicaciones en la definición de una política eficiente de precios.

En el séptimo capítulo se anotan las conclusiones principales del trabajo desarrollado y se proponen algunas líneas futuras de investigación.

Finalmente se muestran las referencias consultadas y el glosario de términos empleados durante el desarrollo del trabajo. 



\section{CAPÍTULO 2}

\section{Precios del agua: teoría y contexto institucional}





\section{Precios del agua. Teoría y contexto institucional}

En este capítulo se ofrece una revisión de los conceptos básicos de la teoría económica en materia de agua. Se comentan algunas perspectivas en cuanto al término de demanda económica del agua y se analizan los distintos mecanismos de asignación del agua, incluyendo el de tarifación marginal. Se tendrán en cuenta los principios de eficiencia económica, el análisis marginal, con particular atención a los conceptos de coste de oportunidad del recurso, valor del agua, precio del recurso y políticas de precios. Por último, se presenta el contexto institucional en materia de agua enmarcado dentro de la Directiva Marco europea del Agua. 


\subsection{Conceptos básicos}

\subsubsection{Definición de Economía}

El concepto de Economía deriva de los vocablos griegos Oikos y Nomos que significan casa y administración respectivamente. La Economía, en su sentido primigenio, viene a ser el conjunto de reglas para el buen gobierno de la casa. Debe notarse que para los griegos de la antigüedad y para otras muchas culturas antiguas y vernáculas, el referente de "casa" era (y es) mucho más amplio que el que hoy se maneja en Europa. Hoy se piensa en la casa individual, separada del resto. Sin embargo, en esas otras culturas, en las que la vida se apoyaba sobre estructuras comunales amplias (como la familia, el clan, la comuna o la tribu), la "casa" era ante todo la casa común y extendía su referencia al poblado, la ciudad y el territorio. De este modo, "economía" era para los antiguos economía doméstica: un conjunto de reglas, local y propio de cada cultura, construido a través del tiempo y en permanente evolución, y aceptado como forma de integración comunitaria (Bookchin, 1974).

Sin embargo, la definición subjetiva o marginalista -según Robbins (1984)- indica que la economía es la ciencia que se encarga del estudio de la satisfacción de las necesidades humanas mediante bienes que, siendo escasos, tienen usos alternativos entre los cuales hay que optar. El problema básico de la economía - y de la Economía del Agua tambiénes, entonces, la escasez; si no hubiera escasez no habría necesidad de ciencia económica.

Si bien es cierto lo que dice Robbins, en materia de escasez del bien se puede acotar que: "la escasez física actual de agua no es la cuestión principal en la mayoría de las regiones. Parece, más bien, que prevalecen las condiciones de escasez económica: hay bastante agua para satisfacer las necesidades de la sociedad, pero pocos incentivos para lograr un uso inteligente y ahorrador de los recursos o para efectuar una asignación eficiente entre demandas alternativas" (Gibbons, 1986).

Desde el punto de vista económico los usos del agua pueden analizarse atendiendo a los parámetros de utilidad, valor, coste y precio del agua. Cada uno de estos términos tiene sin embargo un significado muy preciso que conviene siempre aclarar.

\subsubsection{Utilidad del agua}

El agua es vital para la vida en la tierra, por ello es que sus usos están directamente relacionados con todo aquello que enriquezca y beneficie el desarrollo del ser humano y el medio ambiente que le rodea. 
La primera utilidad que el hombre le dio al agua fue la del abastecimiento para satisfacer su necesidad primaria: la sed. De ahí que, al formarse las grandes comunidades, siempre ha surgido la necesidad de abastecer de agua a los pobladores de dichas sociedades. Fue entonces que el hombre empezó a desarrollar sistemas físicos que le permitiesen conducir el agua y, de esa manera, satisfacer las demandas del recurso de manera más eficaz.

Al igual que para el hombre, el agua es esencial para el desarrollo y crecimiento de la flora y de la fauna y constituye un elemento biológico prioritario. De esta verdad surge una segunda utilidad del agua que se ha dado en el devenir del desarrollo del hombre: la agricultura. El agricultor desarrolla su actividad en aquellas regiones en donde el agua está garantizada durante la mayor parte del tiempo. $Y$ esto es así debido a que las plantas requieren de una cantidad de agua necesaria no solo para subsistir, sino para que su propio desarrollo sea el máximo que pueda alcanzar. Esto último, por supuesto, beneficiará en gran manera al hombre y le proporcionará mayores dividendos en su alimentación.

Ambas actividades, abastecimiento y agricultura, están unidas íntimamente a los procesos de alimentación de los seres humanos y, en consecuencia, constituyen los dos usos principales del agua puesto que de ellos depende su propia supervivencia. Pero el agua, como cualquier otro recurso, es útil si se dispone de ella cuando se necesita. Se puede considerar, por ejemplo, que durante el período de crecidas de un determinado río se tiene agua en gran cantidad. El valor del recurso, como elemento esencial para la vida, se sigue manteniendo pero la utilidad que representa este régimen hidrológico puede ser incluso negativa, es decir, puede causar más daño que beneficio (Heras, 2000).

En la medida en que las sociedades humanas se han ido desarrollando, han surgido nuevos usos del agua. Así, al aprovechar las propiedades químicas y físicas del agua, el hombre la ha podido utilizar en procesos de tipo industrial, los cuales proporcionan al hombre bienestar y seguridad. Nace entonces el uso de tipo industrial. Una vez que el hombre ha sido capaz de producir bienes para su propia satisfacción, los pone a disposición de la sociedad y los empieza a comercializar. Surge así la industria del comercio, industria que también requiere del agua y por ende se le atribuye ese otro uso: comercial.

Los usos también pueden ser clasificados en consuntivos (consumen el agua de su lugar de origen) y no consuntivos (no consumen el agua sino exclusivamente se utiliza y se devuelve al cauce sin perjudicar a los usuarios existentes aguas abajo del mismo). La figura 2.1 muestra el detalle de esta clasificación. 


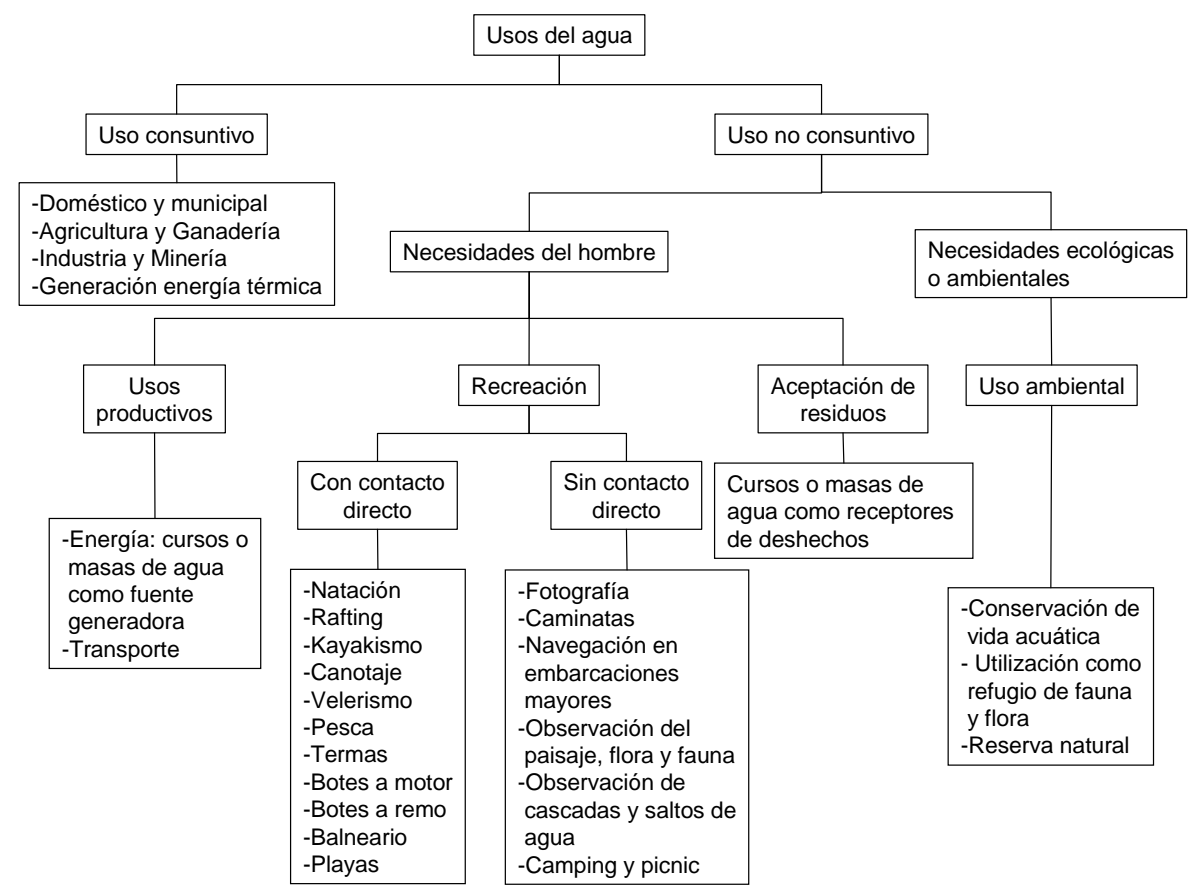

Figura 2.1 Tipos de uso del agua

Fuente:Gayoso e Iroumé (2000)

\subsubsection{Demanda del agua. Perspectivas diferentes.}

El término "demanda" según Merrett (2004) se ha empleado con al menos cuatro significados diferentes en el contexto del balance hidro-social de una región, a saber:

- Uso del agua.

- Consumo del agua.

- Necesidad del agua

- Demanda económica del agua.

\section{Uso del agua}

Este significado se refiere a la cantidad de agua por unidad de tiempo que recibe un cierto usuario. El uso del agua, directa o indirectamente es la base de la vida humana y es uno de los dos grandes pilares del balance hidro-social en un año base o en un año futuro (escenario). 


\section{Consumo del agua}

Este concepto se refiere al agua que no queda disponible para su posterior reuso o devolución al medio hídrico. En el caso del uso agrícola, el término se refiere a la evapotranspiración. La evapotranspiración implica que el agua es consumida totalmente, lo cual es variable dependiendo del tipo de uso que se le dé al recurso.

\section{Necesidad del agua}

La necesidad del agua para uso doméstico es un concepto relacionado con lo social, lo cultural y con la salud. Se refiere a niveles deseables o recomendados de uso para: beber, cocinar, asearse, realizar la limpieza de heces y orina, llevar a cabo la limpieza de la casa y el riego de jardines, y otros usos diversos.

Para el sector agrícola se refiere a los requerimientos netos de riego. Para la minería, la industria y otros sectores, la necesidad del agua es determinada técnica o institucionalmente.

\section{Demanda económica del agua}

Para los economistas, el concepto demanda se refiere a la relación, para un tiempo dado y dentro de un mercado definido, entre el precio por unidad de cualquier producto o servicio y la cantidad en cada periodo de tiempo que los usuarios están dispuestos a adquirir a ese precio.

\section{Disponibilidad de pago}

Desde el punto de vista de la Microeconomía, las curvas de demanda describen el comportamiento de los consumidores en función del precio de un bien.

Un aspecto importante en la economía del recurso hídrico es la disponibilidad de pago del usuario (Pearce y Turner, 1995). Esto está ligado a los beneficios que el usuario puede percibir del uso del recurso, el cual puede ser mayor al precio que tenga ese bien en el mercado. El usuario estará dispuesto a pagar hasta el momento en que el coste adicional por el uso de una unidad más del recurso alcance el beneficio adicional percibido por el uso de esa unidad adicional. Una vez construida la curva de demanda económica, la disponibilidad de pago o el valor del agua se puede encontrar fácilmente calculando la integral bajo esa curva (Gibbons, 1986).

La curva de demanda económica, entonces, puede describir la disponibilidad de pago (total y marginal) por el uso del recurso (figura 2.2 A). 


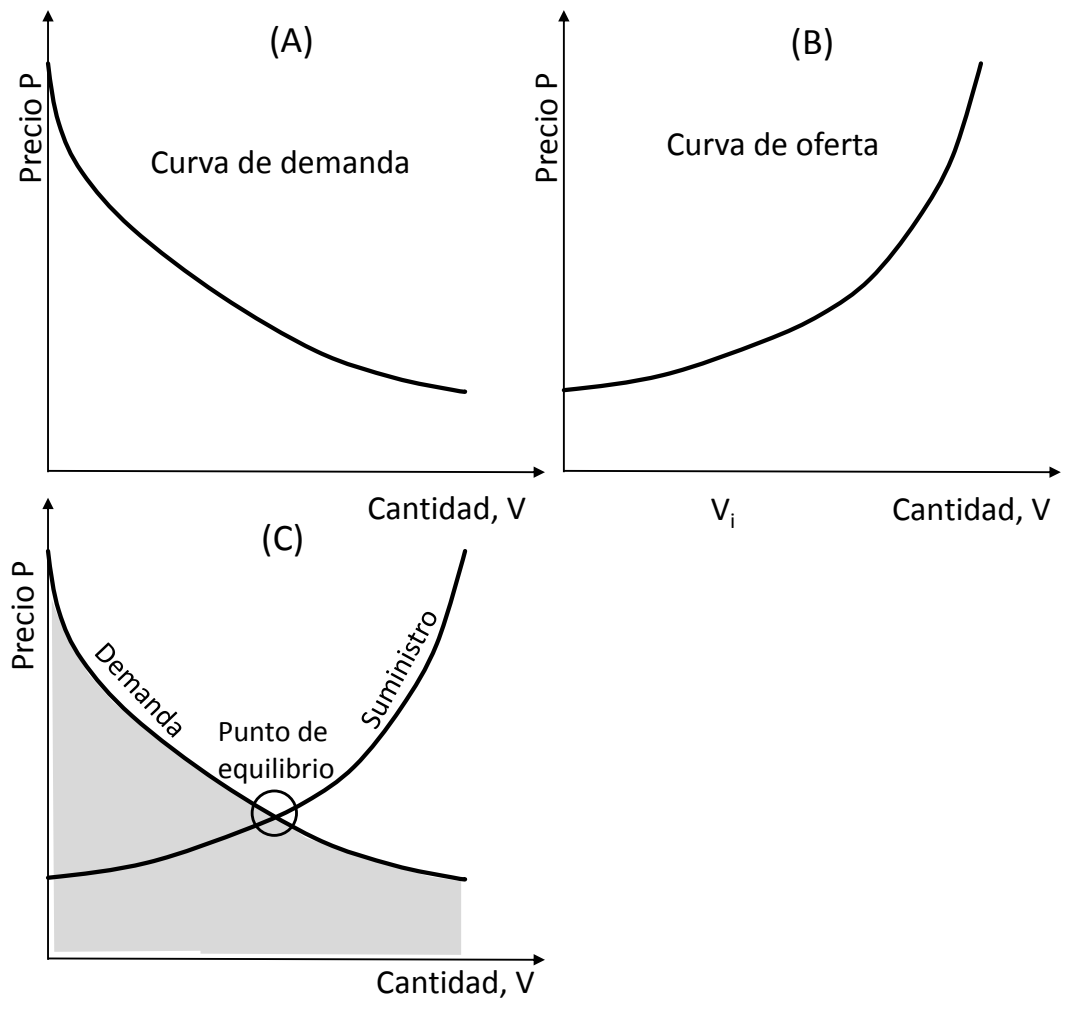

Figura 2.2 Curvas de oferta y demanda

Mientras que la curva de demanda indica el máximo precio que los consumidores pagarían por el agua, la curva de oferta (figura 2.2B) indica el mínimo precio por el que los "productores" están dispuestos a "vender" el recurso. Esto último representará el coste marginal del recurso. La curva de oferta también puede interpretarse como la máxima cantidad de agua que se puede obtener a un determinado coste. Al combinar las dos curvas, la de oferta y la de demanda, se pueden definir algunos conceptos útiles en la economía de los recursos hídricos (figura $2.2 \mathrm{C}$ ).

El cruce de ambas curvas se denomina punto de equilibrio y corresponde a la situación en que el suministro del recurso iguala a la demanda del mismo. En principio la Economía dice que cuando la demanda es mayor que la oferta (escasez), es porque el precio del agua es bajo.

\subsubsection{Mecanismos de asignación del agua}

Según Howe et al. (1986) es posible comparar la bondad de los diferentes mecanismos institucionales de asignación del agua mediante seis criterios: 
- Flexibilidad en la asignación del recurso.

- Seguridad de tenencia para los usuarios actuales.

- Repercusión del coste de oportunidad real a los usuarios.

- Previsibilidad de los resultados del proceso de asignación.

- Equidad del proceso de asignación.

- Aceptabilidad política y pública.

Los criterios citados toman en cuenta el concepto de eficiencia económica e incorporan también el concepto de equidad o justicia. Dinar et al. (1997) añaden dos criterios adicionales a los anteriores propuestos por Winpenny (1994): eficacia pues la forma de asignación modifica situaciones indeseables; y factibilidad y sostenibilidad administrativa para la puesta a punto y desarrollo del mecanismo de asignación.

Los criterios de asignación del agua variarán de región a región, dependiendo de su situación legal e institucional vigente, así como a las condicionantes sociales, políticas y económicas y el grado de desarrollo de infraestructura hidráulica. Los principales mecanismos de asignación del agua entre los distintos sectores son (Dinar et al., 1997): tarificación según el coste marginal, asignación pública y mercados de agua (citado en Pulido-Velázquez, 2003).

Tarificación según coste marginal. Esta política consiste en establecer un precio para el agua igual al coste marginal de proveer la última unidad de recurso o coste marginal. Cuando en un sistema de recursos hídricos el precio del agua es igual al coste marginal el sistema es económicamente eficiente. La tarifa debería incluir no solamente los costes marginales privados, sino los costes sociales (incluyendo costes de oportunidad y externalidades), y de esa manera se podrían establecer diferentes precios según el grado de escasez del agua, su calidad o la mayor o menor garantía de suministro (Spulber y Sabbaghi, 1998). La principal ventaja de este mecanismo de asignación es que es teóricamente eficiente, y su principal desventaja consiste en que el coste marginal es difícil de calcular debido a su variabilidad espacio-temporal. La tarificación marginal es más difícil de calcular que la que utiliza costes medios; además genera incertidumbre y los costes de servicio no se garantizan siempre. Por lo que se ha mencionado, este tipo de tarificación pocas veces es llevado a la práctica; sin embargo ha podido ser implementado en servicios telefónicos y eléctricos de algunos países europeos (Francia y Reino Unido). Dinar et al. (1997) recogen un sistema basado totalmente en tarificación marginal en el regadío de la Sociedad del Canal de Provence, Francia. Por su parte Sumpsi et al. (1998) analiza la puesta en marcha de la propuesta de Hall y Hanemann (1996) en donde aplica ciertos criterios de tasas basadas en costes marginales para el abastecimiento urbano/industrial del Metropolitan Water District del sur de California. 
Para el caso del servicio urbano, Fernández (1995) analiza las divergencias entre la tarificación actual y la tarificación eficiente. Se basa en costes contables pasados y no en costes de oportunidad y para ello utiliza costes medios en vez de costes marginales motivados por cambios en el consumo; incorpora la idea de reparto equitativo referida a costes pasados y no a posibles inversiones futuras. Los criterios básicos para establecer políticas tarifarias en el uso urbano son los de eficiencia económica, autosuficiencia tarifaria y equidad. Sin embargo, los precios que se cobran por el uso urbano son precios medios definidos con los costes medios de captación, transporte, potabilización y distribución de la entidad suministradora del recurso. En ese precio ya establecido suele reflejarse un cargo fijo por el derecho al servicio, un cargo variable por el consumo (volumétrico) y un cargo variable por la depuración del agua residual faltante. El valor marginal se obtiene entonces exclusivamente recurriendo a las curvas de demanda. En España el sistema tarifario en el suministro urbano está compuesto por un cargo fijo de servicio y uno variable por consumo (creciente de acuerdo a la cantidad consumida), mediante facturación en bloques (afecta al 80\% de la población, AEAS,1998).

La demanda de riego tiene actualmente en España una manera diferente de tarificación por el uso del recurso. Los usuarios pagan al Estado un canon de regulación que grava por las obras de regulación y una tarifa adicional de utilización la cual grava por el uso de otras obras hidráulicas. Las dos tarifas compensan al Estado por sus aportaciones financieras. En la actualidad las demandas de agua tan elevadas y los precios generalmente alejados de la realidad han sido provocados por las numerosas subvenciones y ayudas que históricamente las diferentes Administraciones Públicas han concedido al regadío español (MIMAM,2000). Un problema también bastante grave en el caso del regadío con aguas superficiales es que la unidad de cobro frecuentemente es la superficie cultivable, en vez del volumen de agua realmente consumido. Esta situación provoca que el usuario pague casi una tarifa fija aunque se le restrinja el consumo del agua, lo cual no incentiva para nada la economía en el empleo del recurso.

Asignación pública. Este tipo de mecanismo de asignación es el más utilizado en todo el mundo, en los grandes sistemas de riego y en los diferentes tipos de suministro hídrico. Lo cual se debe a las siguientes razones principales: es difícil tratar el agua como un bien de mercado más (Young, 1996a), ya que el agua es percibida socialmente como un bien público (Dinar et al., 1997); y el desarrollo de proyectos a gran escala es demasiado caro para el sector privado. Entre las ventajas que se pueden mencionar en la utilización de este mecanismo de asignación del agua destacan las siguientes: la posibilidad de regulación de externalidades; la regulación o suplantación de monopolios naturales en el suministro del agua; la protección de bienes o servicios públicos (p. ej. humedales); y la posibilidad de considerar objetivos distintos a la eficiencia económica ( $p$. ej. redistribución de rentas, desarrollo regional). Las principales desventajas son las siguientes: al establecerse tarifas por hectárea de riego o tipo de vivienda urbana no se 
transmite al usuario una señal de escasez del recurso; si no hay incentivos económicos para racionalizar el uso del agua, se presenta entonces ineficiencia en el uso del recurso; bajo la gestión pública el incentivo dominante es coercitivo: regulaciones y sanciones para los que las violen; se presentan divisiones en las responsabilidades sectoriales entre los distintos agentes encargados de la gestión de recursos hídricos; a veces los mecanismos de toma de decisiones están muy politizados, respondiendo a grupos de intereses distintos.

Mercados de agua. Los mercados se basan en un intercambio voluntario de bienes y/o servicios con un precio acordado de antemano. Si un mercado es perfectamente competitivo en donde actúan compradores y vendedores en su propio beneficio, entonces se alcanza la máxima eficiencia económica en la asignación del recurso (óptimo de Pareto). Un mercado de competencia perfecta supone la existencia de muchos vendedores y compradores sin poder de mercado, con productos homogéneos, información perfecta, costes de transacción similares, sin barreras a la entrada y salida del mercado, y que actúan en forma independiente para maximizar su beneficio económico. Como las condiciones indicadas anteriormente difícilmente se dan en la realidad, se producen fallos en el mercado por lo cual tiene que intervenir una instancia pública en la asignación del recurso.

Algunos fallos que se dan en los mercados del agua pueden ser los siguientes: la incidencia de externalidades negativas que no quedan internalizadas, como por ejemplo la contaminación que afecte a terceros; la naturaleza del bien público; y las economías de escala. Para el buen desarrollo de un mercado del agua es necesario afrontar las dificultades vinculadas a los problemas legales y a los obstáculos impuestos por altos costes de transacción o de transporte. Para conseguir una asignación eficiente del agua mediante mercados la definición de los derechos de propiedad debe satisfacer las condiciones de especificidad, exclusividad, transferibilidad, integrabilidad, y exigibilidad (Lee y Juralev, 1998).

\subsection{Teoría económica de los precios del agua}

Beber agua ha sido siempre la primera necesidad del ser humano. Esto significa que el agua para el consumo ha tenido siempre las características económicas de utilidad y valor, conceptos ambos sutiles y difíciles de cuantificar en términos monetarios. Desde tiempo inmemorial los asentamientos humanos han tenido lugar en torno a los ríos o fuentes. El agua se tomaba directamente de la corriente y con arreglo a la nomenclatura que hoy suele utilizarse para la gestión de las aguas, decimos que el uso de abastecimiento nació como uso de agua fluyente, es decir como uso del agua que de manera natural podía aprovecharse (Heras, 2000). 
Puede entonces decirse que el agua es un recurso natural indispensable para la vida y el desarrollo de la actividad humana en la Tierra. Desde este punto de vista, el agua posee un valor intrínseco que es difícil de calcular en términos monetarios, dado que se asume que es un bien de utilidad pública.

Durante los siglos pasados y presente, se ha tendido a valorar el agua como un simple recurso productivo, relegando al olvido otros muchos valores de carácter ambiental y social que posee, y que hoy es ineludible considerar. Sin embargo, aunque resulte sorprendente, este enfoque raramente se ha visto avalado por un análisis económico (Arrojo, 1999).

En el siglo XVIII, el economista Adam Smith planteó la paradoja del diamante y el agua. Esta paradoja considera que a pesar de que el agua es tan útil para los seres humanos y esencial para el sustento de la vida, sin embargo, es menospreciada y vendida excesivamente barata. Contradictoriamente, los diamantes, cuya utilidad real para la vida es nula y sirven únicamente en su condición de joya, se venden a precios altísimos.

El razonamiento continúa así: las personas pueden sobrevivir sin diamantes, pero si estuvieran en medio del desierto durante tres días, valorarían un vaso de agua más que todos los diamantes del mundo. Lo que ocurre es que los diamantes tienen precios elevados debido a una cierta utilidad (o satisfacción) marginal alta que se relaciona con su limitada reserva. La utilidad total del agua es mayor, pero tiene una utilidad marginal inferior debido a su abundancia relativa.

El agua, como elemento fundamental del medio ambiente posee tanto valor inmanente (que pertenece a su esencia) como intrínseco o dado por los usuarios del recurso (Azqueta, 2007, p.70). Pero la valoración del recurso hídrico puede ser vista a través de la denominada Ética Antropocéntrica. Los usuarios o bien los gestores del agua son los que asignan valor al agua en función del uso que ésta tenga y el bienestar que otorgue a otros usuarios. Con esta perspectiva, el agua puede tener diferentes valores, además del inmanente y del intrínseco: de uso y de no uso. El valor de uso tiene que ver con el destino que tiene el recurso hídrico como elemento útil para el bienestar humano; el valor de no uso no está ligado a la utilización del agua y considera su valor por el mero hecho de existencia del recurso (Azqueta, 2007, p. 84-87). Para esta última forma de valoración, puede ser que existan personas que otorguen valor al agua y que se ven afectadas por lo que ocurra con ese recurso (no son usuarias del mismo), y lo valoran positivamente por el mero hecho de existir. Su desaparición supondría una pérdida.

Un factor importante en la valoración del recurso hídrico tiene que ver con la disponibilidad y el acceso al mismo. Es obvio que un grupo social en donde la disponibilidad y el acceso al agua fuesen ilimitadas, el concepto de valor del agua 
carecería de sentido; sin embargo, si ese mismo grupo social tuviera dificultades de diferente índole en cuanto a disponibilidad y acceso al recurso hídrico, el concepto de valor del recurso si tendría mucho más sentido. Es lógico pensar que entre menor sea la disponibilidad y menor sea la posibilidad de acceder al recurso, será mayor la importancia que se le dé al agua y, por ende, tendrá mayor significado el valor que se le dé al recurso.

\subsubsection{Valor del agua}

Aunque se han mencionado dos corrientes fundamentales de valoración (intrínseca y antropocéntrica), existen al menos siete tipos de valores que puede alcanzar el agua según las perspectivas de valoración que los gobiernos en diferentes países asumen (Moss et al., 2003). Según estos autores, las perspectivas de valoración del agua son las siguientes:

- Valor ambiental.

- Valor social.

- Valor de salud pública.

- Valor de género.

- Valor político de bajo precio del agua.

- Valor en el uso de productos y la producción.

- Valor económico.

Centrándose en la perspectiva económica, el concepto de "valor" se basa en la economía neoclásica del bienestar según la cual todas las actividades económicas en la sociedad están orientadas a aumentar el bienestar de los individuos y son ellos quienes pueden valorar su propio bienestar. El valor del agua para un usuario es la máxima cantidad que ese usuario está en disposición de pagar por el uso del recurso (Briscoe, 1996). Para cualquier otro bien económico diferente al agua y que son intercambiados entre compradores y vendedores bajo una serie de condiciones establecidas, su valor puede calcularse como el área bajo la curva de demanda. Como los mercados de agua casi no existen y los que existen son imperfectos, es difícil calcular cuál es el valor del agua para diferentes usuarios. Existen muchos métodos para calcular el valor del agua en distintos usos finales (Gibbons,1986) que incluyen los siguientes aspectos: definir las curvas de demanda y calcular el área bajo ellas; examinar las transacciones entre mercados; calcular las funciones de producción y simular las pérdidas de producción resultantes de contar con una unidad menos de agua; calcular los costes de suministro de agua cuando no existe fuente disponible; y preguntar a los usuarios como valoran el recurso (valoración contingente). 
El valor total del agua se puede considerar como la suma de una componente económica y el valor intrínseco (Rogers et al., 1998). La componente económica toma en cuenta cuatro aspectos en su integración: el valor que los usuarios otorgan al agua (disponibilidad de pago); los beneficios por retornos del recurso (recargas y disponibilidad aguas abajo); los beneficios indirectos de los usos del agua; y los ajustes necesarios para beneficios sociales. El valor intrínseco se compone de conceptos como el valor puro de existencia o el valor de legado de generación a generación, no fáciles de cuantificar pero que reflejan un valor real que se da en la mayoría de las sociedades humanas (figura 2.3).

De acuerdo a la clasificación que hacen Rogers et al (1998), para los usos industriales y agrícolas, el valor para los usuarios es al menos tan grande como el valor marginal del producto. Para el uso doméstico, la disposición de pago por el agua representa un límite inferior de su valor, ya que hay un valor adicional al agua. En muchos sistemas de explotación, los retornos de agua excedente suelen usarse para abastecer a poblaciones, a la industria o a la agricultura y es muy importante considerarlos para la valoración económica del recurso hídrico; por ejemplo, una parte de los retornos de agua para el riego puede recargar los acuíferos de la región y/o aumentar los retornos hasta el río o canal de aguas abajo. Sin embargo, los beneficios de los retornos dependerán, fundamentalmente, de la proporción de agua que se "pierde" por la evaporación (debido a los drenajes abiertos y canales) o por otros "sumideros" existentes. Los beneficios indirectos por el uso del agua se producen con los sistemas de riego que abastecen del recurso a las poblaciones (consumo e higiene personal) y a la ganadería, lo cual puede resultar en una mejoría en la salud o contar con mayores ingresos para la población rural pobre. Los objetivos sociales no son directamente cuantificables tales como: reducción de la pobreza, empleo y seguridad alimentaria (sobre todo en las zonas rurales, donde los precios de cereales de consumo humano tienden a ser altos en ausencia de la producción de alimentos adicionales adquirida con la agricultura de regadío, y donde también se dificulta el suministro de cereales importados). El valor económico del agua para un uso específico se representa mediante una curva o función de demanda en la que se relacionan la cantidad de agua utilizada y los precios por el uso de la misma. Lo anterior equivale al valor marginal del agua para diferentes niveles de suministro del recurso. 


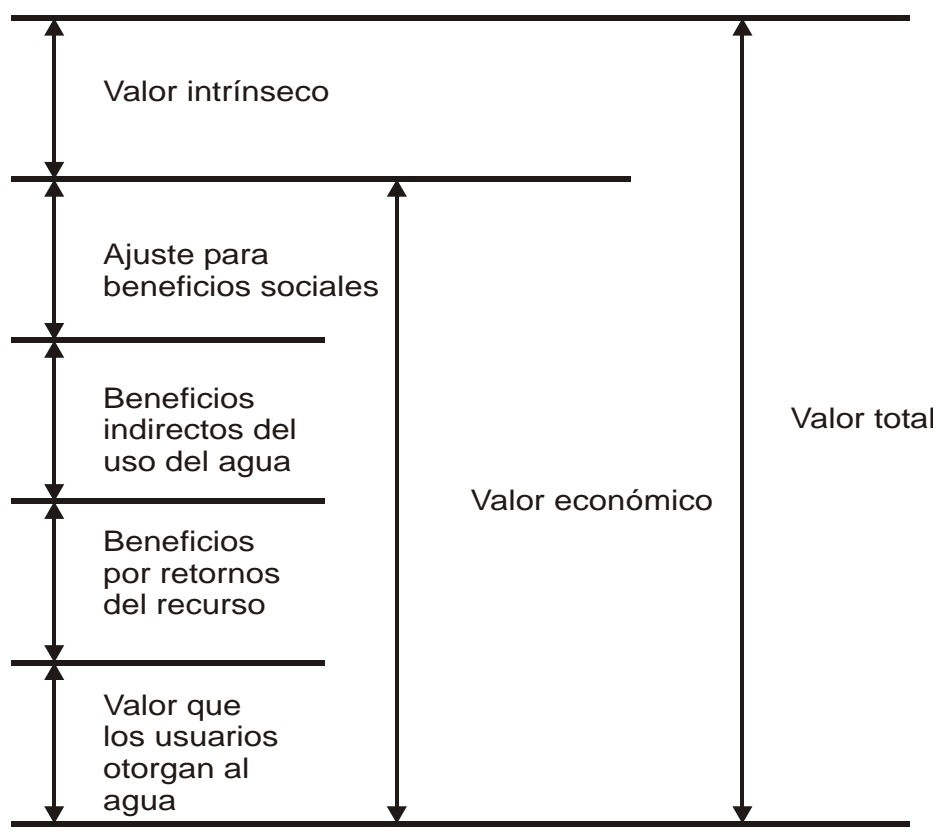

Figura 2.3 Valor de los servicios del agua

(Fuente: adaptado de Rogers, et al, 1998)

Para que el agua pueda tener un valor económico, es necesario que aquella sea considerada como un bien económico. Savenije (2001) considera que aunque el agua es un bien económico, tiene características especiales que la hacen diferente a otros bienes económicos: el agua es esencial, escasa y finita, huidiza, forma sistemas, voluminosa, no sustituible, comercializable, compleja. En forma individual o combinada, esas características implican que en la asignación y uso del agua se tendrán que tomar en cuenta una serie compleja de intereses económicos. Desde esta perspectiva, en la medida que el suministro del recurso hídrico sea escaso en relación con la demanda, el agua tendrá mayor o menor valor económico (Ward y Michelsen, 2002).

Para estudiar la eficiencia económica en la gestión del agua es necesario confrontar los costes involucrados en su suministro, tanto directos como indirectos, con el valor del agua en sus diferentes usos. La DMA pide la recuperación de costes de los servicios del agua incluyendo no solo los costes financieros sino también los medioambientales y del recurso. Aunque se han ido aplicando en mayor o menor medida, no existe unanimidad en cuanto a la forma de considerarlos para la valoración del recurso (véase apartado 3.3 y capítulo 4). Lo óptimo desde el punto de vista del uso sostenible del agua es que el coste total se iguale con el valor del agua en uso. En muchas ocasiones el precio del agua no refleja íntegramente el verdadero valor económico de los servicios del agua. Esas diferencias de concepto provocan que la infraestructura sea ineficiente, que la asignación del recurso no sea apropiada para los diferentes usuarios del recurso y que la protección 
al medio ambiente acuático sea insuficiente. Los modelos pueden ser de utilidad para determinar medidas efectivas del coste del recurso que aseguren el suministro, la prevención de avenidas y la instrumentación de medidas para la conservación de la calidad del agua (Heinz, 2006).

Hoy en día se desarrollan modelos hidro-económicos que tienen en cuenta el valor económico en el recurso hídrico (Harou et al., 2009). Los modelos hidro-económicos representan tanto la ingeniería como los aspectos medioambientales y económicos de los sistemas de recursos hídricos a escala de cuenca dentro de un marco coherente de estudio, incluyendo la componente económica en los modelos de gestión de recursos hídricos. Estos modelos se han convertido en una herramienta privilegiada para la toma de decisiones en la gestión del agua. Los modelos hidro-económicos son diferentes a los modelos tanto ingenieriles (que exclusivamente minimizan los costes financieros) como los modelos de optimización dinámica, modelos de equilibrio general, de análisis inputoutput, y de análisis de coste-beneficio.

Los modelos hidro-económicos representan tanto las componentes de un modelo hidrológico espacialmente distribuido y la infraestructura de un sistema de recursos hídricos como los aspectos económicos derivados de los servicios del agua y los beneficios que aporta su uso a los diferentes usuarios del recurso. Estos modelos toman en cuenta los balances de agua (evaporación, retornos de agua, entradas y salidas del recurso, recargas a los acuíferos, etc.) y las estructuras para el almacenamiento, distribución y suministro del recurso hídrico tales como: embalses, canales, plantas desalinizadoras, plantas hidroeléctricas, tomas en canales de riego, plantas depuradoras de agua, pozos de bombeo de agua, tuberías de suministro del agua, embalses para recarga artificial, etc. 


\subsubsection{Costes de oportunidad}

El concepto de coste de oportunidad se puede encontrar en muchos trabajos desarrollados por economistas de los siglos XIX y XX (por ejemplo, von Thünen, 1826; Mill, 1848, Walras, 1874; y el más notable Wieser, 1876).

El coste de oportunidad se refiere a los beneficios no percibidos o beneficios a los que se renuncia cuando un recurso escaso es asignado a un uso en lugar de a otros posibles que sean más rentables (Young, 2005). Es decir, el coste de oportunidad de una cierta acción es el valor de la siguiente mejor selección que podría haberse llevado a cabo (Griffin, 2006). Cuando el agua es asignada según criterios de mercados competitivos, el coste de oportunidad del recurso hídrico se refleja en los costes financieros. Sin embargo, a causa de la distorsión del mercado los precios no siempre reflejan el coste de oportunidad del agua ni tampoco los beneficios que se obtendrían si el recurso se asignara a un mejor uso alternativo. El coste de oportunidad se establece con base en la productividad marginal de cada uso y al ignorarlo, se infravalora el agua y se conduce a errores en la inversión. En teoría, si las tarifas del agua incluyeran este coste se alcanzaría a largo plazo una asignación óptima en la asignación del agua, en donde la productividad marginal sería la misma para todos los usos y el bienestar de la sociedad sería óptimo (Pulido-Velázquez, 2003).

La medición del coste de oportunidad del agua es una tarea difícil. Para hacerlo es necesario visualizar la solución con un enfoque de sistemas y plantear una serie de hipótesis acerca de los impactos reales y las respuestas a ellos. Los costes de oportunidad están relacionados con el valor del agua en forma no transitiva (Briscoe, 1996). Por ejemplo, si una ciudad y una comunidad de regantes se encuentran en orillas opuestas de un río, el coste de oportunidad impuesto por la extracción para el usuario de mayor valor (en este caso la ciudad) será mucho menor que el coste de oportunidad impuesto por la extracción para la de menor valor (comunidad de regantes). Los costes de oportunidad aumentan sustancialmente conforme el recurso es más utilizado (tanto en cantidad como en términos de calidad). La existencia y la imposición de costes de oportunidad pueden dar lugar a conflictos entre los usuarios, a menos que existan mecanismos institucionales que los reconozcan y que sean tomados en cuenta por los usuarios.

\subsubsection{Precio del agua}

El papel fundamental de poner precios al agua consiste en lograr que la asignación del recurso hídrico entre los diferentes usos y usuarios del mismo sea de una manera eficiente y equitativa. Además, las políticas de precios del agua que se establecen fomenta la conservación de recurso escaso, como lo puede ser el agua (Johansson, 2000). Los 
objetivos habitualmente enunciados en el diseño de políticas de precios son (Griffin, 2006):

- Suficiencia de ingresos. Con ingresos suficientes se pueden sufragar la totalidad de los gastos.

- Eficiencia económica. Los precios deben maximizar los beneficios netos de los usuarios del agua o maximizar el valor presente neto de todos los usuarios del recurso.

- Equidad y justicia. Los usuarios con características similares deberían pagar precios equivalentes y percibir que son justos.

- Simplicidad. Los precios deben ser fácilmente entendidos por el usuario del recurso.

- Legalidad. Los precios deben ser legalmente aceptados.

Sin embargo, en la práctica al agua se le asigna sistemáticamente un precio por debajo de su valor real. Esto es evidente cuando se observa que la cantidad demandada frecuentemente excede al suministro (Rogers et al., 2002).

El énfasis en la suficiencia de ingresos promueve la idea de la tarifación a precios medios. Si el precio unitario es igual al precio medio, los ingresos igualan a los costes totales. Sin embargo es importante determinar e incorporar costes marginales de forma que se transmita a los usuarios una señal del valor del recurso y su escasez mediante el precio. Se hace frente a dos tipos de escasez (Griffin, 2006 p.256): la escasez del capital de infraestructura utilizada para almacenar y distribuir el agua y la escasez del recurso en sí, que corresponde al objetivo principal de estudio en esta tesis.

La maximización de beneficios netos sujetos a los límites de disponibilidad de recurso renovable, asumiendo que los agentes ajustarán su uso de forma que sus beneficios marginales igualen al precio, conducen a la siguiente expresión para el precio (Griffin, 2006):

$$
\boldsymbol{p}=\frac{\partial \boldsymbol{C}}{\partial \boldsymbol{W}}+\boldsymbol{\lambda}=\frac{\partial \boldsymbol{C}}{\partial \boldsymbol{W}}+\boldsymbol{V M A}
$$

donde:

C Coste de suministro.

W Volumen del recurso. 
$\lambda \quad$ Multiplicador de Lagrange, que incluye el valor social del agua o el Valor Marginal del Agua.

VMA Valor Marginal del Agua.

Para el caso del suministro del recurso proveniente de una fuente agotable como podría ser las reservas de acuíferos, o de un embalse que contiene poco volumen para abastecimiento en algunos años, el procedimiento adecuado es seleccionar un precio que maximice el valor neto presente. Para este caso, la siguiente expresión es útil para el cálculo del precio del agua:

$$
\boldsymbol{p}=\frac{\partial \boldsymbol{C}}{\partial \boldsymbol{W}}+\boldsymbol{\delta}_{0}=\frac{\partial \boldsymbol{C}}{\partial \boldsymbol{W}}+\boldsymbol{C M U}
$$

donde:

$\delta_{0} \quad$ Multiplicador de Lagrange representando el valor del agua en el sitio para el periodo en curso.

\section{CMU Coste Marginal del Usuario}

EI CMU se puede calcular como el valor futuro de agua restringida descontada al presente, a través de la solución numérica de un problema de optimización dinámica.

Como se ha comentado, puede existir también escasez en cuanto a la capacidad de las infraestructuras. Al seguir el programa económicamente óptimo de inversiones, pueden alternarse ciclos de exceso de capacidad con ciclos de capacidad totalmente utilizada. Durante los periodos finales, la cantidad demandada puede superar a la cantidad suministrada y es en este caso cuando es necesario racionar eficientemente la capacidad limitada del sistema de explotación. Económicamente, es recomendable incrementar el precio del agua por una cantidad llamada Coste Marginal de Capacidad (CMC):

$$
\boldsymbol{p}=\frac{\partial \boldsymbol{C}}{\partial \boldsymbol{W}}+\boldsymbol{C M C}
$$

Esta tesis se centra en la escasez del recurso teniendo en cuenta las limitaciones de almacenamiento y reparto del recurso, dadas por la infraestructura existente. 


\subsubsection{Políticas de precio, escasez y cambios estacionales}

En la literatura relativa a políticas de precios del agua, se presenta una incompatibilidad entre las recomendaciones de políticas de precio de tipo marginal que proporciona la teoría microeconómica y la política de precios con costes medios que utiliza la industria del agua en forma práctica. Aunque la recuperación de costes es una meta importante, siendo los costes medios de primordial importancia en la determinación de los índices actuales de utilidades, debería ponerse mayor atención a los costes marginales. Tampoco se consideran las diferentes épocas del año para el establecimiento de políticas de precios lo cual hace que se sobre valore o infravalore el agua.

\subsection{Contexto institucional. Directiva Marco europea del Agua}

La Directiva Marco europea del Agua (DMA en adelante, 2000) nace para ordenar y teóricamente simplificar la, hasta hace no mucho tiempo, diversa y compleja legislación comunitaria en materia de aguas y establecer un marco comunitario de acción en materia de política de aguas. La DMA pretende avanzar la legislación comunitaria en materia de agua, garantizar su calidad ecológica, agrupar las diferentes normativas sectoriales y constituir una referencia común para los Estados Miembros a partir de la cual se puedan ir desarrollando otros instrumentos normativos. Para el año 2015 la DMA persigue conseguir un buen estado de todas las masas de agua, incluyendo aguas continentales (superficiales y subterráneas), costeras y de transición.

\subsubsection{Objetivos básicos de la Directiva}

Los principales aspectos que en materia de política de aguas considera la DMA, se pueden agrupar en los siguientes puntos:

- Finalidad. La finalidad de la DMA es proteger y mejorar el estado ecológico de las aguas y de los ecosistemas acuáticos y humedales así como promover el uso sostenible del agua (artículo 1).

- Sustancias peligrosas: prohíbe el vertido de sustancias peligrosas en medio acuático y da un plazo de 20 años (a partir del año 2000) para su total eliminación (artículo 11, apartado 3j; artículo 16).

- Precio del agua y recuperación de costes: el precio del agua deberá tomar en cuenta el principio de la recuperación de los costes de los servicios relacionados con el agua, incluyendo los costes medioambientales y del recurso, de conformidad con el principio de que quien contamina paga (artículo 9, DMA). La política de precios del agua deberá proporcionar incentivos adecuados para que los usuarios utilicen de forma eficiente los recursos hídricos y contribuir adecuadamente a la recuperación de 
los costes de los servicios de los diversos usos del agua (anexo III, DMA). Además se tendrán en cuenta los efectos sociales, medioambientales y económicos de la recuperación y las condiciones geográficas y climáticas de la región o regiones afectadas, y no incumplirán si se decide no aplicar, de acuerdo con prácticas establecidas, las disposiciones de recuperación de costes para una determinada actividad, siempre y cuando ello no comprometa ni los fines ni el logro de los objetivos de la Directiva.

- Sequías: no se considera una infracción de la Directiva si se produce un deterioro del agua por motivos de fuerza mayor o causas naturales que no hayan podido preverse razonablemente, en particular graves inundaciones o sequías prolongadas (artículo 4, apartado 6).

- Aguas subterráneas: los Estados miembros deben tomar medidas para prevenir su deterioro así como evitar o limitar los vertidos de contaminantes en este medio (artículo 11).

\subsubsection{La DMA y los instrumentos económicos}

La teoría económica considera diferentes estrategias políticas e instrumentos para la gestión eficiente del agua en la cuencas hidrográficas (Heinz et al., 2007). Se han hecho algunos intentos institucionales para la gestión del agua (gobierno centralizado y descentralizado, privatización, regionalización, mercado del agua, etc.) y se han analizado desde el punto de vista de aceptación social y eficiencia económica. Se ha observado que instrumentos económicos como políticas de precios del agua, tarificación, subvenciones y seguros incentivan a los usuarios del agua a realizar acciones para satisfacer sus propios intereses y lograr el bienestar para toda la sociedad. Los precios de agua sirven para cubrir los costes de los servicios de manera que se puedan otorgar servicios adecuados de acuerdo con la normativa y los estándares de la población (agua de calidad); y como incentivo para el ahorro y el uso eficiente del agua (Maestu y Del Villar, 2006).

La DMA requiere identificación, valoración y análisis coste-eficacia de las medidas para lograr el buen estado ecológico de las aguas de la manera más eficiente. Una de las principales novedades que introduce la DMA es que para lograr los objetivos de calidad se aplicarán principios (ej. quien contamina, paga), metodologías, herramientas (ej. análisis coste-eficiencia) e instrumentos económicos (ej. poner precio al agua).

En el año 2004 se preparó, para cada Demarcación Hidrográfica, un documento de análisis económico del uso del agua (artículo 5) con información relevante para que de acuerdo con el artículo 9 de la DMA, poder aplicar "el principio de recuperación de los costes de los servicios relacionados con el agua, incluidos los costes medioambientales y los relativos a los recursos. Lo anterior está de acuerdo a lo indicado en el Anexo III, y en particular de conformidad con el principio de quien contamina paga" (Artículo 9, DMA). 
Ese informe incluyó los siguientes apartados:

- Análisis económico de los usos actuales.

- Tendencias económicas para el 2015.

- Niveles actuales de recuperación de costes de los servicios.

- Preparación de información para el análisis coste-beneficio, el cual fue necesario para la siguiente etapa.

En una segunda etapa se analiza la posible brecha entre objetivos de estados de las aguas y tendencias para el 2015 , y se identificaron presiones clave, y coste y eficiencia de posibles medidas. Se lleva a cabo un análisis coste-eficacia para las medidas propuestas que permitieron definir el Programa de Medidas (artículo 11, Anexo VII, DMA) y el coste total de las medidas por establecer, sirviendo de base para la elaboración de los Planes de Gestión de Cuenca, previstos inicialmente para el año 2009 (artículo 13, Anexo VII, DMA). Para el año 2010 se implementaría una política de precios del agua que promueva su utilización eficiente y la recuperación de costes (artículo 9 DMA).

La Guía de Análisis Económico preparada por el grupo de trabajo WATECO (2003) desarrolla la metodología para la elaboración de los análisis económicos requeridos por la DMA. Uno de los puntos que la Guía señala como clave, y que necesita un mayor desarrollo metodológico, es el de hacer operativa la estimación del coste del recurso y el coste medioambiental en el contexto del desarrollo de los planes de gestión de cuenca (p.62, Sección 6). En el Anexo IV de dicha guía se recomienda, para el caso de mercados distorsionados y/o recursos escasos, sustituir precios de mercado por costes de oportunidad o del recurso, definido este último como el beneficio que se obtendría si el recurso fuera asignado al mejor uso alternativo. El coste del recurso se relaciona con el coste de escasez (p. I-20, Anexo IV, WATECO, 2003).

\subsubsection{Recuperación de costes de los servicios del agua}

Se entienden como servicios del agua todas las actividades relacionadas con la gestión de las aguas que posibilitan su utilización tales como la extracción, el almacenamiento, la conducción, el tratamiento y la distribución de aguas superficiales o subterráneas, así como la recogida y depuración de aguas residuales, que vierten posteriormente en las aguas superficiales. Asimismo, se entenderán como servicios las actividades derivadas de la protección de personas y bienes frente a las inundaciones (art. 2 DMA, 2000).

Los costes medioambientales son aquellos que tienen como finalidad recobrar el daño ambiental producido por el uso del agua, internalizando su coste. Coinciden parcialmente con los denominados tributos medioambientales en España, en cuanto: 
- El canon de control de vertidos (Ley de Aguas española, 2003) es una tasa de ámbito estatal, que debe financiar el coste del servicio del control de la calidad, en donde los vertidos al dominio público hidráulico están gravados con una tasa destinada al estudio, control, protección y mejora del medio receptor de cada cuenca hidrográfica y el importe de dicho canon es el producto del volumen de vertido autorizado por un precio unitario de control de vertido;

- Los cánones autonómicos de saneamiento de aguas son instrumentos de recaudación destinados a restituir la calidad de las aguas empleadas en el uso urbano, antes de su reincorporación al Reglamento del Dominio Público Hidráulico (RDPH, 2003). Estos cánones autonómicos son impuestos que gravan el consumo de agua y que afectan a la financiación de las inversiones realizadas por las Comunidades Autónomas en saneamiento y depuración.

Existen otros costes ambientales no ligados a la calidad del agua para los que no existe figura alguna y que tendrían una cierta equivalencia con aquellos cánones por el concepto de compensación previstos en el supuesto de transferencias de recursos hídricos entre cuencas (Art. 22 y 23 de la Ley del Plan Hidrológico Nacional, PHN) que constituye en cierto modo un precedente de este concepto. El concepto de coste del recurso no queda definido en el artículo de la DMA y es objeto de distintas interpretaciones teóricas (ver apartado 3.3).

El análisis de recuperación de costes de los servicios del agua se centra en la evaluación de los ingresos y costes financieros de los servicios a los que se refiere el artículo 2 de la Directiva Marco del Agua. El análisis se realiza para los usuarios agrícolas y urbanos. Dentro de estos últimos se hace una distinción entre usuarios domésticos e industriales. Los costes analizados incluyen los derivados de las actividades de extracción, almacenamiento y transporte en alta, distribución en baja, recogida, tratamiento y depuración de aguas residuales. La expresión que se utiliza para calcular la cobertura de los costes relaciona los ingresos de los usuarios (facturación a los usuarios de los servicios del agua) con los costes totales incurridos por los agentes prestadores de los servicios, a los que se les ha sumado el coste estimado de capital de las subvenciones no imputadas a los usuarios (MMA, 2007).

La información que ha obtenido el Ministerio del Medio Ambiente ha permitido realizar una primera aproximación sobre la repercusión de los costes financieros de los distintos servicios del agua en España sobre los usuarios urbanos y de riego. El nivel de recuperación de costes por la prestación del conjunto de los servicios del agua en España está comprendido en una horquilla que va del $65 \%$ al $96 \%$, dependiendo del servicio, los usuarios y la cuenca contemplada. Las cantidades repercutidas a los usuarios de los servicios de captación vienen a recuperar una magnitud de sus costes comprendida entre 
el $50 \%$ y el $99 \%$ dependiendo de la cuenca hidrográfica y Sistema de Explotación considerado. Los servicios de extracción son pagados prácticamente en su totalidad por los propios usuarios. En parecidas condiciones a los servicios de captación se mueve la recuperación de costes de los servicios de distribución y saneamiento urbano $(57 \%$ al $96 \%)$. Los servicios de riego presentan una menor variación en sus porcentajes de recuperación de costes ( $85 \%$ al $98 \%$ ). Esto se explica porque aunque los importes pagados por una parte importante de los usos de riego a los Organismos de cuenca son reducidos, esto representa una parte muy pequeña de los costes totales de los servicios de agua de riego, representando los costes de los servicios de captación, embalse y transporte de media el 6,64\% de los costes por la prestación del conjunto de los servicios del agua en España (MMA, 2007). 


\section{CAPÍTULO 3}

\section{Estado del Arte}





\title{
3 Estado del arte
}

\begin{abstract}
En este apartado se presenta el estado del arte de temas centrales sobre los que se desarrolla la presente investigación: los modelos hidro-económicos que hoy por hoy son una herramienta muy útil para relacionar la hidrología y la gestión de recursos hídricos con la eficiencia económica y que conforman el campo de acción de la presente investigación; la caracterización económica de un sistema de recursos hídricos, que hará que el sistema sea eficiente hídrica y económicamente; y el coste de oportunidad del recurso, concepto básico en el desarrollo de una política de precios que incorpora costes de oportunidad.
\end{abstract}

\subsection{Modelos hidro-económicos}

Los modelos hidro-económicos combinan conceptos hidrológicos y conceptos económicos, así como herramientas que proporcionan una mejor comprensión para mejorar la gestión de los sistemas de recursos hídricos. Cuando se incluye el concepto de valor en la curva de demanda hídrica, los modelos hidro-económicos completan el 
enfoque de suministro que tradicionalmente se utiliza en la planeación de recursos de agua. El uso de los precios sombra o valores duales, proporcionados por los algoritmos de optimización, dan al usuario información espacio-temporal relativa a la capacidad de expansión y al valor que se tendría al contar con mayor suministro de agua.

Los modelos hidro-económicos han existido desde los inicios en la modelación de los sistemas de recursos hídricos, y se han puesto en práctica tanto por ingenieros como por economistas (Lund y Harou, 2006). Algunos modelos notables se han publicado en materia de gestión de agua subterránea y el uso conjunto con el agua superficial (Burt, 1964; Bear y Levin, 1970; Domenico et al., 1968; Young y Bredehoeft, 1972; Noel y Howitt, 1982). Al inicio de los años setenta, algunos autores propusieron un marco de modelación en el cual las funciones de demanda económica para el agua se relacionaban con modelos de sistemas de recursos hídricos: Bear y Levin, (1970); Gisser y Mercado, (1972, 1973). Tanto Vaux y Howitt (1984) como Booker y Young (1994) utilizaron la misma aproximación para estudiar la factibilidad y los beneficios de transferencias de agua. Los avances recientes incluyen: modelos híbridos de simulación y optimización (Díaz y Brown, 1997); modelos de gestión económica para sistemas recursos hídricos grandes y complejos (Draper et al., 2003); modelos agronómicos endógenos (Cai et al., 2003); modelos que contienen una interacción entre modelos distribuidos de agua subterránea y modelos superficiales del agua (Pulido-Velázquez et al., 2006b); y modelos que suministran el agua de manera que se maximice el beneficio neto obtenido y que incluyen políticas de precios y políticas medioambientales (Fisher et al., 2005).

Braat y Lierop (1987) distinguen dos aproximaciones para el desarrollo de modelos hidro-económicos integrados: modelos que permiten una transferencia efectiva de información desde una componente hacia otra: aproximación modular o compartimentada y una aproximación holística. En el primer caso se construye una conexión entre los modelos hidrológico y económico, en donde, los datos de salida de un módulo proporcionan los datos de entrada para el otro. En principio los módulos operan independientemente entre ellos, y los sistemas de ecuaciones se resuelven de manera exógena (las variables de entrada de un modelo dentro del otro son exógenas). Bajo esta aproximación modular existe una pérdida de conexión entre los diferentes componentes hidrológicos y económicos. Los diferentes sub-modelos suelen ser muy complejos y el problema principal es encontrar la transformación adecuada de datos y de información entre los sub-modelos. Por otro lado, en la aproximación holística, existe una sola unidad que contiene tanto las dos componentes: la hidrológica y la económica. Con el fin de poder resolver la complejidad de las ecuaciones simultáneas, los componentes se tienen que representar de una manera muy simple (McKinney et al., 1999). Cai et al. (2003) desarrollaron un modelo holístico con énfasis en la componente agrícola. 
Mientras que la transferencia de información entre los diferentes sub-modelos es uno de los obstáculos técnicos más importantes en la aproximación modular, la aproximación holística centra su atención en encontrar una técnica singular y un denominador para las cantidades variables y a su vez representar tanto la componente hidrológica como la económica en una forma significativa (Brouwer et al., 2007).

Se puede afirmar que la gestión efectiva del agua combina conceptos económicos y métodos ingenieriles e hidrológicos considerando explícitamente la naturaleza económica de las demandas de agua y sus costes. Los modelos hidro-económicos pueden sugerir combinaciones de acciones de gestión que produzcan máximos beneficios u opciones de coste mínimo con el fin de alcanzar metas específicas, y revisar el efecto de las diferentes opciones en los diversos intereses de los usuarios del agua (Heinz et al., 2007). Más allá de que se minimicen los costes o se maximicen los beneficios, los modelos hidro-económicos proporcionan el marco para considerar el valor de los servicios del agua durante su planeación y operación. Existe una amplia gama de técnicas para calcular el valor económico de los usos del agua y una vez obtenido, el manejo de dicho valor permite que el sistema hídrico sea dinámico y de rápida respuesta a los cambios económicos, sociales y medioambientales (Heinz et al., 2007).

\subsubsection{Modelo CALVIN del sistema de recursos hídricos de California}

Un grupo de la Universidad de California en Davis, coordinado por los profesores Jay R. Lund (Departamento de Ingeniería Civil) y Richar E. Howitt (Departamento de Economía Agrícola) han desarrollado un modelo para evaluar políticas de agua, planificación, impacto de cambio climático y estudios de impacto social. CALVIN (California Value Integrated Network) es un modelo de optimización integrado económico-ingenieril para el sistema de recursos hídricos de California, USA. El modelo de optimización busca minimizar los costes originados por los periodos de escasez y los costes ocasionados por la entrega del agua, sujetos a restricciones de balance de agua, capacidades de la infraestructura física del sistema y a condiciones ambientales para cierto rango de condiciones hidrológicas y operativas del sistema. La formulación matemática del modelo de balance de agua considera un término de pérdidas que puede representar evaporación en los embalses, pérdidas por transporte, uso consuntivo y reutilización del agua, entre otros aspectos. Esta simple formulación matemática se adapta para resolver una amplia variedad de problemas. El algoritmo de optimización lo constituye el módulo HEC-PRM (USACE, 1994). El modelo CALVIN cubre el $92 \%$ de la población de California y el $88 \%$ del área de riego. Esta aproximación de modelación se usa para ilustrar como se puede adaptar la infraestructura y la gestión del agua de California, desde el punto de vista económico, a condiciones de cambio climático (Tanaka et al., 2006), aumento de población, cambios en el uso del territorio y cambios de tecnología (Pulido-Velázquez et 
al., 2004a). En la tabla 3.1 se observan algunas de las implicaciones de la optimización hidro-económica con esta metodología.

Tabla 3.1 Implicaciones de la optimización económica e ingenieril. Modelo CALVIN Fuente: Lund et ál. (2001)

\begin{tabular}{|c|c|}
\hline Área de interés & Resumen de implicaciones \\
\hline Desarrollo de políticas & $\begin{array}{l}\text { La comparación de los impactos económicos a las áreas locales es } \\
\text { más fácil. Sugerencias de oportunidades para la cooperación y el } \\
\text { beneficio mutuo. }\end{array}$ \\
\hline Legal & $\begin{array}{l}\text { Costes y beneficios locales y regionales hacia operaciones de } \\
\text { cooperación. }\end{array}$ \\
\hline Financiera & $\begin{array}{l}\text { Capacidad para identificar beneficiarios durante los cambios en } \\
\text { infraestructura y gestión. Capacidad para los cambios de valor } \\
\text { económico. }\end{array}$ \\
\hline Coordinación institucional & $\begin{array}{l}\text { Proporciona sugerencias para proyectos potenciales de } \\
\text { cooperación y gestión: Uso conjunto de aguas superficiales y } \\
\text { subterráneas; Operaciones coordinadas de embalses y redes de } \\
\text { distribución; Trasvases. }\end{array}$ \\
\hline Planificación & $\begin{array}{l}\text { Valor económico de alternativas adicionales para el suministro o } \\
\text { cambios en la demanda. }\end{array}$ \\
\hline Operaciones & $\begin{array}{l}\text { Recomendaciones para operaciones de cooperación y potencial } \\
\text { económico de esas oportunidades. }\end{array}$ \\
\hline Gestión de las demandas & $\begin{array}{l}\text { Valor económico relativo del cambio de la demanda relativa al } \\
\text { cambio en el suministro. Valor económico del cambio en las } \\
\text { demandas, localmente y estatalmente. }\end{array}$ \\
\hline Regulación medio-ambiental & $\begin{array}{l}\text { Costes o beneficios urbanos y agrícolas en los requerimientos } \\
\text { medio-ambientales de agua. }\end{array}$ \\
\hline Datos & $\begin{array}{l}\text { Se requiere aumentar la documentación y el control en la calidad } \\
\text { de los datos. El manejo y la disponibilidad de los datos es } \\
\text { importante. }\end{array}$ \\
\hline Modelación & $\begin{array}{l}\text { La recolección de los datos y el esfuerzo en la modelación, tanto } \\
\text { local como regional y estatal, sería mejor coordinada. }\end{array}$ \\
\hline
\end{tabular}

\subsubsection{Modelo WAS del río Jordán (Oriente Medio)}

Fisher et al. (2005) han propuesto un modelo de asignación de agua en sistemas de recursos hídricos con el fin de maximizar el beneficio neto obtenido. El modelo está desarrollado en el lenguaje GAMS. El modelo es estacionario y anual. La demanda de agua urbana se ha considerado como una curva de tipo exponencial. Los suministros del recurso, es decir, tanto la cantidad anual renovable como los costes de extracción por metro cúbico, son inputs del modelo. WAS permite incluir aguas tratadas, especificando las plantas de tratamiento juntamente con los sistemas de distribución; además, el modelo permite que el usuario especifique la infraestructura del sistema de recursos hídricos. 
También los autores consideraron muy importante incluir las Políticas públicas del agua tales como: políticas de precios y políticas medioambientales. Dentro de las primeras, pueden considerarse dos tipos de exacciones: pago fijo del metro cúbico con un valor menor al valor sombra del agua que se utiliza o bien pago de un porcentaje por metro cúbico menor al valor sombra del agua que se utiliza; también en este concepto, el modelo puede considerar precios específicos pagados por grupos particulares en distritos particulares. Dentro del segundo grupo de políticas, WAS limita la extracción de una fuente a una cantidad anual renovable y específica. El modelo puede imponer un cargo por vertidos sobre los usuarios de agua limpia que los producen.

El modelo indica que tanto Israel como Palestina pueden obtener ganancias en la cooperación y comercialización del recurso hídrico. Cada una de las partes se beneficia como comprador al adquirir agua más barata; además, cada una de las partes se beneficia como vendedor sobre y por encima de cualquier cantidad requerida para compensar a la gente durante incrementos de gastos de agua. Así por ejemplo, cuando a Israel se le asigna el $80 \%$ de propiedad del acuífero y a Palestina el $20 \%$ restante, entonces el valor como propietarios del acuífero es superior para Palestina que para Israel; y lo mismo sucede en cuanto al valor de cooperación entre ambas partes. Es decir, existe una transferencia de beneficios para ambas partes, en mayor o menor grado, de manera que ambas ganan (esquema ganar-ganar). Los autores concluyen que el modelo propuesto ayuda a separar los conceptos de propiedad del agua y de uso del agua; además permite hacer transferencias de agua y dinero con lo cual se capitalizan y se quitan emociones a los conflictos del agua.

\subsubsection{Modelo agro-hidro-económico}

Cai et al. (2003) desarrollaron un modelo para la cuenca del Río Maipú, Chile, el cual incorpora las relaciones entre la economía, la agricultura, la hidrología y las instituciones de la zona de estudio. El modelo se elaboró para estudiar los efectos de los derechos del agua y los mercados de agua en el reparto del recurso.

Las principales relaciones y procesos hidrológicos en el modelo planteado incluyen el flujo y balance del agua en y desde los embalses hasta los sitios de cultivo, industrias municipales y sitios de demandas; transporte y balance de nutrientes entre los embalses y los sitios de cultivo; flujos de retorno; interacción entre las aguas superficiales y subterráneas; evapotranspiración en las áreas irrigadas y generación hidráulica de energía. En los procesos agrícolas se incluyen funciones de crecimiento, aplicación estacional del agua, concentraciones de nutrientes en el agua irrigada y tecnologías de riego. Por otro lado, las componentes económicas incluyen los beneficios netos del riego, de los usos municipales e industriales y la generación de energía; los derechos del agua y las relaciones del mercado del agua para determinar el precio y el volumen negociado. Las 
entregas de agua se determinan de la operación del sistema hidrológico y la demanda de agua se determina en el modelo, basado en las relaciones entre el agua y los usos productivos.

El modelo trata de maximizar los beneficios netos de utilizar agua para riego, usos municipales e industriales y generación de energía. Los elementos espaciales de la componente hidrológica se delinean de forma que la variabilidad espacial de los recursos hídricos refleje la distribución espacial de las demandas, manteniendo las fronteras y la continuidad del sistema. Los acuíferos se representan como nodos donde almacena el agua. Los nodos de demanda están agregados y se basan en la distribución de las demandas de agua, el sistema de distribución y las fronteras administrativas.

La componente agrícola se trata en detalle con el fin de calcular los perfiles de riego para los cultivos individuales y para determinar la cantidad de aplicación del agua. Los balances de agua se simulan en diferentes escalas espaciales: los campos de cultivos, sitios de demanda, embalses y acuíferos a escala de cuenca, mientras que el riego se modela a escala de cultivo y parcela, y se agrega a cada sitio de demanda y posteriormente a escala de cuenca. Los procesos hidrológicos, los usos urbanos y la generación hidroeléctrica se calculan mensualmente, mientras que los usos agrícolas se calculan con base a una función de riego (cultivo-contra agua aplicada) estacional. Lo anterior ocasiona divergencias entre las componentes hidrológicas y de cultivo. Los déficits para la demanda agrícola dependen de variables físicas, como la evapotranspiración potencial y se reflejan en el modelo de optimización mediante una función de penalización adicionada a la función objetivo. La solución del modelo de optimización se realizó mediante el uso del lenguaje de programación GAMS. La formulación matemática del modelo se presenta detalladamente por Rosegrant et al. (1999) y Cai et al. (2003). Se trata básicamente de una formulación lineal de la función y las restricciones. Adicionalmente se plantean cinco escenarios de optimización: uno para la componente de cultivo con riego variable y otro considerando riego fijo. Además, en los tres escenarios restantes se consideran cambios en las tecnologías de riego, inclusión de los derechos del agua y consideraciones acerca del intercambio del recurso hídrico.

Este ejemplo de aplicación muestra cómo se pueden definir escalas espaciales y temporales que permitan la modelación de un sistema complejo, que considera los procesos hidrológicos y económicos, pero se centra fundamentalmente en la componente agrícola del sistema.

\subsubsection{Modelo AgriCom Mozart DSS-AMDSS}

Heinz et al. (2007) han llevado a cabo investigaciones en torno al desarrollo de una interfaz abierta para la modelación hidro-económica (OpenMI, por sus siglas en inglés 
http://www.openmi.org/reloaded/ ). En este contexto, como parte del proyecto HarmonIT (2002-2005) se desarrolló el modelo AgriCom Mozart DSS-AMDSS, en colaboración con el Institute for Inland Water Management and Waste Water Treatment, RWS RIZA, Holanda. El objetivo principal fue desarrollar un Sistema de Apoyo a la Decisión el cual es capaz de ejecutar dos modelos separados al mismo tiempo: AgriCom y Mozart.

El modelo está enfocado principalmente a enlazar el modelo hidrológico (Mozart) con el modelo agronómico (AgriCom) con el fin de poder comparar la eficiencia económica de diferentes escenarios de la gestión del recurso hídrico. Mozart representa relaciones entre eventos medioambientales (inundaciones, salinidad y escasez del recurso) y los daños producidos. AgriCom calcula pérdidas en las cosechas, costes y beneficios en agricultura sobre la base de los resultados obtenidos con el modelo Mozart, para diferentes condiciones medioambientales. El componente SAD calcula los beneficios económicos netos para cada una de las estrategias seleccionadas (por ejemplo: instalación de más equipos de riego, mejoramiento en los sistemas de drenaje, etc.). En la figura 3.2 se muestra el esquema de funcionamiento de todo el modelo.

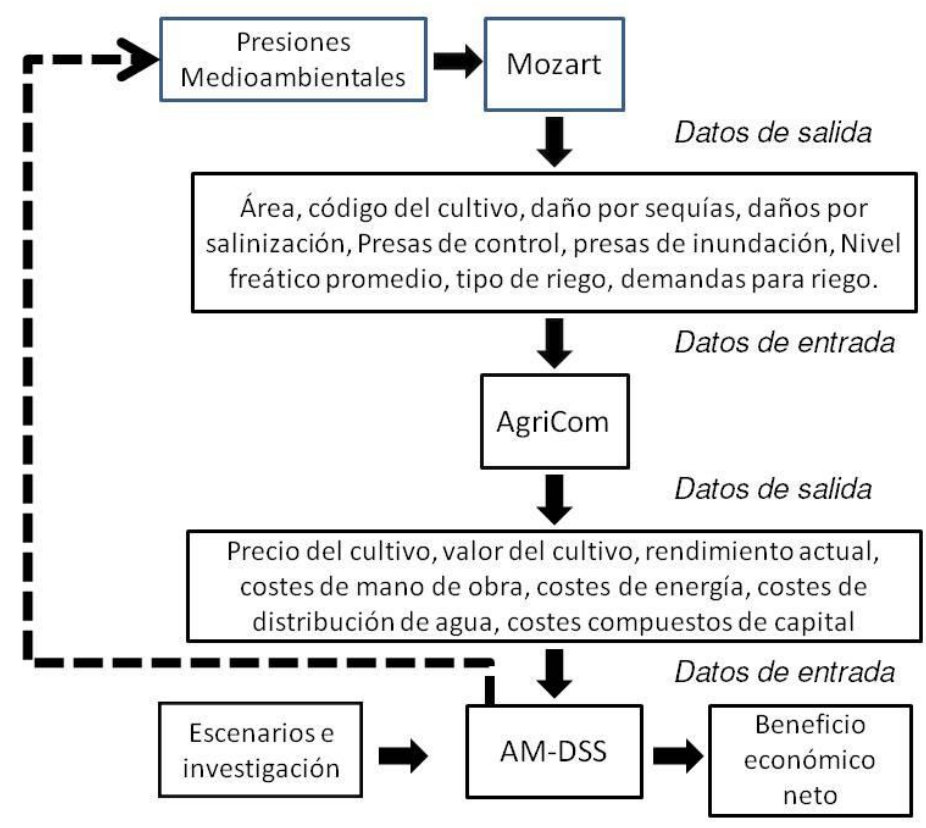

Figura 3.1 Funcionamiento del modelo Agricom-Mozart Fuente: Heinz et al., 2007 


\subsubsection{Modelo integrado para mitigación de sequías en el Río Grande}

Ward et al. (2006) desarrollaron un modelo para el análisis integrado económicohidrológico e institucional de políticas para mitigar los impactos de las sequías en la cuenca del Río Grande, EEUUAA. El modelo optimiza matemáticamente la suma de los beneficios generados por los diferentes usos tanto fuera del río como en él. Las restricciones se plantean para caracterizar la hidrología de la cuenca y los requerimientos institucionales.

El modelo se plantea y se resuelve a escala anual. Las leyes que caracterizan la asignación del agua en el río se definen matemáticamente. En el caso del Río Grande existen dos tratados principales, denominados El Pacto de Río Grande y el Tratado USAMéxico. Así las asignaciones de agua se calculan por medio de la maximización de los beneficios en la cuenca sujetos a restricciones hidrológicas e institucionales (Ward y Pulido-Velázquez, 2008). Las leyes relativas a la distribución legal del agua en el río se modelan mediante restricciones a las asignaciones de agua, con el fin de que los resultados del modelo sean consistentes con los patrones de uso histórico.

Para las regulaciones interestatales la función objetivo es la suma de todos los beneficios netos en usos de agua consuntivos. En este caso, el modelo maximiza los beneficios económicos totales. Dicha maximización está limitada por: las restricciones hidrológicas, las entregas definidas por el Pacto del Río Grande y el Tratado USA-México. El pacto del Río Grande proporciona restricciones de entrega de agua al estado de Nuevo México, por parte del estado de Colorado, en épocas de lluvia. Lo anterior se modela utilizando umbrales de caudal en los canales del Río Grande ubicados en Colorado. Por otro lado, el mismo tratado obliga a Nuevo México a entregar agua a Texas con base en el suministro anual (de Nuevo México). El tratado USA-México impone otras restricciones a la modelación, puesto que define una entrega de ciertas cantidades de agua de EEUU a México cuando no se produzcan sequías extremas. En el modelo se ha considerado la componente ambiental. EI US Fish and Wildlife Service estima que el Rio Grande requiere un caudal mínimo de $50 \mathrm{ft}^{3} / \mathrm{s}\left(1,4 \mathrm{~m}^{3} / \mathrm{s}\right)$ para mantener la vida acuática natural. Se consideran las demandas existentes y futuras, las limitaciones de las infraestructuras y las restricciones legales.

Los valores económicos del agua para la agricultura en Colorado se calculan mediante un modelo de optimización que maximiza el ingreso agrícola anual en el Valle de San Luis para diferentes condiciones de suministro de agua. Aguas abajo, en Nuevo México y Texas, el valor agrícola del agua se estima de acuerdo con la adaptación de los cultivos a diferentes grados de severidad de las sequías. El valor económico del agua para usos urbanos e industriales se basa en estudios de la disposición de pago por el agua en los centros urbanos para evitar la ocurrencia de períodos de sequía. En este modelo se 
escogió la integral de los beneficios marginales del uso del agua para medir los beneficios de su uso.

\subsubsection{Sistema de Apoyo a las Decisiones WSM}

Assimacopoulos et al. (2001) desarrollaron un sistema de apoyo a la decisión (SAD) dentro del marco del proyecto denominado Water Strategy Management (WSM). Dicho sistema se ha desarrollado con el propósito de formular escenarios para la gestión del agua en regiones deficitarias. El sistema es capaz de modelar, simular, analizar y evaluar diferentes respuestas de gestión, operadas bajo el principio básico de la eficacia, de la eficiencia económica de la sostenibilidad medioambiental y de la equidad en la asignación del recurso y el coste entre distintos usuarios. El sistema se basa en un modelo de simulación para la asignación del agua, que minimiza la escasez del agua cuando la disponibilidad de la misma está limitada; los sitios de demanda competitiva se tratan de acuerdo con las prioridades especificadas. Las prioridades pueden referirse a: preferencia social o restricciones; preferencia económica; o un sistema de derechos del agua. Si la distribución puede realizarse desde diferentes fuentes de suministro, las prioridades pueden ser: preferencia de costes; preferencia en el tipo de usos; necesidad de protección de los recursos; y desarrollo de reservas estratégicas.

Uno de los objetivos en el desarrollo del SAD, es la consideración del principio de la recuperación de costes. Bajo esta perspectiva, el sistema puede calcular costes financieros, medioambientales y del recurso, relacionados con las intervenciones en la gestión del agua y las asignaciones que se hagan a los diferentes usuarios. El modelo se utilizó en la región de la isla de Paros, Grecia en donde durante los meses de veraneo, la población urbana es tres veces mayor que la población local. El modelo se formuló de acuerdo con la identificación de medidas e instrumentos apropiados así como sus limitaciones potenciales, como puede observarse en la figura 3.2 


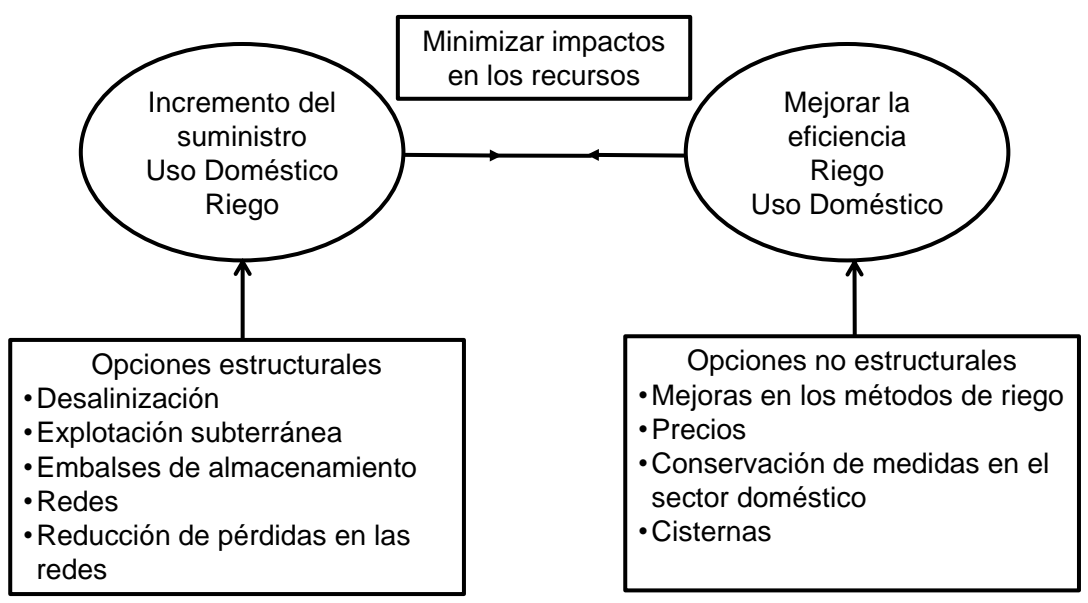

Figura 3.2 Opciones identificadas para la isla de Paros Fuente: Assimacopoulos et al. (2001)

Se distinguieron dos aproximaciones basadas en las rutas para la planificación del recurso hídrico elaboradas por Gleik (2003): el camino duro y el camino suave. El primero está más orientado hacia la mejora a través de soluciones de tipo estructural e incorporando nuevas tecnologías como la desalinización; la segunda solución incluye opciones de gestión de las demandas e intervenciones estructurales a pequeña escala para aliviar la escasez de agua.

Una vez formulados los escenarios y ejecutado el modelo, se concluyó que al hacer una conveniente gestión del suministro y asignación del recurso, la recuperación de los costes de los servicios del agua conduce a una asignación de los recursos disponibles más equilibrada; al mismo tiempo se producen menores costes en la provisión de los servicios del agua, y se promueve la sostenibilidad financiera de los recursos disponibles.

\subsubsection{Sistema de Apoyo a las Decisiones Aquatool-EcoWin}

El Grupo de Ingeniería de Recursos Hídricos del Instituto de Ingeniería del Agua y Medio Ambiente (IIAMA-UPV) desarrolló el módulo SimGes del SAD Aquatool (Andreu et al., 1996) que simula la gestión de un sistema de explotación de recursos hídricos a escala de cuenca, en los que se dispone de elementos de regulación o almacenamiento tanto superficiales como subterráneos, de captación, de transporte, de utilización y/o consumo, y de dispositivos de recarga artificial. Dicho módulo se ha desarrollado con el fin de representar la gestión actual de un sistema de explotación de recursos hídricos a escala mensual. SimGes es un modelo genérico que realiza la asignación del agua minimizando los déficits en los diferentes usos para los cuáles se utiliza el recurso; se basa en prioridades establecidas por el usuario para los distintos elementos que conforman el 
esquema del sistema de explotación (véase el apartado 4.4 para una descripción más detallada del módulo SimGes).

EI SAD está también conformado por un módulo de evaluación económica, EcoWin (para más detalles véase el Anejo B), desarrollado específicamente para calcular el beneficio y/o el coste económico de escasez para cada elemento del sistema y para cada periodo de tiempo considerado. Además permite obtener el Coste Marginal de Oportunidad del Recurso (CMOR), definido como el coste que supone para el sistema el disponer de una unidad menos de agua en un punto y en un instante dado (en el apartado 4.2 se muestra la metodología para su cálculo). También con EcoWin se obtiene el Coste Marginal de Oportunidad de las restricciones operativas sobre la cantidad de agua con finalidad ambiental (usualmente caudales mínimos en ríos o volumen mínimo en embalses). EcoWin funciona con el conocimiento de la asignación o suministro de agua proporcionado por la simulación de la gestión y complementado con las funciones económicas para cada una de las unidades de demanda (curvas de demanda económica) que conforman el sistema de explotación. Estas funciones son consideradas como datos de entrada para el evaluador económico (Collazos et al., 2004).

Pulido-Velázquez (2003) presenta una metodología para la optimización económica de la gestión de un sistema de recursos hídricos. El autor utiliza una función objetivo económica que consiste en maximizar el valor económico neto del uso del agua para todo el periodo horizonte incorporando las restricciones precisas para que garanticen la factibilidad física y sostenible de las políticas desarrolladas. La simulación de la gestión se realizó con el módulo SimGes del SAD Aquatool mientras que la optimización económica de la gestión fue desarrollada en GAMS (véase el apartado 4.3 para descripción más detallada de GAMS). El autor desarrolló un modelo hidro-económico de optimización a escala de cuenca que se aplicó a una cuenca de España. El desarrollo del modelo permitió valorar, mediante el análisis de los precios sombra o valores duales del sistema, el coste marginal del recurso en cada mes en distintos puntos del sistema, la disposición de pago de los distintos usuarios, el coste marginal mensual de las restricciones por razones ambientales o recreativas impuestas y el valor económico del uso conjunto para el sistema y para cada usuario.

\subsection{Caracterización económica de un sistema de recursos hídricos}

Un sistema de recursos hídricos se puede caracterizar económicamente mediante funciones que expresen la relación entre el agua suministrada y su valor marginal a nivel mensual o anual. La precisión en la definición de estas funciones, llamadas curvas de demanda, asumidas como información exógena para los modelos, es fundamental en la 
fiabilidad de los resultados del modelo. La función que proporciona el beneficio para un volumen de agua disponible es igual al área bajo la curva de demanda hasta ese nivel de suministro, y equivale a la disposición total a pagar por esa cantidad de agua.

\subsubsection{Funciones económicas de demanda agrícola}

Las curvas de demanda de agua para riego se basan en la evaluación del valor del agua para los regantes bajo condiciones de escasez. Una curva de demanda de riego consta de tres tramos (figura 3.3): un tramo inelástico inicial (I), en el que el regante no responde al cambio de precio, manteniendo cultivos y niveles de riego a costa de su renta; un tramo elástico intermedio (II), en el que el regante reduce los consumos, cambiando a cultivos de menor consumo o incluso de secano; y un tramo final inelástico (III), en el que el nivel de precios obliga a la reducción de cultivos y al abandono hacia secano, hasta el extremo de dejar de regar si el coste marginal del riego supera al valor marginal del agua aplicada.

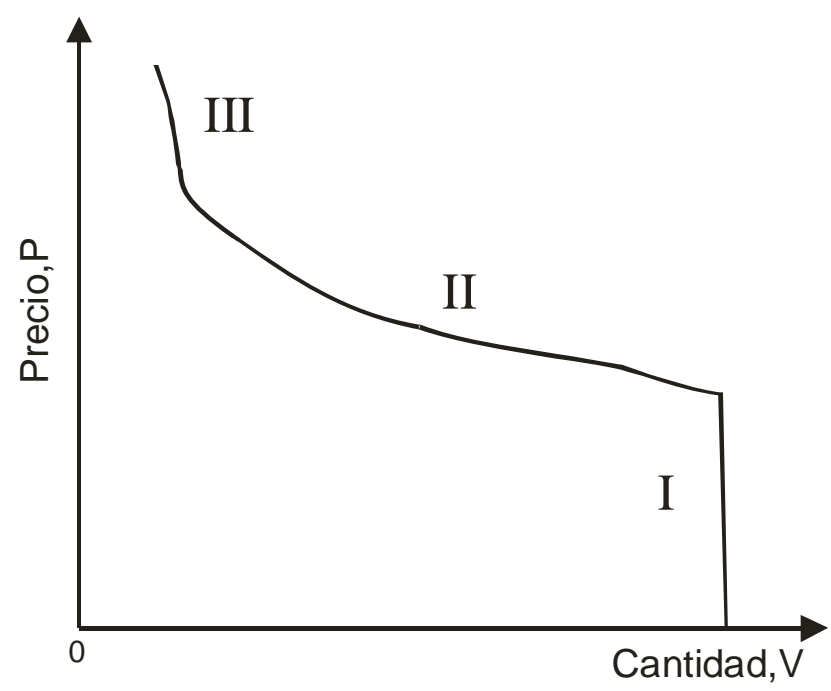

Figura 3.3 Curva de demanda económica en el regadío Fuente: elaboración propia

Cuando se presenta un cambio de precios, los agricultores proceden a realizar alguna de las acciones siguientes: reducción de las dosis de riego, sustitución por cultivos menos exigentes en cuanto a necesidades hídricas (extensificación), paso a cultivos de secano (desafección del regadío), o adopción de tecnologías de riego ahorradoras y realización de un plan de mejora (Hazell y Norton, 1986; Sumpsi et al., 1998). La elasticidad de agua para riego estará condicionada por el grado en que los agricultores reaccionen a un aumento de precio del agua mediante el uso de las acciones que realicen. 
García Mollá (2000) realizó un estudio empírico mediante análisis econométrico de la influencia relativa de distintos factores sobre la demanda de agua en diversas comunidades de regantes en la Comunidad Valenciana mientras que Blanco-Fonseca (1999) analiza, aplicando técnicas estocásticas para poder considerar la influencia de la incertidumbre sobre la disponibilidad del agua, la respuesta de los agricultores ante distintas políticas de modernización de regadíos, estudiando los efectos sobre uso del agua, renta y gasto público. García-Mollá obtuvo que, al nivel de precios actuales y con el sistema de tarificación vigente, el coste no es determinante en el consumo. Los factores que resultan tener mayor influencia sobre el consumo son el cultivo, el clima, el suelo, la tradición de riego, el origen del agua, y variables institucionales $u$ organizativas de las comunidades de regantes. Para Blanco Fonseca, factores como el potencial de diversificación de cultivos, la calidad del terreno, o la disponibilidad de agua resultan más relevantes para explicar la modernización de regadíos que el precio del agua, el cual suele representar un porcentaje reducido del coste total de producción. Aunque desde el punto de vista del agricultor individual la mejora de la eficiencia de riego induce ahorro, esto es relativo, puesto que los flujos de retorno pueden reducirse.

Para un adecuado diseño de políticas de gestión de recursos hídricos es muy importante realizar una correcta evaluación de la demanda económica de agua para riego. Como el riego supone una alto porcentaje del consumo total de agua (casi el $80 \%$ de la demanda de usos consuntivos a nivel del territorio español (MIMAM, 2000), y se ha convertido en un campo creciente de investigación en los últimos años, es vital tener mucho cuidado en la obtención de las curvas de demanda agrícolas. Existe una amplia literatura sobre cómo los regantes responden a un cambio en el precio del agua, y sobre cómo simular la respuesta de los regantes ante distintas políticas tarifarias, de subsidios, y de limitaciones institucionales. La demanda de agua para la agricultura es una demanda derivada: su valor depende de la contribución que como insumo del proceso agrario supone el agua de riego para la obtención del valor de la producción agrícola. Se pueden distinguir dos grandes líneas de valoración: las basadas en análisis residual por desglose del presupuesto de explotaciones agrarias, y las basadas en la valoración de la productividad marginal del agua (Young, 2005, pp. 167-170).

Para definir las curvas de demanda se utilizan métodos econométricos o programación matemática. Los primeros son de difícil aplicación en el riego porque hay poca variación en los precios y por lo tanto pocos pares de valores para realizar un estadístico confiable. Al no tener observaciones reales para un amplio margen de precios, las estimaciones de la elasticidad-precio de las demandas de agua de riego generalmente han requerido programación matemática. Los modelos de programación matemática permiten obtener la curva de demanda formulando un modelo para una explotación representativa con el objetivo de maximizar el beneficio neto de la producción bajo una serie de restricciones de recursos, técnicas, económicas e institucionales. Los enfoques recientes con 
programación matemática positiva incorporan la elección de la distribución de cultivos, distribución temporal de la cantidad de riego, y tecnología de riego como endógenos en el modelo.

\subsubsection{Funciones económicas de demanda en el uso urbano}

En el uso urbano la demanda de agua se caracteriza por la exigencia de un nivel de garantía muy elevado, unas condiciones de calidad muy restrictivas y una distribución temporal de los suministros requeridos sensiblemente uniforme (salvo en zonas turísticas o de segunda residencia). Los retornos se producen de forma puntual y localizada y, en general, con características constantes, por lo que una vez depurados pueden ser reutilizados posteriormente en usos con menores exigencias de calidad. La demanda urbana se suele desagregar en usos residencial, comercial (ej. establecimientos comerciales, restaurantes, hoteles), industrial (suministro a pequeñas y medianas industrias abastecidas por la red urbana) y municipal o servicios públicos (limpieza y riego de calles y jardines, fuentes, servicio de bomberos, etc.).

En viviendas multifamiliares es menor el uso per cápita (Hanemann, 1997). En España, la mayor parte del consumo registrado está catalogado como uso doméstico (69\%), mientras que el consumo comercial e industrial supone un $21 \%$ del total, y el resto, incluyendo servicios públicos y otros consumos, el 10\% restante. El porcentaje que supone el agua no medida es del $25 \%$, del cual un $25 \%$ se debe a pérdidas en la red (AEAS 2002). La dotación media de agua suministrada a la red es de $284 \mathrm{l} / \mathrm{hab} / \mathrm{dia}$, de la que corresponden al consumo doméstico unos 170 l/hab/día (AEAS 1998). Los estudios econométricos muestran que la demanda urbana de agua está influida por diversos factores como: el clima, la configuración urbana, el nivel de renta y el precio del agua (Gibbons, 1986; Hanemann, 1997). En términos generales, los niveles más altos de consumo corresponden a climas más cálidos, al período de verano, a mayores niveles de renta y a menor densidad de población.

La elasticidad de las funciones económicas sigue el comportamiento esperado en el consumidor: elasticidad-precio negativa (disminuyen los consumos al aumentar el precio), y elasticidad-renta positiva, por lo que se trata de un bien normal. Tradicionalmente uno de los "mitos" en relación con la gestión urbana del agua es que los usuarios no responden al precio (Baumann y Boland, 1997). Para justificarlo se han esgrimido diversas razones, entre ellas que el agua es un bien necesario, y por tanto no un bien económico normal (otro mito), que el uso del agua es cuestión de hábitos, que la factura del agua representa una pequeña fracción del presupuesto familiar, etc. Esta corriente de opinión pareciera ser validada por observaciones en los cambios en el uso del agua que muestran cómo los incrementos de precio vienen asociados con el paso del tiempo a los incrementos en el uso, en vez de disminuir el consumo. 
En el caso de España, son muy pocos los estudios tendentes a caracterizar de forma sistemática las funciones de demanda de los abastecimientos urbanos. En el Libro Blanco del Agua (MIMAM, 2000) se determina una curva de demanda agregada para abastecimiento doméstico a partir de datos de precio del agua y consumo per cápita en distintos municipios del territorio nacional, obteniendo un valor de elasticidad-precio de $-0,57$, si bien se deja abierta la posibilidad de que esta alta elasticidad responda realmente a una respuesta elástica a los precios (curva de demanda propiamente dicha) o refleje una "forma estructural de comportamiento vinculada más bien a los sistemas tarifarios y hábitos de vida" (MIMAM, 2000, P. 263). Trujillo (1994) aplica dos funciones de demanda lineales y una de elasticidad constante para analizar la fijación de una tarifa óptima en la ciudad de Las Palmas. García Valiñas (2002) desarrolla modelos lineales dinámicos para generar, utilizando la información de datos de panel de hogares y empresas, las funciones de demanda residencial e industrial en los municipios de Sevilla, Elche y Gijón. Las elasticidades obtenidas son en todos los casos inferiores a la unidad. Otros estudios relevantes en España de funciones de demanda urbana son el de Arbués et al. (2004) para la ciudad de Zaragoza, utilizando también un modelo dinámico con datos de panel, o el de Martínez-Espiñeira (2002), que incorpora el efecto de la condiciones climáticas a escala mensual en la demanda urbana en el noroeste español.

Para la Cuenca Hidrográfica del Júcar se realizó un estudio sobre demanda urbana para el MMA (García Valiñas, 2006). Dicho estudio consistió en realizar un ajuste econométrico que relaciona el volumen anual facturado con la variable precio y otras variables explicativas: renta per cápita, porcentaje de viviendas residenciales y segundas residencias, tamaño medio de los hogares, localización del municipio (costa, interior), así como dos variables destinadas a recoger las actividades industriales (empleo industrial) y turísticas (número de habitaciones disponibles) del municipio. El ajuste se hizo con un panel de datos de 125 municipios de la Comunidad Valencia para el período 2000-2003. El estudio reveló una elasticidad-precio de $-0,65$. Por tanto, una reducción del $1 \%$ en el consumo requeriría un aumento del $1,54 \%$ en el precio. Este valor es superior a los que normalmente se presentan en la literatura. Sin embargo, el ajuste para la variable precio es significativo con un nivel de confianza del $90 \%$.

Las curvas de demanda urbana se caracterizan utilizando una parametrización o forma funcional sencilla y con sentido económico, y calibrándola a partir de un par inicial cantidad-precio medio observado, y una estimación de la elasticidad de la demanda. La forma funcional más utilizada es la Cobb-Douglas (1928), función potencial que asume elasticidad constante a lo largo de la curva (Pulido-Velázquez, 2003). Aunque se espera que la elasticidad varíe a lo largo de la curva frente a precios crecientes, no hay ajustes de elasticidad basados en una base teórica fiable. Asumiendo elasticidad-precio constante la cantidad $Q$ consumida viene dada en función del precio $P$, según la expresión 3.1: 


$$
Q=c p^{\varepsilon}
$$

Conociendo un par $\left(\mathrm{q}_{1}, \mathrm{p}_{1}\right)$ y la elasticidad-precio $\varepsilon$ se puede determinar el valor de la constante $c$. El valor de $c$ se calcula usando el precio unitario medio y la demanda total anual, de acuerdo con la expresión 3.2:

$$
\boldsymbol{c}=\boldsymbol{q}_{1} \boldsymbol{p}_{1}^{-\varepsilon}
$$

Conforme el nivel de suministro se aleja del volumen máximo requerido (nivel de déficit cero) los precios se incrementan notablemente, dado que la dotación per cápita se va aproximando a la estrictamente necesaria por cuestiones de uso personal (aseo e higiene, bebida y alimentación). El comportamiento de la curva para suministros muy escasos no es importante a efectos del modelo, ya que al tener las demandas urbanas prioridad en el suministro, se consideran garantizados unos volúmenes mínimos.

\subsubsection{Valor económico del agua en usos ambientales, estéticos, recreativos}

El principal problema a la hora de valorar mejoras y daños ambientales, o dar un valor a usos ambientales (incluyendo valores de no uso), estéticos o recreativos consiste en que con frecuencia no existe un mercado para obtener directamente su valor. Por ello en los últimos años se ha llevado a cabo un notable esfuerzo por desarrollar técnicas para asignar valores monetarios al medioambiente y los recursos naturales.

Se han desarrollado diversas metodologías de valoración de recursos naturales, para lo que se han seguido dos enfoques principales. El primer enfoque consiste en construir un mercado hipotético y, mediante encuestas, desvelar la disponibilidad a pagar por disfrutar del bien ambiental (métodos directos o de preferencias declaradas). Las técnicas modernas de valoración pueden ser herramientas importantes para obtener información a la hora de acometer decisiones públicas en contextos en los que los precios de mercado son incompletos o imprecisos como señales de las preferencias públicas. Sin embargo, a pesar de los avances en métodos y aplicaciones, la valoración ambiental continúa siendo un "arte imperfecto"; al ser la valoración un ejercicio basado en hacer inferencias en base a hipótesis de partida, estará siempre sujeto a interpretación y debate (Braden, 2000).

\subsubsection{Valor marginal, beneficio y coste de escasez del agua}

Las ecuaciones para cada unidad de demanda se derivan de funciones económicas que expresan la relación entre el agua suministrada y su valor marginal, ceteris paribus. El beneficio económico en cada elemento del sistema se calcula como la integral de la función económica entre cero y la cantidad asignada en la simulación., y equivale a la 
disposición total a pagar por el agua. Un punto singular en la curva es el que representa el caudal máximo o nivel de suministro para el que el beneficio es máximo. Para las demandas agrícolas el caudal máximo corresponde al nivel de suministro que los usuarios demandarían si el agua estuviera disponible a coste marginal cero para maximizar sus beneficios. En el caso de la demanda urbana, podemos definir el caudal máximo como el objetivo de demanda a satisfacer. Este objetivo puede venir definido por el producto de la población por un consumo per cápita medio que incluya posibles medidas de ahorro o conservación previstas (Jenkins et al., 2003). Integrando desde el agua disponible hasta el nivel de suministro máximo (Fig. 5.2) se obtiene la expresión analítica del coste económico asociado a cada nivel de suministro o coste de escasez. De esta forma, las funciones económicas de demanda son convertidas en funciones de pérdidas económicas (coste de escasez) en función del suministro (Pulido-Velazquez, 2003).

\subsection{Coste de oportunidad del recurso}

Como se ha comentado en apartados anteriores, la Directiva Marco Europea de Aguas propugna un análisis económico por demarcación hidrográfica en el que se calculen, entre otros costes, los costes del recurso y medioambiental de los servicios del agua. No existe unanimidad en la literatura sobre los conceptos de coste del recurso y coste medioambiental y de procedimientos metodológicos para su estimación. Así, la Guía de Análisis Económico preparada por el grupo de trabajo WATECO (2003) señala como una de las claves en la implementación de la DMA que necesita de un mayor desarrollo metodológico la cuestión de hacer operativa la estimación del coste del recurso y el coste medioambiental en el contexto del desarrollo de los planes de gestión de cuenca (p. 62, Sección 6). En los párrafos siguientes se comentan cinco puntos de vista en relación con el coste del recurso.

\subsubsection{El grupo de expertos WATECO}

A raíz del establecimiento de la Directiva Marco europea del Agua (DMA), se integró un grupo de expertos, economistas, técnicos y patrocinadores de la Unión Europea, con el fin de resolver específicamente los asuntos relativos a la Economía del Agua. El principal objetivo de este grupo, a corto plazo fue desarrollar una guía práctica para implementar los elementos económicos de la DMA (ver apartado 1.2). En relación al coste del recurso, la guía WATECO lo define como (WATECO, 2003):

"aquellos costes de oportunidad conocidos que otros usuarios sufren debido al agotamiento del recurso, más allá de su recuperación o recarga natural". 
Esta definición es fundamentalmente aplicable al caso de la explotación de recursos no renovables o la sobreexplotación de recursos renovables por encima de su tasa natural de renovación.

\subsubsection{El grupo de expertos ECO 2}

En septiembre de 2003 se creó un grupo de expertos europeos (DG Eco 2) con el fin de clarificar los conceptos de costes medioambientales y del recurso (CMR). Este grupo preparó un documento definiendo esos conceptos y proponiendo una metodología para evaluarlos de acuerdo a lo marcado por la DMA aplicándolos a casos prácticos de los Estados Miembros de la UE (ver apartado 1.2).

La definición del coste del recurso que este grupo propone, más que una aclaración de la definición del grupo WATECO, adopta una lógica diferente y lo interpreta cómo (DG Eco 2, 2004):

"el resultado de una asignación ineficiente del recurso en vez de su sobreexplotación"

Sin embargo, el documento del grupo Eco 2 no propone una guía en cuanto a la estimación de los CMR sino únicamente proporciona una discusión general de los métodos así como algunas sugerencias. La definición propuesta por los expertos está enfocada con el criterio de la teoría económica; así, se sugiere que "los costes de daños medioambientales se refieren a los valores de no-uso agregados a un ecosistema hídrico saludable, mientras que los costes de los que usan el agua en los ecosistemas se refieren a los valores de uso"

\subsubsection{Aplicaciones e implicaciones en Alemania}

El tratamiento de los CMR en Alemania sintetizados en el informe de la consultora Ecologic (Görlach e Interwies, 2004) difieren notablemente tratándose del nivel en donde se trate: político-administrativo o el académico. La figura siguiente muestra los procedimientos seguidos en los dos niveles indicados: 


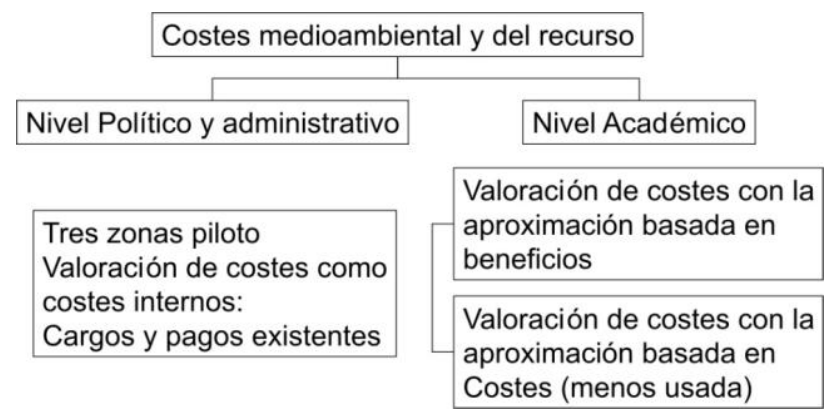

Figura 3.4 Tratamiento de los CMR en Alemania Fuente: Görlach e Interwies (2004) y elaboración propia

En el nivel político-administrativo la situación con respecto al coste de los recursos es un tanto confusa. La orientación que da el documento guía para la aplicación de la DMA sostiene que "los costes medioambientales y los costes del recurso pueden usarse como términos duales que cubran todas las externalidades de los servicios del agua" Si bien el documento del grupo DG Eco 2 ofrece una clara distinción entre los costes ambientales y de recursos, también toma nota de que los costes ambientales y de recursos están estrechamente relacionados. El ejemplo que figura en el documento está estructurado de la siguiente manera: el coste del recurso se puede calcular si el valor del agua actual que se utiliza se compara con el valor de la mejor alternativa del uso del agua. Este uso del agua puede ser "el uso ambiental" en caso de que un valor mayor se asigne para el mantenimiento de un ecosistema acuático en un estado no perturbado. En este sentido, los costes del recurso pueden surgir si a un cuerpo de agua se le da un uso económico (a través de la extracción de agua, o como una ruta de transporte), mientras que el público en general asignará un valor mucho más alto en la conservación de la masa de agua.

Cabe señalar que el entendimiento inicial de los costes del recurso en el debate alemán difiere de la definición propuesta en las conclusiones del grupo DG Eco 2. La actual definición expresada en el documento del grupo Eco2 argumenta que los costes del recurso surgen cuando los recursos hídricos no se usan de forma óptima, de modo que los usos alternativos del agua podrían generar un valor económico más elevado. Siguiendo esta interpretación, los costes del recurso son el resultado de una mala distribución del agua. Por el contrario, la argumentación expresada en la definición WATECO y el comunicado de la comisión sobre las políticas de asignación de precios muestran que los costes del recurso son el resultado del agotamiento del recurso escaso, más allá de la tasa natural de recuperación. En consonancia con esta definición, el debate alemán adopta un concepto de costes del recurso que gira en torno a la sobreexplotación y la escasez de los recursos hídricos. 
En nivel académico, existe un panorama mixto para la evaluación de los costes ambientales y de recursos. El enfoque defendido en el estudio de valoración económica es sin duda el enfoque de beneficios. En comparación con los países de habla Inglesa, la valoración económica de bienes ambientales y servicios aún no tiene una larga tradición en Alemania. En consecuencia, los estudios que han evaluado el valor económico de los usos del agua son pocos y distantes entre sí.

\subsubsection{Proyecto Water Strategy Managment}

Con base en el SAD desarrollado por Assimacopoulos et al. (2001), recientemente el grupo de investigación griego ha presentado un caso de estudio en relación a la asignación y costes del recurso de agua bajo condiciones de escasez (Assimacopoulos et al., 2005).

Los autores presentan un marco para el desarrollo y la evaluación de los planes de gestión del agua y las políticas de recuperación de costes en regiones deficitarias del recurso hídrico. La metodología que utiliza se basa en la aplicación de Sistemas Soporte a la Decisión (SSD) y lo aplica en la isla de Paros en Grecia.

Los costes medioambientales y del recurso los evalúa siguiendo los criterios establecidos por el grupo DG Eco 2. Sin embargo, considera lo siguiente:

Para el caso de los costes medioambientales se consideraron tanto costes de extracción y sobreexplotación como costes de contaminación y costes del impacto por mitigación.

Para el caso de los costes del recurso se evalúan como la renta de escasez definida como los costes de oportunidad menos los costes directos que conlleva utilizar el agua en productos relevantes, menos los costes medioambientales. El coste de oportunidad se refiere al valor marginal del agua. Se realiza una aproximación bajo condiciones noóptimas; se aplican reglas de asignación que reflejan las decisiones bajo el estado de escasez del recurso. Los valores marginales se calculan para los usos: domésticos (curvas de demanda y coste del suministro del recurso más caro) y agrícola.

Los costes del recurso se calculan de acuerdo a lo indicado en la figura siguiente: 


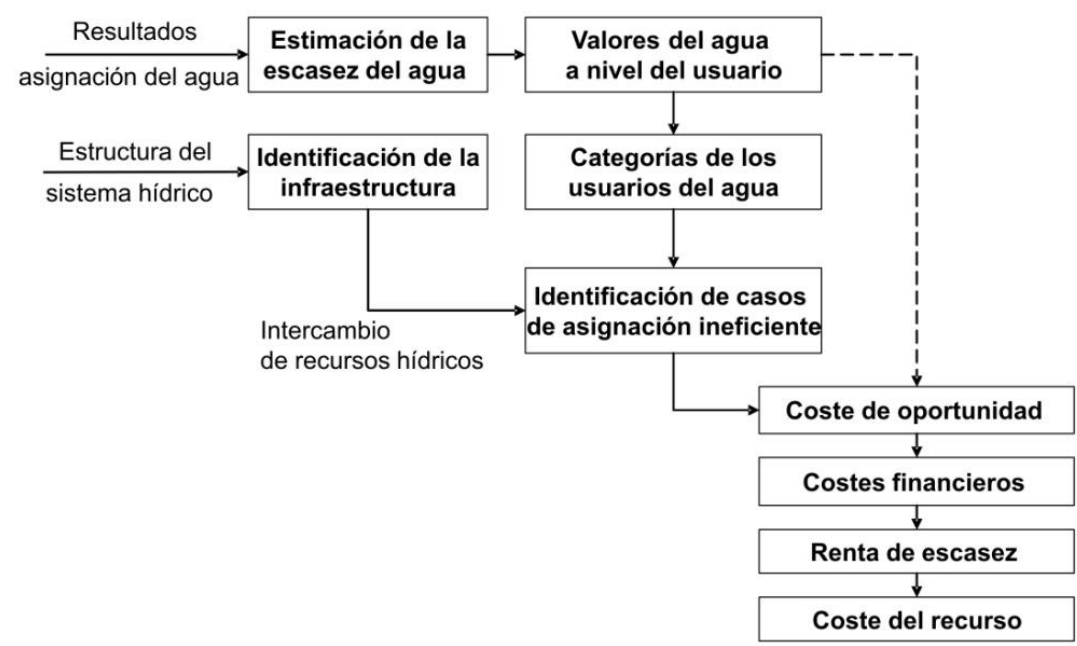

Figura 3.5 Valoración del coste del recurso Fuente: Assimaucopoulos (2005) y elaboración propia

\subsubsection{El proyecto AquaMoney}

El proyecto AquaMoney reúne 16 instituciones líderes de investigación europeos para desarrollar y probar orientaciones prácticas para la evaluación de los costes ambientales y de recursos y los beneficios en el contexto de la Directiva Marco europea del Agua (véase el apartado 1.2). El consorcio cuenta con el apoyo de un Comité consultivo de 24 actores y tomadores de decisiones, dentro de los que está el Instituto para Estudios Mediambientales (IVM).

Brouwer (2004) considera que ni el coste del recurso ni el medioambiental están claramente definidos en la literatura. Indica que los costes económicos totales son, de acuerdo al marco teórico de fondo, la suma de: costes directos de los usuarios (CDU), generalmente considerados como costes internos y costes sociales directos e indirectos (CSDI), generalmente costes externos. Los CDU son los costes financieros del uso del agua, mientras que los CSDI son los beneficios conocidos, tanto los actuales como los futuros de uso o no uso del recurso. Los CSDI son, a su vez, la suma de: costes medioambientales, renta de escasez y coste del uso futuro. El autor considera, entonces, que los dos últimos, forman parte del coste del recurso (ver figura 3.7). 


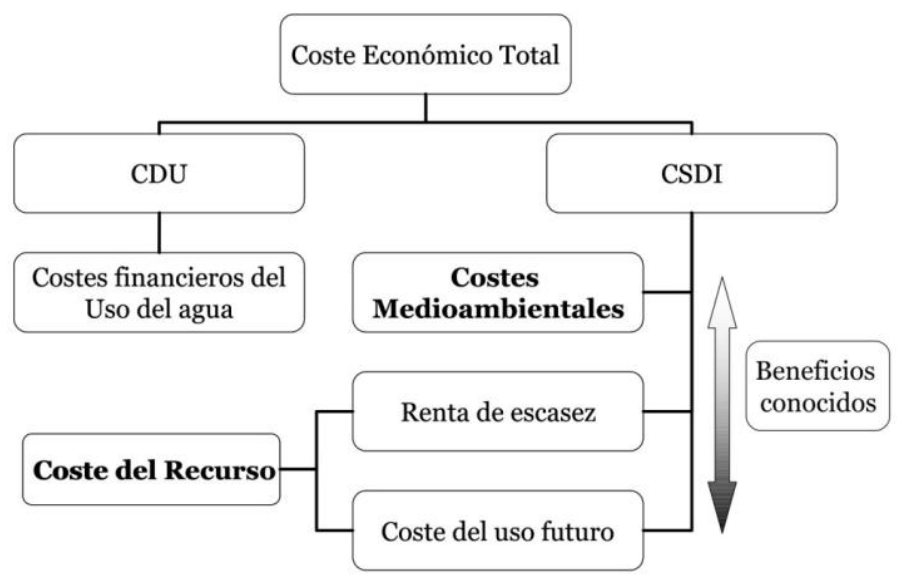

Figura 3.6 Integración del Coste Económico Total en los Países bajos Fuente: Brouwer (2004) y elaboración propia

El autor comenta que la distinción entre los costes ambientales y de recursos en la orientación Wateco parece basarse principalmente en la cuestión de si el agua es un recurso agotable (no renovable) o no, mientras que la hoja de información ECO2 introduce la noción de valores de uso y no uso en la ecuación, donde los costes de daños ambientales podrían servir de argumento para referirse a los valores de no uso que tiene un ecosistema acuático saludable y el coste de oportunidad de los que utilizan el medio acuático y sus correspondientes valores de uso.

Se ha discutido mucho acerca de la valoración práctica del recurso hídrico. Para ello se parte de los siguientes conceptos (Brouwer, 2006):

- El agua es un bien económico, lo que significa que hay una demanda de agua temporal y espacialmente definida por una determinada cantidad y calidad del recurso pudiéndose utilizar en usos diferentes, y por ende provocar escasez hídrica.

- El agua como un bien económico tiene valor económico y coste de oportunidad.

- El coste del recurso se considera por separado de los costes medioambientales con el fin de poder explicar el hecho de que en Europa existen importantes diferencias en términos de volumen del recurso y gestión de la calidad del mismo.

- El coste del recurso se refieren a la competencia y/o a los conflictos humanos por el uso del agua como consecuencia de la limitada disponibilidad cuantitativa en tiempo y espacio del recurso.

El coste del recurso lo refiere explícitamente al valor económico de las oportunidades conocidas del uso del agua en su mejor uso actual o futuro (a fin de evitar tener que medir todos los posibles usos de agua actuales y futuros) debido al uso específico actual de las 
aguas y la explotación de recursos (derechos), lo que resulta en su falta de disponibilidad física (escasez) para su uso actual o futuro. Este coste se mide en términos de la pérdida de beneficio neto del uso actual del agua, y está relacionado con la disponibilidad del recurso.

Los beneficios económicos se definen como el valor económico total de los bienes y servicios proporcionados por el ecosistema hídrico, incluyendo los valores de uso y de no uso asociados con: la calidad del agua potable, el agua de regadío, el agua utilizada comercialmente $\mathrm{y}$ en actividades recreativas de pesca, el hábitat silvestre y la biodiversidad.

\subsubsection{Metodología de la UPV. Modelos hidro-económicos y CMOR}

La metodología propuesta por el IIAMA-UPV se basa en el desarrollo de modelos hidroeconómicos a escala de cuenca para calcular el CMOR o coste de escasez. Para ellos se han utilizado dos enfoques de análisis: el de simulación (véase por ejemplo Collazos et al., 2004) y el de optimización (véase por ejemplo Pulido-Velázquez, 2003). El desarrollo de esta metodología se describe más ampliamente en el capítulo 4. 



\section{CAPITULO 4}

\section{Valoración del coste de oportunidad del recurso}





\section{Valoración del coste del recurso}

La valoración del coste del recurso ha sido un tema de discusión por parte de los diferentes grupos que se han definido para el estudio de la implementación de la DMA y que los diferentes Estados miembro utilizan en sus propios ámbitos y sitios de estudio (véase apartado 3.3.).

El coste del recurso generalmente ser asocia con el coste de oportunidad o beneficio neto al que se renuncia cuando un recurso escaso es asignado a una actividad o uso en lugar de a otras posibles. Surge, por tanto, de una asignación económicamente ineficiente del recurso (en cantidad y/o calidad) en el tiempo y entre diferentes usuarios en el espacio y el tiempo, y está relacionado con la escasez del recurso y su gestión. Desde el punto de vista de la gestión del agua como un recurso económico el reto clave es conseguir que se tenga en cuenta este coste de oportunidad del agua en la asignación del recurso. A pesar de la aparente simplicidad del concepto, su aplicación es muy compleja, ante la inexistencia práctica de precios de mercado que reflejen el valor marginal del agua en cada uso. La complejidad aumenta al considerar la variación en el tiempo y en el espacio del coste marginal de oportunidad del recurso. 
El establecimiento de precios del agua que incorporen el valor del recurso a escala de cuenca desde el punto de vista práctico es por tanto un reto complejo, lo que se agrava por el hecho de que el valor del recurso es variable en el tiempo y espacio, lo que dificultaría su implementación práctica y su aceptabilidad. Por ello en este trabajo se hace un esfuerzo por vincular el coste del recurso con estados de reservas, y definir con ello políticas de precios.

En este capítulo se plantean tanto el concepto de coste utilizado en esta tesis como la metodología para la valoración del mismo, considerando los enfoques de optimización y simulación hidrológica. La valoración del coste mediante el enfoque de simulación se muestra en un caso práctico para la cuenca hidrográfica del río Segura.

\subsection{Coste Marginal de Oportunidad del Recurso}

El coste de oportunidad está relacionado con el valor del agua de forma no transitiva (Briscoe, 1996; Pulido-Velázquez, 2003). El uso urbano de agua es generalmente un uso de poco volumen y alto valor. Los costes de uso son relativamente altos, mientras que los costes de oportunidad (impuestos sobre otros como consecuencia del uso del agua) son relativamente bajos. Por otro lado, el suministro de agua para riego aunque supone un gran volumen por lo general tiene un bajo valor añadido. El coste de uso del agua para riego es con frecuencia modesto, pero cuando compite con el uso urbano el coste de oportunidad es alto. A pesar de esto, el coste de oportunidad del agua de riego frecuentemente se sobrevalora, ya que aunque los requerimientos de agua son grandes, las fluctuaciones temporales son importantes y la garantía de suministro requerida es mucho más baja que para el suministro urbano.

Desde el punto de vista de la gestión del agua como un recurso económico el reto clave es conseguir que se tenga en cuenta el coste de oportunidad real del agua en la utilización del recurso (Pulido-Velázquez, 2003; Pulido-Velázquez et al., 2008). La eficiencia económica en la gestión del recurso exige que se conozcan e incorporen los costes de oportunidad del recurso en las decisiones. Además, las tarifas que incluyen el coste de oportunidad transmiten al usuario una señal de escasez del recurso, incentivando un uso eficiente del mismo. A pesar de la aparente simplicidad del concepto, su aplicación es muy compleja. $\mathrm{Si}$, como ocurre en España y en otros muchos países, la asignación del agua no se realiza generalmente a través del mercado, la determinación del coste de oportunidad del uso del recurso en cada momento y en cada lugar es una tarea muy complicada, y requiere de una metodología de análisis de sistemas apoyada en un adecuado sistema de valoración económica del valor del agua en cada uso.

En el Departamento de Ingeniería Hidráulica y Medio Ambiente de la UPV se ha considerado el concepto de Coste Marginal de Oportunidad del Recurso (CMOR, en 
adelante) para definir el coste del recurso (Pulido-Velázquez, 2003). Para un punto del sistema y en un instante dado, el CMOR es el coste que supone para el sistema el disponer de una unidad menos de agua en ese punto y en ese instante. Ese coste es un indicador de la escasez del agua en el sistema y de la disponibilidad de pago del sistema productivo y los usuarios finales, que tienen para solventar la escasez. La variabilidad espacio-temporal del coste del recurso así valorado, se captura mediante el uso de modelos hidrológicoeconómicos del sistema, ya que estos son capaces de incorporar tanto la variabilidad de las demandas económicas del sistema como la operatividad de la infraestructura que regula y distribuye el recurso hídrico (Pulido-Velázquez et al., 2004b).

\subsection{METOdOLOGÍA PARA EL CÁLCULO DEL CMOR}

Se tienen dos variantes para la valoración del CMOR en este trabajo. Por un lado el enfoque de optimización y, por el otro un enfoque basado en la simulación hidrológica del sistema. Ambos enfoques utilizan diferentes modelos, con sus respectivas ventajas y desventajas, para evaluar el CMOR. En el desarrollo de la presente tesis se utilizaron los modelos GAMS, para el enfoque de optimización, y el módulo SimGes del SAD Aquatool para el enfoque de simulación.

\subsubsection{Enfoque de optimización}

El coste del recurso puede valorarse en función de los valores o precios sombra que se obtienen de un modelo de optimización, en el cuál la función objetivo corresponde a los beneficios económicos derivados del reparto del recurso del agua a los diferentes usos que compongan un sistema de explotación. El valor económico neto se obtiene agregando los beneficios que corresponden al nivel de suministro y deduciendo los costes variables de suministro. Por otro lado, las restricciones en el modelo garantizan que las decisiones finales sean factibles y sostenibles.

Los valores óptimos de las variables del problema dual (precios sombra), definen el cambio en el valor óptimo de la función objetivo como consecuencia de un cambio marginal unitario del término independiente de la restricción que corresponde a cada variable dual. Ya que la función objetivo es el resultado económico por el uso económico del agua en todo el sistema, los precios sombra de las restricciones de balance en los nudos del modelo (embalses, acuíferos, etc.) proporcionan el incremento neto de beneficio neto por incremento infinitesimal del recurso hídrico en ese nudo y en ese instante, y por tanto el Coste Marginal de Oportunidad del Recurso (Pulido-Velázquez, 2003, 2006a). El modelo utilizado mediante el enfoque de optimización proporciona una valoración normativa que constituye un techo ideal o valor máximo para el coste de oportunidad. 


\subsubsection{Enfoque de simulación}

El análisis económico con base en un enfoque de simulación, tiene la virtud de tomar en cuenta las condicionantes de la gestión actual y real del sistema. Los indicadores económicos resultantes del análisis permiten detectar ineficiencias en el sistema, sin que aquellos sean los protagonistas en la gestión.

Un modelo de simulación asume que el sistema es gestionado de acuerdo con unas reglas a priori. EI CMOR puede aproximarse mediante la variación de beneficios que ocurriría si hubiera una unidad menos de recurso en un punto e instante determinados. El modelo de simulación permite una valoración positiva correspondiente a la gestión del sistema mediante reglas predefinidas, por ejemplo prioridades legales en la asignación del recurso, permitiendo reproducir el modus operandi del sistema.

El enfoque de simulación es conceptualmente sencillo, computacionalmente más simple, y consigue resultados aproximados a los que se obtienen mediante optimización. La metodología parte de la puesta a punto de un modelo de simulación de la gestión de la cuenca en el que estén caracterizadas todas las componentes relevantes (recursos superficiales y subterráneos, infraestructuras, demandas, etc.) y que permita una representación razonable de distintas políticas de gestión.

Collazos et al. (2004) proponen un modelo de simulación para realizar un análisis económico a nivel de cuenca, consideran una asignación del agua no basada en aspectos económicos sino en otros distintos, como los referentes a usos históricos, legales, etc. Los autores definen también funciones económicas que, para los distintos usos del recurso, representan las curvas de demanda pero pueden ser también aplicadas a otros elementos del sistema para representar los costes. Utilizan el módulo SimGes del SAD Aquatool para la simulación de la gestión y con ello representar adecuadamente la asignación actual de agua a la cuenca. Indican que para realizar el análisis económico, el SRH bajo análisis ha de haber sido modelado previamente con SimGes. Su propuesta metodológica consiste en: puesta a punto de un modelo de simulación de la gestión de la cuenca; puesta a punto de un evaluador económico de la asignación del recurso obtenida con el modelo de simulación; y utilización de rutinas específicas que permiten el uso secuencial de los modelos anteriores con el fin de obtener los costes marginales.

Los autores comparan los resultados económicos para el caso base, que representa la asignación actual, y el caso modificado, constituido por el caso base más una pequeña perturbación consistente en añadir (o detraer) una unidad diferencial de caudal en el elemento e instante de interés. En el caso modificado el modelo lleva a cabo una nueva asignación del recurso, usando las reglas de reparto, y posteriormente se evalúa el beneficio económico total y se calcula la diferencia de beneficios totales entre el caso base 
y el modificado. El cociente entre la variación del beneficio económico y la variación de caudal, es una aproximación al Coste Marginal de Oportunidad del Recurso, el cual refleja el coste económico de la escasez relativa del recurso hídrico de acuerdo con los criterios de asignación actuales.

\subsection{CMOR como Valores Sombra del Modelo de Optimización GAMS}

Se ha utilizado el lenguaje de programación GAMS (General Algebraic Modeling System, Brooke et al., 1998) en el presente trabajo, por ser una herramienta muy versátil que entra dentro de la clasificación de lenguajes algebraicos especialmente diseñados para el modelado, análisis y resolución de problemas de optimización.

\subsubsection{Descripción general de GAMS}

El modelo de optimización GAMS es un sistema de modelación de alto nivel basado en programación matemática. Está específicamente diseñado para resolver problemas de optimización lineales, no lineales y mixtos. GAMS puede diseñar grandes y complejos modelos a escala, y permitir construirlos de manera que puedan adaptarse de acuerdo a los requerimientos del modelador y/o a nuevas y diversas condiciones del problema por optimizar.

Las características más importantes de GAMS son las siguientes (Pulido-Velázquez, 2003):

- Capacidad para resolver problemas de pequeña dimensión (docenas de variables y restricciones), y problemas mayores (miles de variables y restricciones) sin variar el código de forma importante. El manejo eficiente de sus índices permite escribir, de manera compacta las restricciones mediante una sola ecuación.

- Separa el proceso del modelado por el usuario, del proceso interno de resolución obtenido mediante alguno de los optimizadores disponibles.

- La forma en que GAMS representa un modelo de optimización coincide prácticamente con la descripción matemática del problema, por lo que el código resulta sencillo de comprender.

- Proporciona los mecanismos necesarios para resolver problemas de optimización con estructuras similares, como aquellos que se derivan de técnicas de descomposición.

Existe una amplia literatura sobre técnicas de programación lineal que muestran un amplio rango de métodos aplicables: métodos duales; métodos de penalizaciones; métodos de lagrangiano aumentado; métodos de direcciones factibles; programación 
cuadrática secuencial, etc. GAMS dispone de diferentes optimizadores (solvers) para resolución de problemas no lineales. Los más conocidos son CONOPT y MINOS, siendo sus últimas versiones CONOPT3 (ARKI 2002) y MINOS 5.5 (Murtagh y Saunders, 2002). MINOS 5.5, desarrollado en la Universidad de Stanford, emplea un algoritmo de gradiente reducido combinado con un algoritmo cuasi-newtoniano para facilitar la optimización de variables súper-básicas. En el caso de restricciones no lineales, se utiliza un algoritmo de proyeccción lagrangiana que incorpora una secuencia de iteraciones mayores, cada una de las cuales requiere la solución de un sub-problema linealmente restringido. Cada subproblema contiene versiones linealizadas de las restricciones no lineales, así como las restricciones lineales originales y las cotas de variables.

CONOPT3, desarrollado por una consultora danesa (ARKI Consulting and Development), que implementa un algoritmo basado en el método generalizado de gradiente reducido (algoritmo GRG) es un método más apropiado para resolver problemas de gran tamaño con muchas no linealidades y pocos grados de libertad. A diferencia de las versiones anteriores, CONOPT3 puede utilizar información de segundas derivadas de las funciones para acelerar el proceso de optimización.

MINOS 5.5 y CONOPT3 utilizan, por tanto, un algoritmo de optimización diferente, y uno puede ser más apropiado que el otro dependiendo del problema por resolver siendo muy difícil predecir a priori cual es el más adecuado para resolver un problema particular.

\subsubsection{Optimización económica de la gestión}

Un modelo de optimización busca de forma automática la solución factible óptima para el periodo de optimización seleccionado, de acuerdo con un objetivo único o varios objetivos simultáneos no evaluables en las mismas unidades. A diferencia del modelo de simulación, el de optimización es más limitado en cuanto a la representación real de un sistema real, pero se elimina el largo proceso de prueba y error inherente a un modelo de simulación.

La optimización económica de la gestión se ha realizado mediante un modelo hidroeconómico de optimización a escala de cuenca o sistema de explotación. El modelo integra el sistema superficial de agua, la infraestructura hidráulica y las funciones económicas que definen el valor del recurso para las distintas demandas y costes implicados en el suministro de las mismas. La optimización se hace sobre series hidrológicas extensas, representativas del rango de eventos hidrológicos probables en el futuro, pero para las demandas correspondientes a un nivel de desarrollo determinado.

Se ha asumido que los valores sombra proporcionados por el modelo de optimización mediante el cambio en la función objetivo, como consecuencia de un cambio marginal unitario del término independiente de la restricción que corresponde a cada variable dual, 
corresponden al valor del CMOR. El problema matemático consiste en maximizar el valor de una función escalar objetivo económica, bajo una serie de restricciones que definen el suministro de agua a las demandas de un sistema de explotación. La función objetivo representa los beneficios totales que se proporcionan a las diferentes demandas cuando se asigna el recurso de agua de acuerdo a la disponibilidad y a las aportaciones a los embalses considerados (ecuación 4.1).

$$
M A X \quad B A=\sum_{k=1}^{n T} \frac{1}{(1+i)^{k}}\left(\sum_{e=1}^{n E} \int_{0}^{x_{k e}^{\prime}} f e_{k e}\left(x_{k e}\right) d x_{k e}\right)
$$

La función objetivo está sujeta a las diferentes restricciones para reproducir los condicionantes físicos y de gestión del sistema.

Las restricciones se pueden clasificar en:

- Restricciones de balance en los nudos del sistema. El balance será entradas igual a salidas para los nudos sin capacidad de almacenamiento, y entradas menos salidas igual a variación de volumen en los nudos de embalse.

- Restricciones de signo de las variables. Las variables de decisión (sueltas, bombeos, recarga artificial, caudales de derivación, etc.) son todas positivas. Algunas de las variables de estado pueden ser positivas o negativas (se definen como variables libres o sin restricción de signo en el modelo). Por ejemplo, algunas de las variables de control de los acuíferos pueden alcanzar valores negativos, como ocurre cuando se generan alturas piezométricas o volúmenes por debajo de la situación de referencia.

- Restricciones de capacidad máxima, en variables que representan caudales en conducciones o volúmenes en embalses o acuíferos, de acuerdo con las cotas superiores impuestas bien por limitaciones físicas o de gestión en el sistema. En el caso de las demandas consuntivas se añade la condición de que el suministro máximo a cada unidad de demanda viene definido por el valor máximo de la demanda en cada mes.

- Ecuaciones de procesos físicos. Para el subsistema superficial consisten generalmente en restricciones de igualdad que reproducen mediante una ecuación empírica previamente calibrada procesos físicos como pérdidas por evaporación o filtraciones en conducciones y embalses, y retornos en las demandas. Las evaporaciones suponen pérdidas permanentes de agua para el sistema. Las filtraciones pueden suponer pérdidas de agua para el sistema; en otros casos se considera que esas filtraciones alimentan a un acuífero concreto que se incluye en el modelo. En ese caso la variable de infiltración se suma como recarga en las ecuaciones de balance en el acuífero. Los 
retornos son los reintegros de agua al sistema (superficial o subterráneo) en las unidades de demanda consuntivas.

- Restricciones de valor mínimo. Este valor mínimo puede corresponder a restricciones de caudal mínimo en conducciones o volumen mínimo en embalses, ya sea por motivos operativos, ambientales (por calidad de las aguas o mantenimiento de ecosistemas) o recreativos. A diferencia del resto de restricciones comentadas, que representan limitaciones físicas reales que no pueden ser violadas de ninguna forma, este tipo de restricciones representan metas u objetivos implícitos, que pueden de hecho ser violados, aunque el coste de esa violación sea alto. En el caso de que no haya agua disponible para cumplir las restricciones de valor mínimo no se encontraría solución factible al optimizar, con lo que hay que introducir variables de holgura con alta penalización para detectar no factibilidades.

Las variables de decisión corresponden en este caso a decisiones de sueltas en embalses, bombeos en los acuíferos, y variables de caudal circulante por las conducciones, según las decisiones de reparto del agua para atender a las distintas demandas y requerimientos ambientales. Entre las variables de estado se incluyen las variables de volumen, evaporación y filtraciones en el embalse, y las que representan el estado de los acuíferos.

Las ecuaciones de balance en nudos sin capacidad de almacenamiento vienen definidas por la clásica relación de continuidad que implica que la suma de entradas al nudo desde aguas arriba debe ser igual a las salidas aguas abajo del nudo.

En el caso de embalses, la ecuación de balance se transforma en una ecuación de estado, en la que el estado del embalse viene representado por la variable de volumen embalsado. La ecuación de continuidad consiste en este caso en que la diferencia entre entradas y salidas es igual a variación de volumen,

$$
V_{t}=V_{t-1}+A P_{t}-P E_{t}-P F_{t}-Q S_{t}
$$

donde $V_{t}$ es el volumen en el embalse al final del mes $t, V_{t-1}$ es el volumen en el embalse al final del mes $t-1$ ( $y$, por tanto, el volumen inicial en el mes $\mathrm{t}$ ), $A P_{t}$ es la aportación hidrológica al embalse durante el mes $t, P E_{t}$ y $P F_{t}$ son las pérdidas por evaporación y filtración, y $Q S_{i}$ son las sueltas del embalse a través de la conducción $i$, una de las $n$ conducciones de salida del nudo. Las sueltas pueden deberse tanto a sueltas controladas, que corresponden a decisiones de reparto del agua, como a vertidos, o desembalses producidos por superarse la capacidad máxima de embalse. La limitación de capacidad máxima en el embalse viene definida en el modelo por una restricción del tipo: 


$$
V_{t} \leq V M A X_{t}, \forall t
$$

donde $V M A X_{t}$ es la llamada capacidad útil del embalse, o capacidad de embalse utilizable para regulación, es decir, descontando resguardos para avenidas y volúmenes mínimos por razones operativas. Dado que los resguardos por avenidas pueden variar de unos meses a otros, VMAX puede ser variable a lo largo del año. El volumen mínimo también puede variar dentro del año.

Las pérdidas por evaporación y filtración en el embalse son función del volumen almacenado. Las pérdidas por evaporación se calculan como el producto de la superficie de lámina libre del embalse por las tasas mensuales de evaporación por unidad de superficie (dato). Debido a que la variable de estado es el volumen en el embalse, es necesario realizar un cambio de volumen a superficie de lámina libre, para lo cual se utiliza la función volumen-superficie libre. Dicha función puede aproximarse en forma potencial:

$$
S=a V^{b}
$$

siendo $a$ y $b$ las constantes de ajuste. Con la expresión 4.4 la evaporación en el mes $t, P E_{t}$ se calcula al considerar la superficie media del mes aproximada como la media aritmética entre las superficies al inicio y al final del mes, mediante la expresión:

$$
P E_{t}=c \cdot\left(\frac{V_{t-1}+V_{t}}{2}\right)^{d} e_{t}
$$

siendo $e_{t}$ la tasa media mensual de evaporación; $V_{t-1}$ el volumen al final del mes $t-1$ (igual al volumen al inicio del mes $\mathrm{t}$ ) y $V_{t}$ el volumen al final del mes $t$.

Las pérdidas por filtración se calculan mediante una ecuación empírica, ajustada a una nube de datos empírica que relaciona las pérdidas mensuales (obtenidas mediante balance en el embalse) con los volúmenes correspondientes. Para el caso de un ajuste potencial entre pérdidas mensuales y volumen medio almacenado en el embalse, se utiliza la expresión:

$$
P F_{t}=m \cdot\left(\frac{V_{t-1}+V_{t}}{2}\right)^{n}
$$

siendo $\mathrm{m}$ y $\mathrm{n}$ las constantes de proporcionalidad del ajuste.

Las ecuaciones para cada unidad de demanda se derivan de funciones económicas que expresan la relación entre el agua suministrada y su valor marginal en cada mes del año. 
Por simplicidad, las funciones de demanda se ajustan a un polinomio de grado $n$ (véase apartado 3.2.3). La función que define el beneficio para un volumen disponible de agua es igual al área bajo la curva de demanda hasta ese nivel de suministro y corresponde a la disposición total a pagar por el agua.

En GAMS la única regla que gobierna el orden de las sentencias es que una entidad del modelo no puede ser referenciada antes de ser declarada. Una vez que el programa es compilado en GAMS se llama a un determinado optimizador (solver) que intenta encontrar la solución óptima al problema planteado. En la terminología GAMS los índices, usados para identificar parámetros y variables y definir ecuaciones, se definen en conjuntos denominados Sets. Los datos se definen como Parameters de distinta dimensión, o se pueden configurar como escalares o matrices. Las variables de estado y decisión son definidas mediante el comando Variables. Todas las restricciones y la función objetivo son definidas en el bloque Equations. El bloque Model permite asociar un nombre al modelo e identificar qué conjunto de restricciones lo componen. Mediante le bloque Solve se indica a GAMS que utilice un optimizador determinado para resolver el modelo. Finalmente se puede ordenar a GAMS que muestre los resultados más interesantes en un fichero de salida. En el caso que ocupa el presente trabajo, los resultados se han vinculado a un fichero de Microsoft EXCEL que previamente preparado permite almacenar los resultados de interés en forma de tablas, gráficas y estadísticas.

\subsection{El CMOR mediante modelo de simulación del SAD Aquatool}

Para valorar el Coste Marginal de Oportunidad del Recurso se requiere de un modelo de simulación de la gestión. En el presente trabajo se ha utilizado el modelo de simulación de la gestión denominado SimGes, que forma parte del Sistema de Apoyo a la Decisión (SAD) Aquatool. Es una herramienta para la elaboración de modelos de simulación y optimización de recursos hídricos a escala de cuenca desarrollada por el Grupo de Ingeniería de Recursos Hídricos del IIAMA-UPV (Andreu et al., 1996). El módulo EcoWin es usado para estimar el valor del CMOR de acuerdo con la simulación de la gestión con SimGes.

\subsubsection{Descripción del módulo SimGes}

SimGes es un modelo general para la Simulación de la Gestión de Cuencas, o sistemas de recursos hidráulicos complejos, en los que se dispone de elementos de regulación o almacenamiento tanto superficiales como subterráneos, de captación, de transporte, de utilización y/o consumo, y de dispositivos de recarga artificial (Andreu et al., 2004). La simulación se efectúa a nivel mensual y reproduce, a la escala de detalle espacial que el usuario desee, el flujo del agua a través del sistema. Para los subsistemas superficiales el flujo es calculado simplemente por continuidad o balance, mientras que para los 
subsistemas subterráneos o acuíferos el flujo es simulado mediante modelos de celda, uni o pluricelulares, según convenga, o incluso mediante modelos distribuidos de flujo lineal. Se tiene asimismo en cuenta en la simulación las pérdidas por evaporación y filtración en embalses y cauces, así como las relaciones entre aguas superficiales y aguas subterráneas.

La gestión de los recursos hidráulicos se efectúa mediante reglas de operación que permitan reproducir cualquier regla de gestión en los embalses usando para ello unas curvas de zonas de embalse y otros mecanismos, como indicadores y restricciones asociadas. Estas curvas son las reglas de explotación propiamente dichas y son suministradas por el usuario del modelo. Se admite la definición de caudales mínimos ecológicos, así como de diferentes prioridades de los usuarios para el aprovechamiento del agua. La simulación y gestión del sistema superficial se efectúan a un tiempo mediante el uso de un algoritmo de optimización de redes de flujo conservativo. Dicho algoritmo se encarga de determinar el flujo en el sistema tratando de satisfacer al máximo los objetivos múltiples de minimización de déficits, y de máxima adaptación a las curvas de volúmenes objetivo de embalse y objetivo de producción hidroeléctrica.

Los resultados del modelo incluyen la evolución de todas las variables de interés a nivel mensual, a nivel anual, y los valores medios del período de simulación, así como las garantías. Todo ello permite que el modelo pueda ser utilizado, entre otras finalidades para:

- Determinar las garantías que se obtienen para distintas hipótesis de infraestructura y de evolución de demandas, así como para distintas reglas de explotación de la cuenca;

- Establecer las reglas de explotación más adecuadas para unos niveles exigidos de garantías;

- Estimar los beneficios o perjuicios derivados de la alteración de prioridades de usos del agua;

- Determinar las capacidades de embalse, de conducciones, y de instalaciones de bombeo para unos niveles de demanda y de garantía dados.

\subsubsection{Simulación de la gestión mediante SimGes}

Para poder definir el modelo del sistema de explotación que se requiere representar, el usuario debe realizar lo siguiente:

- Confeccionar un esquema de la cuenca o del sistema (figura 4.1) adaptándose al uso de los elementos tipo arriba mencionados. Para ello se definirá una serie de nudos en el sistema hidráulico de superficie, estando localizados los nudos en cada uno de los siguientes puntos: 
- Embalses.

- Puntos de unión de dos o más cauces o conducciones.

- Puntos de derivación o partición de caudal.

- Puntos de toma y de retorno de las distintas demandas.

- Puntos donde se supone se incorporan las posibles aportaciones intermedias o los posibles bombeos adicionales.

- Puntos de cambio de las características de las conducciones.

- Definir las conexiones (conducciones) que existan entre los nudos, así como el tipo al que pertenecen.

- Situar las aportaciones intermedias que puedan llegar a algún nudo o embalse (si no se definen asociadas al propio embalse).Ubicar las demandas, localizando sus nudos de toma y sus nudos de retorno (elementos), e identificando los acuíferos de los que puedan bombear y los que reciben los retornos por infiltración.

- Identificar los nudos de donde parten los flujos destinados a recarga artificial y aquellos donde se incorporan los bombeos adicionales.

- Definir los criterios de restricción para las situaciones de alarma del sistema. Estos indicadores de alarma, pueden asociarse a tomas de demandas o a tramos de río y canales.

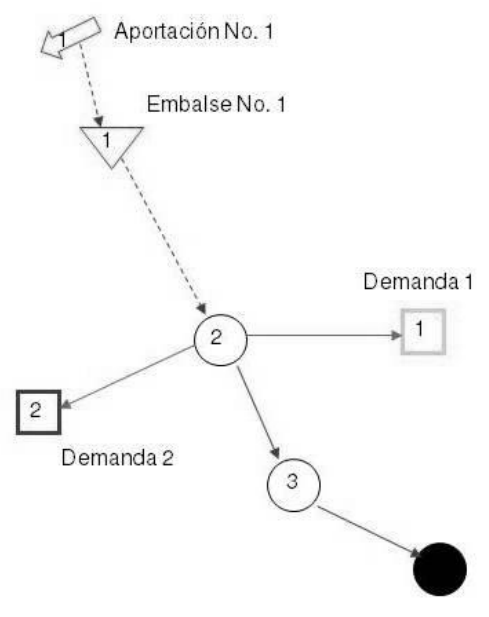

Figura 4.1. Ejemplo de esquema del SRH

La definición del esquema hidráulico del sistema queda completa cuando el usuario suministra al modelo, además de otros datos de cada elemento, su conexión con los nudos previamente definidos. 
El esquema del usuario, previamente confeccionado, constituye una red de flujo. Pero dicha red no cumple el requisito de ser conservativa, ya que no es cerrada y existen nudos en los que hay almacenamiento de agua (los correspondientes a los embalses). Por tanto, lo primero que realiza el modelo, después de la lectura de datos, es la adaptación del esquema del usuario a una red de flujo conservativo. Para ello es necesario, por una parte, el establecimiento de unos nudos de "cierre" de la red, y por otra, el desdoblamiento de cada elemento tipo en un sub-esquema de arcos y nudos tal que aseguren que la simulación del comportamiento hidráulico y de gestión del elemento sea adecuada. El resultado es una red de flujo interna, mucho más compleja que la del usuario, que ya es conservativa, y que es la que utilizará el modelo sin trascendencia exterior para el usuario.

Una vez confeccionada la red interna, el modelo inicia la dinámica de la simulación, en la que para cada mes del período de simulación se resuelve la red de flujo con los valores de aportaciones, demandas, y parámetros de gestión correspondientes a ese mes; utilizando el algoritmo de "out of kilter" (ver por ejemplo Bazaraa et al, 2009) se simulan los acuíferos; se itera entre estos dos últimos pasos (debido a las no linealidades y a las relaciones río-acuífero); y se almacenan valores para su escritura anual y representación estadística.

SimGes realiza la asignación con base en las prioridades relativas, entre los elementos del sistema, establecidas por el modelador. Esto es como si se asignaran a los elementos funciones económicas constantes. Los usos que tienen igual prioridad constituyen un grupo isoprioritario. Si en un mes dado el agua no alcanza para el requerimiento de todos los usos de ese grupo, el déficit se reparte entre ellos proporcionalmente al requerimiento.

SimGes también dispone de un mecanismo para disminuir la asignación en época de escasez: los indicadores de alarma o indicadores de restricción. Estos indicadores afectan a los usos, y los define el usuario. Cada indicador se define con pares de valores, que relacionan el volumen almacenado en uno o varios embalses con un porcentaje del volumen requerido por los usos. De esta forma se consigue que, cuando los embalses están a bajo nivel, la entrega a los usos disminuya, y como consecuencia se reparten los efectos de una posible sequía.

\subsubsection{El evaluador económico EcoWin del SAD Aquatool}

El módulo EcoWin (Anejo B) del SAD AquaTool también ha sido desarrollado por el Grupo de Ingeniería de Recursos Hídricos del IIAMA-UPV, partiendo del trabajo desarrollado por Collazos (2004) y Collazos et al. (2004), y permite calcular tanto los beneficios (y costes de escasez) que reportan a los usuarios una determinada asignación del recurso, como la serie temporal del CMOR en algún punto del sistema. 
Para la aplicación del programa, se necesita tener un esquema (adecuadamente validado) del sistema modelado con SimGes. El uso del modelo de simulación es imprescindible para tener bien definido el comportamiento hidrológico de la cuenca como unidad y preservar las interrelaciones entre los distintos elementos del sistema hídrico.

El programa calcula el beneficio y/o el coste de escasez económico con la ecuación (4.1) para cada elemento del sistema y para cada periodo de tiempo considerado. Además se utiliza una función económica de tipo paramétrico que también puede definirse en forma discreta por medio de puntos, en el caso de que la función no pueda ajustarse o que resulte muy compleja en su estructura.

Para evaluar la ecuación de beneficios o coste de escasez, se utilizan dos grupos de datos:

- La simulación de la gestión que se realiza con el modelo SimGes.

- Las funciones económicas (f.e.) declaradas para cada elemento del sistema. Esta función económica se representa como un polinomio de la forma siguiente:

$$
f . e .=a+b x+c x^{2}+\left(\frac{d}{x+e}\right)+f x^{g}
$$

donde $a, b, c, d, e, f, g$ son parámetros de la función económica y $x$ es la asignación del recurso hídrico.

Las funciones económicas pueden ser de tipo polinomiales cuadráticas, exponenciales o de elasticidad constante para representar la curva de demanda o costes. El beneficio económico asociado para cada elemento del sistema se calcula como la integral de la función económica entre cero y la cantidad asignada en la simulación. Asociado al beneficio se encuentra el coste de escasez, en el caso que la demanda en el sistema no sea satisfecha, y se define como la integral entre la cantidad asignada en la simulación y el total demandado (figura 4.2). 


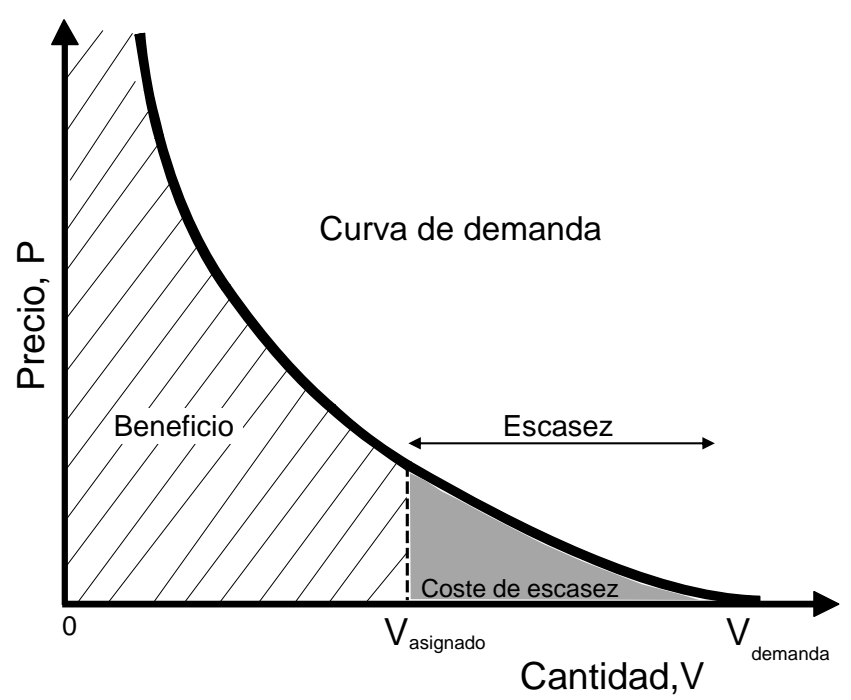

Figura 4.2. Beneficio y coste de escasez

El programa evalúa la función de beneficio (ecuación 4.1) en donde los valores de $x_{k e}$ para cada paso de tiempo, son obtenidos por el modelo de simulación previamente empleado. La función económica no necesariamente deberá ser continua y derivable. Sin embargo, se puede adoptar la función paramétrica (4.7). EcoWin también permite introducir la función económica en forma discreta, proporcionando los datos de varios puntos en forma de valores ordenados $x, y$.

Para la ejecución de EcoWin (Anejo B) se precisan los siguientes elementos:

1. Un esquema completo del sistema hídrico modelado con SimGes;

2. El archivo ejecutable;

3. El archivo con la información de la ruta del esquema a simular;

4. Los archivos con la información económica del sistema por analizar.

Para la caracterización económica del sistema se asocian funciones económicas a los distintos elementos modelados, que expresan el coste/beneficio marginal para el sistema de los distintos niveles de flujo o suministro a cada elemento. Para el cálculo del CMOR se comparan los resultados económicos para el caso base, que representa la asignación actual, y el caso modificado, constituido por el caso base más una pequeña perturbación consistente en añadir (o detraer) una unidad diferencial de caudal en el elemento e instante de interés. En el caso modificado el modelo lleva a cabo una nueva asignación del recurso, usando las reglas de reparto, y posteriormente se evalúa el beneficio económico total y se calcula la diferencia de beneficios totales entre el caso base y el modificado. 
La idea básica es calcular el coste marginal del recurso mediante un cociente de diferencias (figura 4.3) El numerador contiene la diferencia entre los beneficios económicos netos $\left(\mathrm{BA}_{\text {caso modificado }}-\mathrm{BA}_{\text {caso base }}\right)$ y en el denominador se encuentra una diferencia de volúmenes de agua $\left(\Delta=\mathrm{V}_{\mathrm{m}}-\mathrm{V}_{\mathrm{b}}\right)$.

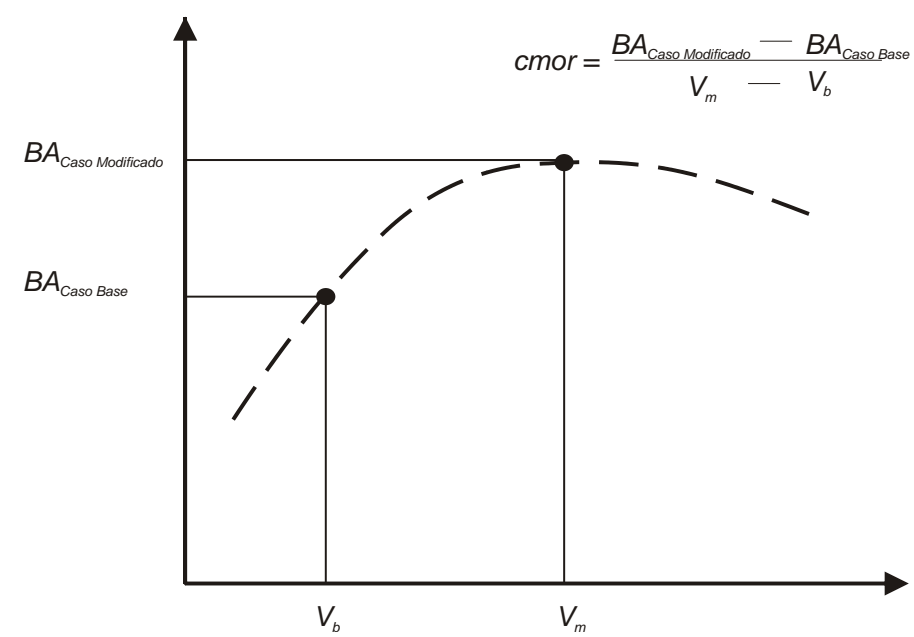

Figura 4.3 Aproximación del CMOR mediante simulación Fuente: Collazos (2004)

El cociente entre la variación de beneficio económico y la variación de caudal es una aproximación al CMOR (sólo se puede hablar estrictamente de coste del recurso en un sistema optimizado económicamente), y se expresa:

$$
C M O R=\frac{B A_{\text {CasoModificado }}-B A_{\text {CasoBase }}}{\Delta_{\text {volumen }}}
$$

Conocida la asignación del recurso y conocidas las funciones económicas se calcula el beneficio asociado. El diagrama de flujo para el cálculo del CMOR en los nudos del sistema (Collazos, 2004) es el mostrado en la figura 4.4. 


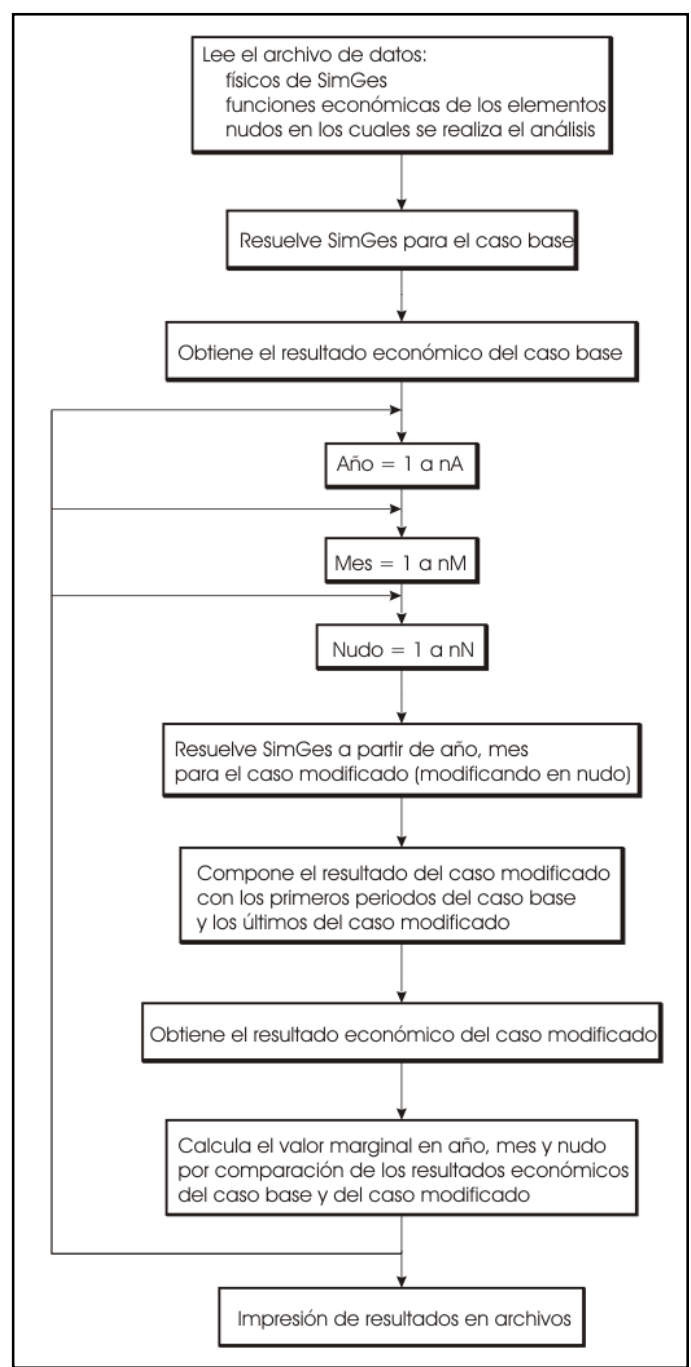

Figura 4.4 Diagrama de flujo para calcular el CMOR Fuente: Collazos (2004)

El CMOR es un indicador de la escasez relativa del recurso, con relación a los usos existentes en el Sistema de Explotación, y además puede medir de alguna manera los efectos económicos que provoca dicha escasez con la asignación de agua que se proporcione actualmente. Dependiendo de cuán económicamente eficiente sea la asignación, la aproximación al valor del recurso será más o menos parecido al valor del recurso obtenido con una optimización económica del sistema (Collazos, 2004). 


\subsection{Ejemplo. Aplicación al sistema de la cuenca del río Segura}

En este apartado se presentan los resultados que se han obtenido del cálculo de CMOR y el coste de escasez de acuerdo al enfoque de simulación de la gestión, utilizando la información proporcionada por la Confederación Hidrográfica del Segura (CHS, en adelante $)^{1}$. Se muestra la descripción, el modelo de gestión, la caracterización económica del sistema y los resultados de la simulación de la gestión y de la evaluación económica.

\subsubsection{Descripción del sistema}

En este apartado se presenta una breve descripción del sistema de explotación de la cuenca del río Segura considerando los siguientes aspectos: extensión territorial, rasgos geográficos y climáticos, recursos hídricos, usos del agua y la infraestructura hidráulica. En el anejo A puede consultarse una descripción más detallada de la zona de estudio.

\section{Extensión territorial}

El ámbito territorial de la CHS (1998), comprende el territorio de las cuencas hidrográficas que vierten al mar Mediterráneo entre la desembocadura del río Almanzora y la margen izquierda de la Gola del Segura en su desembocadura, incluidas sus aguas de transición; además la subcuenca hidrográfica de la Rambla de Canales y las cuencas endorreicas de Yecla y Corral Rubio. Se localiza en la parte Sudeste de la Península Ibérica, y está formado por la agregación de cuencas hidrográficas que vierten sus aguas al mar Mediterráneo con una superficie total de $18.870 \mathrm{~km}^{2}$ (figura 4.5).

1 Este estudio se relizó en el marco de un contrato de Investigación y Desarrollo suscrito entre el IIAMA de la UPV y la empresa INITEC INFRAESTRUCTURAS, S.A.U. 


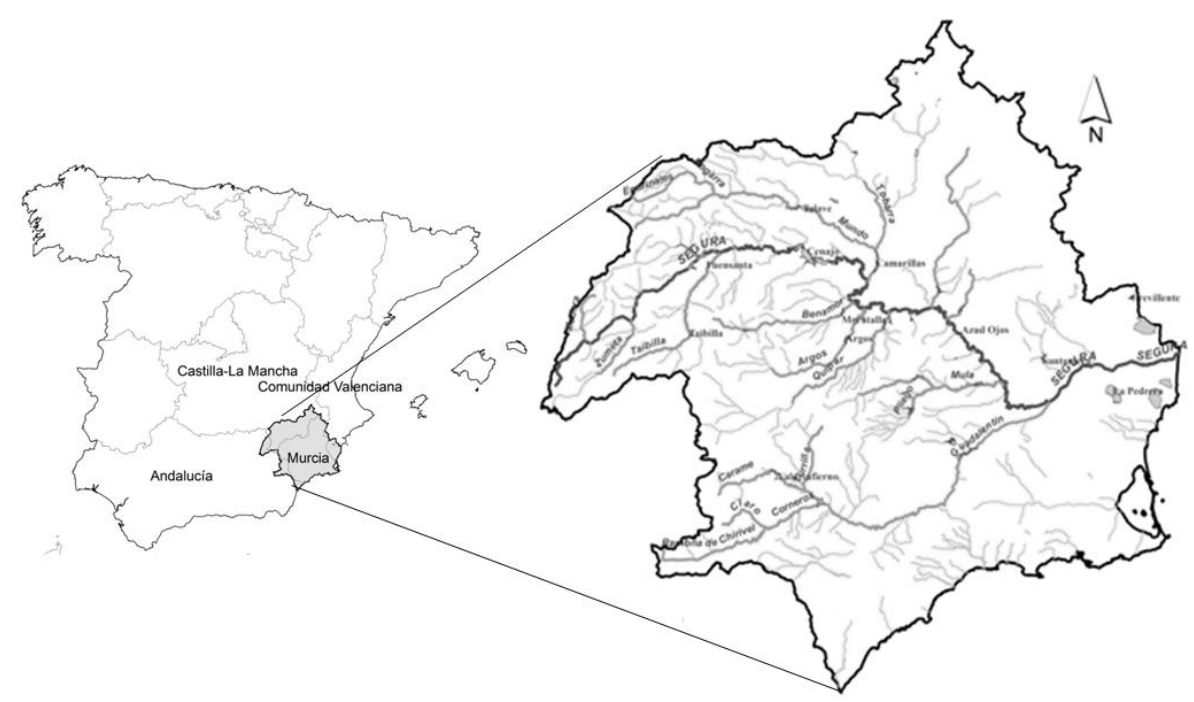

Figura 4.5. Ubicación geográfica de la CHS Fuente: PCHS,1998 y elaboración propia.

\section{Rasgos geográficos y climáticos}

Según indica el Plan Hidrológico de la cuenca del Segura (PHCS, 1998), los principales rasgos fisiográficos alternan las montañas con valles, depresiones y llanuras, con cotas máximas por encima de los $2.000 \mathrm{~m}$. Las sierras superan con frecuencia los $1.000 \mathrm{~m}$, y los valles, corredores y depresiones, no llegan a $500 \mathrm{~m}$ de altitud. Por debajo de los $200 \mathrm{~m}$ de cota sólo aparecen suaves llanuras con pendientes débiles.

Los factores que condicionan el clima de la cuenca se combinan y multiplican dando lugar a topoclimas y a climas locales. En este sentido, la cuenca hidrográfica del Segura se identifica con el denominado grupo Mediterráneo, y los subtipos Mediterráneo templado, Mediterráneo continental, Mediterráneo subtropical, y Mediterráneo semiárido subtropical. Las temperaturas están relacionadas con factores como latitud, altitud y orientación, lo que origina una gran variedad de sus valores en toda la cuenca, pasando de los $10^{\circ} \mathrm{C}$ de media anual en la Sierra de Segura a los $18^{\circ} \mathrm{C}$ de temperatura media anual en la Vega Baja y algunas zonas costeras. En las sierras del noroeste se dan las temperaturas más bajas de la cuenca produciéndose un ascenso de temperaturas medias anuales desde esta zona hasta el litoral.

La precipitación media anual es de $400 \mathrm{~mm}$, y presenta un régimen caracterizado por grandes desequilibrios espaciotemporales y un claro contraste entre las zonas de cabecera (Mundo y Segura hasta su confluencia) y las partes medias y bajas de la cuenca (Vegas y zonas costeras). A esto se suma el predominio de un clima suave y templado, con una evapotranspiración potencial media del orden de $700 \mathrm{~mm}$, una escorrentía media total del orden del $15 \%$ (la más baja de la península), y un marco geológico con numerosas 
formaciones acuíferas, en ocasiones muy reducidas, y con notable complejidad estructural y tectónica.

\section{Recursos hídricos}

La red hidrográfica del sistema del Segura (figura 4.6) está constituida por el cauce del propio río Segura y sus afluentes, principalmente de los ríos Mundo y Guadalentín, además de una serie de afluentes de menor importancia (Moratalla, Argós, Quípar y Mula) tributarios de la margen derecha y de ramblas tributarias por la margen izquierda (Moro y Judío).

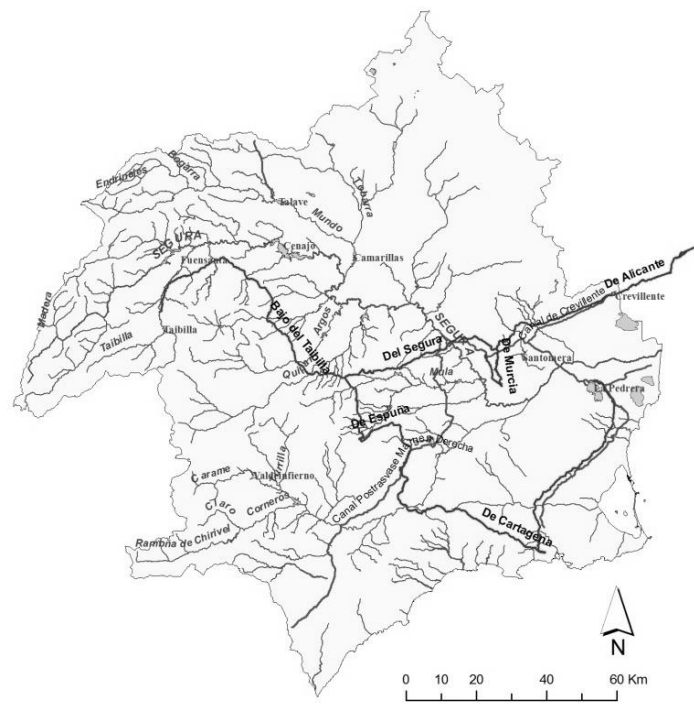

Figura 4.6. Red hidrográfica del sistema del Segura Fuente: CHS y elaboración propia.

Los recursos hídricos naturales en el ámbito de la Confederación Hidrográfica del Segura presentan una importante variabilidad espacial y temporal y son generados por la precipitación que se produce dentro del ámbito, cuyo valor medio es del orden de 380 $\mathrm{mm}$, variando desde los $200 \mathrm{~mm}$ los años más secos hasta los $620 \mathrm{~mm}$ los más húmedos (figura 4.7) 


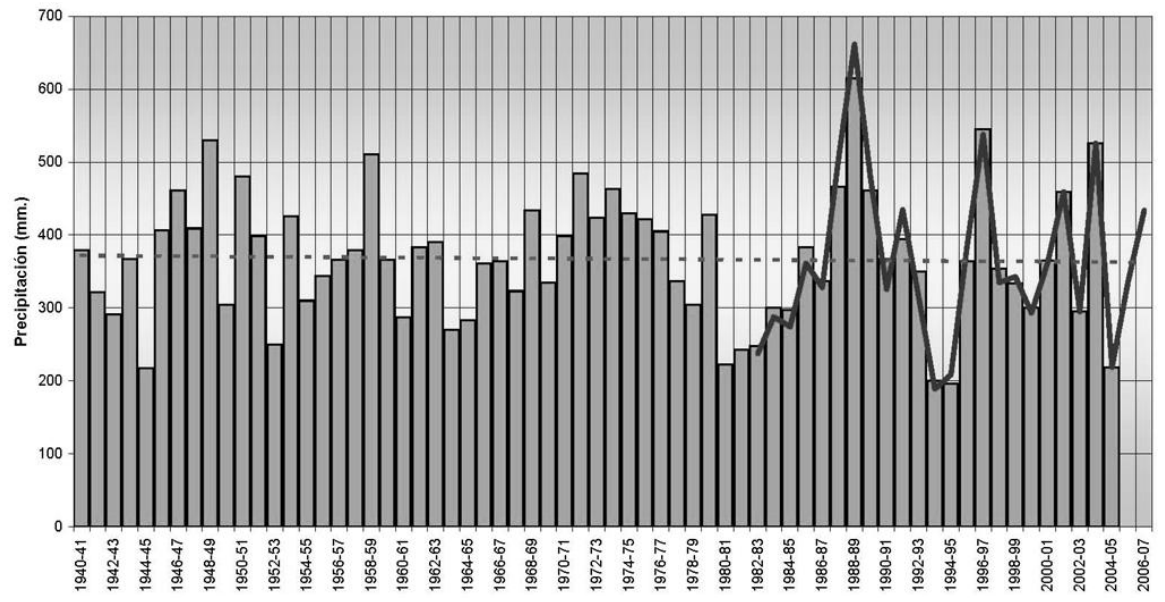

Figura 4.7 Precipitación media anual en el ámbito de la CHS (PHCS, 1998)

Los valores medios presentan importantes diferencias espaciales, ya que si bien en las zonas altas se presentan altos valores de precipitación, del orden de los $900 \mathrm{~mm}$ anuales, la disposición u orientación suroeste-nordeste de los elevados arcos montañosos de las sierras de la cuenca alta del río Segura, dificultan el avance de las influencias atlánticas arrastradas por los flujos del oeste, y hacen que la pluviometría muestre una disminución de la precipitación media anual en una diagonal de orientación noroeste-sudeste, que va desde estas tierras hasta el litoral, con valores mínimos (inferiores a $300 \mathrm{~mm}$ ) en las zonas próximas a la costa (figura 4.8).

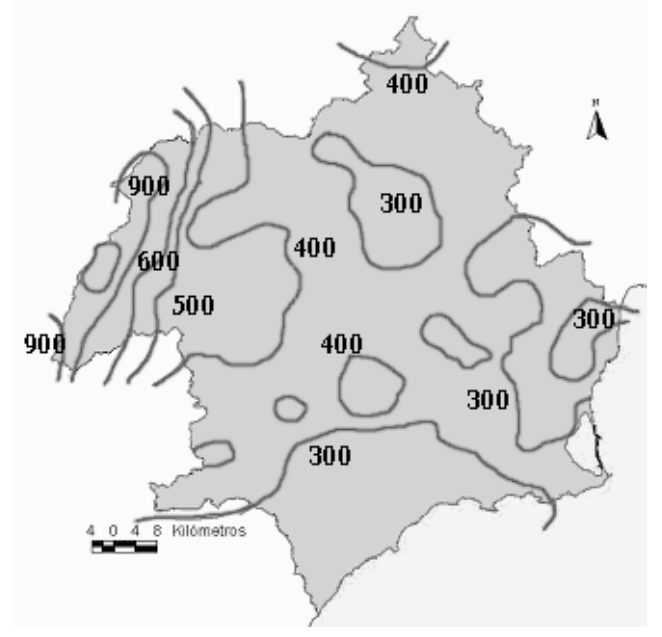

Figura 4.8 Distribución espacial de la precipitación media anual en el ámbito de la CHS

La conjunción de los factores climáticos y geológicos de la zona permite considerar, a efectos de generación de recursos renovables, cinco zonas de comportamiento 
hidrológico diferenciable: la cabecera, la margen derecha del Segura, la margen izquierda del Segura, el Guadalentín, y las ramblas costeras.

La cabecera (ríos Segura y Mundo hasta su confluencia) constituye la fuente principal de recursos de la cuenca. Drena un área de gran extensión dominada por las sierras de Segura, Calar del Mundo y Taibilla. Las aportaciones de cabecera están constituidas por un importante caudal base, tanto de origen nival como procedente del drenaje de los grandes acuíferos calizos, en general sin regular y muy poco afectados, sobre los que se asientan estas cuencas. Este factor contribuye también a la relativa regularidad de las aportaciones, con autocorrelaciones anuales probablemente significativas. Un caso claro de esta regularidad es el río Taibilla, con reducidos estiajes y caudales base muy continuos durante todo el año.

Siguiendo en orden de importancia en cuanto a las aportaciones, se encuentran los afluentes de la margen derecha (Moratalla, Argos, Quipar y Mula). Sus cauces transportan caudales de forma permanente y muy escasa magnitud (unos $65 \mathrm{hm}^{3}$ totales) que son consumidos localmente, sin aportar retornos significativos al Segura. Los afluentes de la margen izquierda se asientan sobre cuencas semiáridas, lo que les confiere un carácter marcadamente torrencial. En la práctica, carecen de importancia como productores de recursos, ya que únicamente llevan agua después de tormentas importantes. Se trata de las ramblas del Judío, Moro, Tinajón, Salada y Abanilla, principalmente.

El río Guadalentín es un importante afluente de la margen derecha que está regulado en su cabecera por los embalses más antiguos de la cuenca (Puentes y Valdeinfierno) y cuya misión es doble: defender a las ciudades del Valle contra la acentuada torrencialidad y procurar recursos (escasos) para el regadío tradicional de Lorca. Los recursos naturales renovables totales del Valle se han estimado inicialmente en unos $40 \mathrm{Hm}^{3}$. Las ramblas litorales, por su parte, no suponen aportes significativos a los recursos renovables totales de la cuenca, funcionando en régimen torrencial y produciendo ocasionales inundaciones en las poblaciones costeras.

Según el modelo precipitación-escorrentía SIMPA (Ruiz, 1998), realizado por el Centro de Estudios Hidrográficos (CEH) del CEDEX para el MMAMRM (2008), los recursos propios del río Segura son de 713,64 hm 3 /año para la serie de aportaciones histórica (1940-2005) y de 574,93 $\mathrm{hm}^{3}$ /año para la serie de aportaciones corta (1980-2006). La estimación total de recursos naturales del río Segura, correspondientes al desagüe medio hiperanual en Guardamar en régimen natural, evaluada mediante restitución por el PHCS es de 871 $\mathrm{hm}^{3} /$ año medios interanuales para el periodo 1940-1990. La evaluación de recursos fue ligeramente inferior en la revisión del PHCS (periodo 1940-2000), $830 \mathrm{hm}^{3} /$ año, y en el PES (periodo 1940-2005), $823 \mathrm{hm}$ /año. La razón por la cual estos dos estudios arrojan un menor volumen de recursos propios de la cuenca que el valor resultante del PHCS se debe 
a la incorporación en la serie de los datos de los últimos años, que corresponden al periodo seco de la serie.

La fracción subterránea representa un $60 \%$ del total de los recursos de la cuenca según el PHS. El inventario hidrogeológico incluye características de 234 acuíferos, agrupados en 57 unidades hidrogeológicas (figura 4.9) en función de una combinación de criterios geológicos, hidrogeológicos y de situación administrativa en cuanto a balance hídrico y declaración de sobreexplotación.

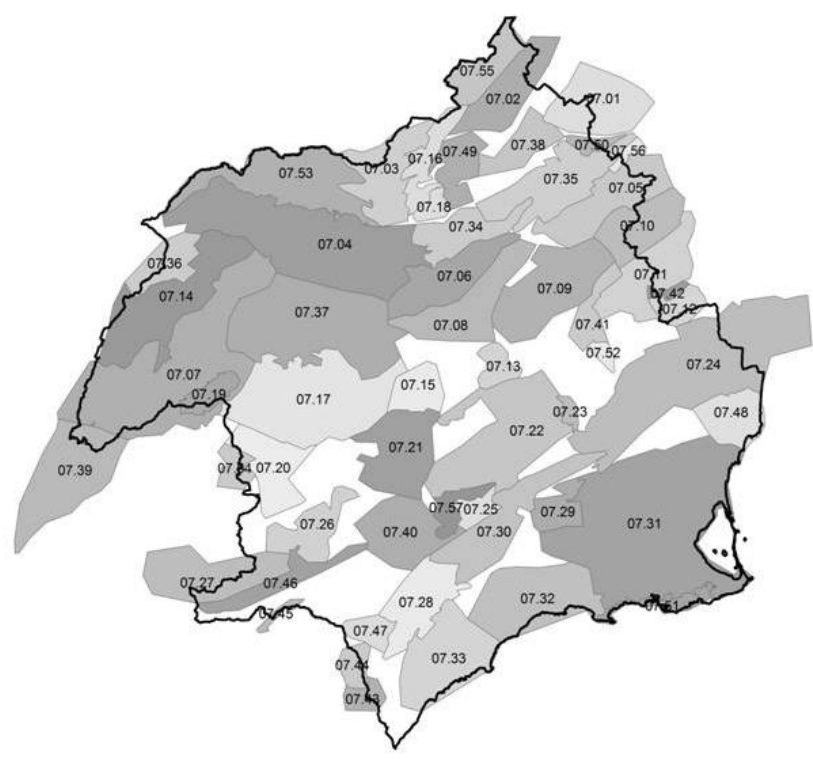

Figura 4.9 Unidades hidrogeológicas de la CHS

\section{Utilización del agua}

Los usos del agua en el ámbito de la Confederación Hidrográfica del Segura alcanzan una cifra global de $1.900 \mathrm{hm}^{3}$, siendo el uso agrícola el principal; este uso representa el $85 \%$ de la demanda total. Le sigue en importancia el uso urbano, el cual demanda el $11 \%$ del total del recurso, mientras que el uso industrial y de servicios demanda únicamente el $1 \%$ del total; finalmente, un $3 \%$ de los recursos disponibles se utiliza como caudal ecológico necesario para la conservación del medio ambiente, de acuerdo con el balance hídrico realizado por la propia Confederación (figura 4.10). 


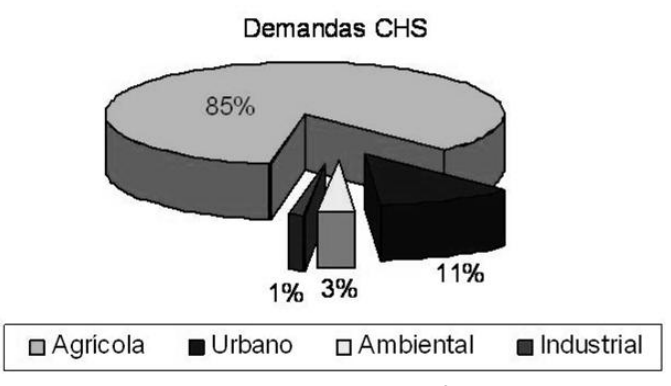

Figura 4.10 Demandas totales en el ámbito de la CHS

\section{Transferencias superficiales de agua}

Los recursos superficiales transferidos al ámbito territorial del Plan Hidrológico del Segura y procedentes de los ámbitos de otros Planes, tienen su origen en su totalidad, en la cuenca alta del Tajo (figura 4.11). Los volúmenes a trasvasar en una primera fase se fijaron

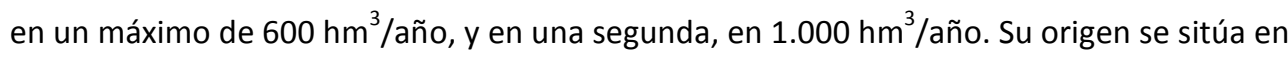
el embalse de Bolarque, desde donde se bombea hasta el embalse de la Bujeda, que se utiliza como depósito superior $\left(7 \mathrm{hm}^{3}\right)$ de la central de Altomira. El canal desagua al embalse de Alarcón, en la cuenca del Júcar, de cuyas inmediaciones, y en régimen de entradas por salidas, parte el otro tramo de canal hacia el embalse de Talave, ya en la cuenca del Segura. El transporte de los recursos a la cuenca se produce físicamente mediante un canal de $33 \mathrm{~m}^{3} / \mathrm{s}$ de capacidad, que sería teóricamente suficiente para trasvasar los indicados $1.000 \mathrm{hm}^{3} /$ año a caudal continuo, aunque nunca se ha pasado de la primera fase. Dentro de la cuenca, las infraestructuras del Postrasvase permiten la distribución de estos recursos trasvasados a sus diferentes áreas de utilización. 


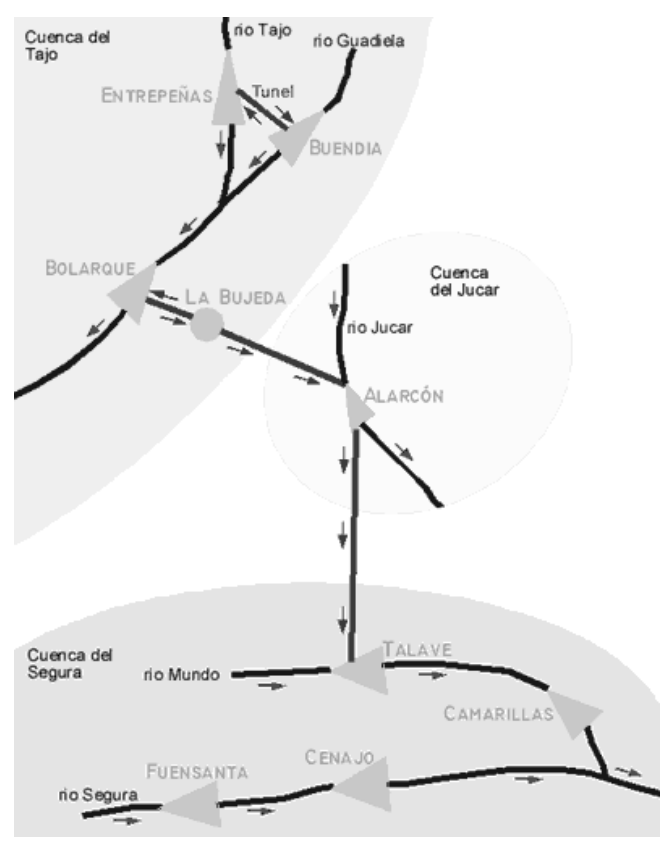

Figura 4.11 Trasvase Tajo-Segura

\section{Demandas de agua}

Demanda Urbana. La mayor parte del volumen de suministro urbano en el ámbito territorial del Plan se lleva a cabo por la Mancomunidad de los Canales del Taibilla que es responsable del suministro de agua potable en alta a municipios en la Comunidad Autónoma Valenciana, ya sean de ámbito territorial del Segura (Vega Baja) como de ámbito territorial del Júcar (Elche, Alicante, Santa Pola, San Vicente del Raspeig), en la Comunidad Autónoma de Murcia (todos excepto Yecla, Jumilla y Aledo) y en la Comunidad Autónoma de Castilla la Mancha (Férez y Socovos). También suministra a establecimientos militares en Cartagena, Mar Menor y Alcantarilla y a compañías del sector industrial como Repsol.

Para proporcionar este servicio, la Mancomunidad cuenta con los recursos del río Taibilla, íntegramente asignado a este fin (unos $60 \mathrm{hm}^{3}$ de media anual, con un máximo observado de 90 y un mínimo de 39), la dotación para abastecimientos prevista de la explotación del acueducto Tajo-Segura (110 hm³/año), y los volúmenes procedentes de contratos de suministro de aguas que la Mancomunidad suscribe con terceros (en cuantías variables, hasta $8 \mathrm{hm}^{3} /$ año). Además de la Mancomunidad, cuentan con concesión para toma directa de aguas del río Segura con destino a abastecimientos los Municipios de Abarán (400.000 m²/año), Alcantarilla $(100 \mathrm{l} / \mathrm{s})$ y Murcia $(208 \mathrm{l} / \mathrm{s})$. Asimismo, $100 \mathrm{l} / \mathrm{s}$ del total de $1 \mathrm{~m}^{3} / \mathrm{s}$ del canal de Hellín están también asignados al abastecimiento (para mayor detalle, véase el Anejo A). 
Demanda industrial. El uso industrial y servicios total asciende en la actualidad a unos 49 $\mathrm{hm}^{3}$, y sumando esta cantidad al uso urbano, se obtiene una utilización actual total urbano-industrial de $240 \mathrm{hm}^{3}$ anuales, que ascenderían a 248 si se añaden los $8 \mathrm{hm}^{3}$ de recursos propios municipales aportados en el ámbito territorial del Júcar.

Demanda agrícola. El regadío constituye, con diferencia, el principal uso del agua en la cuenca en cuanto a los volúmenes de recursos consumidos, y el motor básico que ha contribuido al desarrollo socioeconómico de su territorio. Una estimación del agua con destino a riegos en el Segura en situación normal puede cifrarse en $1.250 \mathrm{hm}^{3}$, que se elevarían a $1.328 \mathrm{hm}^{3}$ si se incluyen las superficies de riego fuera del ámbito territorial del Segura, pero abastecidas desde éste. La superficie de riego existente se estima en 269.029 ha, de las que hay 253.001 ha netas dentro del ámbito territorial del Plan Hidrológico de la cuenca del Segura, y 16.028 ha netas correspondientes a regadíos situados fuera del ámbito territorial de la cuenca del Segura (en el Júcar y Sur), pero que se atienden con recursos suministrados desde este ámbito. Con tales superficies y volúmenes, la aplicación global media bruta resultante son del orden de $4.900 \mathrm{~m}^{3} / \mathrm{ha} / a n ̃ o$ (para un desglose detallado del agua utilizada en el regadío, consultar el Anejo A).

\section{Infraestructura hidráulica}

La conexión entre los recursos y los usos se produce mediante un sistema de infraestructura hidráulica de: captación, transporte, almacenamiento, depuración, potabilización y defensa las cuales tienen gran extensión y complejidad. Algunos ejemplos de estas infraestructuras son los embalses y presas destinados al almacenamiento y defensa de la cuenca, como sucede con el embalse del Talave, que recibe las aguas procedentes del trasvase Tajo-Segura y el embalse de Taibilla, encargado de proporcionar recurso a la Mancomunidad de Canales del Taibilla (MCT, en adelante) o las cuatro grandes redes de distribución, interconectadas entre sí, y superpuestas en el espacio: la red de riegos tradicionales tanto en las Vegas como en los aprovechamientos de los afluentes del Segura, la red de distribución del Post-trasvase Tajo-Segura, la red de distribución de la MCT, y la red de captación y transporte de aguas subterráneas.

Los principales embalses por cuenca (figura 4.12) son los siguientes:

- En el río Segura: Argós $\left(10 \mathrm{hm}^{3}\right)$, Cenajo $\left(437 \mathrm{hm}^{3}\right)$, Fuensanta $\left(210 \mathrm{hm}^{3}\right)$ y los azudes Ojós $\left(1 \mathrm{hm}^{3}\right)$ y Contraparada $\left(1 \mathrm{hm}^{3}\right)$.

- En el río Taibilla: Taibilla $\left(9 \mathrm{hm}^{3}\right)$

- En el río Mundo: Camarillas $\left(36 \mathrm{hm}^{3}\right)$ y Talave $\left(35 \mathrm{hm}^{3}\right)$.

- En el río Benamor: Moratalla $\left(5 \mathrm{hm}^{3}\right)$.

- En el río Mula: La Cierva $\left(7 \mathrm{hm}^{3}\right)$. 
- En el río Guadalentín: Puentes $\left(26 \mathrm{hm}^{3}\right)$ y Valdeinfierno $\left(13 \mathrm{hm}^{3}\right)$.

- En el río Quipar: Quipar-Alfonso XIII $\left(22 \mathrm{hm}^{3}\right)$.

- En la rambla de Algeciras: Algeciras $\left(45 \mathrm{hm}^{3}\right)$.

- En la rambla salada de Santomera: Santomera $\left(26 \mathrm{hm}^{3}\right)$.

- Del post-trasvase ATS: Crevillente $\left(13 \mathrm{hm}^{3}\right)$ y La Pedrera $\left(246 \mathrm{hm}^{3}\right)$

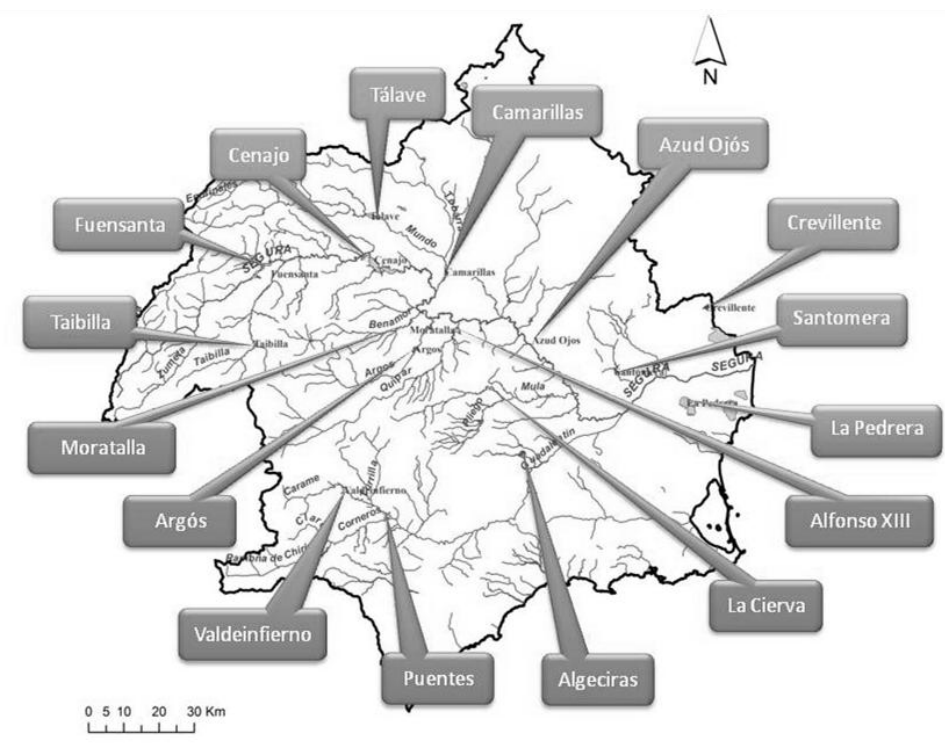

Figura 4.12 Principales embalses en el ámbito de la CHS

Fuente: Confederación Hidrográfica del Segura (1998) y elaboración propia

Además de la infraestructura mencionada, el sistema de recursos hídricos cuenta con otro tipo de infraestructura como son: una importante red de canales del trasvase TajoSegura; plantas desalinizadoras, depuradoras y potabilizadoras; campos de pozos y redes de medida y control (para información detallada puede consultarse el Anejo A.

\subsubsection{Modelo de gestión del sistema del Segura}

El sistema superficial está representado, de acuerdo con los lineamientos del Sistema Soporte a la Decisión Aquatool, por diferentes tipos de conducciones: tipo 1 y tipo 3 (figura 4.13); embalses y azudes; y plantas desalinizadoras. El modelo se simplificó para facilitar el desarrollo e interpretación de los resultados del modelo hidro-económico, aunque manteniendo la representatividad de los resultados.

\section{Modificaciones realizadas.}


A las simplificaciones realizadas al modelo detallado y que se analizaron posteriormente en una comparación entre ambos modelos, se unen otras modificaciones que ha sido preciso realizar al modelo simplificado para su correcto funcionamiento con el evaluador económico y para solucionar deficiencias del modelo hidrológico. Estas modificaciones comprenden los aspectos siguientes:

- Se asignó a los embalses de cabecera (Talave, Cenajo, Fuensanta y Taibilla) un volumen mínimo igual al $10 \%$ del volumen máximo. En el embalse del Talave, al considerar este nuevo volumen mínimo, el volumen objetivo resultaba ser inferior por lo que se ha modificado, dándole el mismo valor que al mínimo para los meses en que esto ocurría.

- Se han cambiado los bombeos directos por bombeos adicionales más una toma.

- Para poder realizar el análisis económico se tuvo que modificar el esquema añadiendo a cada toma una conducción tipo 1 (en los casos en los que no existía) y así poder asignarle un coste.

- Se asignó un caudal mínimo a las conducciones que unen las desalinizadoras a las demandas, así mismo se incluyó recarga continua a las desalinizadoras para que siempre tengan volumen positivo y el bombeo pueda ser continuo.

Por otro lado, el esquema SimGes de la cuenca del río Segura está conformado, como se mencionó, por 43 Unidades Hidrogeológicas agrupadas en 18 acuíferos.

Conducciones tipo 1. Corresponde a una conducción simple, sin filtraciones. Este tipo de conducción se asignó a los siguientes tramos de ríos:

- Río Segura aguas arriba y aguas abajo del embalse de Fuensanta.

- Río Segura aguas abajo del embalse de Cenajo, hasta la confluencia con el río Mundo.

- Río Segura desde la confluencia con el río Mundo, hasta el azud de Almadanes.

- Río Segura desde el pueblo de Cieza, hasta el azud de Ojós.

- Río Segura, desde el azud de Ojós, hasta el azud de la Contraparada.

- Río Segura, desde la Rambla Salada, hasta la desembocadura al mar.

- Río Taibilla, aguas arriba del embalse Taibilla.

- Río Taibilla, aguas abajo del embalse Taibilla, hasta la confluencia con el río segura.

- Río Moratalla, hasta la confluencia con el río Segura.

- Río Argos, aguas arriba del embalse Argos.

- Río Argos, aguas abajo del embalse Argos, hasta la confluencia con el río Segura. 
- Río Quipar, aguas arriba del embalse Alfonso XIII.

- Río Quipar, aguas abajo del embalse Alfonso XIII, hasta la confluencia con el río Segura.

- Río Mula aguas arriba del embalse de la Cierva.

- Río Mula aguas abajo del embalse de la Cierva, hasta el poblado Los Baños de Mula.

- Río Mula desde Los Baños de Mula, hasta la confluencia con el río Segura.

- Rio Carame, aguas arriba del embalse de Valdeinfierno.

- Río Guadalentín, aguas abajo del embalse de Puentes, hasta la confluencia con la rambla de Algeciras.

- Río Guadalentín, desde la confluencia con la rambla de Algeciras, hasta Paso de los Carros.

- Río Guadalentín desde Paso de los Carros, hasta la confluencia con el río Segura.

Conducciones tipo 3. Corresponde a una conducción que presenta "pérdidas" de agua que se infiltran hacia un acuífero. Este tipo de conducciones se asignó a los siguientes tramos de ríos:

- Río Mundo, aguas arriba y aguas abajo del embalse Camarillas para establecer la relación con el acuífero de El Molar y los acuíferos Boquerón, Tobarra y Pinos.

- Río Luchena.

- Río Segura aguas arriba del pueblo de Cieza, con el fin de considerar la relación del río con el acuífero del Sinclinal de Calasparra.

- Río Segura aguas abajo del azud Ojós, para introducir la interconexión entre el río y el acuífero de la Vega Alta.

- Río Segura entre el azud Ojós y el embalse Contraparada, con el fin de establecer la relación con los modelos tipo manantial de Bullas y Sierra Espuña

- Río Segura aguas debajo del embalse Contraparada para representar la conexión del río con los acuíferos de las Vegas Media y Baja. 


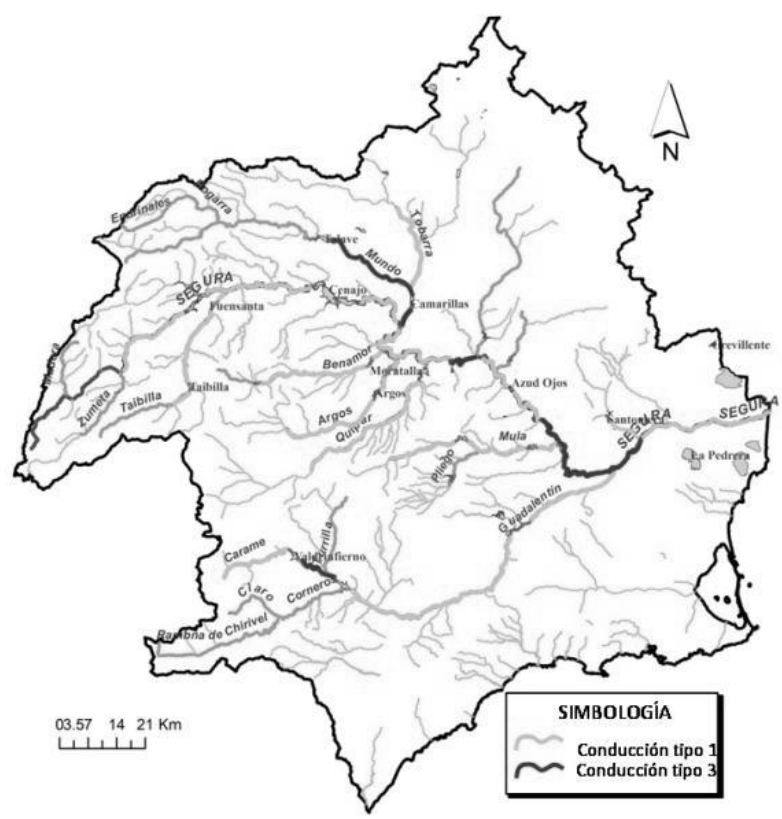

Figura 4.13 Definición del tipo de conducción en el modelo hidrológico Fuente: Confederación Hidrográfica del Segura y elaboración propia

También se han considerado caudales mínimos en los tramos de río mostrados en la tabla siguiente:

Tabla 4.1 Caudales mínimos en los tramos de ríos modelados

\begin{tabular}{|l|c|c|}
\hline \multicolumn{1}{|c|}{ Tramo fluvial } & \multicolumn{2}{c|}{ Caudal mínimo } \\
\hline & $\mathrm{hm}^{3} / \mathrm{mes}$ & $\mathrm{m}^{3} / \mathrm{s}$ \\
\hline Fuensanta-Cenajo. & 2,17 & 0,80 \\
\hline Cenajo-Confluencia río Mundo. & 3,36 & 1,30 \\
\hline Talave-Camarillas. & 1,11 & 0,40 \\
\hline Camarillas-Confluencia río Segura. & 1,45 & 0,60 \\
\hline Confluencia Mundo y Segura-Ojós. & 4,81 & 1,90 \\
\hline Ojós-Contraparada. & 7,90 & 3,00 \\
\hline Contraparada-San Antonio. & 10,40 & 4,00 \\
\hline
\end{tabular}

Embalses y Azudes. Este tipo de infraestructura corresponde al mencionado en el apartado 4.5.1, y en total son quince embalses y dos azudes representados como nudos en el esquema SimGes. En el Anejo A se puede consultar información más detallada relacionada con esta infraestructura. 
Plantas desalinizadoras. Las desalinizadoras se han simulado en el modelo como acuíferos de tipo depósito asociadas a bombeos con volumen máximo igual al volumen de diseño de la propias desalinizadoras (Tabla 4.2):

Tabla 4.2 Plantas desalinizadoras consideradas en el modelo

\begin{tabular}{|l|c|c|}
\hline \multicolumn{1}{|c|}{ Desalinizadora } & \multicolumn{2}{c|}{$\begin{array}{c}\text { Volumen de diseño } \\
\text { (hm } \mathbf{3} \text { /año) }\end{array}$} \\
\hline Horizonte actual & MCT & Regadío \\
\hline Águilas y Mazarrón & & 12,0 \\
\hline Pedrera PHN & & 15,0 \\
\hline Campo de Cartagena PHN & & 7,0 \\
\hline Vega Baja PHN & & 3,3 \\
\hline Vega baja margen izquierda PHN & & 3,3 \\
\hline San Pedro del Pinatar & 48 & \\
\hline Alicante ampliación I y II & 48 & \\
\hline Programa A.G.U.A & & \\
\hline Valdelentisco & 20 & 37 \\
\hline Torrevieja & 40 & 40 \\
\hline Ampliación Águilas & & 6 \\
\hline Ampliación Mojón & & 4 \\
\hline Guardamar & & 43 \\
\hline
\end{tabular}

MCT: Mancomunidad de los canales del Taibilla.

PHN: Plan Hidrológico Nacional.

A.G.U.A. Actuaciones para la Gestión y Utilización del Agua.

En el Anejo A pueden consultarse con mayor detalle las capacidades y volúmenes de diseño de las plantas desalinizadoras consideradas en el modelo de gestión del sistema.

Representación del sistema subterráneo. Los acuíferos que forman parte del sistema de explotación de la cuenca del río Segura, se han representado con diferentes tipos de modelos, a saber: tipo depósito; tipo unicelular; tipo manantial; y tipo autovalores. En los de tipo depósito el acuífero no tiene relación alguna con el sistema superficial; únicamente interesa conocer un parámetro que indica su estado de llenado y vaciado. Los acuíferos definidos con este modelo son aquellos que están sobreexplotados o de los cuales se desconocen varios datos. En la cuenca del Segura, los acuíferos de este tipo son los siguientes: Alto y bajo Guadalentín; Ascoy -Sopalmo; Campo de Cartagena; Crevillente; Quibas; Jumilla-Villena; Mazarrón-Águilas; Serral-Salinas; y Sinclinal de la Higuera. En el modelo tipo celular el acuífero está conectado al sistema superficial, mediante un 
coeficiente de desagüe, afectándose al caudal natural de los ríos. Los acuíferos definidos con este tipo de modelo son los siguientes: El Molar; Anticlinal de Socovos; Somogil y Valdeinfierno. Sin embargo, las infiltraciones que se producen en el embalse del Cenajo, se han considerado también como un acuífero de este tipo. Se denomina modelo tipo manantial al acuífero cuya relación con el sistema superficial es tal que este último recoge el drenaje del primero, normalmente por manantiales. Los acuíferos a los que se les ha supuesto este modelo son: Caravaca, Alto y Bajo Quipar, Boquerón-Tobarra y Sierra Espuña. Finalmente el modelo de autovalores corresponde con aquellos acuíferos para los que se considera necesario un modelo de parámetros distribuidos y, consecuentemente, una localización detallada de las acciones que se ejercen sobre dichos acuíferos, así como de las respuestas del acuífero. Los acuíferos definidos con este tipo de modelo son los siguientes: Vega Alta y Sinclinal de Calasparra (Consultar Anejo A para la delimitación espacial de los acuíferos mencionados).

Representación de las demandas. Las principales demandas representadas en el modelo, corresponden a los usos descritos anteriormente. Cada demanda se denomina como Unidad de Demanda (UD) relativa al uso que tiene: agrícola (UDA); urbana (UDU) e industrial (UDI).

Demanda agrícola. Las UDAs que forman parte del ámbito de la Confederación Hidrográfica de la cuenca del Segura se han agrupado de acuerdo a su ubicación geográfica, su sistema de explotación y el origen del recurso. Las UDAs ubicadas en la cabecera de los diferentes subsistemas de explotación, se han eliminado del modelo y en su lugar se ha introducido una detracción a las aportaciones en régimen natural de los diferentes ríos. El efecto sobre el modelo es equivalente y de esta manera se consigue simplificar el modelo en cabecera. En el Anejo A se detalla la información referente a este tipo de demanda. La aplicación del recurso hídrico al regadío se muestra en el dibujo esquemático de la figura 4.14, en donde se muestran 12 zonas de la cuenca del río Segura que agrupan diferentes unidades de riego (CHS, 2006) 


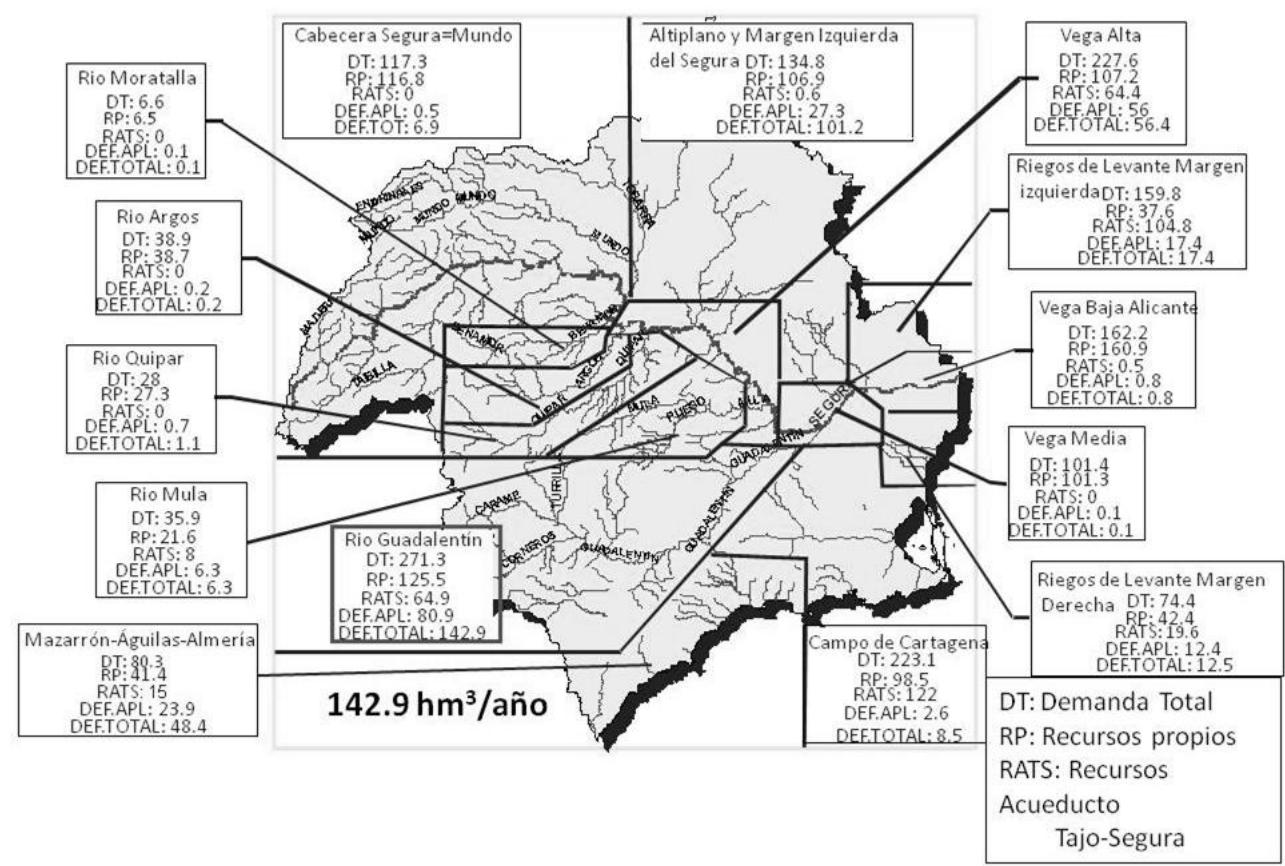

Figura 4.14 Aplicación del recurso hídrico al regadío Fuente: CHS, 2006

Demanda urbana. En el modelo de gestión se han incluido cuatro unidades de demanda urbana, las cuales están consideradas en el Plan Hidrológico de la Cuenca del Segura; además las unidades de demanda urbana de la Mancomunidad de los Canales del Taibilla se han agrupado en una sola demanda (Tabla 4.3):

Tabla 4.3 Unidades de demanda urbana consideradas en el modelo

\begin{tabular}{|c|c|}
\hline Unidad de demanda & Demanda (hm $\mathbf{3}$ /año) \\
\hline UDU M.C. Taibilla & 241 \\
\hline UDU 7 Hellín & 3 \\
\hline UDU 11 Jumilla Yecla & 6 \\
\hline UDU 12 Sierra de Crevillente & 2 \\
\hline UDU 13 Murcia río Segura & 10 \\
\hline
\end{tabular}

Demanda industrial. En el modelo de gestión se han considerado ocho unidades de demanda industrial consideradas en el Plan Hidrológico de la Cuenca del río Segura, que hacen un total de $34 \mathrm{hm}^{3} /$ año (tabla 4.4). 
Tabla 4.4 Unidades de demanda industrial consideradas en el modelo

\begin{tabular}{|c|c|}
\hline Unidad de demanda & Demanda (hm $\mathbf{3}$ /año) \\
\hline UDI 1 Guadalentín & 1,1 \\
\hline UDI 2 Cabecera & 2,8 \\
\hline UDI 3 Centro & 2,7 \\
\hline UDI 4 Murcia & 2,3 \\
\hline UDI 5 Alicante-Segura & 4,9 \\
\hline UDI 6 Litoral & 7,9 \\
\hline UDI 7 Directa & 1,8 \\
\hline UDI 8 Alicante-Júcar & 2,3 \\
\hline
\end{tabular}

Demanda medioambiental. En el modelo se ha considerado una demanda anual de sostenimiento de humedales de $30 \mathrm{hm}^{3}$, la cual procede de recurso superficial sobre el río Segura y ha sido ubicada en la desembocadura.

Aportaciones. Las series de aportaciones restituidas a régimen natural que se han utilizado para definir las aportaciones intermedias que se introducen en el modelo, son las incluidas en el Plan Hidrológico de la Cuenca del Segura ampliadas hasta el año 2000 con datos del seguimiento y revisión del mismo plan. De esta forma se cuenta con las series completas de los años hidrológicos 1940-1941 a 1999-2000. Estas series proporcionan el caudal circulante a su paso por la estación de control, en $\mathrm{hm}^{3} / \mathrm{mes}$, restituido al régimen natural. Dado que las aportaciones tienen el carácter de intermedias, es necesario restar a cada serie de caudal restituido circulante en cada estación los caudales circulantes en las estaciones aguas arriba y los valores de infiltración de lluvia introducidos a los acuíferos tipo depósito que drenaban en régimen natural a la estación (figura 4.15).

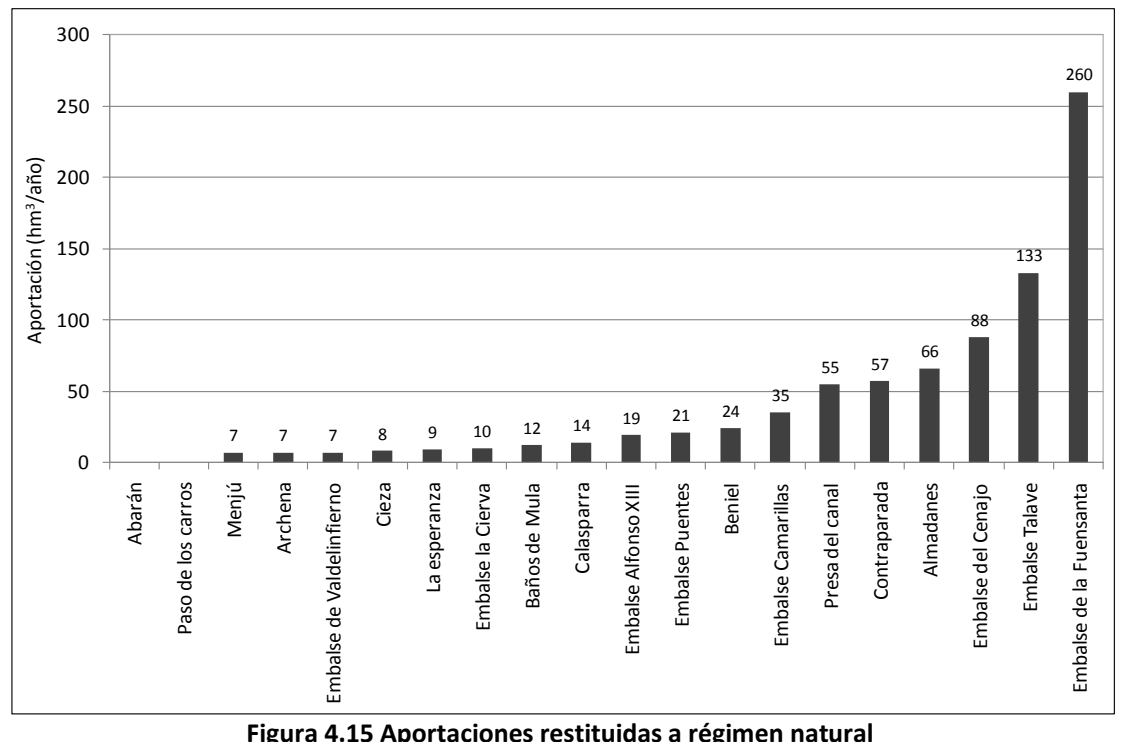

Figura 4.15 Aportaciones restituidas a régimen natural 
La serie histórica que se ha considerado como serie de aportaciones en el análisis corresponde a la serie restituida al régimen natural desde el año hidrológico 1940 hasta el 2000, la cual supone $830 \mathrm{hm}^{3}$ anuales medios en Guardamar (figura 4.16).

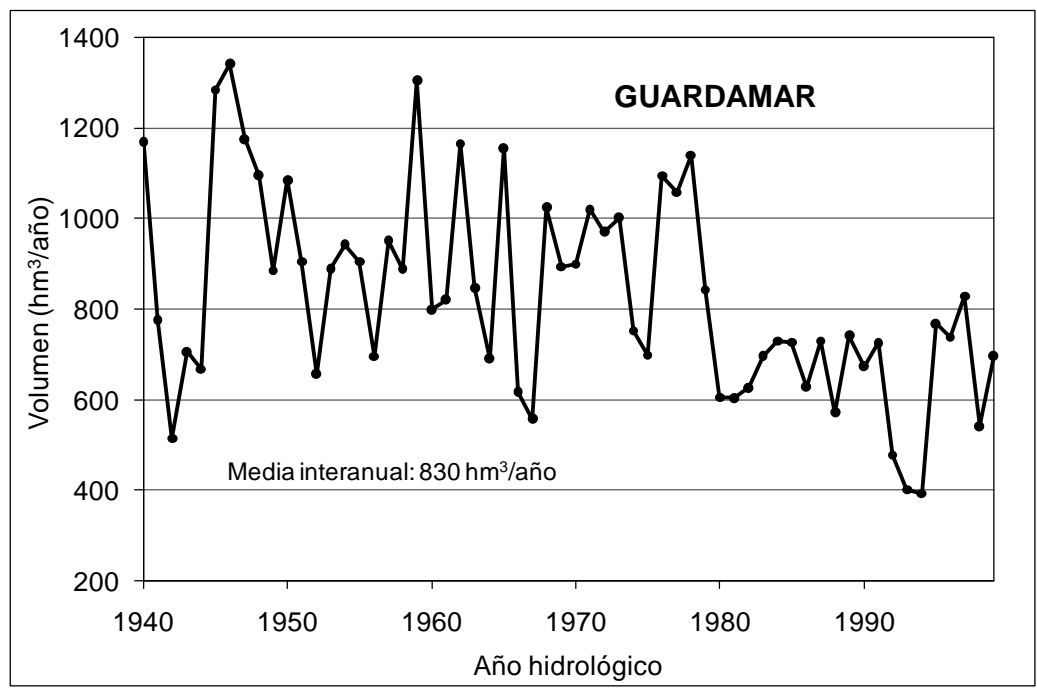

Figura 4.16 Aportaciones restituidas a régimen natural. Guardamar

La serie histórica de aportaciones a la cuenca es muy irregular siendo en el periodo final bastante inferior a los años anteriores. La figura 4.17 muestra la serie de aportaciones para el embalse de Cenajo.

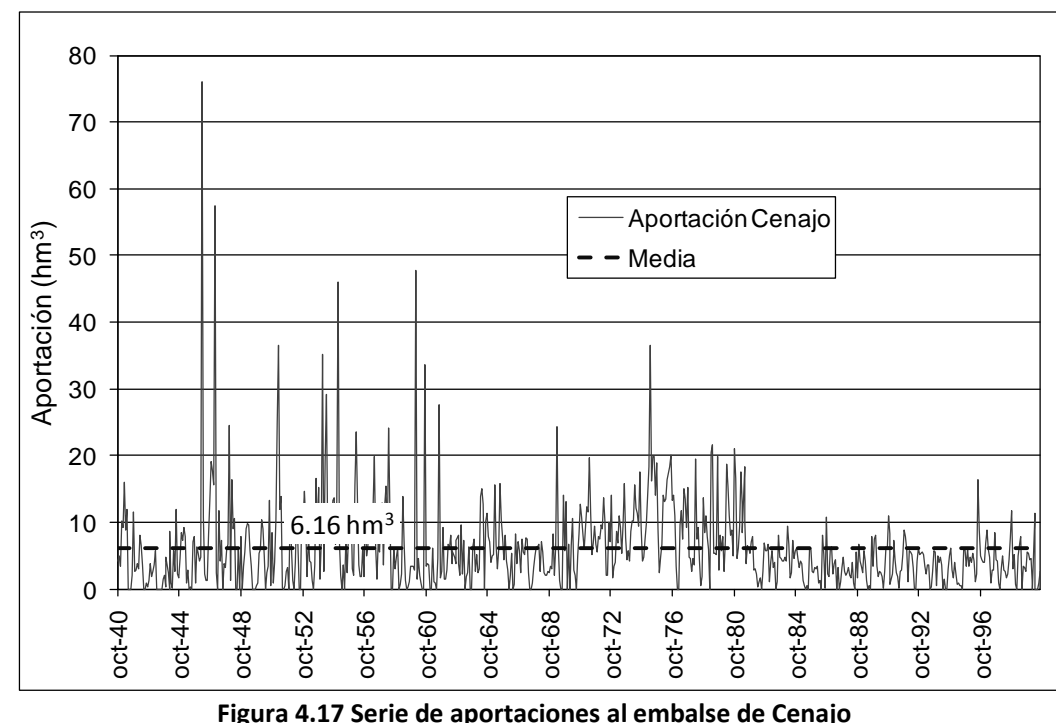

Por otro lado, se ha considerado la regla de explotación procedente del Acueducto Tajo-Segura (ATS, figura 4.18) en vez de los máximos legales que pueden ser trasvasados. 


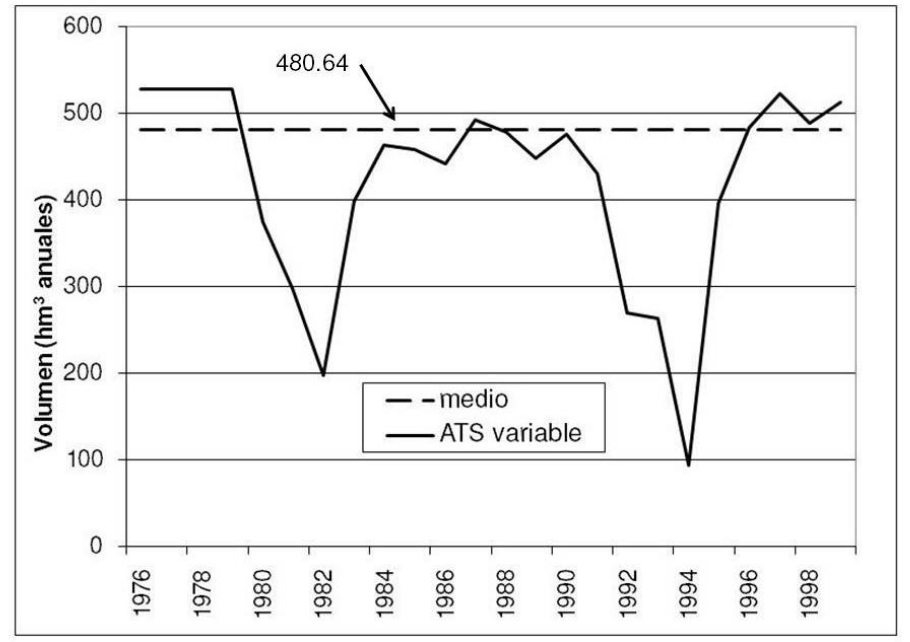

Figura 4.18 Aportación según reglas de explotación del ATS

Prioridades en la gestión. Las prioridades en la gestión del recurso son aquellas que se han definido en el Plan Hidrológico de la Cuenca del Segura:

Las demandas ambientales y los caudales mínimos son restricciones impuestas al sistema, y por lo tanto han de cumplirse siempre. La demanda con mayor prioridad es la urbana. En cuanto a la demanda agraria, la que tiene prioridad es la de los riegos tradicionales. También se ha considerado que los volúmenes mínimos de las desalinizadoras de la Mancomunidad de los Canales del Taibilla, sean iguales a los volúmenes de diseño de las mismas. La razón para esta consideración es que durante todo el año se suministran los volúmenes producidos en las plantas, independientemente de que en los años húmedos existan recursos superficiales de la cuenca.

Reglas de operación. En el modelo de simulación con SimGes, no se utilizaron indicadores de alarma. Sin embargo, se han considerado 15 conducciones tipo 1 y 13 conducciones tipo 3 con caudales mínimos, los cuales se incorporaron al modelo. Las prioridades a la demanda la tienen la Unidades de Demanda Urbana y éstas tienen tres niveles de prioridad. Las Unidades de Demanda Agraria también tienen tres niveles de prioridad, siendo los regadíos tradicionales los prioritarios para el suministro. En cuanto a las prioridades en los embalses, puede indicarse que los de cabecera tienen las prioridad más alta (para más detalle, véase el Anejo A).

Esquema del modelo de simulación. Con lo descrito en los apartados anteriores, el esquema de simulación de la gestión con el módulo SimGes de Aquatool se puede observar en figura 4.19 . 


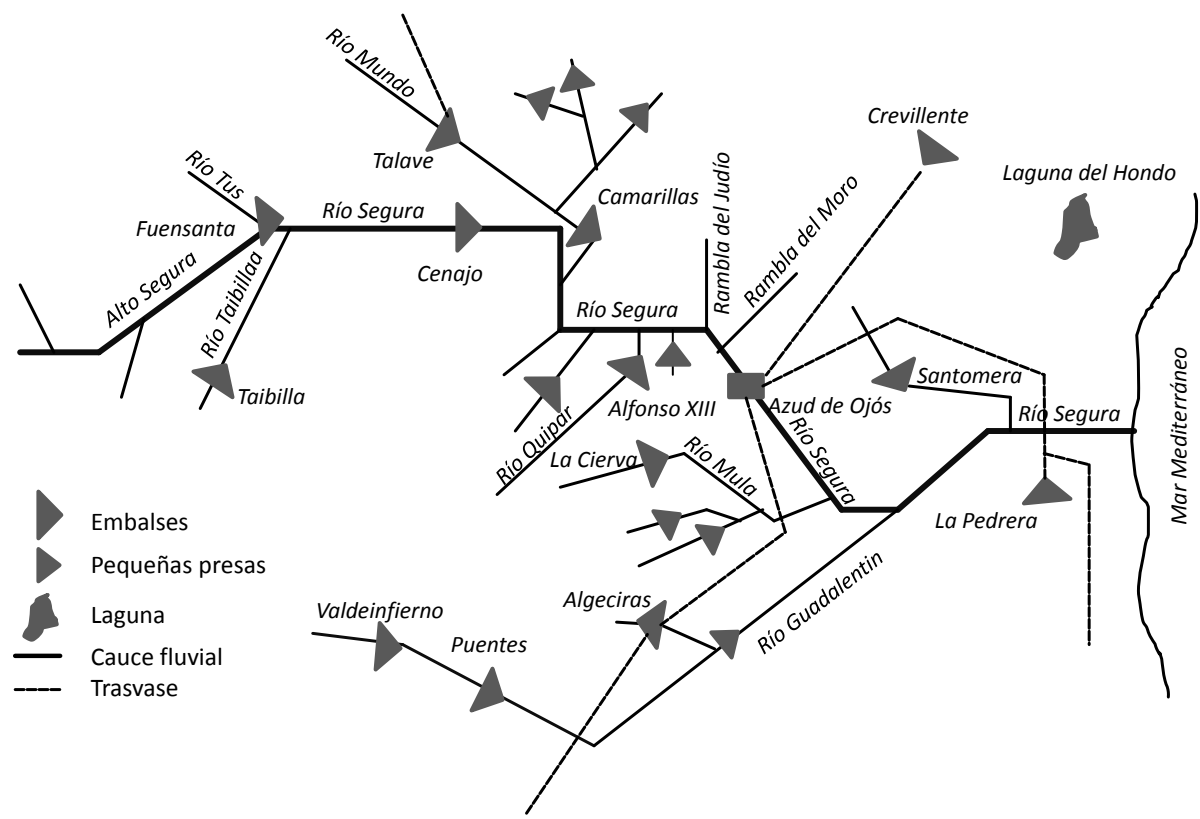

Figura 4.19 Esquema SimGes para la Cuenca del Segura. Principales Cauces y embalses

\subsubsection{Caracterización económica del sistema}

En este apartado se presenta la descripción de las curvas de demanda económica y el resumen de los costes variables de operación que se tomaron en cuenta para el análisis económico.

\section{Curvas de demanda económica}

Las curvas de demanda económica, correspondientes a las diferentes unidades de demanda de la cuenca del Segura, fueron definidas por la Universidad Politécnica de Cartagena (Calatrava, 2007). Esas curvas están definidas en euros corrientes del año 2005. Como ejemplo, se muestra la curva que corresponde a la demanda Valle del Guadalentín (figura 4.20).

Cada una de las curvas de demanda se simplificó en un número considerable de puntos, con el fin de reducir los cálculos en el modelo económico. En el Anejo A puede consultarse la totalidad de las curvas de demanda económica utilizadas en el modelo. 


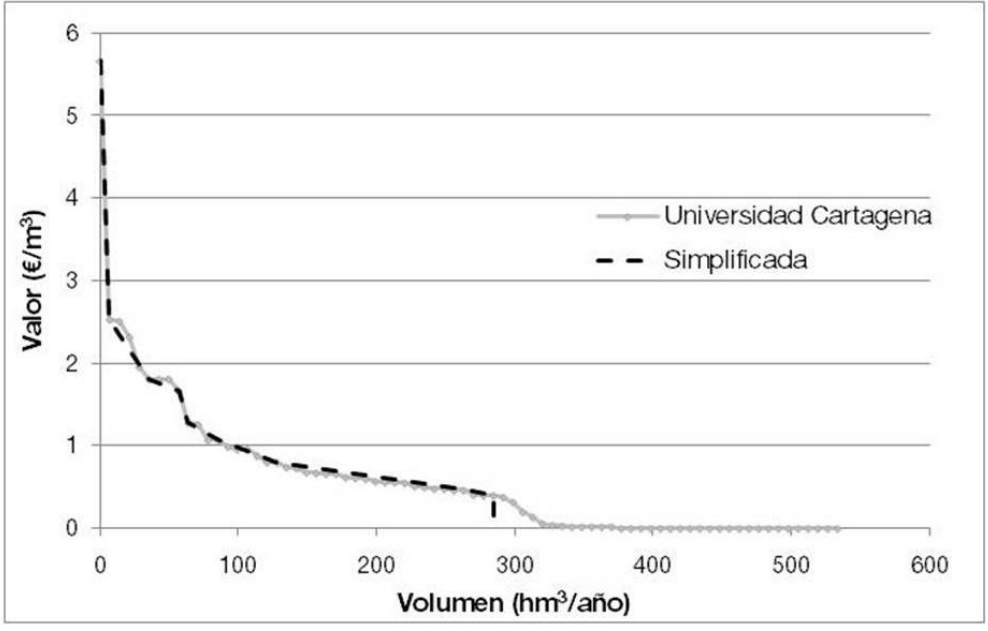

Figura 4.20. Ejemplo de una curva de demanda económica Fuente: Universidad Politécnica de Cartagena y elaboración propia

\section{Costes de operación}

Tanto los usos agrícolas, como los urbanos y los industriales tienen costes variables para la operación del sistema de distribución del recurso. El agua para las zonas agrícolas de la cuenca, es suministrada en parte por los ríos, en parte por los acuíferos, en parte por el transvase Tajo-Segura y en parte por las plantas desalinizadoras. El coste de operación para la demanda urbana toma en cuenta los suministros procedentes de los ríos, del trasvase y de las desalinizadoras. La demanda de uso industrial solamente recibe el recurso procedente de los acuíferos. En el Anejo A se puede consultar el detalle del coste variable de operación por uso y tipo de unidad de demanda.

\section{Tomas de agua superficial en el regadío}

Las tarifas establecidas por la CHS (2005) para las tomas de agua superficial, varían entre 0.0009 y $0.0048 € / \mathrm{m}^{3}$.

\section{Tomas de agua procedente del acueducto Tajo-Segura en el regadío}

Las tarifas establecidas (año 2005) para el metro cúbico del agua proveniente del acueducto Tajo-Segura es de 0,089 €, y es igual para todas las demandas que utilizan este recurso. Los recursos propios de la cuenca del río Segura que se derivan por los canales del postrasvase se han considerado con una tarifa igual a la del trasvase

\section{Tomas de agua subterránea en el regadío}

Tanto las unidades de demanda como las unidades hidrogeológicas se agruparon con el fin de simplificar el esquema de gestión de la cuenca del Segura. Por ello, fue necesario conocer el coste de bombeo de cada acuífero en forma individual y el volumen que cada 
uno de ellos bombea a las diferentes unidades de demanda. Con esa información se calculó, en primer lugar, el coste unitario de bombeo de los acuíferos agregados correspondiente a cada unidad de demanda; y en segundo lugar se calculó el coste de cada demanda agregada para cada acuífero agregado, en forma proporcional a lo que cada una de aquellas bombea individualmente desde cada uno de los acuíferos disgregados. Los costes obtenidos del análisis varían entre 0,11 y $0,40 € / \mathrm{m}^{3}$, aclarando que los valores obtenidos se han calculado con base en los resultados del estudio titulado "Valoración del coste de uso de las aguas subterráneas en España" (MIMAM, 2003), y se han actualizado a euros corrientes del año 2005.

\section{Tomas de agua para el uso urbano}

Al igual que para el regadío, las tarifas que se han asignado a cada toma (euros corrientes del año 2005), se asociaron con los costes variables de operación. Dichos costes, según el origen del suministro del recurso, varían entre 0,01 y $0,40 € / \mathrm{m}^{3}$.

\section{Tomas de agua para el uso industrial}

Como el caso anterior, las tarifas asignadas, se asociaron con los costes variables de operación. Este total incluye tanto la componente de amortización de capital del ATS como los costes variables de operación y mantenimiento. Dichos costes, según el origen del suministro del recurso, varían entre 0,11 y $0,26 € / \mathrm{m}^{3}$.

\section{Tomas de agua procedente de las plantas desalinizadoras}

El coste variable de operación es de $0,4 € / \mathrm{m}^{3}$ para cada una de ellas.

\subsubsection{Resultados}

En este apartado se presentan los resultados hidrológicos y económicos, destacando los aspectos siguientes: coste de escasez y suministro a las demandas; coste del recurso en los embalses del sistema; y coste marginal de restricciones de caudal mínimo y en tramos del cauce.

\section{Coste de escasez y suministro a las demandas}

Las gráficas des las figuras 4.21 a 4.25 muestran el valor del coste de escasez (en millones de euros) de las demandas agrícolas en el sistema del Segura, comparadas con el volumen suministrado y la dotación o suministro óptimo a la demanda. Se puede comprobar que el coste de escasez en las demandas agrícolas crece al aumentar el déficit. Las demandas no representadas tienen coste de escasez nulo. 


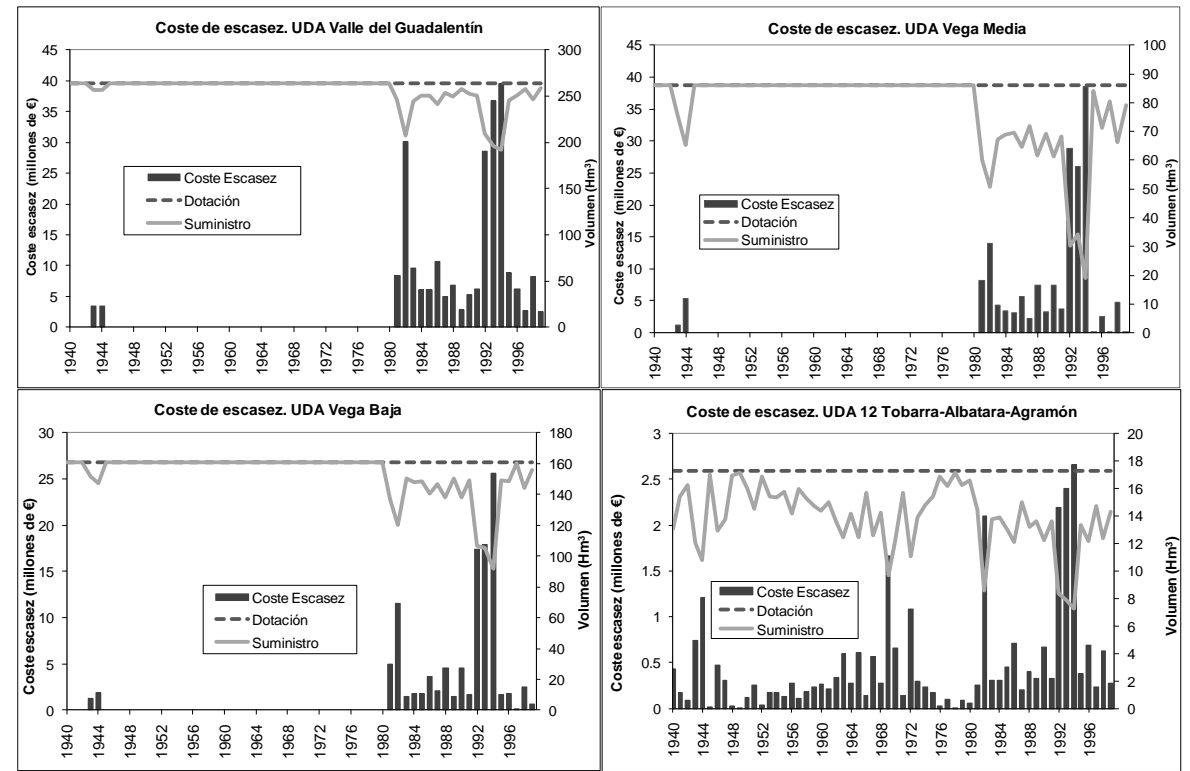

Figura 4.21 Coste de escasez y suministro a la demanda en Valle del Guadalentín, Vega Media, Vega Baja y Regadíos Superficiales Tobarra-Albatara-Agramón

En la figura 4.21 se observa claramente que debido a las deficiencias de suministros en cada UDA se presenta un alto coste de escasez en cada una de ellas. El Valle del Guadalentín presenta una demanda bruta total de $263 \mathrm{hm}^{3} / a n ̃ o$ para cultivos leñosos y herbáceos y tiene un déficit promedio de $7 \mathrm{hm}^{3} /$ año (promedio para el periodo completo 1940/2000) lo que da lugar a un coste de escasez del orden de los 40 millones de euros para el periodo $94-95$ y promedio anual del orden de los 7 millones de euros anuales. El resto de demandas representadas se comportan de forma similar. La UDA 12 tiene un bajo coste de escasez promedio, del orden de 0,47 millones de euros anuales debido a sus bajos déficits en relación con otras demandas, unos $3 \mathrm{hm}^{3}$ anuales. 


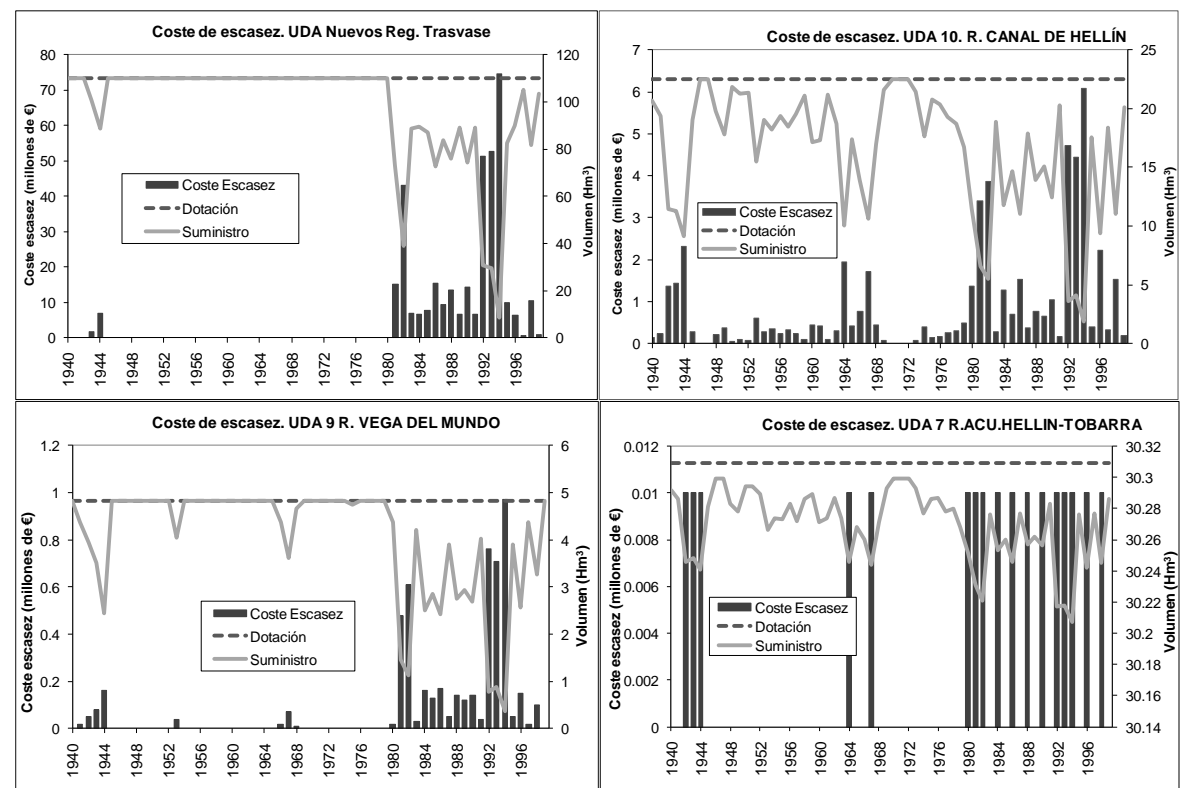

Figura 4.22 Coste de escasez vs. Suministro a la demanda en UDAs: Nuevos Riegos Trasvase, Canal de Helín, Vega del Mundo y Hellín-Tobarra

La unidad de demanda para los regadíos de Hellín-Tobarra tiene uno de los menores

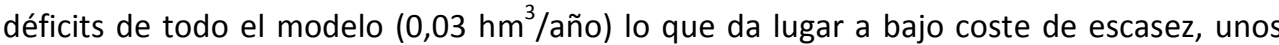
2000 euros anuales, a pesar de que en el periodo simulado todos los años presenten algún déficit.

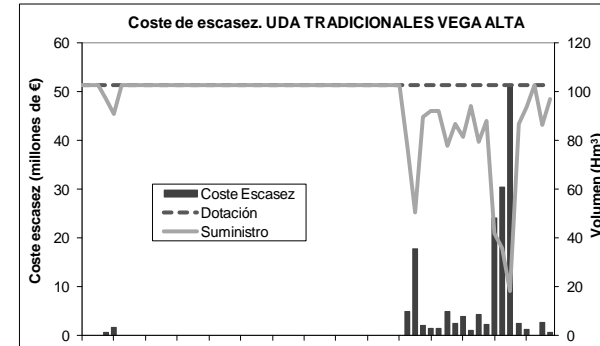

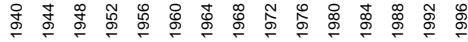

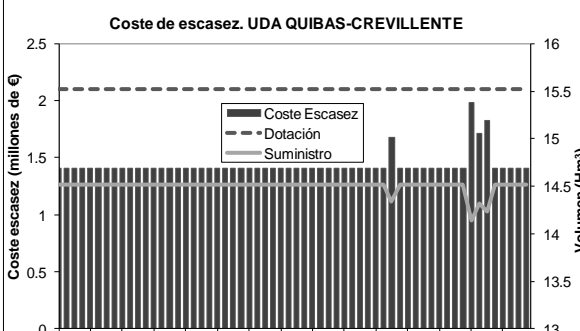

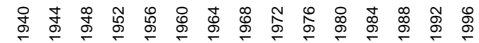

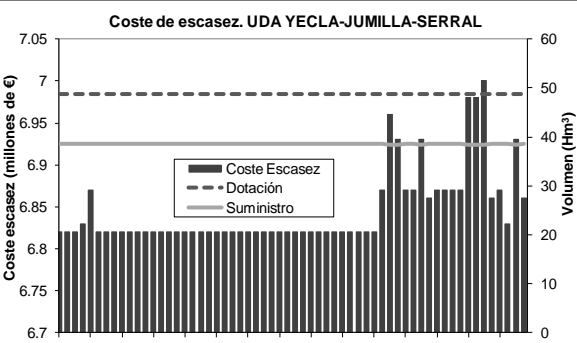

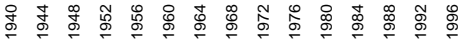

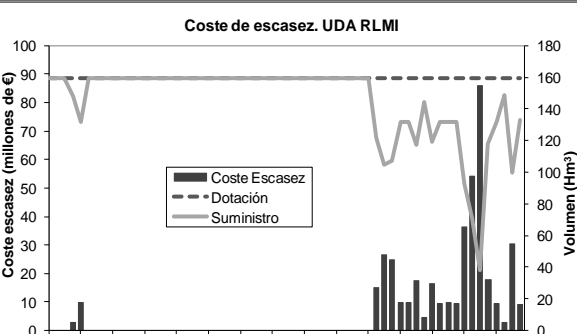

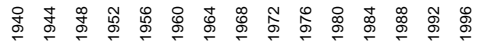

Figura 4.23 Coste de escasez vs. Suministro a la demanda en UDAs: Tradicionales Vega Alta, Yecla-Jumilla, Quibas-Crevillente y Regadíos Levante de la margen izquierda 
Las demandas de Yecla y de Quibas presentan déficits casi constantes durante todo el periodo simulado, lo que da lugar a costes prácticamente constantes. Para el caso de Yecla se alcanza un promedio de 10 millones de euros anuales y para el caso de Quibas tan sólo se alcanza 1 millón de euros al año.

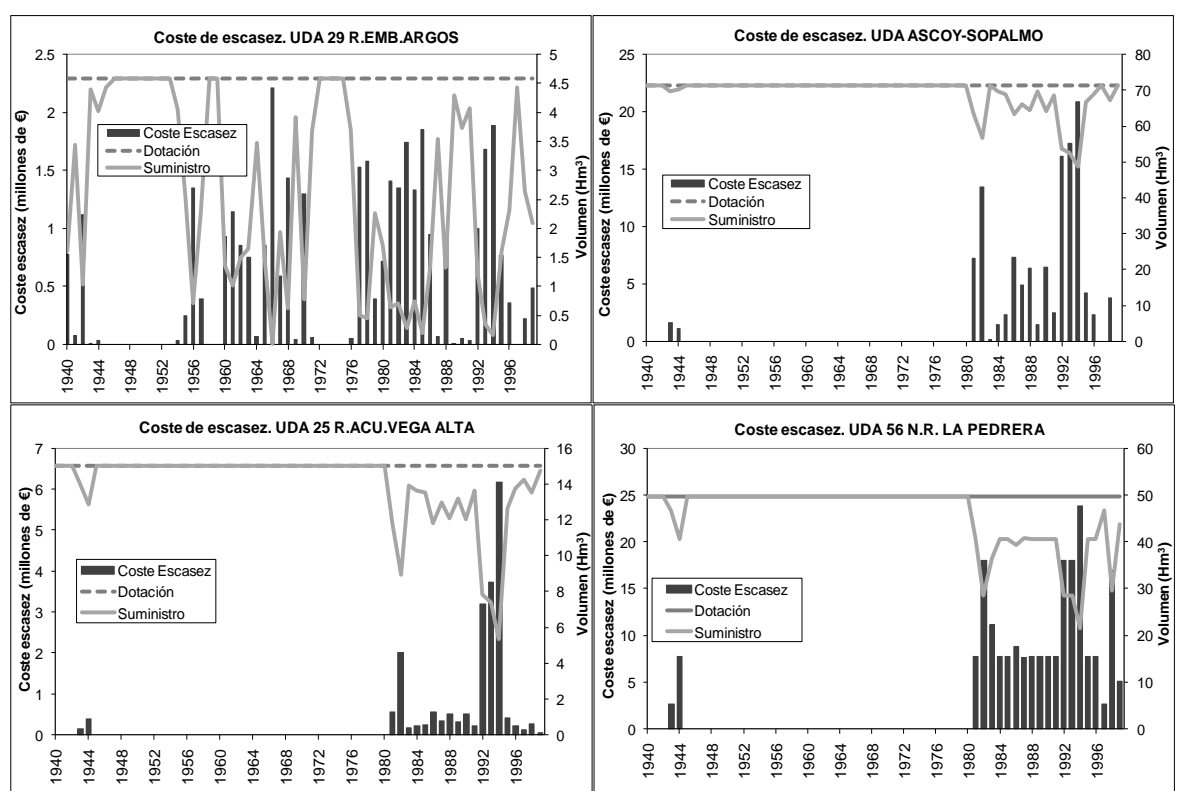

Figura 4.24 Coste de escasez vs. Suministro a la demanda en UDAs: Riegos embalse Argos, Ascoy-Sopalmo, Acuifero Vega Alta, La Pedrera

La demanda de los Nuevos Regadíos de La Pedrera presenta déficits de hasta 28 $\mathrm{hm}^{3} / \mathrm{año}$, lo que da lugar a costes de hasta 23 millones de euros anuales. 


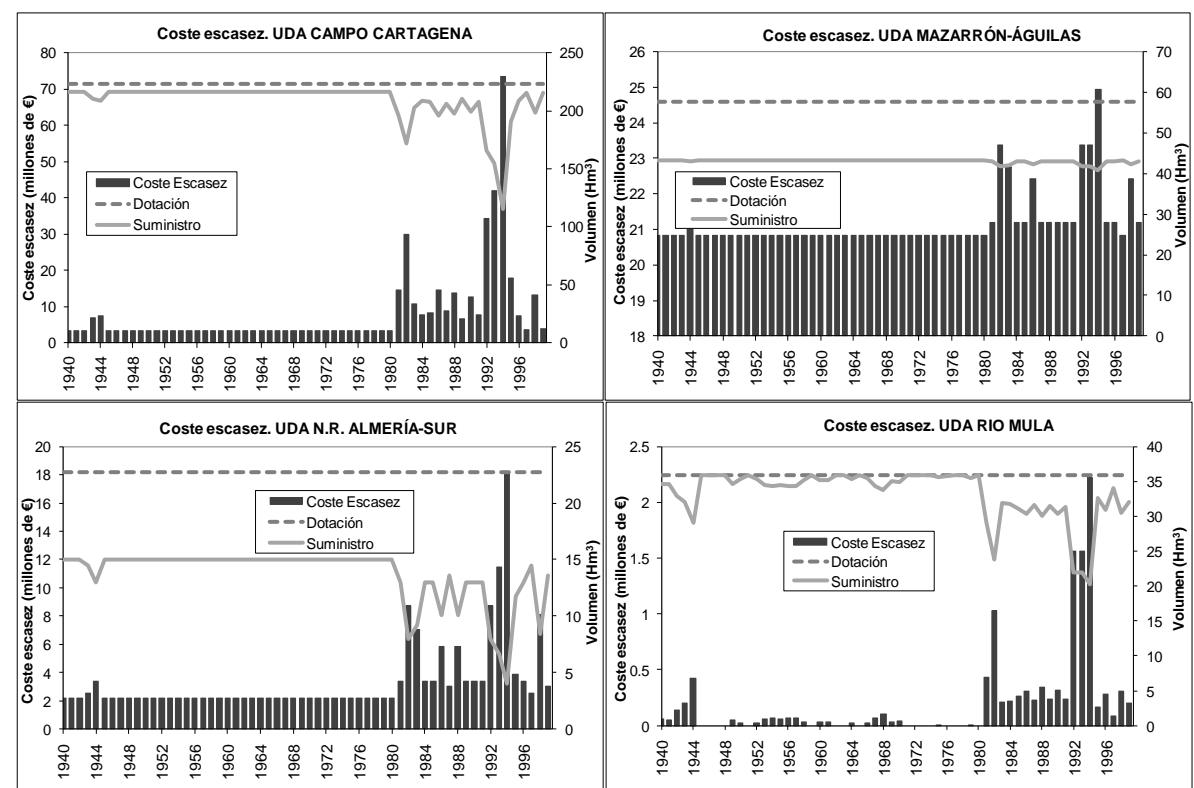

Figura 4.25 Coste de escasez vs. Suministro a la demanda en UDAs: Campo Cartagena, Mazarrón Águilas, Almería Sur y Río Mula

Es en la demanda de Mazarrón-Águilas donde se alcanzan los mayores valores de coste de escasez debido a sus grandes déficits. El coste de escasez en esta demanda tiene un promedio de 21 millones de euros anuales y alcanza picos de hasta 24 millones de euros.

\section{Coste marginal de oportunidad del recurso.}

Para los distintos escenarios especificados se ha estimado el CMOR para los embalses de Talave y Cenajo mediante el enfoque de simulación. Estos embalses cuentan con capacidades de $35 \mathrm{hm}^{3}$ y $437 \mathrm{hm}^{3}$ respectivamente y son embalses de cabecera del sistema del Segura (ver apartado 4.5.1 para su localización geográfica). El valor promedio del CMOR para Cenajo fue de $0.28 € / \mathrm{m}^{3}$ y en Talave de $0.23 € / \mathrm{m}^{3}$.

Ante un modelo que no permite que los recursos propios se deriven a los nuevos regadíos, no existe el CMOR, puesto que los recursos propios del sistema son suficientes (salvo periodos específicos de escasez) para el suministro de las asignaciones de recursos del PHCS y del PHN. Lo anterior es porque los recursos propios de la cuenca del sistema de explotación incluyen los retornos de riego y de abastecimiento. Al no existir posibilidades de que en el modelo se reduzca la escasez del sistema, no es posible el cálculo del CMOR.

El CMOR se ha obtenido para el embalse de Cenajo comparándolo con el volumen almacenado en el embalse al final del periodo de simulación (figura 4.26). 


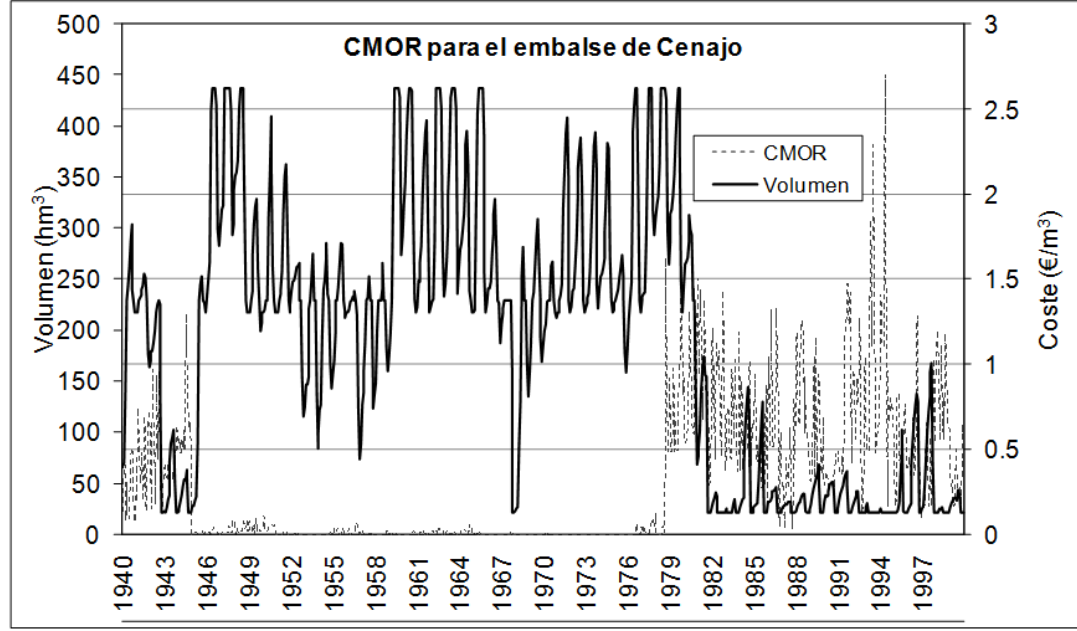

Figura 4.26 CMOR para el embalse de Cenajo

De la figura 4.26 se puede observar que el valor del CMOR es alto debido a que durante todo el periodo el embalse está sujeto a grandes presiones de demanda por lo cual el volumen almacenado es menor provocando con ello escasez del recurso.

El mismo análisis se realizó para el embalse Talave, también de cabecera al igual que Cenajo. Su volumen almacenado durante el periodo de análisis es muy variable debido a que recibe las aguas del trasvase y no tiene suficiente capacidad de regulación por lo que el número de sueltas es muy elevado. En la figura 4.27 se observa el volumen almacenado y el CMOR obtenido con la simulación económica de la gestión del sistema.

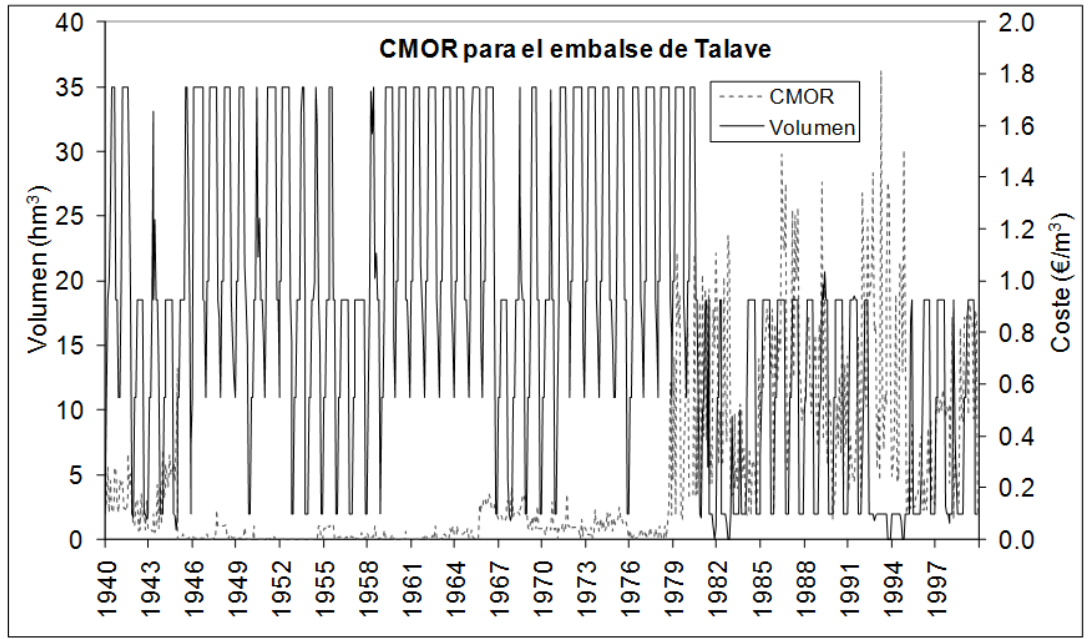

Figura 4.27 CMOR para el embalse de Talave 
En la figura 4.27 se puede observar que el CMOR es muy elevado para el periodo 92-95 ya que los volúmenes almacenados prácticamente son nulos.

Los CMOR calculados para los embalses se han reagrupado en función de diferentes rangos de volumen almacenado en el embalse y se han representado los valores promedio de cada rango (figuras 4.28 y 4.29 ).

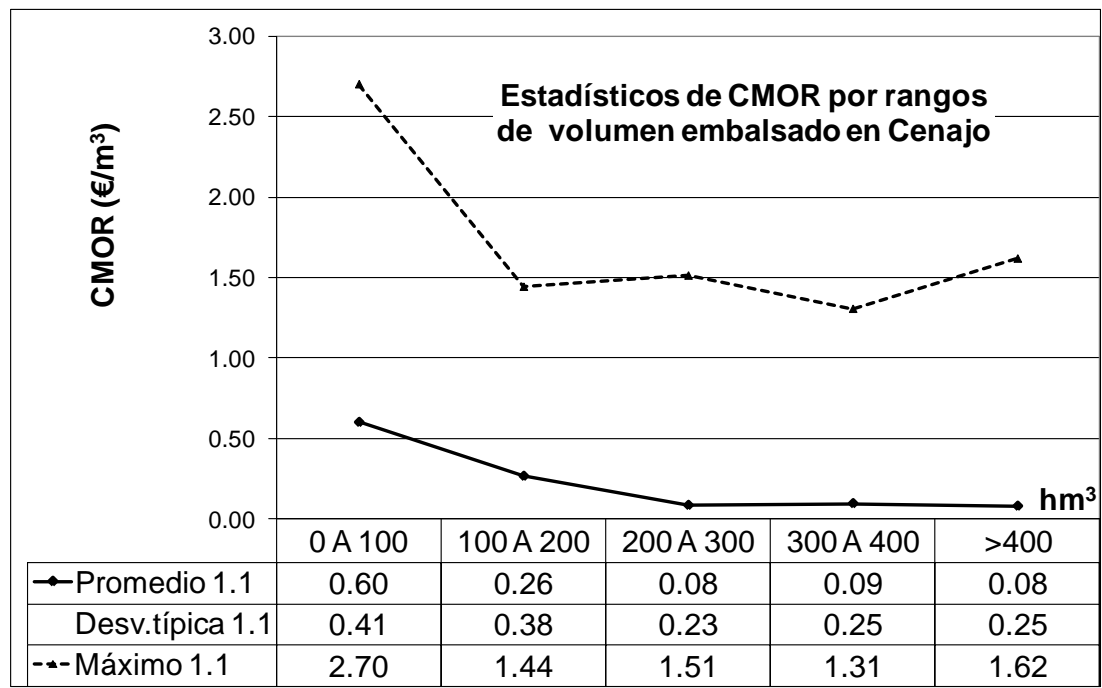

Figura 4.28 Estadísticos del CMOR para el embalse Cenajo

Los valores del CMOR son menores, en promedio, en donde exista mayor capacidad desalinizadora.

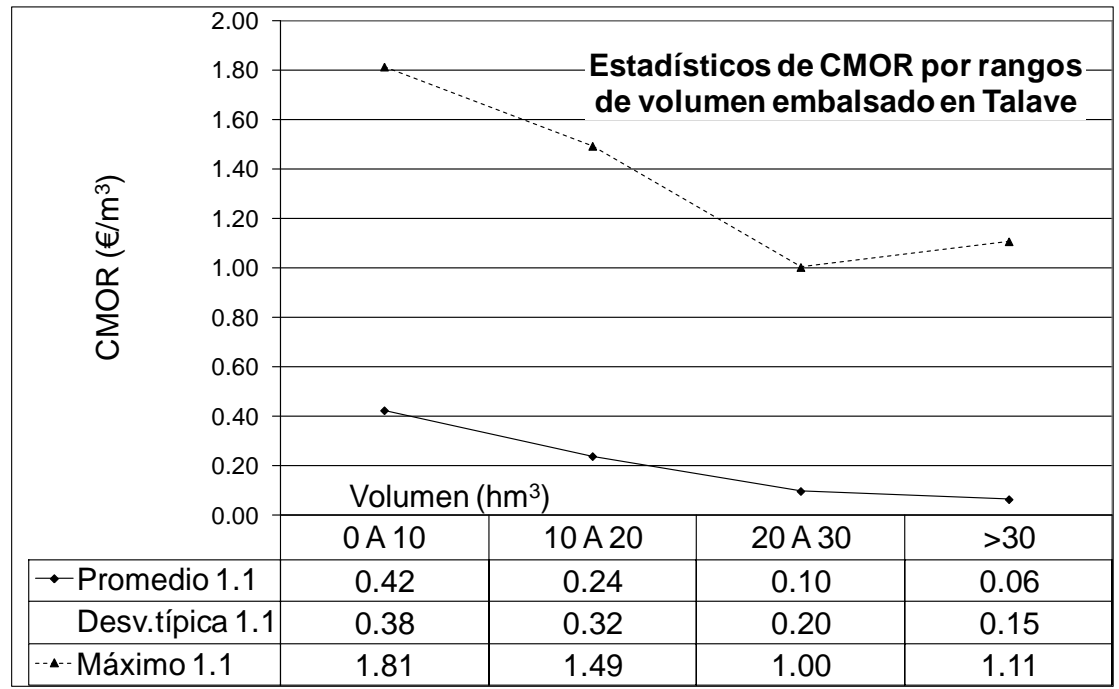

Figura 4.29 Estadísticos del CMOR para el embalse de Talave 
El CMOR obtenido para los embalses de cabecera, da una idea de la posible rentabilidad económica en términos de valor marginal de producción, asociada a la aplicación de una unidad de recurso de cuenca en los nuevos regadíos. En este sentido podría estimarse el coste del recurso como la tarifa asociada al agua de la cuenca aplicada en los nuevos regadíos que asumen los mismos para mejorar su producción y renta; dado que los nuevos regadíos asumen la tarifa del agua trasvasada, el coste del recurso puede asimilarse a la misma. 
CAPÍTULO 5

\section{Metodología para el diseño de una política eficiente de precios}





\section{Metodología para el diseño de una política eficiente de precios}

El CMOR como indicador de la variación del valor marginal del recurso en una cierta ubicación de un sistema de recursos hídricos a lo largo del tiempo, puede ser utilizado para diseñar una política de precios del agua con el objetivo de maximizar la eficiencia económica en la gestión del sistema a escala de cuenca. En este capítulo se estudian y comparan distintos enfoques para estimar políticas de precios eficientes a escala de cuenca partiendo del cálculo del CMOR. Un primer apartado describe la metodología desarrollada para la estimación de políticas eficientes de precios; en seguida se define un esquema sintético de un sistema de explotación al que se le aplican las políticas de precios definidas de acuerdo a la metodología propuesta. Finalmente se presentan los resultados de aplicar políticas de precios eficientes al esquema sintético partiendo del CMOR. 


\subsection{Descripción de la metodología}

Para poder utilizar los resultados del modelo hidro-económico como indicadores para una política de precios que incida en la eficiencia económica del sistema, es necesario tomar en cuenta los siguientes aspectos:

(1) el modelo de la simulación hidrológica del sistema debe ser un modelo que represente fidedignamente al sistema de explotación bajo estudio para lo cual la calibración del mismo deberá ser lo más acertada posible;

(2) las funciones económicas (curvas de demanda, funciones de coste) que se asignen a diferentes elementos que conforman el sistema deberán representar de la mejor manera posible el valor económico del agua suministrada en cada uno de los usos para los cuales es destinado el recurso.

Como se ha mencionado en apartados anteriores, el modelo hidro-económico utiliza un modelo de simulación de la gestión del sistema (SimGes) y un evaluador económico (EcoWin). La metodología se describe mediante la figura 5.1.

El modelo de simulación de la gestión, empleando SimGes (SAD AquaTool) proporciona tanto los volúmenes almacenados en el embalse o embalses del sistema como las series temporales de suministros a las demandas y garantías. El módulo SimGes proporciona también los déficits de suministro a cada una de las demandas del sistema de recursos hídricos bajo estudio. Esta información sirve como datos de entrada para el evaluador económico EcoWin, el cual con esta información y las curvas de demanda económica de cada uno de los usos calcula el CMOR (véase apartado 4.4.3). Junto con el CMOR, el evaluador valora los beneficios netos que cada uno de los usos tendrán con el suministro que ha proporcionado SimGes. Estos beneficios netos son entonces comparados con los beneficios que proporciona el modelo de optimización económica (desarrollado con GAMS) que corresponden al techo ideal o valor máximo que se puede obtener con una gestión económicamente óptima del sistema. 


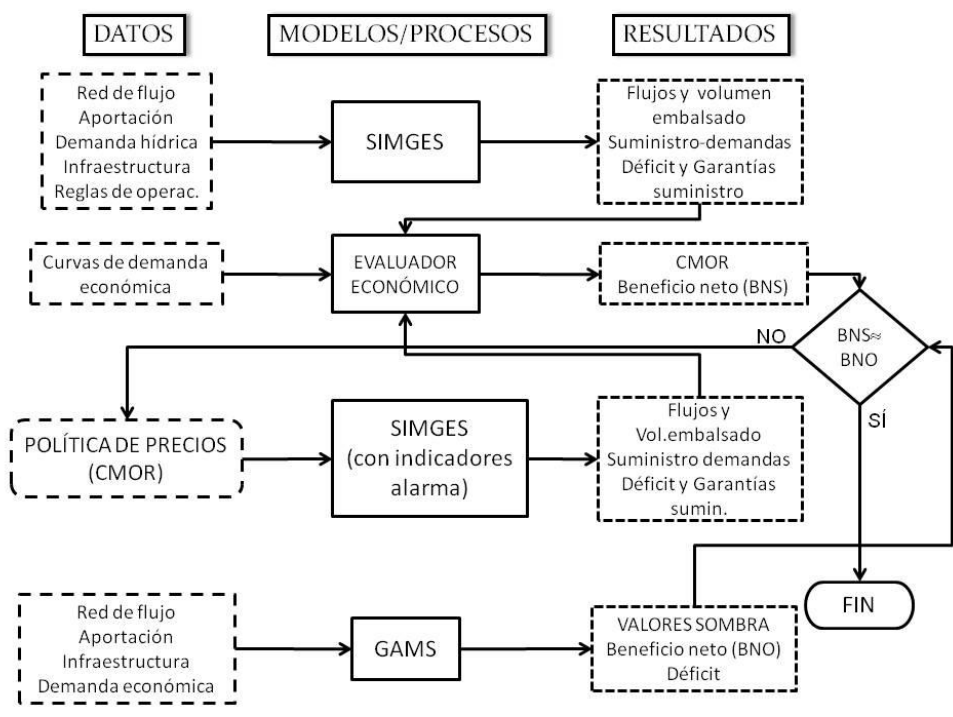

Figura 5.1 Esquema de la metodología propuesta Fuente: elaboración propia

Los resultados del CMOR servirán como punto de partida para el diseño de políticas de precios cuyo efecto se analizará empleando de nuevo el modelo de simulación. El CMOR varía con el volumen de reserva en el embalse o embalses del sistema. Cuando hay escasez de agua, el valor (coste) marginal (o precio máximo por unidad adicional de agua que los usuarios del sistema estarían dispuesto a pagar) será elevado. Cuando se relaciona el CMOR con el volumen embalsado, el resultado es una gran nube de puntos con una alta dispersión, en la que el coeficiente de correlación es por lo general bastante bajo (figura 5.2a). Esto es debido a que mismos valores de embalse pueden corresponder a una situación de inicio de sequías, o a una situación de recuperación de la misma (en cuyo caso el valor marginal del agua, distribuida en el tiempo por el embalse, podría ser menor). A pesar de esto, a partir de la nube de puntos se puede definir una función escalonada de precios que depende del volumen de reserva del embalse (figura $5.2 \mathrm{c}$ ), la cual se obtiene al considerar diferentes rangos de volúmenes de reserva y promediar los correspondientes costes marginales (figura 5.2b). 


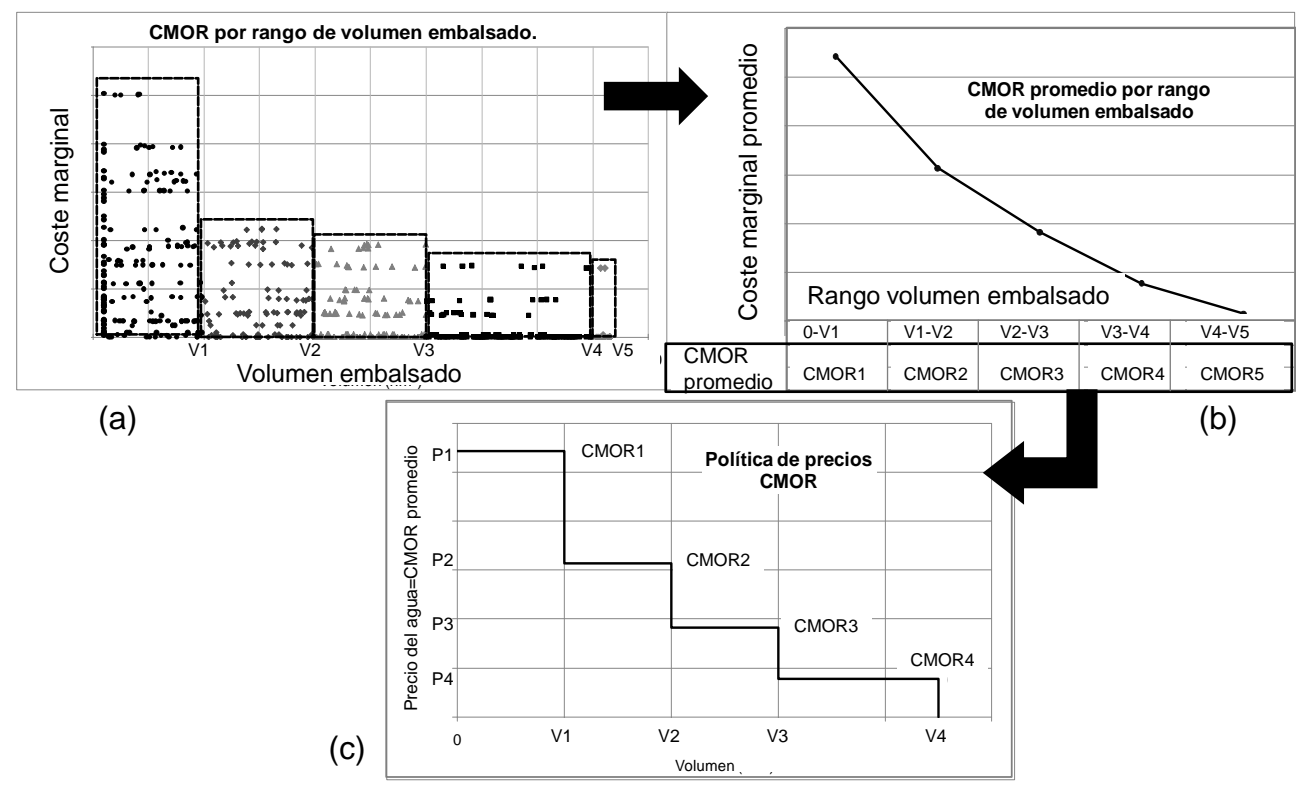

Figura 5.2 Proceso para la obtención de precios escalonados en función del volumen de reserva del embalse

Un precio del agua igual a su valor marginal transmitiría al usuario una señal de escasez del recurso y su valor real en cada paso de tiempo (mes). El precio actuaría reduciendo las cantidades demandadas según las curvas de demanda de cada uso, y así el recurso escaso se asignaría preferentemente a los usos de mayor valor marginal. Esta información se incorpora al modelo de simulación haciendo uso de coeficientes de restricción mediante la utilidad "indicadores de alarma" del módulo SimGes que hacen que, en función volúmenes disponibles en los embalses, se asigne recurso para toda la demanda o sólo para un porcentaje de la misma. Con los precios definidos como el CMOR promedio se busca el volumen correspondiente en las curvas de demanda económica anual de los diferentes usos (figura $5.3 \mathrm{a}$, b). Con ese volumen, se calcula el coeficiente de restricción (figura $5.3 \mathrm{c}$ ), mediante la expresión: 


\section{Coef. Restr . $=1-\frac{\text { Volumen corespon .al precio }}{\text { Volumen DemandaMáxima }}$}

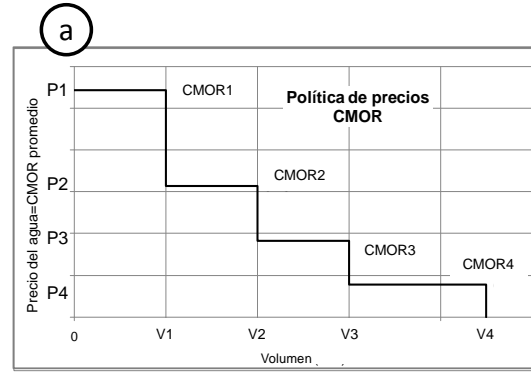

(c)

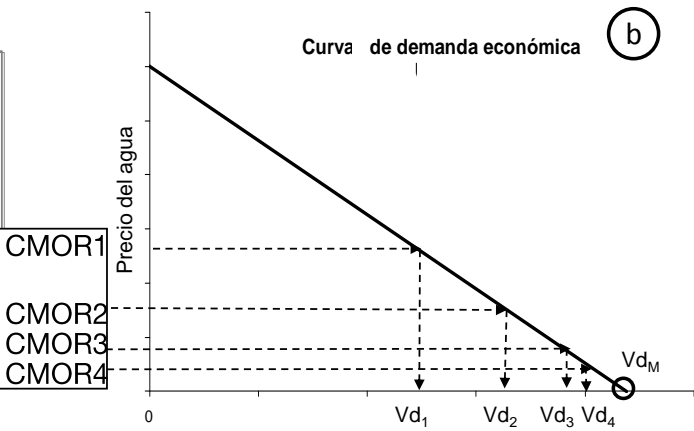

ción CR

\begin{tabular}{|c|c|}
\hline Vol. Emb. entre 0 y $V 1 \quad \longrightarrow C R_{1}=1-\frac{V d_{1}}{V d_{M}}$ & Vol. Emb. entre V2 y V3 $\Rightarrow C R 3=1-\frac{V^{2}}{V_{d}}$ \\
\hline Vol. Emb. entre V1 y V2 $\Rightarrow C R 2=1-\frac{V d_{2}}{V d_{M}}$ & Vol. Emb. entre V3 y V4 \\
\hline
\end{tabular}

Figura 5.3. Políticas de precio. Cálculo de restricciones de suministro

Los coeficientes de restricción así obtenidos, se incorporan al modelo de simulación de la gestión en forma de indicadores de alarma en las tomas de las demandas consideradas en el sistema de explotación (figura 5.4). Se trata de criterios de gestión cuya función es reducir los consumos de agua de menor valor añadido cuando la reserva hidráulica del sistema, o de una parte de éste, está por debajo de límites especificados por el usuario. Cada indicador viene definido por un conjunto de embalses a los que se asocia una tabla que relaciona volúmenes almacenados con coeficientes de restricción. La tabla, definida por el usuario, está constituida por un número no superior a diez de valores crecientes de volumen y sus coeficientes de restricción correspondientes, que han de ser decrecientes de 1,0 a 0,0. Cada indicador de alarma lleva asociado a un grupo de embalses y una tabla de coeficientes de restricción. Puede haber embalses comunes a varios indicadores distintos e incluso se puede definir indicadores distintos asociados al mismo grupo de embalses.

Al principio de cada mes el modelo de simulación en SimGes calcula la suma de los volúmenes almacenados en los embalses asociados y, mediante la tabla dada, obtiene el coeficiente de restricción correspondiente al indicador para dicho mes. Hay que recalcar que estos indicadores se calculan con base en el valor de reservas a principio de mes, $\sin$ tener en cuenta las entradas durante el mismo mes ni la situación en que el embalse pueda quedar a final de mes. Los indicadores de alarma incorporados al modelo de simulación permiten simular por tanto el efecto de cualquier política de precios en función del estado de las reservas del sistema. En esta tesis se analiza la hipótesis de que se puede 
definir políticas eficientes de precios a partir de series temporales del CMOR y de volúmenes de embalse, y por tanto la herramienta descrita va a permitir comprobar la eficiencia real de estas políticas de precios en casos de estudio concretos.

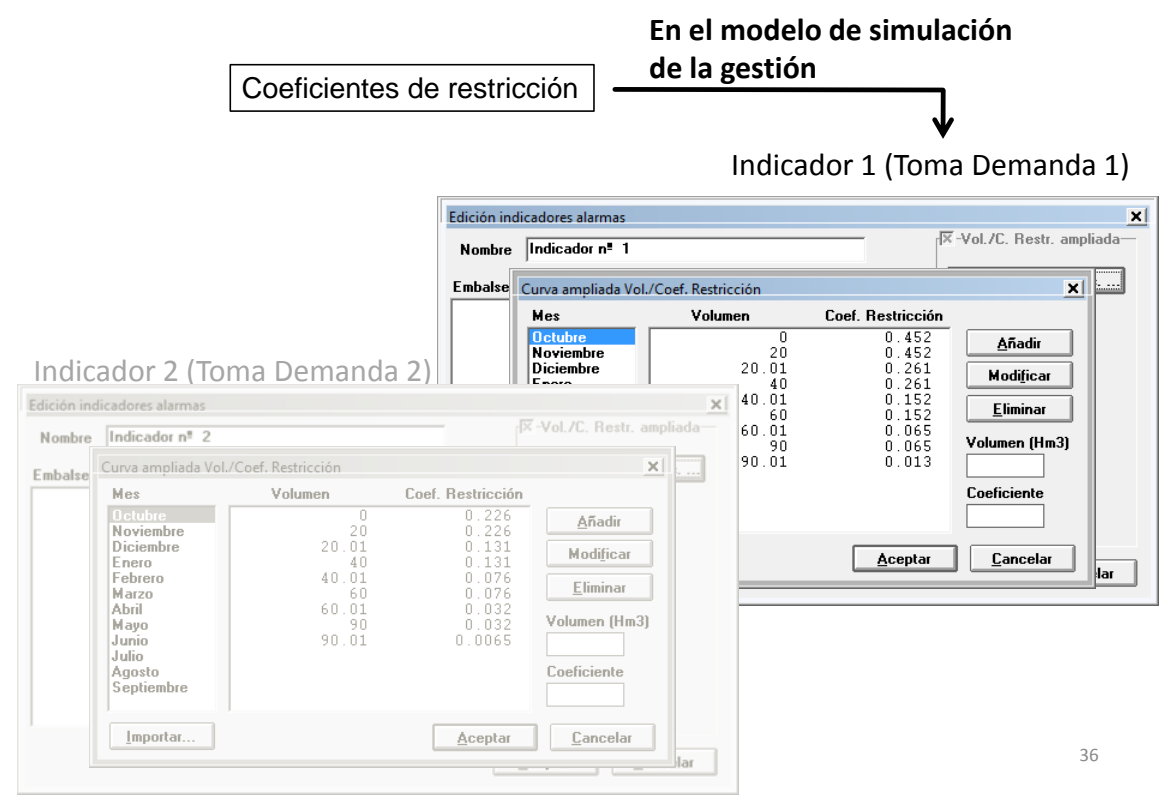

Figura 5.4 Incorporación de precios en SimGes

Los valores del CMOR en los embalses obtenidos mediante el proceso de simulación iterativo descrito en el capítulo 4 representan una primera aproximación al valor marginal del recurso en el sistema en esa localización a lo largo del tiempo. En la optimización, el CMOR se obtiene como los precios sombra de las restricciones de disponibilidad del recurso (balance). Para el caso de la simulación, esos valores se condicionan a unas determinadas reglas de gestión que determinan la asignación del agua en cada paso de tiempo, según el procedimiento indicado en el apartado 4.2.2. Los resultados obtenidos con el nuevo esquema de simulación con restricciones incorporadas mediante indicadores de alarma (políticas de precios incorporadas), sirven de datos de entrada de nueva cuenta para el evaluador económico. Los beneficios obtenidos son comparados con los beneficios que se tienen del modelo de optimización.

Se han analizado diversas opciones para la representación de los precios del agua tomando como base los valores del CMOR tanto del modelo de simulación como del de optimización. La mejora de la eficiencia económica resultante de la aplicación de las políticas de precios, se valorará comparando los resultados de la simulación de la gestión actual del sistema (según criterio de prioridad) con los correspondientes a la política actual de precios. Los resultados del modelo de optimización indican la máxima eficiencia 
económica alcanzable que sirve como nivel de referencia. En este punto es importante aclarar las diferencias entre la simulación y la optimización.

\subsubsection{Diferencias entre simulación y optimización. La predicción perfecta}

Los modelos que representan la gestión de un sistema de explotación son generalmente de dos tipos: uno que simula el comportamiento del agua recursos de conformidad con un conjunto predefinido de normas de reparto del agua y operación de infraestructura, y otro que optimiza el reparto del agua durante un cierto horizonte de tiempo basado en una función objetivo que está sujeta a ciertas restricciones.

Un modelo de simulación (modelo descriptivo) trata de reproducir la gestión de un sistema de recursos hídricos para unas determinadas reglas de operación. Las reglas dependen del estado de las reservas de agua en los embalses. La simulación de agua existente en los embalses. La simulación proporciona decisiones del reparto de agua con base en una serie de prioridades para el suministro del recurso. Este tipo de modelo permite representar el modus operandi actual del sistema.

Un modelo de optimización determinista optimiza de forma simultánea todo el periodo horizonte, actuando por tanto con pleno conocimiento de las aportaciones y demandas futuras (predicción perfecta o perfect foresigth). El volumen en un embalse se ajusta con anticipación perfecta a los periodos húmedos y secos y se aumenta el almacenamiento previo a las sequías mediante restricciones anticipadas utilizando el agua sin restricciones frente a periodos húmedos. Los resultados económicos del modelo de optimización representan un "techo" ideal inalcanzable en la práctica. La "predicción perfecta" subestima el valor de nueva capacidad de almacenamiento y puede subestimar también la escasez, el coste de escasez y por consecuencia los costes marginales de oportunidad del recurso (Pulido Velázquez, 2003).

\subsection{Caso sintético}

La metodología descrita en el apartado 5.2 se ha aplicado primeramente a un esquema sintético de explotación, el cual ha servido de base para corroborar y observar la propuesta metodológica de asignación de precios con base en los resultados del CMOR.

El caso sintético está conformado por un embalse y dos unidades de demanda (Uso A y Uso B) con diferentes prioridades en el suministro del recurso, como se muestra en la figura 5.5 


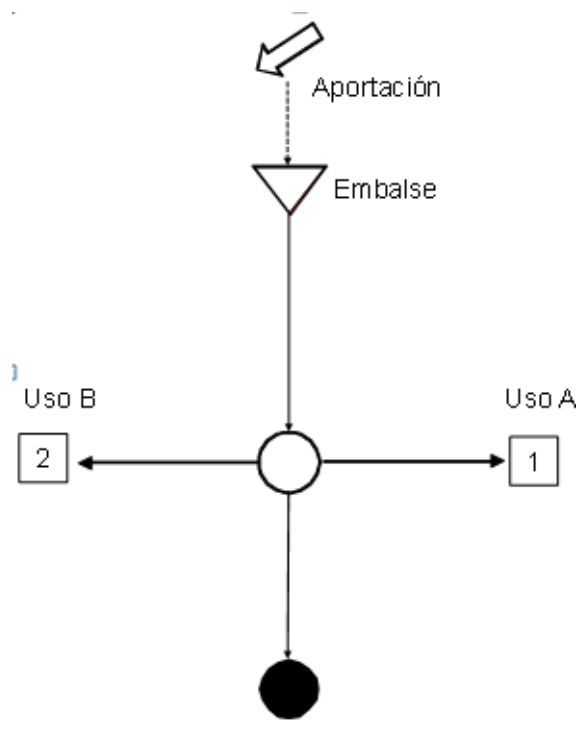

Figura 5.5 Esquema SimGes del caso sintético

\subsubsection{Datos del esquema sintético.}

Caracterización hidrológica. El esquema considera una serie de aportaciones al embalse de cabecera (figura 5.6) con un registro mensual de 55 años, desde 1948 hasta 2003, en la cual se incluyen dos periodos marcadamente secos (1952-1958 y 1978-1987). El embalse tiene una capacidad útil de $93 \mathrm{hm}^{3}$ y un volumen mínimo de $2 \mathrm{hm}^{3}$ (embalse “muerto"). La media de las aportaciones anuales es de $137 \mathrm{hm}^{3}$ presentándose un valor pico superior a los $300 \mathrm{hm}^{3}$ en el año hidrológico 59/60 y otro superior a los $250 \mathrm{hm}^{3}$ en el año hidrológico 90/91 (figura 5.7).

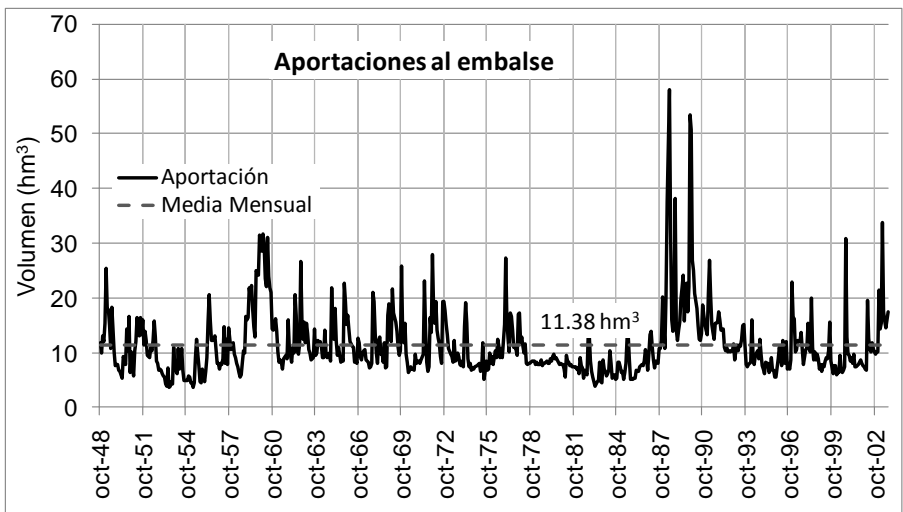

Figura 5.6 Aportaciones mensuales al embalse. Caso sintético 


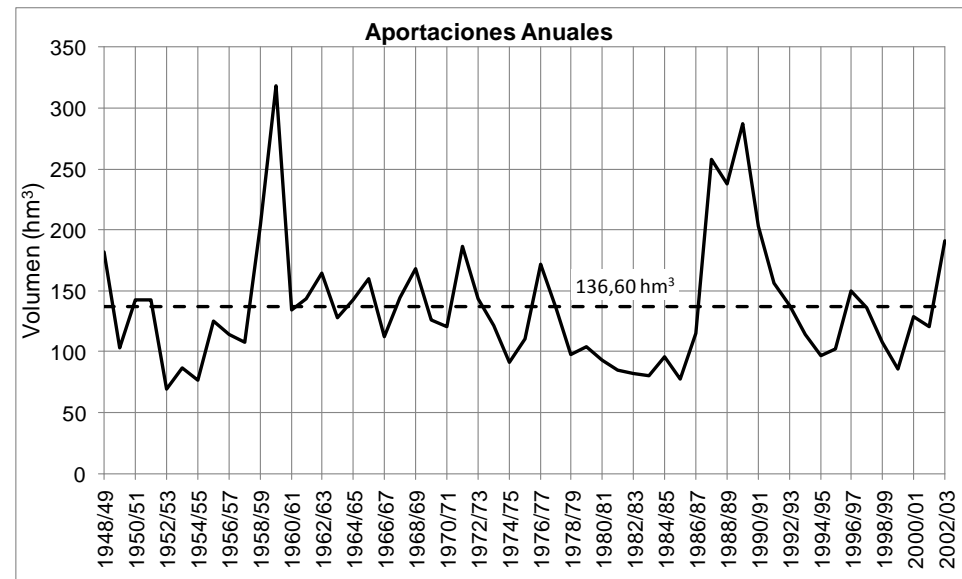

Figura 5.7 Aportaciones anuales al embalse. Caso sintético

Demandas hídricas. Las demandas de agua para los usos considerados varían notablemente. La que corresponde al uso $\mathrm{A}$ es del orden del doble de la demanda del uso B, como se observa en la figura.5.8.

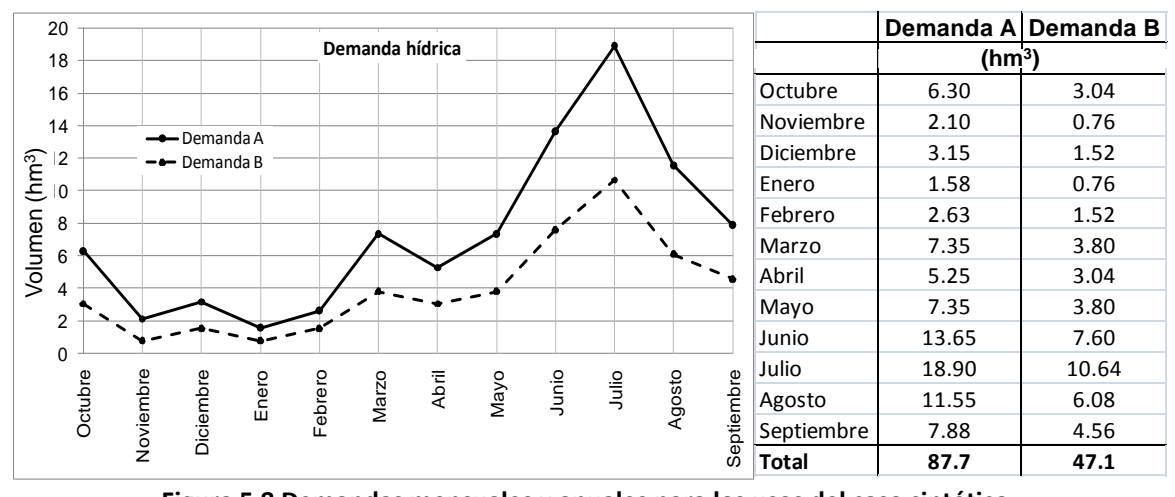

Figura 5.8 Demandas mensuales y anuales para los usos del caso sintético

Caracterización económica. Las funciones económicas asignadas a los dos usos considerados se definieron con un precio de cierre de $0,6 € / \mathrm{m}^{3}$ para el uso $A$ y $1,2 € / \mathrm{m}^{3}$ para el uso $B$ siendo el volumen máximo igual al máximo volumen anual demandado en cada uno de ellos (figura.5.9). 


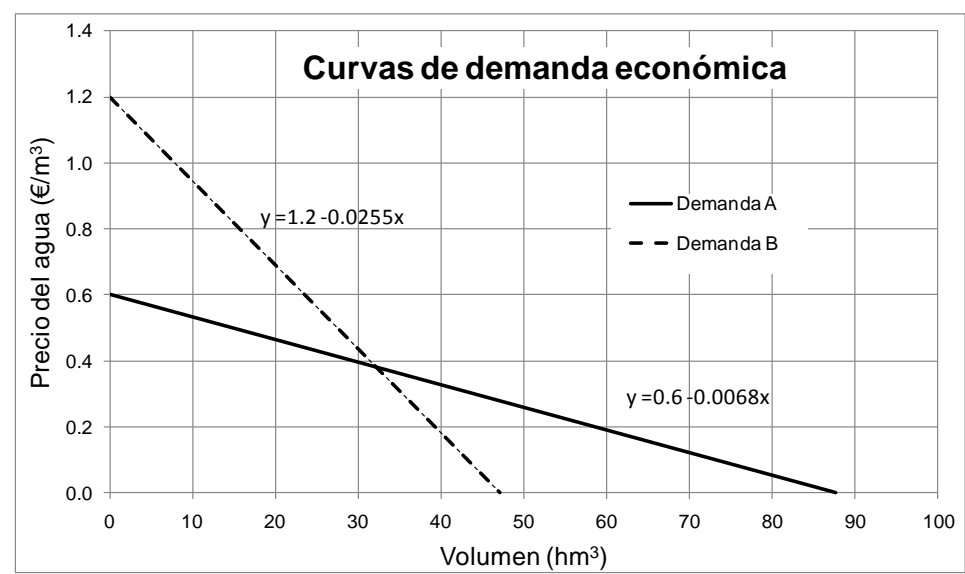

Figura 5.9 Funciones económicas del caso sintético

\subsubsection{Simulación con prioridades y optimización económica}

En la simulación, la gestión se realiza a nivel mensual, utilizando curvas de demanda anual para la valoración de beneficios-costes de escasez y el cálculo de la aproximación del CMOR en embalses. En la optimización, sin embargo, la gestión obtenida maximiza beneficios de forma simultánea para todo el periodo de análisis, considerando en este caso curvas de demanda mensuales (desagregando la curva anual mes a mes, según el calendario de riego) (Pulido-Velazquez, 2003). Debido a que se han considerado funciones de tipo lineal, la desagregación de éstas sigue también un patrón lineal con punto de cierre en los precios de las curvas anuales y demanda máxima mensual.

En el modelo de simulación, a la demanda A se le da prioridad de suministro sobre la demanda $B$, mientras que en el modelo de optimización no se consideran estas prioridades sino que se asigna el agua con el criterio de maximizar los beneficios netos totales para todo el período analizado. La simulación con prioridades permite representar la gestión del recurso hídrico en condiciones actuales y presenta, a su vez, el reparto del agua en función de las prioridades en el suministro establecidas de antemano. Así, el uso A tendrá prioridad en la asignación del recurso; mientras el embalse mantenga los niveles suficientes, el uso B podrá contar con el mayor suministro posible, lo contrario sucederá si el embalse empieza a tener poco volumen almacenado. El modelo utilizado para representar la simulación con prioridades en la gestión del recurso hídrico para el caso sintético es el módulo SimGes del SAD Aquatool (véase el apartado 4.4.2), con una posterior evaluación económica mediante el módulo EcoWin (véase el apartado 4.4 .3 y Anejo B).

La optimización económica tiene como función objetivo maximizar los beneficios económicos totales para las dos demandas consideradas. El modelo proporciona el 
"techo" de beneficios que se pueden conseguir. El modelo de optimización siempre "ve hacia adelante" -conoce la hidrología y demandas futuras- pues se optimiza simultáneamente para todo el periodo de análisis. De esta manera, los volúmenes almacenados en la simulación y la optimización no son coincidentes. El modelo de optimización claramente prevé almacenar agua para solventar los periodos de sequía que vendrán en periodos posteriores (predicción perfecta), mientras que en la simulación se suministra el recurso de acuerdo a lo que el uso requiere y conforme a las reservas que se tengan en el embalse (figura 5.10).

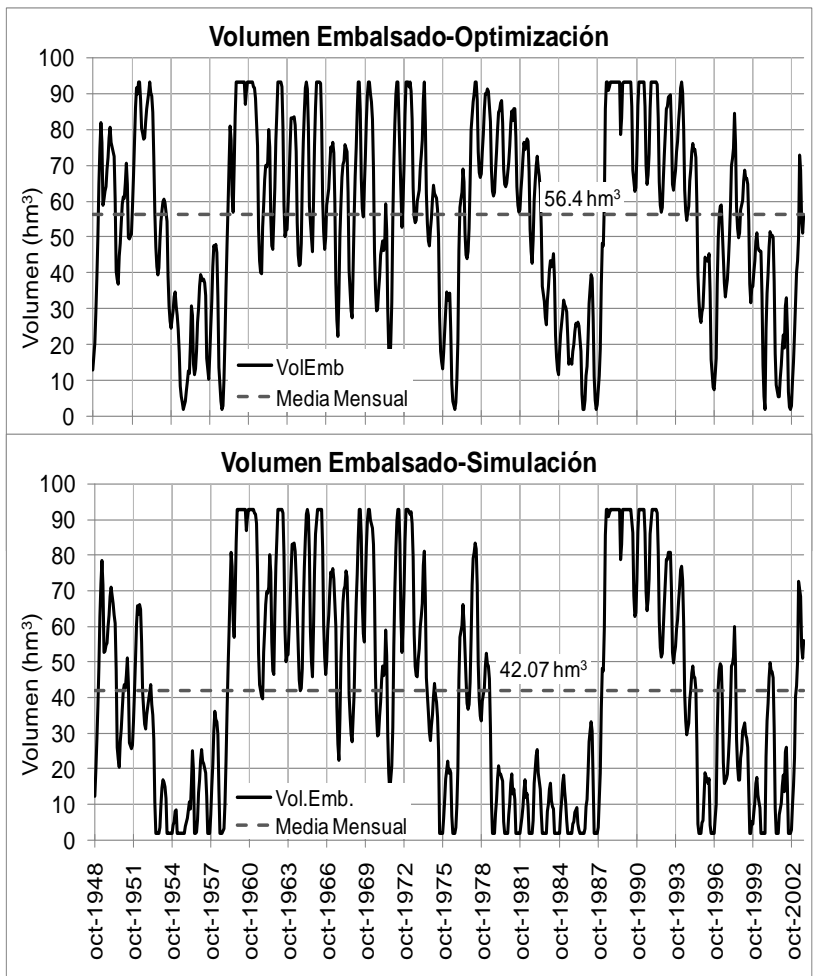

Figura 5.10 Volumen embalsado. Optimización y Simulación

Con lo anterior, los suministros a las demandas varían. Mientras el modelo de simulación considera preferente satisfacer la demanda prioritaria, el modelo de optimización prefiere mejorar el suministro al uso B a costa de penalizar al uso A (figura 5.11) puesto que el objetivo es maximizar el beneficio económico total. 


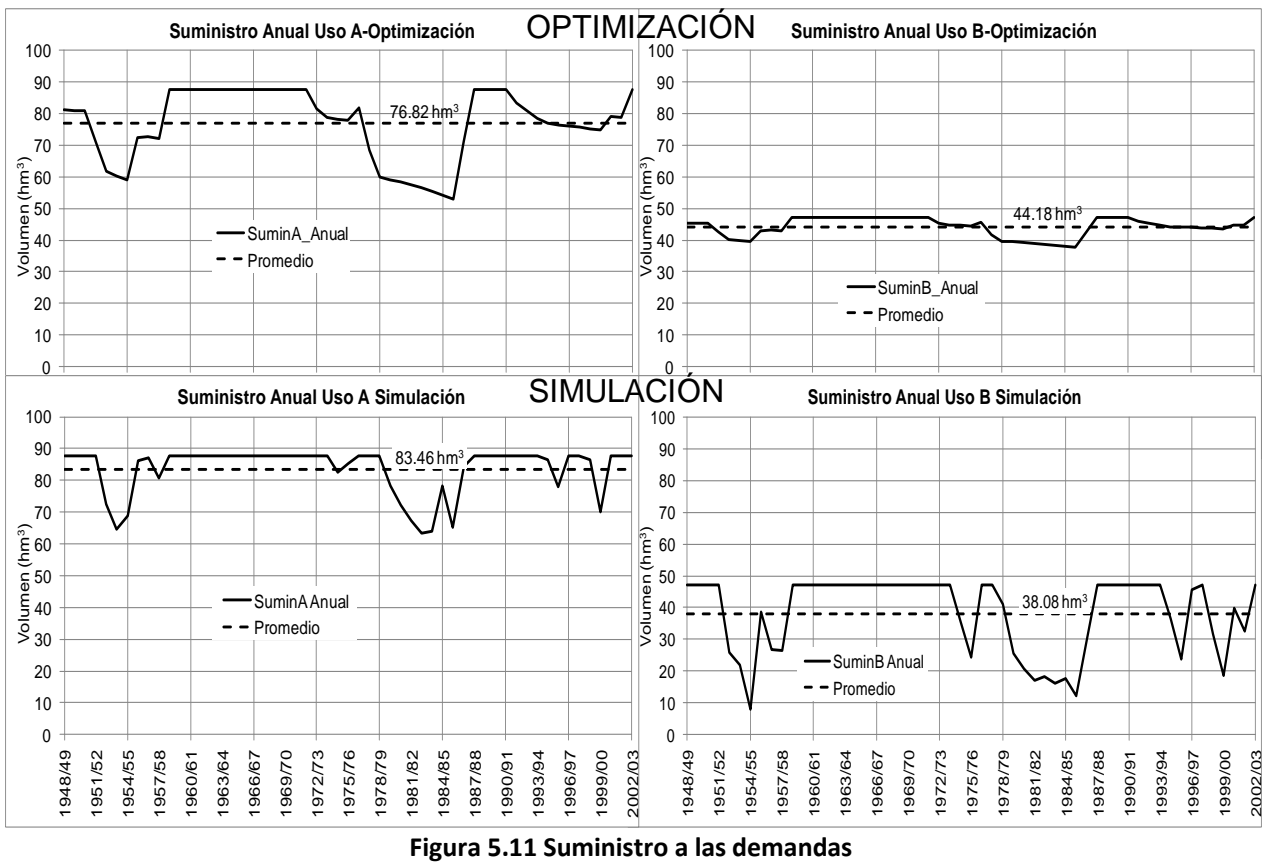

El modelo de optimización reduce el déficit de suministro en el uso $B$, como puede observarse en la figura 5.12. En el modelo de optimización, aunque disminuyen los valores máximos de déficit en el uso $A$, aumenta mucho la frecuencia de los mismos, y también el valor total (ver déficit medio, Tabla 5.1), ya que destina más recursos al uso $B$, que produce mayores beneficios.

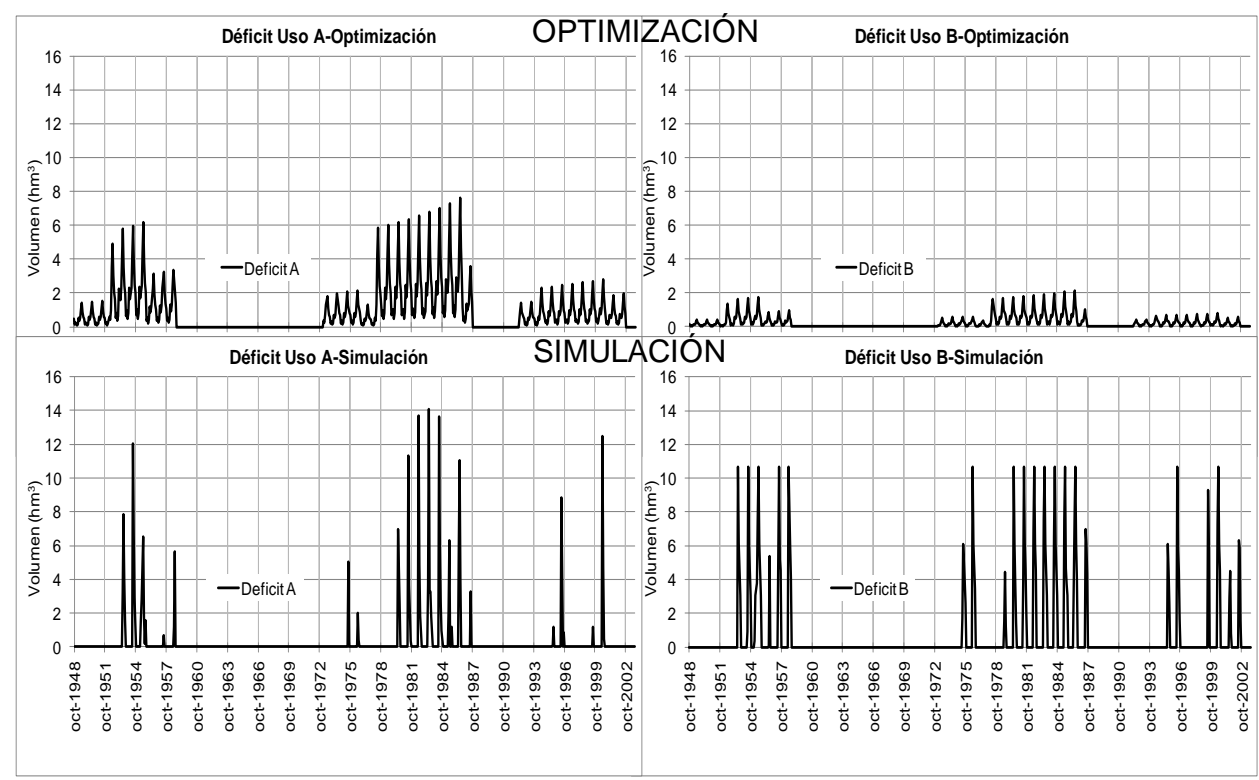

Figura 5.12. Déficit de suministro a la demanda 
El modelo de optimización proporciona mayor beneficio económico total ya que reasigna agua del uso $A$ al uso $B$ (uso de mayor valor), como se resume en la tabla 5.1. En el incremento de beneficio hay también una cierta componente atribuible a la gestión óptima del sistema con perfecta anticipación frente a los episodios de sequía, lo que permite disminuir significativamente los coste de escasez en esos períodos (el coste de escasez aumenta de forma no lineal con el déficit de suministro).

Tabla 5.1 Beneficios y déficits medios anuales

\begin{tabular}{|c|c|c|c|c|c|}
\hline Metodología & $\begin{array}{c}\text { Benef A } \\
\text { (M€/año) }\end{array}$ & $\begin{array}{c}\text { Benef B } \\
\text { (M€/año) }\end{array}$ & $\begin{array}{c}\text { Beneficio } \\
\text { Medio Anual } \\
\text { (M€/año) }\end{array}$ & $\begin{array}{c}\text { Déficit } \\
\text { medio A } \\
\text { (hm }^{\mathbf{3}} \text { ) }\end{array}$ & $\begin{array}{c}\text { Déficit } \\
\text { medio B } \\
\text { (hm }^{\mathbf{3}} \text { ) }\end{array}$ \\
\hline Optimización & 25,49 & 28,05 & 53,54 & 0,91 & 0,25 \\
\hline Simulación & 26,05 & 25,38 & 51,43 & 0,35 & 0,75 \\
\hline
\end{tabular}

\subsubsection{CMOR. Simulación y optimización}

Con el fin de poder definir políticas de precios acorde con lo descrito en los parágrafos anteriores, se estimó el coste marginal de oportunidad del recurso (CMOR) en el embalse tanto en el modelo de simulación como en el de optimización.

Para determinar el CMOR en el embalse se emplearon las curvas de demanda económica mostrada en la figura 5.9 con los caudales de suministros proporcionados por los modelos de simulación y la optimización, y las respectivas metodologías descritas en el capítulo 4. En la figura 5.13 se observa que, en consonancia con lo esperado según la teoría económica, el mayor valor marginal corresponde al periodo en el que hay menos reservas en los embalses, y por tanto, más escasez del recurso. En los períodos de CMOR alto los déficits en las demandas y por consiguiente los costes de escasez y la disposición marginal a pagar son elevados. Cuando los volúmenes embalsados son altos, no hay déficit de suministro y por tanto el valor marginal del agua en el embalse es nulo (el disponer de una unidad más no aporta ningún beneficio adicional para el sistema). 


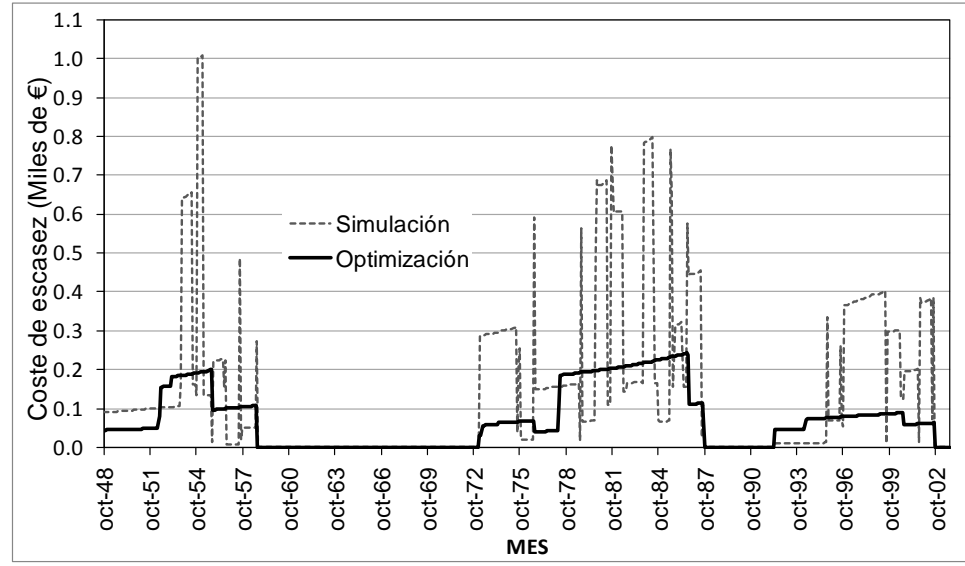

Figura 5.13 Coste de escasez mensual

Como las pérdidas económicas (coste de escasez) no son lineales con el déficit (ecuaciones cuadráticas de pérdidas), la optimización consigue mejores resultados económicos para el uso B (mejora en un $4 \%$ el beneficio medio anual, tabla 5.1) disminuyendo su déficit (del orden de un 30\%). La operación del embalse (figura 5.14) en el esquema óptimo permite conservar más agua para los períodos de sequía más significativos (52-58; 78-87), reduciendo significativamente el coste de escasez (figura 5.13). De esta forma en el modelo de optimización se hace una gestión del embalse con anticipación económicamente óptima frente a los periodos de sequía. Este resultado se ve favorecido por la predicción perfecta del modelo de optimización , como han estudiado diversos autores (Labadie, 1997; Draper y Lund, 2004).

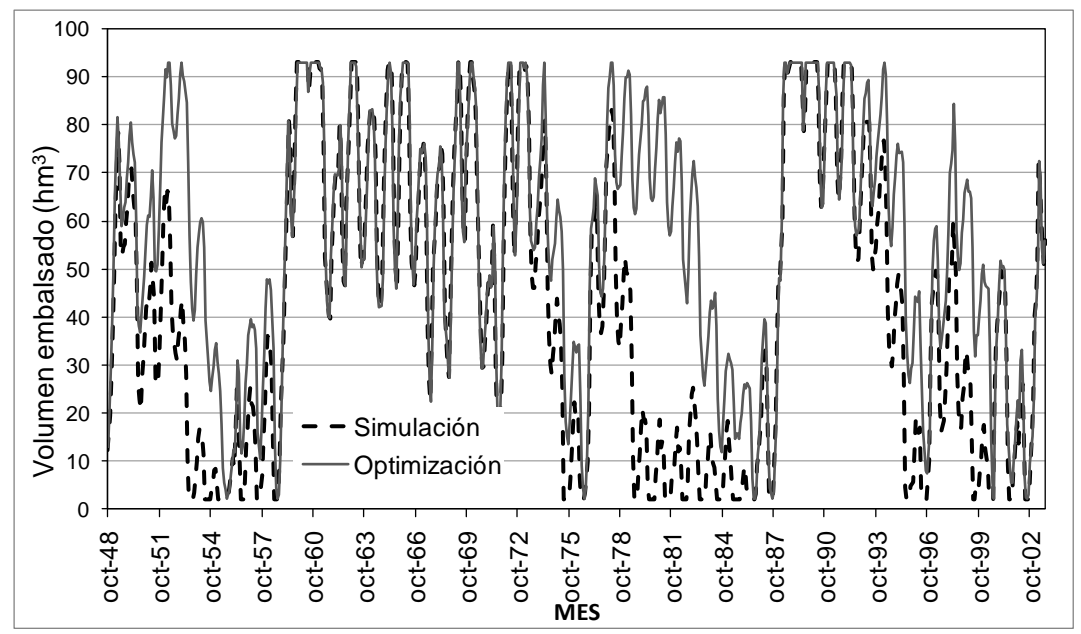

Figura 5.14 Series mensuales de volumen embalsado

El CMOR, base para definir las políticas de precios, presenta una gran dispersión en relación con los volúmenes embalsados (figura 5.15). Los resultados del CMOR del modelo 
de optimización muestran una clara separación de los costes marginales en dos poblaciones, una con valores entre 0 y $0,15 € / \mathrm{m}^{3}$ y otra entre 0,15 y $0,25 € / \mathrm{m}^{3}$.
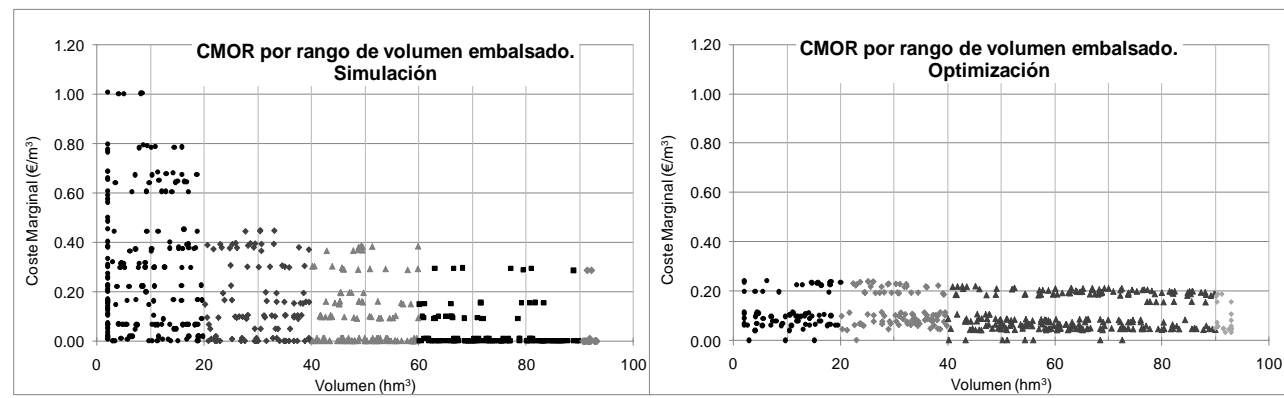

Figura 5.15. CMOR por rango de volumen embalsado. Simulación y optimización

\subsection{Políticas de precios.}

En los parágrafos siguientes se analizan diversas formas de definir políticas de precios a partir de los valores del CMOR en el embalse del sistema obtenidos con los modelos hidroeconómicos de simulación y optimización. Las distintas formulaciones de las políticas de precios se aplican al caso sintético descrito en los apartados anteriores y se comparan los beneficios totales obtenidos con cada una de ellas.

\subsubsection{Políticas de precios escalonados en función del volumen almacenado}

A partir de los valores de CMOR obtenidos en la optimización y la simulación se definen políticas de precios escalonados en función del volumen embalsado y, posteriormente, se simulan estas políticas de precios actuando como nuevas "reglas de gestión" en el modelo de simulación. Esto se consigue mediante el uso de las funciones de demanda de cada uso, entrando con el precio y obteniendo el grado de suministro correspondiente, que se traduce en un coeficiente de restricción sobre la demanda máxima.

Para la definición de la función de precios escalonada, se obtienen los valores medios del CMOR correspondientes a simulación y optimización, para diferentes rangos de volúmenes embalsados, obteniéndose las políticas de precios mostradas en la figura 5.16. 


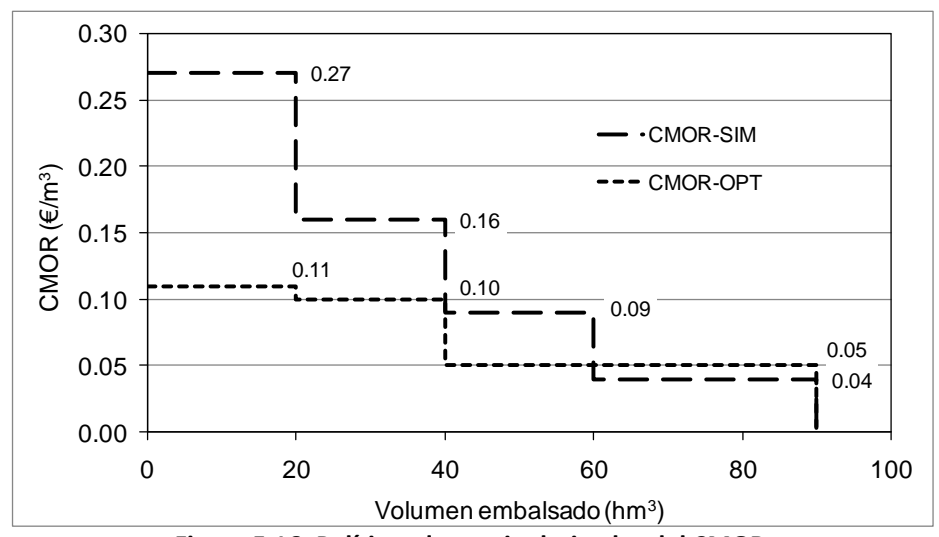

Figura 5.16. Políticas de precio derivadas del CMOR

A continuación se analizan los resultados de las políticas de precios a partir de los valores del CMOR mensuales promedio para distintos rangos de volúmenes embalsados, tanto para el modelo de simulación como para el de optimización.

Precios escalonados a partir de CMOR de simulación. Se consideran las políticas de precios indicadas en la figura 5.16, y se incorporan al modelo de simulación en forma de restricciones de suministro a las demandas del sistema en función del estado del embalse mediante indicadores de alarma (apartado 5.1). Dicho factor de restricción se calcula con base en la curva de demanda económica del uso correspondiente.

Como puede verse en la figura 5.17, al aplicar la política de precios del CMOR de la propia simulación el sistema penaliza al uso A y proporciona mayor recurso al uso $\mathrm{B}$, con mayores beneficios netos por unidad (compárese con figura 5.11). La simple aplicación de una política de precios escalonada en función del volumen embalsado definida a partir de los CMOR de simulación consigue aproximarse bastante al óptimo económico dado por la optimización. 


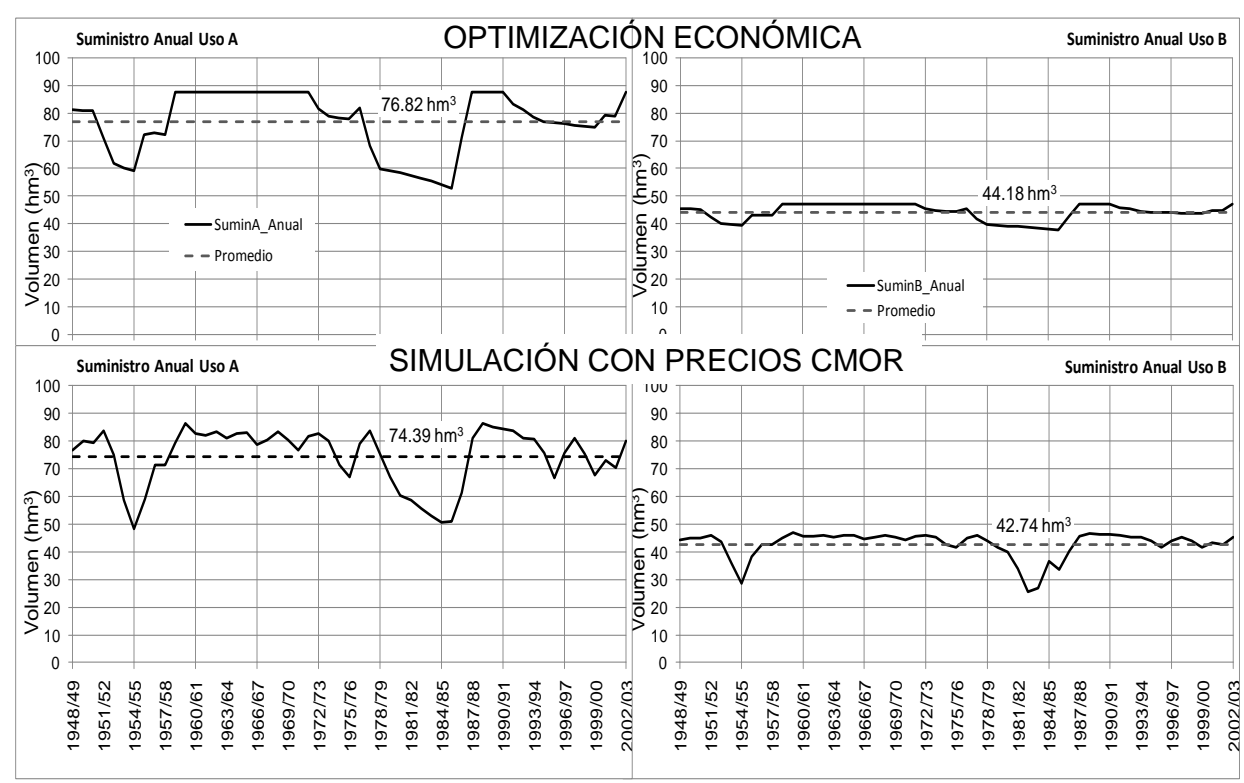

Figura 5.17. Suministro a las demandas. Precios escalonados CMOR de simulación

En la figura 5.18 puede observarse que el uso $B$ es el que mayores beneficios proporciona aunque el beneficio en el uso $A$ es un poco menor que el obtenido con la simulación con prioridades, los beneficios medios totales son mayores al aplicar la política de precios derivada del CMOR de simulación, acercándose mucho a los obtenidos con la optimización económica (tabla 5.2).

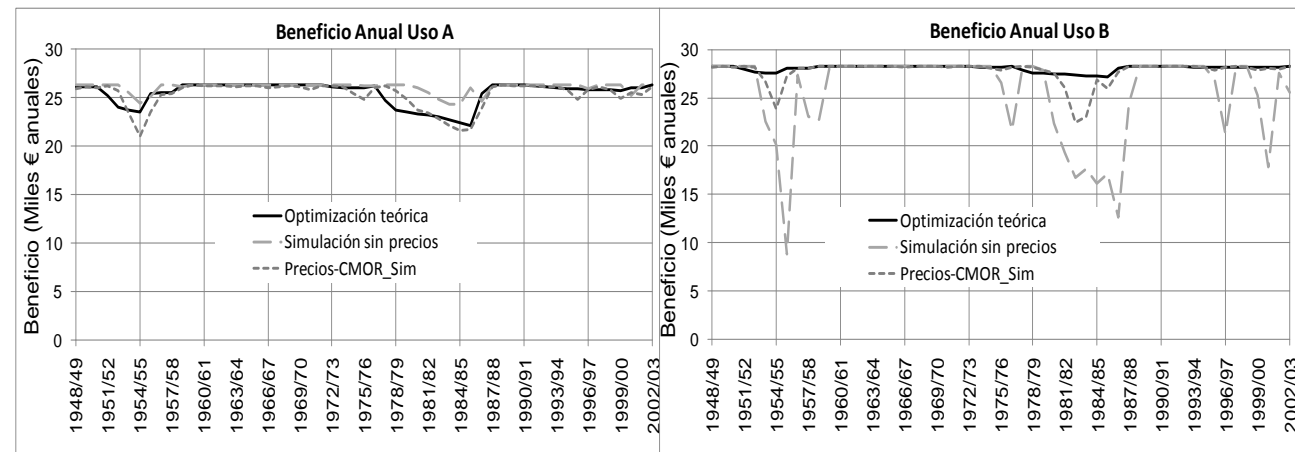

Figura 5.18. Beneficios Anuales. Precios con CMOR de simulación 
Tabla 5.2 Beneficios medios anuales por metodologías. Caso sintético

\begin{tabular}{|l|c|c|c|c|}
\hline \multicolumn{1}{|c|}{ METODOLOGÍA } & $\begin{array}{c}\text { Benef A } \\
\text { (M€/año) }\end{array}$ & $\begin{array}{c}\text { Benef B } \\
\text { (M€/año) }\end{array}$ & $\begin{array}{c}\text { Beneficio } \\
\text { Medio Anual } \\
\text { (M€/año) }\end{array}$ & $\begin{array}{c}\text { Beneficio Total } \\
\text { (M€) }\end{array}$ \\
\hline Optimización teórica & 25,49 & 28,05 & 53,54 & 2944,74 \\
\hline Simulación con prioridades & 26,05 & 25,38 & 51,43 & 2828,53 \\
\hline PRECIOS ESCALONADOS: & & & & \\
\hline Precios CMOR-Sim-Función volumen & 25,34 & 27,73 & 53,07 & 2918,75 \\
\hline
\end{tabular}

Precios escalonados a partir de CMOR de optimización. Al simular la política de precios obtenida a partir de los CMOR promedio de optimización para distintos rangos de volumen embalsado (figura 5.16), los suministros promedio son menores que los que proporciona el modelo de simulación con prioridades, penalizándose también el uso A (figura 5.19). Sin embargo, en este caso se obtuvieron menores beneficios medios/totales que en la simulación de precios a partir del CMOR de la simulación (figura 5.20, tabla 5.3).

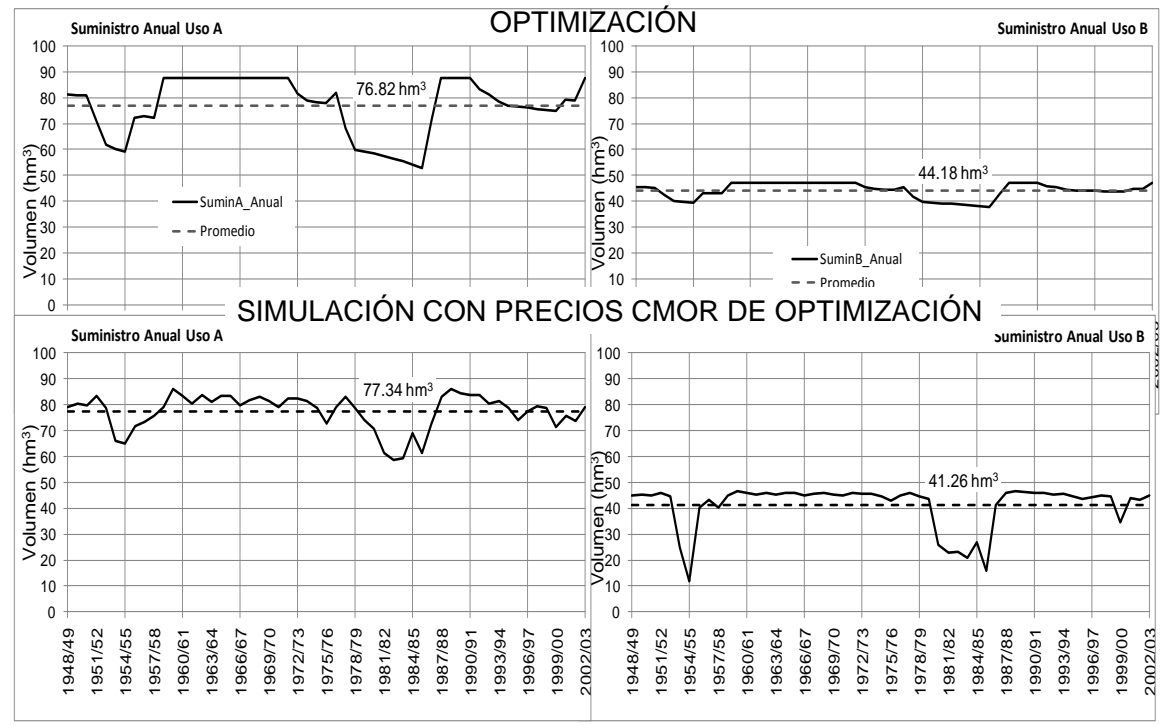

Figura 5.19. Suministro a las demandas. Precios escalonados, CMOR de la optimización 


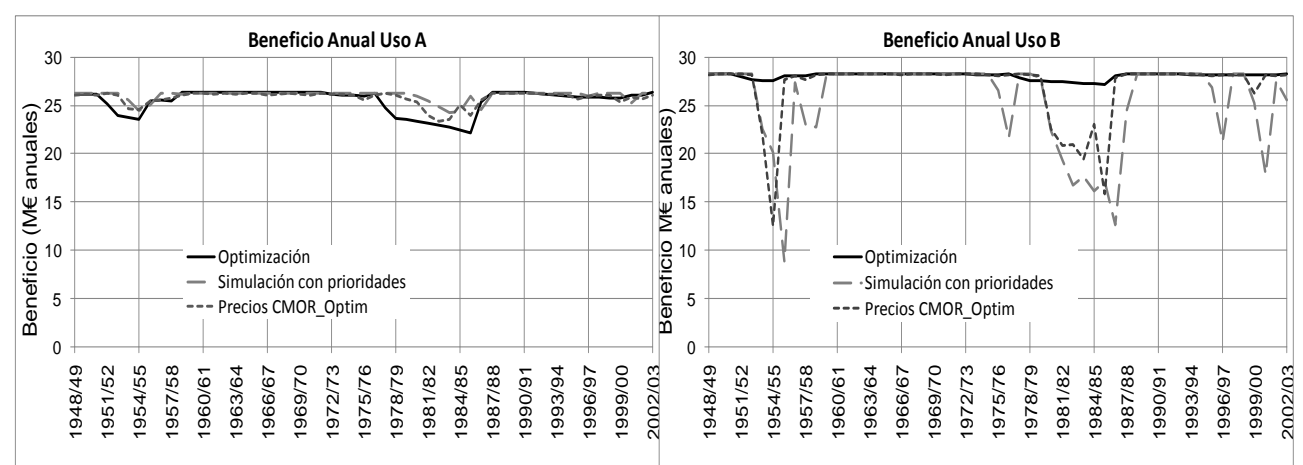

Figura 5.20. Beneficios anuales. Precios con CMOR de la optimización

Tabla 5.3 Beneficios medios anuales por metodologías. Caso sintético

\begin{tabular}{|l|c|c|c|c|}
\hline \multicolumn{1}{|c|}{ METODOLOGíA } & $\begin{array}{c}\text { Benef A } \\
\text { (M€/año) }\end{array}$ & $\begin{array}{c}\text { Benef B } \\
\text { (M€/año) }\end{array}$ & $\begin{array}{c}\text { Beneficio } \\
\text { Medio Anual } \\
\text { (M€/año) }\end{array}$ & $\begin{array}{c}\text { Beneficio } \\
\text { Total } \\
\text { (M€) }\end{array}$ \\
\hline Optimización teórica & 25,49 & 28,05 & 53,54 & 2944,74 \\
\hline Simulación con prioridades & 26,05 & 25,38 & 51,43 & 2828,53 \\
\hline PRECiOS ESCALONADOS: & & & & \\
\hline Precios CMOR-Sim-Función volumen & 25,34 & 27,73 & 53,07 & 2918,75 \\
\hline Precios CMOR-Opt-Función volumen & 25,78 & 26,90 & 52,68 & 2897,40 \\
\hline
\end{tabular}

Precios escalonados óptimos. A continuación se analiza la posibilidad de mejorar la política de precios optimizando los valores de los precios para los distintos escalones de forma que los beneficios económicos sean máximos al aplicarla en el modelo de simulación (optimización de los precios de la función escalonada). Para ello, los escalones de la función de precios se optimizaron con la herramienta solver de Excel, partiendo de los valores iniciales proporcionados por la política de precios de los apartados anteriores. La función objetivo es la suma de los beneficios totales para los dos usos, sujeta a que los precios unitarios sean mayores para los rangos más bajos de volumen almacenado en el embalse. La política de precios "óptima" resultante se muestra en la figura 5.21 con línea continua. Se observa que la política "óptima" es más similar en este caso a la política de precios a partir del CMOR de simulación que a la derivada de los valores marginales de optimización, lo que corrobora los mejores resultados económicos obtenidos con la primera. 


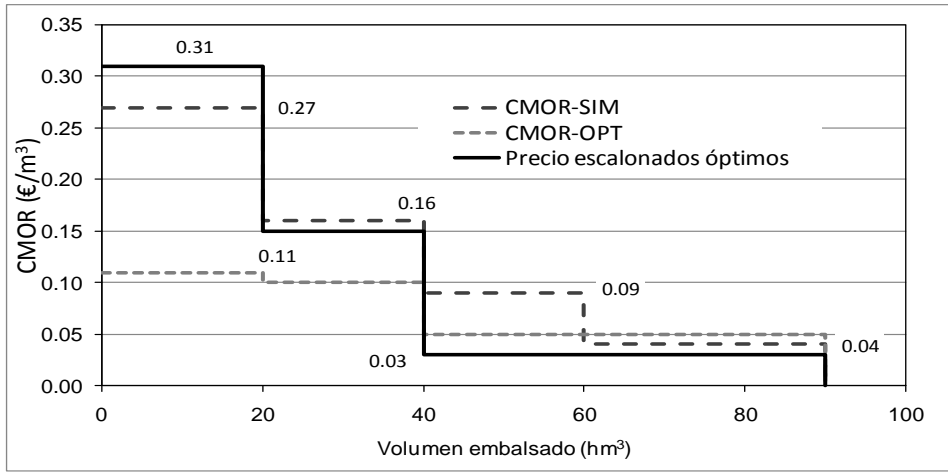

Figura 5.21. Política de precios escalonados óptimos

Al aplicar la política de precios escalonados óptimos las series temporales de suministros para ambos usos se aproximan a las obtenidas con el modelo de optimización (figura 5.22) y por ende los beneficios anuales también (figura 5.23, tabla 5.4).

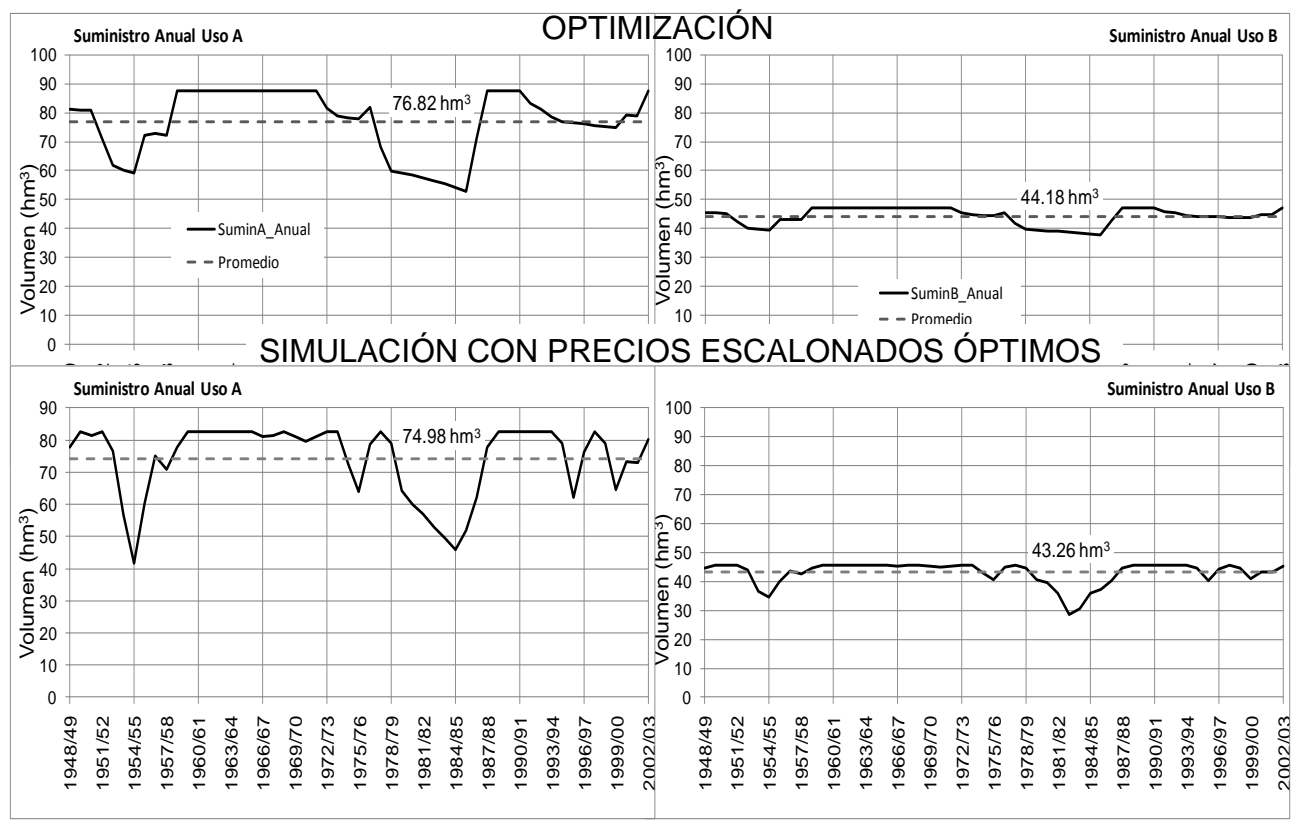

Figura 5.22. Suministro a las demandas. Precios escalonados óptimos 


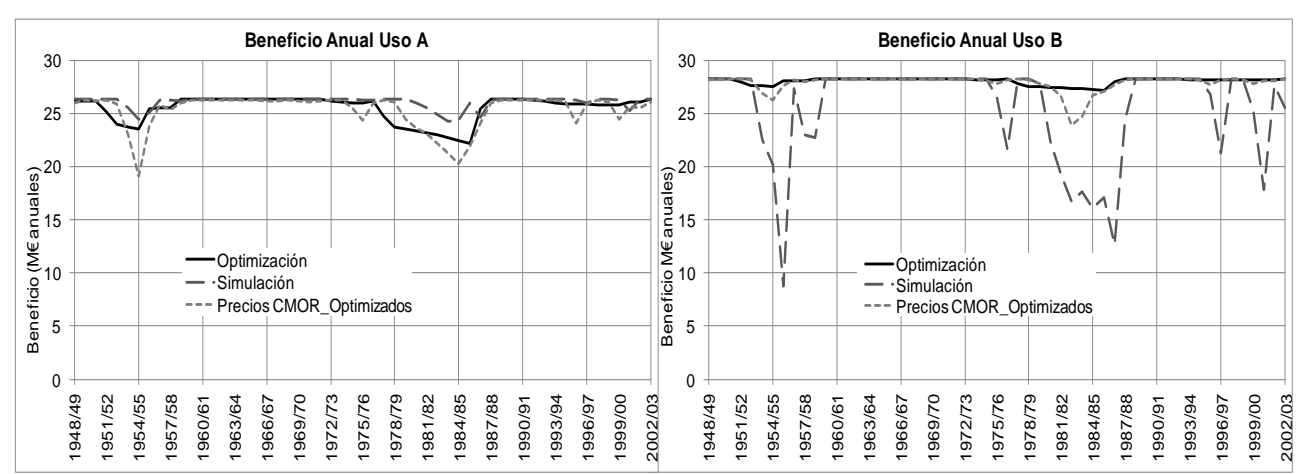

Figura 5.23. Beneficios anuales. Precios escalonados, CMOR de la simulación, óptimos

Tabla 5.4 Beneficios medios anuales por metodologías. Caso sintético

\begin{tabular}{|l|c|c|c|c|}
\hline \multicolumn{1}{|c|}{ METODOLOGÍA } & $\begin{array}{c}\text { Benef A } \\
\text { (M€/año) }\end{array}$ & $\begin{array}{c}\text { Benef B } \\
\text { (M€/año) }\end{array}$ & $\begin{array}{c}\text { Beneficio } \\
\text { Medio Anual } \\
\text { (M€/año) }\end{array}$ & $\begin{array}{c}\text { Beneficio } \\
\text { Total } \\
\text { (M€) }\end{array}$ \\
\hline Optimización teórica & 25,49 & 28,05 & 53,54 & 2944,74 \\
\hline Simulación con prioridades & 26,05 & 25,38 & 51,43 & 2828,53 \\
\hline PRECIOS ESCALONADOS: & & & & \\
\hline Precios CMOR-Sim-Función volumen & 25,34 & 27,73 & 53,07 & 2918,75 \\
\hline Precios CMOR-Opt-Función volumen & 25,78 & 26,90 & 52,68 & 2897,40 \\
\hline Precios escalonados óptimos & 25,24 & 27,87 & 53,11 & 2921,07 \\
\hline
\end{tabular}

\subsubsection{Precios escalonados según umbrales de aportaciones.}

Aunque como se ha indicado en parágrafos anteriores, el CMOR depende del volumen disponible en el embalse, se pueden encontrar valores del CMOR distintos para el mismo volumen de embalse, dependiendo de la situación futura de llenado o vaciado del mismo, y por tanto, de la situación hidrológica de abundancia o de sequía. Para contemplar este aspecto, se han considerado también las aportaciones anuales al sistema para la definición de precios escalonados a partir del CMOR obtenido con la optimización. Las aportaciones juegan un papel importante ya que, junto con el volumen embalsado, definen las sequías que se presentan en el periodo de análisis. Los periodos de sequía hacen que aumente el valor marginal del recurso. La función escalonada de preciosvolumen almacenado puede definirse entonces como una función también dependiente de umbrales de aportaciones anuales (figura 5.7) que ingresen al sistema.

Con la serie de aportaciones al sistema, se realizó un análisis de las sequías presentes, aplicando la teoría de sucesiones o rachas (Yevjevich, 1967; Dracup et al., 1980). Se observó que se presentan diez sequías durante el periodo de 55 años (figura 5.21) tomando como umbral para la definición de sequías la aportación media anual. Se observa 
que la duración media de las sequías es de 3,1 años (con desviación típica de 2,6). Por tanto, la mayoría de los episodios de sequías son multianuales, lo que en principio corresponde a una serie anual de aportaciones con significativa dependencia temporal. La media de la magnitud de las sequías es $97 \mathrm{hm}^{3}$, por lo cual se ha tomado un valor de 100 $\mathrm{hm}^{3}$ como el umbral inferior para definir rangos de aportaciones y sus correspondientes valores medios de CMOR. Se definieron dos rangos más: uno intermedio entre 100 y 120 $\mathrm{hm}^{3}$ y otro superior a $120 \mathrm{hm}^{3}$.

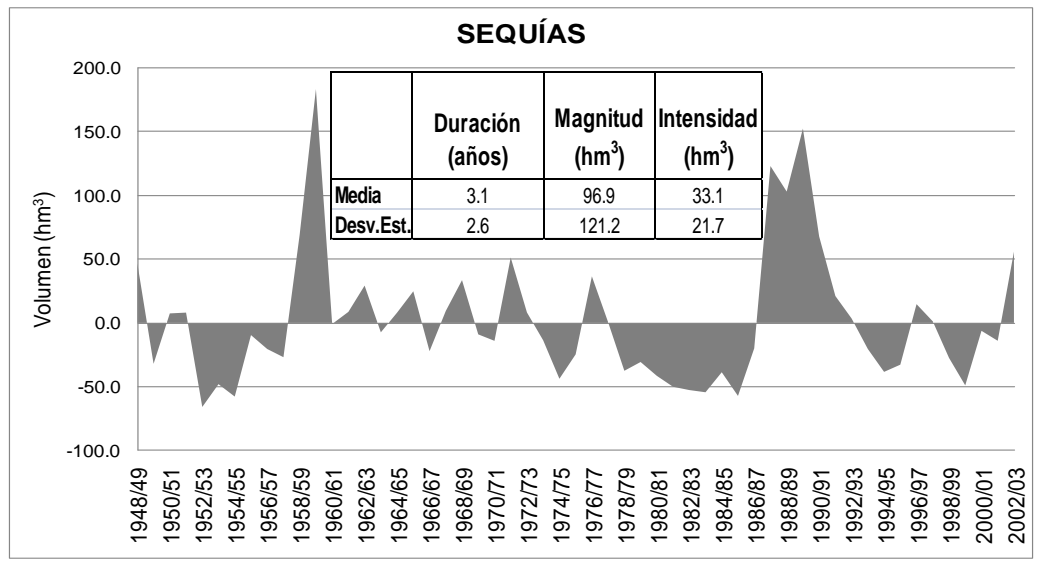

Figura 5.24. Sequías para el Caso sintético (con umbral igual a aportación media)

Para los rangos de aportaciones indicados, se definió una política de precios (figura 5.25) a partir de los valores promedio de los CMOR de embalse para los meses en que la aportación se situase en ese umbral.

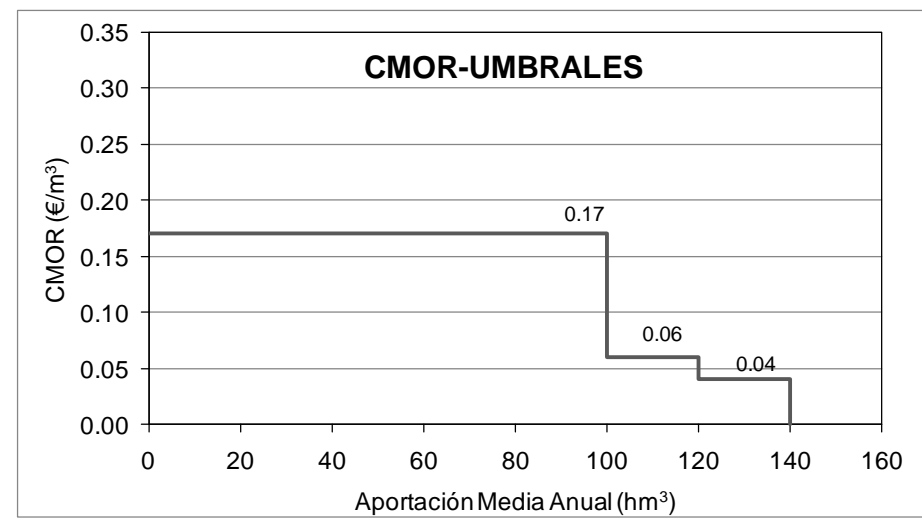

Figura 5.25. Política de precios para umbrales de aportaciones

Para el caso de los umbrales de aportaciones, los suministros de agua a las demandas fueron inferiores al caso anterior. El suministro al uso A se sigue penalizando y el suministro al uso B es mayor que en el caso del modelo de simulación (figura 5.26). Con todo, los beneficios económicos al aplicar este tipo de políticas, aunque superiores al caso 
de la simulación con prioridades, son inferiores al de las políticas de precios escalonados basados en el CMOR de simulación (figura 5.27, tabla 5.5).

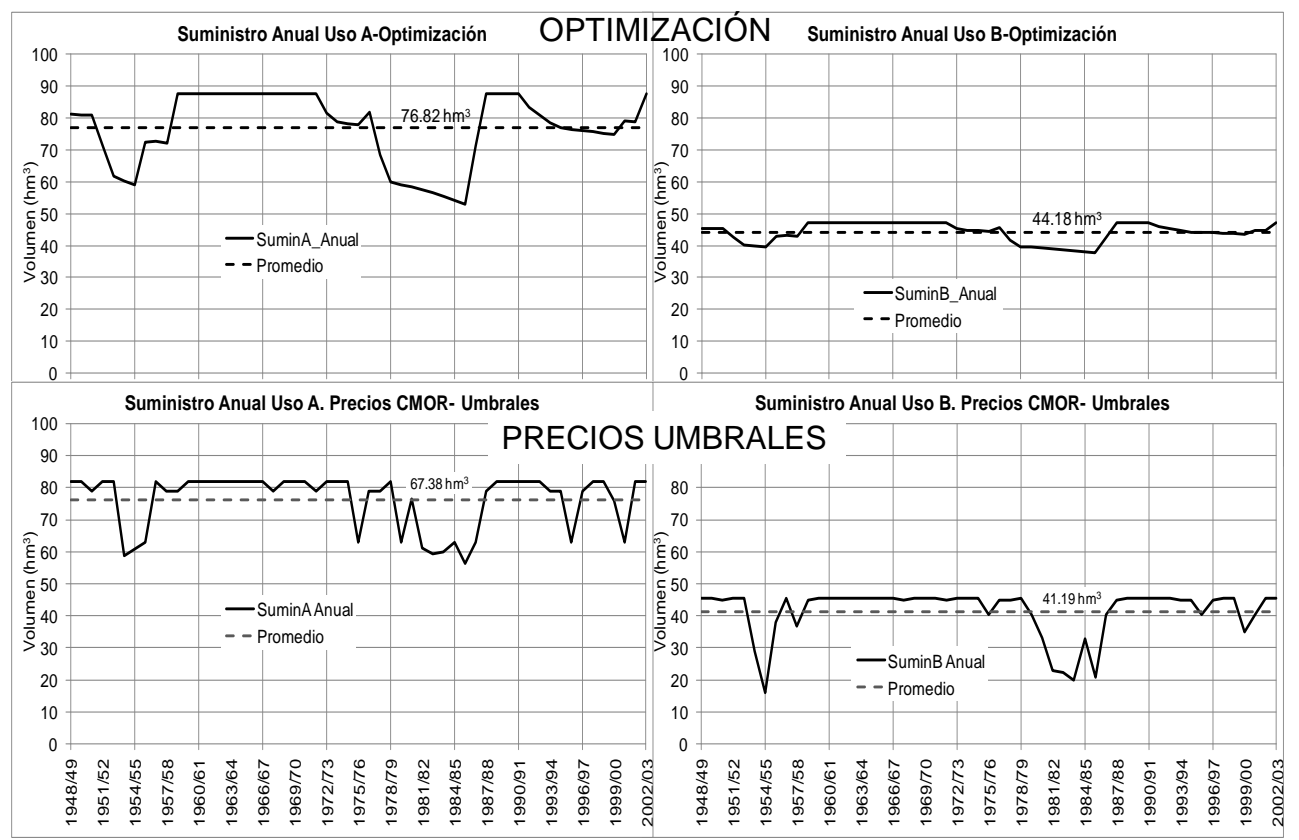

Figura 5.26. Suministro a las demandas. Precios escalonados, CMOR de la simulación, umbrales

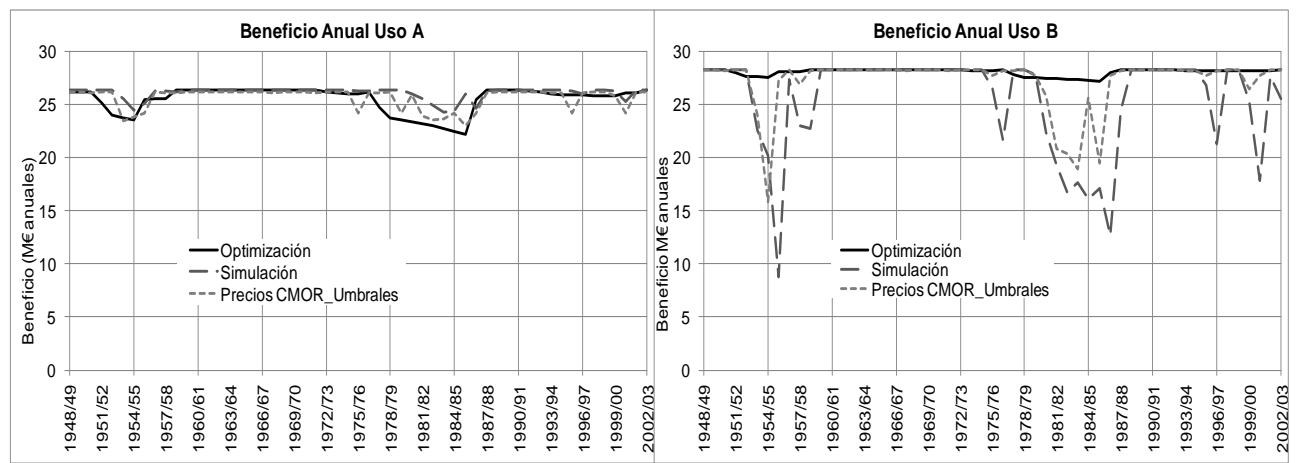

Figura 5.27. Beneficios anuales. Precios escalonados. CMOR de simulación 
Tabla 5.5 Beneficios medios anuales por metodologías. Caso sintético

\begin{tabular}{|l|c|c|c|c|}
\hline \multicolumn{1}{|c|}{ METODOLOGÍA } & $\begin{array}{c}\text { Benef A } \\
\text { (M€/año) }\end{array}$ & $\begin{array}{c}\text { Benef B } \\
\text { (M€/año) }\end{array}$ & $\begin{array}{c}\text { Beneficio } \\
\text { Medio Anual } \\
\text { (M€/año) }\end{array}$ & $\begin{array}{c}\text { Beneficio } \\
\text { Total } \\
\text { (M€) }\end{array}$ \\
\hline Optimización teórica & 25,49 & 28,05 & 53,54 & 2944,74 \\
\hline Simulación con prioridades & 26,05 & 25,38 & 51,43 & 2828,53 \\
\hline PRECiOS ESCALONADOS: & & & & \\
\hline Precios CMOR-Sim-Función volumen & 25,34 & 27,73 & 53,07 & 2918,75 \\
\hline Precios CMOR-Opt-Función volumen & 25,78 & 26,90 & 52,68 & 2897,40 \\
\hline Precios escalonados óptimos & 25,24 & 27,87 & 53,11 & 2921,07 \\
\hline $\begin{array}{l}\text { Precios CMOR-Función de } \\
\text { aportaciones previas }\end{array}$ & 25,60 & 27,11 & 52,71 & 2899,19 \\
\hline
\end{tabular}

\subsubsection{Precios anuales constantes en función del volumen embalsado y aportaciones previas}

Como ya se ha mencionado, no sólo las reservas sino también las aportaciones juegan un papel importante decisivo en la evolución del valor marginal del recurso en el tiempo. De hecho, la información proporcionada por las aportaciones previas y el estado de las reservas del sistema pueden servir de elemento de predicción de caudales futuros, y por tanto, de eventuales sequías para hacer una gestión eficiente con anticipación a las mismas (Salas et al., 1980; Ochoa-Rivera et al., 2007).

Para tener esto en cuenta en el diseño de la política de precios, los escalones de precios pueden hacerse depender de las aportaciones anuales del primero y/o segundo años anteriores al año de análisis y el volumen embalsado que sea significativo para el ajuste y mejor representación del CMOR.

Las consideraciones mencionadas en el párrafo anterior se han hecho para los valores obtenidos del CMOR con los modelos de simulación y de optimización, siendo la función de ajuste de precios la siguiente:

$$
p=a+b \cdot V_{o c t}+c \cdot A p_{a \tilde{n} o(t-1)}+d \cdot\left(A p_{a \tilde{n} o(t-1)}+A p_{a \tilde{n} o(t-2)}\right)
$$

donde:
$p \quad$ Precio del agua.
$V_{\text {oct }} \quad$ Volumen almacenado al inicio del mes de octubre. 
$A p_{a \tilde{n} o(t-1)}$ Aportación anual del año anterior.

$A p_{a \tilde{n} o(t-2)} \quad$ Aportación anual del año antepasado.

$a, b, c, d \quad$ Coeficientes de ajuste.

El análisis de sequías (figura 5.24) y el estudio de la dependencia temporal de las series de aportaciones (presentado en un apartado posterior, 5.3.5) permite decidir sobre la conveniencia de considerar las aportaciones sólo del año anterior o incluir las de varios años atrás. La expresión 5.2 corresponde a un precio que depende tanto de aportaciones anuales anteriores como del volumen embalsado; en este caso se ha seleccionado el del mes de octubre como representativo, que es el volumen de embalse al comienzo de la campaña de riego. Al analizar los volúmenes almacenados en el embalse, claramente se observa que es en los meses de octubre cuando comienza a llenarse de nuevo el embalse tras las demandas mayores del período de verano, por lo que se presenta un valor de CMOR que concuerda con el poco volumen almacenado (figura 5.28).

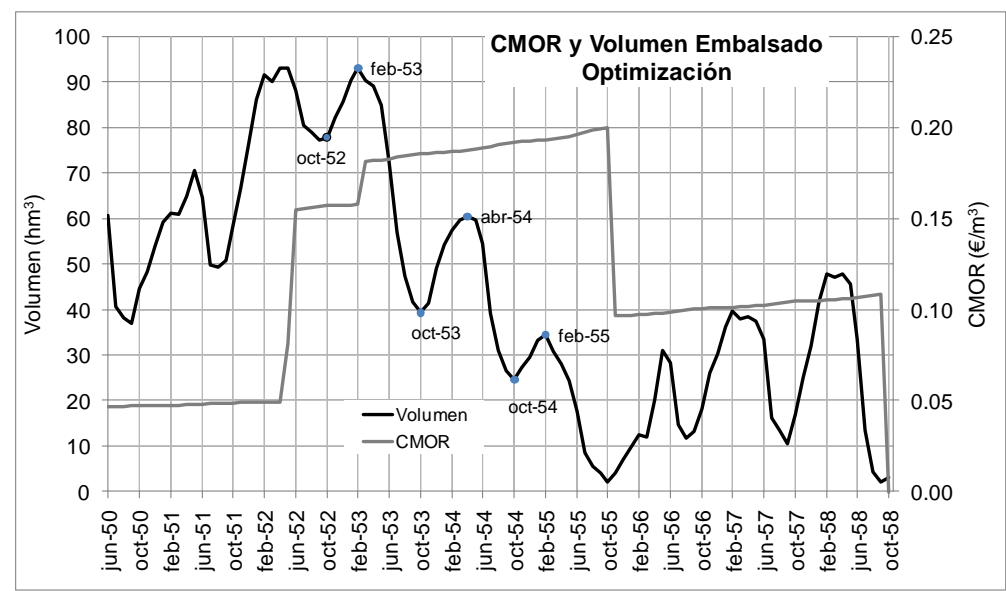

Figura 5.28. CMOR (valor sombra) de la optimización teórica y volumen embalsado

Los parámetros de la ecuación 5.2 se calibraron para ajustar en lo posible los valores de la serie de CMOR de optimización. En la figura 5.29 se observa que los valores de la función de precios obtenidos aproximan bien en general la evolución en el tiempo de los CMOR de optimización, con la excepción del periodo 1959-1972 en el que la variabilidad del CMOR no es adecuadamente capturada por la función de precios. La función de precios dependiente de reservas y aportaciones previas, se traduce en una regla de operación en el embalse mediante el factor de suministro a las demandas en los usos $A$ y B, el cual se utiliza para corregir las curvas de demanda en ambos usos. Dicha corrección permite obtener los coeficientes de restricción al suministro del recurso para los dos usos en el caso sintético para evaluar los beneficios al aplicar esta política de precios. 


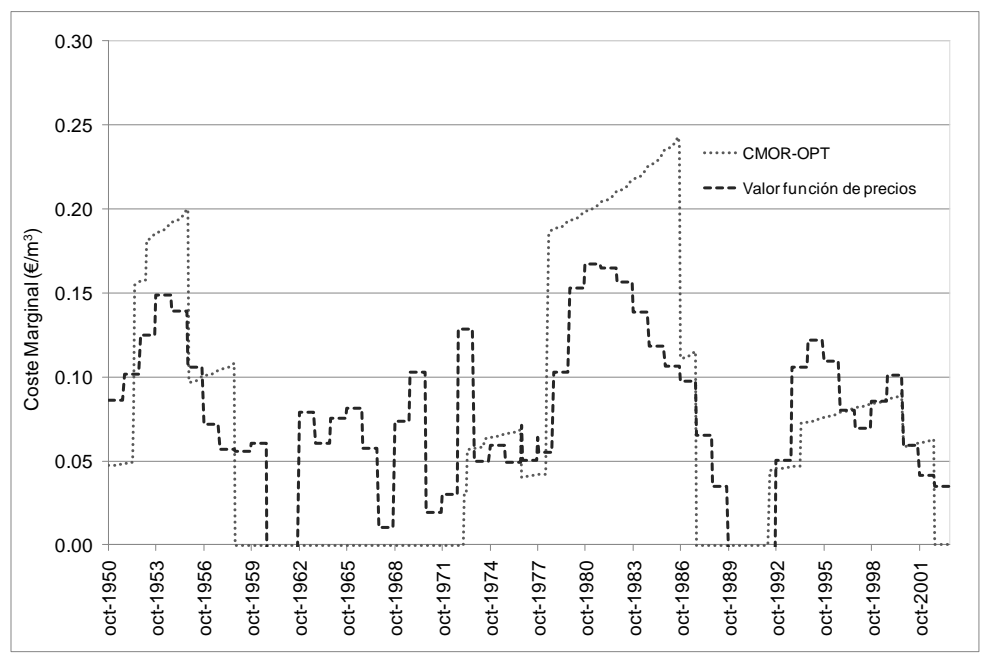

Figura 5.29. Comparativa CMOR de optimización y valores de la función de precios

La expresión 5.2 se utilizó para definir la serie de precios del agua, constante para cada año en función del volumen al inicio del año hidrológico y las aportaciones anuales en los dos años previos. La figura 5.30 representa la serie temporal de precios y volumen de embalse en el período analizado. Los resultados muestran que, a pesar de la ventaja práctica que supone definir un precio constante para todo el año al principio del año y la mayor seguridad que eso proporcionaría a los usuarios en sus decisiones, los beneficios obtenidos en este caso particular no son tan buenos como los correspondientes a una política escalonada de precios (figura 5.31, tabla 5.6).

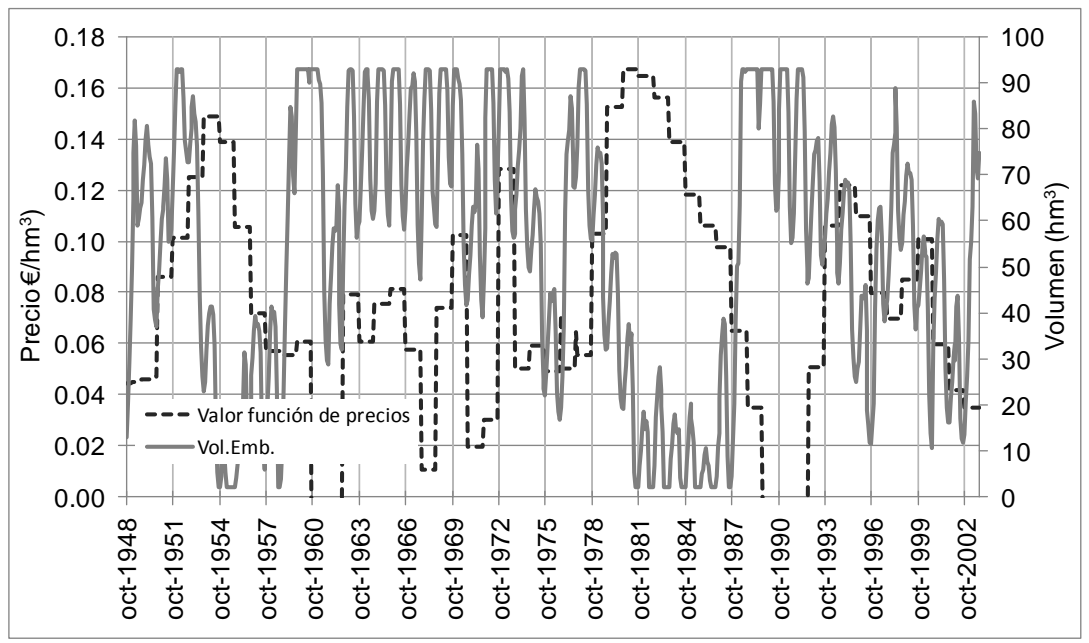

Figura 5.30. Volumen mensual y valores de la función de precios (ctes. para cada año) 


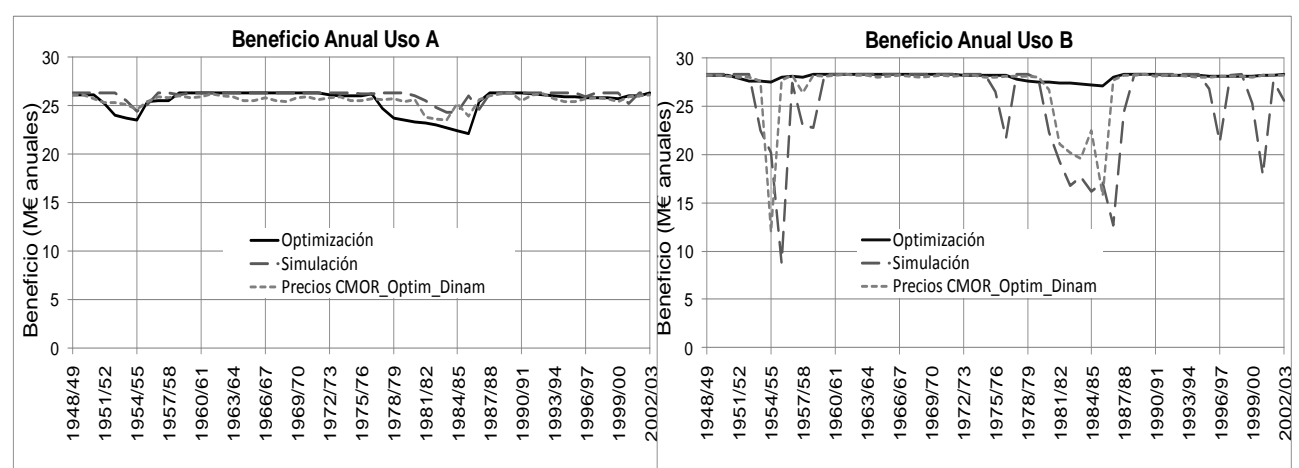

Figura 5.31. Beneficios anuales. Precios utilizando el CMOR de la optimización teórica y aportaciones previas

Tabla 5.6 Beneficios medios anuales por metodologías. Caso sintético
\begin{tabular}{|l|c|c|c|c|}
\hline \multicolumn{1}{|c|}{ METODOLOGÍA } & $\begin{array}{c}\text { Benef A } \\
\text { (M€/año) }\end{array}$ & $\begin{array}{c}\text { Benef B } \\
\text { (M€/año) }\end{array}$ & $\begin{array}{c}\text { Beneficio } \\
\text { Medio Anual } \\
\text { (M€/año) }\end{array}$ & $\begin{array}{c}\text { Beneficio } \\
\text { Total } \\
\text { (M€) }\end{array}$ \\
\hline Optimización teórica & 25,49 & 28,05 & 53,54 & 2944,74 \\
\hline Simulación con prioridades & 26,05 & 25,38 & 51,43 & 2828,53 \\
\hline PRECIOS ESCALONADOS: & & & & \\
\hline Precios CMOR-Sim-Función volumen & 25,34 & 27,73 & 53,07 & 2918,75 \\
\hline Precios CMOR-Opt-Función volumen & 25,78 & 26,90 & 52,68 & 2897,40 \\
\hline Precios escalonados óptimos & 25,24 & 27,87 & 53,11 & 2921,07 \\
\hline $\begin{array}{l}\text { Precios CMOR-Función de } \\
\text { aportaciones previas }\end{array}$ & 25,60 & 27,11 & 52,71 & 2899,19 \\
\hline $\begin{array}{l}\text { PRECIOS FUNCIÓN DE VOLUMEN Y } \\
\text { APORTACIONES PREVIAS }\end{array}$ & & & & \\
\hline $\begin{array}{l}\text { Precios CMOR-Opt-Función volumen } \\
\text { y aportaciones previas }\end{array}$ & 25,60 & 27,01 & 52,61 & 2893,31 \\
\hline
\end{tabular}

Finalmente se calibraron los parámetros de la expresión 5.2 para ajustar los valores del CMOR de simulación. Los resultados muestran unos beneficios mucho menores a los anteriores, aunque mayores a los obtenidos con la simulación sin política de precios (figura 5.32 y 5.33 ; tabla 5.7). 


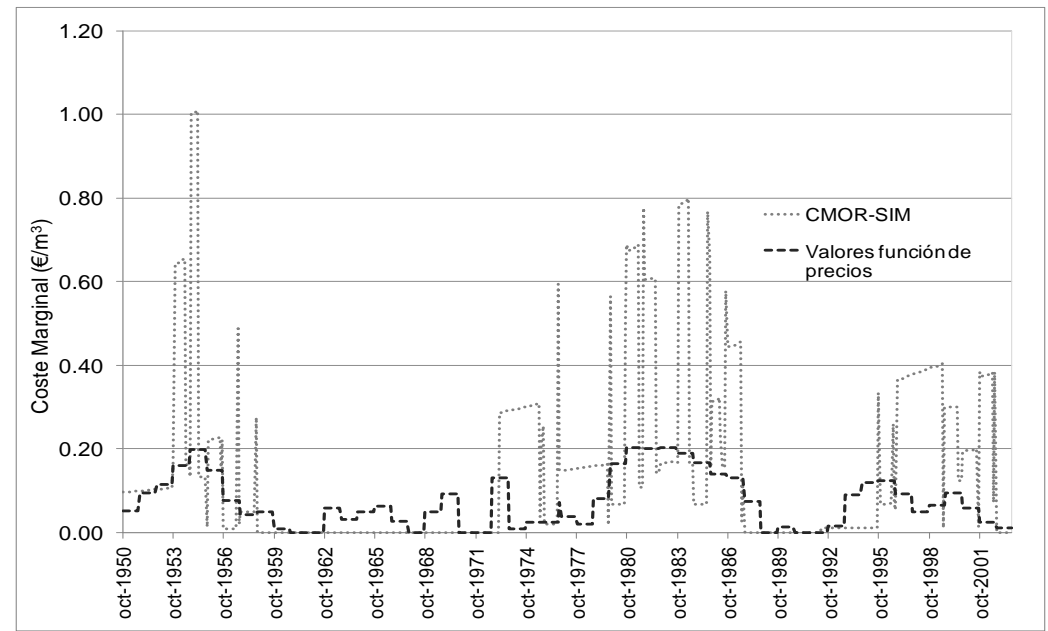

Figura 5.32. Comparativa de CMOR de simulación y función de precios ajustada

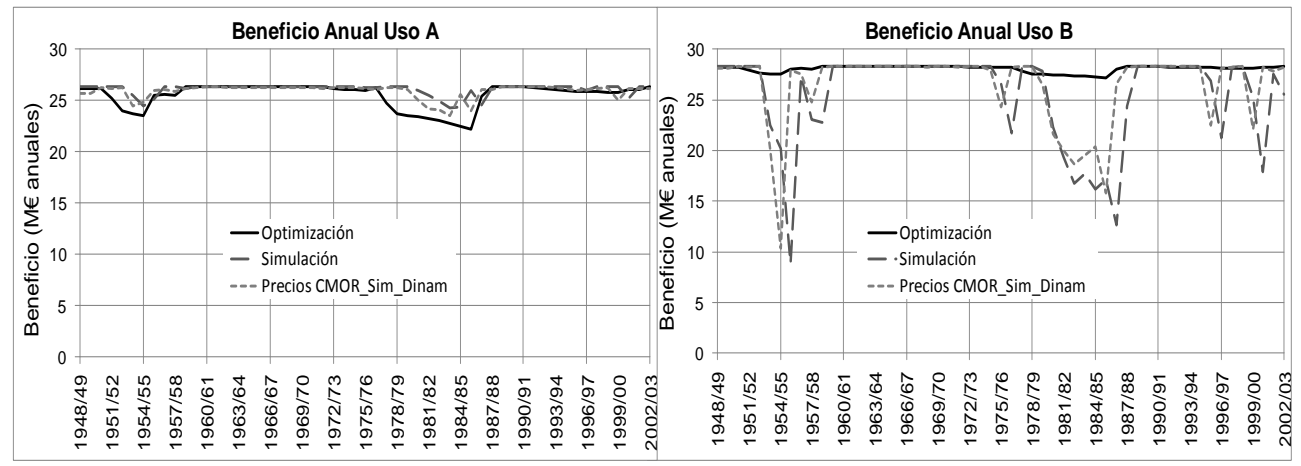

Figura 5.33. Beneficios anuales. Precios utilizando el CMOR de la simulación y aportaciones previas 
Tabla 5.7 Beneficios medios anuales por metodologías. Caso sintético

\begin{tabular}{|l|c|c|c|c|}
\hline \multicolumn{1}{|c|}{ METODOLOGÍA } & $\begin{array}{c}\text { Benef A } \\
\text { (M€/año) }\end{array}$ & $\begin{array}{c}\text { Benef B } \\
\text { (M€/año) }\end{array}$ & $\begin{array}{c}\text { Beneficio } \\
\text { Medio Anual } \\
\text { (M€/año) }\end{array}$ & $\begin{array}{c}\text { Beneficio } \\
\text { Total } \\
\text { (M€) }\end{array}$ \\
\hline Optimización teórica & 25,49 & 28,05 & 53,54 & 2944,74 \\
\hline Simulación con prioridades & 26,05 & 25,38 & 51,43 & 2828,53 \\
\hline PRECIOS ESCALONADOS: & & & & 2918,75 \\
\hline Precios CMOR-Sim-Función volumen & 25,34 & 27,73 & 53,07 & 2897,40 \\
\hline Precios CMOR-Opt-Función volumen & 25,78 & 26,90 & 52,68 & 2921,07 \\
\hline $\begin{array}{l}\text { Precios escalonados óptimos } \\
\text { Precios CMOR-Función de } \\
\text { aportaciones previas }\end{array}$ & 25,24 & 27,87 & 53,11 & 2899,19 \\
\hline $\begin{array}{l}\text { PRECIOS FUNCIÓN DE VOLUMEN Y } \\
\text { APORTACIONES PREVIAS }\end{array}$ & 25,60 & 27,11 & 52,71 & 2873,49 \\
\hline $\begin{array}{l}\text { Precios CMOR-Opt-Función volumen } \\
\text { y aportaciones previas }\end{array}$ & 25,60 & 27,01 & 52,61 & 2,31 \\
\hline $\begin{array}{l}\text { Precios CMOR-Sim-Función volumen } \\
\text { y aportaciones previas }\end{array}$ & 25,90 & 26,35 & 52,25 & 2893 \\
\hline
\end{tabular}

\subsubsection{Precios estacionales en función del volumen embalsado y aportaciones previas.}

En un intento por reflejar la variación del CMOR para igual volumen embalsado en función de que sea época de aumento o disminución de reservas, se ha considerado la posibilidad de que el precio pueda depender del estado previo del sistema en los semestres anteriores al análisis, es decir, considerando periodos estacionales significativos. Las funciones de ajuste son las siguientes:

$$
\begin{aligned}
& p_{o c t-a b r}=a+b \cdot V_{o c t}+c \cdot A p_{a b r, a \tilde{n} o(t-1)} \\
& p_{a b r-s e p}=d+e \cdot V_{a b r}+f \cdot A p_{o c t, a n ̃ o(t-1)}
\end{aligned}
$$

donde:

$V_{a b r} \quad$ Volumen almacenado al inicio del mes de abril.

$V_{\text {oct }} \quad$ Volumen almacenado al inicio del mes de octubre.

$A p_{a b r} \quad$ Suma de aportaciones de abril a septiembre del año anterior. 
$A p_{\text {oct }} \quad$ Suma de aportaciones de octubre a marzo del año anterior.

$a, b, c, d, e, f \quad$ Parámetros de ajuste.

Se tienen entonces dos valores de precios ajustados al CMOR, dependiendo del periodo de análisis en que se encuentre el sistema de explotación. Si se parte del mes de octubre, se consideran los volúmenes almacenados al inicio de octubre, pero las aportaciones de abril a septiembre de ese mismo año. Cuando el análisis es en abril se toman los volúmenes almacenados al inicio de ese mes y las aportaciones de octubre del año anterior a marzo de ese mismo año.

Las funciones de precio se han ajustado a los valores del CMOR de optimización y de simulación usando las expresiones 5.3 y 5.4. Estas funciones se han hecho depender tanto de los volúmenes embalsados durante los semestres anteriores como de las aportaciones anuales igualmente de semestres anteriores. El resultado del ajuste para el caso sintético es el mostrado en la figura 5.34.

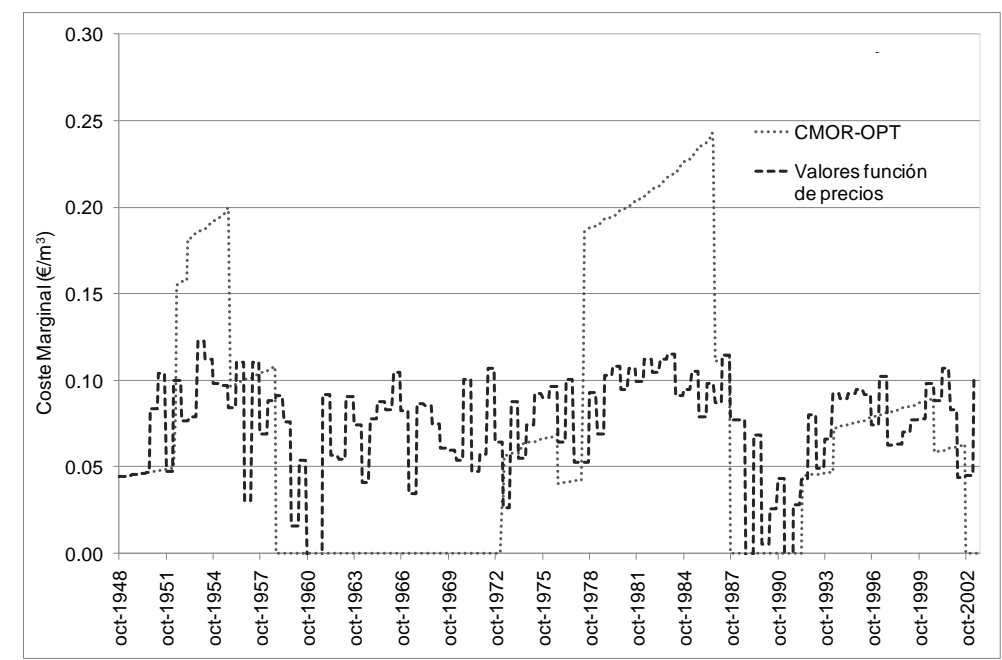

Figura 5.34. Comparativa CMOR de optimización y precios estacionales

La figura 5.35 representa la serie temporal de precios y volumen de embalse en el período analizado. Como se observa en la figura 5.34, el ajuste no es del todo satisfactorio y al aplicar este tipo de política estacional se obtienen beneficios inferiores a los obtenidos con las políticas de precios escalonados pero muy similares a los obtenidos con el ajuste anterior no estacional (figura 5.36, tabla 5.8). 


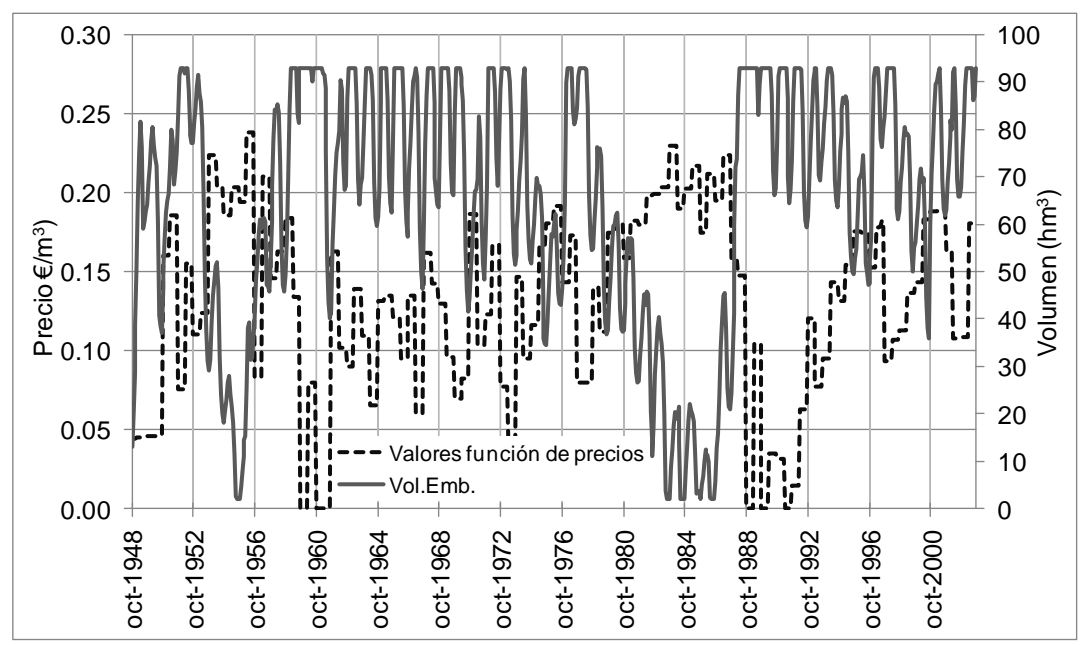

Figura 5.35. Volumen mensual y valores de la función de precios estacionales (ctes. para cada año)

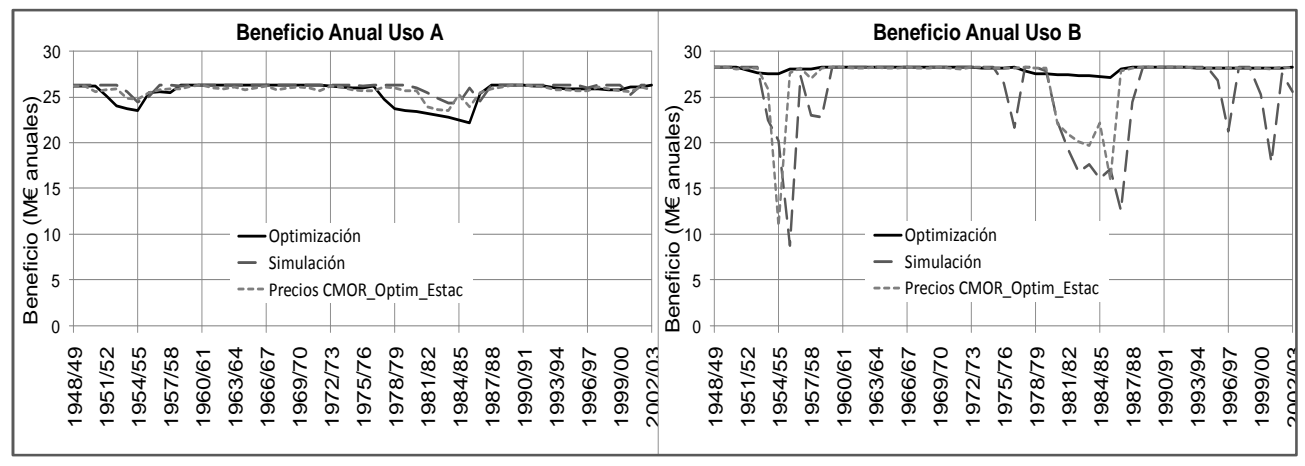

Figura 5.36. Precios en función del volumen embalsado y aportaciones previas con ajustes estacionales utilizando el CMOR (valor sombra) de optimización teórica 
Tabla 5.8 Beneficios medios anuales por metodologías. Caso sintético

\begin{tabular}{|c|c|c|c|c|}
\hline METODOLOGÍA & $\begin{array}{c}\text { Benef A } \\
\text { (M€/año) }\end{array}$ & $\begin{array}{l}\text { Benef B } \\
\text { (M€/año) }\end{array}$ & $\begin{array}{c}\text { Beneficio } \\
\text { Medio Anual } \\
\text { (M€/año) }\end{array}$ & $\begin{array}{c}\text { Beneficio } \\
\text { Total } \\
\text { (M€) }\end{array}$ \\
\hline Optimización teórica & 25,49 & 28,05 & 53,54 & 2944,74 \\
\hline Simulación con prioridades & 26,05 & 25,38 & 51,43 & 2828,53 \\
\hline \multicolumn{5}{|l|}{ PRECIOS ESCALONADOS: } \\
\hline Precios CMOR-Sim-Función volumen & 25,34 & 27,73 & 53,07 & 2918,75 \\
\hline Precios CMOR-Opt-Función volumen & 25,78 & 26,90 & 52,68 & 2897,40 \\
\hline Precios escalonados óptimos & 25,24 & 27,87 & 53,11 & 2921,07 \\
\hline $\begin{array}{l}\text { Precios CMOR-Función de } \\
\text { aportaciones previas }\end{array}$ & 25,60 & 27,11 & 52,71 & 2899,19 \\
\hline \multicolumn{5}{|l|}{$\begin{array}{l}\text { PRECIOS FUNCIÓN DE VOLUMEN Y } \\
\text { APORTACIONES PREVIAS }\end{array}$} \\
\hline $\begin{array}{l}\text { Precios CMOR-Opt-Función volumen } \\
\text { y aportaciones previas }\end{array}$ & 25,60 & 27,01 & 52,61 & 2893,31 \\
\hline $\begin{array}{l}\text { Precios CMOR-Sim-Función volumen } \\
\text { y aportaciones previas }\end{array}$ & 25,90 & 26,35 & 52,25 & 2873,49 \\
\hline \multicolumn{5}{|l|}{$\begin{array}{l}\text { PRECIOS FUNCIÓN DE VOLUMEN, } \\
\text { APORTACIONES PREVIAS Y AJUSTES } \\
\text { ESTACIONALES }\end{array}$} \\
\hline $\begin{array}{l}\text { Precios CMOR-Opt-Función volumen } \\
\text { aportaciones y ajustes estacionales }\end{array}$ & 25,71 & 26,91 & 52,62 & 2893,78 \\
\hline
\end{tabular}

El ajuste para el caso de simulación_(figura 5.37) es mucho peor que para el caso del CMOR de optimización. Los valores del CMOR ajustado quedan muy por debajo de los valores del CMOR de la simulación.

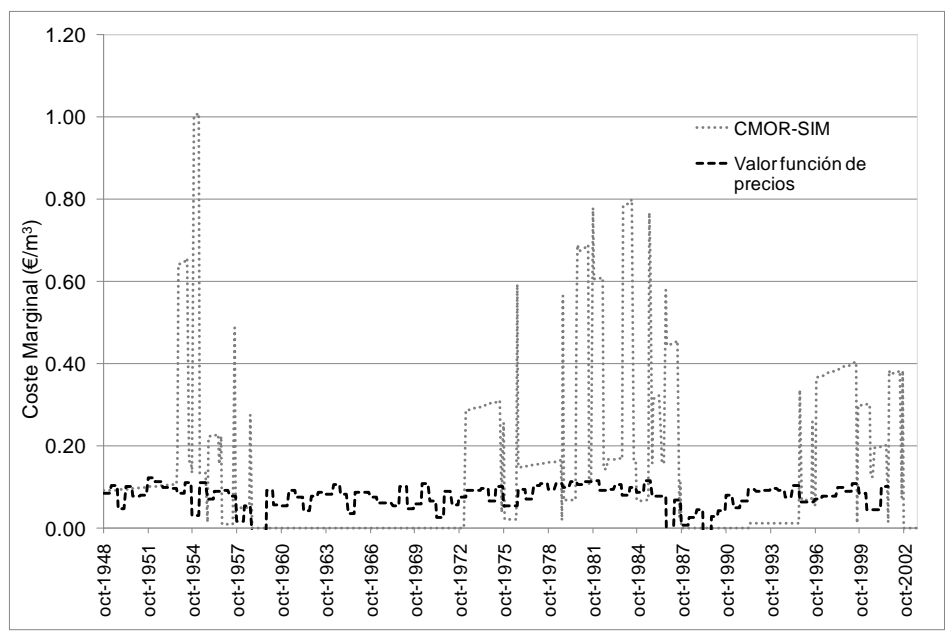

Figura 5.37 Ajuste del CMOR de la simulación por estaciones 
Al aplicar este tipo de política al caso sintético, los beneficios que se obtienen (figura 5.38, tabla 5.9) son menores a los obtenidos con políticas de precios escalonados, pero similares a los de políticas de precios dinámicos.

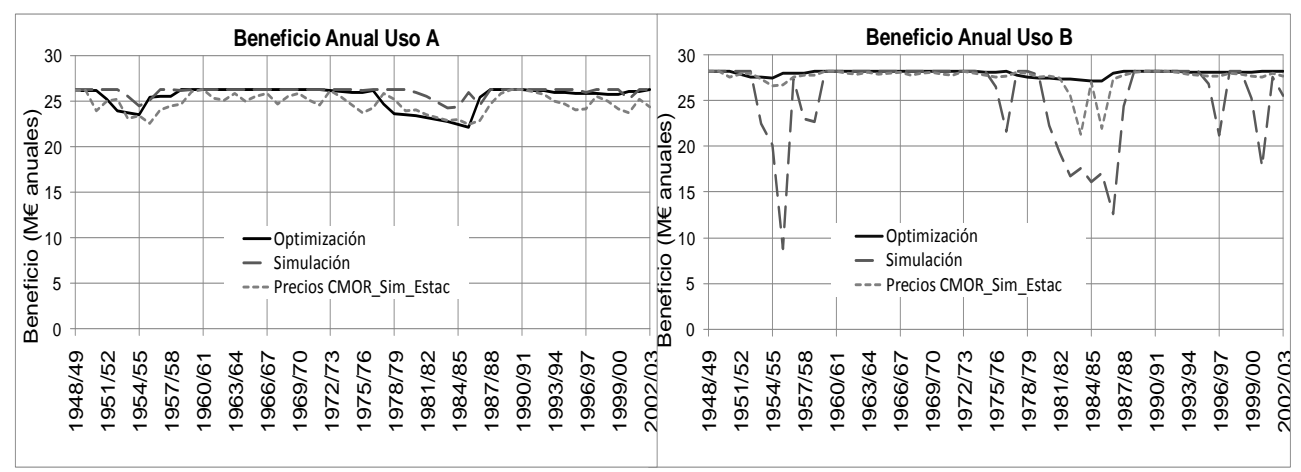

Figura 5.38. Precios en función del volumen embalsado y aportaciones previas con ajustes estacionales utilizando el CMOR de la simulación sin precios

En la tabla 5.9 se muestran en forma comparativa los beneficios medios anuales para cada metodología considerada. 
Tabla 5.9 Beneficios medios anuales por metodologías. Caso sintético

\begin{tabular}{|c|c|c|c|c|}
\hline METODOLOGÍA & $\begin{array}{c}\text { Benef A } \\
\text { (M€/año) }\end{array}$ & $\begin{array}{l}\text { Benef B } \\
\text { (M€/año) }\end{array}$ & $\begin{array}{l}\text { Beneficio } \\
\text { Medio Anual } \\
\text { (M€/año) } \\
\end{array}$ & $\begin{array}{c}\text { Beneficio } \\
\text { Total } \\
\text { (M€) }\end{array}$ \\
\hline Optimización teórica & 25,49 & 28,05 & 53,54 & 2944,74 \\
\hline Simulación con prioridades & 26,05 & 25,38 & 51,43 & 2828,53 \\
\hline \multicolumn{5}{|l|}{ PRECIOS ESCALONADOS: } \\
\hline Precios CMOR-Sim-Función volumen & 25,34 & 27,73 & 53,07 & 2918,75 \\
\hline Precios CMOR-Opt-Función volumen & 25,78 & 26,90 & 52,68 & 2897,40 \\
\hline Precios escalonados óptimos & 25,24 & 27,87 & 53,11 & 2921,07 \\
\hline $\begin{array}{l}\text { Precios CMOR-Función de } \\
\text { aportaciones previas }\end{array}$ & 25.60 & 27.11 & 52.71 & 2899.19 \\
\hline \multicolumn{5}{|l|}{$\begin{array}{l}\text { PRECIOS FUNCIÓN DE VOLUMEN Y } \\
\text { APORTACIONES PREVIAS }\end{array}$} \\
\hline $\begin{array}{l}\text { Precios CMOR-Opt-Función volumen } \\
\text { y aportaciones }\end{array}$ & 25,60 & 27,01 & 52,61 & 2893,31 \\
\hline $\begin{array}{l}\text { Precios CMOR-Sim-Función volumen } \\
\text { y aportaciones }\end{array}$ & 25,90 & 26,35 & 52,25 & 2873,49 \\
\hline \multicolumn{5}{|l|}{$\begin{array}{l}\text { PRECIOS FUNCIÓN DE VOLUMEN, } \\
\text { APORTACIONES PREVIAS Y AJUSTES } \\
\text { ESTACIONALES }\end{array}$} \\
\hline $\begin{array}{l}\text { Precios CMOR-Opt-Función volumen } \\
\text { aportaciones y ajustes estacionales }\end{array}$ & 25,71 & 26,91 & 52,62 & 2893,78 \\
\hline $\begin{array}{l}\text { Precios CMOR-Sim-Función volumen } \\
\text { aportaciones y ajustes estacionales }\end{array}$ & 24,76 & 27,58 & 52,34 & 2878,78 \\
\hline
\end{tabular}

\subsubsection{Análisis de la eficacia de precios con series sintéticas de aportaciones.}

Aunque con frecuencia se adopta un enfoque determinístico en el análisis de sistemas de recursos hídricos, simulando la serie histórica, esta serie representa una realización sólo de los infinitos escenarios hidrológicos futuros, y es improbable que se repita en el futuro. La generación de múltiples series sintéticas equiprobables a la series histórica nos permite analizar el funcionamiento medio del sistema teniendo en cuenta todos esos escenarios.

Se ha realizado un estudio de series sintéticas con el fin de verificar si las conclusiones sobre los beneficios económicos que se obtiene al utilizarlas varían con respecto a las obtenidas con la serie histórica del sistema.

Para la generación de las series sintéticas, se elaboró y calibró un modelo estocástico de aportaciones clásico (Salas et al. 1980). Primeramente se calcularon los estadísticos básicos de las aportaciones anuales y los límites de Snedecor y Cochran para el Test de Normalidad. La tabla 5.10 muestra los resultados correspondientes: 
Tabla 5.10. Estadísticos de las series de aportaciones anuales

\begin{tabular}{|c|c|c|c|c|}
\hline Media & Desviación Típica & Sesgo & Límite inferior & Límite superior \\
\hline 136,60 & 51,76 & 1,56 & $-0,63$ & 0,63 \\
\hline
\end{tabular}

Al salir el sesgo fuera de los límites de Snedecor y Cochran, se probaron distintas transformaciones para normalizar la serie raíz cuadrada, logarítmica y doble logarítmica, siendo esta última la mejor. Solamente se tienen problemas durante los meses de diciembre y enero (figura 5.39)

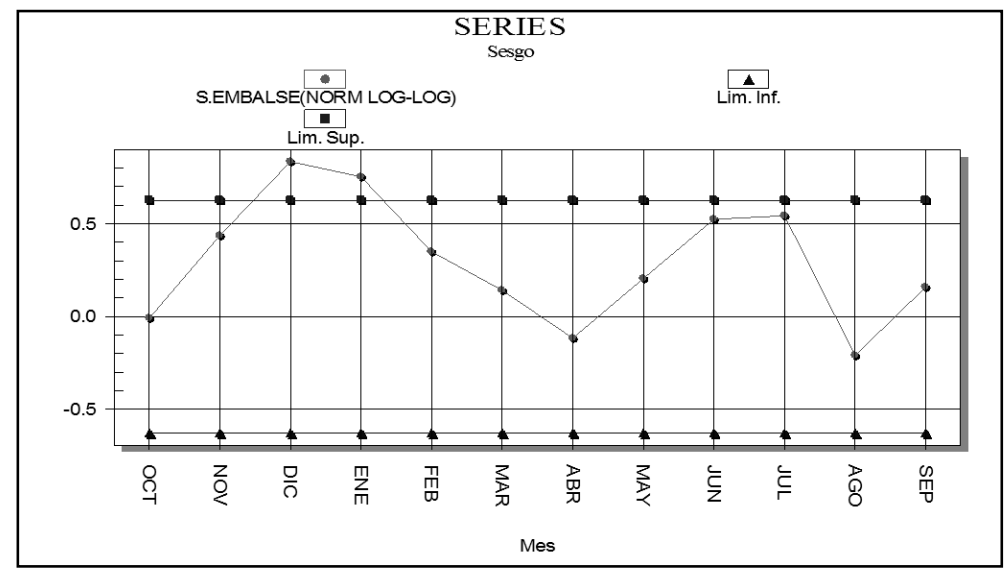

Figura 5.39. Normalización de la serie de aportaciones

Se postularon dos modelos de autocorrelación: AR (1) y AR (2), prefiriendo el primero por ser más sencillo y porque tiene total independencia temporal de los residuos y menor sesgo (figura 5.40). 


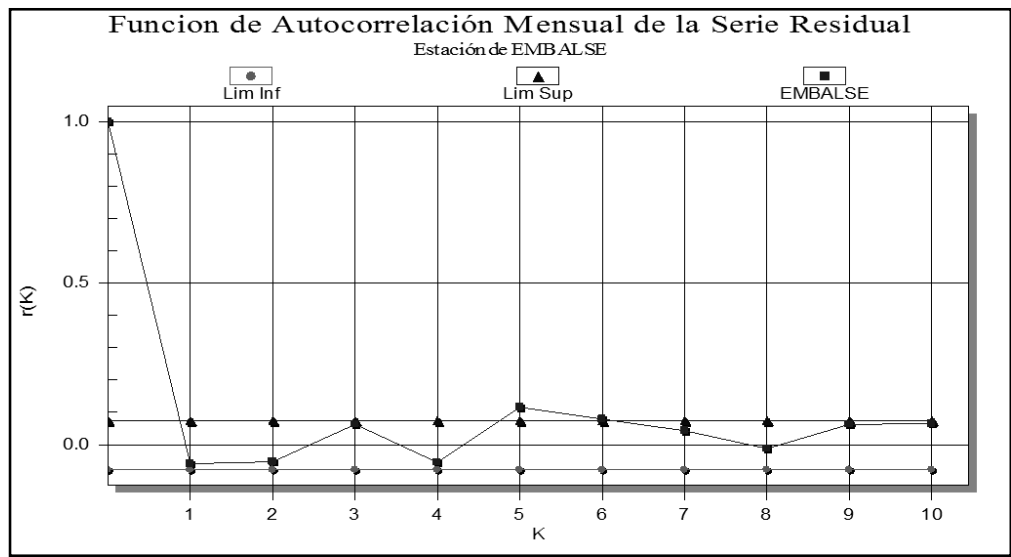

Figura 5.40. Función de autocorrelación mensual de la serie residual

La función de autocorrelación mensual de la serie de caudales tipificada, se muestra en la figura 5.41.

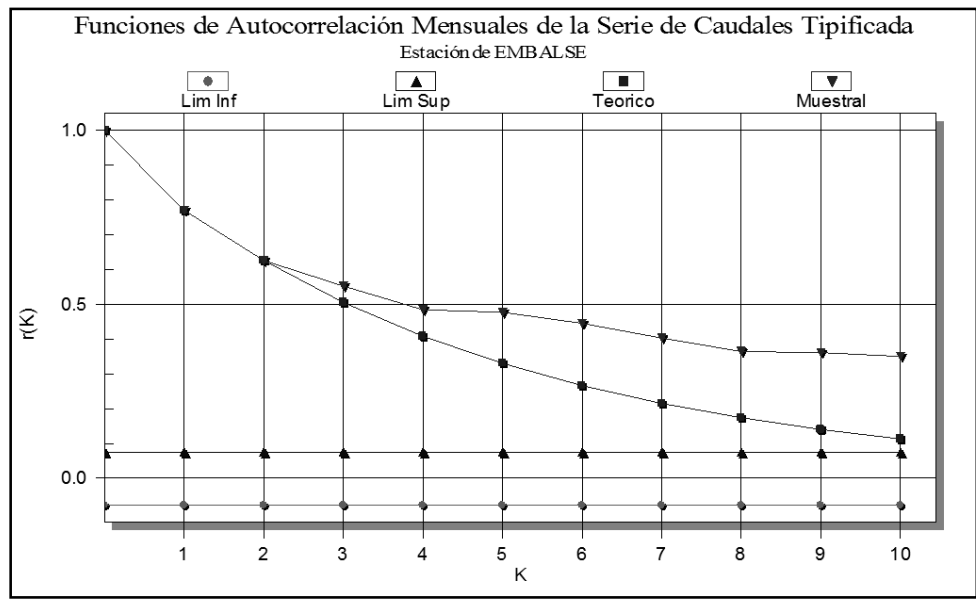

Figura 5.41. Funciones de autocorrelación mensuales

Con base en el modelo AR (1), se generaron 50 series sintéticas mensuales con una longitud total de 60 años y periodo de calentamiento de 5 años. Las medias, el sesgo y la desviación típica mensuales se observan en la figura 5.42. 


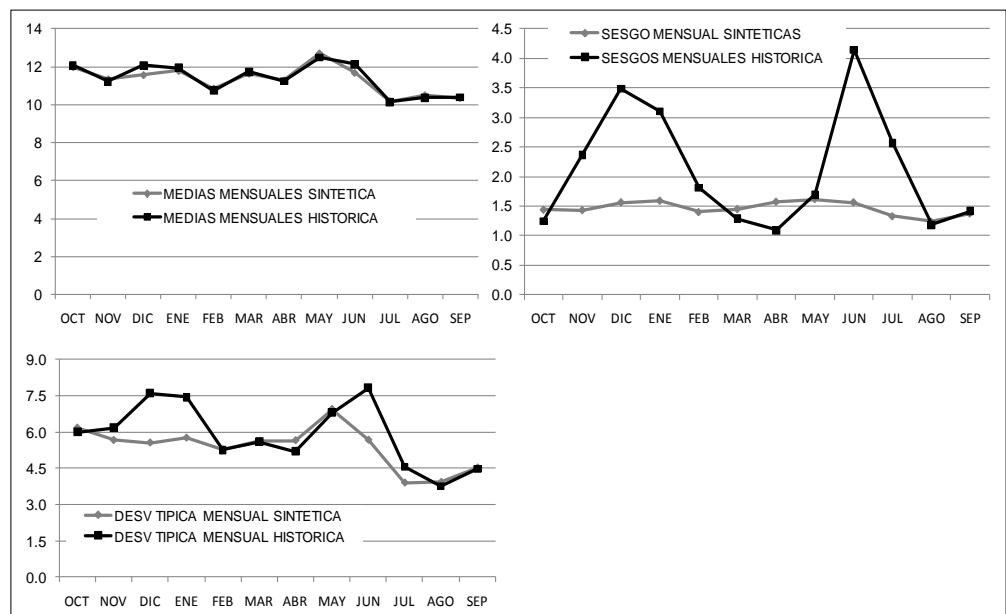

Figura 5.42. Estadísticos modelo AR (1)

Una vez generadas las cincuenta series sintéticas, se utilizaron en el esquema sintético para cada tipo de políticas de precio presentadas en los apartados anteriores. Los beneficios obtenidos se muestran en forma comparativa con los obtenidos de la serie de aportaciones histórica, en la tabla 5.11. 
Tabla 5.11. Beneficios medios anuales por metodologías. Series de aportaciones

\begin{tabular}{|l|c|c|}
\hline \multicolumn{1}{|c|}{ Metodología } & $\begin{array}{c}\text { Histórica } \\
\text { (Mill.€/año) }\end{array}$ & $\begin{array}{c}\text { Medias Sintéticas } \\
\text { (Mill. €/año) }\end{array}$ \\
\hline Beneficios Optimización & 53,54 & 53,99 \\
\hline Beneficios Simulación con prioridades & 51,43 & 52,51 \\
\hline Beneficios Precios Escalonados: & & \\
\hline $\begin{array}{l}\text { Beneficios/Precios CMOR-Optim. Función de } \\
\text { volumen }\end{array}$ & 52,68 & 53,46 \\
\hline $\begin{array}{l}\text { Beneficios/Precios CMOR-Sim. Función de } \\
\text { volumen }\end{array}$ & 53,07 & 53,57 \\
\hline \begin{tabular}{l} 
Beneficios/Precios Optimizados \\
\hline $\begin{array}{l}\text { Beneficios/Precios CMOR-Función de volumen y } \\
\text { aportaciones previas }\end{array}$
\end{tabular} & 53,11 & 53,57 \\
\hline $\begin{array}{l}\text { Beneficios/Precios función de volumen y } \\
\text { aportaciones previas: }\end{array}$ & 52,71 & 52,91 \\
\hline $\begin{array}{l}\text { Beneficios/Precios CMOR-Optim-Función volumen } \\
\text { y aportaciones }\end{array}$ & 52,61 & \\
\hline $\begin{array}{l}\text { Beneficios/Precios CMOR-Sim-Función volumen y } \\
\text { aportaciones }\end{array}$ & 52,25 & 53,24 \\
\hline $\begin{array}{l}\text { Beneficios/Precios función de volumen, } \\
\text { aportaciones previas y ajustes estacionales: }\end{array}$ & & 53,37 \\
\hline $\begin{array}{l}\text { Beneficios/Precios CMOR-Optim-Función volumen } \\
\text { aportaciones y ajustes estacionales }\end{array}$ & 52,61 & 53,00 \\
\hline $\begin{array}{l}\text { Beneficios/Precios CMOR-Sim-Función volumen } \\
\text { aportaciones y ajustes estacionales }\end{array}$ & 52,34 & \\
\hline
\end{tabular}

En la tabla 5.11 se observa que los beneficios obtenidos al simular las series sintéticas son similares a los resultantes de la simulación con la serie histórica, corroborando las conclusiones que se obtienen sobre la aplicación de las diferentes metodologías y que se comentan en el apartado siguiente.

\subsubsection{Conclusiones.}

Se observa que al considerar la política de precios escalonada función de volumen obtenida a partir de los CMOR de la simulación base, los beneficios medios anuales se aproximan mucho a los de la optimización teórica (véase la tabla 5.9). Por otro lado, la optimización de los precios de los escalones no mejora mucho los resultados. Tampoco las metodologías con inclusión de las aportaciones previas, ya sea estacional o no, y con el volumen o no, aportan mejoras sustanciales. Curiosamente, tampoco las políticas de precios obtenidas por los mismos procedimientos a partir de los CMOR de la optimización mejoran los resultados de las que se obtienen usando los CMOR de la simulación base. 
En este caso, asumir los CMOR medios de forma escalonada del modelo de la simulación como política de precios, da como resultado unos beneficios económicos que mejoran en un $80 \%$ los valores que por sí mismo proporciona el modelo de simulación. Estos valores son mejores que los que se obtuvieron cuando se consideró la política de precios con los CMOR del modelo de optimización. Además, los suministros a las demandas son un poco mayores a la de otro tipo de políticas de precios (tabla 5.12)

Tabla 5.12 Suministro medio anual por metodologías. Caso sintético

\begin{tabular}{|c|c|c|c|}
\hline METODOLOGÍA & $\begin{array}{l}\text { Sumin. A } \\
\left(\mathrm{hm}^{3}\right)\end{array}$ & $\begin{array}{l}\text { Sumin. B } \\
\left(\mathrm{hm}^{3}\right)\end{array}$ & $\begin{array}{c}\text { Suministro } \\
\text { Medio Anual (hm3) }\end{array}$ \\
\hline Optimización & 76,82 & 44,18 & 121,00 \\
\hline Simulación con prioridades & 83,46 & 38,08 & 121,54 \\
\hline \multicolumn{4}{|l|}{ Precios escalonados: } \\
\hline Precios CMOR-Opt & 77,34 & 41,26 & 118,60 \\
\hline Precios CMOR-Sim & 74,39 & 42,74 & 117,13 \\
\hline Precios optimizados & 74,98 & 43,26 & 118,24 \\
\hline Precios CMOR-Aportaciones previas & 67,38 & 41,19 & 108,57 \\
\hline \multicolumn{4}{|l|}{$\begin{array}{l}\text { Precios función de volumen y } \\
\text { aportaciones previas: }\end{array}$} \\
\hline Precios CMOR-Opt & 75,77 & 41,24 & 117,01 \\
\hline Precios CMOR-Sim & 79,51 & 39,97 & 119,48 \\
\hline \multicolumn{4}{|c|}{$\begin{array}{l}\text { Precios función de volumen, aportaciones } \\
\text { previas y ajustes estacionales: }\end{array}$} \\
\hline Precios CMOR-Opt & 75,93 & 40,99 & 116,92 \\
\hline Precios CMOR-Sim & 68,16 & 41,11 & 109,27 \\
\hline
\end{tabular}

Por tanto, y como conclusión principal obtenida en el análisis del caso sintético, parece que se obtiene una política de precios bastante buena cuando se utiliza la metodología basada en el CMOR de la simulación base, y con un ajuste escalonado en función del volumen embalsado.

Para definir o proponer una política eficiente de precios, primeramente se calculan los Costes Marginales de Oportunidad del Recurso (CMOR) con el modelo de simulación de la gestión del sistema de explotación aplicando las reglas de gestión existentes. Si fuera posible, se realiza el modelo de optimización económica del sistema tomando como función objetivo la maximización de los beneficios económicos del uso del agua en las unidades de demanda que conformen el mismo. Los resultados de este modelo proporcionan la cota máxima del beneficio que se puede obtener con una política eficiente de precios, y por tanto son útiles para estimar la magnitud de la mejora que se consigue con la política que se proponga. 
A continuación, se define una política de precios escalonada en función del volumen embalsado utilizando los valores medios del CMOR en el rango de volúmenes del escalón correspondiente. Para estimar la validez de la política de precios definida, los beneficios obtenidos pueden compararse con el óptimo económico teórico, y en función de los resultados, puede optarse por proponer la política obtenida o intentar refinarla. Para ello pueden usarse metodologías similares a las vistas anteriormente.

Con el fin de encontrar políticas de precios más eficientes, se procede a optimizar los escalones de la función de precios para diferentes rangos de volumen almacenado en el embalse. También puede tomarse en cuenta la serie de aportaciones al sistema y analizar los CMOR de los modelos de simulación y optimización para umbrales de volúmenes anuales aportados, en vez de volúmenes almacenados, y generar los CMOR promedios correspondientes a los mismos. Este tipo de análisis mejora los beneficios económicos que se tienen en el modelo de simulación, aunque en la práctica será difícil considerar volúmenes de aportaciones en vez de volúmenes embalsados, ya que estos últimos son los que se utilizan en el suministro del recurso a los usuarios.

Por otro lado, el proporcionar políticas de precios que dependan del estado previo del sistema o de periodos estacionales, hacen más complejo el cálculo y no proporcionan una mejora sustancial en los beneficios económicos por el uso del agua.

Finalmente, pueden realizarse series sintéticas de la serie de aportaciones históricas y realizando con cada una de ellas los cálculos para las diferentes políticas de precios previamente mencionadas. Se toma entonces el valor medio de los beneficios obtenidos con cada serie para cada política y se comparan entre ellas. Se observa que en todos los casos, se mejoran los beneficios económicos por el uso del recurso. 


\section{CAPÍTULO 6 \\ Caso de aplicación}





\section{Caso de aplicación. Sistema de explotación del río Mijares}

En este apartado se presentan los resultados que se han obtenido al aplicar la metodología propuesta para la definición de las políticas de precios al sistema de explotación del río Mijares. Se incluyen los siguientes aspectos: la descripción del sistema; descripción del modelo de simulación de la gestión; caracterización económica del sistema; y resultados de la modelación.

\subsection{Descripción del sistema}

En este apartado se presenta una breve descripción del sistema de explotación MijaresPlana de Castellón considerando los siguientes aspectos: extensión territorial, rasgos geográficos y climáticos, recursos hídricos, usos del agua y la infraestructura hidráulica. En el anexo 3 puede consultarse una descripción más detallada de la zona de estudio. Conviene además, tener en cuenta que el uso de este sistema como caso de estudio en la 
presente tesis, si bien representa un caso real, constituye un ejercicio en el que no necesariamente todos los datos e hipótesis efectuadas coinciden exactamente con la realidad, y en el que se han introducido simplificaciones. Por lo tanto, las conclusiones que se obtienen han de contemplarse exclusivamente como resultados del mencionado ejercicio, y pudieran ser diferentes si se introdujeran elementos, datos, o hipótesis que no se consideran aquí en aras de la realización de la tesis en tiempo razonable y adecuación a los objetivos de la misma.

\subsubsection{Extensión territorial}

El sistema de explotación Mijares-Plana de Castellón se encuentra ubicado en la vertiente oriental de la Península Ibérica vertiendo al mar Mediterráneo, y pertenece al ámbito territorial de la $\mathrm{CHJ}$ (figura 6.1). Se encuentra situado en las provincias de Teruel y Castellón. No sólo comprende la totalidad del río Mijares, sino también las pequeñas cuencas próximas a su área de influencia como son las del río Seco, Veo y Belcaire, y las subcuencas litorales comprendidas entre Benicasim (incluyendo su término municipal) y el límite provincial entre Castellón y Valencia. La superficie total comprendida por este sistema es de $5.466 \mathrm{~km}^{2}$ (CHJ, 1997).

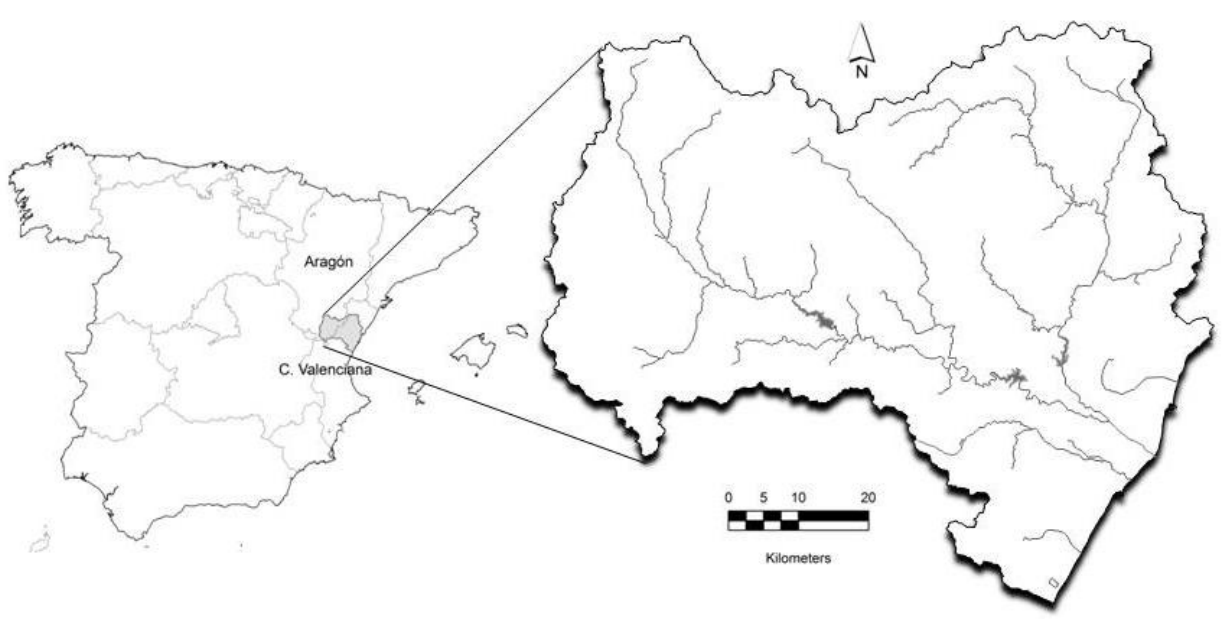

Figura 6.1 Ubicación geográfica del SRH del río Mijares Fuente: $\mathrm{CHJ}$ (1997) y elaboración propia

\subsubsection{Rasgos geográficos y climáticos}

La altitud máxima del Sistema de explotación Mijares-Plana de Castellón se alcanza en el nacimiento del río Albentosa (2024 msnm). El nacimiento de la Rambla de la Viuda también se produce a cotas elevadas (1814 $\mathrm{msnm})$ estando la confluencia con el río Mijares a la cota $35 \mathrm{msnm}$ (CHJ, 1997). 
En el sistema de explotación Mijares-Plana de Castellón se diferencian dos zonas geográficas climatológicamente distintas: una zona costera con un clima litoral mediterráneo y otra aguas arriba del embalse de Arenós, asimilable a un clima de transición al tipo continental. La precipitación media anual de la zona es de $505 \mathrm{~mm}$ y la temperatura media de $14,4{ }^{\circ} \mathrm{C}$.

\subsubsection{Recursos hídricos}

La red hidrográfica del sistema del río Mijares (figura 6.2) está constituida por el cauce del propio río Mijares y sus afluentes, principalmente de los ríos Villahermosa y Rambla de la Viuda, además de una serie de ríos de menor importancia tributarios por su margen izquierda. Constituyen parte del sistema del río Mijares los ríos Seco, Veo y Belcaire. El río Villahermosa discurre durante su trayecto de $60 \mathrm{~km}$ paralelo al Mijares y encajonado al pie de Peñagolosa. Su pendiente es muy fuerte y recibe importantes aportaciones tanto superficiales como subterráneas. La cuenca de la Rambla de la Viuda, de gran extensión, se sitúa paralela a la costa y drena los valles interiores de la provincia de Castellón, presentando un régimen muy irregular con períodos muy secos y fuertes avenidas. Este régimen irregular se explica por estar situado el nivel freático regional por debajo del cauce, por lo que se produce una fuerte infiltración que deja el cauce seco salvo en los grandes temporales de otoño. Las aguas superficiales de la Rambla de la Viuda se regulan en el Embalse de María Cristina. Las aguas del embalse contribuyen a la recarga de los acuíferos de La Plana. Por este motivo, desde la presa de María Cristina hasta su desembocadura en el río Mijares, el cauce de la Rambla de la Viuda permanece seco ( $\mathrm{CHJ}$, 1997).

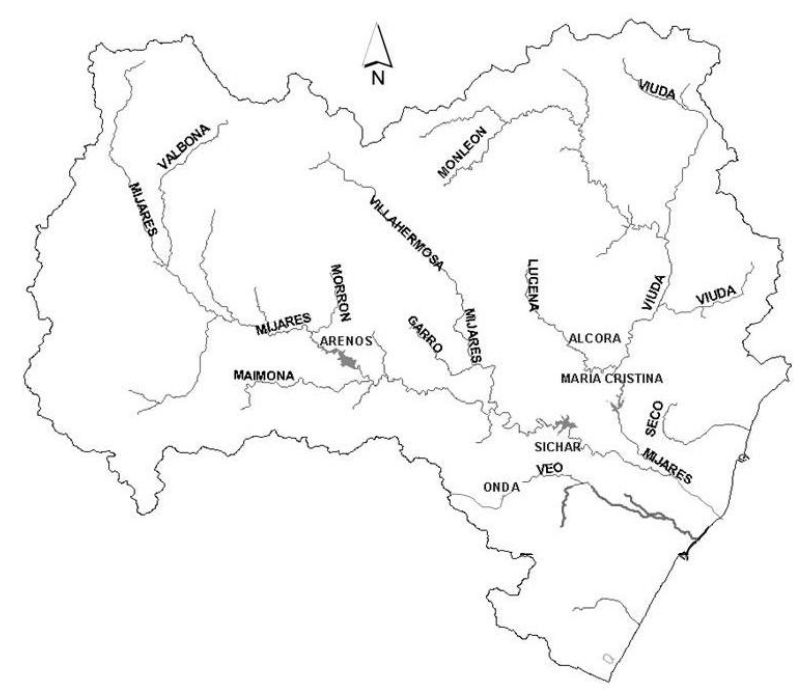

Figura 6.2 Red hidrográfica del sistema del Mijares Fuente: CHJ (1997) y elaboración propia 
Las características más importantes de los cauces que conforman al sistema MijaresPlana de Castellón, se muestran en la tabla siguiente:

Tabla 6.1 Características de los cauces del sistema Mijares-Plana de Castellón

\begin{tabular}{|c|c|c|c|c|}
\hline CUENCA & $\begin{array}{c}\text { LONGITUD } \\
\mathbf{( K m )}\end{array}$ & $\begin{array}{c}\text { SUPERFICIE } \\
\left(\mathbf{K m}^{\mathbf{2}}\right)\end{array}$ & $\begin{array}{c}\text { COTA MÁXIMA } \\
\text { (msnm) }\end{array}$ & $\begin{array}{c}\text { COTA MíNIMA } \\
\text { (msnm) }\end{array}$ \\
\hline Río Belcaire & 18,2 & 103,4 & 877 & 0 \\
\hline Río Seco & 26,0 & 94,30 & 1103 & 0 \\
\hline Río Veo & 42,0 & 238,70 & 2024 & 0 \\
\hline Río Mijares & 156,0 & 4028,20 & 1997 & 245 \\
\hline Villahermosa & 59,0 & 449,90 & 1814 & 35 \\
\hline Rambla la viuda & 81,0 & 1510,30 & & 0 \\
\hline
\end{tabular}

El papel de las aguas subterráneas en el sistema de recursos hídricos de la cuenca del río Mijares es fundamental. Sin ellas sería imposible alcanzar el grado actual de aprovechamiento de los recursos. Aunque no existe conexión hidráulica entre el acuífero y el río, el uso conjunto es un elemento fundamental en la estrategia de gestión del sistema. Sin embargo hay que destacar la importancia del uso conjunto por dos grandes problemas que se han detectado en la zona: por un lado el conflicto existente entre los diferentes usos del agua, especialmente entre riego e hidroelectricidad, y por el otro la sobreexplotación del acuífero que se produce en la zona baja de La Plana de Castellón que ha provocado intrusión salina en diferentes pozos del acuífero costero (Andreu y Sahuquillo, 1987).

La explotación de las aguas subterráneas aumenta en los años más secos, mientras que en los años más húmedos se riega con aguas superficiales la mayor extensión posible de tierras dominadas por acequias y canales. En un estudio previo se dispone de un modelo del acuífero mediante diferencias finitas. Este modelo se ha transformado en un modelo de autovalores para su incorporación en el modelo global de simulación del sistema, y un modelo complementario para estudiar la intrusión marina en el acuífero de La Plana con mayor detalle. Se llegó a la conclusión de la necesidad de aumentar el uso de agua superficial para los riegos de la Cota 100, como forma de controlar las importantes salidas superficiales al mar, y aumentar los bombeos en los riegos tradicionales, al menos en determinados períodos y situaciones, para disminuir las salidas subterráneas al mar y aliviar los problemas de drenaje en la zona de Burriana. 
Las Unidades Hidrogeológicas que se adscriben al Sistema de Explotación MijaresPlana de Castellón (CHJ, 1997) son las siguientes, aunque no de manera exclusiva (figura 6.3):

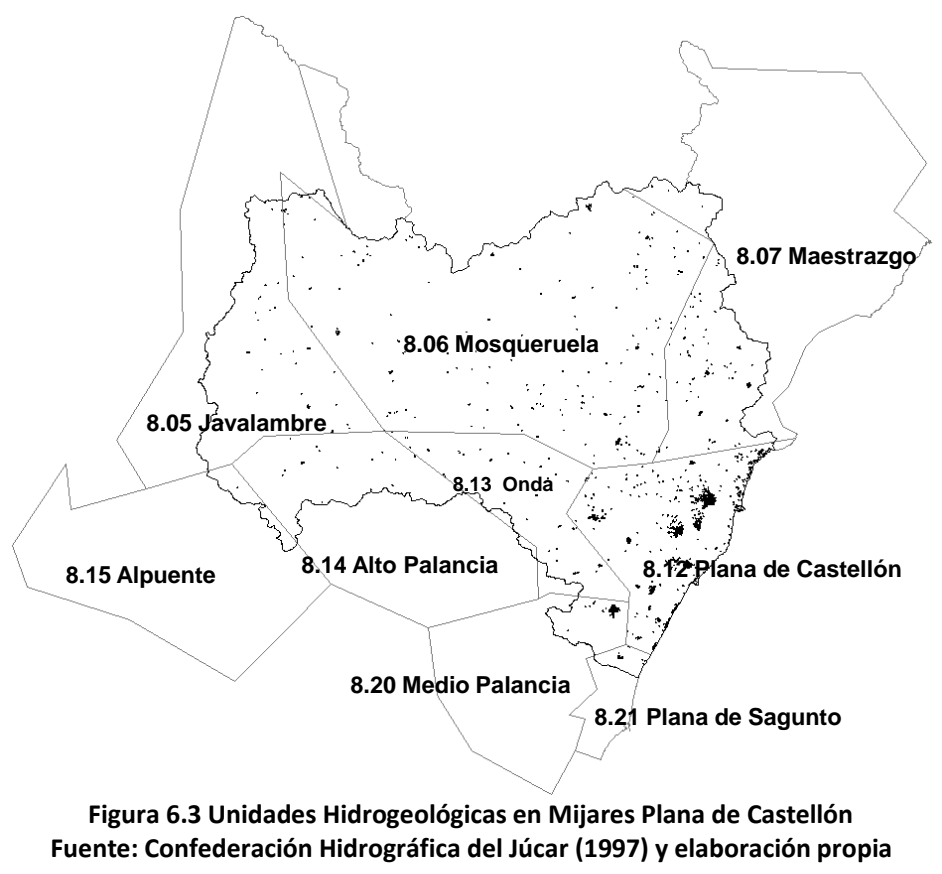

Los balances de las unidades hidrogeológicas se muestran en la tabla siguiente:

\begin{tabular}{|l|c|c|c|c|c|}
\hline \multirow{2}{*}{ NOMBRE UNIDAD } & \multicolumn{3}{|c|}{ ENTRADA 6.2 Balances de las unidades hidrogeológicas } \\
\cline { 2 - 6 } & $\begin{array}{c}\text { Recarga de } \\
\text { lluvia }\end{array}$ & $\begin{array}{c}\text { Infiltración de } \\
\text { riego }\end{array}$ & $\begin{array}{c}\text { Transferencias } \\
\text { laterales }\end{array}$ & Bombeos & (hm $\left.{ }^{\mathbf{3}}\right)$ \\
\hline JAVALAMBRE & 72,94 & 2,83 & 24,00 & 0,41 & 99,36 \\
\hline MOSQUERUELA & 239,02 & 5,45 & 0,00 & 5,97 & 238,50 \\
\hline MAESTRAZGO & 216,24 & 13,75 & 32,00 & 35,65 & 226,34 \\
\hline PLANA DE CASTELLON & 35,94 & 59,73 & 25,60 & 134,23 & $-12,96$ \\
\hline ONDA & 28,92 & 2,79 & 0,00 & 4,05 & 27,66 \\
\hline ALTO PALANCIA & 61,44 & 0,54 & 0,00 & 9,88 & 61,10 \\
\hline ALPUENTE & 71,07 & 2,52 & 0,00 & 9,88 & 63,71 \\
\hline MEDIO PALANCIA & 35,82 & 20,55 & 24,00 & 63,25 & 17,12 \\
\hline PLANA DE SAGUNTO & 7,21 & 26,46 & 11,98 & 45,54 & 0,11 \\
\hline
\end{tabular}




\subsubsection{Usos del agua}

La demanda global del sistema de explotación Mijares-Plana de Castellón alcanza un valor de $277 \mathrm{hm}^{3}$ anuales, de los que 211 corresponden al uso agrícola, 54 al abastecimiento urbano y 12 a la demanda industrial (CHJ, 2009). El uso agrícola representa el $77 \%$ de la demanda total. Le sigue en importancia el uso urbano, el cual demanda el $20 \%$ del total del recurso, mientras que el uso industrial y de servicios demanda únicamente el $3 \%$ del total (figura 6.4).

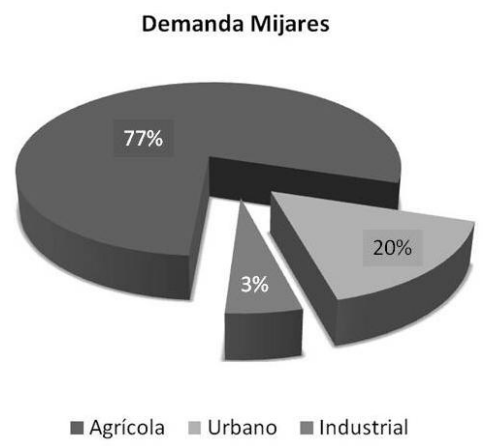

Figura 6.4 Demandas totales del sistema Mijares-Plana de Castellón Fuente: Confederación Hidrográfica del Júcar (2009) y elaboración propia

\subsubsection{Infraestructura hidráulica}

La conexión entre los recursos y los usos se produce mediante un sistema de infraestructura hidráulica de: captación, transporte, almacenamiento, depuración, potabilización y defensa.

Los principales embalses del sistema Mijares-Plana de Castellón (figura 6.5), son los siguientes:

- Arenós $\left(130 \mathrm{hm}^{3}\right)$ y Sichar $\left(52 \mathrm{hm}^{3}\right)$, en el río Mijares;

- María Cristina $\left(28 \mathrm{hm}^{3}\right.$ ), en la rambla de la Viuda;

- Alcora $\left(2 \mathrm{hm}^{3}\right)$, en el río Lucena. 


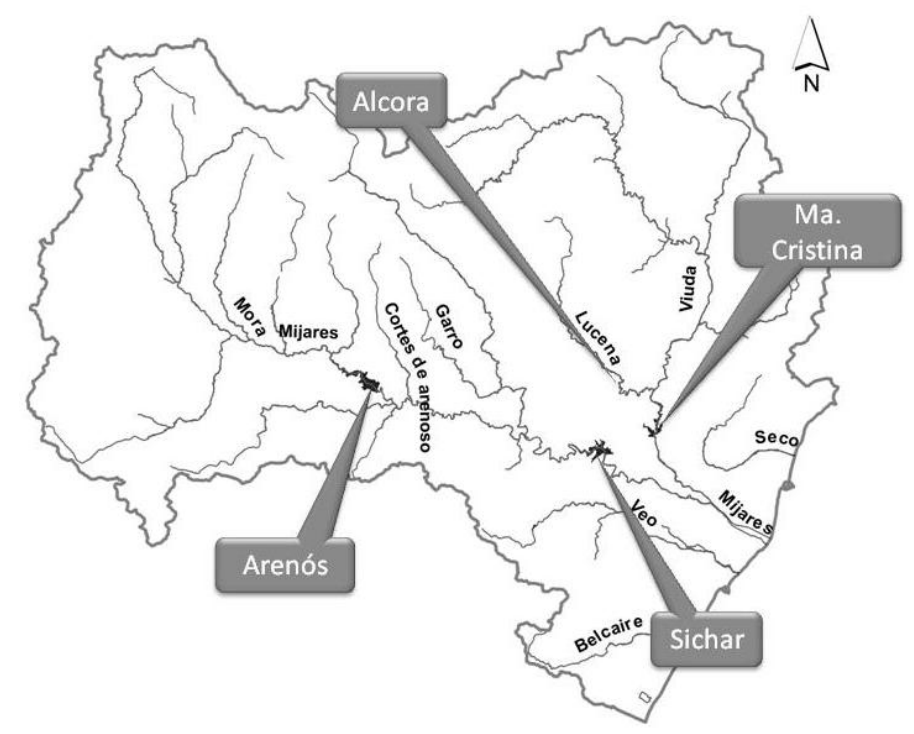

Figura 6.5 Principales embalses del sistema Mijares-Plana de Castellón Fuente: CHJ (1997) y elaboración propia

Además de la infraestructura mencionada el Sistema Mijares-Plana de Castellón cuenta con pequeños embalses de poca capacidad que se utilizan para generación de energía hidroeléctrica y distribución de agua a las acequias de regantes. Otros elementos de la infraestructura son: una importante red de canales y azudes que suministran el agua a diferentes tomas de riego; campos de pozos; piscifactorías; centrales hidroeléctricas; estaciones depuradoras de aguas residuales (EDARs) y redes de medida y control. La información detallada de esta información puede consultarse en el Anejo C y en la página web de la Confederación Hidrográfica del Júcar (http://www.chj.es ).

\subsection{Modelo de gestión del sistema}

En este apartado se presenta la descripción del modelo de la simulación de la gestión de la cuenca del río Mijares y se incluyen los aspectos siguientes: representación del sistema superficial; representación del sistema subterráneo; representación de las demandas; aportaciones; definición de prioridades en la gestión; y la descripción de escenarios de simulación de la gestión.

\subsubsection{Sistema superficial.}


El sistema superficial está representado, de acuerdo con los lineamientos del Sistema Soporte a la Decisión Aquatool, por diferentes tipos de conducciones: tipo 1, tipo 2 y tipo 3 (figura 6.6); embalses y azudes (Sopeña, 2002).

Conducciones tipo 1. Corresponde a una conducción simple, sin filtraciones. Este tipo de conducción se asignó a los siguientes tramos de ríos:

- Río Mijares, aguas abajo del embalse Arenós hasta la confluencia con el río Villahermosa.

- Río Mijares, aguas abajo del embalse Sichar por un corto tramo.

- Río Villahermosa.

- Río Lucena.

- Rambla de la Viuda.

- Río Mijares poco antes de su confluencia con la Rambla de la Viuda y hasta su desembocadura al Mediterráneo.

Conducciones tipo 2. Son aquellas que presentan pérdidas por filtración en el cauce. Este tipo de conducción se asignó al tramo del río Mijares aguas abajo del embalse Sichar (después del tramo con conducción tipo 1) y hasta un poco antes de la confluencia con la Rambla de la Viuda.

Conducciones tipo 3. Corresponde a una conducción que presenta conexión hidráulica con un acuífero. Este tipo de conducciones se asignó al tramo del río Mijares aguas abajo de la confluencia con el río Villahermosa y hasta el embalse Sichar. 


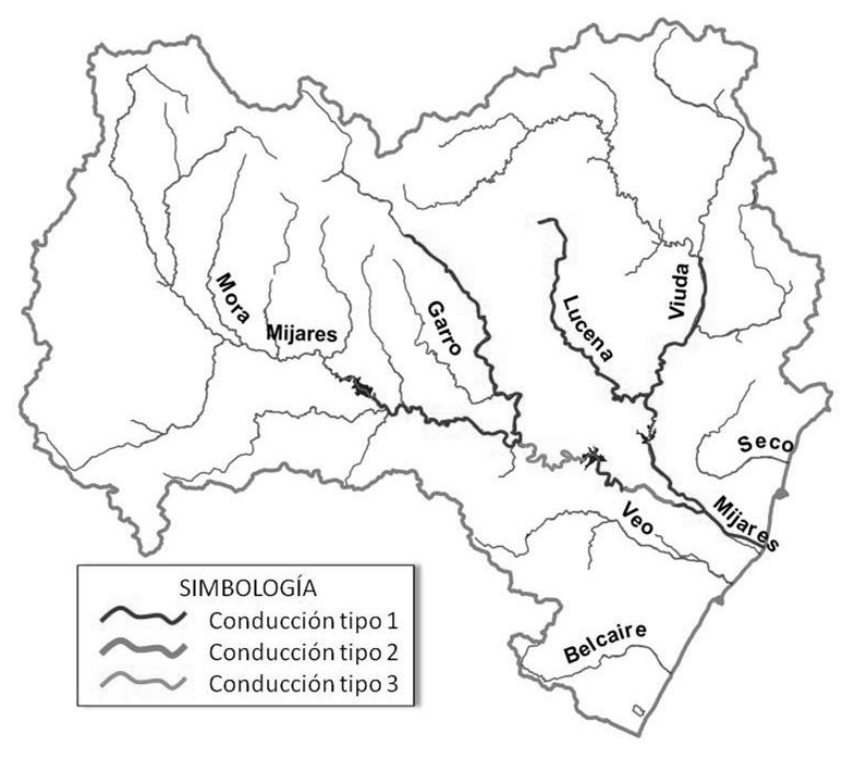

Figura 6.6 Definición del tipo de conducción en el modelo de gestión Fuente: Confederación hidrográfica del Júcar (1997) y elaboración propia

En el tramo final, el río recarga al acuífero, produciéndose importantes pérdidas por filtraciones en el cauce. El primer tramo del río desde la salida del embalse Sichar presenta fuertes filtraciones; este hecho propició la construcción del denominado Tramo Común cuya toma se localiza inmediatamente aguas abajo del reintegro de la central hidroeléctrica de Colmenar. El Tramo Común es un canal artificial situado en la margen izquierda del cauce que permite alimentar el Canal de la Cota 100 y el Canal de enlace de los riegos de $\mathrm{M}$ a Cristina sin que se produzcan pérdidas por filtraciones. Casi la totalidad del agua que lleva el río se deriva hacia el tramo común, dejando únicamente en el cauce del río el caudal ecológico (figura 6.7). Las filtraciones en este primer tramo se estiman en unos $200 \mathrm{l} / \mathrm{s}(\mathrm{CHJ}, 1997)$, unos $0,527 \mathrm{hm}^{3} / \mathrm{mes}$ el cual se ha definido como caudal mínimo ecológico. Las pérdidas en la actualidad se concentran en la zona entre el retorno del tramo común y las tomas de los riegos tradicionales. Se han estimado leyes de pérdidas en función de los caudales circulantes diferentes para los meses de invierno y verano. 


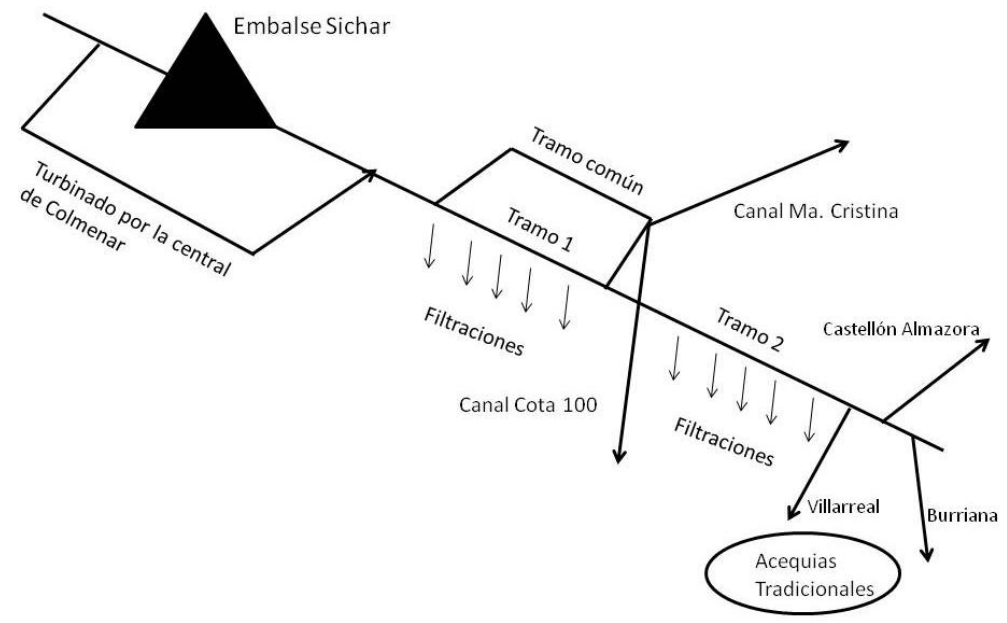

Figura 6.7 Esquema del tramo final del Mijares Fuente: Confederación Hidrográfica del Júcar (1997) y elaboración propia

Embalses y azudes. Este tipo de infraestructura corresponde al mencionado en el apartado 6.1.5, y en total son tres embalses y un azud (Alcora) representados. En el Anejo $\mathrm{C}$ se puede consultar información más detallada relacionada con esta infraestructura.

\subsubsection{Sistema subterráneo.}

Los acuíferos han sido considerados, en este caso, exclusivamente como depósitos de agua no conectados hidráulicamente con el sistema superficial, y cuyo objetivo es contar con una unidad de estado que indica el llenado y vaciado (volumen almacenado).

\subsubsection{Demandas}

Las principales demandas representadas en el modelo corresponden a los usos descritos en el apartado 6.1.4. Cada demanda se denomina como Unidad de Demanda (UD) relativa al uso que tiene: agrícola (UDA); urbana (UDU) e industrial (UDI). Sin embargo, para el análisis del sistema se consideraron exclusivamente las demandas principales: agrícola y urbana. El uso agrícola es el que demanda un mayor volumen del sistema hídrico superficial, mientras que el abastecimiento urbano en su totalidad se hace por medio de la explotación de aguas subterráneas.

Demanda agrícola. Las catorce UDAs que forman parte del ámbito del sistema de explotación del río Mijares (figura 6.8), se han agrupado de acuerdo a su ubicación geográfica, su sistema de explotación y el origen del recurso. 


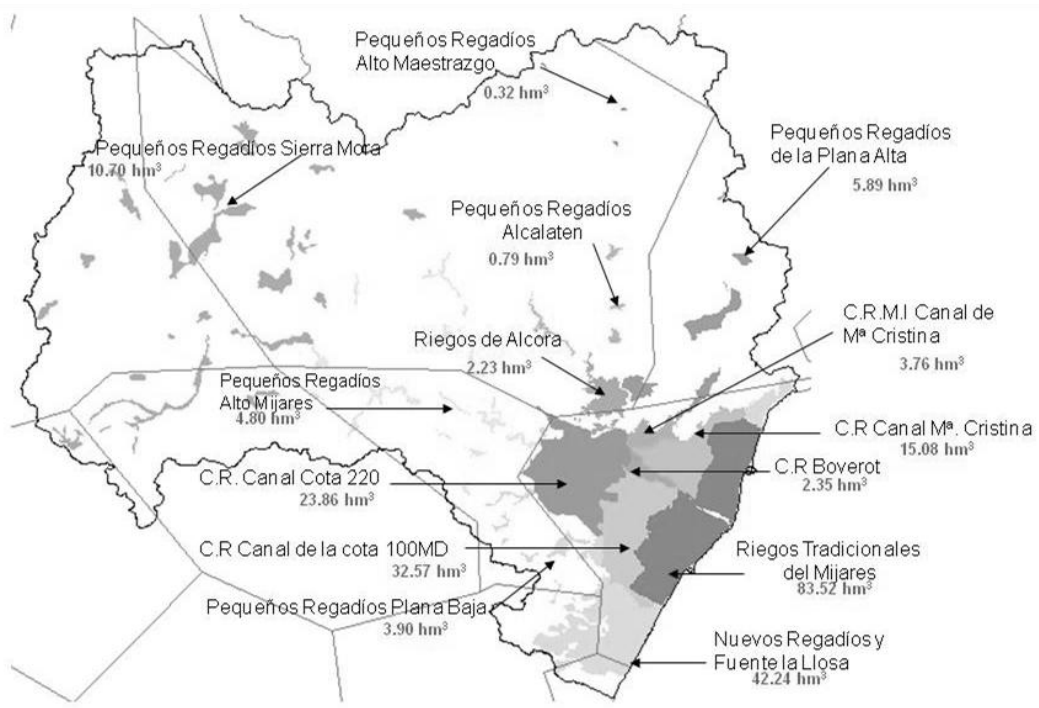

Figura 6.8 Unidades de demanda agrícola del sistema del río Mijares Fuente: Confederación Hidrográfica del Júcar (1997) y elaboración propia

La distribución mensual de cada una de las demandas se estimó considerando una hectárea representativa y utilizando los porcentajes indicados en los informes del CEDEX (1991), (figura 6.9).

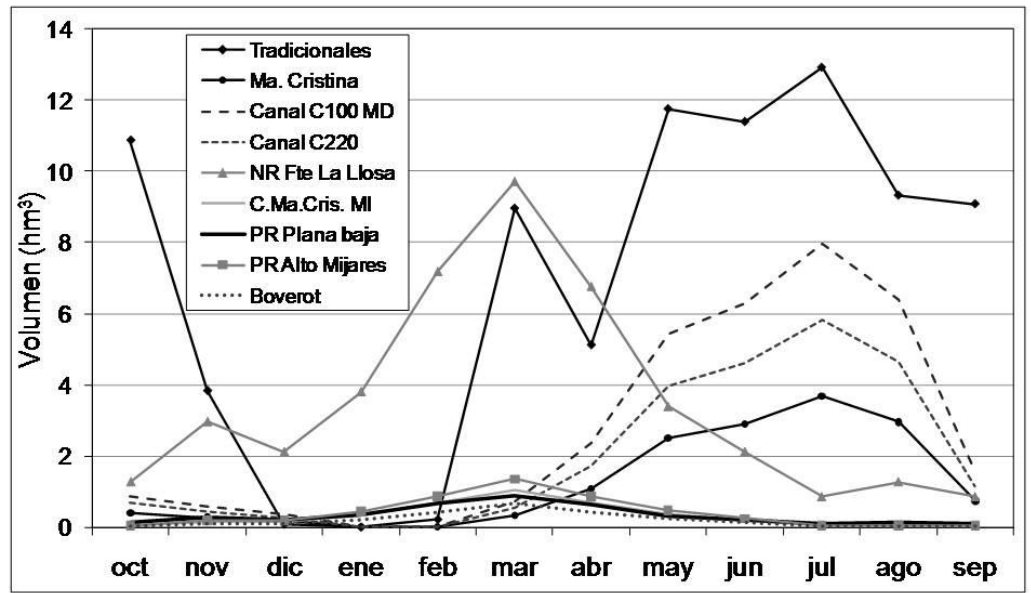

Figura 6.9 Distribución mensual de la asignación del agua en las demandas agrícolas

Demanda urbana. La demanda urbana fue considerada tomando en cuenta las Unidades Hidrogeológicas en las que se encontraban las poblaciones ubicadas en la región del Sistema de Explotación Mijares-Plana de Castellón. El total de la demanda anual por 
Unidad Hidrogeológica (UHG), se muestra en la tabla 6.3 y corresponde a la suma de demandas de los municipios que se encuentran en cada UHG.

Tabla 6.3 Demanda urbana anual por UHG
\begin{tabular}{|c|c|}
\hline UHG & Demanda $\left(\mathbf{h m}^{\mathbf{3}} \mathbf{)}\right.$ \\
\hline 8.05 & 0,27 \\
\hline 8.06 & 3,35 \\
\hline 8.07 & 1,13 \\
\hline 8.12 & 57,00 \\
\hline 8.13 & 1,39 \\
\hline 8.14 & 0,13 \\
\hline 8.15 & 0,01 \\
\hline 8.20 & 3,56 \\
\hline 8.21 & 0,63 \\
\hline TOTAL & $\mathbf{6 7 , 4 7}$ \\
\hline
\end{tabular}

\subsubsection{Aportaciones.}

Las series de aportaciones restituidas a régimen natural que se han utilizado para definir las aportaciones intermedias que se introducen en el modelo son las incluidas en el Plan Hidrológico de la Cuenca del Júcar, ampliadas hasta el año 2002 con datos del seguimiento y revisión del mismo plan. De esta forma se cuenta con las series completas de los años hidrológicos 1940-1941 a 1999-2002 (Sopeña, 2002). Estas series proporcionan el caudal circulante a su paso por las estaciones de control, en $\mathrm{hm}^{3} / \mathrm{mes}$, restituido al régimen natural. Las series de aportaciones fueron asignadas para: (1) las entradas al embalse de Arenós; (2) las aportaciones intermedias Arenós-Sichar; (3) las entradas al embalse de María Cristina y (4) las entradas al embalse de Alcora ( figura 6.10).

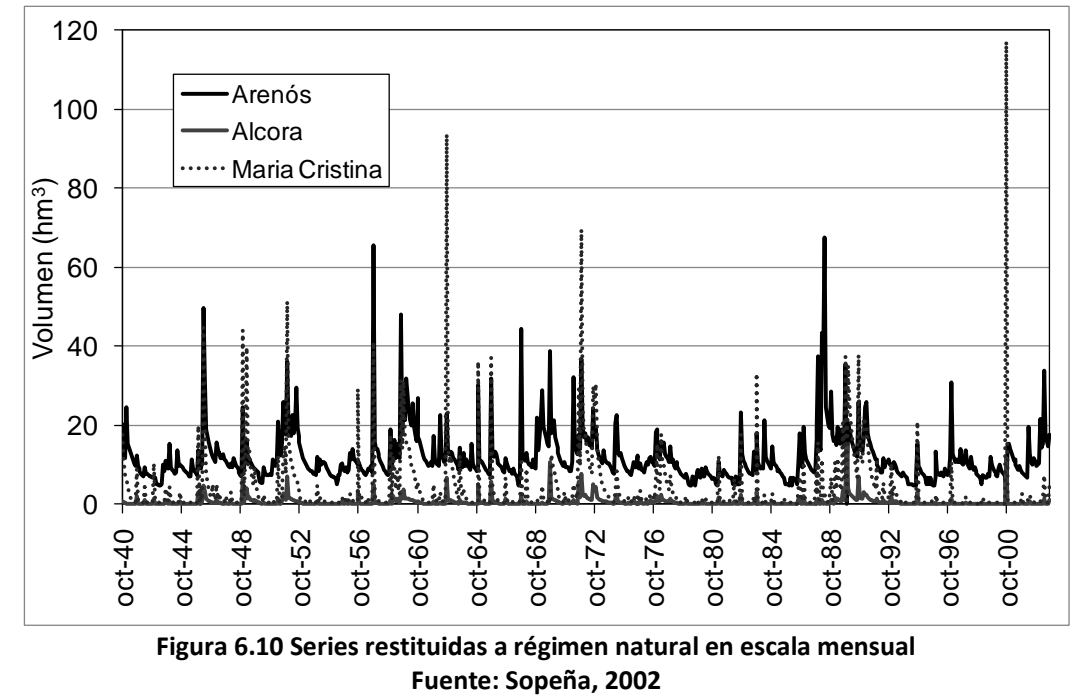




\subsubsection{Reglas de operación.}

Las aguas de la comarca de la Plana, especialmente las del río Mijares, han sido siempre objeto de disputa por parte de las diferentes poblaciones desde el siglo XIII hasta la actualidad. Las poblaciones de Burriana, Almazora, Castellón y Villarreal, desde el siglo XIII, después de la conquista cristiana del territorio, monopolizaron el uso de las aguas del río Mijares, al aprovechar buena parte del preexistente sistema musulmán de regadíos. Con el paso del tiempo otras poblaciones se consideraron con los mismos derechos para una utilización que la historia les había negado sistemáticamente. Esto fue motivo de disputa durante ocho siglos (Sopeña, 2002). Por tales circunstancias, se elaboró el Convenio de bases para la ordenación de las aguas del río Mijares en el año de 1970. Este documento marca un hito en la ordenación de la cuenca pues ha puesto fin a los litigios entre comunidades. El Convenio consta de una relación detallada de los distintos aprovechamientos con determinación de la clase y cuantía de los mismos, superficie regable de cada uno y otras características.

Como resultado de dicho Convenio, la gestión del sistema se realiza mediante una regla de explotación determinista (figura 6.11). En esa curva se define un volumen útil como curva de reserva para el embalse de Sichar, variable mes a mes y con un máximo en febrero de $36 \mathrm{hm}^{3}$. Tras la construcción de Arenós, la gestión del conjunto de embalses de Arenós y Sichar consiste en satisfacer las demandas existentes desde el embalse de Sichar, por encontrarse, este último, aguas abajo del anterior. Una vez agotada la reserva del embalse de Sichar, se realizarán las sueltas necesarias desde el embalse de Arenós. Si el volumen almacenado en el conjunto de Arenós-Sichar es menor que el umbral de la curva, entonces no se suministra agua a los riegos mixtos, y sólo se suministran los regadíos tradicionales, más prioritarios. Existen unos volúmenes mínimos en cada embalse, que lleva a modificar la curva de reserva, adicionando $5 \mathrm{hm}^{3}$ durante todos los meses.

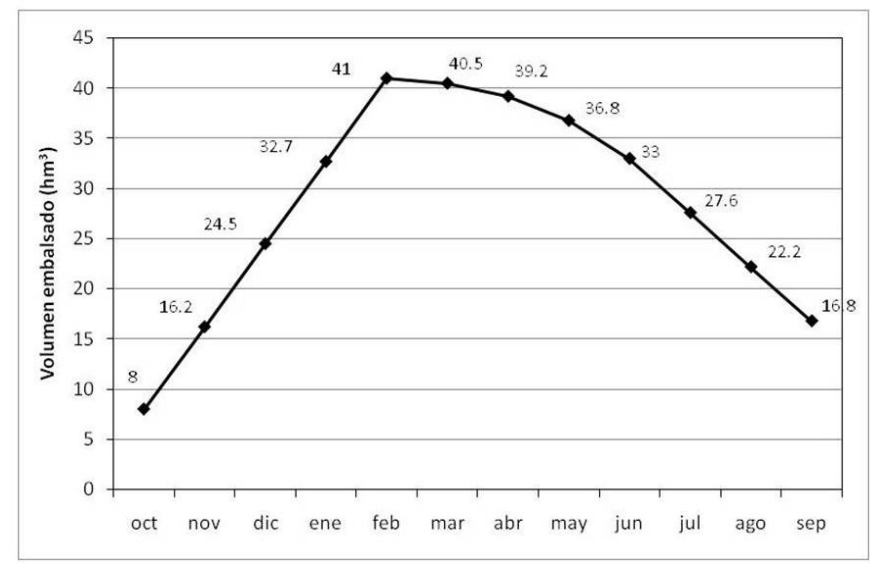

Figura 6.11 Curva de reserva del Convenio 1970 Fuente: CHJ (1997), modificada por Sopeña,2002 
La simulación de la gestión del sistema del Mijares se llevó a cabo para el total de las demandas indicadas anteriormente (figura 6.12a). Sin embargo, para realizar el análisis de políticas de precios se utilizó un esquema más sencillo con el fin de simplificar los cálculos (6.12b). Dicho esquema consistió en utilizar exclusivamente las demandas agrícolas de los riegos Tradicionales y la de los Riegos Mixtos que se dividen en las demandas de: Ma Cristina, Canal Cota 100 y Canal Cota 220 (Sopeña, 2002) actualizándose de acuerdo con los últimos datos disponibles en la Confederación Hidrográfica del Júcar (2006). Los valores de las demandas superficiales para el caso de los Riegos Mixtos, se consideraron como el $50 \%$ de la superficial, debido al tipo de concesión utilizado por la CHJ (las demandas hídricas para los riegos considerados en el esquema simplificado se pueden ver en la figura 6.9). Para no complicar el modelo durante el análisis de políticas de precios, tampoco se consideró el acuífero de la Plana pues no hay conexión directa entre el río y el acuífero. Únicamente se introdujo como filtraciones en el tramo final del modelo. De igual manera no se incluyen las centrales hidroeléctricas, ya que las sueltas de agua están supeditadas a los riegos. Tampoco se han incluido las demandas urbanas ya que éstas son abastecidas por el acuífero de la Plana. 


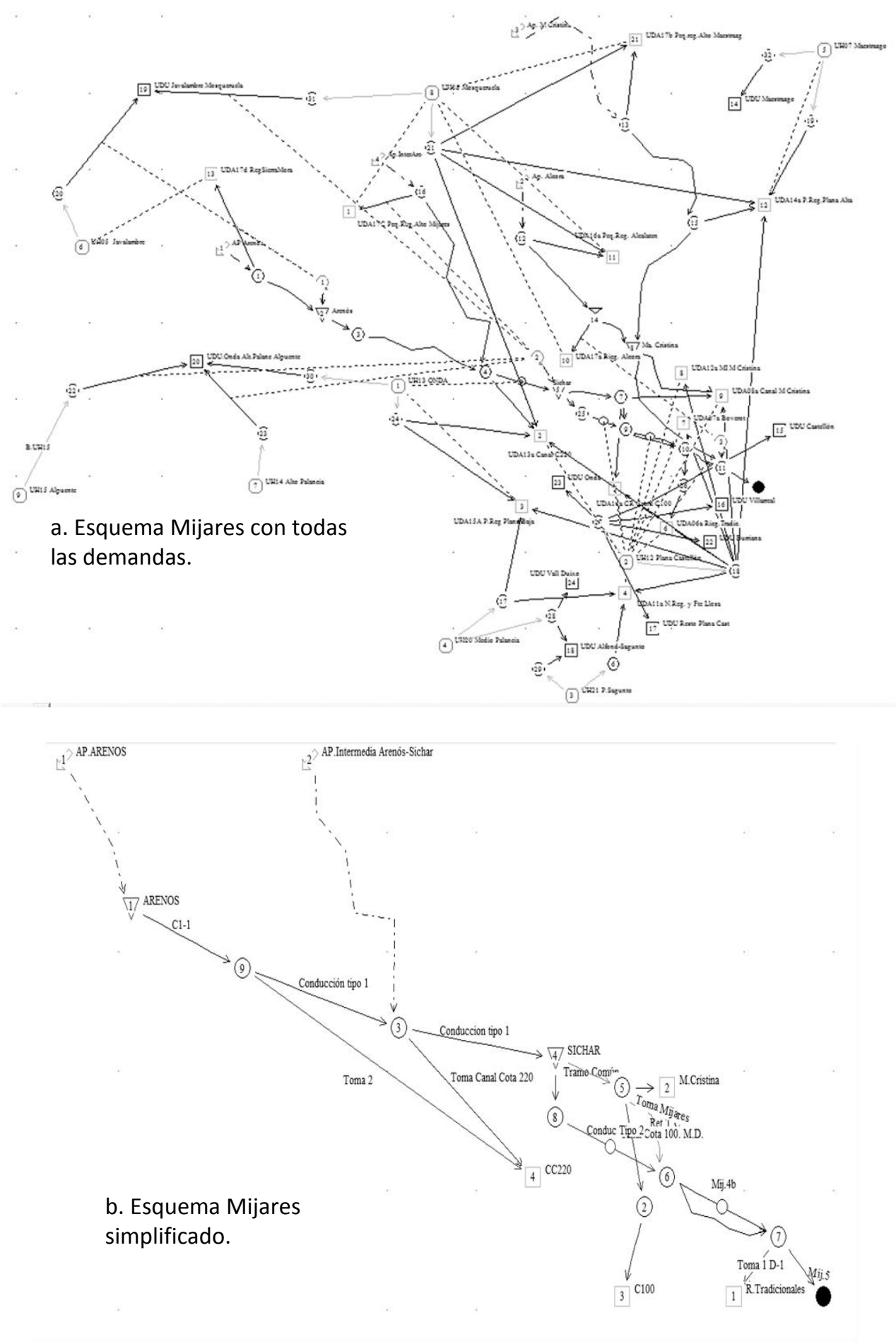

Figura 6.12 Esquemas correspondientes al modelo de simulación de la gestión del sistema del río Mijares 


\subsection{Caracterización económica del sistema.}

En este apartado se presenta la descripción de las curvas de demanda económica y el resumen de los costes variables de operación que se tomaron en cuenta para el análisis económico.

\subsubsection{Curvas de demanda económica.}

\section{Demanda agrícola.}

El Plan Hidrológico Nacional (MIMAM, 2002) identificó cinco grandes zonas en España caracterizadas por: una estructura productiva común; (la especialización de cultivos; y una estructura socioeconómica similar. Entre ellas está la de Castellón. Los dato disponibles de

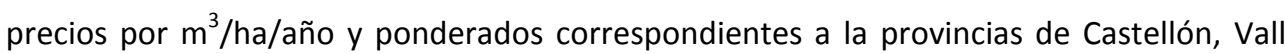
d'Uxó y Onda Canal 220, se ajustaron a una curva LOWESS (Cleveland y Devlin, 1988) no paramétrica (Figura 6.13), con objeto de obtener una función que caracterice la región bajo análisis.

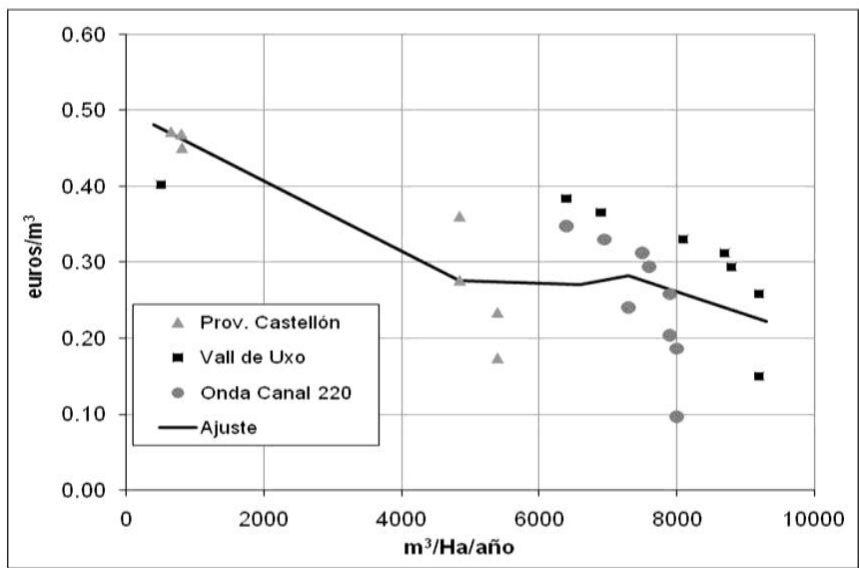

Figura 6.13 Curva de demanda ajustada para la zona de Castellón

Cuando se analiza la economía de los regadíos desde el punto de vista de las posibles transferencias externas, es importante considerar, conjuntamente con las curvas de demanda, el efecto de mermas de rentas, pues es posible que precios muy elevados de la curva de demanda, teóricamente alcanzables, lo sean a costa de una pérdida de renta tal que se desincentive la actividad del sector. Las curvas de la figura 6.14 realizadas para diferentes regadíos de la Comunidad Valenciana (Sumpsi et al, 1998) muestran los efectos sobre la renta agraria (miles de pts/ha) de imponer nuevas tasas del agua (pts $/ \mathrm{m}^{3}$ ) en algunas zonas regables de la cuenca del Júcar. En los tramos iniciales de la curva de demanda, que son totalmente inelásticos, la pérdida de renta del agricultor se debe exclusivamente a la dotación inicial de agua al suponer que nuevas tarifas se pagan por el 
volumen de agua consumida. Esto sucede porque los agricultores no siguen alguna estrategia para ahorrar agua, aunque pierden renta al pagar más por la dotación inicial. Se aprecia que las mayores pérdidas de renta agraria se producen en la Comunidad de regantes de la Acequia Real del Júcar.

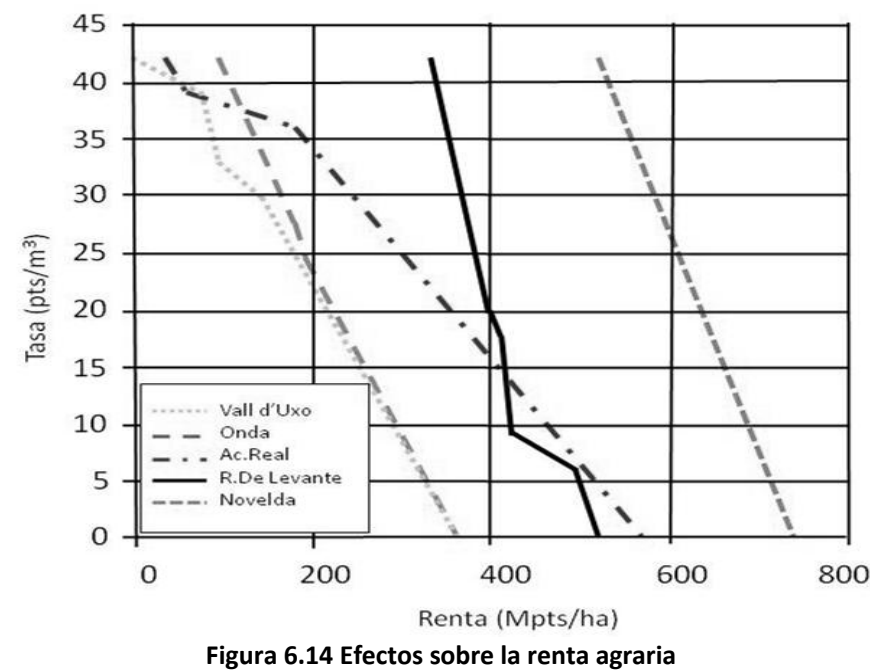

Fuente: Sumpsi et al. (1998)

La zona cultivable que el sistema Mijares-Plana de Castellón riega presenta predominantemente una superficie para cítricos que representa el 91\% del total del área cultivada. El 5\% del total cultivado corresponde a hortalizas y, el resto, a frutales, arroz y otros cultivos (García Mollá, 2000).

El Ministerio de Medio Ambiente (MIMAM, 2000), con base en los trabajos de Blanco (2008) e Iglesias y Blanco (2008) han propuesto una serie de curvas de demanda económica, dándole un valor al agua por hectárea regada del cultivo en cada una de las comunidades de regantes. Estas curvas se han obtenido mediante la técnica de Programación Matemática Positiva (PMP), desarrollada inicialmente por Howitt (1995). Este método supera algunas limitaciones importantes de la programación matemática tradicional. Una gran ventaja de este enfoque es que se rescata la información adicional de los datos observados en el comportamiento de los agricultores, lo que permite una interpretación teórica de los datos observados en una situación real. Además el método permite utilizar menor cantidad de datos con un modelo que considera los cambios graduales de las variables exógenas.

Como ejemplo, se muestra la curva correspondiente a los riegos tradicionales (figura 6.15). Según Sumpsi et al. (1998), en las UDAs del Mijares, tanto la existencia de prácticamente un monocultivo (cítricos) como la pequeña dimensión de las explotaciones, 
hace que no interese la sustitución entre cultivos de regadío y que tampoco se traspase de regadío a secano, lo que explica la baja elasticidad en las curvas de demanda.

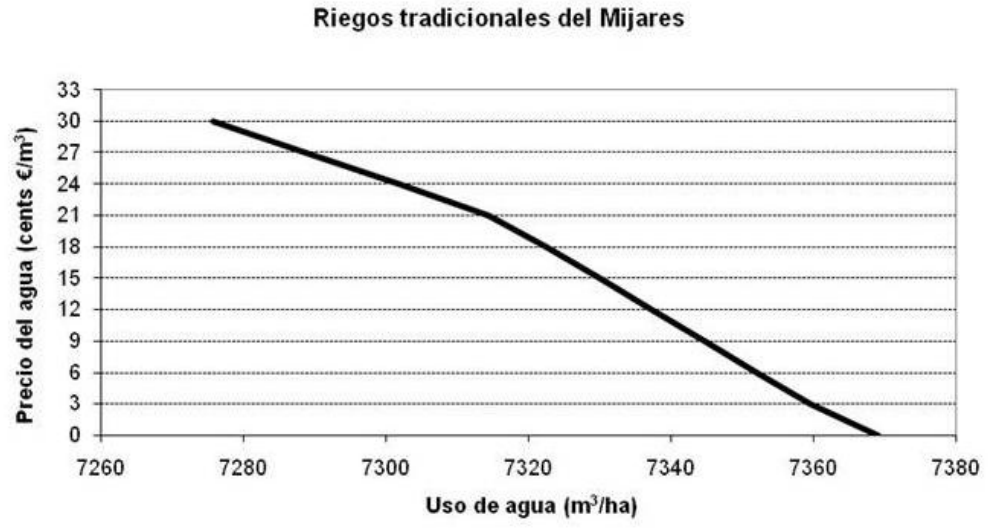

Figura 6.15 Ejemplo de una curva de demanda económica Fuente: Ministerio del medio Ambiente (2000)

Las curvas anteriores representan un rango muy pequeño de la dotación de agua en cada una de las comunidades de regantes. Sin embargo, para efectos del presente análisis económico, se requiere tener curvas que abarquen un mayor rango en las dotaciones de agua, por lo que se han extendido dichas curvas (figura 6.16) con base a ciertas hipótesis.

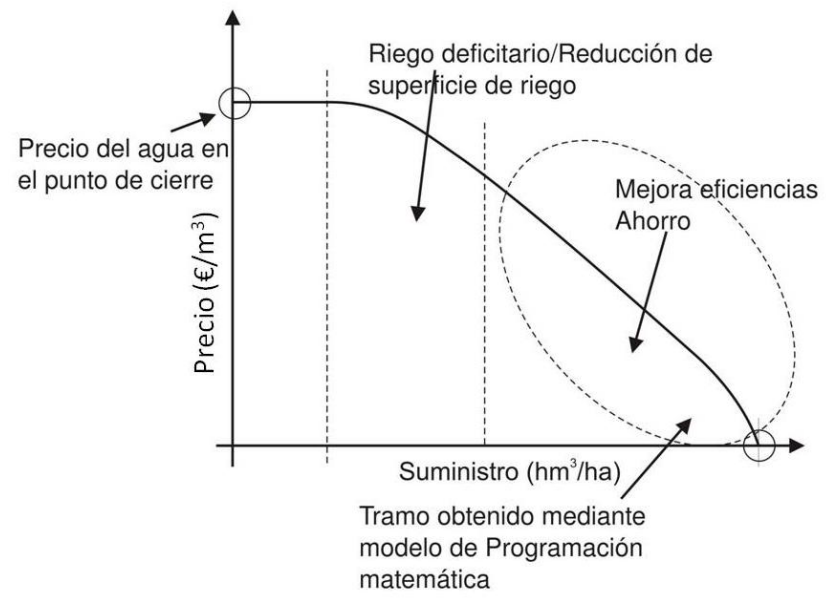

Figura 6.16 Consideraciones en las curvas de demanda

El punto de corte con el eje de abscisas corresponde a la dotación con la que están regando en promedio las distintas UDAs analizadas. El primer tramo (en círculo punteado) se basa en las curvas obtenidas mediante programación matemática. En este primer tramo, la respuesta de los agricultores ante el aumento de precio del agua se traduce en 
mejores prácticas de riego, ahorro y mejora de eficiencia en general. Con eficiencias altas, aumenta el valor económico unitario del agua (mayor producción neta por $\mathrm{m}^{3}$ utilizado).

Se selecciona un precio del agua en el punto de cierre de la curva, que para los cítricos ronda los $0,70 € / \mathrm{m}^{3}$ en la mayoría de las fuentes consultadas (ej. Colino y Martínez, 2002). El precio de cierre representa el nivel del precio del agua en el que, ceteris paribus, los costes totales se igualan a los ingresos totales. A ese nivel de precio del input, los ingresos sólo son capaces de cubrir los costes variables, por lo que al agricultor le será indiferente seguir produciendo o no. Cualquiera que sea su decisión, debe hacer frente a unas pérdidas inevitables en el corto-medio plazo como son las del pago de costes fijos. Niveles de suministro por debajo de la dotación mínima requerida con la máxima eficiencia alcanzable suponen introducir un efecto de riego deficitario. El riego deficitario es factible en los cultivos leñosos, pudiendo obtenerse importantes reducciones del suministro sin grandes pérdidas en la producción final (siempre que el agua aplicada se distribuya de forma óptima a lo largo de las etapas de desarrollo del cultivo).

Con lo anterior, las curvas de demanda utilizadas en el análisis económico toman la forma de la mostrada en la figura 6.17 como ejemplo. En esa figura se observa la curva de demanda en las modalidades de dotación ( $\mathrm{m}^{3} /$ ha-año) y demanda volumétrica $\left(\mathrm{hm}^{3} / a n ̃ o\right)$. En el Anejo C puede observarse la totalidad de las curvas de demanda utilizadas.

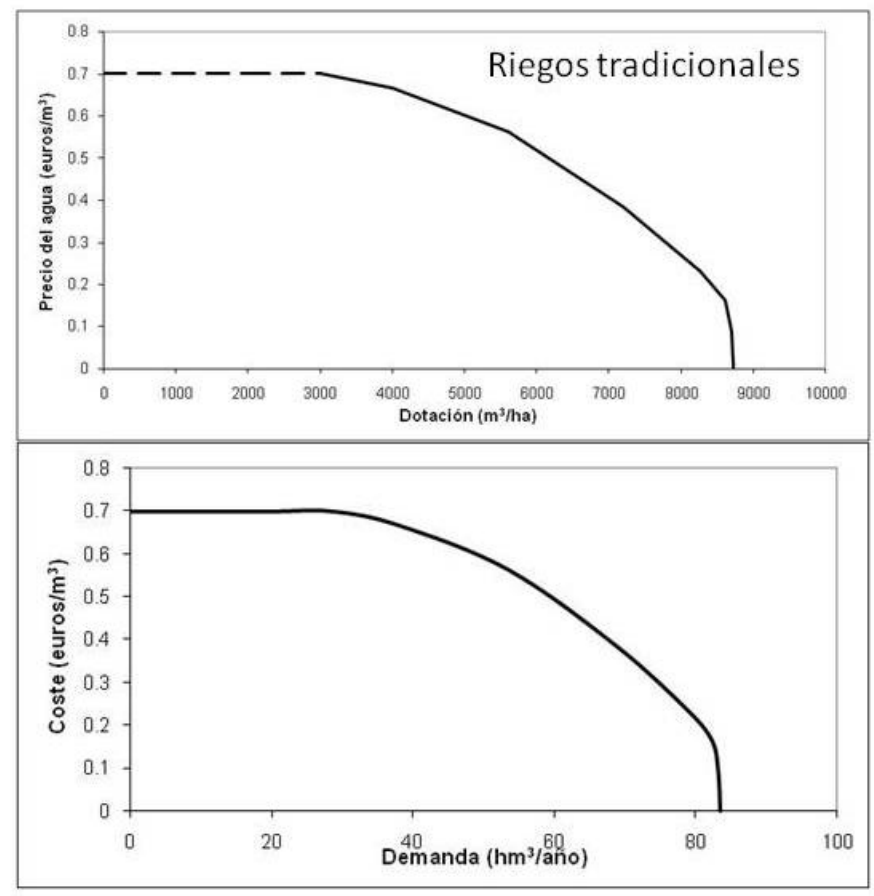

Figura 6.17 Ejemplo de curva de demanda económica completa Fuente: MMA (2000) y elaboración propia 


\section{Demanda urbana.}

Los servicios de agua urbana en la Demarcación Hidrográfica del Júcar (DHJ, en adelante) se prestan a una población de 4,3 millones, junto con otros consumos urbanos (industria, comercio y servicios públicos). El agua total suministrada ha sido estimada en 360 $\mathrm{hm}^{3} /$ año, con una eficiencia media en la red del $80 \%$ (CHJ, 2005). Los servicios incluyen el suministro y tratamiento de agua potable (gestionados por los Ayuntamientos o a través de empresas mixtas o concesiones), y la recogida, transporte, depuración y vertido de aguas residuales (la mayoría gestionadas por la Entidad Pública de Saneamiento de Aguas de la Comunidad Valenciana). La recuperación de costes de los servicios urbanos de agua en 2005 se estima en un $95 \%$ (CHJ, 2005).

El coste unitario por metro cúbico facturado de estos servicios se ha estimado en 1,06 $€(\mathrm{CHJ}, 2005)$, cifra que se ha adoptado como precio medio al nivel de consumo actual para las UDUs modeladas (figuras 6.18 a y b). En esta cifra no se incluye el coste del servicio de alcantarillado, $0,42 € / \mathrm{m}^{3}$, ya que éste no es estrictamente un coste asociado al suministro de agua urbana.

Las curvas de demanda urbana para el sistema del río Mijares se determinaron con base en funciones de Cobb-Douglas como se ha explicado en el apartado 3.2, usando una elasticidad-precio constante de -0,65.
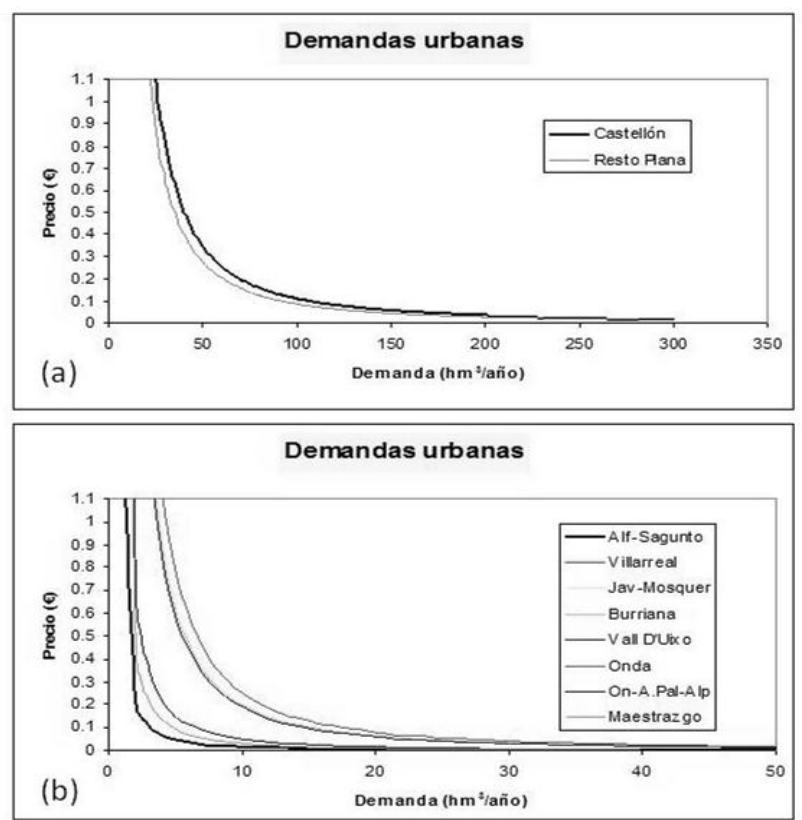

Figura 6.18 Curvas de demanda urbana Fuente: $\mathrm{CHJ}$ y elaboración propia 
En las curvas de la figura 6.18 , se observa que la elasticidad-precio es negativa (disminuyen los consumos al aumentar el precio) y las demandas son inelástica en los rango de demanda menores a $50 \mathrm{hm}^{3}$ en las curvas de la figura $6.18 \mathrm{a}$ y $3 \mathrm{hm}^{3}$ en las curvas de la figura $6.18 \mathrm{~b}$.

\subsubsection{Costes variables de operación del agua subterránea.}

Los costes variables de operación corresponden a los costes de bombeo, los cuales corresponden a los reportados en el Informe Técnico del Coste del Uso de Aguas Subterráneas en España (DGHO, 2003). Según dicho informe, la cuenca del Júcar es la que tiene el mayor grado de explotación de aguas subterráneas de todas las cuencas españolas, llegando a sobrepasar los $1580 \mathrm{hm}^{3}$ /año para las 41 unidades hidrogeológicas. Los costes de extracción del agua subterránea, para las Unidades Geohidrológicas que forman parte del Sistema del río Mijares, se muestran en la tabla 6.4.

Tabla 6.4 Costes de extracción del agua subterránea. Mijares

\begin{tabular}{|l|l|c|c|c|c|c|}
\hline \multirow{2}{*}{ Unidad Hidrogeológica } & \multicolumn{2}{|c|}{ Coste $\left(€ / \mathrm{m}^{3}\right)$} & \multicolumn{3}{|c|}{ Coste total $(€)$} \\
\cline { 3 - 7 } & Abast. & Riego & Abast & Riego & Total \\
\hline 8.05 & Javalambre & 0,07 & & 137,992 & & 137,992 \\
8.07 & Maestrazgo & 0,06 & 0,09 & 120,747 & $1.086,726$ & $1.207,473$ \\
8.12 & Plana de Castellón & 0,05 & 0,08 & $2.017,598$ & $7.413,501$ & $9.431,099$ \\
8.13 & Onda & 0,12 & 0,24 & 736,171 & 490,781 & $1.226,952$ \\
8.20 & Medio Palancia & 0,08 & 0,13 & 152,352 & $3.047,035$ & $3.199,387$ \\
8.21 & Plana Sagunto & 0,04 & 0,07 & 126,009 & $3.343,449$ & $3.469,458$ \\
\hline
\end{tabular}

\subsection{Simulación con prioridades. Coste del Recurso}

Al igual que para el caso sintético, la simulación de la gestión se ha realizado con paso de tiempo mensual. Aunque la simulación de la gestión se hace a escala mensual (Álvarez, et al, 2006), los resultados económicos se calculan mediante agregación de valores mensuales en las curvas de demanda económica anuales, considerando para cada año hidrológico (de octubre a septiembre) la suma de los flujos mensuales generados por el simulador.

En este apartado se presentan los resultados de simulación de la gestión y su valoración económica con base en las curvas de demanda. Para proceder a la simulación económica se ha considerado lo siguiente:

- El periodo temporal está definido por la serie histórica de aportaciones de 30 años, desde octubre de 1970 hasta septiembre de 2000. El empleo de series hidrológicas extensas permite considerar la variabilidad temporal en la disponibilidad del recurso. 
- Se han elegido dos puntos de interés para el cálculos del CMOR en el Sistema MijaresPlana de Castellón que corresponden a los embalses de Arenós (nudo 2) y Sichar (nudo 5).

- La prioridad en el suministro corresponde a los riegos Tradicionales mientras que los riegos mixtos están sujetos al volumen almacenado en los embalses Arenós y Sichar una vez suministrada la demanda Tradicional.

- En la simulación se suministra el recurso de acuerdo a lo que el uso requiere y conforme a las reservas en el embalse (figura 6.19)

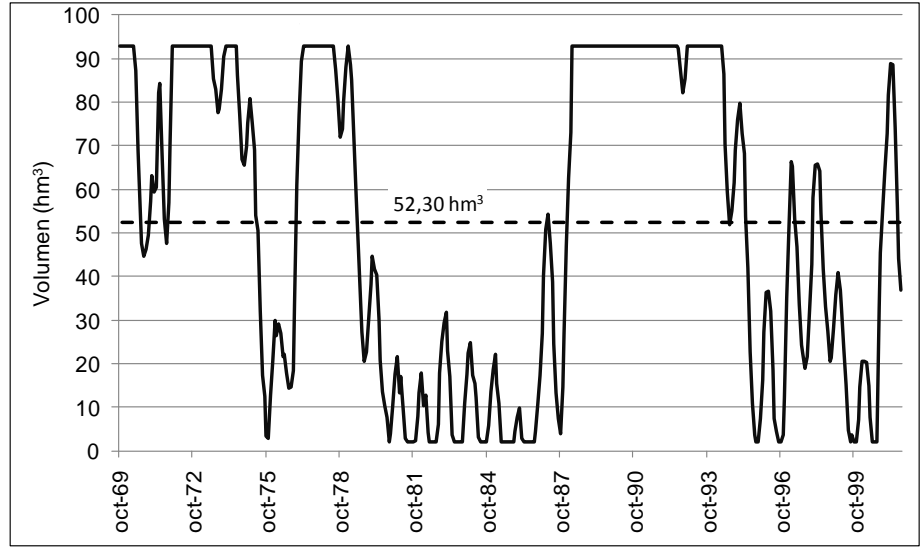

Figura 6.19 Volumen embalsado en Arenós. Simulación

Las demandas agrícolas son las que más agua superficial requieren del Sistema de Explotación. El modelo en SimGes garantiza que la demanda de agua a los Riegos Tradicionales sea satisfecha en un 95\%, al igual que para las demandas de los Canales Cotas 100 y 220 y Canal de Ma Cristina. En el modelo se han considerado también otras demandas que aunque no necesariamente toman agua directamente del Mijares, lo hacen de alguno de sus afluentes.

Las demandas de agua para las poblaciones inmersas en la zona del Sistema de explotación del río Mijares son abastecidas en su totalidad por los diferentes acuíferos que conforman las nueve Unidades Hidrogeológicas mostradas (véase tabla 6.1, apartado 6.1.3). Los resultados de SimGes muestran garantías de suministro del $100 \%$ para las demandas urbanas.

\subsubsection{Análisis de resultados de la simulación. Coste de escasez}

El coste de escasez de agua está íntimamente ligado al déficit que se presente en el suministro a cada una de las demandas agrícolas. El esquema completo del sistema, 
contempla un mayor número de demandas que deberá satisfacer con un buen grado de garantía. El modelo en SimGes se calibró para que las demandas fueran satisfechas con el menor déficit posible. Sin embargo, los costes de escasez de agua para los cultivos suministrados a las demandas de Riegos Tradicionales presentan un mayor valor que el correspondiente a las demandas suministradas por los Canales de las Cotas 100 y 220 (figura 6.20). Lo anterior se debe a que el déficit que presentan los Riegos Tradicionales es mucho mayor que el de los Riegos Mixtos (figura 6.21). El coste de escasez de agua para los cultivos suministrados por el Canal Ma Cristina es nulo, lo cual indica que el suministro está siempre garantizado para dicha demanda.
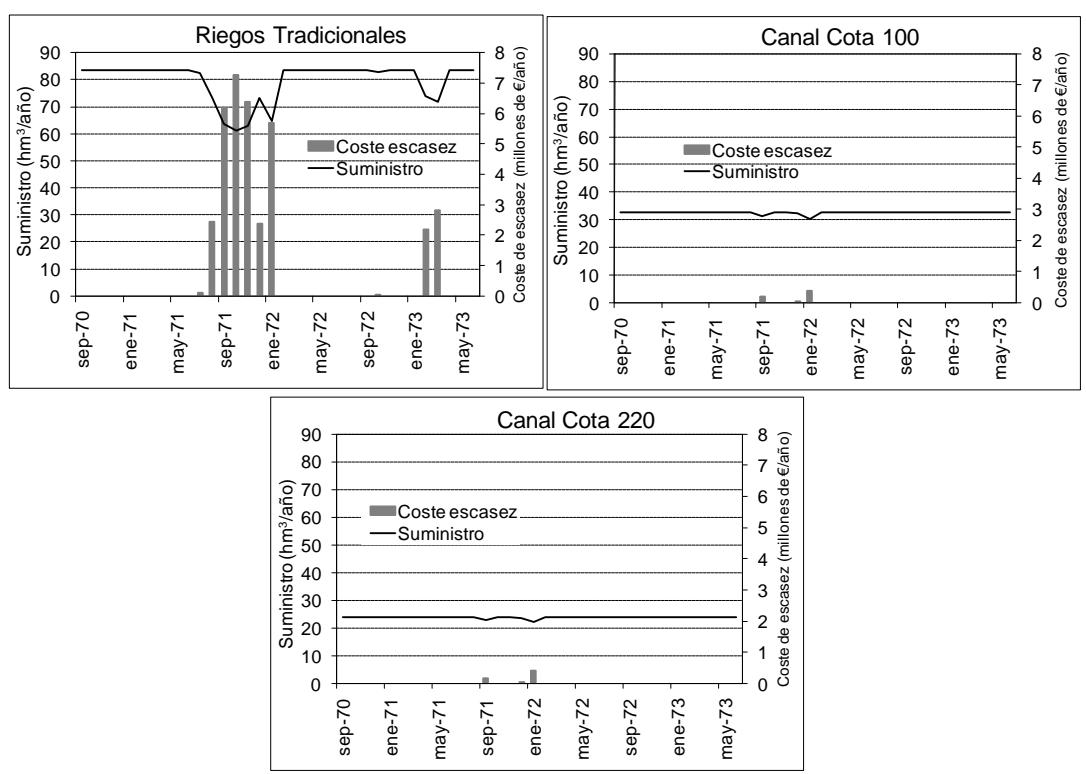

Figura 6.20 Coste de escasez y suministro en las UDAs consideradas en la simulación 


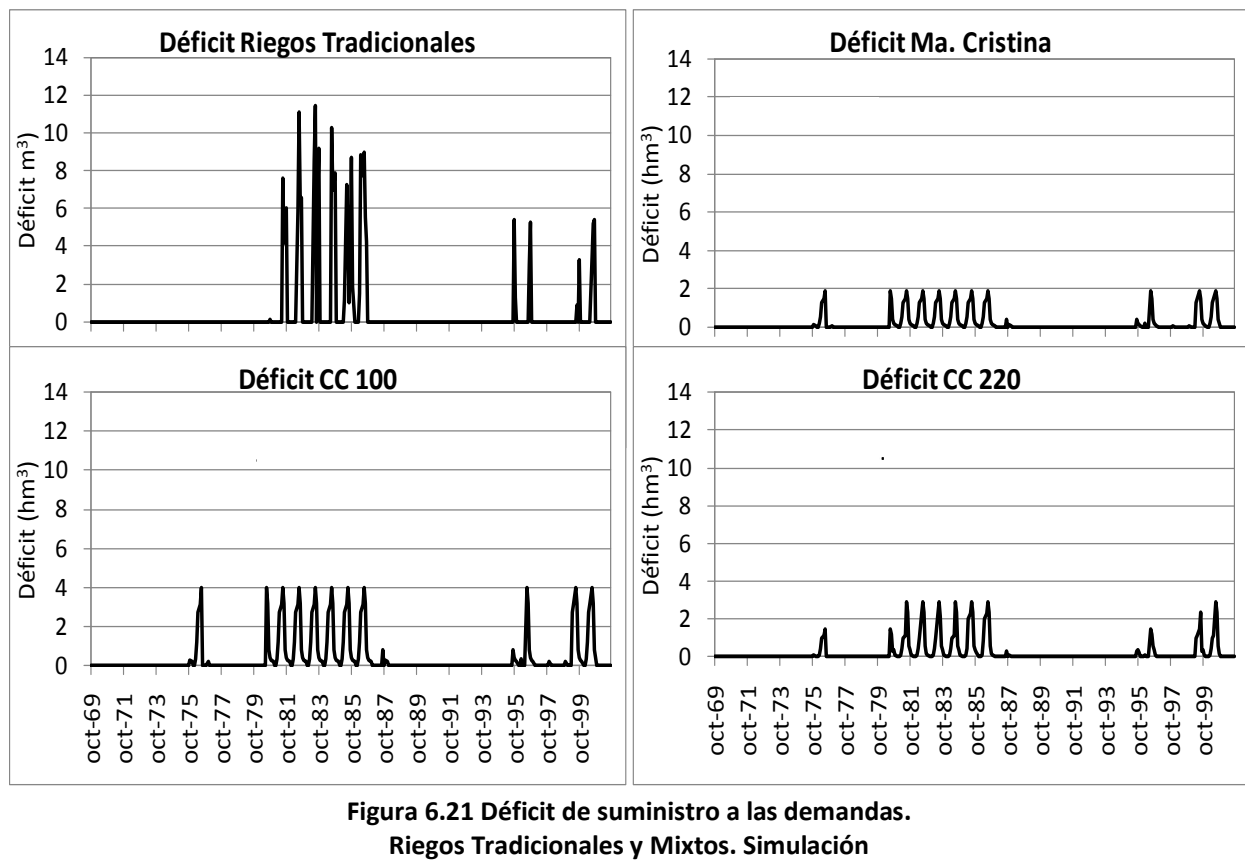

Como era de esperarse los mayores costes de escasez (figura 6.22) se presentan cuando los volúmenes en los embalses de Sichar y Arenós se sitúan en los niveles mínimos En épocas de grandes sequías (1982-88 y 1995-2000) se presenta el mayor valor marginal del recurso en los embalses.

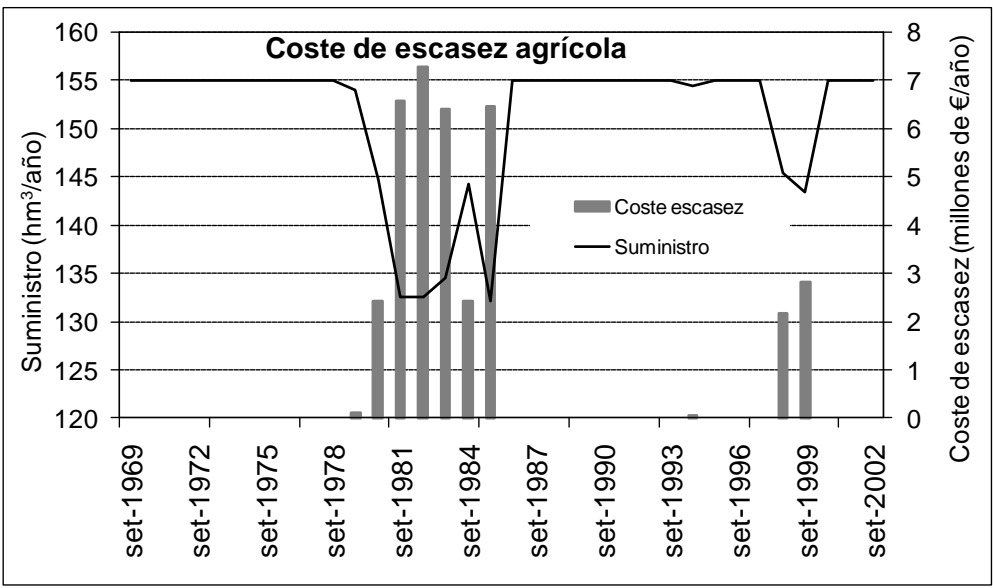

Figura 6.22 Coste de escasez agrícola y volumen embalsado

La figura 6.23 muestra el coste de escasez del recurso en unidades de demanda agrícola clasificadas según tipos de cultivo que se practican: cítricos, herbáceos y leñoso herbáceos. 

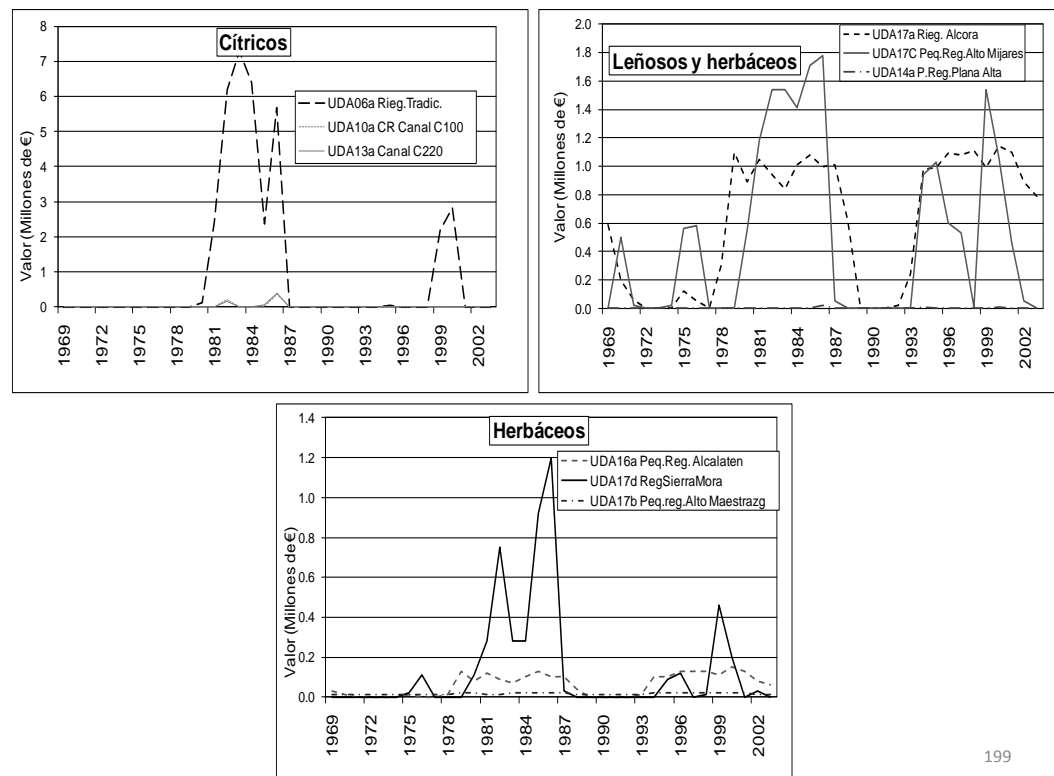

Figura 6.23 Costes de escasez en diferentes UDAs

Los Riegos Tradicionales, fundamentalmente cítricos (98\%), presentan mayor coste de escasez, del orden de los 7 millones de euros durante el periodo 82-84, que el de los riegos de los canales Cotas 100 y 220 (de un orden máximo de medio millón de euros anuales para el mismo periodo), mientras que los riegos del canal de $M$ a Cristina presentaron un coste de escasez menor al medio millón de euros anuales.

Los cultivos herbáceos y leñosos de la UDA Alto Mijares presentan costes de escasez entre 0,5 y 1,8 millones de euros en el periodo 1975-1986, mientras que los regadíos de Alcora tienen un coste de escasez más uniforme en todo el periodo de análisis, con máximos anuales de 1,1 millones de euros. Cabe destacar que estos últimos regadíos, son abastecidos por un pequeño embalse considerado como azud en el esquema SimGes y presenta déficits de suministro de un orden máximo de $0,6 \mathrm{hm}^{3}$.

Los riegos de la Sierra Mora, de herbáceos en su mayoría, presentan un contrastado coste de escasez, con picos de hasta 1,2 millones de euros anuales, en comparación a lo de Alcalaten y Alto Maestrazgo, cuyos picos máximos son menores a 0,2 millones de euros anuales.

Dado que no se presentan déficits en el suministro a las demandas urbanas, no existe coste de escasez para las mismas. De acuerdo a los suministros para cada una de las unidades de demanda, se han obtenido los beneficios económicos mostrados en la figura 6.24 . 

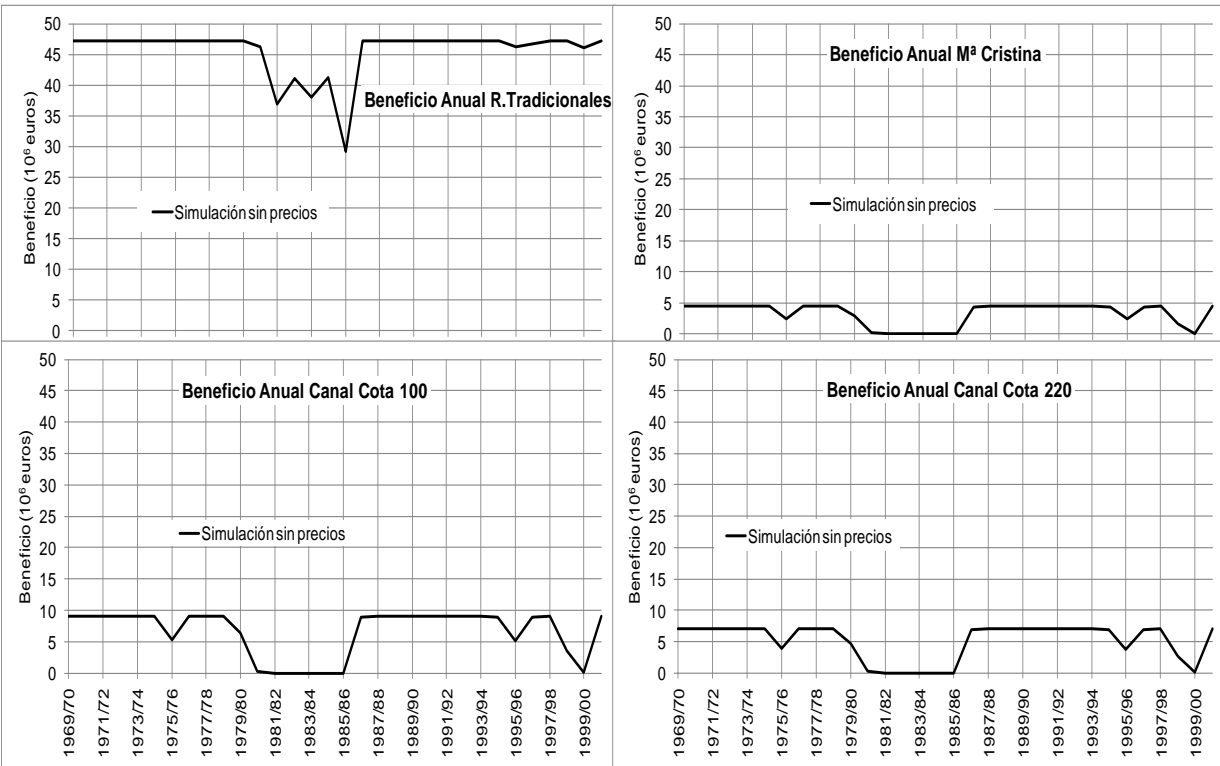

Figura 6.24 Beneficios anuales en las diferentes UDAs del Mijares. Simulación

\subsubsection{Análisis de resultados de la simulación. Coste del recurso en los embalses}

Como ya se ha comentado anteriormente, el CMOR se aproxima en la simulación mediante el cálculo de la variación de beneficios que ocurriría si hubiera una unidad menos de recurso en un punto e instante determinados. En la figura 6.25 se observa que el mayor valor marginal en el embalse de Arenós corresponde al periodo en donde hay menos reservas en los embalses, y por tanto más escasez del recurso. En los períodos de coste de recurso alto, los déficit en las demandas y por consiguiente los costes de escasez son elevados. Cuando los volúmenes embalsados son altos, no hay déficit de suministro y por tanto el valor marginal o valor de una unidad adicional de agua en el embalse es nulo (el disponer de una unidad más no aporta ningún beneficio adicional para el sistema). 


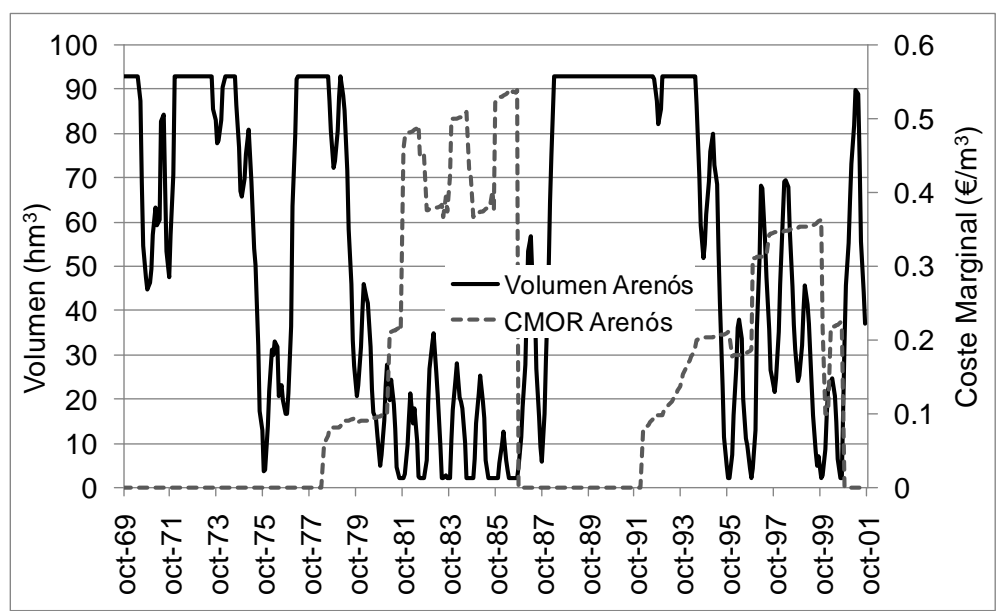

Figura 6.25 Valor del recurso en el embalse Arenós. Simulación

Durante el primer período crítico (1978-1985 de la serie histórica de aportaciones), el valor medio del coste del recurso es de $0,15 € / \mathrm{m}^{3}$, con un máximo de $0,54 € / \mathrm{m}^{3}$, bajando a $0,14 € / \mathrm{m}^{3}$ y un máximo de $0,36 € / \mathrm{m}^{3}$ en el segundo periodo (1995-2000). En la figura 6.26 se compara el valor del recurso en los dos embalses principales del sistema, obteniendo resultados prácticamente iguales, excepto para el periodo 1995-2000 que presenta pequeñas diferencias.

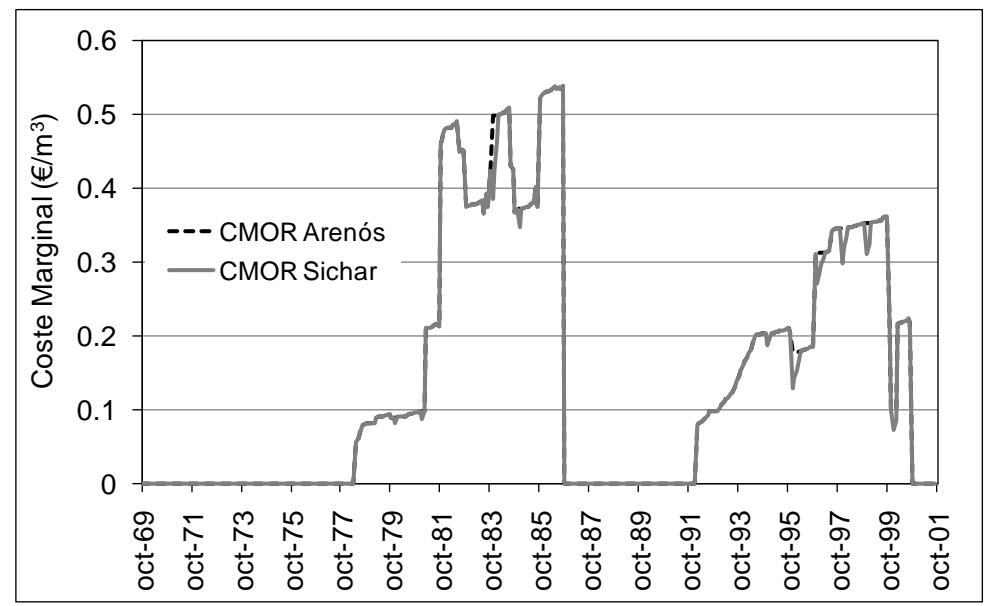

Figura 6.26 CMOR en los embalses.

En un intento de profundizar en el análisis de la relación que pueda existir entre volumen almacenado y coste del recurso, se ha calculado el promedio de este en distintos rangos de volúmenes, obteniendo los resultados que pueden verse en la figura 6.27 . El promedio mensual del CMOR en el embalse de Arenós es de $0,30 € / \mathrm{m}^{3}$ para el rango de 
volumen almacenado comprendido entre 0 y $20 \mathrm{hm}^{3}$. Cuando el embalse está prácticamente lleno, el CMOR tiende a cero (figura 6.27).

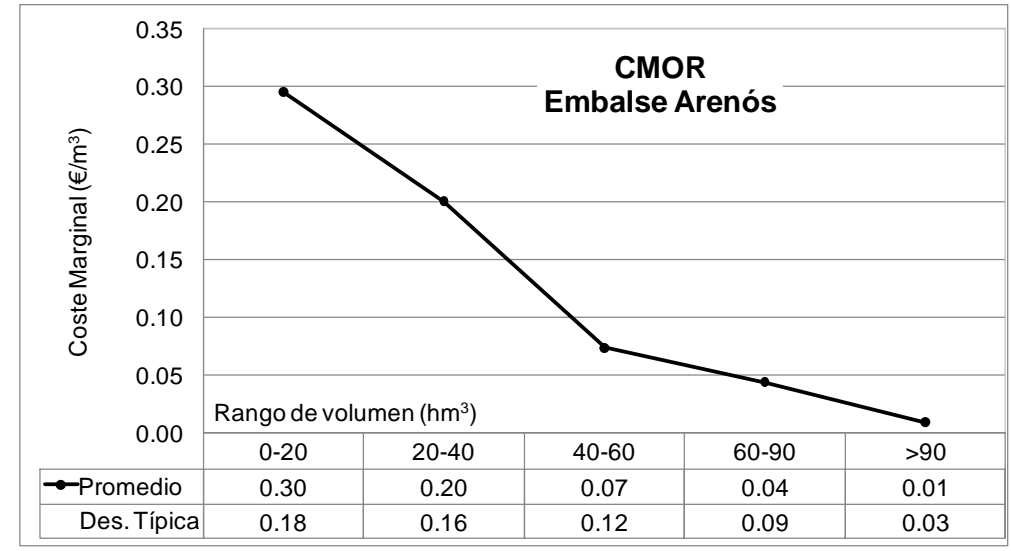

Figura 6.27 Promedio mensual del CMOR en Arenós. Simulación

\subsubsection{Coste marginal de oportunidad de caudal ecológico (CMOCE)}

De conformidad con el vigente Plan Hidrológico del Júcar (artículo 22), el caudal medioambiental del tramo aguas abajo del embalse de Sichar hasta el punto donde retorna el caudal derivado para la Central Hidroeléctrica de Colmenar, se fija en $200 \mathrm{l} / \mathrm{s}$. Como se ha comentado en el apartado 4.2.2, el coste marginal (o por unidad adicional) que supone para el sistema el mantenimiento de las restricciones ambientales de caudal ecológico puede ser analizado calculando la diferencia de beneficios simulados entre el caso base y el caso base relajando en una unidad dicha restricción en un mes determinado.

Al calcular el coste marginal de oportunidad de la restricción de caudal mínimo ecológico (CMOCE) que se tiene en el tramo de río mencionado (figura 6.28), se observa que el mayor coste marginal, entre 0,15 y $0,7 € / \mathrm{m}^{3}$, se presenta cuando hay poco volumen de agua circulando por el río; corresponde también al periodo en donde es mayor el coste del recurso en el embalse Sichar (1975-1985). El coste marginal de la restricción de caudales mínimos se hace cero en los períodos en que el volumen almacenado es alto y no hay costes de oportunidad en mantener los caudales ecológicos. 


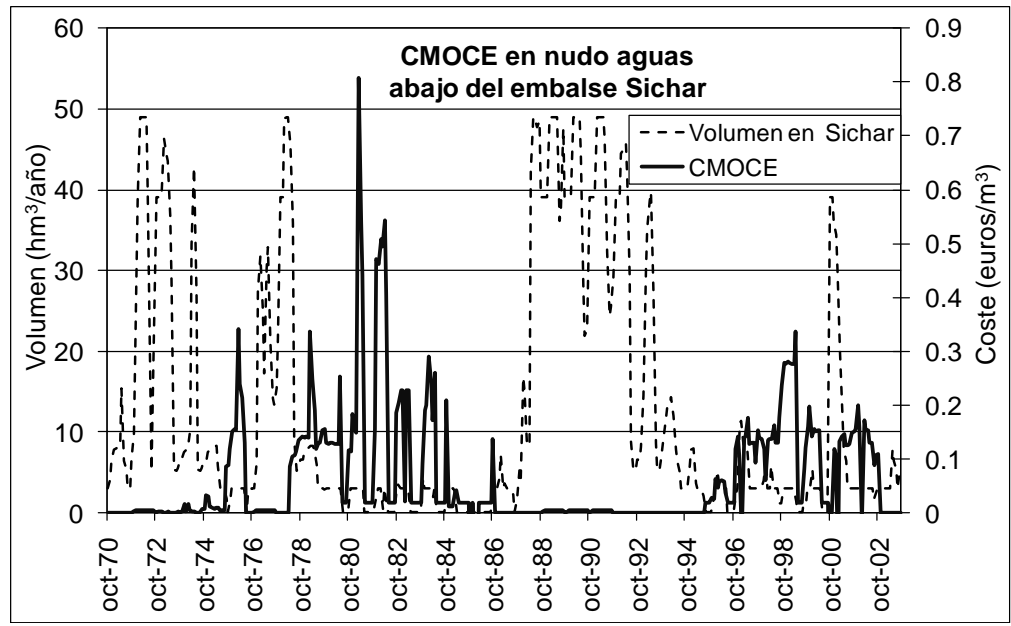

Figura 6.28 Coste marginal del recurso para caudal ecológico

\subsubsection{Análisis de sensibilidad del CMOR}

Se llevó a cabo un análisis para comprobar la sensibilidad de los cálculos del CMOR a las curvas de demandas, considerando tres coste como punto de cierre para las curvas de demanda en los principales riegos del sistema: $0,70,0,55$ y $0,45 € / \mathrm{m}^{3}$. Las curvas de demanda en las cuatro UDAs principales (Riegos Tradicionales, Canal Cota 100, Canal Cota 220 y Ma Cristina) se muestran en la figura 6.29.
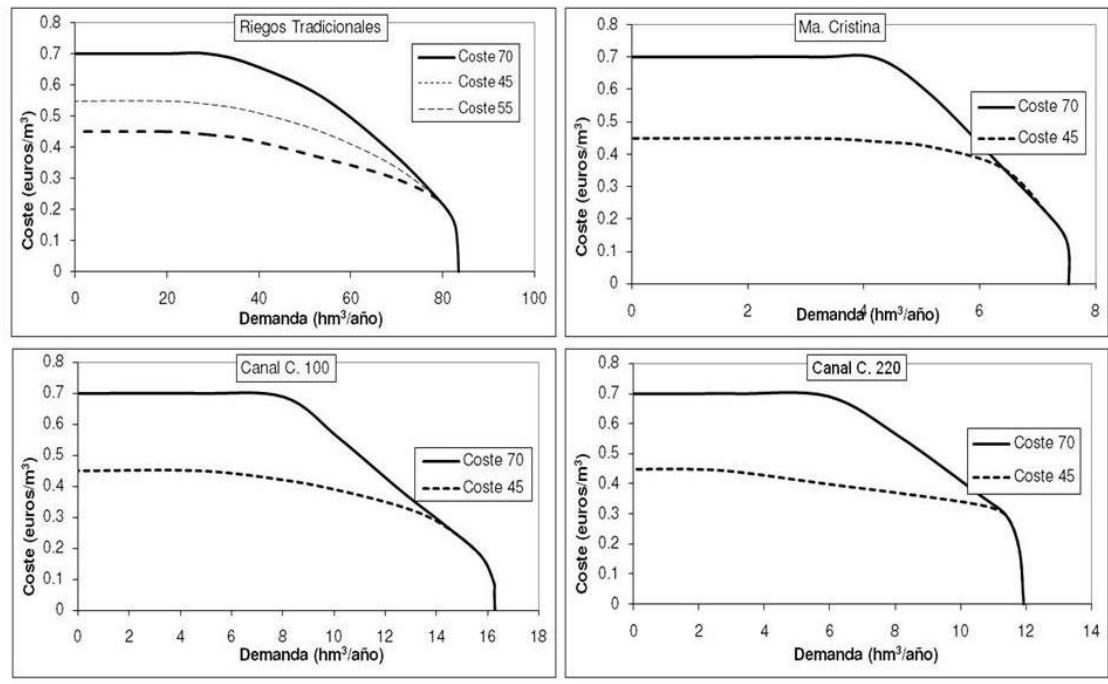

Figura 6.29 Variación en las curvas de demanda económica

Al realizar el cálculo del CMOR, se observa que la distribución temporal de los valores se mantiene con la misma forma para los tres grupos de curvas de demandas. Para el 
periodo 1981-1987 el resultado (figura 6.30) resulta más sensible al cambio en la curva de demanda ( 25 céntimos $/ \mathrm{m}^{3}$ ), ya que se alcanza un déficit mayor de suministro, mientras que para el periodo final las variaciones en el coste del recurso presentan una menor variabilidad (10 céntimos $\left./ \mathrm{m}^{3}\right)$.

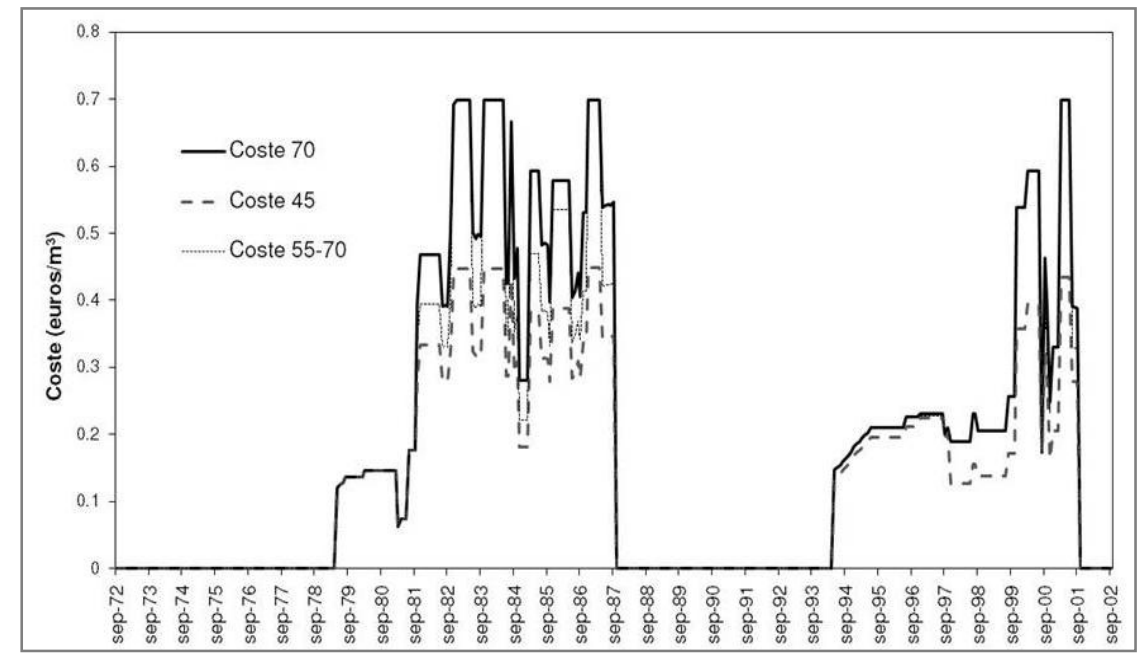

Figura 6.30 Variación del CMOR. Embalse de Arenós

\subsection{Optimización económica de la gestión. Coste de escasez y CMOR}

Como se ha comentado en el apartado 4.3.2, en el modelo de optimización los valores óptimos de las variables del problema dual (precios sombra o multiplicadores de Lagrange) nos definen directamente el cambio en el valor óptimo de la función objetivo como consecuencia de un cambio marginal unitario en el término independiente de la restricción correspondiente a cada variable dual. Al referirse la función objetivo al resultado económico derivado del uso del agua en el sistema, los precios sombra de las restricciones de balance en nudos del modelo (incluyendo embalses y acuíferos) proporcionan el incremento de beneficio neto por incremento infinitesimal del recurso en ese nudo y en ese instante, y por tanto el coste marginal de oportunidad del recurso (CMOR).

En este apartado se presentan los resultados de optimización de la gestión y su valoración económica con base en las curvas de demanda, destacando los aspectos siguientes: descripción del modelo de optimización; coste de escasez y suministro a la demanda y beneficios medios anuales; coste del recurso en los embalses del sistema; y comparación entre la simulación de la gestión y la optimización económica. 
Para proceder a la optimización económica se ha considerado lo siguiente:

- El periodo temporal está definido por la serie histórica de aportaciones de 30 años, desde octubre de 1970 hasta septiembre de 2000.

- Se han elegido los mismos puntos de interés que en la simulación de la gestión para el cálculos del CMOR en el Sistema Mijares-Plana de Castellón los cuales corresponden a los embalses de Arenós (nudo 2) y Sichar (nudo 5).

- Se ha considerado exclusivamente una opción de análisis: Incluir únicamente las cuatro demandas agrícolas del Sistema de Explotación correspondientes a los Riegos Tradicionales y a los Riegos Mixtos.

- Se trabaja con curvas económicas de demanda mensuales, para lo que fue necesario desagregarlas las curvas anuales originales de acuerdo con el calendario de riego. La función que proporciona el beneficio para un volumen de agua disponible es igual al área bajo la curva de demanda hasta ese nivel de suministro, y equivale a la disposición total a pagar por esa agua. Integrando desde un nivel genérico de agua disponible hasta el nivel de suministro máximo se obtiene la expresión del coste económico de escasez versus nivel de suministro.

Al tratarse de optimización, no se da prioridad en el suministro a ninguna de las UDAs consideradas en el análisis.

\subsubsection{Modelo de optimización de la gestión del río Mijares}

La optimización económica tiene como función objetivo maximizar los beneficios económicos totales para las cuatro demandas consideradas (Riegos Tradicionales y Riegos Mixtos). El modelo en GAMS optimiza el conjunto de todas las variables involucradas en el balance de masa; comprueba el balance hídrico en cada nodo del sistema y maximiza la suma de beneficios de cada demanda del esquema, sin considerar la regla del convenio 70 (análisis mensual). El modelo mejora la eficiencia económica en la gestión del sistema y proporciona el "techo" de beneficios que se pueden conseguir o tratar de alcanzar con la metodología indicada en el capítulo 5. El modelo de optimización siempre "ve hacia adelante" -conoce la hidrología y demandas futuras- pues se optimiza simultáneamente para todo el periodo de análisis. De esta manera, los volúmenes almacenados en la optimización son diferentes a los de la simulación. El modelo de optimización claramente prevé almacenar agua para solventar los periodos de sequía que vendrán en periodos posteriores (debido al conocimiento perfecto de futuro hidrológico). En la figura 6.33 se observa que el volumen embalsado en el embalse de Arenós para el caso de la optimización económica es mayor al embalsado con el modelo de simulación. 


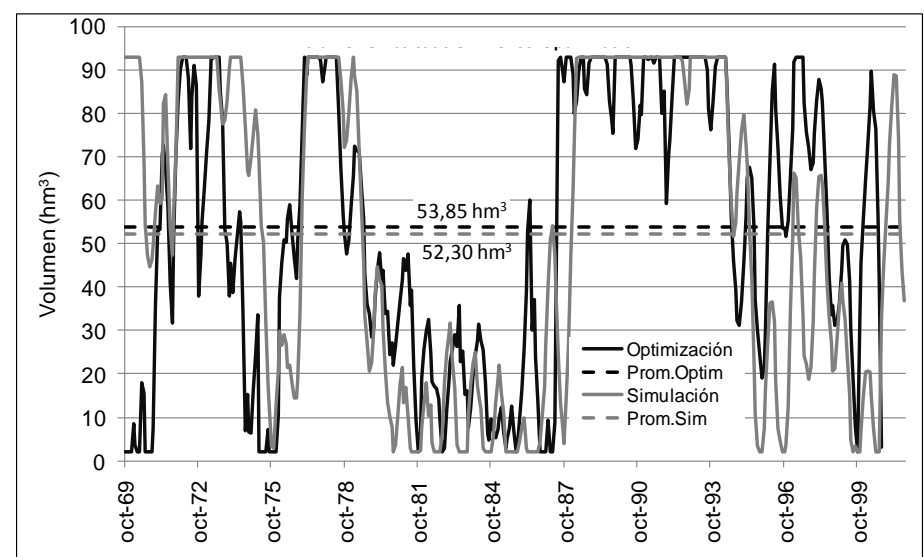

Figura 6.31 Volumen embalsado en Arenós. Optimización

\subsubsection{Análisis de resultados de la optimización económica. Coste de escasez y suministro a la demanda}

Se realizó la optimización económica del sistema, observándose que se suministra el recurso penalizando a los riegos tradicionales y mejorando el suministro a los riegos mixtos del sistema (figura 6.34).
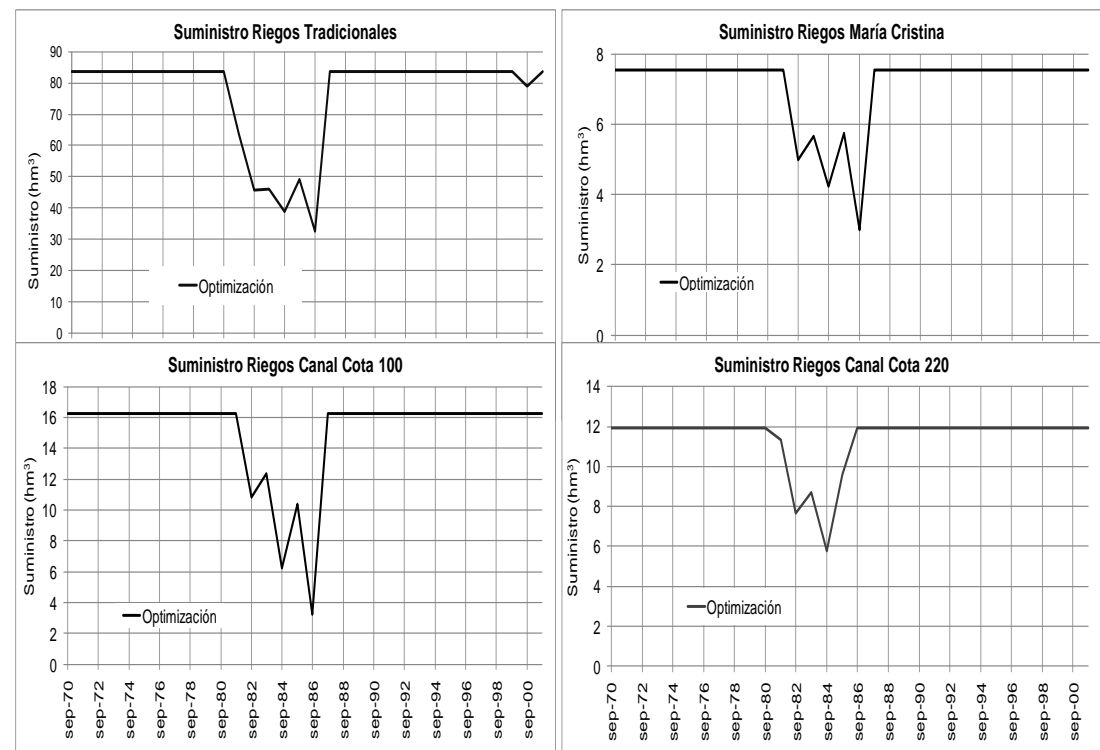

Figura 6.32 Suministro a las demandas.

Riegos Tradicionales y Mixtos Optimización 
El modelo de optimización reduce el déficit de suministro en los usos mixtos en una proporción mayor que el de los riegos Tradicionales, ya que no considera prioridades como lo hace el modelo de simulación (figura 6.35).

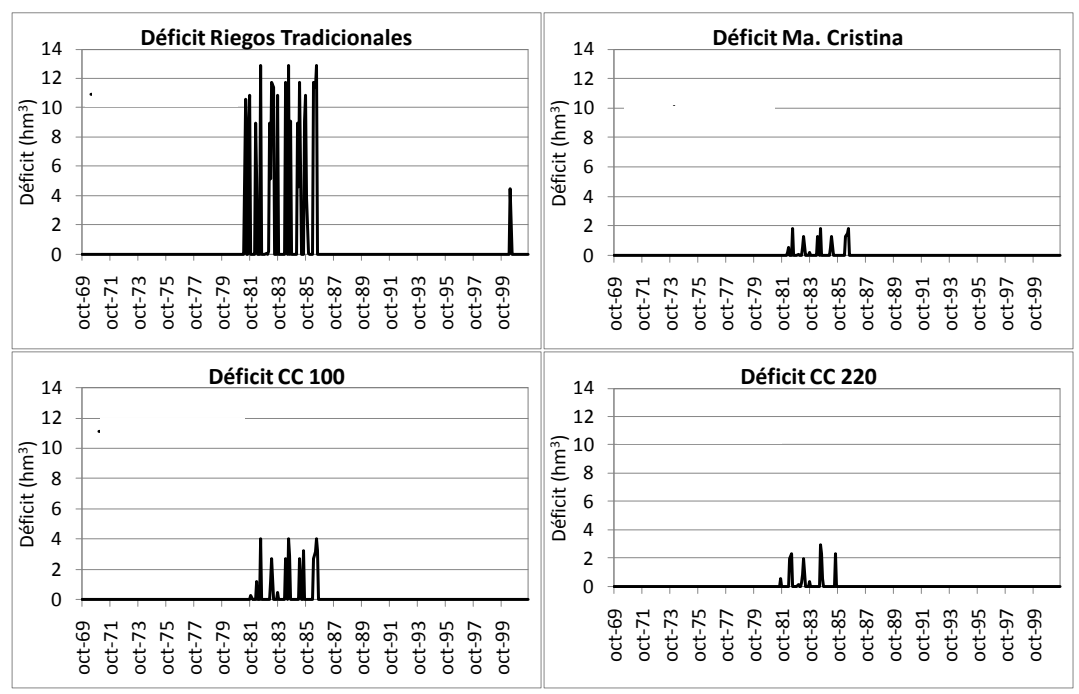

Figura 6.33 Déficit de suministro a las demandas.
Riegos Tradicionales y Mixtos. Optimización

De acuerdo a los suministros para cada una de las unidades de demanda, se han obtenido los beneficios económicos mostrados en la figura 6.36. Se observa que se penalizan los riegos tradicionales y por lo tanto los beneficios son menores que los proporcionados por la simulación, mientras que se mejora el beneficio en los riegos mixtos del sistema.

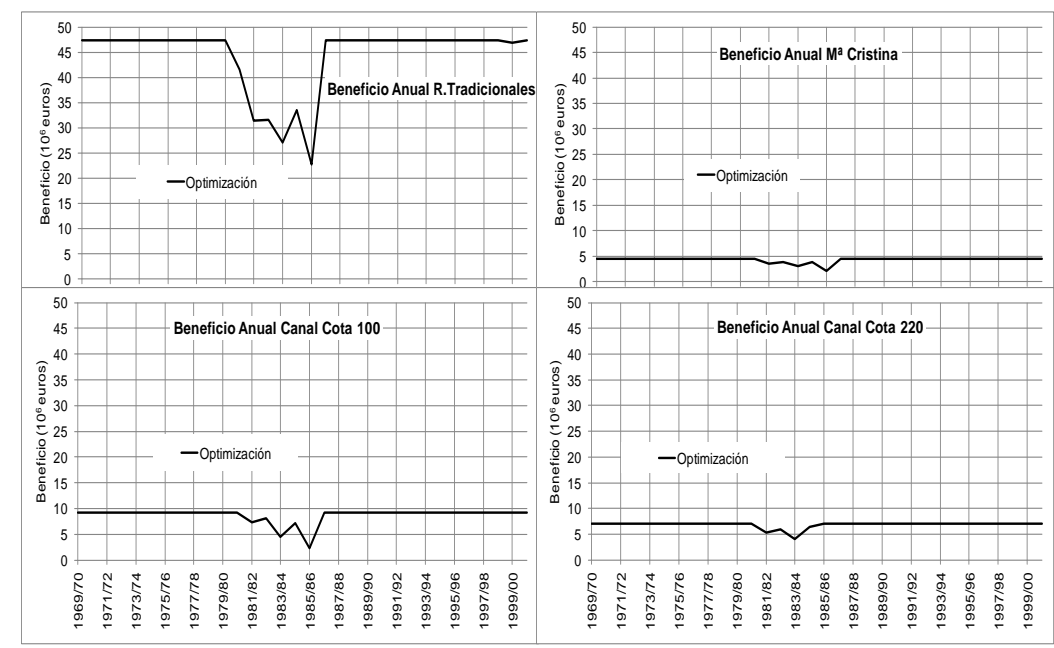

Figura 6.34 Beneficios anuales en las diferentes UDAs del Mijares. Optimización 


\subsubsection{Análisis de resultados de la optimización económica. Coste del recurso en los embalses del sistema.}

Para determinar el coste del recurso en los embalses de Arenós y Sichar se consideraron las curvas de demanda económica mostradas en las figura 6.17, 6.18 y del Anejo C, con los caudales de suministro dados por la optimización económica con GAMS.

El mayor valor marginal (CMOR optimización) (figura 6.37) corresponde al periodo en donde hay menos reservas en los embalses, y por tanto más escasez del recurso. En la optimización económica no se consideran las prioridades en la asignación del recurso a las demandas. El valor marginal de una unidad de agua para un instante dado depende de las demandas y escasez, siendo gestionado el recurso en este caso con pleno conocimiento del periodo futuro. El volumen en el embalse se ajusta con anticipación perfecta a los periodos húmedos y secos y se aumenta el almacenamiento previo a las sequías mediante restricciones anticipadas utilizando el agua sin restricciones frente a periodos húmedos.

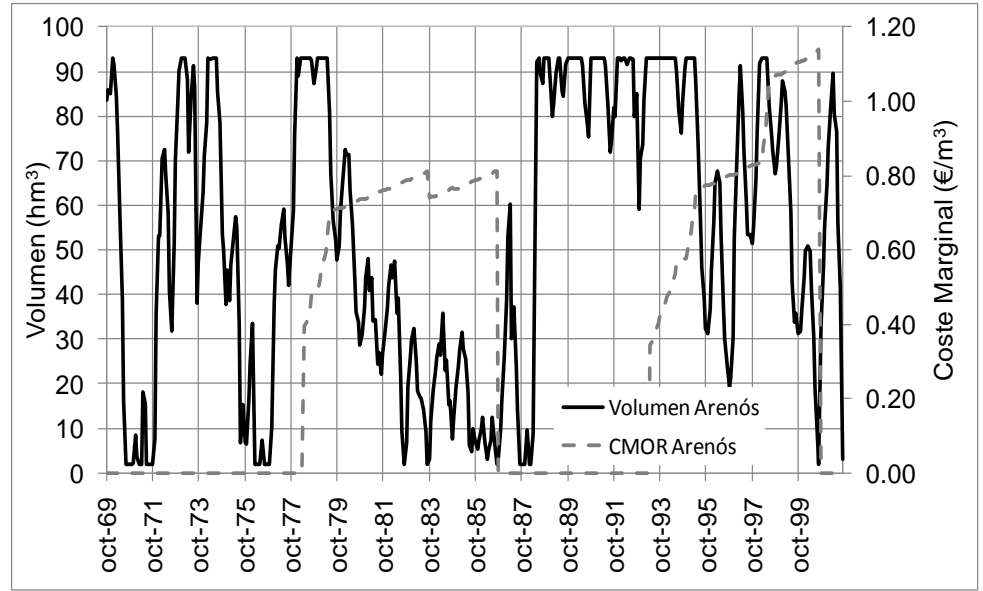

Figura 6.35 Valor marginal del recurso (CMOR) en el embalse Arenós. Optimización

\subsubsection{Comparación entre la simulación de la gestión y la optimización económica}

El modelo de simulación de la gestión del sistema del río Mijares toma en cuenta las prioridades a las demandas establecidas por la Curva del Convenio de 1970. Debido a ella, los Riegos Tradicionales tienen prioridad de suministro sobre los Riegos Mixtos. El modelo de optimización siempre "ve hacia adelante" -conoce la hidrología y demandas futuras- y por ello optimiza simultáneamente para todo el periodo de análisis, y además no considera algún tipo de prioridad en el reparto. De esa manera la optimización económica, 
al maximizar los beneficios, penaliza los suministros a los Riegos Tradicionales mejorando el reparto a los Riegos Mixtos (tabla 6.5).

Tabla 6.5 Comparación de suministros anuales. Mijares

\begin{tabular}{|c|c|c|c|c|c|}
\hline \multicolumn{7}{|c|}{ SUMINISTRO ANUAL $\left(\mathrm{hm}^{\mathbf{3}}\right)$} \\
\hline Escenario & Tradicionales & Ma. Cristina & CC100 & CC220 & Total \\
\hline Optimización & 6,36 & 0,59 & 1,26 & 0,95 & 9,16 \\
\hline Simulación & 6,39 & 0,43 & 0,94 & 0,76 & 8,52 \\
\hline
\end{tabular}

Ya que el objetivo del modelo de optimización es maximizar los beneficios sin considerar prioridades en el suministro, los beneficios de los Riegos Tradicionales son menores (3\%) que los que proporciona la simulación. Sin embargo se ven favorecidos los beneficios de los Riegos Mixtos en un 30\% (tabla 6.6).

Tabla 6.6 Comparación de beneficios anuales. Mijares

\begin{tabular}{|c|c|c|c|c|c|c|}
\hline \multicolumn{6}{|c|}{ BENEFICIO MEDIO ANUAL (Millones de euros) } & \multirow[b]{2}{*}{ Benef.Tot } \\
\hline Escenario & Tradicionales & Ma. Cristina & CC100 & CC220 & Total & \\
\hline Optimización & 44,38 & 4,28 & 8,65 & 6,89 & 64,19 & 2054,09 \\
\hline Simulación & 45,56 & 3,20 & 6,59 & 5,08 & 60,43 & 1933,79 \\
\hline
\end{tabular}

Los beneficios totales proporcionados por el modelo de optimización económica son mayores en un $6 \%$ a los que proporciona la simulación de la gestión.

\subsection{Políticas de precios}

De acuerdo a los resultados obtenidos para el caso sintético, se aplicó la metodología descrita en el capítulo 5 , con el fin de proponer una política de precios eficiente para el Sistema de Explotación del río Mijares.

\subsubsection{Precios escalonados a partir del CMOR en embalses}

El CMOR calculado para el embalse Arenós se ha utilizado como base para definir una política eficiente que incentive la eficiencia económica en la gestión del Sistema de Explotación del río Mijares. El CMOR se clasificó de acuerdo a diferentes rangos de volúmenes. Para esos rangos, se obtuvo el valor promedio del CMOR y se definieron políticas escalonadas de precios iguales al Coste Marginal de Oportunidad del Recurso (figura 6.38) para los modelos de simulación de la gestión y de optimización económica. 


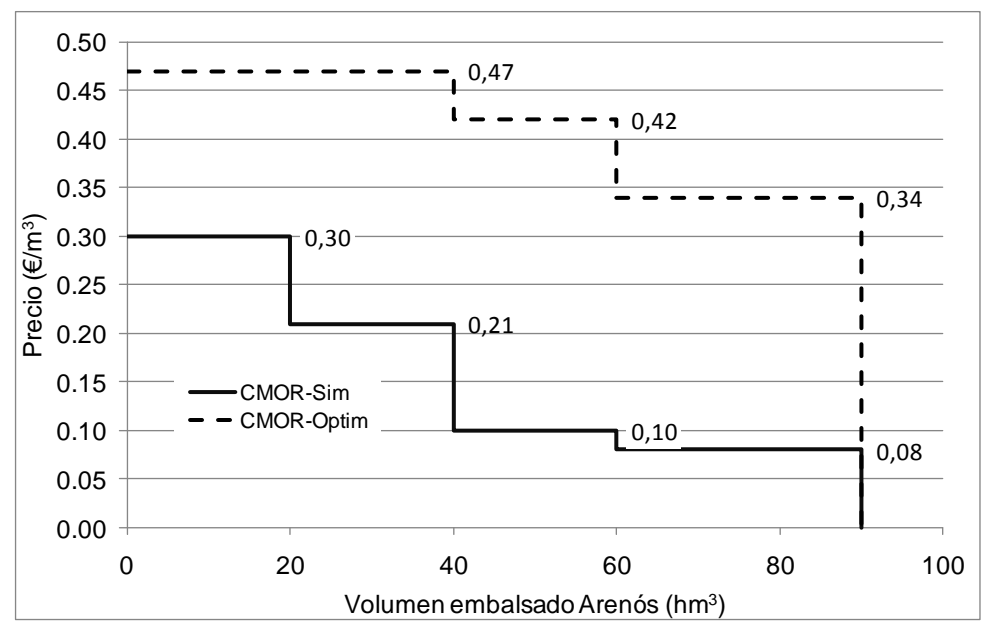

Figura 6.36. Políticas de precios derivadas del CMOR de simulación y de optimización económica. Mijares

Precios escalonados usando los CMOR de simulación. La simulación con este tipo de política de precios se realizó considerando restricciones al suministro de las demandas en función de la suma de los volúmenes embalsados en Arenós y Sichar. Los factores de restricción se han calculado con base en la curva de demanda económica del uso correspondiente (ver apartado 6.3.1).

En la figura siguiente puede observarse que el suministro a los Riegos Tradicionales disminuye ligeramente con respecto a la simulación, aumentando significativamente en los Riegos de Ma Cristina y Canal de la Cota 100 (figura 6.39), obteniéndose con esta política de precios un acercamiento al techo de eficiencia obtenido con la optimización teórica. 


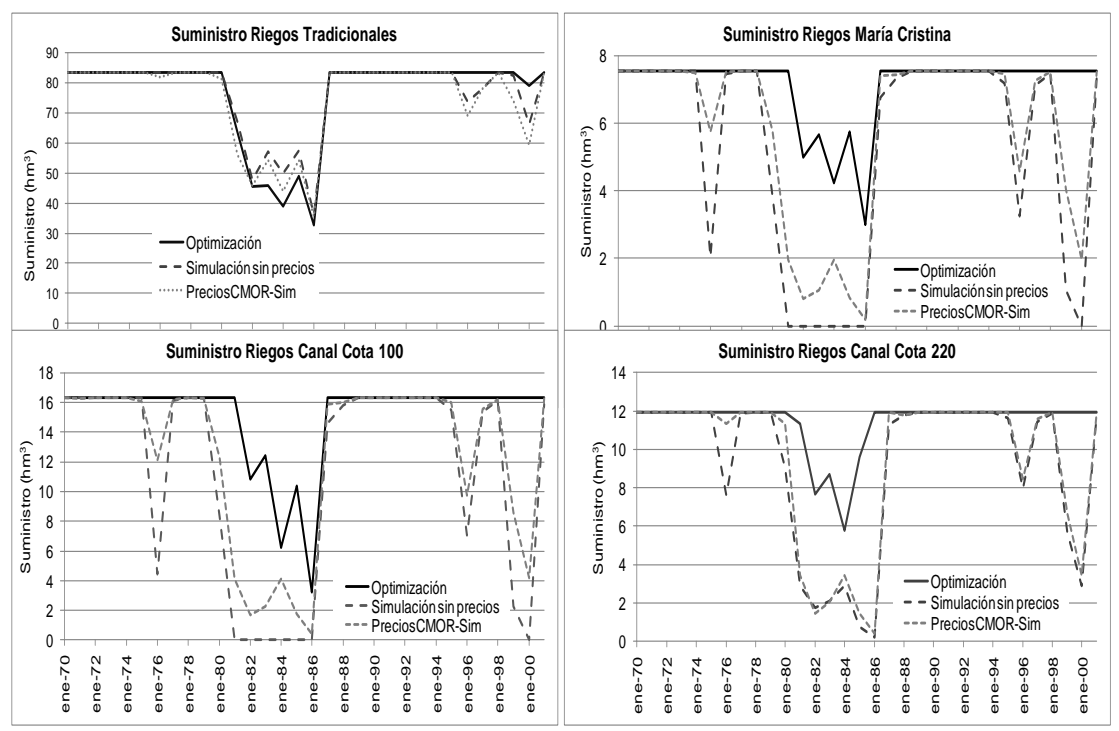

Figura 6.37. Suministros a las demandas. Precios del CMOR de simulación

Los beneficios medios totales en los riegos mixtos son mayores a los de la simulación penalizando un poco a los Riegos Tradicionales (figura 6.40).
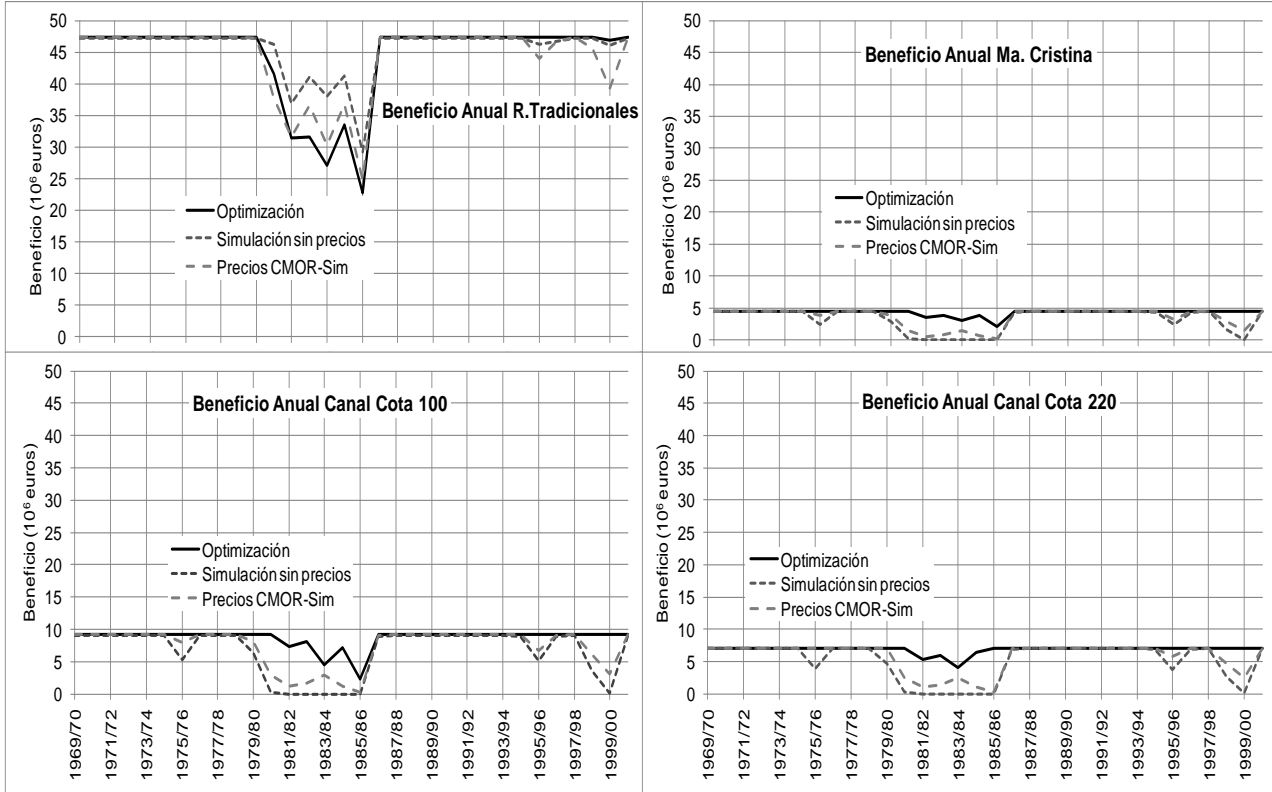

Figura 6.38. Beneficios medios anuales por uso. Precios del CMOR de simulación

Precios escalonados usando los CMOR de la optimización. Al simular la política de precios obtenidos a partir de los CMOR promedio del modelo de optimización para distintos rangos de volumen embalsado, los suministros (figura 6.41) tienden a ser menores que los que proporciona el modelo de simulación con prioridades (sin precios), penalizándose de igual manera a los Riegos Tradicionales. 


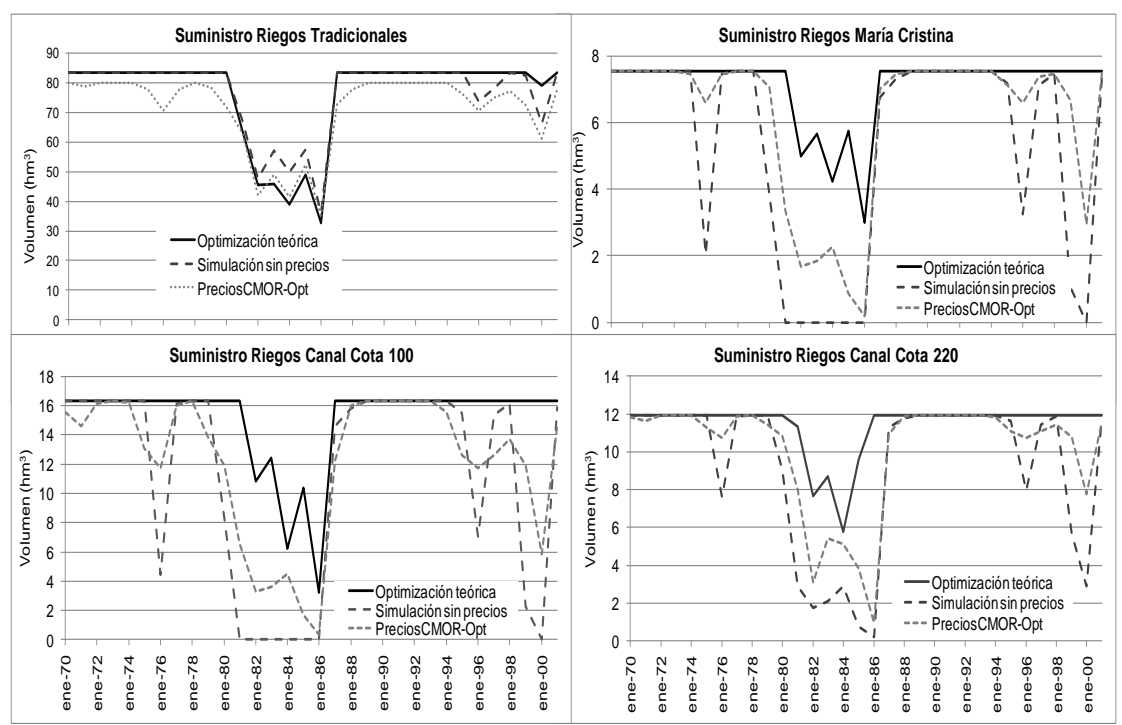

Figura 6.39. Suministros a las demandas. Precios del CMOR de la optimización

Los suministros resultantes se aproximan más a los obtenidos con el modelo de optimización económica (tabla 6.7).

Tabla 6.7 Suministro anual. Precios escalonados

\begin{tabular}{|c|c|c|c|c|c|}
\hline Política & $\begin{array}{c}\text { Tradicionales } \\
\left(\mathrm{hm}^{3}\right)\end{array}$ & $\begin{array}{l}\text { Ma. Cristina } \\
\left(\mathrm{hm}^{3}\right)\end{array}$ & $\begin{array}{l}\mathrm{CC100} \\
\left(\mathrm{hm}^{3}\right) \\
\end{array}$ & $\begin{array}{l}\mathrm{CC} 220 \\
\left(\mathrm{hm}^{3}\right) \\
\end{array}$ & $\begin{array}{r}\text { Total } \\
\left(\mathrm{hm}^{3}\right) \\
\end{array}$ \\
\hline Optimización económica & 6,36 & 0,59 & 1,26 & 0,95 & 9,16 \\
\hline $\begin{array}{l}\text { Simulación con prioridades (sin } \\
\text { precios }\end{array}$ & 6,39 & 0,43 & 0,94 & 0,76 & 8,52 \\
\hline \multicolumn{6}{|l|}{ Precios escalonados } \\
\hline Precios CMOR-Sim. Función volumen & 6,26 & 0,49 & 1,04 & 0,79 & 8,58 \\
\hline Precios CMOR-Opt. Función volumen & 5,94 & 0,51 & 1,02 & 0,84 & 8,31 \\
\hline
\end{tabular}

El incremento de suministro y su diferente distribución temporal se traduce en mayores beneficios medios anuales que los obtenidos con el CMOR de la simulación (Figura 6.42). 

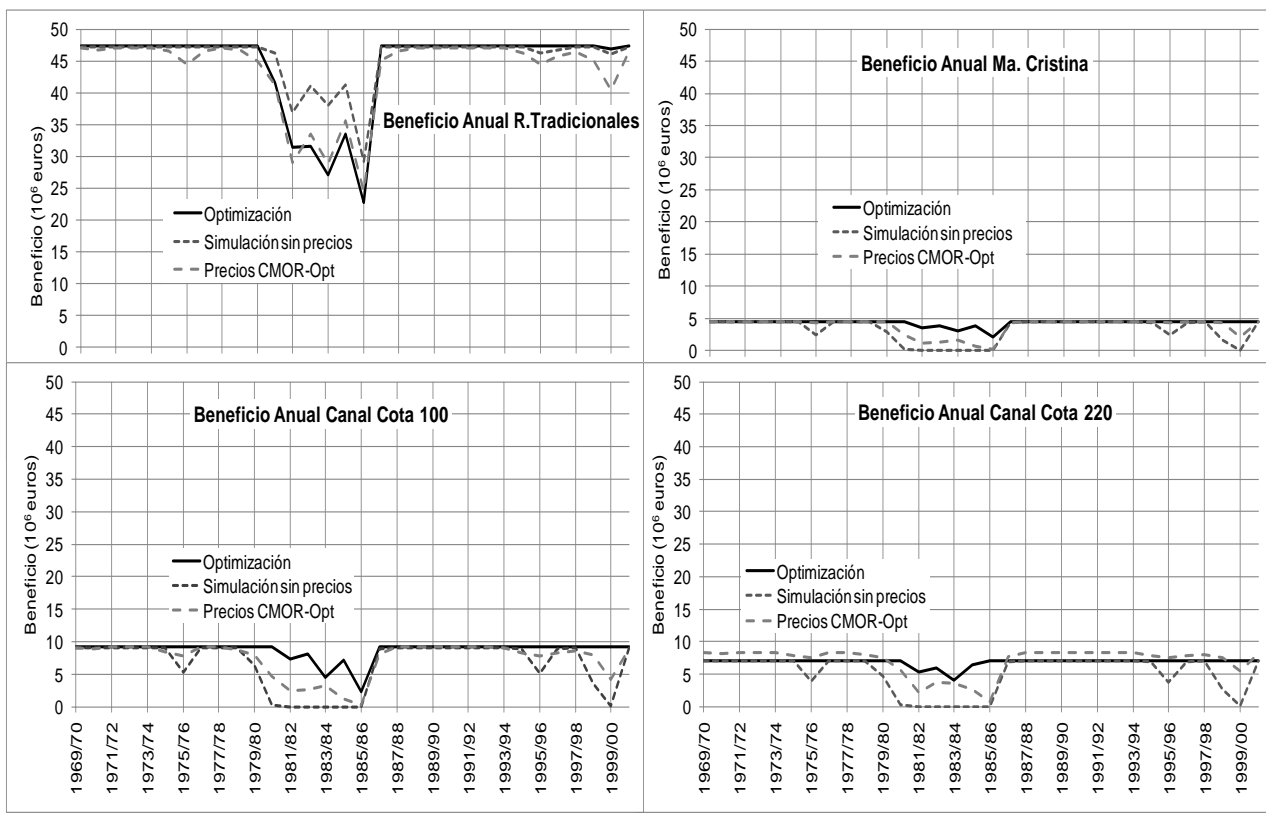

Figura 6.40 Beneficios medios anuales por uso. Precios del CMOR de optimización

En la tabla 6.8 puede observarse que efectivamente los beneficios mayores utilizando políticas de precios escalonados corresponde a los basados en los promedios del CMOR de la optimización para distintos rangos de volumen de embalse, aproximándose notablemente a los beneficios del propio modelo de optimización económica.

\begin{tabular}{|c|c|c|c|c|c|c|}
\hline Política & $\begin{array}{c}\text { Tradicionales } \\
\text { (mill. de } € \text { ) }\end{array}$ & $\begin{array}{c}\text { Ma. Cristina } \\
\text { (mill. de } € \text { ) }\end{array}$ & $\begin{array}{c}\text { CC100 } \\
\text { (mill. de } € \text { ) }\end{array}$ & $\begin{array}{c}\text { CC220 } \\
\text { (mill. de } € \text { ) }\end{array}$ & $\begin{array}{c}\text { Total } \\
\text { (mill. de } € \text { ) }\end{array}$ & $\begin{array}{c}\text { Benef.Tot } \\
\text { (mill. de } € \text { ) }\end{array}$ \\
\hline Optimización económica & 44,38 & 4,28 & 8,65 & 6,89 & 64,19 & 2054,09 \\
\hline $\begin{array}{l}\text { Simulación sin política de } \\
\text { precios }\end{array}$ & 45,56 & 3,20 & 6,59 & 5,08 & 60,43 & 1933,79 \\
\hline \multicolumn{7}{|l|}{ Precios escalonados } \\
\hline $\begin{array}{l}\text { Precios CMOR Sim. } \\
\text { Función volumen }\end{array}$ & 44,24 & 3,55 & 7,32 & 5,76 & 60,88 & 1948,04 \\
\hline $\begin{array}{l}\text { Precios CMOR Opt. } \\
\text { Función volumen }\end{array}$ & 43,49 & 3,75 & 7,41 & 7,05 & 61,70 & 1974,32 \\
\hline
\end{tabular}

\subsubsection{Precios escalonados óptimos.}

Las políticas de precios obtenidas con los CMOR de la simulación y de la optimización se sometieron a un proceso de mejora por aproximaciones con el fin de encontrar políticas más eficientes que las descritas en los parágrafos anteriores. Se realizaron 13 diferentes combinaciones de políticas de precios a partir de los CMOR de la simulación y 9 para el 
caso de los CMOR de la optimización. Cada una de esas políticas conserva tres escalones mostrándose como ejemplo algunas de ellas en la figura 6.43.
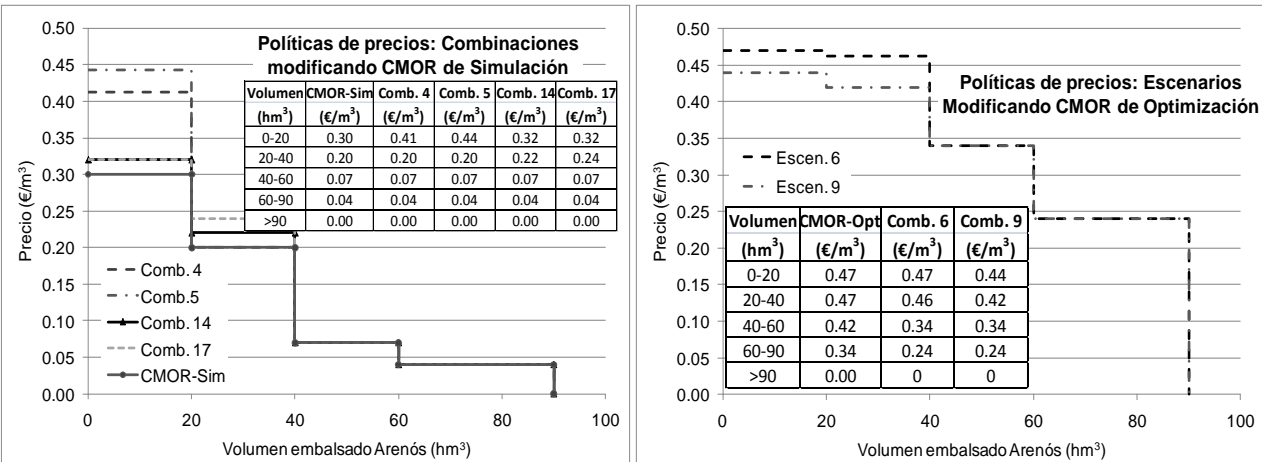

Figura 6.41.Políticas de precios CMOR óptimos

Los suministros obtenidos con las políticas mostradas en la figura 6.43 son superiores a los proporcionados por las políticas de precios escalonados descritos en el apartado anterior, aproximándose más a los que proporcionó el modelo de optimización económica teórica (tabla 6.9, compárese con tabla 6.7).

Tabla 6.9 Suministro anual. Precios escalonados óptimos

\begin{tabular}{|c|c|c|c|c|c|}
\hline Política & $\begin{array}{c}\text { Tradicionales } \\
\left(\mathrm{hm}^{3}\right)\end{array}$ & $\begin{array}{c}\text { Ma. Cristina } \\
\left(\mathrm{hm}^{3}\right)\end{array}$ & $\begin{array}{l}\mathrm{CC100} \\
\left(\mathrm{hm}^{3}\right)\end{array}$ & $\begin{array}{l}\mathrm{CC} 220 \\
\left(\mathrm{hm}^{3}\right)\end{array}$ & $\begin{array}{l}\text { Total } \\
\left(\mathrm{hm}^{3}\right)\end{array}$ \\
\hline Optimización económica & 6,36 & 0,59 & 1,26 & 0,95 & 9,16 \\
\hline $\begin{array}{c}\text { Simulación con } \\
\text { prioridades (sin precios) }\end{array}$ & 6,39 & 0,43 & 0,94 & 0,76 & 8,52 \\
\hline \multicolumn{6}{|l|}{$\begin{array}{c}\text { Precios escalonados } \\
\text { óptimos } \\
\end{array}$} \\
\hline Combinación 6 & 5,91 & 0,52 & 1,02 & 0,84 & 8,29 \\
\hline Combinación 9 & 5,98 & 0,51 & 1,01 & 0,82 & 8,32 \\
\hline Combinación 4 & 6,22 & 0,49 & 1,05 & 0,80 & 8,56 \\
\hline Combinación 5 & 6,20 & 0,49 & 1,05 & 0,80 & 8,55 \\
\hline Combinación 14 & 6,25 & 0,49 & 1,05 & 0,79 & 8,59 \\
\hline Combinación 17 & 6,25 & 0,49 & 1,05 & 0,79 & 8,59 \\
\hline
\end{tabular}

Los beneficios obtenidos con las políticas de precios optimizados a partir del CMOR de la simulación son mayores a los de la propia simulación y a los obtenidos con la política de precios con CMOR de la simulación (Tabla 6.10). 
Tabla 6.10 Beneficio medio anual. Precios escalonados óptimos. Mijares

\begin{tabular}{|c|c|c|c|c|c|c|}
\hline Política & $\begin{array}{c}\text { Tradicionales } \\
\text { (mill. } \mathbf{\epsilon})\end{array}$ & $\begin{array}{c}\text { Ma. Cristina } \\
\text { (mill. } \mathbf{\epsilon})\end{array}$ & $\begin{array}{c}\text { CC100 } \\
\text { (mill. } \mathbf{\text { f }}\end{array}$ & $\begin{array}{c}\text { CC220 } \\
\text { (mill. €) }\end{array}$ & $\begin{array}{c}\text { Total } \\
\text { (mill. €) }\end{array}$ & $\begin{array}{c}\text { Benef.Tot } \\
\text { (mill. €) }\end{array}$ \\
\hline Optimización económica & 44,38 & 4,28 & 8,65 & 6,89 & 64,19 & 2054,09 \\
\hline Simulación sin precios & 45,56 & 3,20 & 6,59 & 5,08 & 60,43 & 1933,79 \\
\hline Precios óptimos & & & & & & \\
\hline Combinación 6 & 43,37 & 3,80 & 7,48 & 6,22 & 60,87 & 1947,86 \\
\hline Combinación 9 & 43,65 & 3,74 & 7,38 & 6,09 & 60,86 & 1947,41 \\
\hline Combinación 4 & 44,12 & 3,57 & 7,34 & 5,86 & 60,89 & 1948,53 \\
\hline Combinación 5 & 44,07 & 3,58 & 7,36 & 5,89 & 60,89 & 1948,51 \\
\hline Combinación 14 & 44,18 & 3,56 & 7,37 & 5,83 & 60,95 & 1950,47 \\
\hline Combinación 17 & 44,18 & 3,56 & 7,37 & 5,76 & 60,88 & 1948,23 \\
\hline
\end{tabular}

\subsubsection{Conclusiones en la determinación de políticas eficientes de precios para la cuenca del Mijares.}

Las políticas de precios que se simularon para la cuenca del Mijares mejoran los beneficios totales (Tabla 6.11) del uso del agua en la cuenca con respecto a los resultados económicos de la simulación de la gestión actual. La política de precios escalonada derivada de los CMOR de la optimización (precios CMOR-Opt. En función del volumen embalsado) ha proporcionado los mejores beneficios económicos, mejorando en un $2 \%$ los beneficios que proporciona la simulación sin precios (gestión actual). Las políticas propuestas, además de dar mayores beneficios económicos, hacen más eficiente el suministro del recurso a las demandas.

La combinación 14, cuya política está basada en los CMOR de la simulación pero incrementados en el rango de mayor volumen almacenado en el embalse de Arenós (véase la figura 6.43), proporcionó el mayor beneficio total respecto a los demás escenarios probados con precios escalonados.

Con todo, los resultados muestran que el sistema del Mijares es poco sensible a la variación de precios para los rangos de volúmenes considerados. En forma desagregada, los mayores beneficios son para los Riegos Tradicionales los cuales ya tienen la prioridad sobre los Riegos Mixtos. 
Tabla 6.11 Beneficio medio anual. Mijares

\begin{tabular}{|c|c|c|c|c|c|c|}
\hline Política & $\begin{array}{c}\text { Tradicionales } \\
\text { (mill. } € \text { ) }\end{array}$ & $\begin{array}{l}\text { Ma. Cristina } \\
\text { (mill. } € \text { ) }\end{array}$ & $\begin{array}{l}\text { CC100 } \\
\text { (mill. } € \text { ) }\end{array}$ & $\begin{array}{l}\text { CC220 } \\
\text { (mill. €) }\end{array}$ & $\begin{array}{c}\text { Total } \\
\text { (mill. } € \text { ) }\end{array}$ & $\begin{array}{c}\text { Benef.Total } \\
\text { (mill. €) }\end{array}$ \\
\hline Optimización económica & 44,38 & 4,28 & 8,65 & 6,89 & 64,19 & 2054,09 \\
\hline Simulación sin precios & 45,56 & 3,20 & 6,59 & 5,08 & 60,43 & 1933,79 \\
\hline \multicolumn{7}{|l|}{ Precios escalonados } \\
\hline Precios CMOR Sim & 44,24 & 3,55 & 7,32 & 5,76 & 60,88 & 1948,04 \\
\hline Precios CMOR Opt & 43,49 & 3,75 & 7,41 & 7,05 & 61,70 & 1974,32 \\
\hline \multicolumn{7}{|l|}{$\begin{array}{c}\text { Precios escalonados } \\
\text { óptimos }\end{array}$} \\
\hline Combinación 6 & 43,37 & 3,80 & 7,48 & 6,22 & 60,87 & 1947,86 \\
\hline Combinación 9 & 43,65 & 3,74 & 7,38 & 6,09 & 60,86 & 1947,41 \\
\hline Combinación 4 & 44,12 & 3,57 & 7,34 & 5,86 & 60,89 & 1948,53 \\
\hline Combinación 5 & 44,07 & 3,58 & 7,36 & 5,89 & 60,89 & 1948,51 \\
\hline Combinación 14 & 44,18 & 3,56 & 7,37 & 5,83 & 60,95 & 1950,47 \\
\hline Combinación 17 & 44,18 & 3,56 & 7,37 & 5,76 & 60,88 & 1948,23 \\
\hline
\end{tabular}

La Combinación 9, obtenido con los CMOR de optimización pero con un escalón adicional (véase la figura 6.43), presenta los beneficios más bajos. Esto sucede porque se disminuyeron los precios para el rango menor de volumen embalsado en Arenós y esto provoca ineficiencia económica en el sistema, a pesar de tener precios mucho mayores que los de la simulación, además de suministrar menor cantidad promedio del recurso en todas las unidades de demanda.

Se puede afirmar por tanto que no necesariamente aumentar los precios implicará una mejora en los beneficios totales del sistema, sino que es conveniente realizar este tipo de análisis y con los resultados de las posibles políticas de precios tomar la decisión conjuntamente con todos los agentes involucrados en la gestión del sistema de recursos hídricos. 


\begin{tabular}{|c|c|c|c|c|c|}
\hline Política & $\begin{array}{c}\text { Tradicionales } \\
\left(\mathrm{hm}^{3}\right)\end{array}$ & $\begin{array}{c}\text { Ma. Cristina } \\
\left(\mathrm{hm}^{3}\right)\end{array}$ & $\begin{array}{l}\mathrm{CC} 100 \\
\left(\mathrm{hm}^{3}\right)\end{array}$ & $\begin{array}{l}\mathrm{CC220} \\
\left(\mathrm{hm}^{3}\right)\end{array}$ & $\begin{array}{r}\text { Total } \\
\left(\mathrm{hm}^{3}\right)\end{array}$ \\
\hline Optimización teórica & 6,36 & 0,59 & 1,26 & 0,95 & 9,16 \\
\hline Simulación sin precios & 6,39 & 0,43 & 0,94 & 0,76 & 8,52 \\
\hline \multicolumn{6}{|l|}{ Precios escalonados } \\
\hline $\begin{array}{l}\text { Precios CMOR Sim. } \\
\text { Función volumen }\end{array}$ & 6,26 & 0,49 & 1,04 & 0,79 & 8,58 \\
\hline $\begin{array}{l}\text { Precios CMOR Opt. } \\
\text { Función volumen }\end{array}$ & 5,94 & 0,51 & 1,02 & 0,84 & 8,31 \\
\hline \multicolumn{6}{|l|}{$\begin{array}{c}\text { Precios escalonados } \\
\text { óptimos }\end{array}$} \\
\hline Combinación 6 & 5,91 & 0,52 & 1,02 & 0,84 & 8,29 \\
\hline Combinación 9 & 5,98 & 0,51 & 1,01 & 0,82 & 8,32 \\
\hline Combinación 4 & 6,22 & 0,49 & 1,05 & 0,80 & 8,56 \\
\hline Combinación5 & 6,20 & 0,49 & 1,05 & 0,80 & 8,55 \\
\hline Combinación 14 & 6,25 & 0,49 & 1,05 & 0,79 & 8,59 \\
\hline Combinación 17 & 6,25 & 0,49 & 1,05 & 0,79 & 8,59 \\
\hline
\end{tabular}





\section{CAPÍTULO 7 \\ Conclusiones y líneas futuras de investigación}





\section{Conclusiones y líneas futuras de investigación.}

Las contribuciones de esta tesis se pueden sintetizar en el desarrollo de metodologías y herramientas para:

- la simulación de diferentes políticas de precios del agua vinculadas a la disponibilidad del recurso o su escasez relativa.

- y la definición de políticas eficientes de precios que incorporen el valor marginal del recurso a escala de cuenca, enviando a los usuarios una señal del valor real del recurso y los costes de oportunidad.

La aplicación de la metodología a dos casos de estudio, el sintético y el del sistema del río Mijares, ha permitido analizar las ganancias en términos de eficiencia económica de la aplicación de diferentes políticas (precios escalonados basados en CMOR de simulación o de optimización, precios dinámicos, precios estacionales, etc.) y extraer algunas 
conclusiones. A continuación de sintetizan los principales resultados y conclusiones del trabajo, y finalmente se presentan líneas de investigación futuras.

\subsection{Metodología y etapas}

Desde el punto de vista de la gestión del agua como un bien económico un reto clave es conseguir que se tenga en cuenta de algún modo el coste de oportunidad real del agua en la utilización del recurso. La eficiencia económica en la gestión del recurso exige que se conozcan e incorporen los costes de oportunidad del recurso en las decisiones. Además, las tarifas que incluyen el coste de oportunidad transmiten al usuario una señal de escasez del recurso, incentivando un uso eficiente del mismo. A pesar de la aparente simplicidad del concepto, su aplicación es muy compleja. Sin embargo, la Directiva Marco del Agua (DMA) europea exige la implementación de una política de precios del agua que por un lado, contribuya a la recuperación de los costes de los servicios del agua (y por costes se entiende no sólo los financieros, sino también los ambientales y del recurso), y por otro, a una gestión más eficiente del recurso contribuyendo al logro de los objetivos ambientales de la DMA.

Poner precio al recurso hídrico siempre es un asunto trascendente para promover una asignación y un uso eficiente de un recurso escaso. En la literatura relativa a políticas de precios del agua se señala la incompatibilidad entre las recomendaciones de políticas de precio de tipo marginal que proporciona la teoría microeconómica y la política de precios con costes medios que se utiliza en la industria del agua en forma práctica. Generalmente las políticas de precios con costes medios están enfocadas hacia el suministro a nivel de usuario. Pero existe poca o nula investigación relativa a políticas de precios con costes marginales a nivel de cuenca.

En la tesis se ha presentado una metodología y herramientas para simular el efecto de distintas políticas de precios relacionadas con la disponibilidad del recurso en la gestión del recurso, y analizar el impacto económico (agregado e individual sobre cada demanda) de las mismas. Se ha desarrollado también un método para definir y simular políticas eficientes de precio del recurso basadas en la estimación sistemática del coste de oportunidad del recurso (CMOR). Se ha descrito la aplicación de la metodología y herramienta a un caso sintético y posteriormente a la gestión del sistema del río Mijares.

La metodología parte del cálculo del CMOR (Coste Marginal de Oportunidad del Recurso). El CMOR en un punto del sistema y en un instante determinado se calcula como el coste que supone para el sistema el disponer de una unidad menos de recurso en ese punto y en ese instante. Este valor es un indicador de la escasez de agua en el sistema y de la disposición de pago del sistema productivo y de los usuarios finales del agua para mitigar esa escasez y varía de forma dinámica en el espacio y el tiempo. La caracterización 
económica del sistema se hace mediante curvas económicas de demanda para cada uso (que expresan la relación entre el agua suministrada y su valor marginal) y costes variables de operación del sistema. La precisión en la definición de estas curvas de demanda, asumidas como información exógena para el modelo, es fundamental en la fiabilidad de los resultados del modelo. El beneficio para un cierto volumen de agua disponible es igual al área bajo las curvas de demanda hasta ese nivel de suministro. Integrando desde un nivel genérico de agua disponible hasta el nivel de suministro máximo se obtiene la expresión del coste económico de escasez en función del nivel de suministro.

La estimación del CMOR se hace mediante dos enfoques: simulación de la gestión según prioridades y modus operandi actual y optimización económica. El primer enfoque considera la simulación hidro-económica de la gestión del sistema, empleando para ello dos módulos del Sistema de Apoyo a la Decisión AquaTool: el módulo de simulación (SimGes) y el de evaluación económica (EcoWin). Los resultados de la asignación mensual del recurso simulados en SimGes, junto con las funciones de valor económico del agua en los distintos usos, y de costes de operación, son inputs de entrada en el modelo de evaluación económica, que aproxima el valor del CMOR mediante comparación de los resultados económicos de la simulación del caso base con los de las simulaciones de la gestión del sistema disponiendo de una unidad adicional de agua en cada período de tiempo en el lugar seleccionado. El enfoque de optimización económica maximiza el valor económico neto del uso del agua durante el período de optimización. Se optimiza a nivel mensual sobre series hidrológicas extensas, representativas del rango de eventos hidrológicos probables en el futuro, obteniendo el flujo del agua en el sistema durante el período optimizado y los resultados económicos asociados. La función objetivo a minimizar representa el coste total para el período de optimización, incluyendo como costes las pérdidas económicas derivadas de la escasez o déficit en el suministro a las demandas, sumadas a los costes variables de operación del sistema. En el modelo de optimización, programado en GAMS, los valores óptimos de las variables del problema dual (precios sombra) nos definen directamente el cambio en el valor óptimo de la función objetivo como consecuencia de un cambio marginal en el término independiente de la restricción correspondiente a cada variable dual. Como la función objetivo representa el beneficio económico agregado del uso del agua, los precios sombra obtenidos para las restricciones de balance en embalse representan la variación de beneficio neto por unidad adicional de agua en el sistema, y por tanto, las series de coste (valor) marginal del recurso en ese embalse.

Para el análisis económico en cada sistema se han completado las siguientes etapas:

- Puesta a punto de un modelo de simulación de la gestión del sistema de recursos hídricos en cuestión, incorporando la información relevante sobre la hidrología, 
infraestructura, reglas de operación y criterios de asignación (ej. prioridades) y demanda

- Caracterización económica del sistema mediante curvas económicas de demanda para los usos de cada unidad de demanda y costes variables de operación. Los resultados económicos son sensibles a las curvas de demanda utilizadas, con lo que esta información, exógena a los modelos desarrollados, resulta muy relevante. Su determinación en algunos casos requeriría de más datos, de modelos específicos y de un análisis más completo del que se ha podido emplear en los casos de estudio del presente trabajo.

- Simulación de la gestión del sistema y análisis de suministros, déficits y costes de escasez (pérdidas de beneficio por déficit) en el suministro a las distintas demandas (individual y agregado)

- Determinación de la evolución del CMOR en los embalses principales del sistema mediante simulación iterativa de la gestión (comparando el escenario base con escenarios con una unidad adicional de agua a lo largo del tiempo).

- Puesta a punto del modelo de optimización económica de la gestión, incluyendo la función objetivo económica y las restricciones correspondientes (esto es, restricciones de balance en nudos, embalses y acuíferos; de capacidad máxima en infraestructura; de caudales o volúmenes mínimos por motivos ambientales, legales, operativos o recreativos; ecuaciones de procesos físicos, filtración y evaporación en embalses y conducciones, retornos, relación río-acuífero, etc.; y restricciones de signo de las variables).

- Optimización económica de la gestión y análisis de beneficios, suministros, déficits y costes de escasez. Este resultado representaría el techo o máximo beneficio económico alcanzable en la gestión del recurso.

- Determinación de la serie temporal de CMOR de optimización mediante los precios sombra de las restricciones de balance en el embalse.

- Análisis de los resultados del CMOR de simulación y de optimización, incluyendo estadísticas del mismo (promedios, desviaciones típicas) y clasificación de valores de MOR para distintos rangos de volumen de embalse.

- Análisis de sensibilidad del CMOR a las curvas de demanda utilizadas 
- Propuestas de políticas eficientes de precios, con base en los CMOR de los modelos de simulación y de optimización, teniendo en cuenta diferentes rangos de volumen de embalse e incluso aportaciones hidrológicas al sistema.

- Simulación de las diferentes políticas de precios (mediante el modelo SIMGES, con transformación precios-restricciones a través de los indicadores de alarma).

- Análisis de resultados económicos para distintas políticas de precios y determinación de la mejora de beneficios alcanzada respecto al escenario de gestión sin precios y al techo de la optimización económica

\subsection{Políticas de precios y CMOR. Conclusiones de la aplicación a los casos de estudio}

Como norma generalizada, para definir políticas eficientes de precios primeramente ha de calcularse el CMOR en los embalses principales con el modelo de simulación de la gestión del sistema de explotación. Si es posible, se desarrolla el modelo de optimización del sistema tomando como función objetivo la maximización de los beneficios económicos del uso del agua en las unidades de demanda que conformen al sistema. Para este modelo, se calculan los beneficios ( $y$ costes de escasez) y los CMOR en embalses. La distancia entre los beneficios simulados con la gestión actual y los beneficios máximos obtenidos en la optimización nos muestran el margen de ganancia sobre el que pueden actuar las políticas de precios.

Se pueden definir políticas de precios eficientes con los escalones de precios correspondientes a valores promedios del CMOR de simulación y de optimización para distintos rangos de volumen de embalse. En el caso de estudio sintético, asumir precios escalonados derivados de los CMOR promedios del modelo de la simulación conduce a unos beneficios económicos que ya capturan un $80 \%$ de la distancia que separa la gestión sin política de precios de la gestión optimizada teórica. En este caso, se da la circunstancia de que estos valores resultaron mejores incluso que los que se obtuvieron cuando se consideró la política de precios derivada de los CMOR del modelo de optimizzación. Sin embargo, en el caso de estudio del sistema del río Mijares los mayores beneficios se obtuvieron para la política de precios derivada de los CMOR de optimización. El que resulte mejor una política de precios $u$ otra depende de muchos factores que son inherentes a la propia complejidad del sistema. Entre ellos podemos citar la estructura de dependencia temporal de las series de aportaciones y las propiedades estadísticas de las sequías del sistema, la configuración y características de la infraestructura del sistema, la capacidad de regulación, etc. Por tanto, a priori no es posible saber si una política de precios derivada del CMOR de optimización o de simulación ha de ser económicamente 
más eficiente. Como se ha comentado, la comparación de beneficios entre la simulación de la gestión y la optimización económica nos permite ver el margen de ganancia de eficiencia. Si los resultados obtenidos con una determinada política de precios no mejoran mucho la eficiencia, es posible analizar entonces distintas alternativas.

Con el fin de encontrar políticas de precios más próximas al óptimo teórico se pueden realizar diversas tentativas de mejora. Para ello se procedió a optimizar los valores medios escalonados del CMOR de la simulación, para diferentes rangos de volumen almacenado en el embalse. También se pueden incorporar los valores de las aportaciones previas al sistema en la definición de los precios. Esto último puede ser especialmente importante en la corrección de precios para mejorar su eficiencia en sistemas con alta dependencia temporal en las series de aportaciones (identificada por el autocorrelograma de la serie), ya que en este caso las aportaciones previas proporcionan una información relevante sobre el riesgo de sequía en los meses posteriores.

Por otro lado, definir políticas de precios que dependan del estado previo del sistema o de periodos estacionales, hacen más complejo el cálculo. En el caso sintético no proporcionan una mejora sustancial en los beneficios económicos por el uso del agua. Sin embargo, el definir un precio constante al principio de cada año o estación según la disponibilidad de recursos tiene la ventaja práctica de proporcionar una mayor seguridad a los usuarios a la hora de tomar decisiones y programar actividades dependientes del uso del agua.

Finalmente, pueden generarse series sintéticas a partir de la serie de aportaciones históricas mediante un modelo estocástico (por ejemplo, un modelo ARMA de aportaciones) y simular con cada una de ellas las diferentes políticas de precios. En este caso se puede usar con más propiedad el valor medio de los beneficios obtenidos con cada serie como representativo de la contribución de la política de precios a la mejora de la eficiencia económica.

La metodología de simulación de políticas de precios es novedosa y puede incorporase en cualquier modelo de simulación de la gestión de un sistema de recursos hídricos para el que se definan las correspondientes curvas de demanda. Mediante el uso de los indicadores de alarma del módulo SimGes del SAD Aquatool, se transforman los precios en restricciones de suministro a las demandas del sistema. La política de precios propuesta queda así definida como una serie de restricciones que al simular la gestión producirán cambios en el suministro a las demandas, información a partir de la cual se puede estimar los beneficios de la aplicación de esa política. 


\subsection{Líneas futuras de investigación.}

La propuesta metodológica para definir políticas eficientes de precios puede ampliarse investigando sobre los aspectos siguientes:

- Incluir políticas en sistemas complejos incorporando la interacción río-acuífero y el uso conjunto de aguas superficiales y subterráneas. La mayoría de los sistemas en explotación cuentan con acuíferos en explotación que están relacionados con el sistema superficial de la cuenca. Valorar el coste del recurso en sistemas complejos, como lo es la cuenca del río Segura -por poner un ejemplo- es de suma importancia para que los usuarios sean incentivados a mejorar la eficiencia de su propia infraestructura de suministro. Al considerar políticas eficientes de precios tomando en cuenta todos los elementos que conformen dicho sistema, producirá incentivos de eficiencia de gestión y beneficios mayores en el uso del recurso.

- Profundizar en el análisis de la caracterización económica de los sistemas de recursos hídricos. En la bibliografía actual existe mucha información referente al cálculo de las curvas de demanda económica para distintos usos en función de la información disponible y los objetivos del estudio. Como ya se ha comentado, la precisión en la definición de estas curvas de demanda, asumidas como información exógena para el modelo, es fundamental en la fiabilidad de los resultados del modelo. Aunque en este estudio se hace una "idealización" de la información aportada por las curvas de demanda, es necesario analizar y considerar las limitaciones e incertidumbres en la caracterización económica de los sistemas mediante curvas económicas de demanda. Entre ellas, la adecuación de las distintas escalas temporales que intervienen (anual y mensual) y el tema de los efectos acumulados en el tiempo de los déficits en el suministro. Otros aspectos relevantes para la valoración económica de la gestión (por ejemplo, el papel de la tasa de descuento; beneficios y costes secundarios e indirectos; las externalidades; el papel de los mercados, etc.) han quedado fuera de los objetivos de este estudio pero sin duda sería importante abordarlos en una extensión de este trabajo.

- Estudiar la contribución de las políticas de precios al logro del buen estado de las masas de agua establecidos por la DMA. En este trabajo los requerimientos ambientales han sido tratados como restricciones a la gestión (así son considerados por la actual Ley de Aguas y en cierto modo por la DMA), y son tenidas en cuenta de esta forma en la definición de los precios a partir del CMOR. Hoy en día existen muchas técnicas de valoración de bienes ambientales sin mercado que permiten definir un valor económico del agua para mejorar las condiciones ambientales. Se puede explorar también el papel de estas funciones económicas en el diseño de precios eficientes. 
- Adaptar el módulo de simulación SimGes del SAD AQUATOOL de manera que pueda incorporar de manera directa y flexible diferentes políticas de precios que el investigador proponga utilizar para un caso en particular.

- Integrar los conceptos de costes financieros, del recurso y ambientales en las políticas de precios. 


\section{Referencias bibliográficas}





\section{Referencias}

AEAS, 1998. El Suministro de agua potable y saneamiento en España.VI Encuesta Nacional. Asociación Española de Abastecimiento y Saneamiento.

AEAS, 2002. El Suministro de Agua Potable y Saneamiento en España. VIII Encuesta Nacional. Asociación Española de Abastecimiento y Saneamiento

Álvarez, E., M. Pulido -Velázquez, J. Andreu, 2006. Estimación del Coste Marginal de Oportunidad del Recurso mediante modelos hidro-económicos a escala de Cuenca. Aplicación al Sistema del río Mijares en España. XXII Congreso Latinoamericano de Hidráulica. Ciudad Guyana, Venezuela.

Andreu, J. y A. Sahuquillo, 1987. Efficient aquifer simulation in complex systems. Water Resources Planning and Management, 113(1), 110-129.

Andreu, J., J. Capilla y E. Sanchis, 1996. AQUATOOL, a generalized decision support system for water resources planning and management. Journal of Hydrology (177) 269-291. 
Andreu, J., Abel Solera, José Capilla, Ferrer Polo, 2004. Modelo SIMGES de Simulación de la Gestión de Recursos Hídricos, incluyendo Utilización Conjunta. Manual de usuario. Servicio Publicaciones, Universidad Politécnica de Valencia, Valencia, España.

Arbués, F., R. Barberán e I. Villanúa, 2004. Price Impact on Urban Residencial Demand: A Dynamic Panel Data Approach. Water Resources Research (40).

ARKI, 2002. GAMS/CONOPT. ARKI Consulting Development in GAMS the Solver Manual. Development Corporation. Washington DC, USA.

Arrojo, A., 1999. El valor económico del agua. Revista CIDOB d'Afers Internacionals, 45-46.

Assimacopoulos, D., A. Schuman, E. Todini, J.M. Berland y E. Feinerman, 2001. The WaterStrategyMan Project. The WaterStrategyMan Project. Disponible en: http://environ.chemeng.ntua.gr/wsm/.

Assimacopoulos, D., B. Barraque, J.M. Berland, E. Feinerman, P. Katsiardi y E. Manoli, 2005. Estimation of the level of cost recovery of different scenarios of water allocation in arid areas - an easy-to-implement approach. París, Francia.

Azqueta, D., 2007. Introducción a la Economía Ambiental. McGraw Hill/Interamericana de España; 2a edición. 456 pp. Aravaca, Madrid.

Bauer, C.J., 2004. Canto de Sirenas. El derecho de aguas chileno como modelo para reformas internacionales. RFF Press. Bakeaz. Centro documentación estudios para la paz. 1 a edición. 237 pp.

Baumann, D., J. Boland.y M. Hanemann, 1997. Urban Water Demand Management and Planning. McGraw-Hill, Inc., NY. 1ạ edición. 350 pp.

Bazaraa, M. S.; John Jarvis y Hanif Sherali, 2009. Linear Programming and Network Flows. Wiley \& Sons Publication, New Jersey. 768 pp.

Bear, J. y O. Levin, 1970. Optimal Utilization oí an Aquifer as an Element of a Water Resource system. Proceeding of the Seleeted Works in Operations Research. Shechter M, \& Baer, J, ed. Operations Research Center and Water Resources Center, USA.

Blanco Fonseca, M., 1999. La economía del agua: análisis de políticas de modernización y mejora de regadios en España. Tesis doctoral, Universidad Politécnica de Madrid, Madrid, España.

Blanco, M., 2008. Decision Support System to Assess Environmental and Socioeconomic Effects of Water Pricing Policies in Agriculture. En Pulido et al. eds., Hydro-economics models in Water Management: Applications to the EU Framework Directive. Springer, Environment and Policy series (por publicar).

Bookchin, M., 1974. The limits of the city. Harper and Row. 147 pp. 
Booker, J., R. Young, 1994. Modeling intrastate and interstate markets for Colorado River water resources. Journal of Environmental Economic Management 26(1) 66-87.

Braat, L., W. Lierop, 1987. Integrated economic-ecological modeling. En Economicecological Modeling (Studies in regional science and urban economics). Elsevier Science Ltd. $1^{\text {st }}$ edition, 342 pp. North-Holland, Amsterdam.

Braden, J.B., 2000. Value of valuation: Introduction. Journal of Water Resources Planning and Management, 126 (6)

Briscoe, J., 1996. Water as an economic good. The idea and what it means in practice. Proceedings of the World Congress of the International Commission on Irrigation and Drainage (ICID) El Cairo, Egypt.

Brooke, A., D. Kendrick, A. Meeraus, y R. Raman, 1998. GAMS:A User's Guide. Scientific Press. Red Wood City, California, USA.

Brouwer, R., 2004. The concept of environmental and resource cost. Lessons learned from ECO2. En Environmental and Resource Cost and the Water Framework Directive. An overview of European practices. RIZA Working Paper 2004 112x. Amsterdam, Holland.

Brouwer, R., 2006. Practical working definition Environmental and Resource Costs and Benefits. Institute for Environmental Studies, Vrije Universiteit, Amsterdam.

Brouwer, R., D. Barton, F. Oosterhuis., 2007. Economic Methods, models and instruments for the Water Framework Directive. Conference at Vrije Universiteit, Amsterdam.

Burt, O., 1964. The economics of conjunctive use of ground and surface water. Hilgardia 36(2) 31-111.

Cai, X., D.C. McKinney, L.S. Lasdon, 2003. Integrated hydrologic-agronomic-economic model for river basin management. Journal of Water Resources Planning and Management 129(1) 4-17.

Calatrava, J., 2007. Curvas económicas de demanda en las UDAs de la cuenca del Segura. Informe para INITEC y la CHS. Murcia, España: Universidad Politécnica de Cartagena.

CEDEX, 1991. Anexos 9 y 14: Determinación de las dotaciones de riego en los planes de regadío de la cuenca del Júcar.

CHJ, 1997. Plan Hidrológico del Júcar, Anexo IV Sistemas de Explotación. Valencia, España.

CHJ, 2005. Informe para la Comisión Europea sobre los artículos 5 y 6 de la Directiva Marco del Agua. Demarcación hidrográfica del Júcar. Valencia, España.

CHJ, 2009. Documento técnico de referencia: Metodología y resultados de la estimación de demandas. Valencia, España. 
CHS, 1998. Plan Hidrológico del Segura. Memoria. Ministerio del Medio Ambiente.

CHS, 2006. Determinación y análisis del coste del recurso de los servicios del agua y de restricciones ambientales en la cuenca del Segura. Estudio realizado para la Confederación Hidrográfica del Segura. INITEC-UPV, Valencia, España.

Cleveland, W.S., S.J. Devlin, 1988. Locally-Weighted Regression. An approach to regression Analysis by Local Fitting. Journal of the American Statistical Association 84 (403): pp. 596-610.

Cobb, C.W., P.H. Douglas, 1928. A Theory of Production. American Economic review 18 (supplement): 139-165.

Colino Sueiras, Martínez Paz, 2002. El Agua en la Agricultura del sureste español: productividad, precio y demanda. No. 2 de la Colección Mediterráneo Económico. "La Agricultura mediterránea en el siglo XXI".

Collazos, G., 2004. Sistema soporte de decisión para evaluación y optimización económica de sistemas de recursos hídricos. Tesis Doctoral. Universidad Politécnica de Valencia. Valencia, España.

Collazos, G., M. Pulido-Velázquez, J. Andreu, 2004. SSD para el análisis económico de sistemas de recursos hídricos. IV Congreso Ibérico de Gestión y Planificación del Agua. Tortosa, España.

Comisión Europea, 2000. Comunicación de la Comisión al Consejo, al Parlamento Europeo y al Comité Económico y Social. COM (2000) 477, pp 13-24. Bruselas, Bélgica.

DG Eco 2, 2004. Assessment of Environmental and Resource Costs in the Water Framework Directive. The Netherlands.

DGHO, 2003. Asistencia Técnica. Valoración del coste de uso de las aguas subterráneas en España.

Díaz, G. e I. Brown, 1997. Aquarius: A general model for efficient water allocation in river basins. Proceedings of $27^{\text {th }}$ Congress of the International Association for Hydraulic. San Francisco, CA: American Society of Civil Engineers, New York, USA.

Dinar, A. y J. Letey, 1996. Modeling Economic Management and Policy Issues of Water in Irrigated Agriculture. Praeger Publishers. $1^{\text {st }}$ edition, 264 pp. USA.

Dinar, A., M. Rosegrant y R. Meinzen-Dick, 1997. Water allocation mechanisms. Principles and examples. World Bank, Policy research Paper No. 1779.

DMA, 2000. Directiva 2000/60/CE del Parlamento Europeo y del Consejo. 23 de octubre de 2000. PE-CONS 3639/00. Bruselas, Bélgica. 
Domenico, P., D.V. Anderson y C.M. Case, 1968. Optimal Groundwater Mining. Water Resources Research 4(2).

Dracup, J., K. Lee, E. Paulson, 1980. On the statistical characteristics of drought events. Water Resources Research 16(2) 289-296.

Draper, M. Jenkins, K. Kirby, J.R. Lund y R.E. Howitt, 2003. Economic-Engineering Optimízation for California Water Management. Journal of Water Resources Planning and Management 129(3) 155-164.

Draper, A. y J. Lund, 2004. Optimal Hedging and Carryover Storage Value. Journal of Water Resources Planning and Management 130(1) 83-87.

Fernández Pérez D., 1995. Gestión del agua urbana. Madrid, España. Colegio de Ingenieros de Caminos, Canales y Puertos.

Fisher, F.M., Annette Huber-Lee, Ilan Amir, et al., 2005. Liquid Assets: An Economic Approach for Water Management and Conflict Resolution in the Middle East and Beyond. RFF Press, 256 pp. Washington DC, U.S.A.

García Mollá, M., 2000. Análisis de la influencia de los costes en el consumo de agua en la Comunidad Valenciana. Caracterización de las entidades organizativas para riego. Tesis Doctoral. Universidad Politécnica de Valencia. Valencia, España.

García Valiñas, M., 2002. La demanda de agua en las ciudades: estimación comparada para tres municipios españoles. Memorias del III Congreso Ibérico sobre Gestión y Planificación del Agua. La Directiva Marco del Agua, realidades y futuros. Sevilla, España: L. del Moral (ed.), 232-253.

García Valiñas, M., 2006. Demanda Urbana de Agua en la Región de Valencia. Un enfoque econométrico. En Jornadas Internacionales sobre Modelos HidroEconómicos y Herramientas para la implementación de la Directiva Marco europea del Agua. Valencia, España.

Gayoso, J. e A. Iroumé, 2000. Catastro y Localización de Usos Públicos no Extractivos o Usos in situ del Agua. Informe del Ministerio de Obras Públicas, Dirección General de Aguas. Chile.

Gibbons, D.C., 1986. The Economic Value of Water. RFF Press. $1^{\text {st }}$ edition, $116 \mathrm{pp}$.

Gisser, M. y A. Mercado, 1972. Integration of the agricultural demand functions for water and the hydrologic model of the Pecos Basin. Water Resources Research 8(6) 1373-1384.

Gisser, M. y A. Mercado, 1973. Economic aspects of ground water resources and replacement flows in semiarid agricultural areas. American Journal of Agricultural Economics 55 461-466. 
Gleick, P., 2003. Global Freshwater Resources: Soft-Path Solutions for the 21st Century. Science 302 1524-1528.

Görlach, B. y E. Interwies, 2004. Assesing Environmental and Resource Costs in the Water Framework Directive: the Case of Germany. Ecologic Institut fü Internationale und Europäische Umweltpolitik. Berlín, Germany

Griffin, R.C., 2006. Water Resource Economics: The Analysis of Scarcity, Policies, and Projects. The MIT Press. $424 \mathrm{pp}$.

Hall, W. y W. Hanemann, 1996. Water rate design based on marginal cost. En Advances in the economic of environmental economics. Marginal cost rate design and wholesale water markets. Marginal cost rate design and wholesale water markets. JAI Press, 95122. Greenwich, Connecticut

Hanemann, W., 1997. Determinants of urban water use. En Urban Water Demand Management and Planning. McGraw-Hill, Inc. New York, pp 31-75.

Harou, J.J., Manuel Pulido-Velazquez, David E. Rosenberg, Josué Medellín-Azuara, Jay R. Lund, and Richard E. Howitt, 2009. Hydro-economic models: Concepts, design, applications, and future prospects. Journal of Hydrology (375) 627-643.

Hazell, P. y R. Norton, 1986. Mathematical Programming for Economic Analysis in Agriculture. Macmillan USA. $432 \mathrm{pp}$

Heinz, I., 2006. The Economic Value of Water. In International Workshop on Hydroeconomic Modeling and Tools for the Implementation of the European Water Framework Directive. Valencia, Spain.

Heinz, I., M. Pulido-Velázquez, Jay R. Lund, y J. Andreu, 2007. Hydro-economic Modeling in River Basin Management: Implications and Applications for the European Water Framework Directive. Water Resources Management (21) 1103-1125.

Heras, G., 2000. Particularidades económicas del agua en España. 6ạ Conferencia internacional del seminario permanente "ciencia y tecnología del agua" Economía del agua: hacia una mejor gestión de los recursos hídricos.

Howe, C., D.R. Shurmeier, and D.W. Shaw, 1986. Innovative approaches to water allocation: the potential for water markets. Water Resources Research 22(4) 439-445.

Howitt, R., 1995. Positive mathematical programming. American Journal of Agricultural Economics 2(77) 329-342.

Iglesias, E., M. Blanco, 2008. New directions in water resources management: The role of water pricing policies. Water Resources Research, 44(W06417).

Jenkins, M.W., 2003. Using Economic loss functions to value urban water scarcity in California. Journal American Water Works Association. 95 (2), 58-70 
Johansson, R.C., 2000. Pricing irrigation water: a literature survey. World Bank, Rural Development Department. 80 pp.

Labadie, J., 1997. Reservoir system optimization models. Water Resources Update 108(summer) Universities Council on Water resources.

Lee, T. y A. Juravlev, 1998. Los precios, la propiedad y los mercados en la asignación del agua. Comisión Económica para América Latina y Medio Ambiente. 100 pp.

Ley de Aguas Española, 2003. Canon de control de vertidos contemplado en el artículo 113 del Texto Refundido de la Ley de Aguas (TRLA), aprobado por el Real Decreto Legislativo 1/2001, de 20 de julio, y modificado por la Ley 62/2003, de 30 de diciembre, y el Reglamento del Dominio Público Hidráulico (RDPH), aprobado por el Real Decreto 849/1986, de 11 de abril, y modificado por el Real Decreto 606/2003, de 23 de mayo. Disponible en: http://www.chj.es/ciudadano/tasasycanones/

Ley del Plan Hidrológico Nacional, 2001. Ley 10/2001, de 5 de julio, artículos 22 y 23.

Lund, J.R., R.E. Howitt, M.W. Jenkins, A.J. Draper, and S. Tanaka, 2001. Improving California Water Management: Optimizing Value and Flexibility. Executive Summary. State of California, USA: University of California.

Lund, J.R. y J.J. Harou, 2006. How to Build a Regional Hydro-Economic Engineering Model. Proceedings of the International Workshop on Hydro-Economic Modeling and Tools for Implementation of the European Water Framework Directive. Valencia, Spain.

Maestu, J., A. Del Villar, 2006. El sector de los servicios del agua en España: Recuperación de costes y perspectivas financieras. Ambienta (59) 6.

Martínez-Espiñeira, R., 2002. Residential water demand in the Northwest of Spain. Environmental and Resource Economics 21(2) 161-187.

McKinney, D., X. Cai, M. Rosegrant, C. Ringler, and C. Scott, 1999. Modeling Water Resources Management at the Basin Level: Review and Future Directions. Technical Report. International Water management Institute. Paper 6, 71 pp. Colombo.

Merrett, S., 2004. The Demand for Water: Four Interpretations. Water International 29(1) 27-29.

Mill, J. S., 1848. Principios de economía política; con algunas de sus aplicaciones a la filosofía social.

MIMAM, 2000. Libro Blanco del Agua en España. España: Ministerio de Medio Ambiente.

MIMAM, 2002. Plan Hidrológico Nacional. Anexo de Análisis Económicos. 
MIMAM, 2003. Valoración del coste de uso de las aguas subterráneas en España. Ministerio del Medio Ambiente.

MMA, 2007. Precios y Costes de los Servicios del Agua en España. Informe integrado de recuperación de costes de los servicios de agua en España. Artículo 5 y anejo III de la Directiva Marco de Agua.

MMAMRM, 2008. Esquema Provisional de Temas Importantes. Ministerio de Medio Ambiente y Medio Rural y Marino. Confederación Hidrográfica del Segura.

Moss, J., G. Wolf, G. Gladden y E. Gutiérrez, 2003. Valuing Water for Better Governance. How to Promote Dialogue to Balance Social, Environmental, and Economic Values? Proceedings of the 3rd Word Water Forum. Kyoto, Japan.

Murtagh, B. and M. Saunders, 2002. MINOS 5.5 User's Guide. Technical Report SOL 8320R. Departament of Operation Research, Stanford University. Stanford, California, USA.

Noel, J. and R.E. Howitt, 1982. Conjunctive multibasin management: an optimal control approach. Water Resources Research 18 753-763.

Ochoa-Rivera, J.C., Andreu, J., Garci'a-Bartual, R., 2007. Influence of inflows modeling on management simulation of water resources system. Journal of Water Resources Planning and Management 133 (2), 106-116

Pearce, D. y R. Turner, 1995. Economía de los Recursos Naturales y Medio Ambiente. Colegio de Economistas de Madrid.

PHCS, 1998. Plan Hidrológico de la Cuenca del Segura. Memoria

Pulido-Velázquez, M., 2003. Optimización Económica de la Gestión del Uso Conjunto de Aguas Superficiales y Subterráneas en un Sistema de Recursos Hídricos. Contribución al Análisis económico propuesto en la Directiva Marco Europea del Agua. Tesis Doctoral. Universidad Politécnica de Valencia. Valencia, España.

Pulido-Velázquez, M., M. Jenkins and J. Lund, 2004a. Economic Values for Conjunctive Use and Water Banking in Southern California. Water Resources Research 40(3).

Pulido-Velázquez, M., Joaquín Andreu, Guillermo Collazos y Miguel A. Pérez, 2004b. Metodologías y herramientas para el análisis económico de sistemas de recursos hídricos. Aplicación a la DMA. Memorias del IV Congreso lbérico de Gestión y Planificación del Agua. Tortosa, España.

Pulido-Velázquez, M., 2006a. Metodología y Herramientas para la valoración integrada del coste del recurso y coste ambiental. Aplicación a la Cuenca del Júcar. Memorias del $V$ Congreso Ibérico. Faro, España 
Pulido-Velázquez, M., Joaquín Andreu and Andrés Sahuquillo, 2006b. Economic Optimization of Conjunctive Use of Surface Water and Groundwater at the basin, scale. Journal of Water Resources Planning and Management 132(6) 454-467.

Pulido -Velázquez, M., J. Andreu, A. Sahuqillo and D. Pulido -Velázquez, 2008. Hydroeconomic river basin modeling: The application of a holistic surface-groundwater model to assess opportunity costs of water use in Spain. Ecological Economics 66(1) 51-65.

Reglamento del Dominio Público Hidráulico, 2003. Disposición transitoria primera en el Real Decreto 606/2003, de 23 de mayo, por el que se modifica el Real Decreto 849/1986, de 11 de abril, por el que se aprueba el Reglamento del Dominio Público Hidráulico, que desarrolla los Títulos preliminar, I, IV, V, VI y VIII de la Ley 29/1985, de 2 de agosto, de Aguas. Disponible en http://noticias.juridicas.com/base_datos/Admin/rd606-2003.html

Robbins, L., 1984. An Essay On The Nature and Significance of Economic Science. Palgrave MacMillan. $3^{\text {ed }}$ edition. 208 pp.

Rogers, P., R. Bhatia, A. Huber, 1998. Water as Social and Economic Good: how to put the principles into practice. Background paper. Stockholm, Sweden: Global Water Partnership TAC.

Rogers, P., R. De Silva and R. Bhatia, 2002. Water is an economic good: How to use prices to promote equity, efficiency, and sustainability. Water Policy 4 1-17.

Rosegrant, M., X. Cai, C. Ringler, A. Séller, G. Donoso and D. McKinney, 1999. Report for the Inter-American Development Bank on the integrated economic-hydrologic water modeling at the basin scale: The Maipo River Basin in Chile. IFPRI, Washington DC.

Ruiz, J.M., 1998. Desarrollo de un modelo hidrológico conceptual-distribuido de simulación continua integrado con un sistema de información geográfica. Tesis Doctoral. Universidad Politécnica de Valencia. Valencia, España.

Salas, J., J. Delleur, V. Yevjevich and W. Lane, 1980. Applied modeling of hydrologic time series. Water Resource Publications. 484 pp.

Savenije, H., 2001. Why water is not an ordinary economic good? Proceedings of the Second WaterNet/WARFSA Symposium on 'Integrated Water Resources Management: Theory, Practice, Cases' Cape Town, South Africa: IHE, Delft.

Sopeña, M., 2002. Análisis del sistema del río Mijares y diseño de un plan de gestión óptimo para la mitigación de sequías. Proyecto final de Carrera tipo III. Universidad Politécnica de Valencia. Valencia, España.

Spulber, N., A. Sabbaghi, 1998. Economics of Water Resources: from regulation to privatization. (Natural Resource Management and Policy) Springer; 2nd edition Publishers; $376 \mathrm{pp}$. 
Sumpsi, J., M Fonseca, C. Ortega y E. Martínez, 1998. Economía y política de gestión del agua en la agricultura 1o ed. Madrid, España: Ediciones Mundi-Prensa. 351 pp.

Tanaka, S., T. Zhu, J. Lund, et al, 2006. Climate Warming and Water Management Adaptation for California. Climatic Change 76(3-4) 361-384.

Thünen J.H. von, 1826. «Der Isolierte Staat in Beziehung auf Landwirtschaft un Nationalökonomie ». Perthes, Hamburg. (Traducción inglesa: " The Isolated State in relation to agriculture un economics ». Pergammon Press, Oxford, 1966).

Trujillo, L., 1994. Fijación de precios óptimos en el suministro urbano de agua. Revista de Economía Aplicada 2(5) 111-135.

USACE (U.S. Army Corps of Engineering), 1994. Hydrologic Engineering Center's Prescriptive Reservoir Model, Program Description. U.S. Army Corps of Engineering. Hydrologic Engineering Center, Davis, California, USA.

Vaux, H., R.E. Howitt, 1984. Managing water scarcity: An evaluation of interregional transfers. Water Resources Research 20 785-792.

Walras, L., 1874. Éléments d'économie politique pure, ou théorie de la richesse sociale

Ward, F., A. Michelsen, 2002. The Economic Value of Water in Agriculture: concepts and policy applications. Water Policy 4 423-446.

Ward, F.A., J.E. Booker, A.M. Michelsen, 2006. Integrated Economic, Hydrologic, and Institutional Analysis ofPolicy Responses to Mitigate Drought Impacts in Rio Grande Basin. Journal of Water Resources Planning and Management 132(6) 488-502.

Ward, F., M. Pulido-Velázquez, 2008. Efficiency, equity, and sustainability in a water quantity-quality optimization model in the Rio Grande basin. Ecological Economics 66(1) 23-37.

WATECO, 2003. Guidance Document No.1: Economics and the Environment. The implementation challenge of the Water Framework Directive. $72 \mathrm{pp}$. Produced by Working Group 2.6-WATECO. Luxembourg.

Wieser, F.V., 1876. Über das Verhältnis der Kosten zum Wert (On the Relation of Cost to Value). En Gesammelte Abhandlungen. 377-404.

Winpenny, J., 1994. Managing water as an economic resource. Routledge $1^{\text {st }}$ edition, 144 pp. London.

Yevjevich, V., 1967. An Objective Approach to Definition and Investigation of Continental Droughts. Hydrology Paper 23. Colorado State University; Fort Collins, Colorado. 
Young, J. and J.D. Bredehoeft, 1972. Digital computer simulation for solving management problems of conjunctive groundwater and surface water systems. Water Resources Research 8(3) 533-556.

Young, R, 1996. Water Economics in L.A. En Handbook of Water resources Mays, ed. McGraw Hill, 3.1-3.57.

Young, R., 2005. Determining the Economic value of Water. Washington DC, U.S.A. RFF Press. 340 pp. 

Glosario de términos 



\section{Glosario de términos}

Beneficio económico. Es el valor económico que se tiene en una unidad de demanda para cierto nivel de suministro del recurso. En términos matemáticos, es el área bajo la curva de demanda para cierto suministro del recurso hídrico en una unidad de demanda.

Céteris Páribus: Término utilizado en Economía al suponer que un conjunto de variables puede cambiar mientras que el resto de variables van a permanecer constantes, independientemente de sus relaciones con el resto del modelo.

Coste de oportunidad: Término utilizado en Economía para representar el coste de algo en términos de una oportunidad conocida (y los beneficios que pudieran recibirse de esa oportunidad), o la alternativa más valiosa conocida. Valor del recurso en el uso más productivo al que se ha renunciado.

Coste de los servicios del agua: Es la suma de los costes de recursos económicos consumidos (de capital, administración, etc.), los costes de oportunidad y los costes inducidos sobre terceros (externalidades ambientales y económicas) 
Coste Marginal: Función que indica el cambio de costes como respuesta a los cambios en la cantidad suministrada. Es la primera derivada de la función de costes totales.

Coste Marginal de Oportunidad del Recurso: Coste que supone para un sistema de recursos hídricos disponer de una unidad menos en un punto y un instante dados.

Curva de demanda económica: Se refiere a la relación, para un tiempo dado y dentro de un mercado definido, entre el precio por unidad de volumen de agua y la cantidad demandada en cada periodo de tiempo y por la que los usuarios están dispuestos a pagar a ese precio.

Disposición de aceptar por renuncia: Cantidad de dinero que un usuario está en disposición de recibir en compensación por un bien o un servicio.

Disposición de pago: Cantidad de dinero que un usuario está en disposición y en posibilidad de pagar por un bien o un servicio.

Elasticidad: Función de respuesta, definida como el cambio en porcentaje de una variable dependiente que ocurrirá por un cambio en porcentaje de una variable independiente. Describe la respuesta de la función de demanda al precio del bien.

Externalidades: Diferencia entre costes privados y sociales o entre beneficios privados y sociales, para los cuales no se paga una compensación.

Función de demanda: Relación entre el precio y la cantidad de agua que un usuario desea comprar. En teoría económica, la función de demanda se indica por la función de beneficio marginal.

Modelo hidro-económico: Es una herramienta que proporciona una mejor comprensión para mejorar el manejo de los sistemas de recursos hídricos combinando conceptos hidrológicos y conceptos económicos.

Precio: Cantidad que el usuario paga a cambio del servicio del agua y/o el derecho de utilización, establecida por el sistema político-social con objetivos como recuperación de costes, equidad o sostenibilidad. Pueden incluirse subsidios.

Política de precios: Es una manera importante para mejorar las asignaciones del agua y fomentar su conservación.

Política de precios escalonados. Es una política de precios obtenida de promediar los CMOR calculados en los modelos de simulación y optimización, y que depende de los volúmenes embalsados y/o aportaciones de agua al sistema bajo estudio. 
Política de precios dinámicos. Es una política de precios obtenida de ajustar los valores del CMOR calculados en los modelos de simulación y optimización, y que depende del volumen embalsado en cierto mes y de las aportaciones de años anteriores.

Política de precios estacionales. Es una política de precios obtenida de ajustar los valores del CMOR calculados en los modelos de simulación y optimización, y que depende de volúmenes embalsados y aportaciones en diferentes periodos estacionales.

Precio sombra: Es el valor implícito o coste marginal asociado con una restricción. Es decir, el incremento de valor que se consigue al relajar las restricciones en una unidad. Cuando el cambio está racionado, el precio sombra del cambio llega a ser lo relevante en las decisiones sobre la tasa de cambio.

Renta de escasez: Véase Renta de Hotelling.

Renta de Hotelling: Es la renta económica causada por el suministro limitado de recursos no renovables que se reducen entre periodos de tiempo. La Renta de Hotelling es la diferencia entre el coste marginal de producir (extraer) un recurso no renovable y el precio de mercado. En un artículo del Journal of Political Economy, Harold Hotelling suponía que esta renta de escasez se incrementaría con la tasa de interés del mercado hasta el punto en el tiempo cuando el recurso fuera agotado. Esto puede resultar socialmente óptimo (en ausencia de fallos del mercado). Esta teoría se conoce como La regla de Hotelling en economía de los recursos. La renta de escasez es la renta que acumula el propietario de un recurso natural por el solo hecho de que éste sea escaso.

Valoración contingente: Método utilizado para averiguar la disposición de pago por servicios o comodidades medioambientales. Aplicable para la estimación de funciones de demanda. Determinación de la "disponibilidad de pago" o de la "disponibilidad de aceptar" mediante investigaciones de algunos bienes y servicios.

Valor de uso: El valor que un usuario le asigna a un bien o servicio en su uso.

Valor de no-uso: Valor que un usuario le asigna a un bien o servicio en uso que no está asociado con el uso personal del bien o servicio

Valoración directa: Determinación del valor de un bien o servicio mediante observación directa de las opciones que hacen los diferentes agentes en los mercados reales o simulados para ese bien o servicio.

Valor económico del agua: Beneficio neto para los usuarios. Es la suma de los beneficios de retornos, beneficios indirectos y el valor intrínseco del agua 
Valoración hedónica: Método de valoración fuera del mercado que estadísticamente infiere valores de las transacciones del mercado de bienes mayores, especialmente de la tierra. Uso de técnicas estadísticas como el análisis de regresión para determinar, a partir de los precios de bienes con diferentes características mensurables, los precios que se le asocian con esas características. 
ANEJO A 



\section{Anejo A: Recursos hídricos, infraestructura, modelo de gestión y datos económicos de la cuenca del río Segura}

\section{Extensión territorial}

Conforme al Real Decreto 650/1987, de 8 de mayo, el ámbito territorial de la Confederación Hidrográfica del Segura la distribución territorial de la demarcación hidrográfica del Segura es de $18,870 \mathrm{~km}^{2}$, y afecta a cuatro comunidades autónomas: Murcia, Valencia, Castilla-La Mancha y Andalucía. La distribución territorial es la siguiente:

Tabla A.1 Distribución territorial de la cuenca del Segura

\begin{tabular}{|c|c|c|}
\hline Comunidad Autónoma & $\begin{array}{c}\text { Superficie en la } \\
\text { cuenca }\left(\mathrm{km}^{2}\right)\end{array}$ & $\begin{array}{c}\text { Fracción de la } \\
\text { cuenca (\%) }\end{array}$ \\
\hline Región de Murcia & 11,150 & 59 \\
\hline Com. Valenciana & 1,227 & 7 \\
\hline Castilla-La Mancha & 4,713 & 25 \\
\hline Andalucía & 1,780 & 9 \\
\hline TOTAL : & 18,870 & 100 \\
\hline
\end{tabular}

\section{Geología}

La cuenca del Segura queda casi en su totalidad dentro del dominio geológico de las Cordilleras Béticas, estas, al igual que sucede con la mayoría de las cordilleras alpinas, presentan dos grandes conjuntos de características netamente diferentes: Zonas Externas y Zonas Internas. Las Zonas Externas se localizan geográficamente al Norte y están formadas fundamentalmente por materiales del mesozoico - terciarios. Las Zonas Internas, situadas al Sur, están formadas en su mayor parte por rocas metamórficas o que han sufrido algún principio de metamorfización. Esta complejidad da lugar a la existencia de numerosos acuíferos de mediana y pequeña extensión, y que contribuyen apreciablemente al sostenimiento de los caudales naturales de los ríos. 


\section{Edafología y uso del suelo}

La naturaleza, limitación de uso y capacidad productiva de los suelos es consecuencia de las características climáticas, geológicas, litológicas, de vegetación y actividad antrópica que acompañan al suelo en su desarrollo. Aunque la diversidad geológica y litológica no esté siempre acompañada por diversidad edafológica.

Considerando estas características se pueden encontrar que las tierras más aptas para el riego, en la cuenca del Segura, están transformadas desde hace tiempo, y están situadas en los valles del río Segura, río Guadalentín y Campo de Cartagena. Además, por toda la cuenca, se encuentran tierras que están siendo utilizadas para riego pero que presentaban deficiencias de suelo o drenaje y han tenido que ser corregidas por la acción antrópica. También se encuentra la denominada tierra "arable de uso especial", cuya limitación viene impuesta por el método de riego y que se dedican principalmente a frutales de secano. Todas estas tierras ocupan aproximadamente el 50\% de la cuenca; el otro 50\% corresponde con zonas montañosas ocupadas por especies forestales o matorral.

El agua es una limitación básica para el desarrollo de la vegetación en amplias zonas de la cuenca, y la productividad del territorio es enorme si se dispone de ella, tanto en regadíos (vegas) como en secanos y, en general, en toda la vegetación natural (caso de los densos bosques en las zonas de montaña). La superficie productiva labrada representa el $43 \%$ de la superficie total de la cuenca, y dentro de ella, la relativa importancia del regadío, que supone el $30 \%$ de la superficie labrada y el $13 \%$ de la superficie total de la cuenca. Las excepcionales condiciones climáticas de la cuenca hacen que esta superficie de riegos pueda aún ampliarse de forma muy significativa.

\section{Recursos hídricos.}

Estimando los aportes naturales totales de las ramblas costeras en unos $100 \mathrm{hm}^{3} /$ año, y considerando los intercambios, en principio, como poco significativos a estos efectos, puede redondearse la magnitud de los recursos naturales totales propios del ámbito territorial del Plan en unos $1.000 \mathrm{hm}^{3} /$ año.

Los afluentes de la margen izquierda del río Segura se asientan sobre cuencas semiáridas, lo que les confiere un carácter marcadamente torrencial. En la práctica, carecen de importancia como productores de recursos, ya que únicamente llevan agua después de tormentas importantes. Se trata de las ramblas del Judío, Moro, Tinajón, Salada y Abanilla, principalmente.

El río Guadalentín es un importante afluente de la margen derecha que está regulado en su cabecera por los embalses más antiguos de la cuenca (Puentes y Valdeinfierno) y cuya misión es doble: defender a las ciudades del Valle contra la acentuada torrencialidad 
y procurar recursos (escasos) para el regadío tradicional de Lorca. Los recursos naturales renovables totales del Valle se han estimado inicialmente en unos $40 \mathrm{hm}^{3}$.

Las ramblas litorales, por su parte, no suponen aportes significativos a los recursos renovables totales de la cuenca, funcionando en régimen torrencial y produciendo ocasionales inundaciones en las poblaciones costeras.

\section{Aguas subterráneas}

En el caso de las aguas subterráneas los recursos ( $\left.\mathrm{hm}^{3} / \mathrm{año}\right)$ que estima el PHCS (1997) son los siguientes $(\mathrm{E}=$ entrada, $\mathrm{S}=$ salida):

\begin{tabular}{|c|c|c|c|c|c|c|c|}
\hline E-Lluvia & E-Retorno & E-Cauces & E-Embals & S-Manant & S-Bombeo & S-Submar & Balance \\
\hline 678,25 & 85,95 & 33,30 & 22,22 & 554,36 & 485,45 & 11,60 & $-215,36$ \\
\hline
\end{tabular}

La revisión del PHCS de 2002 ha reducido el volumen total de sobreexplotación de acuíferos a $185 \mathrm{Hm}^{3}$ /año, debido sobre todo a los mayores retornos de riego proveniente del incremento de caudales del Trasvase Tajo-Segura.

En todo caso, se observa como el uso masivo de los recursos subterráneos de la Demarcación ha generado la sobreexplotación de varios acuíferos en la cuenca, lo que ha provocado la declaración de sobreexplotación de los siguientes acuíferos:

- Cresta del Gallo

- Cabo Roig

- Aquellos pertenecientes a las unidades hidrogeológicas: Alto y Bajo Guadalentín, Águilas, Mazarrón, Torrevieja, Triásico de Carrascoy, Ascoy-Sopalmo, Jumilla-Villena, Aledo y Santa Yéchar.

- Sector Triásico de las Victorias del acuífero Campo de Cartagena 


\section{Aportaciones}

Los datos resumen de las series de aportaciones que tienen como base el PHCS de 1997 se muestran en la tabla 9.2. Los datos que recoge el Plan se refieren a series completas de 50 años 1940/41-1989/90. En el año 2002 este plan fue objeto de revisión (Rev. PHCS, 2002), modificando ligeramente los valores de los recursos al actualizarse las series de precipitación.

\begin{tabular}{|c|c|c|c|c|c|c|}
\hline Estación & Río & Estación & $\begin{array}{c}\text { Plan } \\
(1)\end{array}$ & $\begin{array}{c}\text { Revisión } \\
\text { (2) }\end{array}$ & $\begin{array}{c}\text { Variación } \\
(2-1)\end{array}$ & $(2) /(1)$ \\
\hline 102 & Taibilla & Presa del Canal & 57,40 & 55,08 & $-2,32$ & $96,0 \%$ \\
\hline 11 & Moratalla & La Esperanza & 8,73 & 9,31 & 0,58 & $106,6 \%$ \\
\hline 14 & Argos & Calasparra & 13,67 & 14,42 & 0,75 & $105,5 \%$ \\
\hline 7 & Quipar & E. Alfonso XIII & 19,12 & 19,06 & $-0,06$ & $99,7 \%$ \\
\hline 19 & Mula & E. La Cierva & 9,88 & 10,00 & 0,12 & $101,2 \%$ \\
\hline 20 & Mula & Baños de Mula & 21,72 & 22,32 & 0,60 & $102,8 \%$ \\
\hline 22 & $\begin{array}{c}\text { Guadalentí } \\
\mathrm{n}\end{array}$ & Valdeinfierno & 7,63 & 7,02 & $-0,62$ & $91,9 \%$ \\
\hline 33 & $\begin{array}{c}\text { Guadalentí } \\
\mathrm{n}\end{array}$ & E. Puentes & 29,09 & 28,04 & $-1,06$ & $96,4 \%$ \\
\hline 25 & $\begin{array}{c}\text { Guadalentí } \\
\mathrm{n}\end{array}$ & Paso los Carros & 39,78 & 39,03 & $-0,75$ & $98,1 \%$ \\
\hline 3 & Mundo & E. Talave & 138,46 & 133,27 & $-5,19$ & $96,3 \%$ \\
\hline 24 & Mundo & E. Camarillas & 181,56 & 174,22 & $-7,34$ & $96,0 \%$ \\
\hline 1 & Segura & E. Fuensanta & 282,31 & 260,28 & $-22,03$ & $92,2 \%$ \\
\hline 13 & Segura & E. Cenajo & 432,80 & 402,80 & $-30,00$ & $93,1 \%$ \\
\hline 6 & Segura & Almádenes & 725,26 & 685,22 & $-40,04$ & $94,5 \%$ \\
\hline 16 & Segura & Cieza & 733,97 & 693,44 & $-40,52$ & $94,5 \%$ \\
\hline 67 & Segura & Menjú & 741,31 & 700,38 & $-40,93$ & $94,5 \%$ \\
\hline 17 & Segura & Abarán & 759,10 & 717,19 & $-41,91$ & $94,5 \%$ \\
\hline 18 & Segura & Archena & 766,69 & 724,36 & $-42,33$ & $94,5 \%$ \\
\hline 63 & Segura & Contraparada & 789,69 & 751,37 & $-38,32$ & $95,1 \%$ \\
\hline 64 & Segura & Beniel & 854,35 & 814,11 & $-40,24$ & $95,3 \%$ \\
\hline 30 & Segura & Guardamar (Cuenca) & 871,44 & 830,39 & $-41,05$ & $95,3 \%$ \\
\hline
\end{tabular}


La estimación total de recursos naturales del río Segura realizada por el PHCS es de 871 $\mathrm{hm}^{3} /$ año, cantidad disminuida por la revisión del PHCS de 2002 a $830 \mathrm{hm}$ /año, que corresponden al desagüe medio hiperanual en Guardamar en régimen natural. La razón por la cual la revisión del PHCS de 2002 arroja un menor volumen de recursos propios de la cuenca que el valor consignado en el PHCS se debe a que en la revisión del PHCS se amplió la serie de aportaciones a las que se aplicó la restitución al régimen natural, incorporándose desde el año hidrológico 1990-1991 a 1999-2000 (periodo seco que reduce la media de aportaciones en régimen natural en la serie histórica). Es destacable el hecho de que la media de aportaciones restituidas al régimen natural en Guardamar (figura 9.1), según la metodología empleada en el PHCS para la restitución y los datos disponibles, para el periodo $1940-2000$ sea de $830 \mathrm{hm}^{3} /$ año, mientras que para el periodo 1980-2000 se reduce a $645 \mathrm{hm}^{3} / a n ̃ o$, es decir, un $22 \%$ inferior.

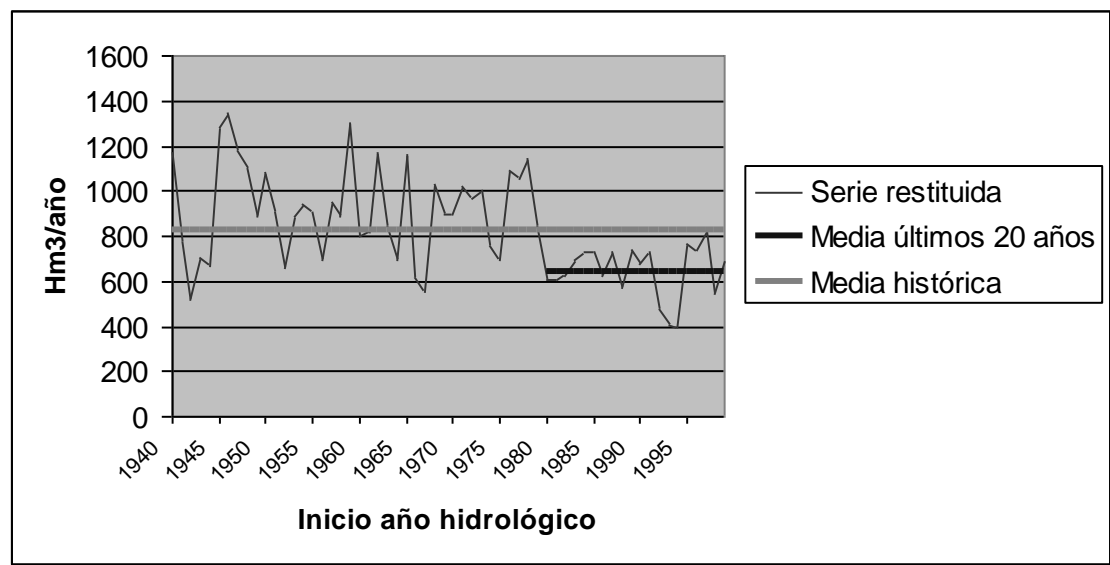

Figura A.1 Aportaciones naturales restituidas en Guardamar

\section{Transferencias superficiales}

Los recursos transvasados hasta el año 2003 se muestran en la figura A.2. 


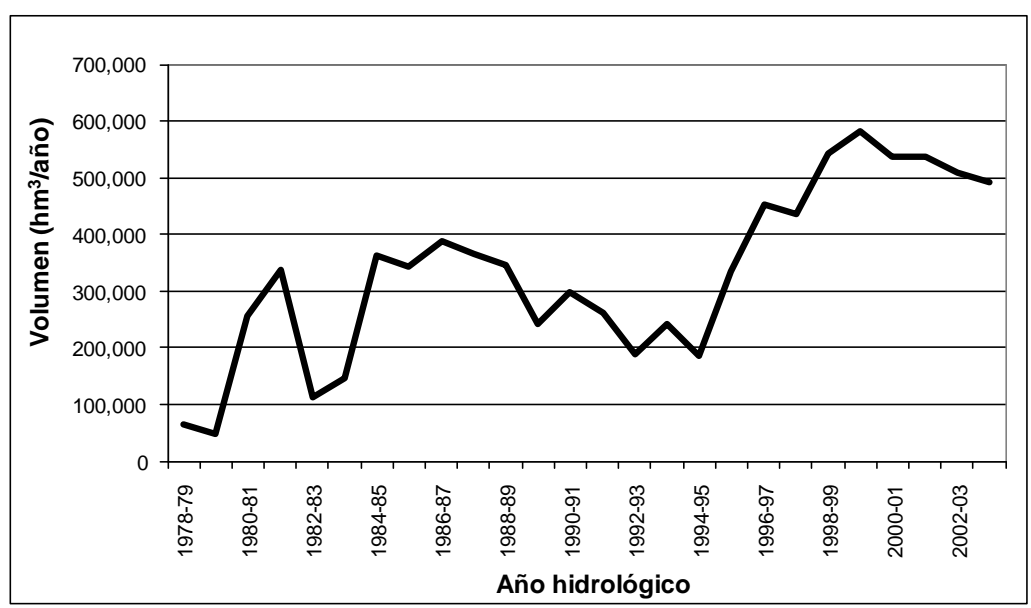

Figura A.2 Evolución histórica de las aportaciones del trasvase Tajo-Segura

No toda el agua procedente del trasvase Tajo-Segura que llega a la Demarcación del Segura, concretamente al embalse del Talave, tiene como destino la propia Demarcación. Así, parte de los recursos procedentes de la cuenca del Tajo se emplean para el abastecimiento de municipios de la Demarcación del Júcar, municipios de la Demarcación del Sur y regadíos físicamente ubicados en la Demarcación del Júcar. El reparto se realiza de forma proporcional según el máximo volumen trasvasable: de los $140 \mathrm{hm}$ /año destinados a abastecimiento 131 corresponden a la Mancomunidad de los Canales del Taibilla y 9 a la Confederación Hidrográfica del Sur; de los $400 \mathrm{hm}^{3} /$ año destinados al riego, 335 tienen como destino la Demarcación del Segura, 50 la del Júcar y 15 la del Sur.

En cuanto a transferencia de recursos superficiales desde el ámbito territorial del Plan Hidrológico del Segura, ésta se produce hacia los ámbitos de los Planes Hidrológicos del Júcar y del Sur. En el Júcar, la transferencia se produce para regadíos de los Riegos de Levante Margen Izquierda y el abastecimiento de poblaciones del bajo Vinalopó y área de Alicante. En el segundo caso, la transferencia se produce para regadíos en Almería.

Con respecto a los usos urbanos, la transferencia actual de recursos al ámbito del Júcar (servida por la M.C.T.) se cifra en unos $45 \mathrm{hm}^{3}$, de los que 35 tendrían un uso estrictamente urbano y 10 tendrían un uso industrial a través de las redes urbanas, se complementan con aportaciones propias externas al Segura (aguas subterráneas para Alicante y Elche) estimadas en $8 \mathrm{hm}^{3}$, con lo que el total abastecido en el ámbito del Júcar asciende a unos $53 \mathrm{hm}^{3}$ anuales.

Los recursos del trasvase actualmente transferidos al ámbito territorial del Sur con destino a riegos en Almería ascienden a unos $7 \mathrm{hm}^{3}$. En resumen, la transferencia de recursos superficiales hacia otros ámbitos territoriales puede cifrarse en unos $92 \mathrm{hm}^{3}$ 
anuales, de los que 30 son propios del ámbito del Segura y se aplican en el Júcar, y 62 proceden del trasvase desde el Tajo y se aplican en el Júcar y en el Sur.

\section{Transferencias subterráneas}

Existen transferencias subterráneas de recursos con los tres ámbitos vecinos (Júcar, Guadalquivir y Sur) mediante los acuíferos a caballo con ellos. Estas transferencias se producen fundamentalmente con el Júcar, ámbito con el que existen siete unidades hidrogeológicas a caballo (Sinclinal de la Higuera, Sierra de la Oliva, Jumilla-Villena, SerralSalinas, Quibas, Sierra de Argallet y Sierra de Crevillente). El análisis de la situación actual de estos acuíferos arrojaría un balance global de unos $11 \mathrm{hm}^{3} / a n ̃ o$ transferidos desde el ámbito del Segura al del Júcar, con el agravante de que la mayor parte de estos volúmenes procede de la sobreexplotación de reservas.

En cuanto al Guadalquivir, pueden considerarse a caballo también siete unidades (Calar del Mundo, Segura-Madera-Tus, Frente de Segura-Fuensanta, Castril, Taibilla, Sierra de la Zarza y Orce María). Estas unidades están equilibradas, sin problemas de sobreexplotación, y la tasa de transferencias intercuencas puede considerarse despreciable. Con el ámbito de la cuenca Sur, se encuentran 3 unidades (Saliente, Saltador y Sierra de Almagro) en los que la transferencia intercuencas se estima despreciable.

\section{Desalinización}

La enorme presión económica por disponer de recursos en las zonas no cubiertas por aguas reguladas propias de la cuenca o procedentes del trasvase sumada al progresivo agotamiento de recursos subterráneos y degradación de la calidad de los existentes hace de esta tecnología como una de las que contribuyan al suministro de caudales con destino a riegos a corto y medio plazo. Estos recursos, con calidades que los hacen inservibles para ningún uso, podrían ser tratados con el objetivo de reducir su salinidad y posibilitar su aplicación directa o de ser mezclados con aguas de mayor calidad para conseguir niveles intermedios que sean económicamente asumibles y permitan el cultivo en estas zonas.

No obstante, es obligado alertar sobre el riesgo que puede suponer el desarrollo indiscriminado de estas extracciones de aguas salobres de acuíferos, pues no debe olvidarse que, en definitiva y con una diferencia meramente analítico-química, forman parte de los recursos hidrogeológicos susceptibles de sobreexplotación y agotamiento por extracción excesiva, por lo que no debe estimarse como recurso permanente, sino como un recurso que se moviliza en situaciones de sequía.

\section{Demandas de agua}


Demanda urbana. La agrupación de demandas actuales de abastecimiento urbano $\left(\mathrm{Hm}^{3}\right)$ queda establecida en la tabla A.3.

\begin{tabular}{|c|c|c|}
\hline UDU & DESCRIPCION & TOTAL $\left(\mathrm{hm}^{3}\right)$ \\
\hline 1 & MCT-TAIBILLA & 48,0 \\
\hline 2 & MCT-SIERRA ESP. & 29,0 \\
\hline 3 & MCT-CAMPOTEJAR & 16,0 \\
\hline 4 & MCT-TORREALTA & 49,0 \\
\hline 5 & MCT-PEDRERA & 42,0 \\
\hline 6 & MCT-LORCA & 8,0 \\
\hline 7 & HELLIN & 2,0 \\
\hline 8 & CABEC. SEGURA & 1,0 \\
\hline 9 & CABEC. MUNDO & 3,0 \\
\hline 10 & CABEC. GUADAL. & 3,0 \\
\hline 11 & JUMILLA-YECLA & 4,0 \\
\hline 12 & CREVILL-ORIHUELA & 2,0 \\
\hline 13 & MURCIA- SEGURA & 8,0 \\
\hline SA & SIN ASIGNACION & 2,0 \\
\hline & TOTAL & 217,0 \\
\hline
\end{tabular}

Para los retornos se adopta, de forma estándar un valor del $80 \%$ del suministro, con su misma distribución temporal.

Demanda industrial. Las demandas anuales totales de las distintas unidades identificadas son:

Tabla A.4 de demanda industrial

\begin{tabular}{|c|c|c|c|}
\hline UDI & DESCRIPCIÓN & TOTAL $\left(\mathrm{hm}^{3}\right)$ & $\%$ \\
\hline 1 & Guadalentín & 1,63 & 3,33 \\
\hline 2 & Cabecera & 3,92 & 7,99 \\
\hline 3 & Centro & 3,34 & 6,82 \\
\hline 4 & Murcia & 2,97 & 6,06 \\
\hline 5 & Alicante-Segura & 7,38 & 15,06 \\
\hline 6 & Litoral & 9,41 & 19,20 \\
\hline 7 & Directa MCT & 3,18 & 6,49 \\
\hline \multirow[t]{2}{*}{8} & Alicante-Júcar & 17,18 & 35,07 \\
\hline & TOTAL & 49,00 & \\
\hline
\end{tabular}


Demanda agrícola. De los $1328 \mathrm{hm}^{3}$ que se utilizan en el regadío, $350 \mathrm{hm}^{3}$ tienen su origen en los recursos propios de cabecera; $200 \mathrm{hm}^{3}$ son aportados por el trasvase; $208 \mathrm{hm}^{3}$ son generados por todos los afluentes y el propio río fuera de la cabecera; $470 \mathrm{hm}^{3}$ corresponden a extracciones de aguas subterráneas mediante bombeos; y $100 \mathrm{hm}^{3}$ son de reutilización de retornos tanto de riego como de abastecimiento. Del total de extracciones subterráneas, unos $210 \mathrm{hm}^{3}$ proceden de sobreexplotación de reservas no renovables, por lo que, con las dotaciones anteriores, unas 60,000 ha de la cuenca tienen comprometida su permanencia a medio y largo plazo.

Los cultivos básicos en la cuenca del Segura pueden agruparse en cinco tipos diferentes con características y problemáticas diferentes, en función del origen del agua y la infraestructura hidráulica que se emplea para los mismos:

- Regadíos tradicionales, legalizaciones y ampliaciones de las Vegas del Segura.

- Regadíos de la cuenca con recursos superficiales propios, excluidos los de las Vegas del Segura.

- Regadíos con aguas trasvasadas.

- Regadíos atendidos con bombeos de aguas subterráneas.

- Regadíos con aguas reutilizadas.

El regadío efectuado con reutilización de recursos puede asociarse a aguas residuales procedentes de retornos urbanos o a aguas procedentes del drenaje de otros riegos. Estas zonas de regadíos se encuentran divididas en unidades de demanda que agrupan distintos

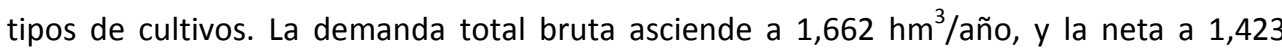
$\mathrm{hm}^{3} /$ año, lo que supone unas dotaciones medias de 6,176 y $5,288 \mathrm{~m}^{3} / \mathrm{ha} / \mathrm{año}$ respectivamente, magnitudes que pueden considerarse muy reducidas, y que dan idea del excelente aprovechamiento de las aguas en la zona. De los 1,662 $\mathrm{hm}^{3} /$ año totales demandados, 1,571 corresponden a demandas propias del ámbito territorial del Segura, y $91 \mathrm{hm}^{3}$ corresponden a demandas situadas fuera de este ámbito pero atendidas desde el mismo. 


\section{Infraestructura}

Redes de distribución. Existen cuatro redes de distribución de recursos, interconectadas entre sí, y superpuestas en el espacio: la red de riegos tradicionales tanto en las Vegas como en los aprovechamientos de los afluentes del Segura; la red de distribución del Postrasvase Tajo-Segura; la red de distribución de la Mancomunidad del Canales del Taibilla; y la red de captación y transporte de aguas subterráneas.

Red de distribución en las Vegas y afluentes. En la Vega Alta, desde la confluencia del Segura y el Mundo hasta el azud de la Contraparada, los aprovechamientos toman sus recursos en pequeños azudes de derivación que alimentan acequias normalmente de corto recorrido. Los sobrantes vuelven al río Segura. La Vega Media, desde el azud de la Contraparada hasta el límite provincial entre Murcia y Alicante, también derivan sus recursos de acequias. La Vega Baja se extiende desde el límite provincial hasta el mar. Esta vega se alimenta tanto de los caudales fluyentes en el río, que son recogidos por nuevas acequias desde sus azudes de derivación, como de los retornos de los riegos procedentes de la Vega Media. Unida a esta red de acequias se encuentra la de azarbes, que son los cauces para el drenaje de tierras regadas, y con cuyas aguas se vuelve a regar en zonas aguas abajo si la calidad del retorno lo permite.

Las ampliaciones de regadíos aprovechan recursos de la regulación adicional creada por la construcción de los embalses de Cenajo y Camarillas, y superponen sus tomas sobre las redes de acequias de los riegos tradicionales y el río Segura, para regar otros terrenos mediante nuevas captaciones, impulsiones y canales. La Comunidad General Riegos de Levante, M.I. aprovecha los caudales sobrantes en la cuenca, derivados del propio río y de los azarbes, para servir a una amplia zona regable en la vega baja que se expande incluso fuera del ámbito territorial de la Confederación Hidrográfica del Segura. Los Riegos de Levante Margen Derecha realizan la toma aguas arriba de la anterior mediante una elevación hasta su canal principal que domina la zona regable.

Red de distribución del post-trasvase. La red de distribución del Post-Trasvase Tajo-Segura emplea los propios cauces del Mundo y Segura como elementos de transporte en un tramo comprendido entre el embalse de Talave y el azud de Ojós; además sirve de fuente de suministro adicional a la vega baja del Segura y a la Mancomunidad de Canales del Taibilla. El aprovechamiento del trasvase se realiza a través de dos canales principales que arrancan del azud por ambas márgenes del Segura. El canal de la margen izquierda parte por gravedad con una capacidad máxima de $30 \mathrm{~m}^{3} / \mathrm{seg}$ cruza el río Segura en el sifón de Orihuela y termina en el embalse de la Pedrera, origen del Canal del Campo de Cartagena. En un punto intermedio se encuentra el partidor de Santomera, donde da comienzo el Canal de Crevillente, que llega hasta el embalse del mismo nombre, que regula las aguas destinadas a los Riegos de Levante margen izquierda. El canal de la margen derecha tiene como origen la impulsión de Ojós que eleva el agua 150 m, para circular después por 
gravedad hasta llegar al embalse del Mayés, que actúa como depósito regulador. Desde este embalse el canal sigue funcionando por gravedad llegando hasta el Valle del Guadalentín donde se encuentra la impulsión de Alhama que abastece la prolongación del canal hasta Lorca, continuando hasta el Valle de Almanzora. Entre el embalse del Mayés y la impulsión de Alhama existe una toma, que deriva agua mediante la correspondiente impulsión hacia el embalse de la Cierva, almacén de los recursos destinados a la zona regable de Yechar y de Mula.

Red de distribución de la Mancomunidad. Como suministra la práctica totalidad de los recursos distribuidos para el abastecimiento de la cuenca mediante una extensa red de transporte constituida por los canales principales (conducciones por gravedad de capacidad comprendida entre 1,0 y $4,5 \mathrm{~m}^{3} / \mathrm{s}$ ) y ramales a poblaciones (conducciones forzadas con diámetros y timbrajes variables).

Red de distribución de aguas subterráneas. En esta red varían mucho sus características dependiendo del tipo y antigüedad de la captación de la que se trate, y de la mayor o menor productividad de las tierras por regar. Existe un sinfín de aprovechamientos basados en explotaciones de aguas subterráneas, formando un subsistema con una extensa y densa red de canales y tuberías de distribución. 
Embalses. En la tabla A.5 se pueden observar todos los embalses de la demarcación del Segura, su función o funciones principales, así como su capacidad:

Tabla A.5 Características de las presas en la demarcación del Segura

\begin{tabular}{|c|c|c|c|}
\hline Presa & Cauce & Tipo/Material & $\begin{array}{c}\text { Capacidad } \\
(\mathrm{hm} 3)\end{array}$ \\
\hline \multicolumn{4}{|c|}{ Regulación general de la cuenca } \\
\hline Fuensanta & Segura & Gravedad. Hormigón & 210 \\
\hline Talave & Talave & Gravedad. Hormigón & 35 \\
\hline Cenajo & Segura & Gravedad. Hormigón & 437 \\
\hline Camarillas & Mundo & Gravedad. Hormigón & 36 \\
\hline Alfonso XIII & Quípar & Gravedad. Hormigón & 22 \\
\hline Santomera & Rambla Salada & Gravedad. Hormigón & 26 \\
\hline La Pedrera & Rambla de Alcoriza & Gravedad. Materiales sueltos & 246 \\
\hline Crevillente & Rambla del Bosch & Gravedad. Materiales sueltos & 13 \\
\hline Azud de Ojós & Segura & Gravedad. Hormigón & 1 \\
\hline Mayés & Rambla del Mayés & Gravedad. Materiales sueltos & 2 \\
\hline \multicolumn{4}{|c|}{ Regulación regadíos propios } \\
\hline Argos & Argos & Gravedad. Materiales sueltos & 10 \\
\hline La Cierva & Mula & Gravedad. Hormigón & 7 \\
\hline Valdeinfierno & Luchena & Gravedad. Mampostería. & 13 \\
\hline Puentes & Guadalentín & Gravedad. Hormigón & 48 \\
\hline \multicolumn{4}{|c|}{ Abastecimiento } \\
\hline Taibilla & Taibilla & Gravedad. Materiales sueltos & 9 \\
\hline Presa de toma del Canal del Taibilla & Taibilla & Gravedad. Hormigón & 0.3 \\
\hline \multicolumn{4}{|c|}{ Aprovechamiento hidroeléctrico } \\
\hline Anchuricas(Miller) & Segura & Contrafuertes. Hormigón & 6 \\
\hline La Novia(La Vieja) & Zumeta & Gravedad. Hormigón & 0.6 \\
\hline \multicolumn{4}{|c|}{ De laminación de avenidas } \\
\hline Moro & Rambla del Moro & Gravedad. Hormigón & 6 \\
\hline Pliego & Pliego & Gravedad. Hormigón & 10 \\
\hline Judío & Rambla del Judio & Gravedad. Hormigón & 9 \\
\hline Algeciras & Rambla de Algeciras & Gravedad. Materiales sueltos & 50 \\
\hline Cárcabo & Rambla del Cárcabo & Gravedad. Hormigón & 3 \\
\hline El Romeral & Guadalentín & Gravedad. Hormigón & 6 \\
\hline Doña Ana & Rambla de Doña Ana & Gravedad.Hormigón & 3 \\
\hline Los Rodeos & Rio Mula & Gravedad. Hormigón & 14 \\
\hline Los Charcos & Rambla de Los Charcos & Gravedad. Hormigón & 4 \\
\hline Boquerón & Rambla del Boquerón & Gravedad. Hormigón & 13 \\
\hline Bayco & Rambla del Bayco & Gravedad. Materiales sueltos & 9 \\
\hline
\end{tabular}

\section{Desalinizadoras}

El empeoramiento generalizado de la calidad del agua de riego, ha promovido en los últimos años la proliferación de plantas desalinizadoras realizadas en su mayor parte por particulares y comunidades de regantes. Actualmente existen en la Demarcación del orden de 80 desalinizadoras en funcionamiento o fase de construcción de las cuales están funcionando alrededor de la mitad, con una capacidad potencial de producción del orden de $35 \mathrm{hm}^{3} /$ año destinándose a usos agrícolas. De esta producción potencial se estima que

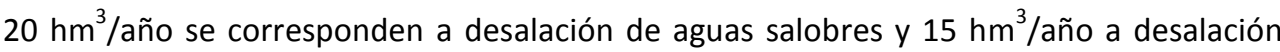
aguas marinas. De esta producción teórica se están desalando actualmente unos 20 $\mathrm{hm}^{3}$ /año. La mayor parte de estas plantas se realizaron en épocas de sequía (años 93-97) y tras el aumento de recursos disponibles, una proporción significativa de las mismas dejaron de ser utilizadas. Hay que destacar que se encuentran en fase de construcción dos plantas desalinizadoras de agua de mar que elevarán de forma significativa el caudal desalado: 


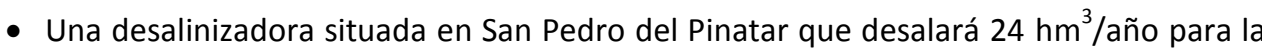
Mancomunidad de los Canales del Taibilla. Actualmente se encuentra en fase de proyecto la ampliación de la citada desaladora, para ampliar en $24 \mathrm{hm}^{3}$ la capacidad de la planta.

- La desalinizadora ubicada en Valdelentisco, una de las mayores de Europa, con un volumen teórico de desalación de $57 \mathrm{hm}^{3} /$ año, de los cuales $20 \mathrm{hm}^{3} /$ año serán para la Mancomunidad de los Canales del Taibilla y el resto para uso agrícola, tanto en el Campo de Cartagena, Mazarrón y Valle del Guadalentín. Se está analizando actualmente su futura ampliación.

El programa AGUA del MMA prevé la construcción de varias plantas desalinizadoras de agua de mar en la Demarcación, junto con actuaciones de modernización de regadíos.

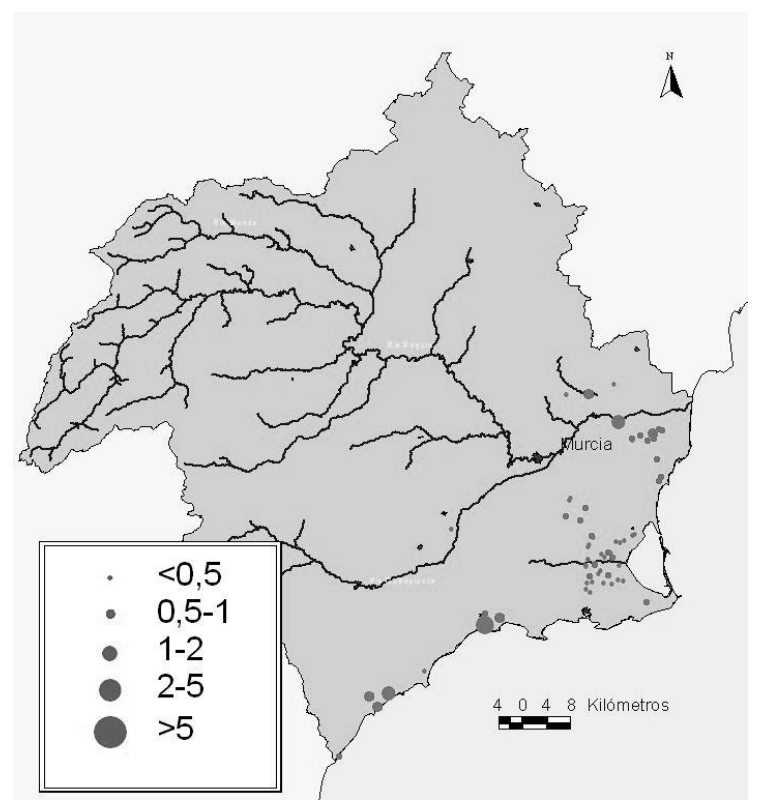

Figura A.3 Plantas desalinizadoras y capacidad teórica de desalación ( $\mathrm{Hm}^{3}$ /año). Fuente: Comisaría de Aguas, 2004 


\section{Modelo de simulación de la gestión}

El modelo de simulación de la gestión del sistema de explotación de la cuenca del río Segura se desarrolló con base en el SAD Aquatool y se simplificó y modificó del esquema original realizado con anterioridad. Una de las modificaciones consistió en realizar un esquema equivalente para los acuíferos de tres niveles de la Vega Baja.

Esquema equivalente. Un acuífero con desagüe a tres niveles diferentes, es un modelo simplificado que permite considerar la conexión con dos niveles distintos de aguas superficiales: drenaje intermedio por la red de azarbes y conexión hidráulica con el río y además permite considerar también la evapotranspiración variable a lo largo del año. El esquema del modelo es el siguiente:

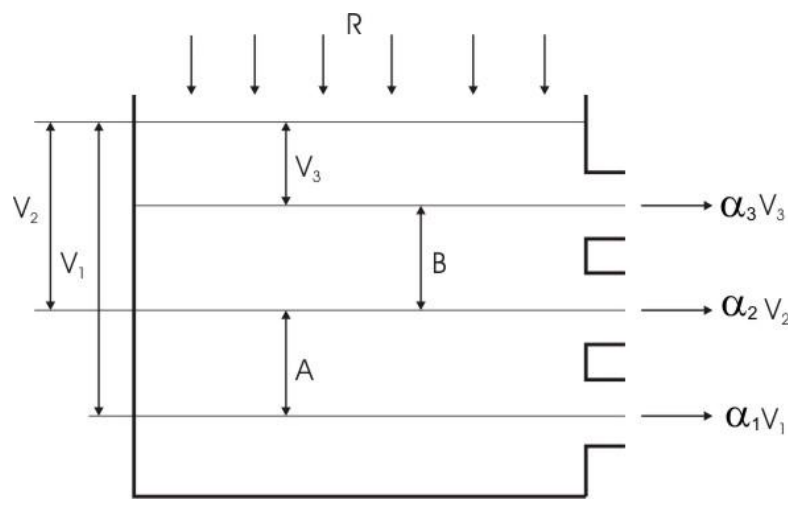

Figura A.4 Esquema de un acuífero de tres niveles

Siendo $\alpha_{1} V_{1}$ el volumen desaguado hacia o desde el río; $\alpha_{2} V_{2}$ corresponde al volumen por azarbes y $\alpha_{3} V_{3}$ a la evapotranspiración potencial.

La ecuación general que gobierna el funcionamiento de este tipo de acuífero es la siguiente:

$$
V_{1}(t)=V_{1}(0) e^{\left(-\left(\alpha+\alpha_{2}+\alpha_{3}\right) t\right)}+\frac{R+\alpha_{3}(A+B)+\alpha_{2} A}{\alpha_{1}+\alpha_{2}+\alpha_{3}}\left(1-e^{\left(-\left(\alpha_{1}+\alpha_{2}+\alpha_{3}\right) t\right)}\right)
$$

En la figura A.5 se muestra una ampliación del esquema de tres niveles del acuífero de la Vega Baja: 


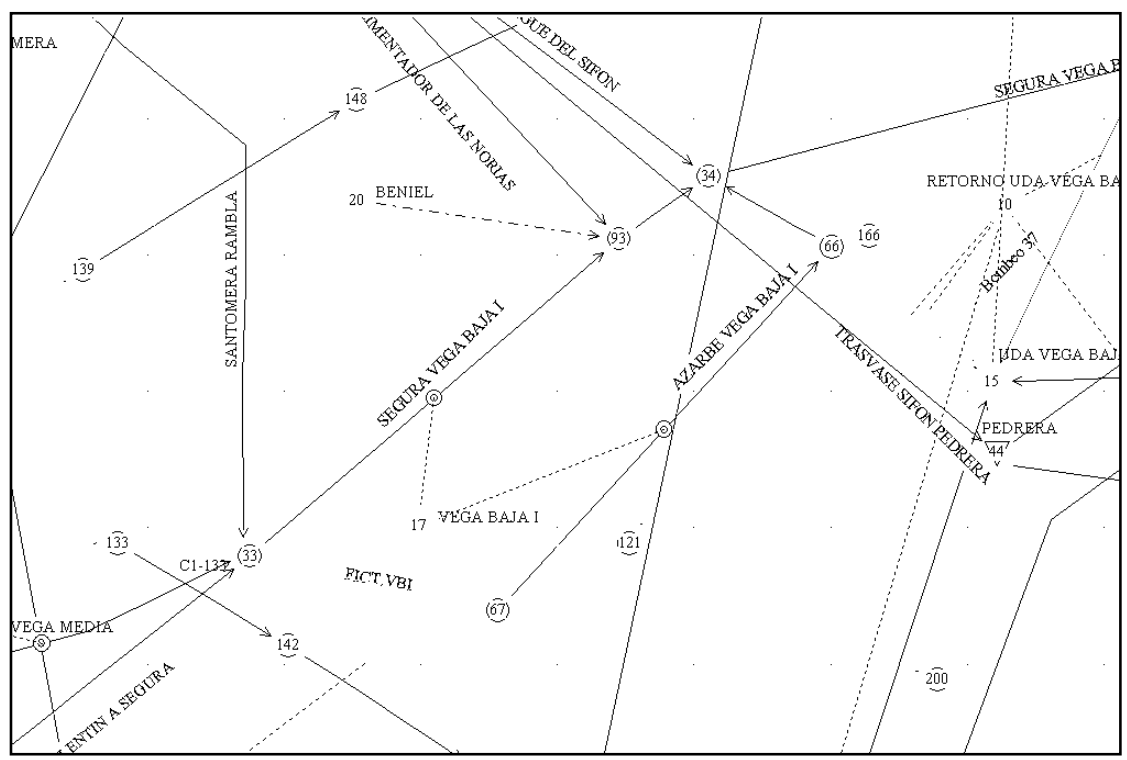

Figura A.5 Esquema tres niveles del acuífero de la Vega Baja

La representación del acuífero de tres niveles se ha sustituido por un esquema equivalente como el mostrado en la figura A.6.

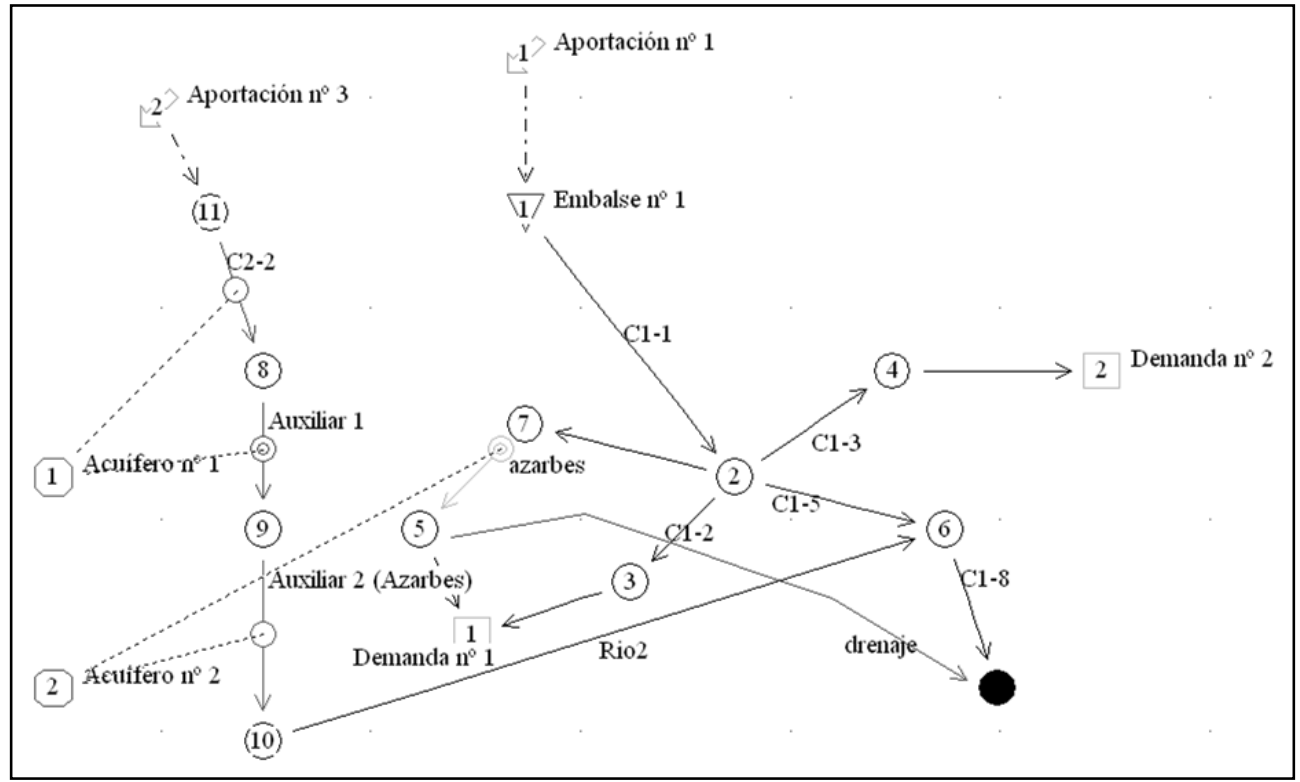

Figura A.6 Esquema equivalente al de tres niveles 
En el esquema, se ha cambiado el acuífero de tres niveles por dos acuíferos unicelulares. Uno de ellos, el No. 1, permite captar la recarga y darla a la conducción tipo 3 denominada Auxiliar 1. La recarga del modelo de tres niveles, se considera, en el esquema equivalente, como una aportación al nudo 11 para que la conducción tipo 2 denominada C2-2 la ceda totalmente al acuífero. Para hacer esto, los parámetros de pérdidas de la conducción en principio son los siguientes: $A=0 ; B=C=1$. El flujo de la conducción Auxiliar 1 pasa a la conducción tipo 2 denominada Auxiliar 2 (Azarbes). Está conducción tiene pérdidas que van a parar al Acuífero No.2. Este a su vez cede el agua a la conducción tipo 3 llamada azarbes. El volumen de estos azarbes corresponde al de los volúmenes de azarbes del acuífero de tres niveles. Finalmente, el flujo al río se obtiene del volumen circulante por la conducción tipo 1 Rio2. El término de la evapotranspiración se incluyó restándosela a la recarga histórica, considerada en la aportación No. 3. Como la evapotranspiración depende de los niveles del acuífero, puede suceder que al hacer la diferencia RecargaEvapotranspiración se obtenga un valor negativo; en ese caso, se considera un valor igual a cero.

Ajuste de parámetros. Una vez planteado el esquema equivalente en la Cuenca del Segura, se procedió al ajuste de los parámetros siguientes: los dos volúmenes iniciales de los acuíferos unicelulares; los dos coeficientes de desagüe de los acuíferos; y los cuatro parámetros de las conducciones tipo2. Para esto, se planteó el balance hídrico del sistema equivalente utilizando las ecuaciones de pérdidas de las conducciones tipo 2 y las ecuaciones que gobiernan los acuíferos unicelulares. Los volúmenes obtenidos que fluyen por río y azarbes, se compararon con los obtenidos por el acuífero de tres niveles; se obtuvo la suma de las diferencias al cuadrado y se ejecutó el "SOLVER" de Excel para encontrar el valor de los parámetros que hicieran mínima esa suma.

Para el caso del acuífero de Vega Baja I, las diferencias existentes son muy pequeñas (ver figura A.7) y los parámetros utilizados en SimGes son los siguientes:

\begin{tabular}{|c|c|c|c|c|}
\hline VEGA BAJA I & & & & \\
\hline Parámetro & Acuífero 1 & Acuífero 2 & Conducción. 1 & Conducción 2 \\
\hline$\alpha$ & 0,2185 & 1 & & \\
\hline$V_{0}$ & 10 & 0 & & \\
\hline$B$ & & & 1 & 0,926 \\
\hline$C$ & & & 1 & 1,067 \\
\hline \multicolumn{5}{|l|}{ VEGA BAJA II } \\
\hline$\alpha$ & 0.07 & 1.36 & & \\
\hline$V_{0}$ & 19 & 2 & & \\
\hline$B$ & & & 1,01 & 0,892 \\
\hline$C$ & & & 0,05 & 1,046 \\
\hline
\end{tabular}



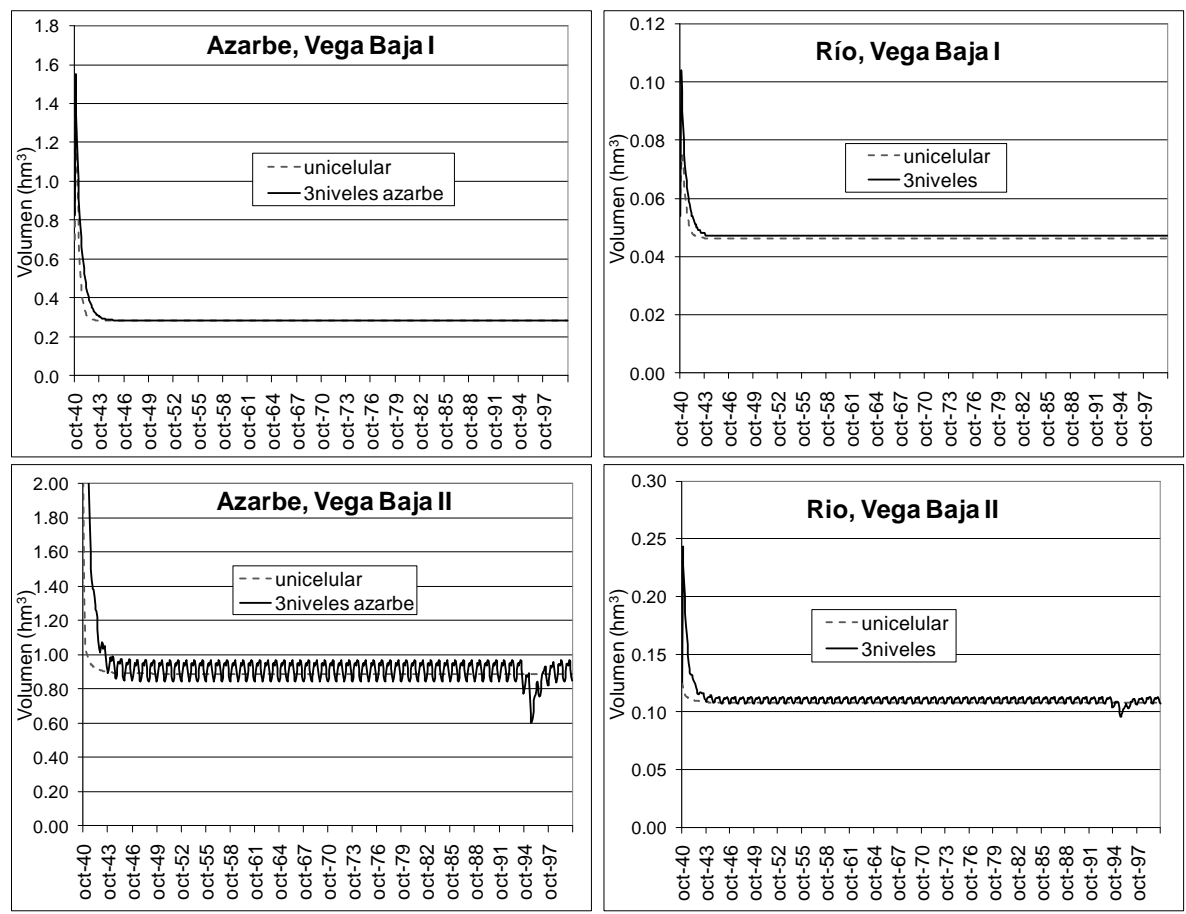

Figura A.7 Comparación volúmenes estimados entre unicelular y tres niveles

Descripción del modelo de simulación. Las capacidades y caudales en los embalses que conforman el modelo de simulación del río Segura son:

Tabla A.6. Capacidades y caudales en los embalses

\begin{tabular}{|l|l|l|l|l|}
\hline \multicolumn{1}{|c|}{ EMBALSES } & Vol. Max & Vol. Min & Vol. inicial & Q. Max. sueltas \\
\hline Argos & 10,2 & 0 & 0 & 3,9 \\
\hline Camarillas & 34,5 & 0 & 0 & 134,7 \\
\hline Cenajo & 415 & 0 & 65 & 259 \\
\hline Crevillente & 12 & 0,7 & 0 & 29,5 \\
\hline E. Algeciras & 50 & 3 & 0 & 26 \\
\hline Fuensanta & 198,6 & 0 & 15 & 129,2 \\
\hline Hondo & 14 & 10 & 2 & 100 \\
\hline La Cierva & 11,8 & 0 & 0 & 15,5 \\
\hline Pedrera & 200 & 28,6 & 30,5 & 46,6 \\
\hline Puentes & 24 & 0 & 0 & 43,5 \\
\hline Quipar A. XIII & 21 & 0 & 0 & 25,9 \\
\hline Santomera & 25,5 & 0 & 0 & 32,1 \\
\hline Taibilla & 8,1 & 0 & 0 & 6,3 \\
\hline Tálave & 33 & 0 & 6 & 244,6 \\
\hline Valdeinfierno & 12,9 & 0 & 0 & 11,7 \\
\hline
\end{tabular}


La distribución espacial de los acuíferos en el sistema del Segura se muestra en las figuras A.8 a la A.11.

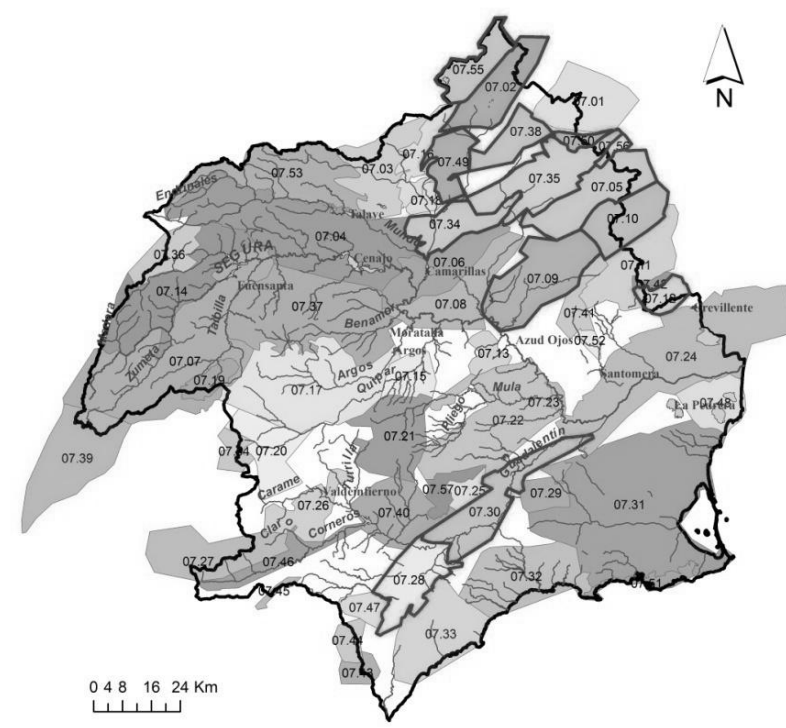

Figura A.8 Acuíferos modelados como depósito.

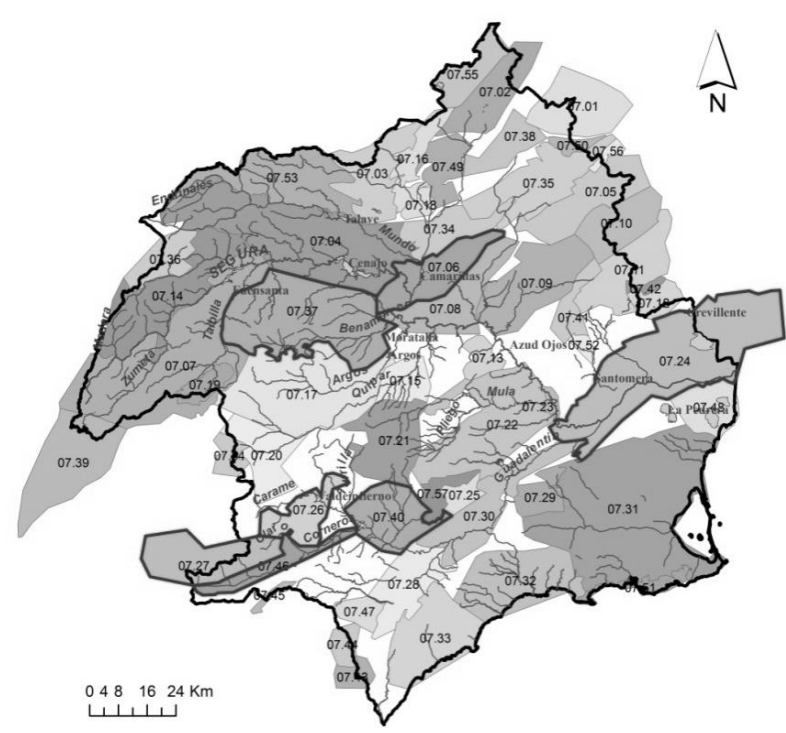

Figura A.9 Acuíferos modelados como unicelulares. 


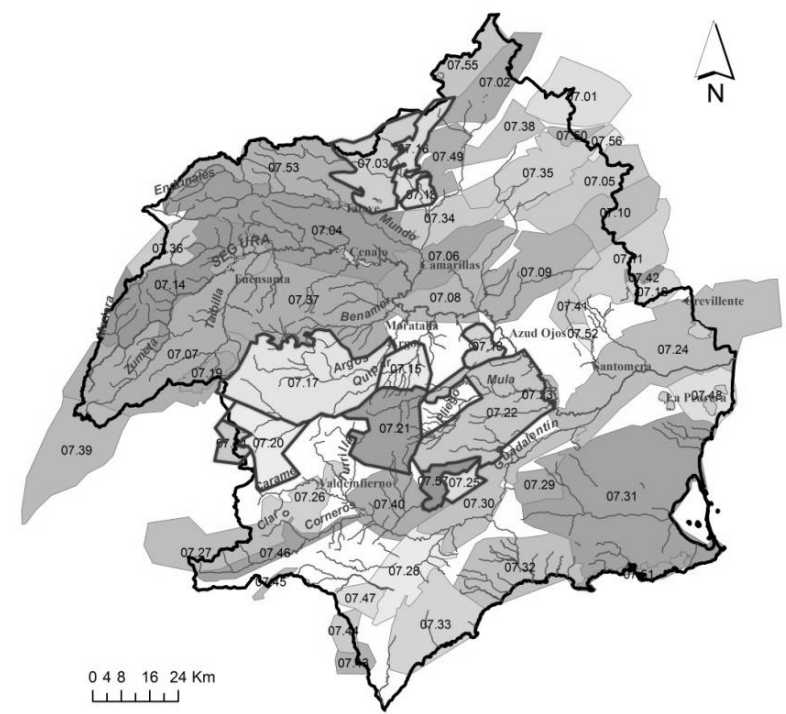

Figura A.10 Acuíferos modelados como manantiales.

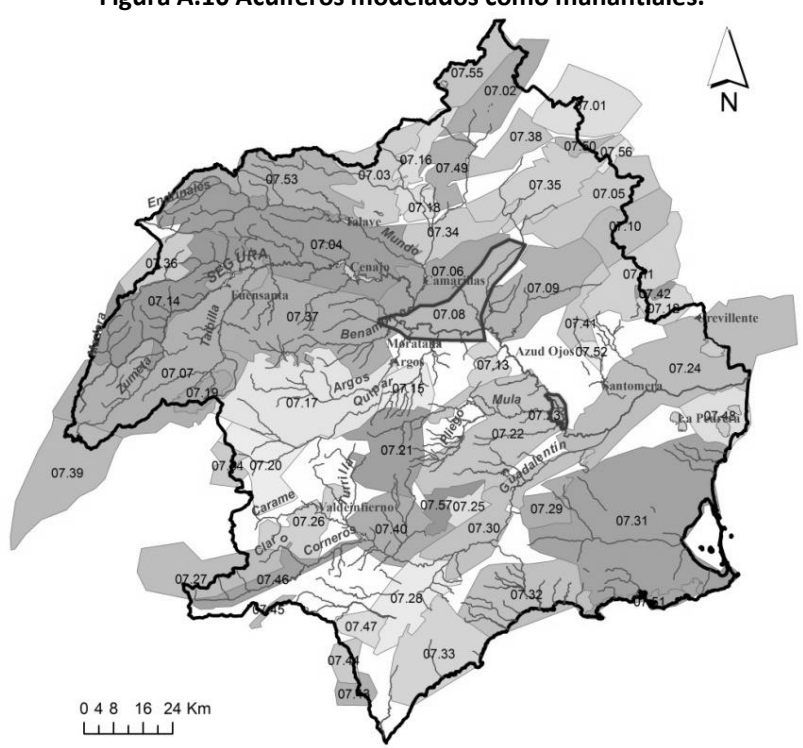

Figura A.11 Acuíferos modelados como Autovalores.

Fuente: Confederación Hidrográfica del Segura y elaboración propia

Las principales unidades hidrogeológicas que se encuentran en la cuenca del Segura se muestran en la tabla A.7. Estas unidades se encuentran agrupadas para representarlas en el modelo como un acuífero, el cual también se muestra en la tabla. Así mismo, se muestra el tipo de modelo empleado para simular cada acuífero en SimGes. 
Tabla A.7. Acuíferos: unidades hidrogeológicas englobadas y tipo de modelo empleado

\begin{tabular}{|c|c|c|c|}
\hline \multirow[b]{2}{*}{ Acuíferos } & \multicolumn{2}{|c|}{ Unidad hidrogeológica } & \multirow{2}{*}{$\begin{array}{c}\text { Tipo } \\
\text { modelo }\end{array}$} \\
\hline & Nombre & Número & \\
\hline Ascoy Sopalmo & Ascoy Sopalmo & 07-09 & Depósito \\
\hline \multirow{2}{*}{ Bajo Quipar-Bullas } & Bajo Quipar & 07-15 & \multirow{2}{*}{ Manantial } \\
\hline & Bullas & $07-21$ & \\
\hline \multirow{3}{*}{ Boquerón Tobarra Otros } & Boquerón & 07-03 & \multirow{3}{*}{ Manantial } \\
\hline & $\begin{array}{l}\text { Tobarra-Tedera- } \\
\text { Pinilla }\end{array}$ & 07-16 & \\
\hline & Pino & 07-18 & \\
\hline \multirow{4}{*}{ Campo Cartagena, otros } & Campo Cartagena & 07-31 & \multirow{4}{*}{ Depósito } \\
\hline & Terciario Torrevieja & $07-48$ & \\
\hline & Sierra Cartagena & 07-51 & \\
\hline & Triásico Carrascoy & $07-29$ & \\
\hline Crevillente & Crevillente & $07-12$ & Depósito \\
\hline El Molar & El Molar & 07-06 & Unicelular \\
\hline \multirow{6}{*}{ Jumilla - Villena Serral Salinas } & Jumilla - Villena & 07-05 & \multirow{6}{*}{ Depósito } \\
\hline & Moratilla & $07-50$ & \\
\hline & Lácera & $07-56$ & \\
\hline & Cuchillos-Cabras & $07-34$ & \\
\hline & Cingla & $07-35$ & \\
\hline & Serral-Salinas & $07-10$ & \\
\hline \multirow{5}{*}{ Mazarrón Águilas, otros } & Mazarrón & $07-32$ & \multirow{5}{*}{ Depósito } \\
\hline & Águilas & 07-33 & \\
\hline & $\begin{array}{l}\text { Enmedio-Cabeza de } \\
\text { Jara }\end{array}$ & $07-47$ & \\
\hline & Sierra Almagro & $07-43$ & \\
\hline & Sin Definir 2 & $07-00$ & \\
\hline Quibas & Quibas & $07-11$ & Depósito \\
\hline \multirow{5}{*}{ Sierra Espuña } & Sierra Espuña & $07-22$ & \multirow{5}{*}{ Manantial } \\
\hline & Santa Yechar & $07-25$ & \\
\hline & Medo & $07-57$ & \\
\hline & Sin definir 1 & $07-00$ & \\
\hline & Oro-Ricote & $07-13$ & \\
\hline Sinclinal de Calasparra & S. de Calasparra & 07-08 & Autovalores \\
\hline \multirow{4}{*}{ Sinclinal de la Higuera-Otros } & S. Higuera & 07-02 & \multirow{4}{*}{ Depósito } \\
\hline & Corral Rubio & 07-55 & \\
\hline & Ontur & 07-38 & \\
\hline & Conejeros Albatana & 07-49 & \\
\hline \multirow{3}{*}{ Valdeinfierno, otros } & Valdeinfierno & $07-26$ & \multirow{3}{*}{ Unicelular } \\
\hline & Orce-María & $07-27$ & \\
\hline & Chirivel-Velez & $07-46$ & \\
\hline
\end{tabular}




\begin{tabular}{|l|l|l|l|}
\cline { 2 - 3 } \multicolumn{1}{c|}{} & \multicolumn{2}{c|}{ Unidad hidrogeológica } & \multicolumn{1}{c|}{ Tipo } \\
\cline { 2 - 3 } \multicolumn{1}{c|}{ Acuíferos } & \multicolumn{1}{c|}{ Nombre } & Número & \multicolumn{1}{c|}{ modelo } \\
\hline Valle del Guadalentín & Puentes & $07-40$ & Depósito \\
\hline Vega Alta & $\begin{array}{l}\text { Vega Alta del } \\
\text { Segura }\end{array}$ & $07-23$ & Autovalores \\
\hline Vega Baja I & Vega Media y Baja & $07-24$ & Tres niveles \\
\hline Vega Baja II & Vega Media y Baja & $07-24$ & Tres niveles \\
\hline Vega Media & Vega Media y Baja & $07-24$ & Unicelular \\
\hline
\end{tabular}

Se ha utilizado un modelo de acuífero auxiliar, llamado Infiltración Cenajo, que se utiliza para recibir las infiltraciones del embalse del Cenajo y retornarlas aguas abajo del embalse. Se ha modelado como un acuífero unicelular.

Representación de las desalinizadoras. Se han simulado como acuíferos de tipo depósito. La desalinizadora de San Pedro es de $48 \mathrm{hm}^{3} /$ año, en dos fases San Pedro I y II. La primera fase $\left(24 \mathrm{hm}^{3}\right.$ ) está ya inaugurada (aunque no en pleno funcionamiento) y la segunda está en construcción. Idéntica situación se da en Alicante, con $48 \mathrm{hm}^{3} / a n ̃ o$ en dos fases. La desalación la Pedrera PHCS es el valor que en esta zona daba el PHCS debido a la desalación (en pequeñas plantas particulares) con un volumen de $15 \mathrm{hm}^{3} / a n ̃ o$. Idéntica situación ocurre desde la desalación del Campo Cartagena PHCS, que es el valor que en esta zona daba el PHCS debido a la desalación (en pequeñas plantas particulares) con un volumen de $7 \mathrm{hm}^{3} /$ año. Estas pequeñas plantas se modelan con un acuífero tipo depósito C. Cartagena Desalación PHCS. La desalinizadora de Valdelentisco tendrá $57 \mathrm{hm}^{3} /$ año, de los que 22 son para la MCT. En el caso de estas desalinizadoras (San Pedro I y II, Alicante I y II y Valdelentisco en su parte de la MCT), se procede a su inclusión en el modelo ya que su puesta en marcha es inminente. Las desalinizadoras pequeñas contempladas en el PHCS también se consideran en el modelo. Las desalinizadoras del modelo de Águilas (4.4 $\mathrm{hm}^{3} /$ año) y Mazarrón ( $9 \mathrm{hm}^{3} /$ año) son las que actualmente están en funcionamiento. ACUAMED, dentro del programa AGUA ejecutará grandes desalinizadoras para riego:

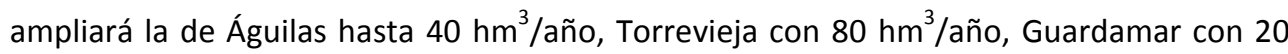
$\mathrm{hm}^{3} /$ año y Mojón con $8 \mathrm{hm}^{3} / a n ̃ o$. Es posible que la MCT también se comprometa a la compra de agua de la desalinizadora de Águilas y Torrevieja. Estas últimas desalinizadoras de ACUAMED se incorporarán al modelo más tarde, en un escenario de puesta en marcha de la totalidad del programa AGUA. 


\section{DEMANDAS}

\section{Demanda Agraria}

Se ha dividido la cuenca en diferentes zonas: Cabecera, Argos, Mula, Guadalentín, Mazarrón, Vega Alta, Altiplano y M.I, Vega Media, Vega Baja, R.L.M.D., R.L.M.I., y Cartagena. Cada una de estas zonas contiene distintas demandas, y considerando la situación geográfica de las mismas y el origen del recurso estas demandas se han reagrupado dentro de su propia zona, quedando finalmente:

Tabla A.8. Agrupación de demandas.

\begin{tabular}{|c|c|c|}
\hline ZONA & DEMANDA & AGRUPACION \\
\hline \multirow{4}{*}{ CABECERA } & & UDA 7 R. ACU. HELLÍN TOBARRA \\
\hline & & UDA 9 R. VEGA DE MUNDO \\
\hline & & UDA 10 R. CANAL DE HELLÍN \\
\hline & & SUPERFICIAL TOBARRA \\
\hline ARGOS & & UDA 29 R EMB. ARGOS \\
\hline \multirow{5}{*}{ MULA } & UDA 41 Nuevos regadíos Yéchar & \multirow{5}{*}{ UDA RIO MULA } \\
\hline & UDA 42 Tradicionales de Mula & \\
\hline & UDA 43 Mula, manantial de los Baños & \\
\hline & UDA 44 Pliego & \\
\hline & UDA 73 Nuevos regadíos Mula y Pliego & \\
\hline \multirow{5}{*}{ GUADALENTÍN } & UDA 61 Regadío de Lorca & \multirow{5}{*}{ UDA VALLE GUADALENTÍN } \\
\hline & UDA 63 Acuífero del Alto Guadalentín & \\
\hline & UDA 64 Mixtos del Bajo Guadalentín & \\
\hline & $\begin{array}{l}\text { UDA } 65 \text { Subterráneas zona del Bajo } \\
\text { Guadalentín }\end{array}$ & \\
\hline & $\begin{array}{l}\text { UDA } 66 \text { Nuevos regadíos Lorca y Valle del } \\
\text { Guadalentín }\end{array}$ & \\
\hline \multirow{4}{*}{ MAZARRÓN } & UDA 67 Mazarrón & \multirow{3}{*}{ UDA MAZARRÓN ÁGUILAS } \\
\hline & UDA 68 Águilas & \\
\hline & UDA 69 Almería-Segura & \\
\hline & & UDA 70 N.R. ALMERIA SUR \\
\hline \multirow{8}{*}{ VEGA ALTA } & UDA 17 Tradicional Vega Alta, Calasparra & \multirow{5}{*}{$\begin{array}{l}\text { UDA REGADIOS TRADICIONALES VEGA } \\
\text { ALTA }\end{array}$} \\
\hline & UDA 21 Tradicional Vega Alta, Cieza & \\
\hline & $\begin{array}{l}\text { UDA } 18 \text { Tradicional Vega Alta, Abarán- } \\
\text { Blanca }\end{array}$ & \\
\hline & $\begin{array}{l}\text { UDA } 20 \text { Tradicional Vega Alta, Ojós- } \\
\text { Contraparada }\end{array}$ & \\
\hline & $\begin{array}{l}\text { UDA } 22 \text { Vega Alta, post. al } 33 \text { y ampl. del } \\
53\end{array}$ & \\
\hline & & UDA 25 R. ACU VEGA ALTA \\
\hline & $\begin{array}{l}\text { UDA } 26 \text { Nuevos regadíos Zona I Vega } \\
\text { Alta-Media }\end{array}$ & \multirow[t]{2}{*}{ UDA NUEVOS REGADIOS TRASVASE } \\
\hline & UDA 37 Nuevos regadíos Zona II Vega & \\
\hline
\end{tabular}




\begin{tabular}{|c|c|c|}
\hline ZONA & DEMANDA & AGRUPACION \\
\hline & Alta-Media & \\
\hline & $\begin{array}{l}\text { UDA } 38 \text { Nuevos regadíos Zona III Vega } \\
\text { Alta-Media }\end{array}$ & \\
\hline & $\begin{array}{l}\text { UDA } 39 \text { Nuevos regadíos Zona IV Vega } \\
\text { Alta-Media }\end{array}$ & \\
\hline & $\begin{array}{l}\text { UDA } 40 \text { Nuevos regadíos Zona V Vega } \\
\text { Alta-Media }\end{array}$ & \\
\hline \multirow{8}{*}{ ALTIPLANO Y M.I } & UDA 1 Yecla-Corral Rubio & \multirow{3}{*}{ UDA YECLA-JUMILLA-SERRAL } \\
\hline & UDA 2 Jumilla & \\
\hline & UDA 5 Acuífero de Serral-Salinas & \\
\hline & UDA 3 Regadíos sobre Ascoy-Sopalmo & \multirow{3}{*}{ UDA ASCOY SOPALMO } \\
\hline & $\begin{array}{l}\text { UDA } 4 \text { Regadíos del Ascoy-Sopalmo sobre } \\
\text { el Sinclinal Calasparra }\end{array}$ & \\
\hline & $\begin{array}{l}\text { UDA } 45 \text { Regadíos del Ascoy-Sopalmo, } \\
\text { Fortuna-Abanilla-Molina }\end{array}$ & \\
\hline & UDA 6 Acuífero de Quibas & 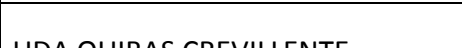 \\
\hline & UDA 55 Acuífero de Crevillente & UDA QUIBAS CREVILLEIVIE \\
\hline \multirow{3}{*}{ VEGA MEDIA } & & UDA 36 R. ACU. VEGA MEDIA \\
\hline & UDA 32 Tradicional Vega Media & \multirow[b]{2}{*}{ UDA VEGA MEDIA } \\
\hline & $\begin{array}{l}\text { UDA } 34 \text { Vega Media, post. al } 33 \text { y ampl. } \\
\text { del } 53\end{array}$ & \\
\hline \multirow{3}{*}{ VEGA BAJA } & & UDA 51 R. ACU. VEGA BAJA \\
\hline & UDA 46 Tradicional Vega Baja & \multirow[b]{2}{*}{ UDA VEGA BAJA } \\
\hline & $\begin{array}{l}\text { UDA } 48 \text { Vega Baja, post. al } 33 \text { y ampl. del } \\
53\end{array}$ & \\
\hline \multirow{3}{*}{ R.L.M.D. } & & UDA 56 N.R. LA PEDRERA \\
\hline & $\begin{array}{l}\text { UDA } 52 \text { Riegos de Levante Margen } \\
\text { Derecha }\end{array}$ & \multirow{2}{*}{ UDA R.L.M.D. } \\
\hline & $\begin{array}{l}\text { UDA } 71 \text { Nuevos regadíos Riegos de } \\
\text { Levante Margen Derecha }\end{array}$ & \\
\hline \multirow{3}{*}{ R.L.M.I. } & $\begin{array}{l}\text { UDA } 53 \text { Riegos de Levante Margen } \\
\text { Izquierda-Poniente }\end{array}$ & \multirow{3}{*}{ UDA R.L.M.I. } \\
\hline & $\begin{array}{l}\text { UDA } 54 \text { Riegos de Levante Margen } \\
\text { Izquierda-Levante }\end{array}$ & \\
\hline & $\begin{array}{l}\text { UDA } 72 \text { Nuevos regadíos Riegos de } \\
\text { Levante Margen Izquierda-Poniente }\end{array}$ & \\
\hline \multirow{3}{*}{ CARTAGENA } & $\begin{array}{l}\text { UDA } 57 \text { Acuíferos del Campo de } \\
\text { Cartagena }\end{array}$ & \multirow{3}{*}{ UDA CAMPO DE CARTAGENA } \\
\hline & $\begin{array}{l}\text { UDA } 58 \text { Campo de Cartagena redotado } \\
\text { con trasvase }\end{array}$ & \\
\hline & $\begin{array}{l}\text { UDA } 59 \text { Nuevos regadíos Campo de } \\
\text { Cartagena }\end{array}$ & \\
\hline & & ALMERIA TRASVASE \\
\hline & & DEMANDA JUCAR S CREVILLENTE \\
\hline & & DEMANDA SERRAL SALINA \\
\hline & & DEMANDA JUCAR SOBRE JUMILLA \\
\hline & & UDA 74 N.R. LEVANTE M.I. / JUCAR \\
\hline
\end{tabular}


Hay UDAS que no aparecen en la tabla anterior y que se han considerado como detracciones en régimen natural de los diferentes ríos. En la tabla A.9 se muestra, para cada agrupación de UDA, la demanda anual en $\mathrm{hm}^{3}$.

Tabla A.9 Dotación de cada demanda agrupada en $\mathrm{hm}^{3}$

\begin{tabular}{|c|c|}
\hline DEMANDA & DEMANDA ANUAL \\
\hline UDA 7 R. ACU. HELLÍN TOBARRA & 30,31 \\
\hline UDA 9 R. VEGA DE MUNDO & 4,83 \\
\hline UDA 10 R. CANAL DE HELLÍN & 22,48 \\
\hline SUPERFICIAL TOBARRA & 17,27 \\
\hline UDA 29 R EMB. ARGOS & 4,58 \\
\hline UDA RIO MULA & 35,87 \\
\hline UDA VALLE GUADALENTÍN & 263,82 \\
\hline UDA MAZARRÓN ÁGUILAS & 57,63 \\
\hline UDA 70 N.R. ALMERIA SUR & 22,7 \\
\hline UDA REGADIOS TRADICIONALES VEGA ALTA & 102,63 \\
\hline UDA 25 R. ACU VEGA ALTA & 14,99 \\
\hline UDA NUEVOS REGADIOS TRASVASE & 109,98 \\
\hline UDA YECLA-JUMILLA-SERRAL & 48,88 \\
\hline UDA ASCOY SOPALMO & 71,47 \\
\hline UDA QUIBAS CREVILLENTE & 15,52 \\
\hline UDA 36 R. ACU. VEGA MEDIA & 15,38 \\
\hline UDA VEGA MEDIA & 85,99 \\
\hline UDA 51 R. ACU. VEGA BAJA & 1,28 \\
\hline UDA VEGA BAJA & 160,95 \\
\hline UDA 56 N.R. LA PEDRERA & 49,8 \\
\hline UDA R.L.M.D. & 24,57 \\
\hline UDA R.L.M.I. & 159,74 \\
\hline UDA CAMPO DE CARTAGENA & 123,13 \\
\hline ALMERIA TRASVASE & 90 \\
\hline DEMANDA JUCAR S CREVILLENTE & 8,04 \\
\hline DEMANDA SERRAL SALINA & 8,304 \\
\hline DEMANDA JUCAR SOBRE JUMILLA & 26,64 \\
\hline UDA 74 N.R. LEVANTE M.I. / JUCAR & 0 \\
\hline
\end{tabular}


Las tablas A.10 a la A.17 muestran las demandas por procedencia del recurso:

- Recurso Superficial

Tabla A.10. Volumen de demanda superficial en $\mathrm{hm}^{3}$

\begin{tabular}{|c|c|}
\hline DEMANDA & A.SUP \\
\hline UDA 9 R. VEGA DE MUNDO & 4,8 \\
\hline UDA 10 R. CANAL DE HELLÍN & 22,5 \\
\hline SUPERFICIAL TOBARRA & 10.7 \\
\hline UDA 29 R EMB. ARGOS & 4,6 \\
\hline UDA RIO MULA & 8,1 \\
\hline UDA VALLE GUADALENTÍN & 19,2 \\
\hline UDA REGADIOS TRADICIONALES VEGA ALTA & 94,9 \\
\hline UDA QUIBAS CREVILLENTE & 1,7 \\
\hline UDA VEGA MEDIA & 86 \\
\hline UDA VEGA BAJA & 133,4 \\
\hline UDA R.L.M.D. & 16 \\
\hline
\end{tabular}

- Recurso del ATS

Tabla A.11. Volumen de demanda del ATS en $\mathrm{hm}^{3}$

\begin{tabular}{|c|c|}
\hline DEMANDA & A.TRASVA \\
\hline UDA RIO MULA & 8 \\
\hline UDA VALLE GUADALENTÍN & 64,9 \\
\hline UDA 70 N.R. ALMERIA SUR & 15 \\
\hline UDA REGADIOS TRADICIONALES VEGA ALTA & 0,1 \\
\hline UDA 25 R. ACU VEGA ALTA & 1,5 \\
\hline UDA NUEVOS REGADIOS TRASVASE & 62,8 \\
\hline UDA ASCOY SOPALMO & 0,4 \\
\hline UDA QUIBAS CREVILLENTE & 0,2 \\
\hline UDA VEGA BAJA & 0,5 \\
\hline UDA 56 N.R. LA PEDRERA & 14,1 \\
\hline UDA R.L.M.D. & 5,5 \\
\hline UDA R.L.M.I. & 104,8 \\
\hline UDA CAMPO DE CARTAGENA & 122 \\
\hline
\end{tabular}

- Recurso procedente de azarbes

Tabla A.12 Recurso procedente de azarbes en $\mathrm{hm}^{3}$

\begin{tabular}{|c|c|}
\hline DEMANDA & A.AZR \\
\hline UDA VEGA BAJA & 21,5 \\
\hline UDA R.L.M.I. & 22 \\
\hline
\end{tabular}


- Recursos procedentes de aguas residuales

Tabla A.13 Recurso de agua residual en $\mathrm{hm}^{3}$

\begin{tabular}{|c|c|}
\hline DEMANDA & A.RES \\
\hline UDA 7 R. ACU. HELLÍN TOBARRA & 0,1 \\
\hline UDA RIO MULA & 2,5 \\
\hline UDA VALLE GUADALENTÍN & 5,7 \\
\hline UDA MAZARRÓN ÁGUILAS & 3,1 \\
\hline UDA REGADIOS TRADICIONALES VEGA ALTA & 0,7 \\
\hline UDA YECLA-JUMILLA-SERRAL & 0,3 \\
\hline UDA ASCOY SOPALMO & 0,2 \\
\hline UDA QUIBAS CREVILLENTE & 0,1 \\
\hline UDA 51 R. ACU. VEGA BAJA & 0,1 \\
\hline UDA VEGA BAJA & 1,4 \\
\hline UDA 56 N.R. LA PEDRERA & 1,8 \\
\hline UDA R.L.M.D. & 1,6 \\
\hline UDA R.L.M.I. & 12,3 \\
\hline UDA CAMPO DE CARTAGENA & 21,1 \\
\hline
\end{tabular}

- Otros recursos: desalación.

Tabla A.14 Recurso procedente de desalación en $\mathrm{hm}^{3}$

\begin{tabular}{|c|c|}
\hline DEMANDA & A.OTRO \\
\hline UDA VEGA BAJA & 3,3 \\
\hline UDA 56 N.R. LA PEDRERA & 15 \\
\hline UDA R.L.M.I. & 3,3 \\
\hline UDA CAMPO DE CARTAGENA & 7 \\
\hline
\end{tabular}

- Recursos procedentes de bombeos renovables y no renovables.

Tabla A.15 Recurso procedente de bombeos en $\mathrm{hm}^{3}$

\begin{tabular}{|c|c|c|}
\hline DEMANDA & B.REN & B.NOREV \\
\hline UDA 7 R. ACU. HELLÍN TOBARRA & 24,9 & 5,3 \\
\hline SUPERFICIAL TOBARRA & 5.4 & 1.1 \\
\hline UDA RIO MULA & 11 & \\
\hline UDA VALLE GUADALENTÍN & 33,3 & 59,9 \\
\hline UDA MAZARRÓN ÁGUILAS & 13,8 & 24,5 \\
\hline UDA REGADIOS TRADICIONALES VEGA ALTA & 6,6 & 0,1 \\
\hline UDA 25 R. ACU VEGA ALTA & 4,6 & 0,3 \\
\hline UDA YECLA-JUMILLA-SERRAL & 24,2 & 23,3 \\
\hline
\end{tabular}




\begin{tabular}{|c|c|c|}
\hline DEMANDA & B.REN & B.NOREV \\
\hline UDA ASCOY SOPALMO & 2 & 43,1 \\
\hline UDA QUIBAS CREVILLENTE & 4,5 & 7,5 \\
\hline UDA 36 R. ACU. VEGA MEDIA & 15,3 & \\
\hline UDA 51 R. ACU. VEGA BAJA & 1,2 & \\
\hline UDA 56 N.R. LA PEDRERA & 7,9 & 0,1 \\
\hline UDA CAMPO DE CARTAGENA & 64,5 & 5,9 \\
\hline
\end{tabular}

Estas últimas demandas bombean de distintos acuíferos, que son:

Tabla A.16 Acuíferos y demandas asociadas

\begin{tabular}{|c|c|}
\hline DEMANDA & ACUÍFEROS \\
\hline UDA 7 R. ACU. HELLÍN TOBARRA & TOBARRA \\
\hline SUPERFICIAL TOBARRA & TOBARRA \\
\hline UDA RIO MULA & VEGA ALTA Y SIERRA ESPUÑA \\
\hline UDA VALLE GUADALENTÍN & SIERRA ESPUÑA Y VALLE DEL GUADALENTÍN \\
\hline UDA MAZARRÓN ÁGUILAS & VALLE DEL GUADALENTÍN Y MAZARRÓN \\
\hline UDA REGADIOS TRADICIONALES VEGA ALTA & VEGA ALTA Y EL MOLAR \\
\hline UDA 25 R. ACU VEGA ALTA & EL MOLAR Y SINCLINAL DE CALASPARRA \\
\hline UDA YECLA-JUMILLA-SERRAL & $\begin{array}{l}\text { JUMILLA, SINCLINAL DE LA HIGUERA, SINCLINAL DE } \\
\text { CALASPARRA Y EL MOLAR }\end{array}$ \\
\hline UDA ASCOY SOPALMO & ASCOY Y SIERRA DE CALASPARRA \\
\hline UDA QUIBAS CREVILLENTE & QUIBAS Y CREVILLENTE \\
\hline UDA 36 R. ACU. VEGA MEDIA & VEGA MEDIA Y VEGA BAJA \\
\hline UDA 51 R. ACU. VEGA BAJA & VEGA BAJA \\
\hline UDA 56 N.R. LA PEDRERA & VEGA BAJA \\
\hline UDA CAMPO DE CARTAGENA & CAMPO DE CARTAGENA \\
\hline
\end{tabular}

Además, se consideraron las demandas que reciben agua de las desalinizadoras:

Tabla A.17 Desalinizadoras y demandas asociadas

\begin{tabular}{|c|c|}
\hline DESALACIÓN ÁGUILAS & UDA MAZARRÓN ÁGUILAS \\
\hline DESALACIÓN C. CARTAGENA PHCS & $\begin{array}{c}\text { UDA CAMPO DE CARTAGENA Y UDA 56 N.R. } \\
\text { LA PEDRERA }\end{array}$ \\
\hline DESALACIÓN MAZARRÓN & UDA MAZARRÓN ÁGUILAS \\
\hline DESALACIÓN VEGA BAJA M.D. PHCS & UDA VEGA BAJA \\
\hline DESALACIÓN VEGA BAJA M.I. PHCS & UDA R.L.M.I. \\
\hline VALDELENTISCO & UDA CAMPO DE CARTAGENA \\
\hline
\end{tabular}




\section{Demanda Urbana}

Tabla A.18 Dotación de cada demanda agrupada en $\mathrm{hm}^{3}$

\begin{tabular}{|c|c|}
\hline DEMANDA & DEMANDA ANUAL \\
\hline UDU M.C. TAIBILLA & 240,6 \\
\hline UDU 11 JUMILLA YECLA & 6,1 \\
\hline UDU 12 SIERRA DE CREVILLENTE & 2,2 \\
\hline UDU 7 HELLÍN & 2,8 \\
\hline
\end{tabular}

La demanda de la M.C.T. agrupa a las siguientes demandas:

Tabla A.19 Demandas agrupadas por la MCT

\begin{tabular}{|c|}
\hline UDU 1 MCT- Taibilla \\
\hline UDU 2 MCT - Sierra de la Espada \\
\hline UDU 3 MCT - Campotejar \\
\hline UDU 4 MCT - Torrealta \\
\hline UDU 5 MCT - Pedrera \\
\hline UDU 6 MCT - Lorca \\
\hline UDU 8 Cabecera del Segura \\
\hline UDU 9 Cabecera del Mundo \\
\hline UDU 10 Cabecera del Guadalentín \\
\hline UDU 13 Murcia - Rio Segura \\
\hline
\end{tabular}

Esta agrupación de demandas se ha realizado como en el caso de las demandas agrarias, es decir, considerando la localización geográfica y la procedencia del recurso.

Las desalinizadoras de San Pedro del Pinatar, Valdelentisco y Alicante aportan recurso a la demanda M.C.T. También tiene aportaciones de procedencia superficial y del trasvase Tajo-Segura.

Además, hay aportación de recurso procedente de bombeos:

Tabla A.20 Recurso procedente de bombeos en $\mathrm{hm}^{3}$ y acuíferos asociados

\begin{tabular}{|c|c|c|}
\hline UDU & ACUIFERO & DEMANDA \\
\hline UDU 11 JUMILLA YECLA & Jumilla-Villena & 6,1 \\
\hline UDU 12 SIERRA DE CREVILLENTE & Crevillente & 2,2 \\
\hline UDU 7 HELLÍN & Boquerón-Tobarra & 2,8 \\
\hline
\end{tabular}

La demanda de Hellín tiene también recurso superficial. 


\section{Demanda Industrial}

Se modelaron ocho unidades de demanda:

Tabla A.21 Dotación de cada demanda en $\mathrm{hm}^{3}$

\begin{tabular}{|c|c|}
\hline DEMANDA & DEMANDA ANUAL \\
\hline UDI 1 GUADALENTÍN & 1,073 \\
\hline UDI 2 CABECERA & 2,807 \\
\hline UDI 3 CENTRO & 2,65 \\
\hline UDI 4 MURCIA & 2,344 \\
\hline UDI 5 ALICANTE - SEGURA & 4,888 \\
\hline UDI 6 LITORAL & 7,787 \\
\hline UDI 7 DIRECTA & 1,81 \\
\hline UDI 8 ALICANTE JUCAR & 10,67 \\
\hline
\end{tabular}

Las siguientes demandas toman recurso de distintas procedencias:

- Recursos procedentes de bombeos

Tabla A.22 Recurso procedente de bombeos en $\mathrm{hm}^{3}$ y acuíferos asociados

\begin{tabular}{|c|c|c|}
\hline UDI & ACUIFERO & DEMANDA \\
\hline UDI 1 GUADALENTÍN & Guadalentín & 1,073 \\
\hline UDI 2 CABECERA & Jumilla-Villena & 2,807 \\
\hline UDI 3 CENTRO & Vega Alta & 2,65 \\
\hline UDI 4 MURCIA & Vega Media & 2,344 \\
\hline UDI 5 ALICANTE - SEGURA & Vega Baja II & 4,888 \\
\hline UDI 6 LITORAL & Campo de Cartagena & 2,251 \\
\hline
\end{tabular}

- Recurso procedente del Trasvase Tajo-Segura

Tabla A.23 Recurso asignado procedente del trasvase Tajo-Segura
\begin{tabular}{|c|c|}
\hline UDI & DEMANDA \\
\hline UDI 6 LITORAL & 5,61 \\
\hline UDI 7 DIRECTA & 1,81 \\
\hline UDI 8 ALICANTE JUCAR & 10,67 \\
\hline
\end{tabular}

Además, se ha considerado una demanda de sostenimiento de humedales con una demanda anual de $30 \mathrm{hm}^{3}$ que procede de recurso superficial sobre el río Segura.

Reglas de operación. En el modelo, las conducciones tipo 1 con caudal mínimo son: 
Tabla A.24 Caudal mínimo en las conducciones tipo 1

\begin{tabular}{|l|c|}
\hline \multicolumn{1}{|c|}{ NOMBRE CONDUCCIÓN } & Qmínimo(hm ${ }^{\mathbf{3}}$ /año) \\
\hline 1-SEGURA DESPUES FUENSANTA & 26,04 \\
\hline 2-SEGURA ANTES CENAJO & 26,04 \\
\hline 4-MUNDO DESPUES TALAVE & 13,32 \\
\hline 8-SEGURA ANTES MORATALLA & 57,72 \\
\hline 9-SEGURA ANTES UDA17 & 57,72 \\
\hline 10-SEGURA ANTES ARGOS & 57,72 \\
\hline 23-TRASVASE DERECHA IV & 90 \\
\hline 48-SEGURA ANTES MENJÚ & 57,72 \\
\hline 53-SEGURA DESPUES TAIBILLA & 26,04 \\
\hline 54-SEGURA ANTES QUIPAR & 57,72 \\
\hline 55-MORATALLA ACU.SOMOGIL & 4,81 \\
\hline 75-OJOS A ARCHENA & 94,8 \\
\hline 77-SEGURA ANTES ALMADENES & 57,72 \\
\hline 79-SEGURA ANTES ABARAN & 57,72 \\
\hline 80-ARCHENA A CONTRAPARADA & 94,8 \\
\hline 94-TOMA HUMEDALES & 30 \\
\hline 95-SEGURA ANTES OJOS & 57,72 \\
\hline 109-SEGURA DESPUES BENIEL & 124,8 \\
\hline 199-SEGURA VEGA BAJA I & 124,8 \\
\hline 201-SEGURA VEGA BAJA II & 124,8 \\
\hline
\end{tabular}

Y de tipo 3:

Tabla A.25 Caudal mínimo en las conducciones tipo 3

\begin{tabular}{|c|c|}
\hline NOMBRE CONDUCCIÓN & Qmínimo(hm $\left.{ }^{3} / \mathrm{año}\right)$ \\
\hline * 1-SEGURA.Con V.A. & 124,8 \\
\hline * 2-SEGURA DESPUES CENAJO & 40,32 \\
\hline * 4-MUNDO ACU.EL MOLAR & 13,32 \\
\hline * 5-SEGURA ACU.CALASPARRA & 57,72 \\
\hline * 10-SEGURA CON BULLAS & 124,8 \\
\hline * 11-MUNDO DESPUES CAMARILLAS & 17,4 \\
\hline * 12-SEGURA CON SIERRA ESPUÑA & 124,8 \\
\hline * 13-SEGURA VEGA MEDIA & 124,8 \\
\hline
\end{tabular}


Prioridades. Las prioridades de embalse son las siguientes:

Tabla A.26 Prioridades en los embalses

\begin{tabular}{|c|c|}
\hline EMBALSE & PRIORIDAD \\
\hline ARGOS & 4 \\
\hline CAMARILLAS & 11 \\
\hline CENAJO & 8 \\
\hline CREVILLENTE & 9 \\
\hline E. ALGECIRAS & 14 \\
\hline FUENSANTA & 7 \\
\hline HONDO & 14 \\
\hline LA CIERVA & 6 \\
\hline PEDRERA & 13 \\
\hline PUENTES & 3 \\
\hline QUIPAR - ALFONSO XIII & 5 \\
\hline SANTOMERA & 14 \\
\hline TAIBILLA & 1 \\
\hline TÁLAVE & 10 \\
\hline VALDEINFIERNO & 2 \\
\hline
\end{tabular}

Volúmenes objetivo. Los volúmenes objetivo se muestran en la s tabla A.27

\begin{tabular}{|c|c|c|c|c|c|c|c|c|c|c|c|c|}
\hline \multirow[b]{2}{*}{ EMBALSES } & \multicolumn{12}{|c|}{ VOL. OBJETIVO por mes $\left(\mathrm{hm}^{3}\right)$} \\
\hline & 10 & 11 & 12 & 1 & 2 & 3 & 4 & 5 & 6 & 7 & 8 & 9 \\
\hline ARGOS & 10,2 & 10,2 & 10,2 & 10,2 & 10,2 & 10,2 & 10,2 & 10,2 & 10,2 & 10,2 & 10,2 & 10,2 \\
\hline CAMARILLAS & 0,5 & 0,5 & 0,7 & 11,6 & 23,2 & 25,2 & 34,5 & 31,4 & 21,1 & 12 & 7 & 3,5 \\
\hline CENAJO & 390 & 390 & 415 & 415 & 415 & 415 & 415 & 415 & 415 & 415 & 415 & 390 \\
\hline CREVILLENTE & 11 & 11 & 12 & 12 & 12 & 12 & 12 & 12 & 12 & 12 & 12 & 11 \\
\hline E. ALGECIRAS & 37 & 37 & 50 & 50 & 50 & 50 & 50 & 50 & 50 & 50 & 50 & 37 \\
\hline FUENSANTA & 169 & 169 & 198,6 & 198,6 & 198,6 & 198,6 & 198,6 & 198,6 & 198,6 & 198,6 & 198,6 & 169 \\
\hline HONDO & 14 & 14 & 14 & 14 & 14 & 14 & 14 & 14 & 14 & 14 & 14 & 14 \\
\hline LA CIERVA & 11,8 & 11,8 & 11,8 & 11,8 & 11,8 & 11,8 & 11,8 & 11,8 & 11,8 & 11,8 & 11,8 & 11,8 \\
\hline PEDRERA & 50,4 & 48,7 & 48,6 & 74,5 & 140,7 & 186,6 & 189 & 171,5 & 142,3 & 102,7 & 71,3 & 55,1 \\
\hline PUENTES & 16 & 16 & 24 & 24 & 24 & 24 & 24 & 24 & 24 & 24 & 24 & 16 \\
\hline $\begin{array}{l}\text { QUIPAR - } \\
\text { ALFONSO XIII }\end{array}$ & 10 & 10 & 21 & 21 & 21 & 21 & 21 & 21 & 21 & 21 & 21 & 10 \\
\hline SANTOMERA & 5,5 & 5,5 & 5,5 & 5,5 & 5,5 & 5,5 & 5,5 & 5,5 & 5,5 & 5,5 & 5,5 & 5,5 \\
\hline TAIBILLA & 8,1 & 8,1 & 8,1 & 8,1 & 8,1 & 8,1 & 8,1 & 8,1 & 8,1 & 8,1 & 8,1 & 8,1 \\
\hline TÁLAVE & 3,3 & 3,3 & 3,3 & 4,6 & 10,4 & 29,5 & 30,7 & 27,4 & 20,3 & 14,4 & 8,3 & 3,3 \\
\hline VALDEINFIERNO & 9 & 9 & 12,9 & 12,9 & 12,9 & 12,9 & 12,9 & 12,9 & 12,9 & 12,9 & 12.9 & 9 \\
\hline
\end{tabular}

Los volúmenes mínimos de Talave, Cenajo, Fuensanta y Taibilla corresponden a un 10\% del volumen máximo. 


\section{Curvas de demanda agrícola}

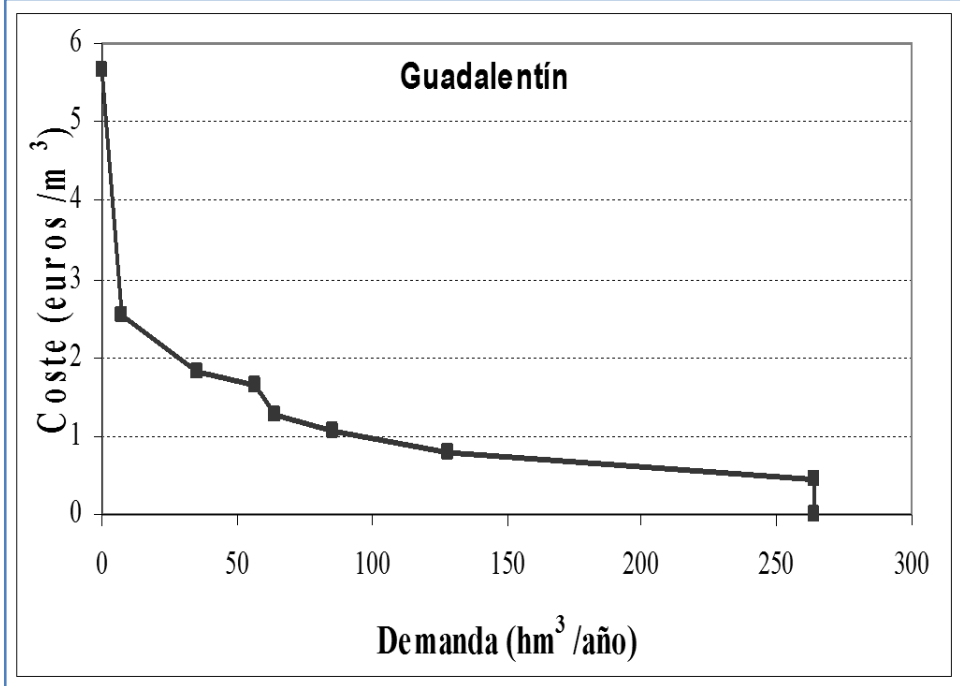

Figura A.12 Curva demanda económica. Guadalentín

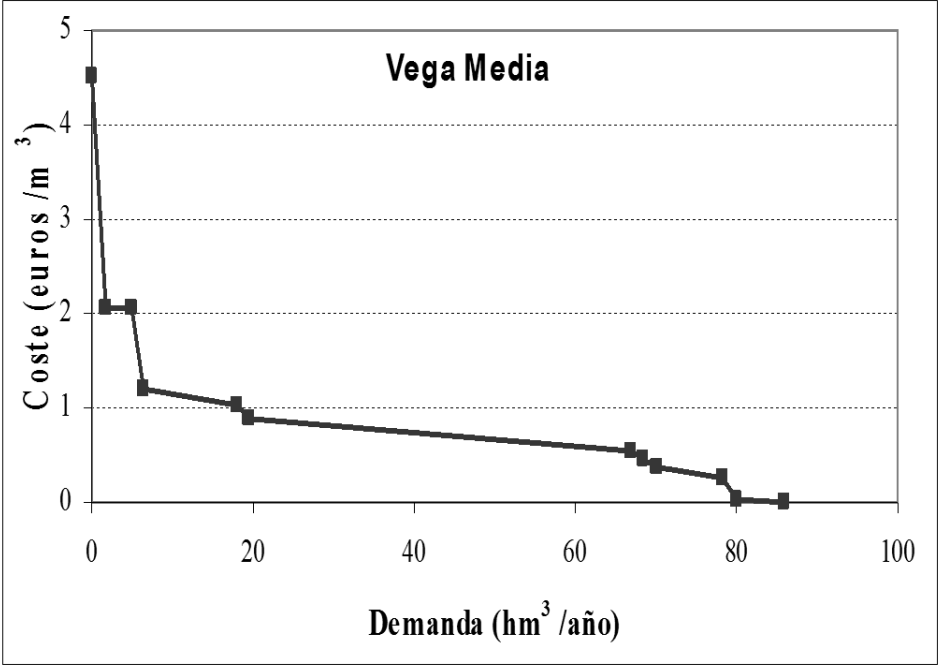

Figura A.13 Curva demanda económica. Vega Media 


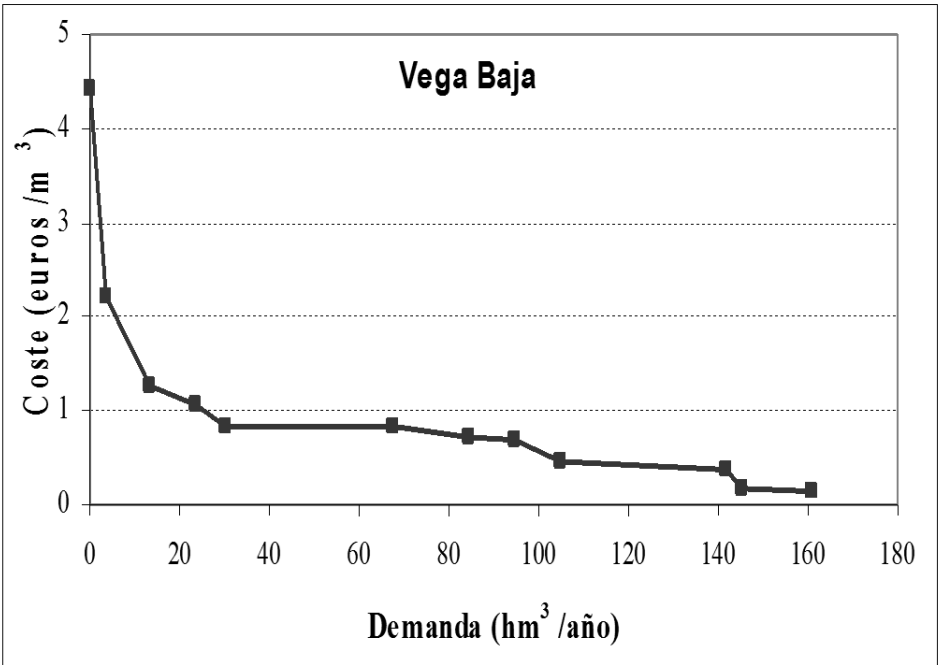

Figura A.14 Curva demanda económica. Vega Baja

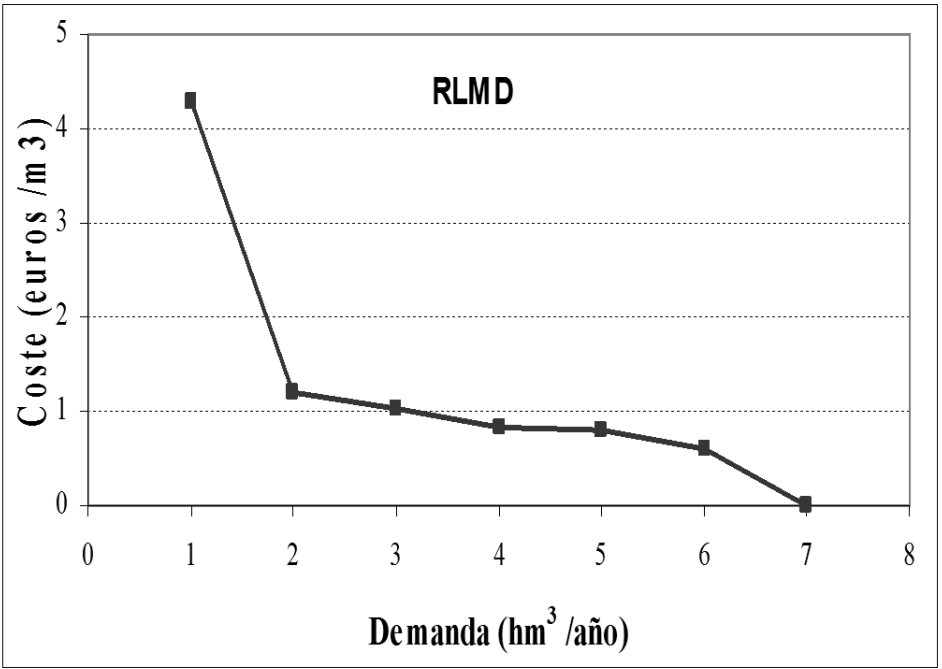

Figura A.14 Curva demanda económica. Riegos de Levante margen derecha 


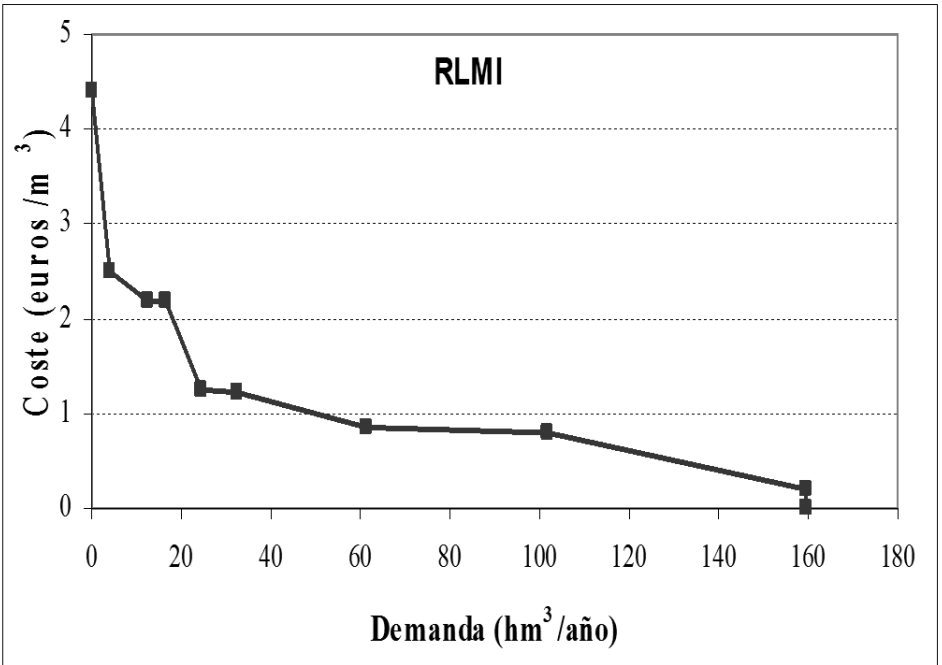

Figura A.15 Curva demanda económica. Riegos de Levante margen izquierda

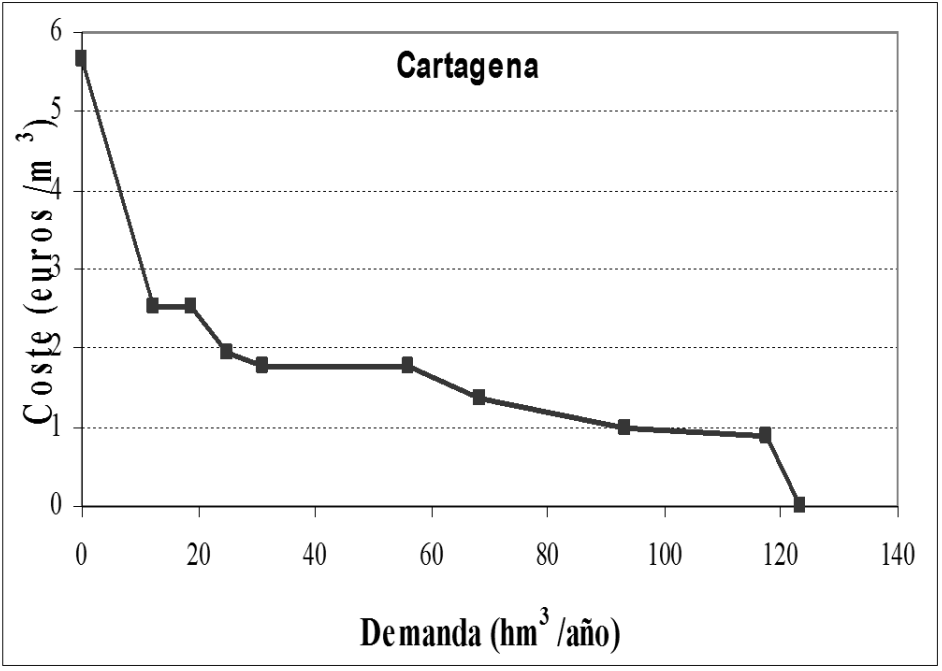

Figura A.16 Curva demanda económica. Cartagena 


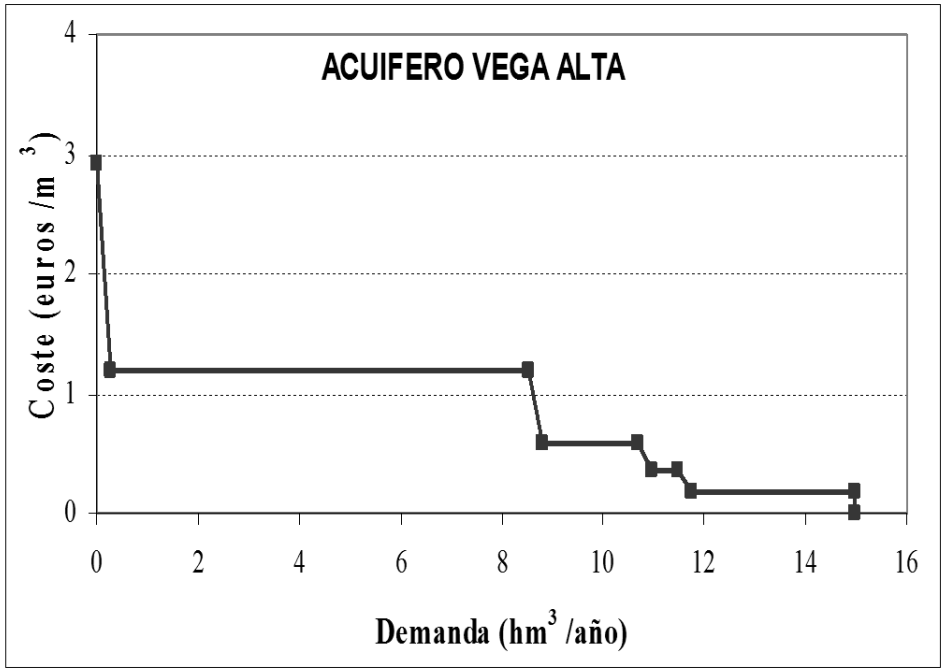

Figura A.17 Curva demanda económica. Acuífero Vega Alta

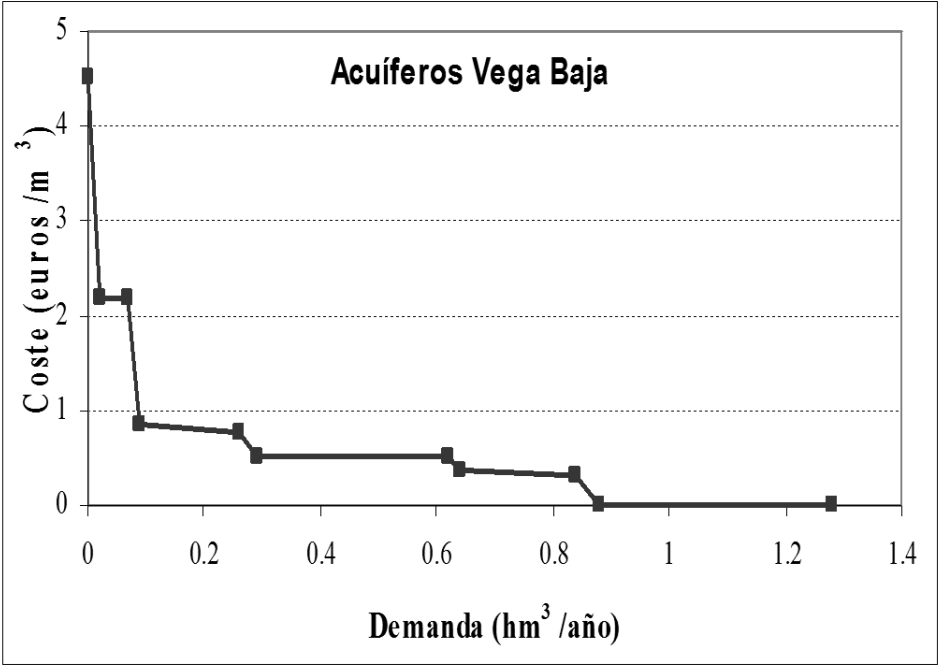

Figura A.18 Curva demanda económica. Acuífero Vega Baja 


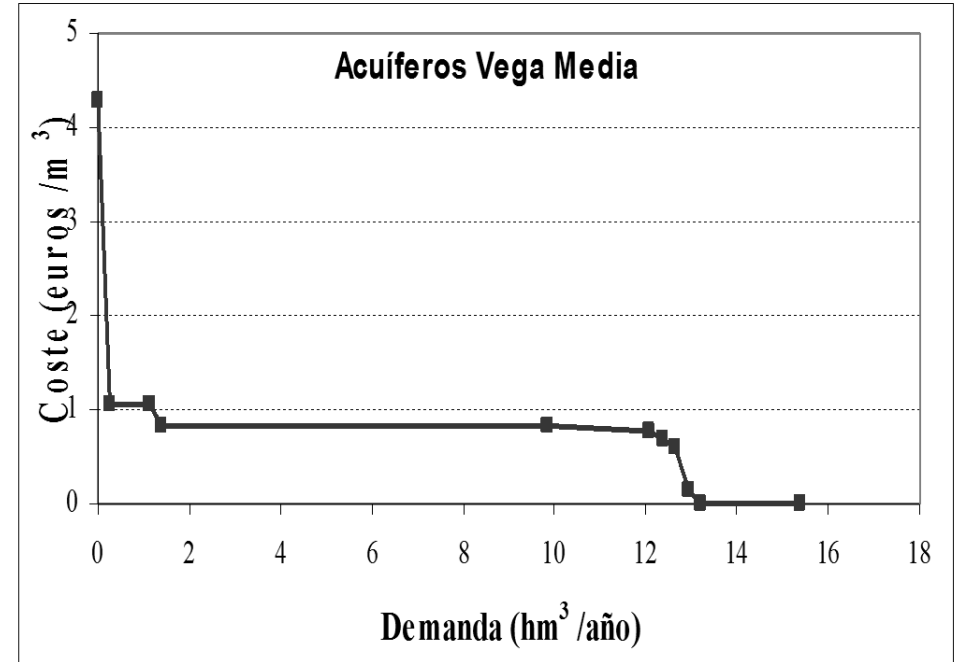

Figura A.19 Curva demanda económica. Acuífero Vega Media

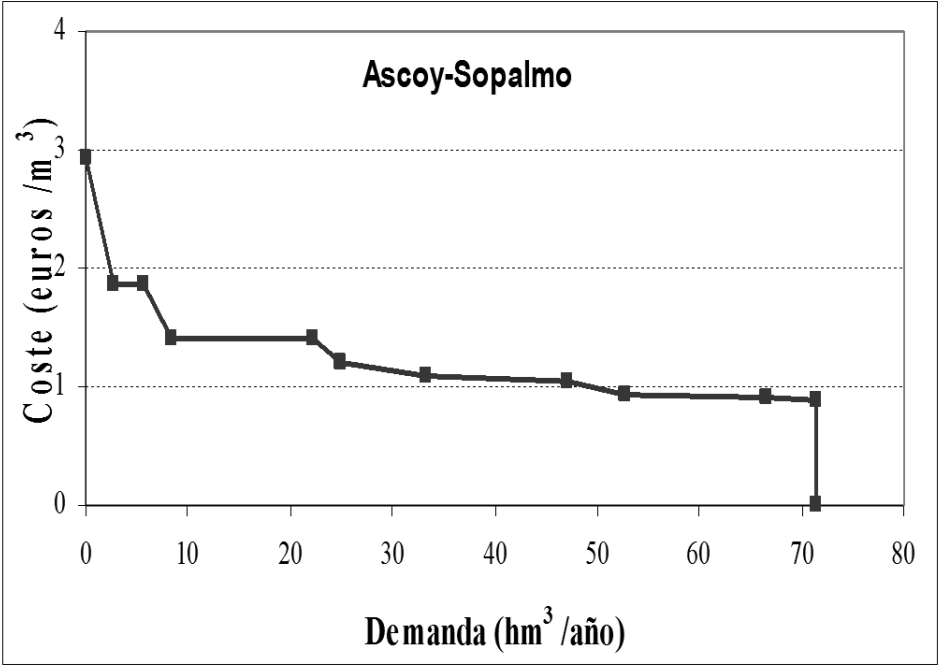

Figura A.20 Curva demanda económica. Ascoy-Sopalmo 


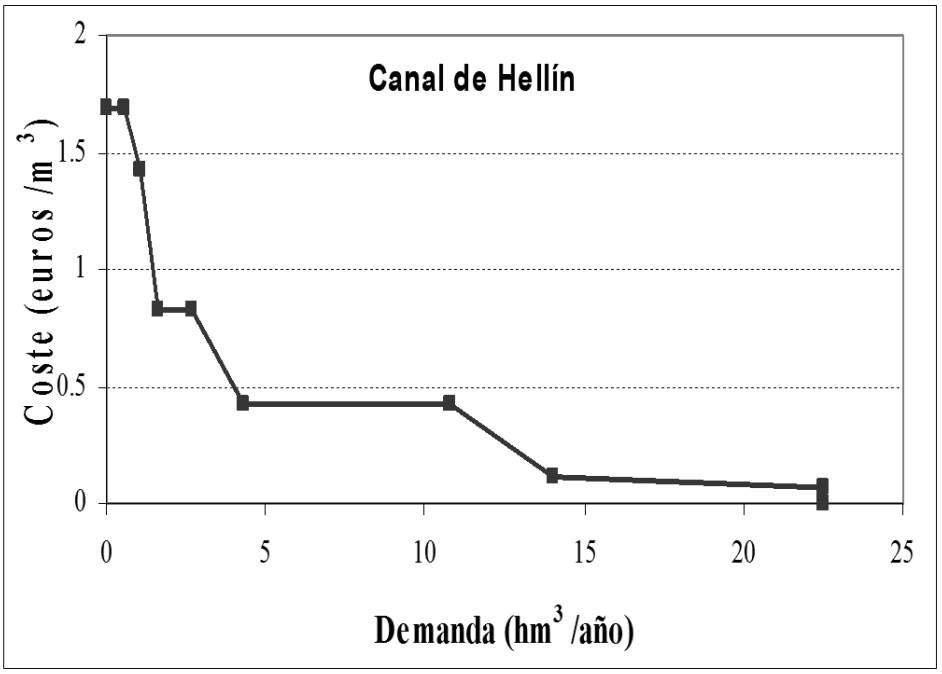

Figura A.21 Curva demanda económica. Canal Hellín

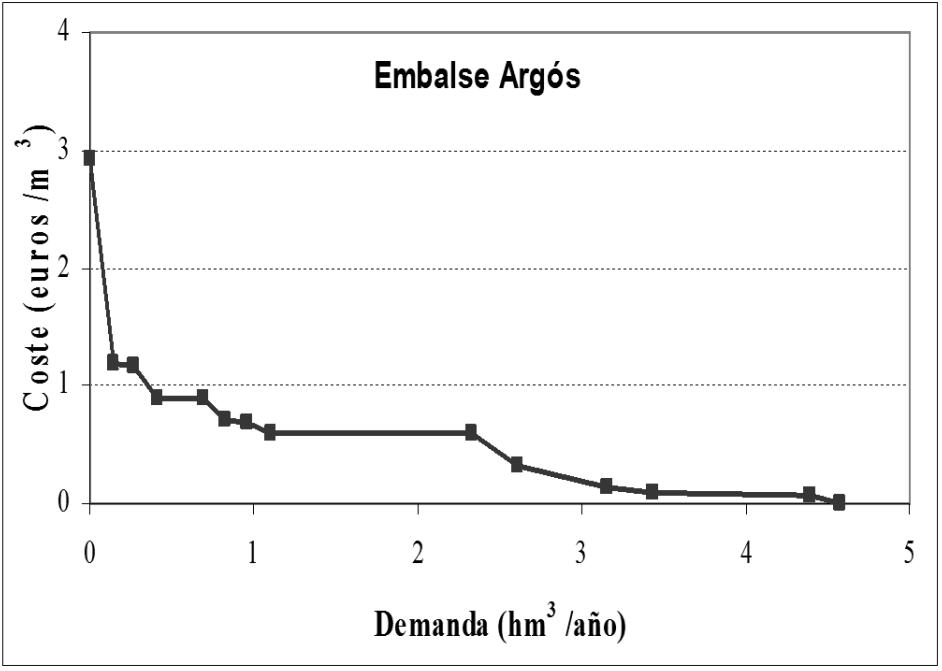

Figura A.22 Curva demanda económica. Embalse Argós 


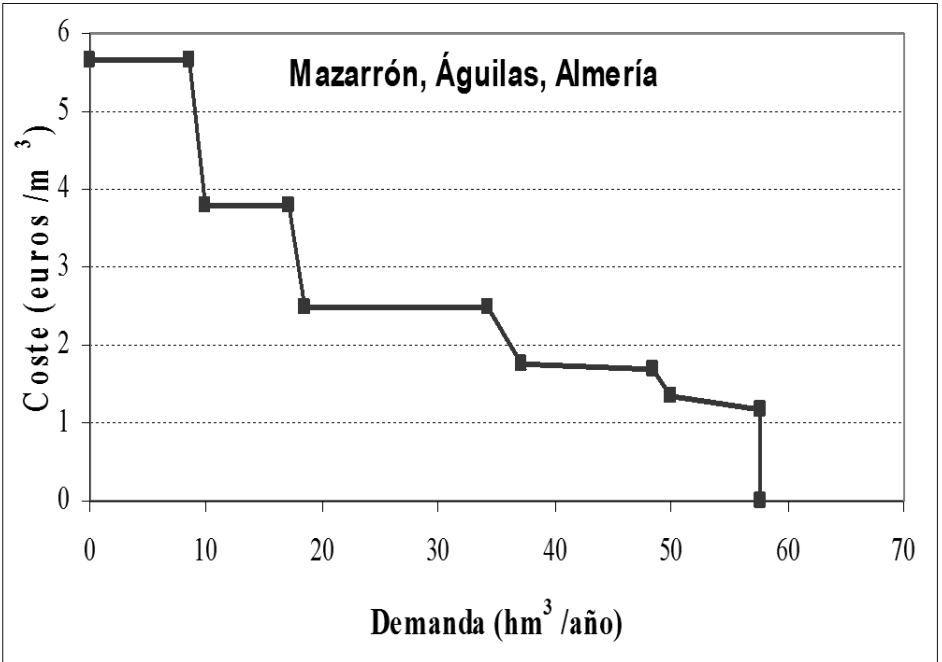

Figura A.23 Curva demanda económica. Mazarrón, Águilas, Almería

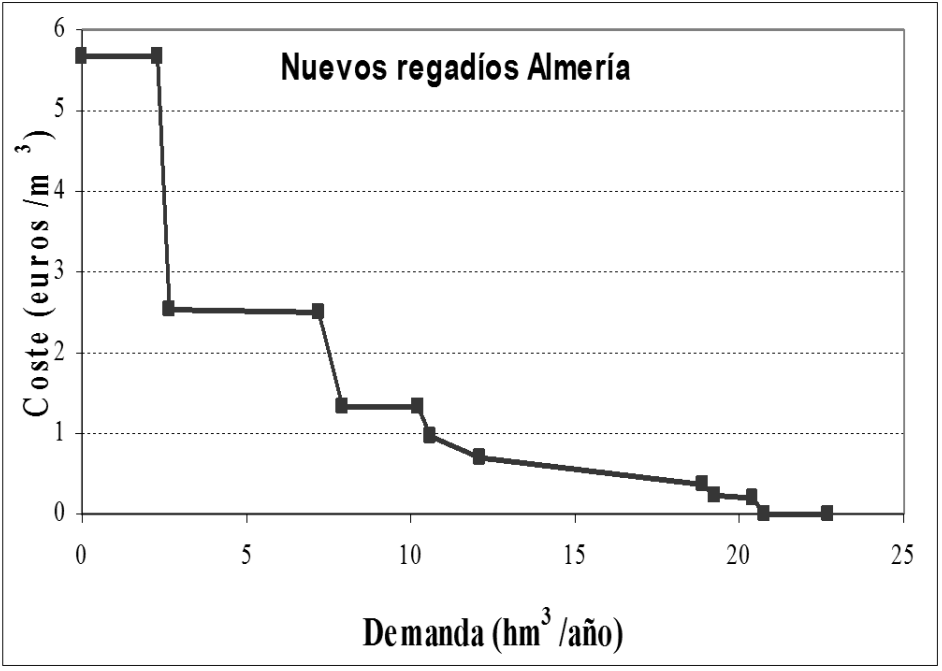

Figura A.24 Curva demanda económica. Nuevos Regadíos Almería 


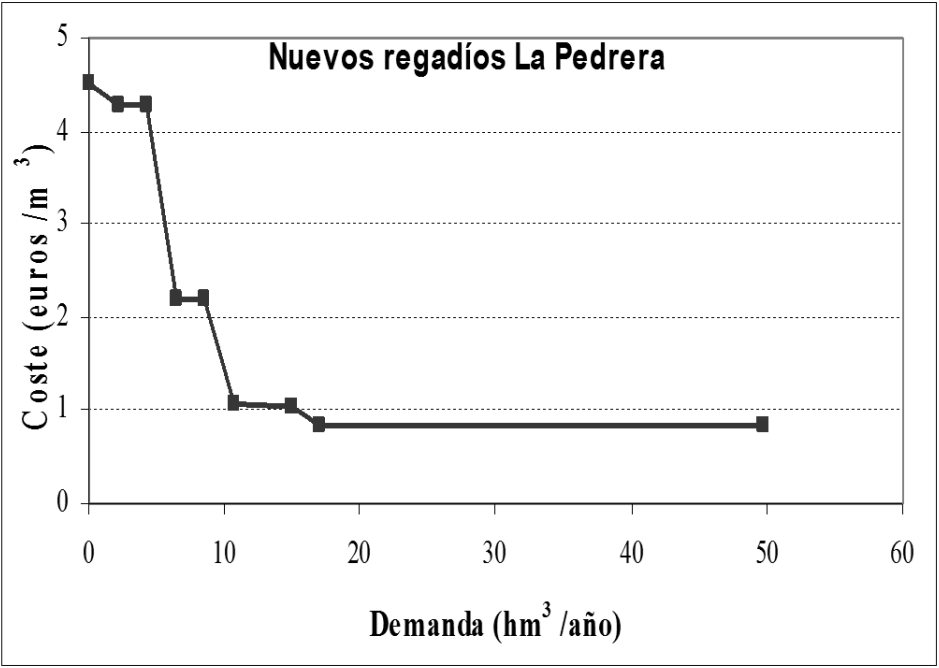

Figura A.25 Curva demanda económica. Nuevos Regadíos La Pradera

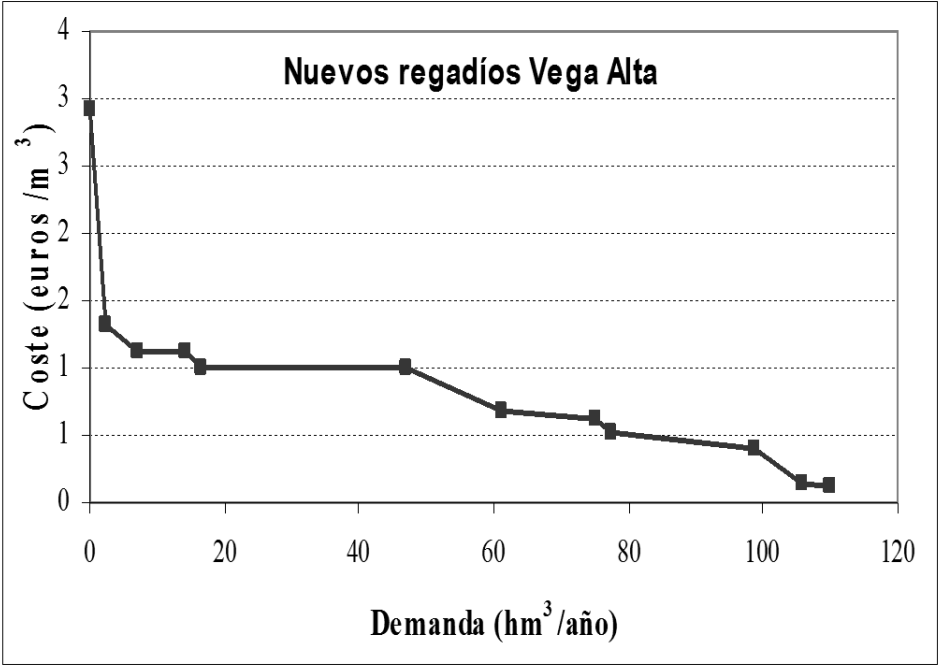

Figura A.26 Curva demanda económica. Nuevos Regadíos Vega Alta 


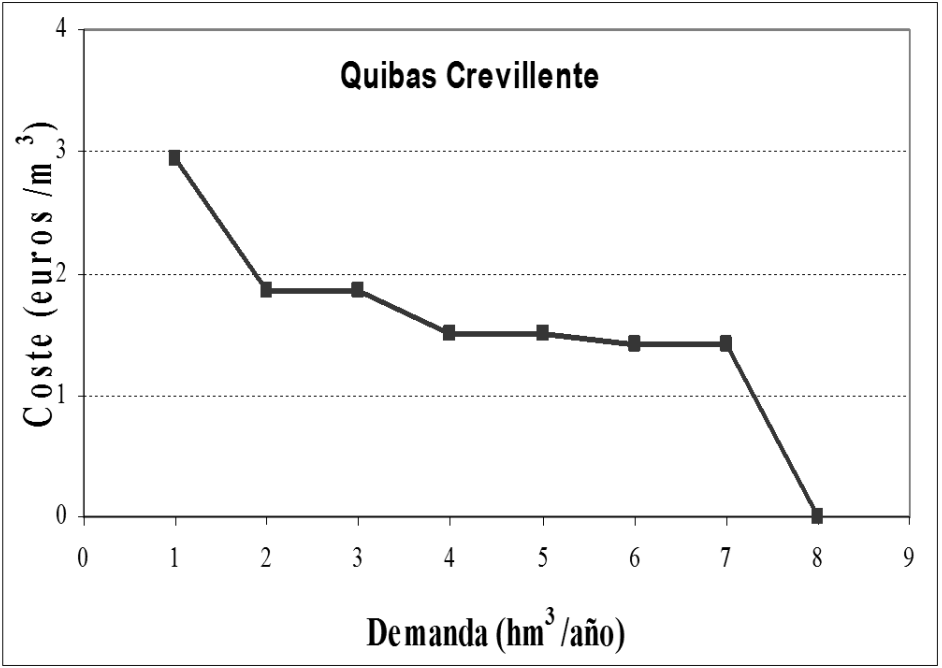

Figura A.27 Curva demanda económica. Quibas-Crevillente

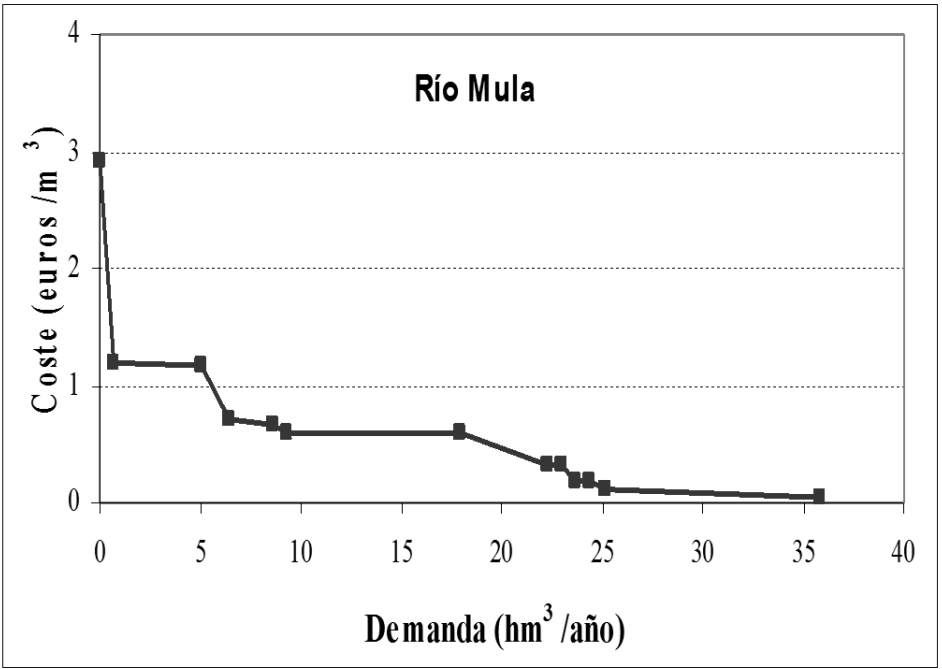

Figura A.28 Curva demanda económica. Río Mula 


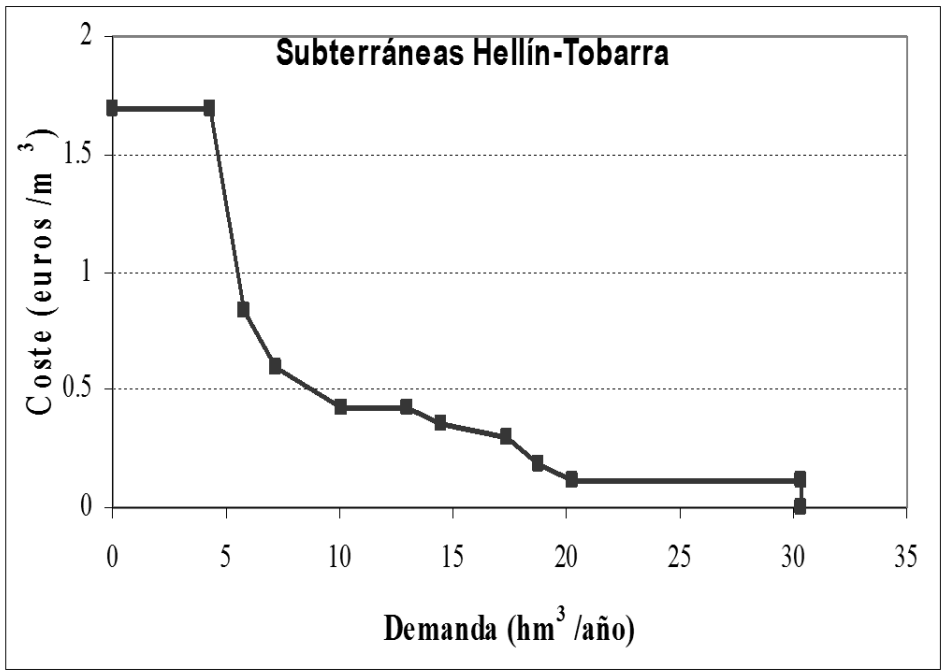

Figura A.29 Curva demanda económica. Subterráneas Hellín-Tobarra

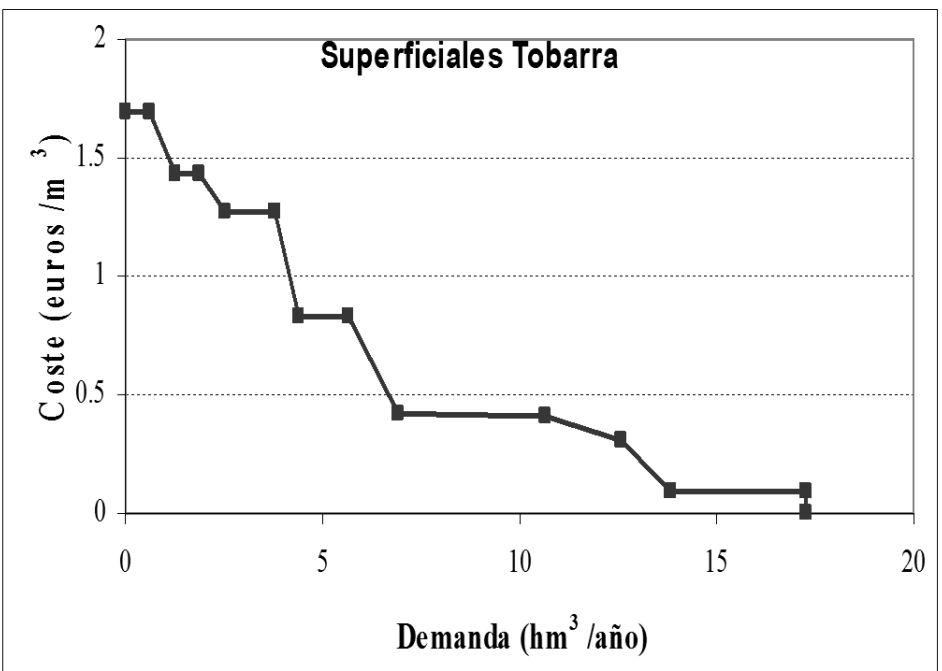

Figura A.30 Curva demanda económica. Superficiales Tobarra 


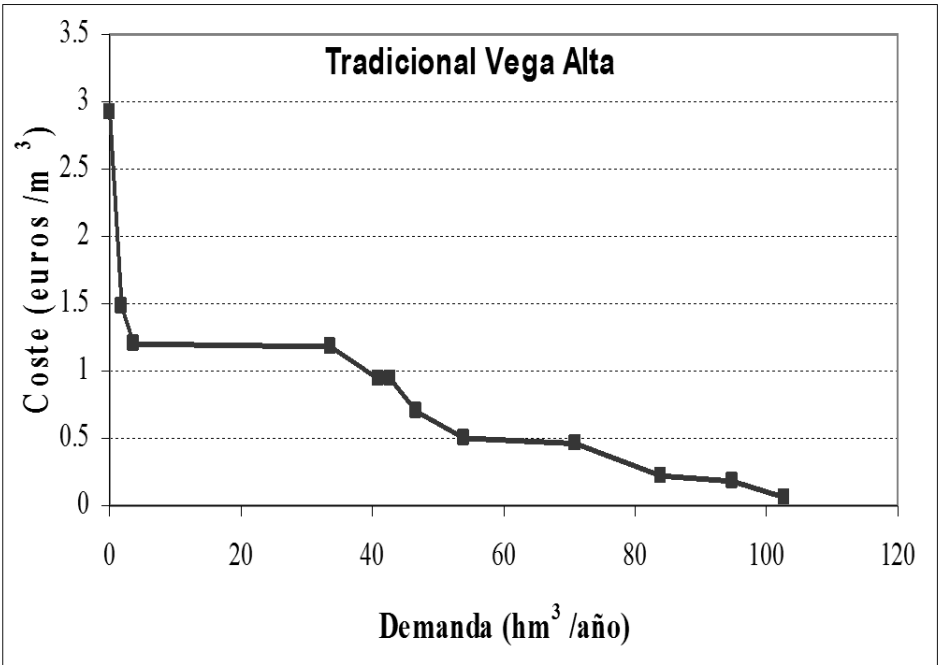

Figura A.31 Curva demanda económica. Tradicional Vega Alta

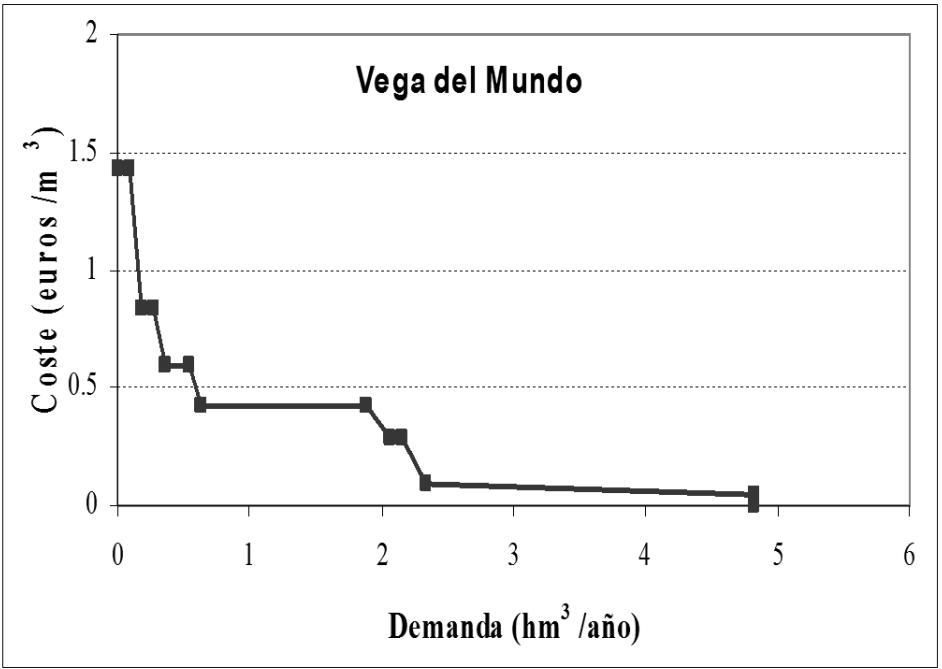

Figura A.32 Curva demanda económica. Vega del Mundo 


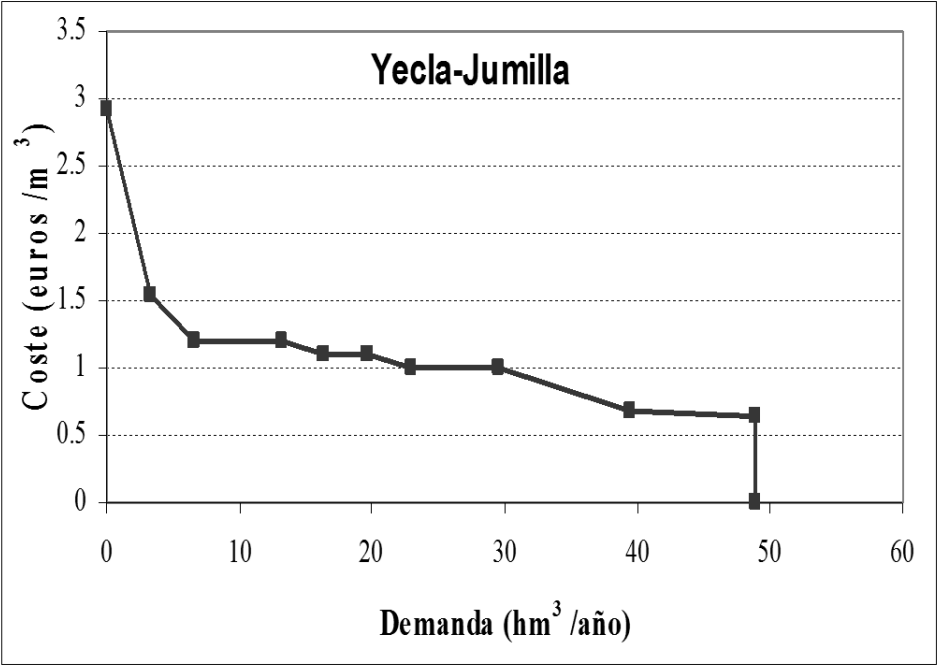

Figura A.33 Curva demanda económica. Yecla-Jumilla 

ANEJO B 



\section{Anejo B: ECOWIN: evaluador económico del SAD AquaTool.}

EcoWin, está dividido en dos partes fundamentales: una parte matemática, encargada de realizar todas las operaciones lógicas y matemáticas, y otra parte de interacción con el usuario (interfaz gráfica) para la introducción de parámetros y visualización de resultados.

La parte matemática está escrita en lenguaje Fortran. La interfaz gráfica está escrita en lenguaje Visual Basic. Es natural haber elegido este programa ya que es un lenguaje orientado a objetos que permite crear formularios "amigables" para el usuario, con las clásicas ventanas, botones, cuadros de selección, etc. usuales en entorno Windows.

Las dos partes del programa comentadas anteriormente tienen un punto de conexión conformado por una serie de archivos, tanto de entrada de parámetros como de salida de resultados.

Generalmente el usuario utilizará la interfaz gráfica para la entrada de parámetros y visualización de resultados. Juntamente con ello, es necesario utilizar el módulo de cálculo, denominado "Evaluador Económico". El Evaluador Económico es un programa que realiza la evaluación económica de los sistemas de recursos hídricos. Está compilado en Fortran 90 y se desarrolló en el Departamento de Ingeniería Hidráulica y Medio Ambiente de la UPV (Collazos 2004). El autor lo denominó en un principio Gestal y a la interfaz gráfica que utiliza, se le llama EcoWin.

Al iniciar la ejecución de EcoWin, aparece una ventana inicial vacía. Es necesario abrir el proyecto o esquema SimGes. Una vez abierto éste (figura B.1) se abre la ventana de captura de los datos económicos (figura B.2) en la cual se introducen los valores de las funciones de demanda, ya sea en forma escalonada o como función continua, previamente calculada por el usuario. 


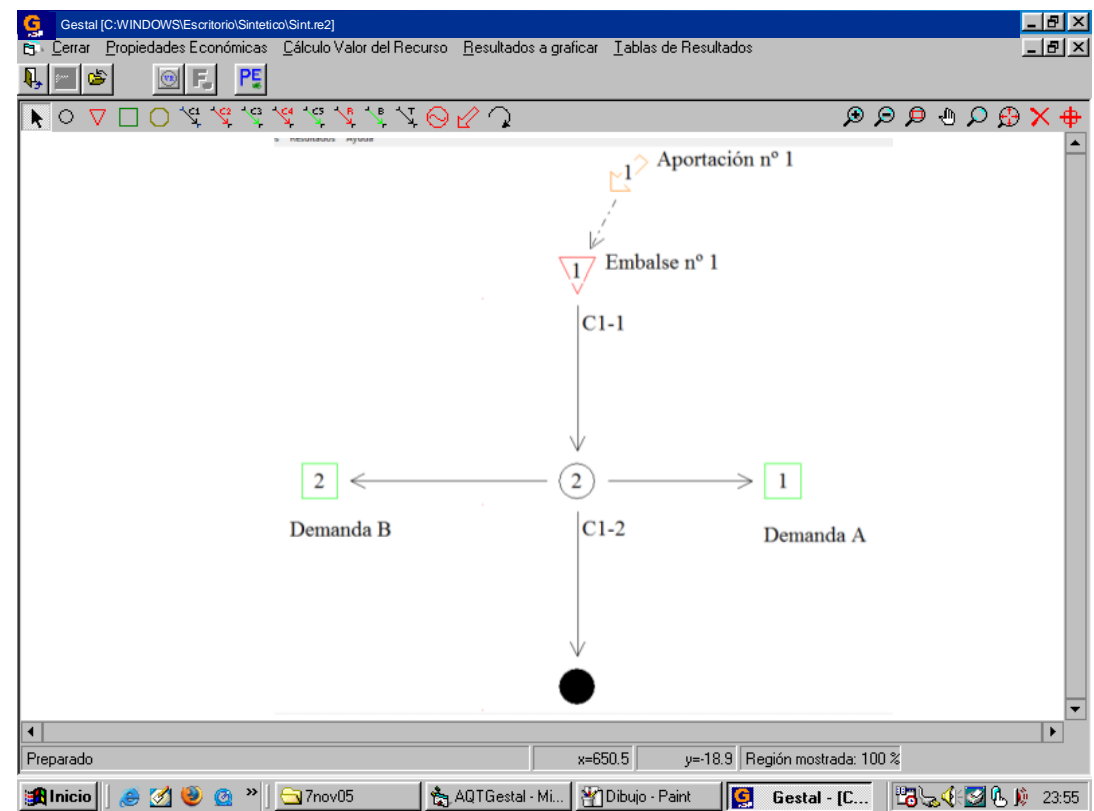

Figura B.1 Ventana inicial de EcoWin

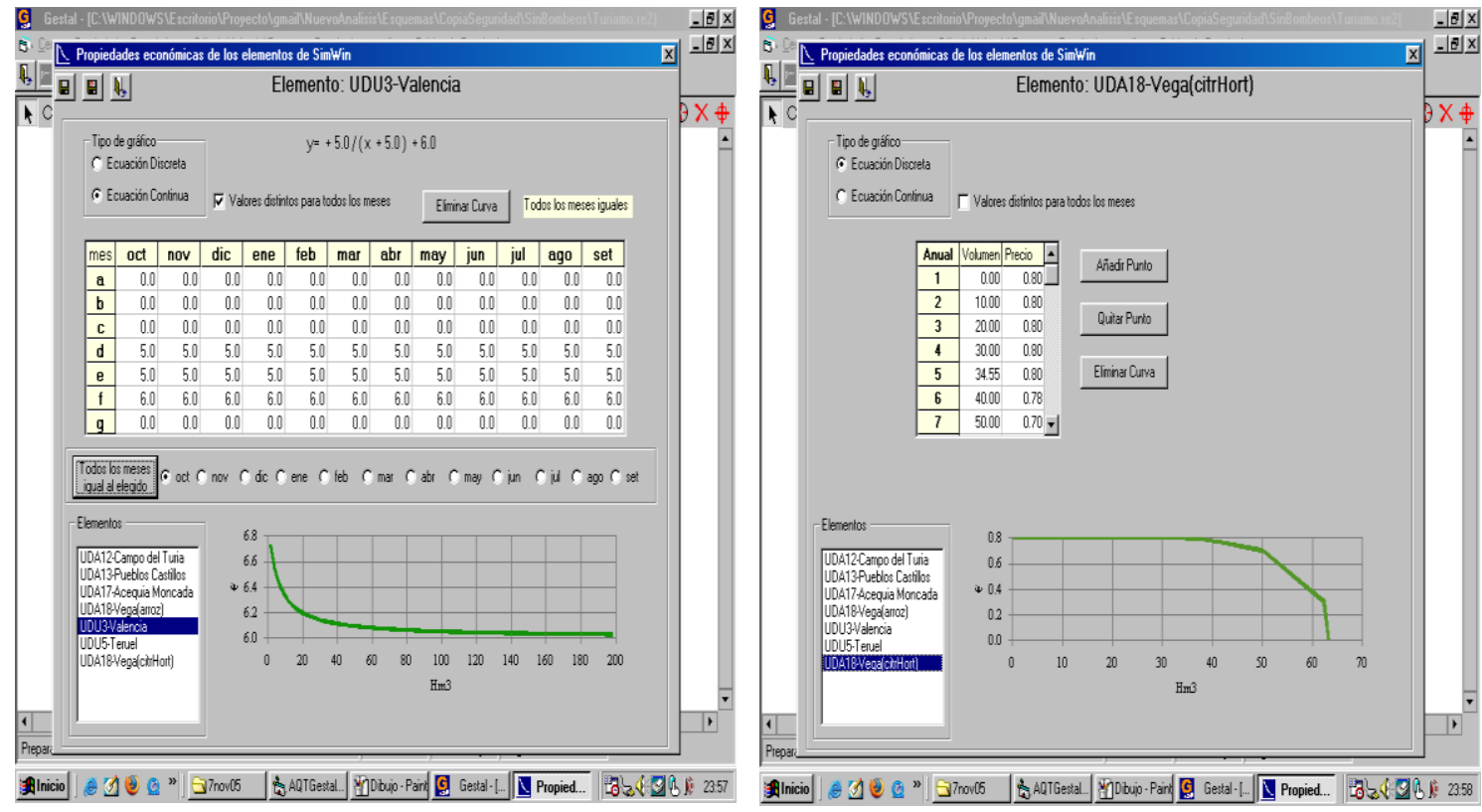
Figura B.2 Ventana de captura de curvas de demanda.

Finalmente, los resultados se presentan en una tabla de resultados, los cuales pueden exportarse a formato de Excel para generar los gráficos correspondientes (figura B.3). 


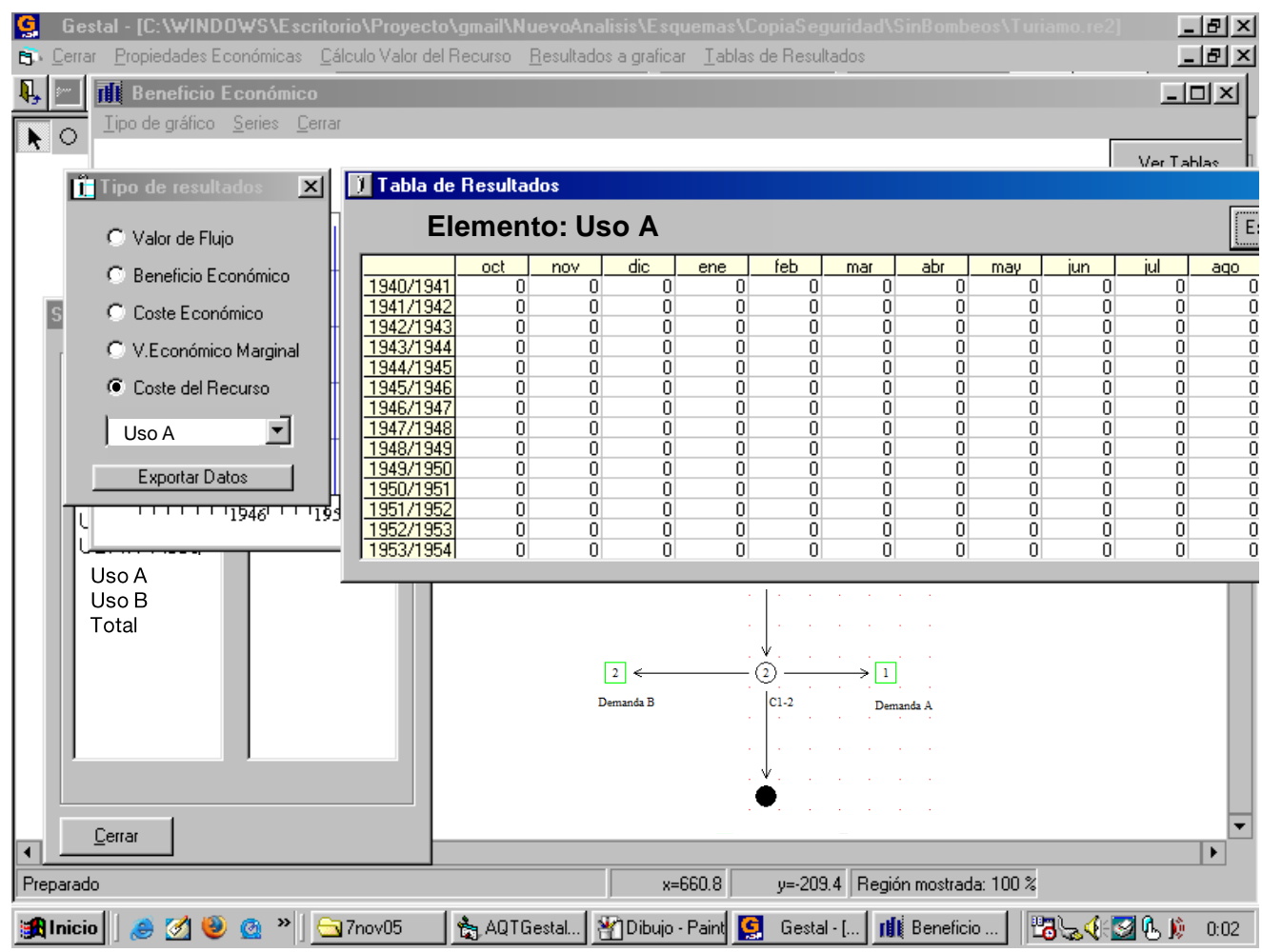

Figura B.3. Ventana con los resultados del cálculo del CMOR 

ANEJO C 



\section{Anejo C. Infraestructura del Sistema de Explotación del Río Mijares, curvas de demanda y coste de}

escasez

El Sistema de Explotación Mijares-Plana de Castellón cuenta con la siguiente infraestructura, según el Plan Hidrológico de la Cuenca del Júcar (CHJ, 1997):

\section{Embalses}

Los principales embalses que conforman el sistema de explotación Mijares-Plana de Castellón son: Arenós, Sichar, Ma. Cristina y Alcora, aunque existen algunos pequeños cuerpos de agua que funcionan más como azudes que como embalses, ya que no poseen capacidad de regulación. Las capacidades útiles se muestran en la tabla C.1.

\begin{tabular}{|c|c|c|}
\multicolumn{2}{c}{ Tabla C.1 Embalses del sistema Mijares } \\
\hline \multirow{2}{*}{ EMBALSES } & Río & CAPACIDAD UTIL $\mathbf{( h m}^{\mathbf{}} \mathbf{)}$ \\
\hline Valbona & Valbona & 0,52 \\
\hline Los Toranes & Mijares Palomarejas & 0,52 \\
\hline Balagueras & Mijares & 0,12 \\
\hline Arenós & Mijares & 93 \\
\hline Cirat & Mijares & 0,05 \\
\hline Vallat & Mijares & 0,60 \\
\hline Ribesalbes & Mijares & 0,30 \\
\hline Sichar & Mijares & $39-49$ \\
\hline Alcora & Lucena & 2,02 \\
\hline Ma Cristina & Rambla de la Viuda & 19,70 \\
\hline Onda & Veo & 1,10 \\
\hline
\end{tabular}




\section{Centrales Hidroeléctricas.}

El sistema de explotación Mijares-Plana de Castellón cuenta con diez centrales hidroeléctricas, todas ellas ubicadas en el río Mijares (figura C.1).

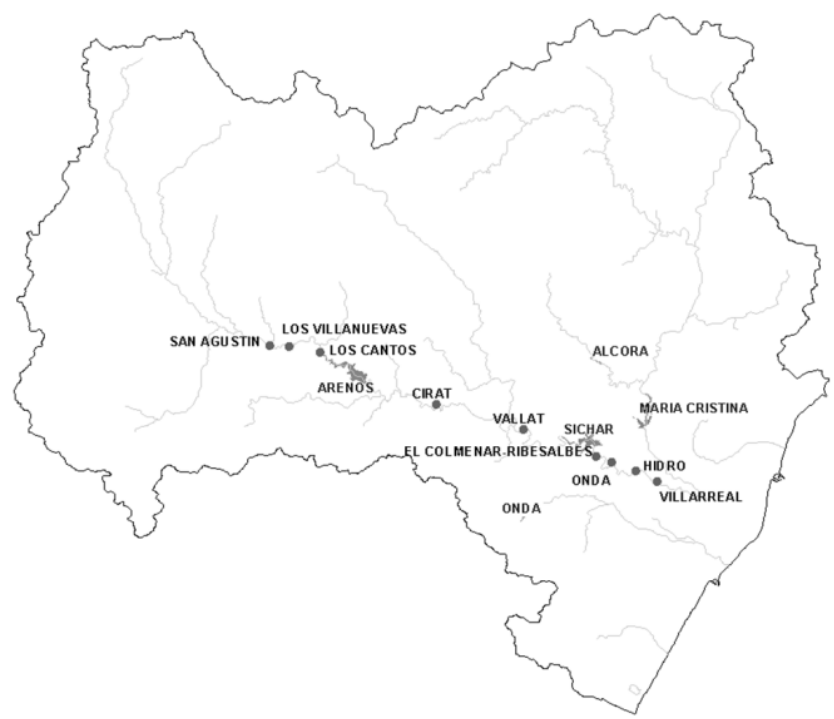

Figura C.1 Centrales Hidroeléctricas.

La potencia, caudal y salto de cada una de ellas, se muestran en la tabla C.2

Tabla C.2 Características de las centrales hidroeléctricas

\begin{tabular}{|c|c|c|c|}
\hline $\begin{array}{l}\text { APROVECHAMIENTOS } \\
\text { HIDROELÉCTRICOS }\end{array}$ & $\begin{array}{l}\text { POTENCIA } \\
\text { (Mw) }\end{array}$ & $\begin{array}{l}\text { CAUDAL } \\
\left(\mathrm{m}^{3} / \mathrm{s}\right)\end{array}$ & $\begin{array}{l}\text { SALTO } \\
\text { (m) }\end{array}$ \\
\hline Central de San Agustín & 11,84 & 6,80 & 127,00 \\
\hline Central de Los Villanuevas & 3,60 & 9,83 & 48,50 \\
\hline Central de Los Cantos & 4,80 & 9,81 & 62,50 \\
\hline Central de Cirat & 14,73 & 14,72 & 118,70 \\
\hline Central de Vallat & 14,72 & 15,91 & 104,50 \\
\hline Central de Ribesalbes & 7,04 & 12,92 & 73,15 \\
\hline Central de Colmenar & 5,60 & 13,27 & 55,59 \\
\hline Central de Onda & 0,90 & 7,12 & 19,30 \\
\hline Central de Hidro & 0,64 & 7,72 & 13,15 \\
\hline Central de Villarreal & 0,27 & 6,76 & 7,28 \\
\hline
\end{tabular}




\section{Canales}

Los principales canales que forman parte del sistema Mijares, así como sus características, se muestran en la tabla C.3

Tabla C.3 Canales y sus características principales

\begin{tabular}{|c|c|c|}
\hline CANALES & $\begin{array}{c}\text { CAUDAL } \\
\left(\mathbf{m}^{\mathbf{3}} \mathbf{/ s}\right)\end{array}$ & $\begin{array}{c}\text { LONGITUD } \\
\mathbf{( \mathbf { k m } )}\end{array}$ \\
\hline Canal del Tramo Común & 24,4 & 5,5 \\
Canal de la Cota 100 & 4,1 & 18,0 \\
Canal de la cota 220 & 5,0 & 9,0 \\
Canal de Ma Cristina & 3,0 & 15,2 \\
\hline
\end{tabular}

\section{Estaciones Depuradoras de Aguas Residuales (EDARs)}

Existen 41 estaciones depuradoras, de las cuales la de Castellón de la Plana es la que depura mayor volumen de agua, del orden de $14 \mathrm{hm}^{3}$, siendo el volumen total depurado del orden de $40 \mathrm{hm}^{3}$. En la figura C.2 se muestra la localización de las estaciones depuradoras.

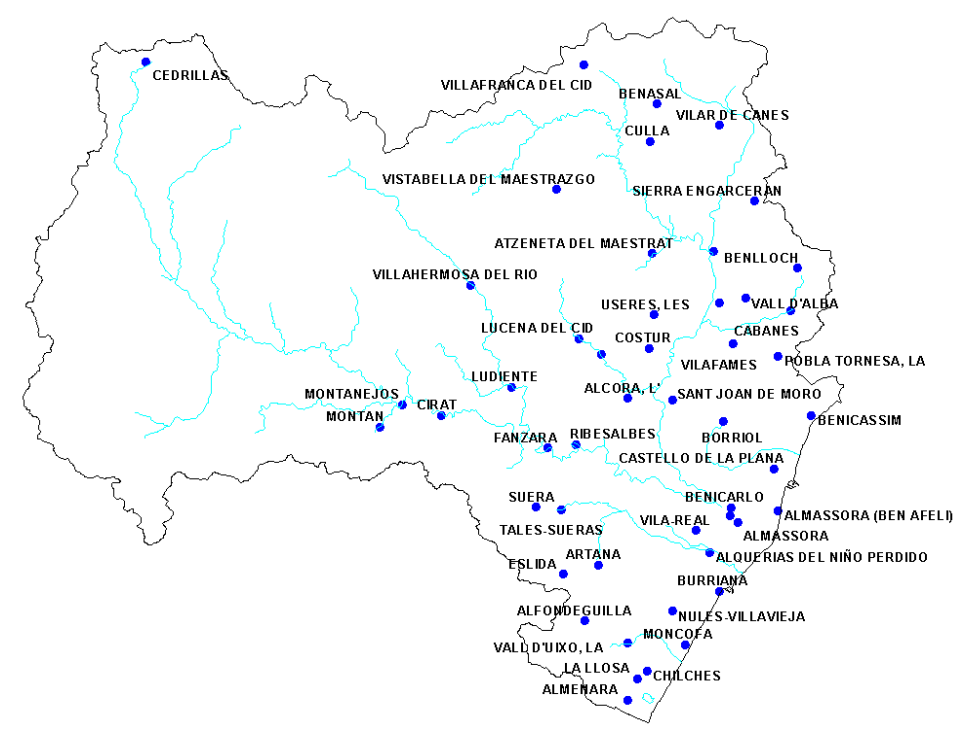

Figura C.2 Localización de las Estaciones Depuradoras 


\section{CURVAS DE DEMANDA DE LOS USOS EN EL SISTEMA DE EXPLOTACIÓN DEL RÍO MIJARES}

Demanda agrícola. La zona cultivable que el sistema Mijares-Plana de Castellón riega predominantemente una superficie para cítricos, que representa el 91\% del total del área cultivada. El 5\% del total cultivado corresponde a hortalizas y, el resto, a frutales, arroz y otros cultivos (García Mollá, 2000).

El Ministerio de Medio Ambiente ha propuesto una serie de curvas de demanda económica, dándole un valor al agua por hectárea regada del cultivo en cada una de las comunidades de regantes (Figura C.3). Según Sumpsi (1988), en las Unidades de Demanda Agrícola del Mijares, tanto la existencia de prácticamente un monocultivo (cítricos) como la pequeña dimensión de las explotaciones, hace que no interese la sustitución entre cultivos de regadío y que tampoco se traspase de regadío a secano, lo que explica la alta inelasticidad en las curvas de demanda.

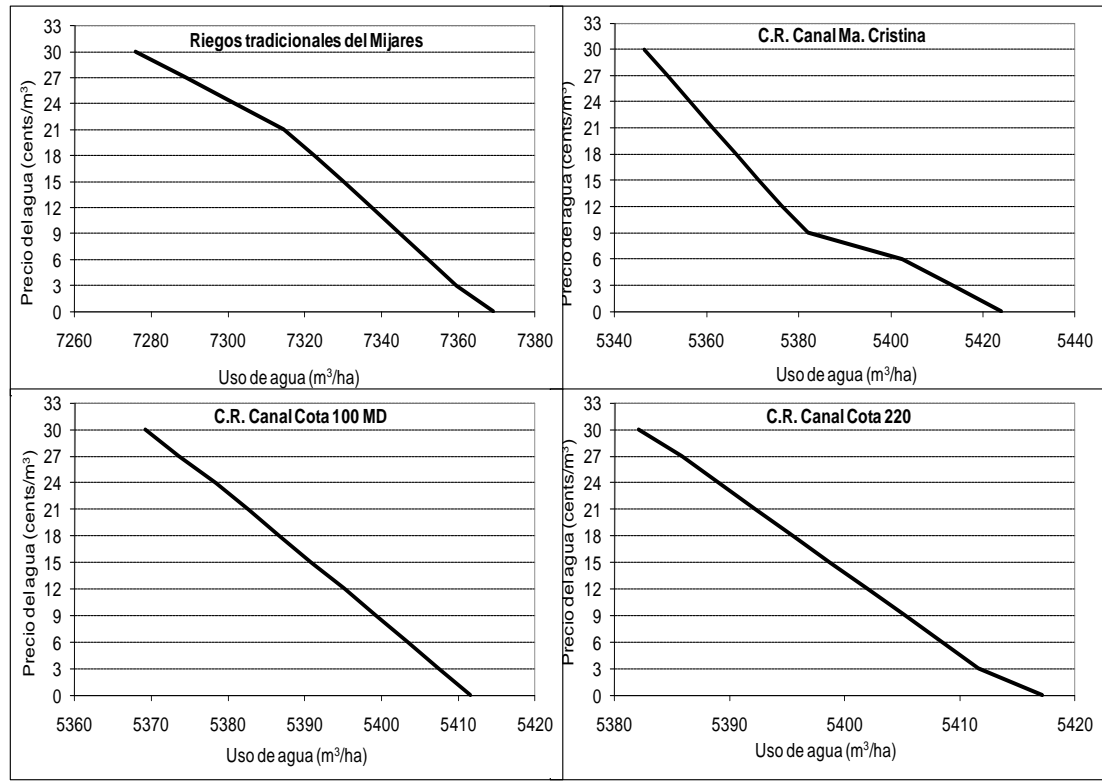

Figura C.3 Curvas de demanda económica. Fuente: Ministerio de Medio Ambiente (2002)

Las curvas de demanda utilizadas en el análisis económico toman la forma de las mostradas en las figuras C.4 a C.7 En esas figuras se observan las curvas de demanda en las modalidades de dotación ( $\mathrm{m}^{3} /$ ha.-año) y demanda volumétrica ( $\mathrm{hm}^{3} /$ año) 

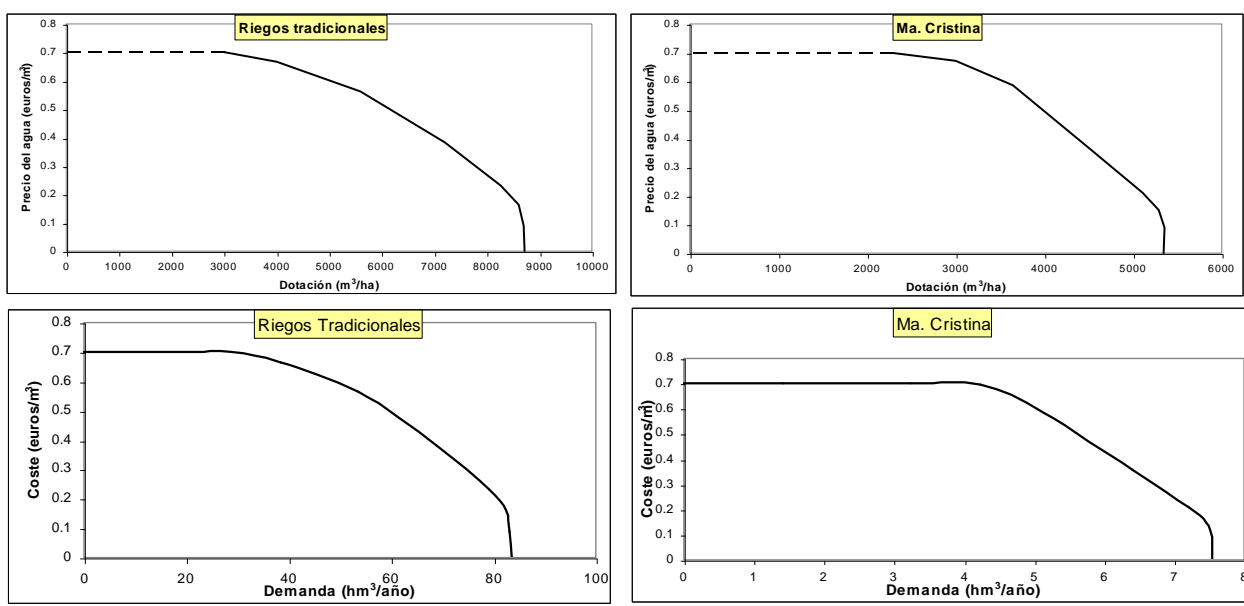

Figura C.4 Curvas de demanda Riegos Tradicionales y Ma. Cristina
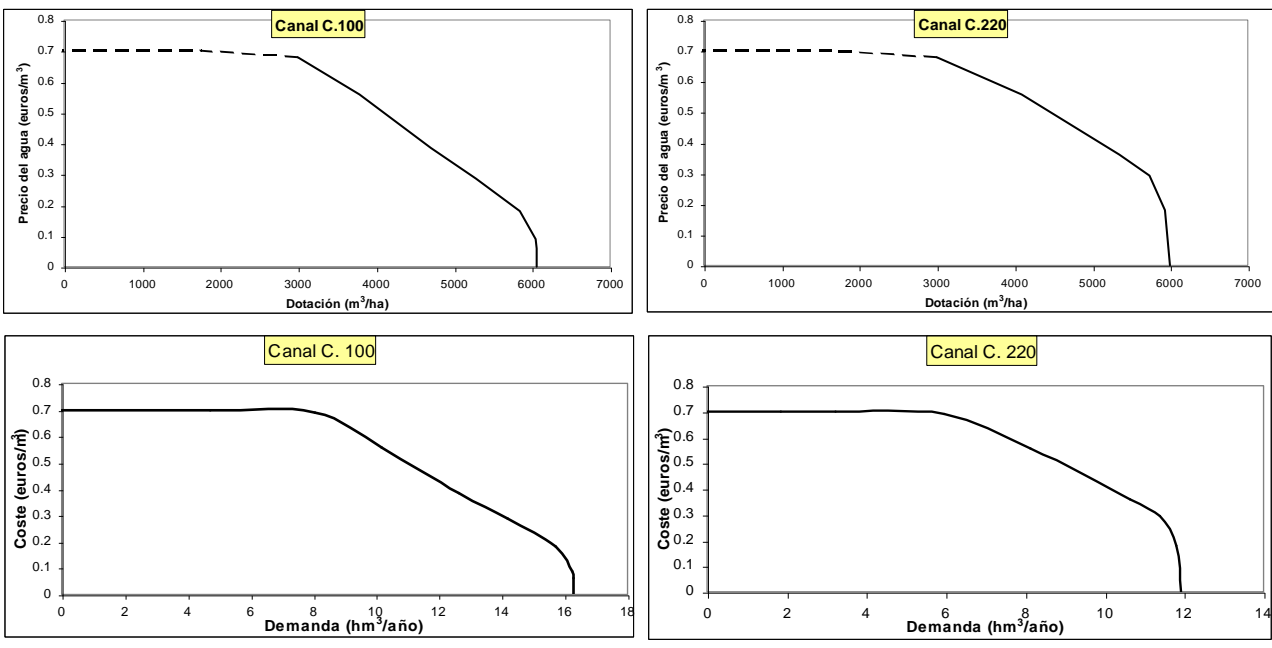

Figura C.5 Curvas de demanda Canal Cota 100 y Canal Cota 220 

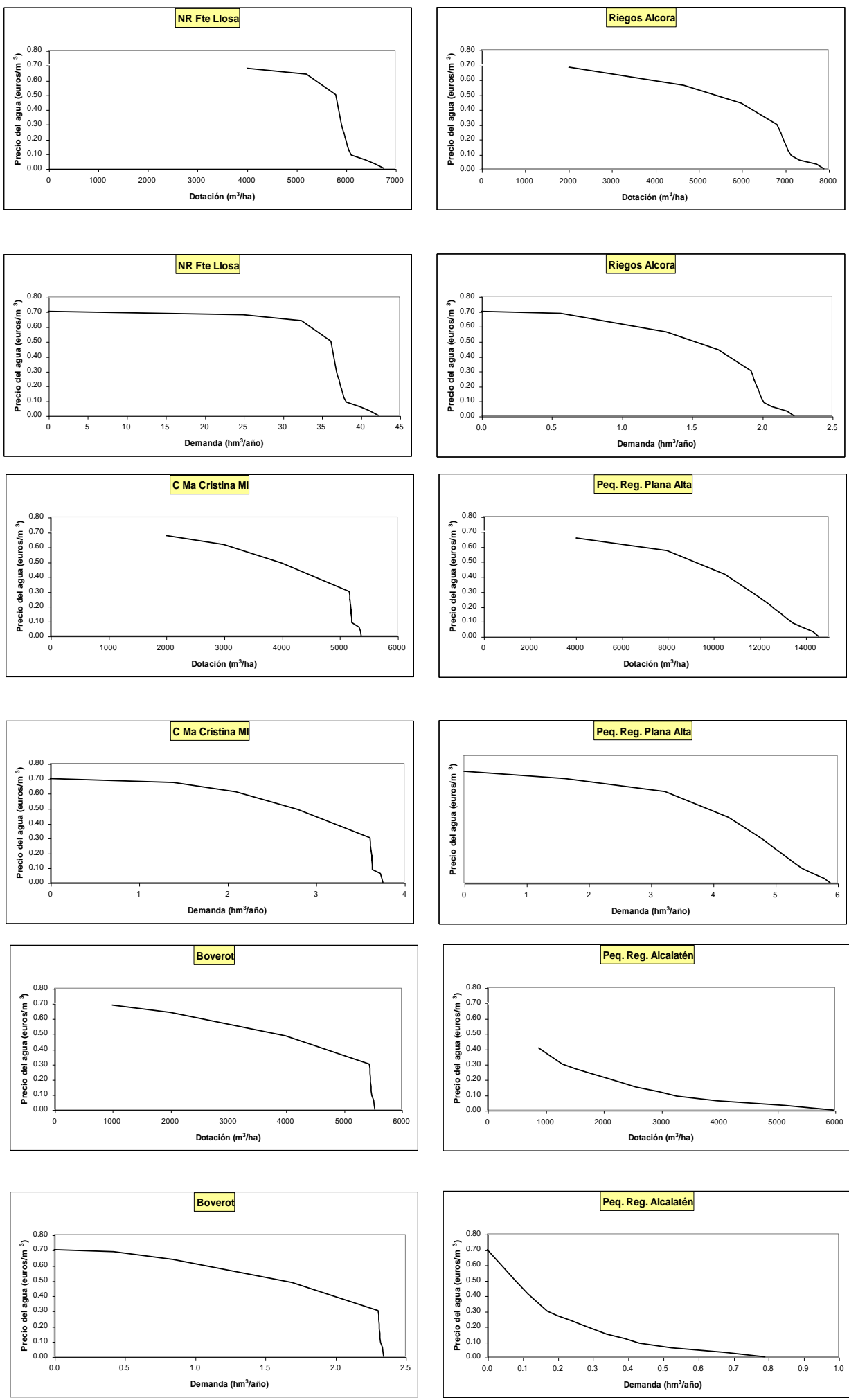

Figura C. 6 Curvas de demanda agrícola (cont.) 

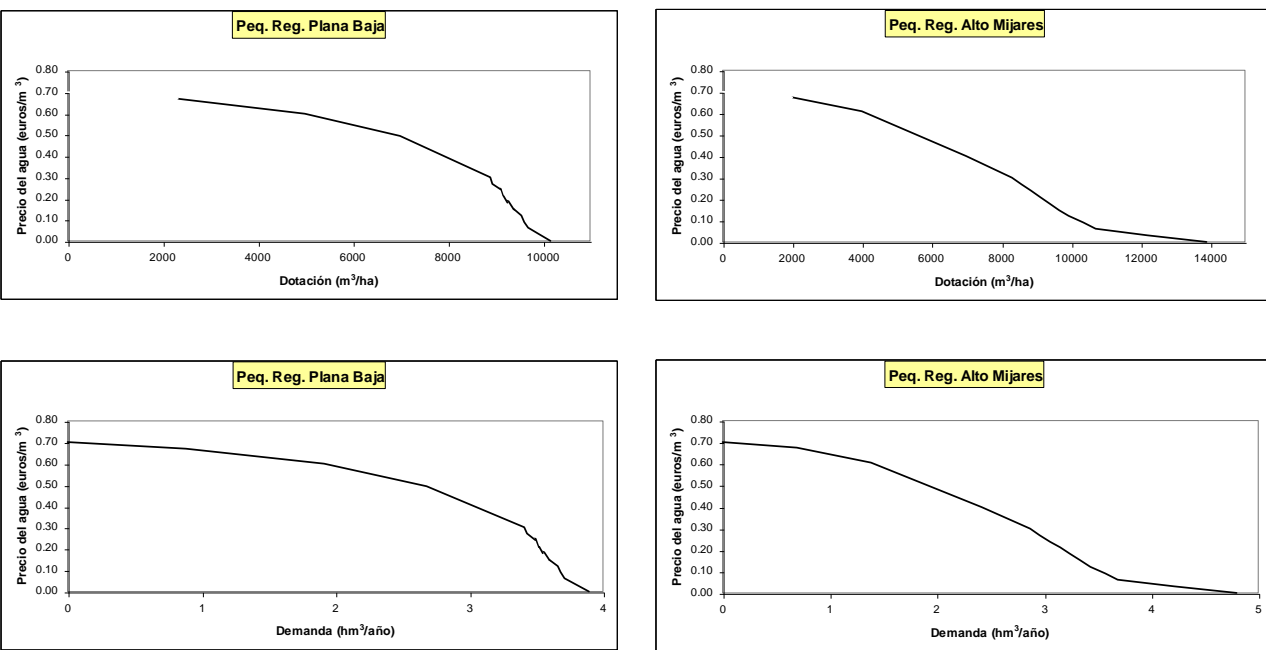

Figura C.7 Curvas de demanda agrícola (cont.)

\section{COSTE DE ESCASEZ DE LAS DEMANDAS EN EL SISTEMA DE EXPLOTACIÓN DEL RÍO} MIJARES

\section{Coste de escasez y suministro a la demanda}

El esquema completo del Sistema, contempla un mayor número de demandas que deberá satisfacer con un buen grado de garantía. El modelo en SimGes, se calibró para que las demandas fueran satisfechas con el menor déficit posible. Sin embargo, los costes de escasez de agua para los cultivos suministrados a las demandas de Riegos Tradicionales presentan un mayor valor que el correspondiente a las demandas suministradas por los canales de las cotas 100 y 220 (figura 12.8) El coste de escasez de agua para los cultivos suministrados por el Canal María Cristina es nulo, lo cual indica que el suministro está siempre garantizado para dicha demanda. 


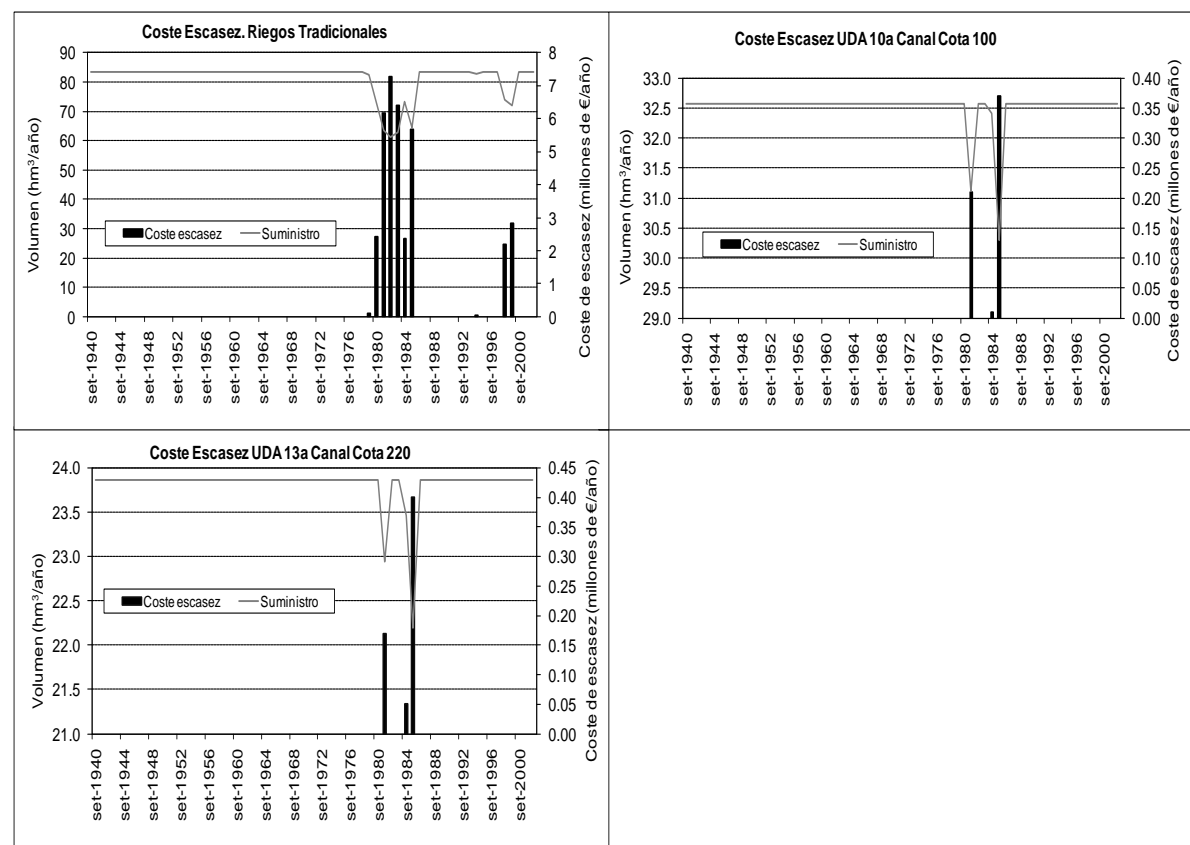

Figura C.8 Coste de escasez de agua en las UDAs más importantes

Los mayores costes de escasez se presentan cuando los volúmenes en los embalses de Sichar y Arenós se encuentran por debajo de los niveles mínimos (figura C.9) Las épocas de las grandes sequías (1982-88 y 1995-2000) son las que presentan el mayor valor de escasez del recurso.

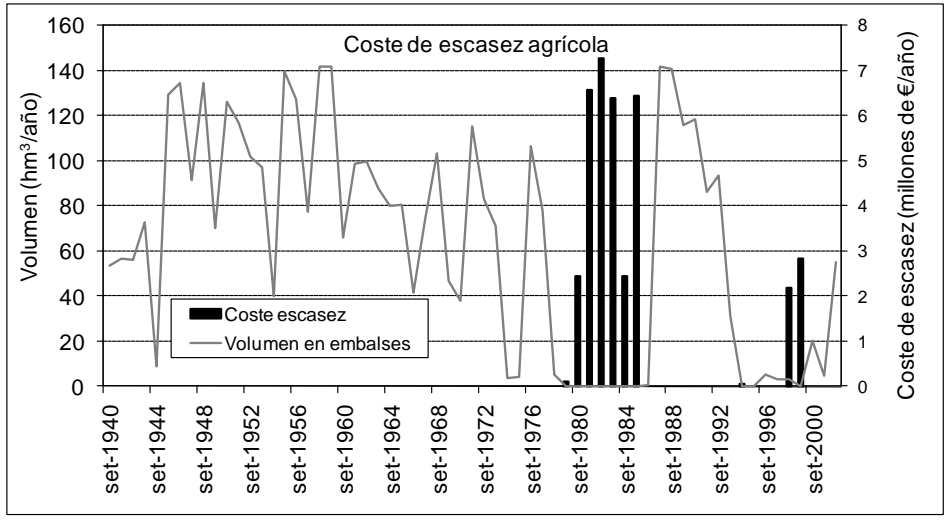

Figura C.9 Coste de escasez agrícola

El coste de escasez de agua para las demandas agrícolas restantes se muestra en la figura C.10. Es notorio resaltar que la Unidad de demanda de los Pequeños Regadíos del Alto Maestrazgo, presentan un coste de escasez constante de diez mil euros anuales durante los meses en que el suministro es mayor aunque deficitario en un $30 \%$. 
Evidentemente, cuando el suministro es menor aún, el coste de escasez entonces se incrementa anualmente hasta el doble. Algo similar ocurre para los Pequeños Regadíos de Alcalaten, Alcora Alto Mijares y Sierra Mora, pues el suministro a dichas demandas depende exclusivamente de las precipitaciones ya que derivan directamente de los ríos antes de que el agua se embalse en Arenós y/o Sichar. 

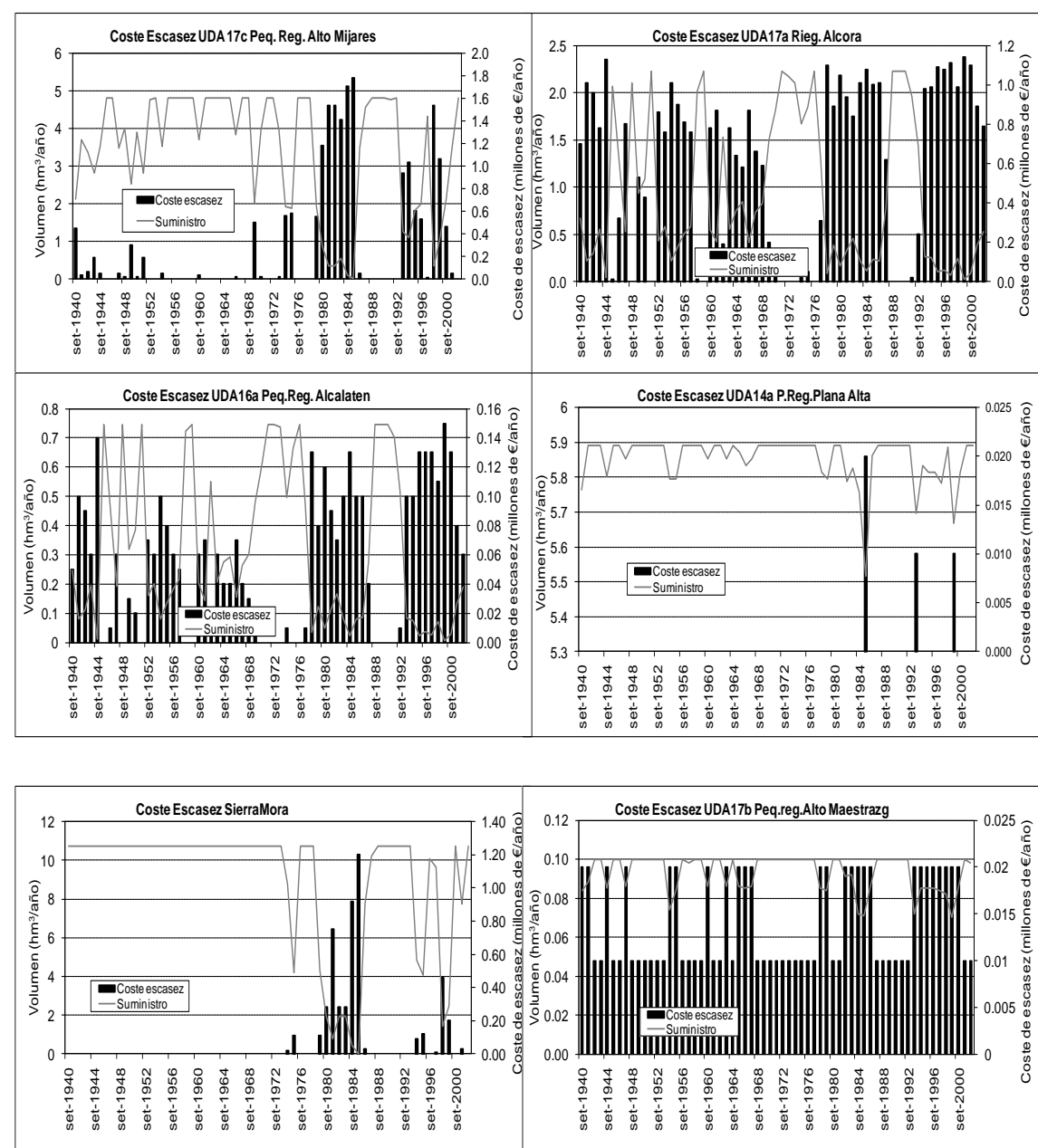

Figura C.10 Coste de escasez agrícola en unidades de demanda. Mijares 
La figura C.11 muestra el coste de escasez del recurso en las cuatro principales unidades de demanda agrícola.

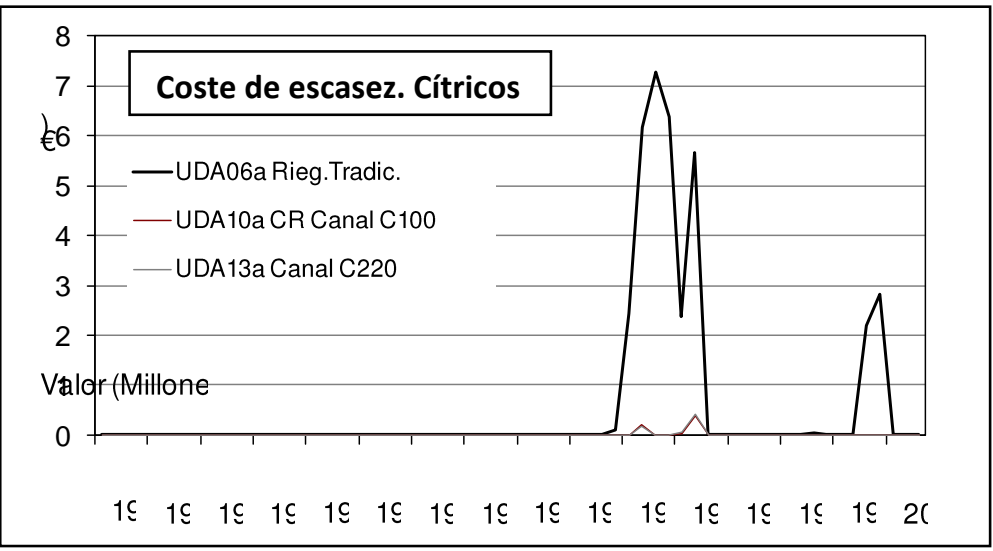

Figura C.11 Coste de escasez en diferente Unidades de Demanda Agrícola 